\title{
La Geografía de las Redes Económicas y la Geografía Económica en Red
}

Coordinación:

Maria del Pilar Alonso

Teresa Sá Marques

Hélder Santos

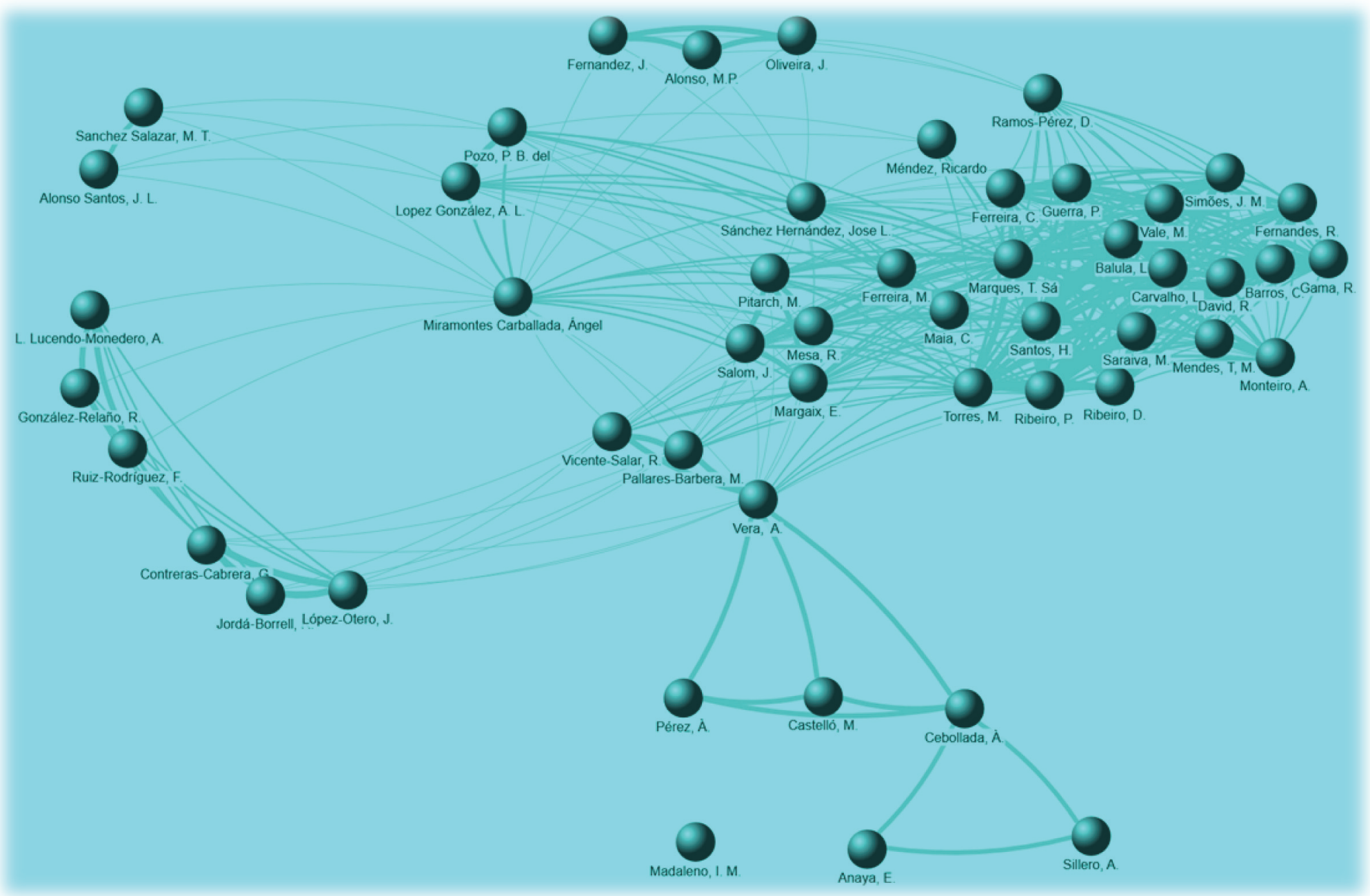


Página intencionalmente dejada en blanco 


\title{
La Geografía de las Redes Económicas y la Geografía Económica en Red
}

\author{
Coordinación: \\ Maria del Pilar Alonso \\ Teresa Sá Marques \\ Hélder Santos
}

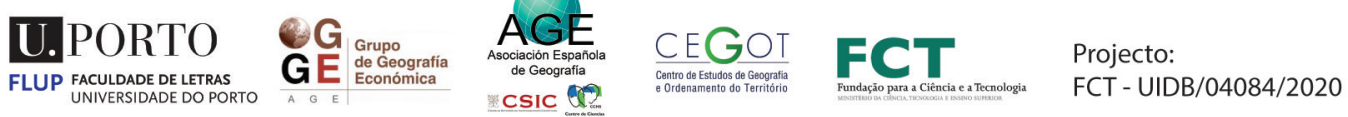


Edición: Faculdade de Letras da Universidade do Porto, Asociación de Geógrafos Españoles (Grupo de Geografía Económica)

Coordinadores: M. Pilar Alonso Logroño; Teresa Sá Marques; Hélder Santos

Título: La Geografía de las Redes Económicas Y la Geografía Económica en Red

Año: 2020

ISBN: 978-989-8969-46-0

DOI: https://doi.org/10.21747/9789898969460/geo

Diseño Gráfico: Claudia Manuel

Imagen de Portada: Diogo Ribeiro 


\section{ÍNDICE}

Introdución: la geografía económica en red

M. P. Alonso, T. Sá Marques, H. Santos

\section{DESAFÍOS PARA LA GEOGRAFÍA ECONÓMICA}

Otras economías, otros espacios, otros retos para la Geografía Económica

José Luis Sánchez Hernández

Desafíos de futuro para la investigación en Geografía Económica

Ricardo Méndez

\section{ESPECIALIZACIÓN INTELIGENTE}

Instituições de Ensino Superior e Especialização Inteligente: o contributo dos Institutos Superiores Politécnicos para a Implementação da RIS3 em Portugal

M. Vale, L. Balula, L. Carvalho, J. M. Simões

Especialização inteligente: as redes de projetos europeus $\mathrm{H} 2020$ com ancoragem em Portugal

H. Santos, T. Sá Marques, P. Ribeiro, M. Torres

Especialização inteligente e redes de conhecimento. A Universidade de Coimbra num contexto de globalização

R. Gama, C. Barros, R. David, R. Fernandes

Especialização inteligente à escala urbana: análise dirigida ao diagnóstico do PDM da Cidade do Porto

T. Sá Marques, H. Santos, D. Ribeiro, P. Ribeiro

A especialização inteligente na área central da cidade do Porto: domínios, ação pública e desafios

C. Ferreira, T. Sá. Marques, P. Guerra

\section{TICS Y NUEVOS ESPACIOS ECONÓMICOS}

Smart city research meets the geography of innovation. The smart city programme of Enel in Rio de Janeiro and Santiago de Chile

L. Carvalho

El Desarrollo Digital de los Hogares e Individuos. Una Tipología de Regiones Europeas

R. González-Relaño, A. L. Lucendo-Monedero, F. Ruiz-Rodríguez

Factores de Mayor Incidencia en la Adopción de Innovaciones TIC a Escala de Pais. Importancia de las Relaciones Directas e Indirectas Entre Factores

R. M. Jordá-Borrell, J. López-Otero, G. Contreras-Cabrera

De clústeres a microclústeres: coworkings como nuevos espacios económicos en el Distrito Textil de Trafalgar en Barcelona

R. Vicente-Salar, M. Pallares-Barbera, A. Vera-Martin 


\section{INOVACIÓN ECONÓMICA Y SOCIAL}

Redes de inovação no ecossistema da Região Centro de Portugal

T. Sá Marques, H. Santos, P. Ribeiro

Identificando Regiões de Referência na produção de conhecimento: o caso das publicações científicas voltadas para o Ébola

T. M. Mendes, T. Sá Marques, A. Monteiro, L. Carvalho

El papel de las redes en la innovación social: la ciudad de Valencia

J. Salom, M. Pitarch, R. Mesa, E. Margaix

Resiliencia en ciudades medias españolas: praxis económica y evidencias sociales en León y Oviedo

A. López González, P. B. del Pozo

Dinámicas espaciales recientes de las redes bancarias de España y Brasil: un estudio de las ciudades de Lleida y Presidente Prudente

Indagando en Sant Antoni (Barcelona) en torno a la relación de la bicicleta con la gentrificación

À. Cebollada, A. Sillero, E. Anaya

\section{COMERCIO Y SERVICIOS}

Propuesta metodológica para el estudio del uso y dinámicas del espacio público de las áreas comerciales de los centros urbanos

A. Vera, À. Cebollada, À. Pérez, M. Castelló

Multi-diversity clusters of commercial activities in the city of Porto: how neighbourhood concentrations shape the municipal hierarchy

M. Saraiva, T. Sá Marques, D. Ribeiro, P. Ribeiro

As feiras de rua em contextos metropolitanos: Porto e Barcelona

M. Ferreira, C. Maia, T. Sá Marques

El Fondo de Desarrollo de Vuelos de Canarias: incentivos públicos para nuevas rutas aéreas en un destino turístico maduro

Relaciones económicas España-México en la era de la globalización. Las exportaciones de España

J. L. A. Santos, M. T. S. Salazar 


\title{
Introdución: la geografía económica en red
}

\author{
Maria del Pilar Alonso (a), Teresa Sá Marques (b), Helder Santos (c) \\ (a) Universitat de Lleida, p.alonso@geosoc.udl.cat \\ (b) CEGOT/Faculdade de Letras da Universidade do Porto, teresasamarques@gmail.com \\ (c) CEGOT/Faculdade de Letras da Universidade do Porto, hfcs75@hotmail.com
}

El imaginario de los territorios en red ha merecido una atención creciente por parte de la geografía en general y de la geografía económica en particular. La narrativa del territorio en red parte de análisis contenidos dentro de fronteras territoriales (redes locales, redes regionales), evolucionando hacia lecturas multi-escalares de relaciones que atraviesan esas fronteras territoriales, conectando, desconectando y volviendo a conectar lugares próximos o distantes (redes globales multi-escalares).

La exploración de los sistemas locales y regionales (de producción, de distribución, de información, de conocimiento, de innovación, de emprendimiento, etc.) surge, normalmente, integrada en sistemas más globales. Así el desarrollo económico de los territorios está asociado a su capacidad para establecer, anclar y aprovechar esas relaciones multi-escalares. Mientras tanto, las redes no son realidades abstractas. Son formas de interacción, implicando a individuos, ideas, organizaciones e instituciones, todos ellos insertados en territorios concretos, subrayando el carácter geográfico de las redes.

En este contexto, este libro cuenta con la participación de numerosos investigadores españoles y portugueses que abordan diferentes temas y responden a la diversidad de desafíos a los que ha de hacer frente la disciplina de Geografía Económica que cada vez se tiene que apoyar en la formación de redes para la comprensión de los procesos económicos. Esta diversidad reúne a los investigadores en torno a diferentes temáticas y escuelas, pero también en torno a proyectos de investigación colectiva que pretenden satisfacer tanto las actuales agendas de la investigación como las necesidades de la acción política.

Empezamos esta publicación con las aportaciones de Ricardo Méndez y José Luis Sánchez Hernández, en ambas nos encontramos con reflexione sobre los desafíos que se plantean en el futuro a la investigación en geografía económica.

Ricardo Méndez (2020) desarrolla su reflexión en torno a cuatro puntos interrelacionados: las transformaciones y demandas del entorno, los enfoques teóricos y metodológicos, el contexto institucional de la geografía económica y las temáticas emergentes para la geografía económica. José Luis Sánchez Hernández (2020) responde a este desafío abordando cuatro aspectos interrelacionados: transformaciones y demandas del entorno, contexto institucional de la disciplina, enfoques teóricos y metodológicos y temáticas de investigación emergentes.

El resto de libro hemos recogido aportaciones al funcionamiento territorial en red, centrados en cuatro ejes: Especialización inteligente; Tic, nuevos espacios económicos y ciudades inteligentes; Innovación económica y social; Comercio y servicios. Han sido varios los artículos centrados en el papel de la especialización inteligente que abordan el desarrollo intensivo del conocimiento, subrayado el papel de las instituciones -verbigracia, las instituciones de enseñanza superior - y reflejado los abordajes a diferentes escalas: europea, nacional, regional y local. Se identifican ecosistemas de innovación basados en redes de producción de conocimiento e innovación que involucran a diferentes actores y escalas territoriales. Estas redes representan conexiones asociadas a procesos de creación, producción y transferencia de conocimiento e innovación que pueden desencadenar una especialización compartida y una variedad relacionada entre los diferentes actores de la región.

Mário Vale et al. (2020) analizan la contribución de los institutos politécnicos a la concretización de las prioridades de la RIS3, mientras que Rui Gama et al. (2020) se centran en el papel de la Universidad de Coímbra en el desarrollo regional. Estas contribuciones permiten redactar orientaciones para una mejor coordinación entre las instituciones de enseñanza superior y la economía regional.

Helder Santos et al. (2020) abordan la especialización inteligente siguiendo las redes de proyectos de I+D+i H2020 ancladas en Portugal, atendiendo a la Estrategia Nacional de Investigación e Innovación para una Especialización Inteligente (ENEI) y las Estrategias Regionales de Investigación e Innovación para una Especialización Inteligente (RIS3). Pretenden caracterizar de este modo los ecosistemas de innovación (nacional y regionales) que parecen surgir en el periodo inicial de la implementación de la Estrategia H2020. 
Teresa Sá Marques et al. (2020) estudian el ecosistema propio de la Región Centro de Portugal y los subsistemas regionales de innovación a partir de los proyectos de innovación impulsados por organizaciones con sede en la región (entre 2007 y 2015). Identifican las redes organizativas y territoriales presentes en este ecosistema, y las tendencias de la especialización. Con ello, pretenden reconocer el conocimiento base que hace posible esos procesos, y los sectores de aplicación a los que van dirigidos, para caracterizar las capacidades regionales orientadas a la estrategia regional de especialización inteligente.

A través de las publicaciones internacionales relacionadas con el ébola (entre 1995 y 2017, en base a Web of Science), Thiago Mendes et al. (2020) identifican las regiones más destacadas en los procesos de producción de conocimiento a lo largo del tiempo, y confirman que las regiones de los países que ya sufrieron crisis epidemiológicas tienden a integrar en los periodos siguientes al grupo de regiones de referencia.

La política de especialización inteligente, tal como fue propuesta por la Unión Europea, se dirige a la escala regional. Sin embargo, a escala local existen instrumentos de política de desarrollo del territorio que son estructurales para el desarrollo y la planificación territorial. Teresa Sá Marques et al. (2020) defienden que los instrumentos de la política local deben ser valorados en los procesos de construcción y aplicación de las políticas de especialización inteligente, y pusieron a prueba el abordaje en la ejecución del plan director municipal de Oporto. Célia Ferreira et al. (2020) se centran todavía más territorialmente, e identificn y caracterizan los dominios de especialización inteligente más evidentes, las dinámicas recientes y el papel de la acción pública en la zona central de la ciudad de Oporto.

Ángel Miramontes Carballada (2020) reflexiona sobre la aeronáutica como sector estratégico a escala internacional que plantea grandes exigencias en materia de desarrollo tecnológico, por lo que constituye una apuesta de las políticas públicas. Se centra en la comunidad autónoma de Galicia, evidencia la red de innovación existente tanto a nivel de instituciones privadas como públicas, y plantea toda una serie de interrogantes.

Otros artículos giran en torno a las TIC, los nuevos espacios económicos y las ciudades inteligentes. Estas ciudades se centran en el crecimiento inteligente, en una economía de conocimiento y en la fuerza de los datos en red. Últimamente, las TIC han estado muy relacionadas con las ciudades gobernadas por dispositivos en red que generan una multitud de datos. A través del «internet de las cosas» circulan datos sobre flujos, transportes, calidad del aire, estacionamiento, consumo de energía o residuos urbanos, entre otros. Esos desarrollos movilizan a diferentes tipos de actores, desde empresas multinacionales de tecnología a empresas y comunidades locales, construyendo diferentes geografías locales y globales, unas más duraderas y otras claramente temporales.

Luís Carvalho (2020) combina nociones de geografía económica con estudios sociotécnicos de la innovación para explorar cómo una cartera «móvil» de tecnologías de redes/ciudades inteligentes (desarrollada por una empresa global de servicios públicos de energía) se ancla y recombina en diferentes ciudades y redes. R. González-Relaño et al. (2020) enuncian las variables clave que definen el desarrollo digital de hogares e individuos, e identifican siete tipos de regiones europeas con diferente grado de desarrollo digital. Rosa M. Jordá-Borrella et al. (2020) modelan los factores que influyen en la adopción de innovaciones de TIC por parte de las empresas. Este modelo permitie subrayar la importancia de los procesos de globalización de las empresas y la existencia de un ambiente tecnológico asociado a las TIC. Terminan señalando la importancia de que las instituciones públicas apoyen el incremento del conocimiento TIC, el fomento de la legislación relativa a las TIC y el establecimiento de criterios de contratación pública dirigidos a la innovación y adopción de TIC.

La innovación socioeconómica y resiliencia urbana como resultado del impacto de la crisis económica y financiera son cuestiones que obligan al incremento en la formación de redes desde diferentes perspectiva y que las aportaciones de estudios concretos sobre distintas ciudades permiten comprender. Julia Salom et al. (2020) conceptualizan la importancia de la innovación social en cuanto estrategia de desarrollo, y evaluan la red de actores y los niveles de colaboración en la ciudad de Valencia (España). Para finalizar, plantean un conjunto de recomendaciones de carácter político que ponen en evidencia la necesidad de incrementar la gobernanza transversal y participativa asociada al liderazgo público, para aumentar la resiliencia de los procesos de innovación social y ampliarlos desde el punto de vista territorial. A. López González (2020) aborda la resiliencia de dos ciudades medias españolas (León y Oviedo) a partir del impacto de la crisis económica y financiera. Identifica patrones comunes de resiliencia, pero también diferencias derivadas de las especificidades de cada ciudad. Los resultados permiten orientar la toma de decisiones en las redes de ciudadanos y establecer compromisos públicos.

Ángel Cebollada et al. (2020) dan fe del proceso de cambio social y económico en determinados barrios de las grandes ciudades. En Barcelona, los procesos de globalización y de financiarización de la ciudad se reflejan en la dinámica del mercado inmobiliario - altamente desregulado por el gran atractivo turístico- y en la acusada gentrificación urbana. Los procesos de internacionalización dan lugar a cambios socioeconómicos dirigidos a atraer segmentos residenciales de rentas altas. En este panorama, la bicicleta desempeña un papel simbólico, porque representa una mejor calidad de vida en la ciudad y mejora el atractivo residencial.

R. Vicente-Salar et al. (2020) analizan el papel de las economías externas en las evolución productiva del distrito textil de Trafalgar. El clúster textil ha desaparecido casi por completo para dar lugar a microclústeres creativos y de conocimiento retratados en un creciente número de coworkings en el espacio urbano de Barcelona. La popularización de esta ciudad como lugar innovador atrajo a empresas y recursos humanos altamente cualificados, lo que 
derivó en la aparición de un nuevo "soho barcelonés». A ello contribuyeron tanto la oferta de servicios de apoyo empresarial, formativos y de animación social como la dinamización de sentimientos de pertenencia en torno a ciertos barrios-comunidades intraurbanas.

El comercio y los servicios eran las actividades centrales por excelencia de las ciudades, ya que modelaban las estructuras urbanas y polarizaban su funcionamiento. Como consecuencia de los acusados procesos de urbanización experimentados sobre todo a finales del siglo XX, estas actividades se desplazaron a la periferia urbana, abandonando parcialmente el casco antiguo. En la actualidad, además de la actividad de las áreas urbanas centrales y los procesos de gentrificación urbana (turismo y nuevos residentes), el comercio y ciertos servicios se encuentran inmersos en un proceso de reestructuración espacial. Aunque que los mercadillos en la calle han desempeñado un importante papel en la dinamización y animación de las ciudades, hay también otro aspecto que hay que valorar en la escena de las ciudades como es la agricultura urbana ocupa una nueva centralidad en las estrategias urbanas De estos temas se ocupan los siguientes capítulos del libro.

Ana Vera et al. (2020) analizan ocho ciudades medias de Cataluña y, basándose en el comercio, se centran en los usos y las dinámicas de los espacios públicos de los centros urbanos tradicionales en cuanto lugares cruciales para la producción de identidades y la intensificación de sociabilidades urbanas.

Miguel Saraiva et al. (2020) relacionan el comercio con los patrones morfológicos y analizan las jerarquías intraurbanas de la ciudad de Oporto. Al introducir en el análisis variables relacionadas con la proximidad geográfica, la morfología y los propios establecimientos comerciales permiten mejorar el conocimiento de la estructura comercial y la gestión del comercio urbano con vistas a un acceso más equitativo.

Márcio Ferreira et al. (2020) se centran en la animación urbana a partir de los mercadillos de calle en Oporto y Barcelona durante la crisis económica y financiera posterior a 2008. Su papel durante la crisis y después de ella se vio alterado. Las actividades vinculadas a una economía alternativa emergieron como respuesta a un acusado aumento del desempleo durante la crisis. Sin embargo, tanto lo que ofrecen como la demanda que atraen reproducen la segmentación socioespacial de las propias ciudades. Tras la crisis, desempeñaron funciones de animación urbana alternativa, si bien todavía siguen reproduciendo la segmentación socioespacial anteriormente existente.

Maria del Pilar Alonso et al. (2020) abordan la reestructuración de las redes bancarias y sus repercusiones espaciales en tiempos de crisis en Lleida (España) y Presidente Prudente (Brasil), entre 2008 y 2016. En las últimas décadas se han registrado cambios globales en la organización del sistema financiero -mayores interdependencias globales que se han traducido en la concentración económica del sector y en un incremento de los servicios a través de internet- que conllevan una mayor selectividad en la distribución territorial de las sucursales y agencias bancarias, y generan nuevos patrones espaciales en las ciudades.

La agricultura urbana responde a la demanda diaria de los consumidores residentes en una ciudad o metrópolis a través del uso del suelo disponible en las zonas urbanas y periurbanas. I.M. Madaleno (2020) se centró en la agricultura urbana presente en la ciudad de Panamá -cultivo de alimentos, especias y plantas medicinales- y en el comercio de plantas americanas y exóticas y sus usos.

Las infraestructuras siguen influyendo en las dinámicas del desarrollo económico. Por otro lado, las trayectorias culturales o económicas pueden fomentar nuevas dinámicas de cooperación que enlazan a los territorios.

David Ramos-Pérez (2020) evidencian la generalización de los incentivos públicos para la creación de nuevas conexiones aéreas debido a la liberalización del mercado comunitario del transporte aéreo. A partir del Fondo de

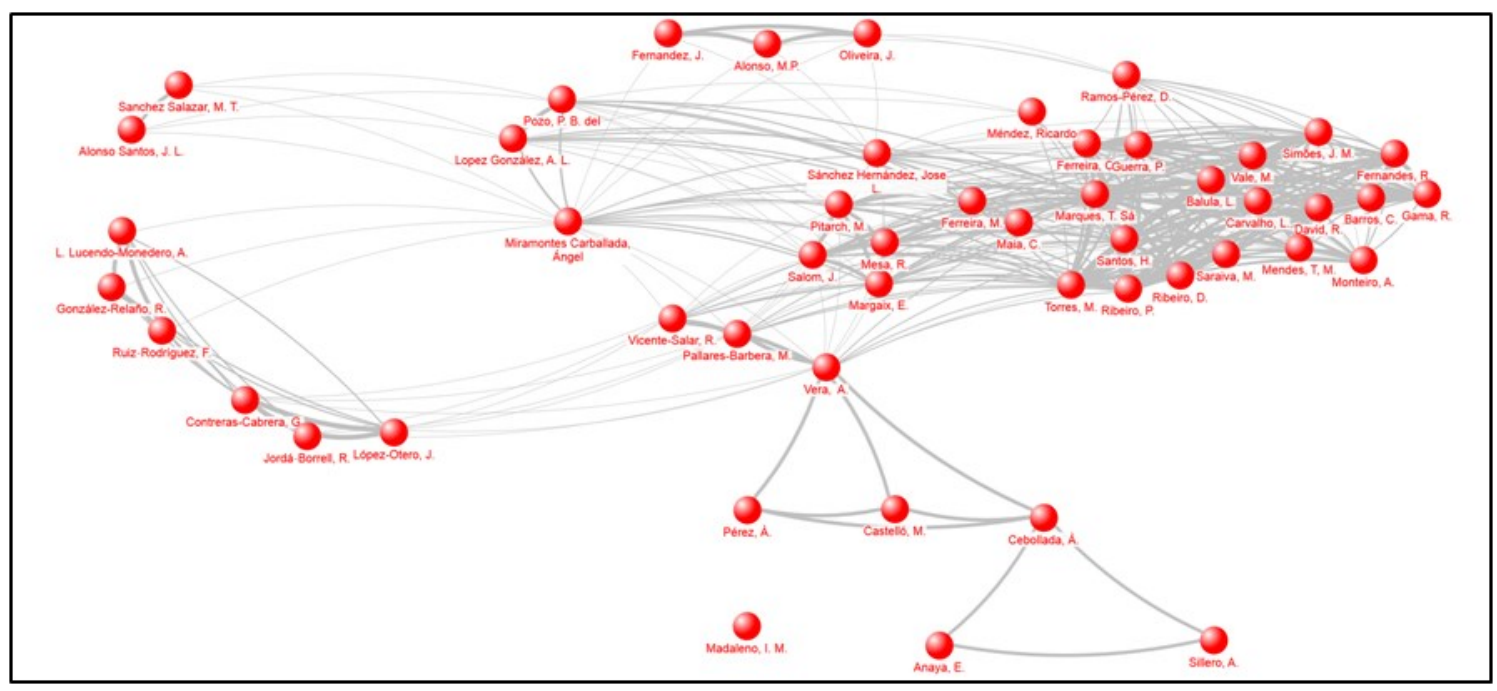

Figura 1. Proximidad de los autores de acuerdo la bibliografía común 
Desarrollo de Vuelos, en vigor desde 2014 en las islas Canarias - un destino turístico maduro y con una elevada conectividad aérea-, evalua el impacto de tales incentivos teniendo en cuenta los objetivos previamente definidos.

Las relaciones económicas entre España y México en la era de la globalización reflejan identidades históricas y afinidades culturales entre ambos países. José L. Alonso Santos et al. (2020) demuestran que la proximidad y la afinidad cultural deben ser incentivadas, ya que permiten abrir camino a nuevas inversiones económicas y al intercambio cultural. México puede convertirse en una plataforma de acceso al mercado centroamericano si se produce una apuesta estratégica por una mayor cooperación científica, cultural y económica.

En conclusión, La Geografía de las Redes Económicas y la Geografía Económica en Red permite incluir diferentes actividades de investigación llevadas a cabo por la comunidad científica del grupo de Geografía Económica de España, al que se sumó un importante número de investigadores de Portugal (figura 1). Al analizar los autores citados en la bibliografía de cada uno de los artículos de esta publicación, se pueden detectar varias comunidades científicas construidas a partir de esas referencias bibliográficas comunes. Los autores más citados en los artículos de esta publicación son R. Boschma, D. F. Campbell, E. G. Carayannis, P. A. Balland, H. Bathelt, R. Camagni, J. Glückler, B. A. Lundvall, R. Méndez y J. L. Sánchez Hernández.

\section{REFERENCIAS BIBLIOGRÁFICAS}

ALONSO, M.P; OLIVEIRA, J.; FERNÁNDEZ, F. (2020). Dinámicas espaciales recientes de las redes bancarias de España y Brasil: un estudio de las ciudades de Lleida y Presidente Prudente. In: M. Pilar Alonso Logroño, Teresa Sá Marques \& Helder Santos (Coord.), La Geografía de las Redes Económicas Y la Geografía Económica en Red, Porto, Faculdade de Letras da Universidade do Porto, Asociación de Geógrafos Españoles: 177-188. DOI: https://doi.org/10.21747/9789898969460/geoa17

ALONSO SANTOS, J. L.; SANCHEZ SALAZAR, M. T. (2020). Relaciones económicas España-México en la era de la globalización. Las exportaciones de España. In: M. Pilar Alonso Logroño, Teresa Sá Marques \& Helder Santos (Coord.), La Geografía de las Redes Económicas Y la Geografía Económica en Red, Porto, Faculdade de Letras da Universidade do Porto, Asociación de Geógrafos Españoles: 237-247. DOI: https://doi.org/10.21747/9789898969460/geoa23

CARVALHO, L. (2020). Smart city research metes the geography of innovation. The smart city programme of Enel in Rio de Janeiro and Santiago de Chile. In M. Pilar Alonso Logroño, Teresa Sá Marques \& Helder Santos (Coord.), La Geografía de las Redes Económicas Y la Geografía Económica en Red, Porto, Faculdade de Letras da Universidade do Porto, Asociación de Geógrafos Españoles: 91-98. DOI: https://doi.org/10.21747/9789898969460/geoa8

CEBOLLADA, À.; SILLERO, A.; ANAYA, E. (2020). Indagando en Sant Antoni (Barcelona) en torno a la relación de la bicicleta con la gentrificación. In: M. Pilar Alonso Logroño, Teresa Sá Marques \& Helder Santos (Coord.), La Geografía de las Redes Económicas Y la Geografía Económica en Red, Porto, Faculdade de Letras da Universidade do Porto, Asociación de Geógrafos Españoles: 189-197. DOI: https://doi.org/10.21747/9789898969460/geoa18

FERREIRA, C.; MARQUES, T. SÁ; GUERRA, P. (2020). A especialização inteligente na área central da cidade do Porto: domínios, ação pública e desafios. In M. Pilar Alonso Logroño, Teresa Sá Marques \& Helder Santos (Coord.), La Geografía de las Redes Económicas Y la Geografía Económica en Red, Porto, Faculdade de Letras da Universidade do Porto, Asociación de Geógrafos Españoles: 81-87. DOI: https://doi.org/10.21747/9789898969460/geoa7

FERREIRA, M.; MAIA, C.; MARQUES, T. SÁ (2020). As feiras de rua em contextos metropolitanos: Porto e Barcelona. In: M. Pilar Alonso Logroño, Teresa Sá Marques \& Helder Santos (Coord.), La Geografía de las Redes Económicas Y la Geografía Económica en Red, Porto, Faculdade de Letras da Universidade do Porto, Asociación de Geógrafos Españoles: 219-225. DOI: https:// doi.org/10.21747/9789898969460/geoa21

GAMA, R.; BARROS, C.; DAVID, R.; FERNANDES, R. (2020). Especialização inteligente e redes de conhecimento. A Universidade de Coimbra num contexto de globalização. In: M. Pilar Alonso Logroño, Teresa Sá Marques \& Helder Santos (Coord.), La Geografía de las Redes Económicas Y la Geografía Económica en Red, Porto, Faculdade de Letras da Universidade do Porto, Asociación de Geógrafos Españoles: 55-64. DOI: https://doi.org/10.21747/9789898969460/geoa5

LOPEZ GONZÁLEZ, A. L.; POZO, P. B. del (2020). Resiliencia en ciudades medias españolas: praxis económica y evidencias sociales en León y Oviedo. In: M. Pilar Alonso Logroño, Teresa Sá Marques \& Helder Santos (Coord.), La Geografía de las Redes Económicas Y la Geografía Económica en Red, Porto, Faculdade de Letras da Universidade do Porto, Asociación de Geógrafos Españoles: 167-175. DOI: https://doi.org/10.21747/9789898969460/geoa16

JORDÁ-BORRELLA, R. M.; LÓPEZ-OTERO, J.; CONTRERAS-CABRERA, G. (2020). Factores de mayor incidencia en la adopción de innovaciones tic a escala de pais. Importancia de las relaciones directas e indirectas entre factores. In: M. Pilar Alonso Logroño, Teresa Sá Marques \& Helder Santos (Coord.), La Geografía de las Redes Económicas Y la Geografía Económica en Red, Porto, Faculdade de Letras da Universidade do Porto, Asociación de Geógrafos Españoles: 109-117. DOI: https:// doi.org/10.21747/9789898969460/geoa10

GONZÁLEZ-RELAÑO, R.; L. LUCENDO-MONEDERO, A.; RUIZ-RODRÍGUEZ, F. (2020). El desarrollo digital de los hogares e individuos. una tipología de regiones europeas. In: M. Pilar Alonso Logroño, Teresa Sá Marques \& Helder Santos (Coord.), La Geografía de las Redes Económicas Y la Geografía Económica en Red, Porto, Faculdade de Letras da Universidade do Porto, Asociación de Geógrafos Españoles: 99-107. DOI: https://doi.org/10.21747/9789898969460/geoa9

MADALENO, I.M. (2020). Spices and Medicines Cultivated and Traded in Panama-City. In: M. Pilar Alonso Logroño, Teresa Sá 
Marques \& Helder Santos (Coord.), La Geografía de las Redes Económicas Y la Geografía Económica en Red, Porto, Faculdade de Letras da Universidade do Porto, Asociación de Geógrafos Españoles: 249-257. DOI: https://doi.org/10.21747/9789898969460/ geoa24

MARQUES, T. SÁ; SANTOS, H.; RIBEIRO, D.; RIBEIRO, P. (2020). Especialização Inteligente à Escala Urbana: Análise Dirigida ao Diagnóstico do PDM da Cidade do Porto. In: M. Pilar Alonso Logroño, Teresa Sá Marques \& Helder Santos (Coord.), La Geografía de las Redes Económicas Y la Geografía Económica en Red, Porto, Faculdade de Letras da Universidade do Porto, Asociación de Geógrafos Españoles: 65-79. DOI: https://doi.org/10.21747/978989896a9460/geoa6

MARQUES, T. SÁ; SANTOS, H.; RIBEIRO, P. (2020). Redes de inovação no ecossistema da Região Centro de Portugal. In: M. Pilar Alonso Logroño, Teresa Sá Marques \& Helder Santos (Coord.), La Geografía de las Redes Económicas Y la Geografía Económica en Red, Porto, Faculdade de Letras da Universidade do Porto, Asociación de Geógrafos Españoles: 141-150. DOI: https://doi.org/10.21747/9789898969460/geoa13

MENDES, T. M.; MARQUES, T. SÁ; MONTEIRO, A.; CARVALHO, L. (2020). Identificando Regiões de Referência na produção de conhecimento: o caso das publicações científicas voltadas para o Ébola. In: M. Pilar Alonso Logroño, Teresa Sá Marques \& Helder Santos (Coord.), La Geografía de las Redes Económicas Y la Geografía Económica en Red, Porto, Faculdade de Letras da Universidade do Porto, Asociación de Geógrafos Españoles: 151-158. DOI: https://doi.org/10.21747/9789898969460/ geoa14

MÉNDEZ, R. (2020). Desafíos de futuro para la investigación en Geografía Económica. In: M. Pilar Alonso Logroño, Teresa Sá Marques \& Helder Santos (Coord.), La Geografía de las Redes Económicas Y la Geografía Económica en Red, Porto, Faculdade de Letras da Universidade do Porto, Asociación de Geógrafos Españoles: 17-20. DOI: https://doi.org/10.21747/9789898969460/ geoa2

MIRAMONTES CARBALLADA, ÁNGEL (2020). La aeronáutica como sector estratégico en España. Situación actual y perspectivas en Galicia. In: M. Pilar Alonso Logroño, Teresa Sá Marques \& Helder Santos (Coord.), La Geografía de las Redes Económicas Y la Geografía Económica en Red, Porto, Faculdade de Letras da Universidade do Porto, Asociación de Geógrafos Españoles: 129138. DOI: https://doi.org/10.21747/9789898969460/geoa12

RAMOS-PÉREZ, D. (2020). El Fondo de Desarrollo de Vuelos de Canarias: incentivos públicos para nuevas rutas aéreas en un destino turístico maduro. In: M. Pilar Alonso Logroño, Teresa Sá Marques \& Helder Santos (Coord.), La Geografía de las Redes Económicas Y la Geografía Económica en Red, Porto, Faculdade de Letras da Universidade do Porto, Faculdade de Letras da Universidade do Porto, Asociación de Geógrafos Españoles: 227-235. DOI: https://doi.org/10.21747/9789898969460/ geoa22

SALOM, J.; PITARCH, M.; MESA, R.; MARGAIX, E. (2020). El papel de las redes en la innovación social: la ciudad de Valencia. In: M. Pilar Alonso Logroño, Teresa Sá Marques \& Helder Santos (Coord.), La Geografía de las Redes Económicas Y la Geografía Económica en Red, Porto, Faculdade de Letras da Universidade do Porto, Asociación de Geógrafos Españoles: 159-165. DOI: https://doi.org/10.21747/9789898969460/geoa15

SÁNCHEZ HERNÁNDEZ, JOSE L. (2020). Otras economías, otros espacios, otros retos para la Geografía Económica. In: M. Pilar Alonso Logroño, Teresa Sá Marques \& Helder Santos (Coord.), La Geografía de las Redes Económicas Y la Geografía Económica en Red, Porto, Faculdade de Letras da Universidade do Porto, Asociación de Geógrafos Españoles: 11-16. DOI: https:// doi.org/10.21747/9789898969460/geoa1

SANTOS, H.; MARQUES, T. SÁ; RIBEIRO, P.; TORRES, M. (2020). Especialização inteligente: as redes de projetos europeus H2020 com ancoragem em Portugal. In: M. Pilar Alonso Logroño, Teresa Sá Marques \& Helder Santos (Coord.), La Geografía de las Redes Económicas Y la Geografía Económica en Red, Porto, Faculdade de Letras da Universidade do Porto, Asociación de Geógrafos Españoles: 33-54. DOI: https://doi.org/10.21747/9789898969460/geoa4

SARAIVA, M.; MARQUES, T. SÁ; RIBEIRO, D.; RIBEIRO, P. (2020). Multi-diversity clusters of comercial activities in the city of Porto: how neighbourhood concentrations shape the municipal hierarchy. In: M. Pilar Alonso Logroño, Teresa Sá Marques \& Helder Santos (Coord.), La Geografía de las Redes Económicas Y la Geografía Económica en Red, Porto, Faculdade de Letras da Universidade do Porto, Asociación de Geógrafos Españoles: 209-217. DOI: https://doi.org/10.21747/9789898969460/ geoa20

VALE, M.; BALULA, L.; CARVALHO, L.; SIMÕES, J. M. (2020). Instituições de Ensino Superior e Especialização Inteligente: o contributo dos Institutos Superiores Politécnicos para a Implementação da RIS3 em Portugal. In: M. Pilar Alonso Logroño, Teresa Sá Marques \& Helder Santos (Coord.), La Geografía de las Redes Económicas Y la Geografía Económica en Red, Porto, Faculdade de Letras da Universidade do Porto, Asociación de Geógrafos Españoles: 23-31. DOI: https:// doi.org/10.21747/9789898969460/geoa3

VERA, A.; CEBOLLADA, À.; PÉREZ, A; CASTELLÓ, M. (2020). Propuesta metodológica para el estudio del uso y dinámicas del espacio público de las áreas comerciales de los centros urbanos. In: M. Pilar Alonso Logroño, Teresa Sá Marques \& Helder Santos (Coord.), La Geografía de las Redes Económicas Y la Geografía Económica en Red, Porto, Faculdade de Letras da Universidade do Porto, Asociación de Geógrafos Españoles: 201-207. DOI: https://doi.org/10.21747/9789898969460/geoa19

VICENTE-SALAR, R.; PALLARES-BARBERA M.; VERA-MARTIN, A. (2020). De clústeres a microclústeres: coworkings como nuevos espacios económicos en el Distrito Textil de Trafalgar en Barcelona. In: M. Pilar Alonso Logroño, Teresa Sá Marques \& Helder Santos (Coord.), La Geografía de las Redes Económicas Y la Geografía Económica en Red, Porto, Faculdade de Letras da Universidade do Porto, Asociación de Geógrafos Españoles: 119-128. DOl: https://doi.org/10.21747/9789898969460/geoa11 
Página intencionalmente dejada en blanco 


\section{DESAFÍOS PARA LA GEOGRAFÍA ECONÓMICA}


Página intencionalmente dejada en blanco 


\title{
Otras economías, otros espacios, otros retos para la Geografía Económica ${ }^{1}$
}

\author{
José Luis Sánchez Hernández \\ Universidad de Salamanca
}

La reflexión sobre el futuro de la investigación en Geografía Económica puede desarrollarse a partir de la definición misma de la disciplina. En un texto anterior (Sánchez, 2003), he propuesto definir la Geografía Económica como el estudio de la concreción desigual y diferenciada de la actividad económica en el territorio. En otras palabras, la Geografía Económica se afana por comprender, primero, cómo y por qué las actividades económicas se distribuyen de forma desequilibrada en el territorio y, segundo, cómo y por qué los agentes económicos operan de forma territorialmente distinta. La combinación contingente de ambas tendencias estructurales en cada territorio concreto (de escala local, regional, nacional) genera un paisaje o espacio económico diverso y también cambiante en el tiempo. Las corrientes o escuelas de pensamiento más actuales en Geografía Económica, como el enfoque relacional (Bathelt \& Glückler 2011) o el evolucionista (Boschma \& Martin eds. 2010), examinan esa concreción con herramientas conceptuales y metodológicas específicas. Por su parte, los grandes temas de interés actual que distinguen Barnes y Christhopers (2018: 42), a saber, las geografías del capitalismo, las geografías de las empresas, las geografías de la localización y las geografías económicas alternativas, desentrañan las particularidades de dicha concreción en procesos económicos determinados que implican interacciones entre todas las escalas geográficas, desde la global a la más puramente local.

En todo caso, y desde cualquier perspectiva teórica o preocupación temática, reflexionar sobre el futuro de la investigación en Geografía Económica requiere una reconsideración de las dos categorías básicas de la definición propuesta: la economía y el territorio. ¿Qué entendemos hoy por economía? ¿En qué territorios actúan actuamos- los agentes económicos para satisfacer nuestras necesidades? El resto de esta intervención se dedica a avanzar algunas ideas sobre ambas cuestiones, para terminar sintetizando los desafíos que plantean a la Geografía Económica unas nociones ampliadas de economía y de territorio como las que siguen a continuación y que, conviene aclararlo, están elaboradas desde una óptica básicamente española.

\section{REPENSANDO LA ECONOMÍA, OTRA VEZ}

Desde la aportación de Gibson-Graham (2008), al menos, la Geografía Económica es consciente de que la economía es un proceso social de satisfacción de las necesidades humanas mucho más amplio y diverso que el limitado conjunto de actores que operan en el mercado y de relaciones que se establecen su seno a través de un precio fijado en condiciones más o menos competitivas. Como quiera que la Geografía Económica española se ha dedicado, casi exclusivamente, al análisis de actividades de este tipo, se dibujan aquí dos potenciales líneas de trabajo que, sin ser del todo novedosas, han recibido muy escasa atención hasta el momento.

En primer término, el estudio de la profundísima reestructuración registrada en el sector público, que ha pasado de regirse por una lógica más o menos distributiva a adoptar condiciones de competencia que, en determinados ámbitos, generan pingües beneficios. Es el caso de los sectores productivos que se han liberalizado en

${ }^{1}$ Este texto se encuadra en el proyecto de investigación "Espacios y prácticas económicas alternativas para la construcción de la resiliencia en las ciudades españolas" (20162018). Programa Estatal de Investigación, Desarrollo e Innovación Orientada a los Retos de la Sociedad - financiado por el Ministerio de Economía, Industria y Competitividad y por el Fondo Europeo de Desarrollo Regional (FEDER), referencia CSO2015-65452-R (MINECO/FEDER). Este proyecto participa en la Red de Excelencia "Retos para las ciudades del siglo XXI: una agenda de investigación para la construcción de espacios urbanos sostenibles e innovadores" (junio de 2017 - junio de 2019 ). Plan Estatal de Fomento de la Investigación Científica y Técnica de Excelencia 2013-2016, referencia CSO2016-81718-REDT. 
las últimas décadas tras la disolución de los monopolios estatales requerida por el ingreso en la Unión Europea, caso de la distribución de agua y energía o del transporte aéreo y ferroviario. No sabemos mucho sobre las estrategias espaciales de las compañías que distribuyen agua, energía, personas y mercancías por el territorio español y lo conectan con el exterior. Una geografía económica de grandes corporaciones como lberia, Renfe, Repsol, ENDESA, Iberdrola, o de conglomerados como Ferrovial, ACS o Eulen, todos ellos estrechamente dependientes de la regulación y/o el presupuesto de las Administraciones Públicas, generaría un conocimiento tan atractivo para la Academia como útil a la Sociedad que la sustenta.

En esta misma línea hay que subrayar la necesidad de considerar la vertiente espacial de otras actividades económicas formales, pero no destinadas a la venta, como los servicios públicos. La persistente denuncia genérica de los efectos demoledores de las políticas de austeridad sobre el modesto Estado del bienestar español tampoco ha venido acompañada de una indagación cuidadosa sobre la reestructuración espacial de la oferta de los servicios públicos fundamentales; el estudio de Hamnet (2014) sobre el Reino Unido puede servir como punto de partida para un apasionante programa de investigación en España. En particular, conviene dedicar un esfuerzo riguroso y sostenido a una cuestión largamente debatida como es la de la paulatina penetración de la lógica del mercado -y la competencia- en los servicios públicos que todavía permanecen en manos del Estado (educación, sanidad, asistencia social), al menos en la mayor parte de sus respectivos campos de actuación.

El caso de la enseñanza universitaria es suficientemente ilustrativo del impacto que tiene la introducción de la competencia como principio parcialmente orientador (al menos, y de momento) en una actividad tradicionalmente ajena al escrutinio del mercado. Es bien conocido el efecto que la economía de la prescripción tiene en actividades concretas como la alta cocina o el mundo del vino. La publicación periódica de guías (Michelin, Parker) que ensalzan unos locales o productos y relegan otros puede decidir el destino económico no sólo de determinadas empresas, sino también de los territorios donde actúan y que generan los recursos tangibles e intangibles que comercializan esas compañías. La normalización y estandarización de las condiciones de acceso a y promoción en la carrera científico-universitaria se traduce en el envío masivo de artículos a las revistas con factores de impacto más elevados, mientras las menos citadas languidecen con frecuencia por falta de originales y terminan por desaparecer o caer en el más triste de los olvidos.

Del mismo modo empiezan a actuar los tan traídos y llevados ranking de universidades. Originarios de contextos culturales muy distintos, celosos de la libre competencia y de la minimización de la intervención pública en la vida social y económica, su llegada a la Europa meridional no será neutral desde una perspectiva geográfica. Siguiendo la lógica del mercado, las universidades mejor calificadas en los ranking reciben más fondos del sector privado (becas a estudiantes con talento, financiación de investigaciones, donaciones de antiguos alumnos) e incluso de gobiernos de países en desarrollo que buscan una formación de excelencia para sus élites. Cuando los gobiernos autonómicos en España se plantean distribuir sus presupuestos entre las universidades de su región conforme a contratos-programa vinculados a la consecución de ciertos objetivos, se está introduciendo también una lógica de competencia en el sistema universitario que tiene, sin duda, algunos efectos positivos en un entorno regulatorio con frecuencia ayuno de estímulos, pero cuyas consecuencias territoriales a largo plazo deben ser analizadas con detenimiento. La definición de la calidad de una universidad conforme a estos criterios competitivos (por ejemplo, la llamada "empleabilidad" de sus titulados) puede estar detrás de la burbuja de universidades privadas que se especializan, precisamente, en la oferta de estudios muy cotizados en el mercado laboral y pueden exhibir altas tasas de inserción profesional en comparación con otros centros públicos que portan la pesada carga de enseñar saberes anticuados o inútiles. Tampoco se sabe mucho, por cierto, sobre los actores que impulsan estas universidades privadas y los patrones geográficos que guían sus decisiones de inversión. Desconozco ahora si desde otras disciplinas se han elaborado estudios concretos, pero desde luego los geógrafos económicos en España no hemos analizado la relación entre los factores territoriales y los resultados de las universidades medidos en términos de estudiantes, publicaciones, financiación... ni el impacto que la economía de la prescripción tiene sobre dicha relación. ¿Cuál es la capacidad de una universidad mal financiada en una región o provincia poco desarrollada para competir con centros bien calificados y localizados en regiones ricas, con presupuestos públicos mejor dotados y un tejido económico intensivo en conocimiento? ¿Qué consecuencias traerá la competencia interuniversitaria sobre ciudades medias con universidades poco especializadas que se fundaron por razones distributivas?

Lamentablemente, no es la enseñanza universitaria la única actividad económica de servicio público afectada por la extensión de la lógica del mercado y la competencia de una forma, además, territorialmente diferenciada. También la sanidad y la asistencia social, por ejemplo a personas mayores o dependientes, se ha convertido en un mercado donde operan grupos privados de dimensión creciente cuya lógica espacial está todavía por desvelar- 
se. A la par, la percepción popular de que esos mismos servicios se prestan por el sector público con una dotación de recursos muy desigual entre las regiones españolas es confirmada por algunos informes especializados (García y otros. 2018) que ponen de relieve unas formas de desigualdad e injusticia social y espacial que tampoco se han tenido en consideración desde la Geografía Económica.

A la vez que trata la transformación, parcial pero patente, de determinados servicios públicos en mercados crecientemente sujetos a la competencia, la Geografía Económica española de los próximos años debería también tomar en consideración las modalidades de coordinación económica que se reclaman ajenas, distintas o contrarias al capitalismo convencional centrado en la búsqueda del beneficio personal, en la empresa privada como unidad básica de organización de la producción, en el mercado competitivo como espacio de interacción y en la relación salarial como vía principal de acceso personal a las rentas.

La primera de todas esas formas distintas de coordinación económica es la economía doméstica, de la reproducción y de los cuidados, que es la base imprescindible de toda forma de sociedad humana, sea capitalista o no. En el hogar se hace patente la existencia y sostenibilidad de otras formas no retribuidas ni lucrativas de coordinación económica, como el altruismo, la redistribución y la reciprocidad (recuérdese aquí el imprescindible texto de Karl Polanyi La Gran Transformación, 1944). La economía feminista lleva muchos años reivindicando la centralidad de la esfera doméstica en el entramado socioeconómico y denunciando con fuerza, una vez más, su mercantilización a manos de la expansión social de las relaciones capitalistas, que está generando tensiones y desigualdades entre quienes pueden pagar en el mercado por los servicios de cuidados (del hogar, de niños, de ancianos, de enfermos) y quienes no pueden hacerlo. Se trata de una tensión especialmente lacerante porque los estudios de White y Williams (2012, entre otros muchos) en el Reino Unido demuestran una preferencia mayoritaria por cubrir los cuidados a través de relaciones comunitarias con familiares, amigos y vecinos, y no mediante la contratación impersonal de servicios o suministros externos. Según dichos autores, esa preferencia explicaría el hecho de que hasta el $44 \%$ del tiempo sea dedicado a trabajo doméstico no remunerado en los países avanzados, cifra que contradice la tesis de que vivimos en una sociedad exclusivamente regida por las relaciones mercantilizadas. Existe aquí, pues, un punto de confrontación entre percepción y realidad, entre deseo y posibilidad, que merece una lectura geográfica, ya que los trabajos de estos autores apuntan a diferencias territoriales apreciables en el continuo autoabastecimiento-externalización de la economía de los cuidados.

Este apego social hacia soluciones económicas no competitivas ni lucrativas se manifiesta también en la persistencia de lo que Gibson-Graham (2008) denominaron economías comunitarias y otros autores califican como prácticas económicas alternativas (Conill y otros 2012). Bancos de tiempo, huertos urbanos, grupos de consumo, monedas sociales, mercados de productores, talleres Do It Yourself, repair cafés, junto con fórmulas más complejas como la banca ética, el comercio justo, las cooperativas integrales, la agricultura ecológica o las criptomonedas, comparten la visión de que otra economía es posible (Castells y otros, 2017). Estas prácticas económicas alternativas se componen de pequeñas comunidades que practican una democracia directa, comparten las tareas de manera equitativa, excluyen el lucro de sus objetivos y manifiestan un profundo respeto por la naturaleza en todos los órdenes de su actividad productiva (Sánchez 2017). Recientemente, se ha puesto en marcha un proyecto de investigación en España dedicado al estudio del funcionamiento interno y el impacto económico de estas prácticas en algunas ciudades españolas (PRESECAL [en línea]). Con todo, hace falta una labor más sostenida en el tiempo y más extensiva en el espacio para evaluar la auténtica magnitud del fenómeno de las economías alternativas y, sobre todo, su capacidad para construir esa economía diferente, más humana, democrática y sostenible que resulta tan atractiva en el discurso como difusa en la realidad concreta.

Particular interés reviste la investigación sobre la relación entre estas formas de coordinación económica horizontal y el capitalismo global contemporáneo. La agricultura ecológica comenzó como un movimiento extravagante, pero hoy todos los supermercados ofrecen comida bio, eco, orgánica... Lo que fueron propuestas puramente colaborativas y desinteresadas como AirBnB o Uber se han convertido, gracias a las posibilidades de las plataformas digitales, en negocios sumamente lucrativos cuyas externalidades negativas se proyectan en el espacio urbano de mucha ciudades. Del mismo modo, el proyecto MARES, promovido en Madrid por el gobierno municipal surgido de las elecciones de 2015 y una serie de colectivos ciudadanos involucrados en distintas modalidades de economía comunitaria, recibe financiación de la Unión Europea, habitualmente denostada como avalista de las políticas de austeridad. El debate sobre el riesgo de convencionalización de las economías comunitarias y su posible cooptación por parte del sistema capitalista y el Estado, entendido en sentido amplio, permanece abierto y corresponde a los geógrafos indagar sobre las diversas formas en que se resuelve esa tensión en territorios con trayectorias económicas, sociales y políticas específicas. 


\section{OTROS ESPACIOS ECONÓMICOS}

Tras apuntar la conveniencia de examinar la concreción desigual y diferenciada de una serie de actividades económicas en el territorio, es preciso advertir que los espacios donde actúan los agentes económicos también han cambiado en los últimos años. La Geografía Económica debe ahora ocuparse de dos espacios económicos no convencionales que interactúan entre sí y a la vez se complementan con el espacio público donde se desenvuelve la vida económica más tangible: se trata del hogar y el ciberespacio.

El hogar no es solamente la sede de la economía de los cuidados, sino también un espacio significativo para el desarrollo de un número creciente de actividades económicas muy dependientes de las tecnologías digitales y de la creatividad, así como de otras sumergidas en la precariedad y la marginalidad. ¿Cuántas empresas comienzan su andadura en un domicilio particular, como ilustra la monografía colectiva de Mason y otros (2016)? ¿Cuánto trabajo intelectual se efectúa en el hogar? ¿Qué ha sido del teletrabajo, una de las primeras esperanzas y temáticas surgidas tras la difusión de Internet? Sabemos que las TIC han extendido el horario -y con él, el espacio - de trabajo hasta el punto de que en Francia acaba de aprobarse el derecho del trabajador a no contestar correos electrónicos fuera de la jornada laboral. Pero la desmaterialización de numerosas tareas productivas hace muy difícil ya deslindar con nitidez el trabajo ordinario en espacios convencionales del que se efectúa en otros espacios frecuentados por el trabajador, incluyendo aquí el desplazamiento en trenes o aviones, y las consiguientes esperas en estaciones o aeropuertos. Tampoco tenemos claro si la impresión en 3D va a propiciar un retorno a los hogares de algunas actividades productivas y un consiguiente rediseño de las ciudades y de las cadenas de valor, como sugiere la monografía coordinada por Nawratek ed. (2017).

En el otro extremo, el ciberespacio todavía no ha despertado el interés de la Geografía Económica española, aunque ya hay trabajos estupendos basados en big data, como los del grupo de investigación t-GIS [en línea] dirigido por Javier Gutiérrez Puebla. La geografía física del ciberespacio español (redes de cableado, nodos de conexión, ubicación de los centros de almacenamiento de datos) y la gestión del tráfico de datos (volumen de flujos, tarifas asociadas, empresas operadoras) son asuntos poco conocidos. La indagación sobre esta interfaz ciberespacio-espacio extenso no se debe limitar, en todo caso, a la escala nacional, dado que la red tiene dimensiones mundiales a través del cableado submarino y los satélites de comunicaciones, cuya gestión neutral está precisamente en cuestión en estos tiempos.

Ahora bien, también la interfaz ciberespacio-hogar encierra temas de interés geográfico. Las implicaciones de la generación de infinidad de datos en nuestra vida cotidiana ya fueron teorizadas por Echeverría (1994) en su Telépolis, donde define el telesegundo como una mercancía que los espectadores producimos gratuitamente cuando vemos un programa de televisión y que las cadenas televisivas revenden a las empresas de publicidad. El hogar, pues, no es solamente un espacio de los cuidados o un espacio productivo no convencional, sino también un yacimiento de riqueza -en forma de datos- explotada por toda clase de compañías. Ahora bien, habrá que considerar con detalle la distribución regional y local de esa riqueza digital y las posibles desigualdades territoriales en la oferta de bienes y servicios que las empresas produzcan en función de la rentabilidad esperada de cada hogar, barrio, ciudad o región.

El comercio electrónico es otro nexo entre el hogar y el ciberespacio con profundas implicaciones geográficas por su efecto directo sobre la actividad logística y sobre el despliegue espacial del comercio minorista tradicional. El célebre problema de la última milla sigue sin resolverse -probablemente porque es insoluble- y aparecen nuevas fórmulas como el reparto con drones, en bicicleta o, quizá pronto, mediante automóviles autónomos. Como toda forma de comercio, el comercio electrónico (y sus implicaciones en otras ramas de la economía, en el mercado de trabajo y en la reconfiguración de la ciudad) es un proceso netamente geográfico al que tampoco se ha atendido debidamente en España, pese a la rápida penetración de esta forma de distribución en los años más recientes.

Finalmente, toda investigación sobre los espacios económicos, en su versión más clásica o en esta formulación extendida, debería ir acompañada de una meta-reflexión sobre la posición relativa de cada uno de ellos en el paisaje económico global. Desde el artículo clásico de Inmaculada Caravaca (1998), la Geografía Económica española está habituada a identificar y caracterizar los espacios ganadores y emergentes. Esa labor de síntesis requiere una actualización periódica que la misma autora ya ha intentado recientemente (Caravaca, 2017) y que debe acompañarse de una atención no menor a los espacios perdedores y rezagados, en la línea propuesta por Rodríguez-Pose (2018) para relacionar la trayectoria económica de los territorios y la irrupción de partidos políticos de dudosas convicciones democráticas. 


\section{HACIENDO GEOGRAFÍA ECONÓMICA}

Ante una economía más compleja que se desenvuelve en espacios económicos más diversos, la Geografía Económica española se enfrenta a varios retos disciplinares si quiere seguir siendo fiel a la definición propuesta al comienzo de este texto, con independencia del marco teórico que adoptemos sus practicantes o de la cuestión empírica que se procure iluminar en cada investigación concreta.

Primero, hay que manejar nuevas fuentes de información, como big data y los conjuntos de datos abiertos que ofrecen las administraciones más comprometidas con la transparencia y la ciudadanía. Pero las técnicas cualitativas tradicionales (entrevistas, observación de campo, grupos de discusión...) seguirán siendo imprescindibles para estudiar los hogares, las economías alternativas o las estrategias de las grandes compañías, entre otros temas sobre los que falta información estadística sistematizada. Esta esquizofrenia metodológica nos obligará a conocer el manejo de aplicaciones informáticas muy dispares con el fin de almacenar los datos, organizarlos, extraer sus múltiples significados y después elaborar representaciones carto-gráficas expresivas y, a ser posible, explicativas en sí mismas.

Por eso, en segundo lugar, será cada vez más difícil trabajar de forma individual; ya lo es, en realidad, si reparamos en el decreciente número de publicaciones firmadas por una sola persona. Incluso los grupos de investigación pequeños y mono-disciplinares -típicos de la Geografía Económica española- experimentan ya notables complicaciones para dominar las competencias teóricas, metodológicas e instrumentales que requiere la investigación puntera. La participación en marcos interdisciplinares y la constitución de extensas redes de investigación integradas por nodos locales más o menos especializados en ciertos temas y técnicas se impondrá como fórmula organizativa habitual, al estilo de la RETURBAN [en línea] que funciona en España desde 2017.

Tercero, y último. Las dos constataciones precedentes no son inocuas para el desempeño cotidiano de nuestra investigación. Quienes sentimos pasión por la Geografía Económica sufriremos -más todavía- la desagradable sensación de llegar tarde a todos los temas, o de no saber lo suficiente sobre tantas líneas de investigación cruciales como caben en el seno de nuestra querida disciplina. Y esa desazón se verá acrecentada por la imperiosa necesidad de dedicar una fracción creciente de nuestro tiempo -el bien más preciado por su naturaleza finita- a la coordinación de personas, actividades y recursos, en detrimento de la lectura reposada, de la reflexión calmada y de la escritura sosegada. Sólo las ganas de saber más Geografía Económica nos mantendrán activos, mientras el cuerpo aguante.

\section{BIBLIOGRAFÍA}

BARNES, T.J. \& CHRISTOPHERS, B. (2018). Economic Geography: a Critical Introduction. Oxford: Wiley-Blackwell.

BATHELT, H. \& GLÜCKLER, J. (2011). The Relational Economy. Geographies of Knowing and Learning. Oxford: Oxford University Press.

BOSCHMA, R.A. \& MARTIN, R. eds. (2010). The Handbook of Evolutionary Economic Geography. Chentelham: Edward Elgar.

CARAVACA BARROSO, I. (1998). Los nuevos espacios emergentes. Revista de Estudios Regionales, 50, 39-80.

CARAVACA BARROSO, (2017). Globalización neoliberal y crisis en los espacios ganadores y emergentes. Ciudad y Territorio Estudios Territoriales, $\quad$ 194, 613-628.

CASTELLS, M. y otros (2017). Otra economía es posible. Cultura y economía en tiempos de crisis. Madrid: Alianza Editorial.

CONILL, J. y otros (2012). Otra vida es posible: prácticas económicas alternativas durante la crisis. Barcelona: Editorial UOC.

ECHEVERRÍA, J. (1994). Telépolis. Barcelona: Destino.

GARCÍA, G.; BARRIGA, L. RAMÍREZ, J.M., ZUBIRÍA, A., VELASCO, L. \& IZQUIERDO, A. (2018). Índice DEC - Índice de Desarrollo de los Servicios Sociales 2017. Asociación Estatal de Directoras y Gerentes en Servicios Sociales.

GIBSON-GRAHAM, J.K. (2008). Diverse Economies: Performative Practices of 'Other Worlds'. Progress in Human Geography, 32, 613-632.

HAMNETT, CH. (2014). Shrinking the Welfare State: the Structure, Geography and Impact of British Government Benefit Cuts. Transactions of the Institute of British Geographers, 39, 490-503.

MASON, C., REUSCHKE, D., SYRETT, S. \& VAN HAM, M. eds. (2016). Entrepreneurship in Cities: Neighbourhoods, Households and Homes. Northampton: Edward Elgar.

NAWRATEK, K. ed. (2017). Urban re-industrialization. Goleta (CA): Punctum Books. 
POLANYI, K. (1944). La gran transformación. Los orígenes políticos y económicos de nuestro tiempo. México: Fondo de Cultura Económica (edición de 2003).

PRESECAL <en línea> Espacios y prácticas económicas alternativas para la construcción de la resiliencia en las ciudades españolas. URL: https://www.researchgate.net/project/Espacios-y-practicas-economicas-alternativas-para-la-construccion-dela-resiliencia-en-las-ciudades-espanolas-IP-Jose-Luis-Sanchez-Hernandez

RETURBAN <en línea> Red de Grupos de Investigación sobre conocimientos, técnicas y experiencias innovadoras para desarrollar y gestionar espacios urbanos sostenibles y resilientes, desde una perspectiva económica, espacial y social. URL: Www.returban.com

RODRÍGUEZ-POSE, A. (2018). The revenge of places that don't matter (and what to do about it). Cambridge Journal of Regions, Economy and Society, 11, 189-209.

SÁNCHEZ HERNÁNDEZ, J.L. (2003). Naturaleza, localización y sociedad. Tres enfoques para la Geografía Económica. Salamanca: Ediciones Universidad de Salamanca.

SÁNCHEZ HERNÁNDEZ, J.L. (2017). Las prácticas económicas alternativas en perspectiva geográfica. Salamanca: Ediciones Universidad de Salamanca (edición institucional).

t-GIS - Transporte, Infraestructura y Territorio <en línea>: https://www.ucm.es/tgis

WHITE, R.J. Y WILLIAMS, C.C. (2012). The Pervasive Nature of Heterodox Economic Spaces at a Time of Neoliberal Crisis: towards a "Postneoliberal" Anarchist Future. Antipode, 44, 1625-1644. 


\title{
Desafíos de futuro para la investigación en Geografía Económica
}

\author{
Ricardo Méndez \\ Profesor Honorífico Departamento de Geografía \\ Universidad Complutense de Madrid
}

Toda disciplina científica necesita hacer de forma periódica un esfuerzo de transformación o adaptación para mantener su vigencia tanto en el plano científico como por su capacidad de respuesta ante los nuevos retos y la Geografía Económica no es una excepción. Ese desafío se ve dificultado por la amplia diversificación -tanto teórica como metodológica, en las técnicas de análisis o en las líneas de investigación- que la caracteriza. cionados:

Para poder dar una respuesta suficiente, ese esfuerzo debería considerar al menos cuatro aspectos interrela-

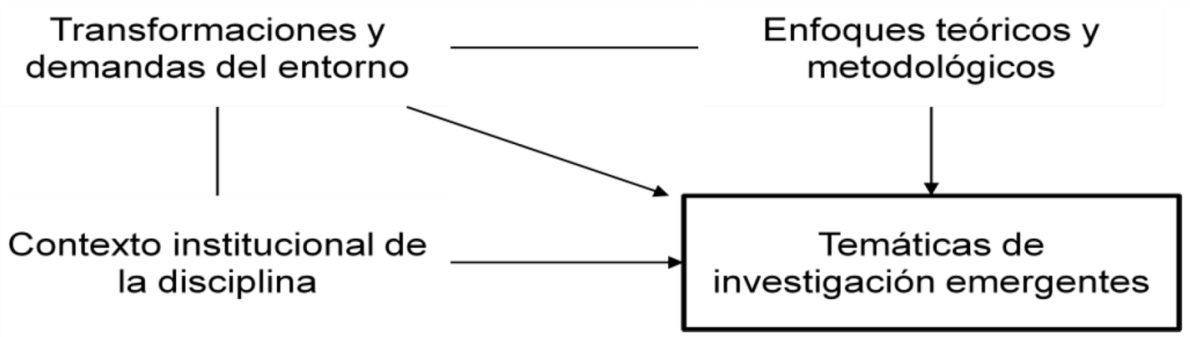

\section{a) Transformaciones y demandas del entorno}

Transcurrida una década desde el estallido de la profunda crisis identificada con frecuencia como la Gran Recesión, cabe pensar que estamos en un periodo de transición similar en cierto modo al que tuvo lugar tras las anteriores grandes crisis del capitalismo. A partir de esta hipótesis interpretativa, este periodo parece caracterizado por:

- La profundización de ciertas tendencias anteriores a la crisis (desarrollo de las tecnologías digitales y sus aplicaciones en el ámbito de la robotización, así como de la biogenética, reforzamiento de la agenda neoliberal tras la aplicación de políticas de austeridad fiscal, intensificación en los procesos de financiarización, etc.).

- La aparición de ciertos cambios significativos (en las relaciones geoeconómicas o el cuestionamiento del libre comercio a escala global, la emergencia de un nuevo ciclo inmobiliario o de prácticas económicas alternativas a escala local, etc.).

- El aumento de ciertas contradicciones (la difusión de la precariedad, incluso en ciertos segmentos laborales cualificados, la creciente polarización social, el deterioro ambiental, etc.).

En un contexto de elevada incertidumbre respecto a las tendencias de futuro, tanto en el plano económico como territorial, parece conveniente recordar dos ideas en absoluto nuevas, pero que cobran especial importancia. Por un lado, la necesidad de orientar la investigación en geografía económica hacia temáticas que, junto a su interés científico, sean relevantes y capaces de conectar con las demandas del entorno. Por otro, una mayor atención a completar los análisis con propuestas o alternativas que puedan contribuir al debate colectivo sobre cuestiones que despierten interés más allá del restrictivo mundo académico. 


\section{b) Enfoques teóricos y metodológicos.}

Los estudios de geografía económica no pueden ser hoy ajenos al patrimonio que han supuesto los sucesivos giros epistemológicos que han impregnado buena parte de las ciencias sociales y también de nuestra disciplina, ayudando a renovar y ampliar las temáticas, las interpretaciones y, en ocasiones, las técnicas de investigación.

En una evidente simplificación, con esto se alude al giro cultural, que ayudó a considerar la influencia de factores no racionales en los comportamientos económicos, o el protagonismo de actores influidos por su propia subjetividad y por el ambiente sociocultural de pertenencia. Al giro institucional, que destacó la influencia de los valores, normas o convenciones en las estrategias espaciales de esos actores, así como de las reglas formales y normas legales, las organizaciones o la acción del gobierno, que puede dar origen a formas de regulación diversas según esos contextos. Al giro relacional, que puso en evidencia la importancia de la interacción, la creación de capital relacional/social a que puede dar lugar, las externalidades que puede generar la pertenencia a una red, o la multiescalaridad de los flujos materiales e inmateriales que constituyen la base de esas redes. Finalmente, al giro evolucionista, que nos recordó la influencia de la trayectoria histórica de cada territorio a la hora de entender sus dinámicas actuales, el carácter acumulativo de los procesos, o la existencia de inercias espaciales no explicables sólo en términos de racionalidad.

No obstante, este tipo de enfoques que pueden calificarse como postestructuralistas dejaron de lado la permanente influencia de ciertas tendencias generales cuya interpretación remite al margen de posibilidades y de limitaciones que define la evolución del sistema capitalista en sus sucesivas fases de desarrollo. La profunda crisis sistémica desatada hace una década debería recordarnos la sucesión de periodos de expansión y de crisis que se repiten de forma cíclica, la consiguiente importancia de los procesos estructurales para entender lo que ha ocurrido en nuestros países en las últimas décadas (y de conceptos como régimen de acumulación o modo de regulación), así como la historicidad de las soluciones espaciales adoptadas en cada momento y lugar.

\section{c) Contexto institucional de la Geografía Económica.}

Hacer frente a esos desafíos exige también no ignorar algunas circunstancias relacionadas con la posición de la propia disciplina en el marco de la evolución registrada por la relación con otras disciplinas próximas, con las que se comparten temáticas, conceptos, técnicas de análisis, etc., las exigencias actuales del entorno académico y la posición ocupada en el ámbito de la enseñanza universitaria.

Desde esta perspectiva, parece evidente que desde su aparición a finales del pasado siglo, se mantiene una relación asimétrica con la denominada por Krugman y otros como nueva geografía económica, que supone medida en buena una evolución de la economía espacial, planteando la necesidad de debatir hasta qué punto desde la geografía se opta por un seguimiento de sus temáticas y metodologías de investigación para acceder a determinadas revistas internacionales, o bien se definen con claridad enfoques alternativos y fundamentados. Al mismo tiempo, los estudios de geografía económica parecen haber sufrido cierto retroceso relativo en el interés que suscitaban hace tres décadas -al menos en casos como el español- ante el mayor dinamismo de otras temáticas, lo que se puede reflejarse en una proporción relativamente modesta de artículos, tesis doctorales, etc., dentro del conjunto de la producción geográfica; los actuales planes de estudio en bastantes universidades tampoco favorecen la posibilidad de una enseñanza suficiente de la disciplina, lo que es otro desafío a considerar.

\section{d) Temáticas emergentes para la geografía económica.}

En el transcurso de las tres últimas décadas, la geografía económica ha experimentado un proceso de expansión y especialización de sus temáticas de investigación, con una mayor fragmentación y heterogeneidad de sus contenidos y métodos. Ese proceso es común a muchas ciencias sociales a lo largo de su ciclo de vida, pero dificulta la pretensión de ofrecer una propuesta sobre temáticas a desarrollar en el próximo futuro, lo que exige algún criterio de selección.

Puede ser de utilidad en este sentido recordar lo que Mattei Dogan y Robert Pahre, en su libro sobre "Las nuevas ciencias sociales", llamaron la paradoja de la densidad, señalando que en toda disciplina científica existe un núcleo consolidado de temáticas que cuentan con numerosos investigadores e investigaciones ya realizadas, lo que permite avanzar tan sólo mediante pequeñas innovaciones incrementales al incorporar nuevos casos de estu-dio, profundizar en algún aspecto concreto, etc. Pero, al mismo tiempo, existen unas márgenes de la disciplina en donde se sitúan determinadas temáticas ignoradas o apenas trabajadas pero que cobran un interés creciente, o bien temáticas híbridas, en las que se confluye con otras disciplinas y se intercambian conceptos, teorías, técnicas de análisis, fuentes de información, etc., siendo en esas márgenes donde podrían lograrse innovaciones y avances más significativos. 
Con ese criterio, conscientes de la existencia de un núcleo de temáticas consolidado y aceptado dentro de la geografía económica que sigue teniendo plena vigencia, aquí se proponen otras que cuentan con menor desarrollo -al menos en el ámbito ibérico- y pueden resultar de especial interés en el contexto actual.

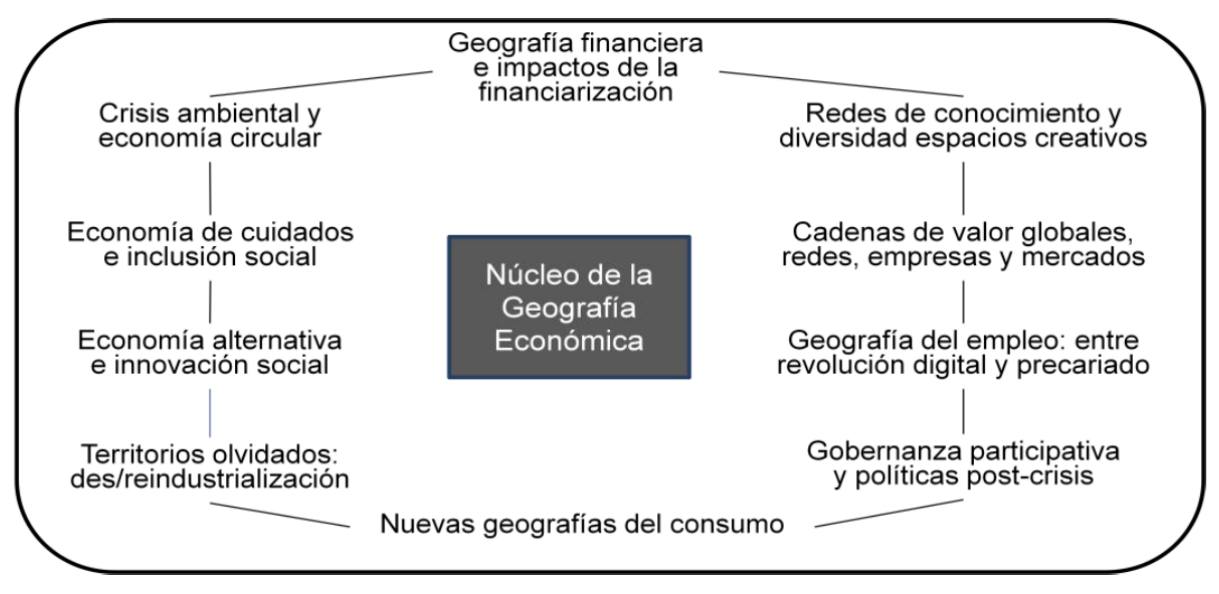

Fonte: Elaboração própria

Por un lado, están aquellas temáticas que se relacionan con diferentes actividades que hoy suelen ser consideradas de creciente interés. En primer lugar, en una era de hegemonía financiera, en donde este sector ha adquirido especial relevancia, sería necesario profundizar en una geografía financiera que considere las estrategias espaciales y las nuevas pautas de localización de los actores financieros (bancos e inversores institucionales: aseguradoras, fondos de pensiones, fondos de inversión, fondos soberanos, empresas fintech), los circuitos del capital (áreas de captación, gestión e inversión) a diferentes escalas, la organización espacial de los espacios donde se concentran estas actividades o la particular geografía de las denominadas finanzas offshore.

En segundo lugar, dentro de la economía real surgen hoy expectativas asociadas al desarrollo de actividades como la llamada economía circular en el ámbito de la crisis ambiental, la economía de cuidados y los servicios sociales de proximidad, o las diversas formas de economía alternativa y solidaria, muy ligadas a diferentes formas de innova-ción social. Además, si hace dos décadas la industria era un objeto de particular atención entre nosotros, los proce-sos de desindustrialización provocaron un creciente abandono de su estudio, pero hoy vuelve a reivindicarse la geografía de la desindustrialización - para conocer qué vino a ocupar el lugar de la industria allí donde desapareció y sus efectos sobre el desarrollo territorial- y la geografía de la reindustrialización, para comprender por qué en algu-nos otros territorios ha sobrevivido una industria renovada. Finalmente, junto a estas geografía de la producción estaría aquella otra ligada a las nuevas formas de consumo, en particular el comercio electrónico y las grandes redes logísticas que lo hacen posible, o un mayor estudio sobre las cadenas de franquicias, temática iniciada hace tiempo pero que apenas tuvo continuidad pese a la invasión producida en numerosos espacios urbanos.

Al mismo tiempo, aún sin ser novedosa, la temática de las redes de conocimiento y su reflejo en la multiplicación de espacios creativos de diferente naturaleza aún necesita mucha más investigación. La inserción de los antiguos distritos industriales y sistemas productivos locales en cadenas de valor globales ha transformado en muchos casos su estructura interna, densificado las relaciones externas y eso puede haberse traducido en impactos positivos o negativos según los casos. La geografía del empleo sigue siendo una asignatura pendiente, estudiada desde hace tiempo pero sin profundizar suficientemente en el impacto que está teniendo la revolución digital sobre las nuevas formas de empleo y, como contrapunto, la expansión de lo que Standing calificó como precariado.

Las políticas económicas y territoriales post-crisis y las nuevas formas de gobernanza participativa, con una presencia más significativa que en el pasado de nuevos movimientos sociales y redes ciudadanas, pueden aportar nuevos debates a una temática tradicional como esta. Finalmente, la expansión del capital y la lógica financiera va mucho más allá de las finanzas y da origen a un proceso de financiarización que se refleja, por ejemplo, en su creciente control sobre un gran número de empresas industriales y de servicios a las que los nuevos gestores imponen nuevas formas de funcionamiento, con frecuentes reestructuraciones internas e intensificación de los procesos de deslocalización; además, la movilidad del capital y la competencia entre territorios por atraer inversores o 
evitar su desplazamiento a lugares más rentables en un contexto de desregulación neoliberal afecta a aspectos como la calidad del empleo o el reforzamiento de las desigualdades, al tiempo que la recuperación del interés mostrado por los actores financieros por la inversión inmobiliaria promueve nuevas formas de mercantilización del crecimiento urbano.

\section{BIBLIOGRAFÍA}

BENNER, C. et al. (2011). "Emerging Themes in Economic Geography: Outcomes of the Economic Geography 2010 Workshop". Economic Geography, 87(2), pp. 111-126.

MACKINNON, D. \& CUMBERS, A. (2014). Introduction to Economic Geography. Globalization, Uneven Development and Place. Londres\&Nueva York: Routledge.

ROSALES, R. (2010). "Aprendizaje colectivo, redes sociales e instituciones: hacia una nueva geografía económica". En A. Lindón y D. Hiernaux (dirs.) Los giros de la Geografía Humana. Desafíos y horizontes. Ciudad de México: UAM Iztapalapa-Anthropos.

TALANDIER, M. \& PECQUEUR, B. dirs. (2018). Renouveler la géographie économique. París: Economica-Anthropos.

VALDIVIA, M. Y DELGADILLO, J. coords. (2013). La Geografía y la Economía en sus vínculos actuales. Una antología comentada del debate contemporáneo. Cuernavaca: UNAM-CRIM. 
Página intencionalmente dejada en blanco 


\title{
Instituições de Ensino Superior e Especialização Inteligente: o contributo dos Institutos Superiores Politécnicos para a Implementação da RIS3 em Portugal
}

\author{
Mário Vale (a), Luís Balula (b), Luís Carvalho (c), José Manuel Simões (d) \\ (a) CEG, IGOT-Universidade de Lisboa, mario.vale@campus.ul.pt \\ (b) CEG, IGOT-Universidade de Lisboa, luis.d.balula@gmail.com \\ (c) CEGOT, Faculdade de Letras-Universidade do Porto, Icarvalho@letras.up.pt \\ (d) CEG, IGOT-Universidade de Lisboa, jmsimoes@campus.ul.pt
}

\begin{abstract}
Resumo
O desenvolvimento de um sistema de inovação não dispensa as instituições de ensino superior (IES), cujas funções se aproximam progressivamente do modelo triple helix (Etzkowitz e Leydesdorff, 2000). Apesar de tudo, os benefícios do investimento na ciência e tecnologia fazem-se sentir lentamente nas regiões periféricas, ainda que as IES se afirmem como um ator primordial nas estratégias de desenvolvimento das regiões periféricas (Goddard et al, 2012). Esta comunicação discute o contributo dos institutos politécnicos para a concretização das prioridades da RIS3. A metodologia seguida assenta na análise de informação de fontes indiretas e diretas (inquérito) sobre os cursos, estudantes e graduados, publicações e projetos de investigação e contratos de transferência de tecnologia pertinentes em cada um dos politécnicos para a RIS3 da região onde se localizam. No final, formulam-se algumas sugestões para uma articulação mais profícua entre os politécnicos e a economia regional.
\end{abstract}

Palavras-chave: RIS3, Inovação, Institutos Superiores Politécnicos, Desenvolvimento Regional

\section{INTRODUÇÃO}

A política europeia tem vindo a promover ativamente o papel regional das Instituições de Ensino Superior (IES), quer através de uma Agenda para a Modernização do Ensino Superior que salienta a importância da economia do conhecimento para o desenvolvimento regional (EC, 2011), quer ao determinar que as estratégias de especialização inteligente (RIS3, ENEI, EREI) constituem um pré-requisito para o acesso a financiamento através dos fundos estruturais (EC, 2016). Destes dois fatores resulta um reforço claro da posição das IES regionais, que passam a ter, potencialmente, um papel ativo na definição e implementação de projetos e políticas regionais, assente em parcerias apoiadas por incentivos financeiros significativos, quer com agentes económicos privados, quer com entidades públicas.

Partindo de uma análise introdutória da literatura relevante sobre a importância das IES para o desenvolvimento regional, esta comunicação propõe uma metodologia para a avaliação do grau de alinhamento estratégico entre a ação dos Institutos Superior Politécnicos (ISP) e as Estratégias Regionais de Especialização Inteligente (RIS3/EREI) em Portugal.

Enquanto centros de conhecimento inseridos nas regiões, em contacto direto com as oportunidades, desafios e riscos das suas cidades e territórios, os ISP constituem parceiros incontornáveis nos processos de desenvolvimento regional. Dependendo do contexto local, das estruturas políticas e da liderança institucional, os ISP podem desempenhar seu papel de diferentes maneiras. No entanto, a sua ação será tanto mais eficaz quanto maior for o alinhamento entre as prioridades nos vários domínios de especialização RIS3/EREI da região e a estra-tégia de produção e difusão de conhecimento do ISP.

Neste sentido, esta comunicação desenvolve uma metodologia capaz de avaliar a adequação da ação regional dos ISP aos domínios prioritários da RIS3/EREI, em três dimensões críticas: ensino e formação; investigação e produção científica; transferência de conhecimento e tecnologia. A título de conclusão, formula-se um conjunto de sugestões para uma articulação mais profícua entre os politécnicos e a economia regional.

A avaliação contempla 13 ISP localizados em quatro regiões NUTS II distintas, nomeadamente: Norte 
(Bragança, Cávado e Ave e Viana do Castelo); Centro (Castelo Branco, Coimbra, Guarda, Leiria, Tomar e Viseu); Alentejo (Beja, Portalegre, Santarém); Área Metropolitana de Lisboa (Setúbal).

Ressalva-se que o objetivo do estudo não é o de estabelecer uma comparação competitiva entre os vários ISP, mas sim, antes do mais, o de fazer um diagnóstico geral propositivo, com vista a identificar os pontos fortes e as oportunidades estratégicas de cada ISP em função das especificidades da região que serve e onde se insere.

\section{ENSINO SUPERIOR, DESENVOLVIMENTO E COESÃO TERRITORIAL}

A relevância da ciência no progresso tecnológico tem sido evidente desde meados do séc. $X X$, constituindo uma fonte de conhecimento essencial para o crescimento económico centrado na inovação. A relação entre a ciência e tecnologia é indiscutível, sendo evidente a incorporação de conhecimento científico na inovação da oferta de bens e serviços, assim como na mudança de processos de organização da produção e do trabalho. Todavia esta relação é complexa, envolvendo múltiplos agentes e funcionando numa lógica de sistema de inovação, de âmbito nacional (Lundvall, 1988) e regional (Cooke, 1992).

O desenvolvimento de um sistema de inovação não dispensa as instituições de ensino superior. Tradicionalmente, as IES desempenha(ra)m funções de ensino e formação avançada e de investigação, evoluindo, mais recentemente, para um modelo triple helix (Etzkowitz e Leydesdorff, 2000), assente na articulação entre universidade - empresa - Estado. No entanto, esta 'terceira missão' nem sempre constitui um objetivo central nas IES.

O desenvolvimento das cidades e regiões ancorado em estratégias high-road implica apostas claras na inova -ção. Deve, no entanto, sublinhar-se que a era da inovação linear, top-down, conduzida por especialistas e orienta -da para a produção de bens e serviços está a perder terreno para diferentes formas e níveis de coprodução e coo -peração generalizada entre produtores, consumidores, clientes e cidadãos (Arnkil et al., 2010). Emergem novas formas de criação de conhecimento, que incluem a aprendizagem contínua, exploração, co-criação, experimentação, plataformas de consumidores e utilizadores, já designadas por quadruple ou quintuple helix (cultura e socieda -de civil) (Carayannis e Campbell, 2011). Trata-se, na verdade, de uma nova plataforma de inovação centrada nos cidadãos.

As IES têm privilegiado a formação de graduados (licenciados, mestres e doutores), apoiando deste modo o crescimento económico e o desenvolvimento social. Todavia, este papel tem vindo a ser complementado com a transferência de tecnologia e ligação à sociedade. As IES produzem conhecimento com potencial de valorização económica que pode ser transferido para os agentes económicos, através do estabelecimento de parcerias com empresas, que visam a transferência de tecnologia, do registo e licenciamento de propriedade intelectual (patentes), ou por via do empreendedorismo académico dirigido à comercialização direta do conhecimento (Goddard et al., 2012). Neste último caso, o empreendedorismo de origem académica está na base da génese de clusters em novas atividades intensivas em conhecimento.

Enquanto centros de produção de novo conhecimento, as IES potenciam knowledge spillovers (Jaffe, 1989), um tipo de externalidade do conhecimento que permite um aumento do ritmo de inovação dos agentes económi$\cos$ da região. Paralelamente, os spin-offs induzidos pelas universidades geram importantes benefícios económicos locais e regionais devido ao reforço das dinâmicas de clusterização em atividades inovadoras (Antonelli, 1999). Estas dinâmicas retroalimentam a mudança institucional nas IES, progressivamente mais focadas na criação de estruturas de transferência de tecnologia, no apoio ao empreendedorismo académico e na criação de programas interdisciplinares de formação e investigação alinhados com as prioridades económicas nacionais e regionais.

A relação entre a formação e a investigação científica e inovação é imprescindível na economia do conhecimento, onde as IES desempenham um papel central no crescimento das atividades inovadoras e contribuem ativamente para o desenvolvimento da agenda social e ambiental da cidades e regiões. Esta inter-relação é tão ou mais pertinente nas regiões menos desenvolvidas, atendendo a que o crescimento económico alavancado por atividades inovadoras depende, em grande medida, de externalidades do conhecimento gerado pela academia, conhecidas que são as debilidades de muitas empresas e instituições destas regiões.

Os benefícios do investimento em Investigação e Desenvolvimento (I\&D) não são imediatos para a economia e talvez ainda sejam mais lentos nas regiões periféricas, precisamente onde é mais pertinente o investimento em ciência e tecnologia. Este paradoxo da inovação regional decorre da aparente contradição entre a maior necessidade de investir em inovação nas regiões periféricas e menor capacidade de absorção de fundos públicos para apoiar o investimento em atividades inovadoras (Oughton et al., 2002) ou de implementação de aplicações resultantes da investigação realizada pelas universidades da região (Christopherson e Clark, 2010). 
A influência das IES nas políticas territoriais é concomitante com o abandono das orientações de política regional que favoreciam exclusivamente a atração de investimento em favor da capacitação institucional e do place-based development (Barca Report). Neste sentido, as IES afirmam-se como um elemento primordial nas estratégias de desenvolvimento territorial, o que se tem traduzido por uma maior integração entre as políticas de ciência e as políticas de desenvolvimento regional (Goddard et al., 2012).

A relevância das IES para as regiões não se resume à inovação e ao desenvolvimento económico. Com a emergência de perspetivas mais holísticas de desenvolvimento, abarcando as esferas da equidade social, sustentabilidade ambiental, bem-estar, dinâmica cultural, reconfigura-se o envolvimento das IES na cidade e região. Ainda que em fase embrionária em algumas IES, diferentes elementos da academia desenvolvem investigação e estabelecem ligações com as comunidades locais em temáticas que extravasam, embora contribuam para, o desenvolvimento económico, tais como a inovação social, a cultura e as artes (Goddard e Vallance, 2013).

O sistema de ciência e tecnologia em Portugal evoluiu muito favoravelmente ao longo dos últimos anos em resultado da prioridade atribuída à política de I\&D e ao apoio decisivo dos Fundos Estruturais ${ }^{1}$. Com a publicação do RJIES em 2007, consagra-se o sistema binário de ensino superior, formado pelo ensino universitário e pelo ensino politécnico, com objetivos diferenciados: aquele de índole mais teórica e científica e este de cariz fundamentalmente mais prático e experimental. Os Institutos Superiores Politécnicos (ISP) públicos cobrem amplamente o território nacional, diferenciando-se o seu padrão geográfico pela presença em áreas menos desenvolvidas do país.

A ligação dos ISP ao tecido económico e social das regiões de acolhimento é determinante para o desenvolvimento e coesão territorial do país. Atendendo à especificidade da missão dos ISP, a sua inserção e contextualização territorial é preponderante nas estratégias e nas ações destas IES, tendo visto o seu papel reforçado com a agenda da RIS3 (EC, 2012).

A Estratégia de Investigação e Inovação para uma Especialização Inteligente preconiza o desenho e implementação de estratégias de desenvolvimento alinhadas com as vantagens específicas de cada região, quer sejam regiões avançadas ou periféricas, de alta ou média-baixa tecnologia, evitando o problema de one-size-fits-all patente em diversas políticas e estratégias de desenvolvimento. A racionalidade teórica desta abordagem assenta no conceito de path dependency do processo de desenvolvimento, historicamente contingente e específico de em cada lugar e região (Martin, 2010).

A capacidade institucional das regiões molda o sistema de inovação, com relevo para as instituições de ciência e tecnologia, empresas e organizações financeiras. A dinâmica de inovação assenta em processos de aprendizagem coletiva regional de natureza interativa e cumulativa. Pode afirmar-se que a geração de dinâmicas territorializadas de inovação requere não só empresas inovadoras como também instituições - em particular as IES preparadas para apoiar a troca e a exploração de diferentes tipos de conhecimento (básico/aplicado, genérico/ específico, tácito/codificado) (Tödtling, 1999).

As instituições de ciência e tecnologia, onde se destacam necessariamente os ISP pela sua vocação territorial, são um interface de articulação de redes globais e locais e desempenham um papel pivot na produção, difusão e recirculação do conhecimento entre os agentes económicos locais e regionais. São um ativo determinante para o desenvolvimento da base de conhecimento das empresas, para a qualificação do mercado de trabalho e para o desenvolvimento social e cultural das cidades e regiões.

\section{FUNDAMENTOS DE UMA PROPOSTA METODOLÓGICA PARA A AVALIAÇÃO DO ALINHAMENTO DOS ISP COM AS PRIORIDADES DAS EREI/RIS3}

Em conformidade com o novo papel das IES no desenvolvimento das regiões, a estratégia metodológica para a avaliação dos ISP deve incidir nas inter-relações que se estabelecem entre as três principais funções que estes desempenham, nomeadamente o ensino, a investigação e relação com a comunidade e com a sociedade em geral. A Figura 1 exemplifica as múltiplas relações entre ensino e investigação (integração de atividades na academia), ensino e envolvimento social e comunitário (participação alargada entre academia e sociedade) e investigação e envolvimento social e comunitário (impacto socioeconómico).

As novas funções das IES extravasam o ensino e a investigação, não se esgotando, porém, na transferência

${ }_{1}^{1}$ Um diagnóstico recente do sistema nacional de investigação científica pode ser consultado em Diagnóstico do Sistema de Investigação e Inovação: Desafios, Forças e Fraquezas Rumo a 2020, FCT, Lisboa, 2013. 
tecnológica e apoio à atividade económica e comercialização de tecnologia. Breznitz e Feldman (2012) mencionam um conjunto diverso de novos papéis desempenhados pelas IES, designadamente nas vertentes da iniciativa económica e das políticas públicas.

O diagrama da Figura 2 é ilustrativo da forma como a cooperação institucional entre um ISP e os ato-res locais e regionais influentes nos processos de governança, com particular destaque para os diversos serviços da administração pública (entidades municipais, CIM, CCDR, ou os serviços desconcertados do Estado nas áreas da saúde, segurança social, emprego e formação profissional), pode contribuir para a otimização de um sistema de inovação regional competitivo, capaz de projetar a região no exterior, posicionando-a, eventualmente, na economia global.

A estratégia de desenvolvimento das regiões está vinculada às estratégias regionais de especialização inteligente (EREI ou RIS3). O conceito de especialização inteligente refere-se a uma abordagem baseada na especificidade dos lugares e caracteriza-se pela identificação de áreas estratégicas de intervenção capazes de influenciar a especialização económica, científica e tecnológica de uma região e, consequentemente, a sua produtividade, competitividade e trajetória de crescimento económico (OECD, 2013). Estas estratégias foram definidas no âmbito da preparação da programação do Portugal 2020, seguindo orientações específicas da UE. As estratégias foram desenhadas levando em linha de conta a evolução da especialização económica das regiões e os objetivos dos agentes económicos e dos atores regionais, procurando evitar a seleção a priori de setores/atividades económicas sem que se fizesse uma demonstração do seu real potencial de crescimento.

A evolução tecnológica das regiões segue determinadas trajetórias decorrentes de opções estratégicas e das competências dos atores. As IES - tanto as Universidades como os Politécnicos - são atores cruciais do sistema de ciência, tecnologia e inovação e contribuem para a melhoria das qualificações e para a inovação tecnológica as regiões e do país. É, portanto, relevante avaliar o contributo dos ISP para a concretização das EREI, numa trajetória de evolução tecnológica regional.

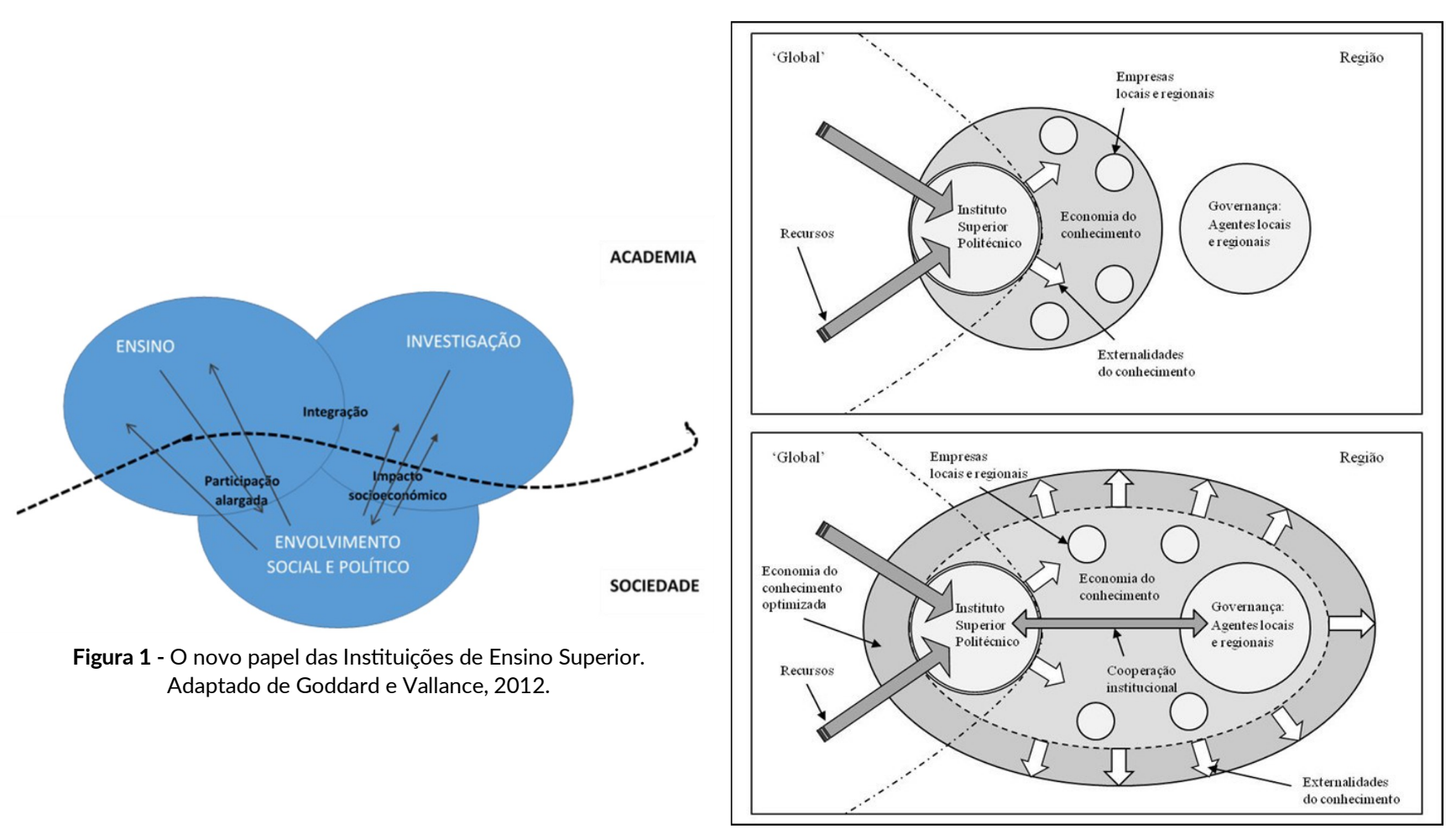

Figura 2. Importância da cooperação institucional entre o ISP e os agentes de governança local/regional para a otimização de um sistema de inovação regional competitivo. Adaptado de Benneworth \& Hospers (2006). 


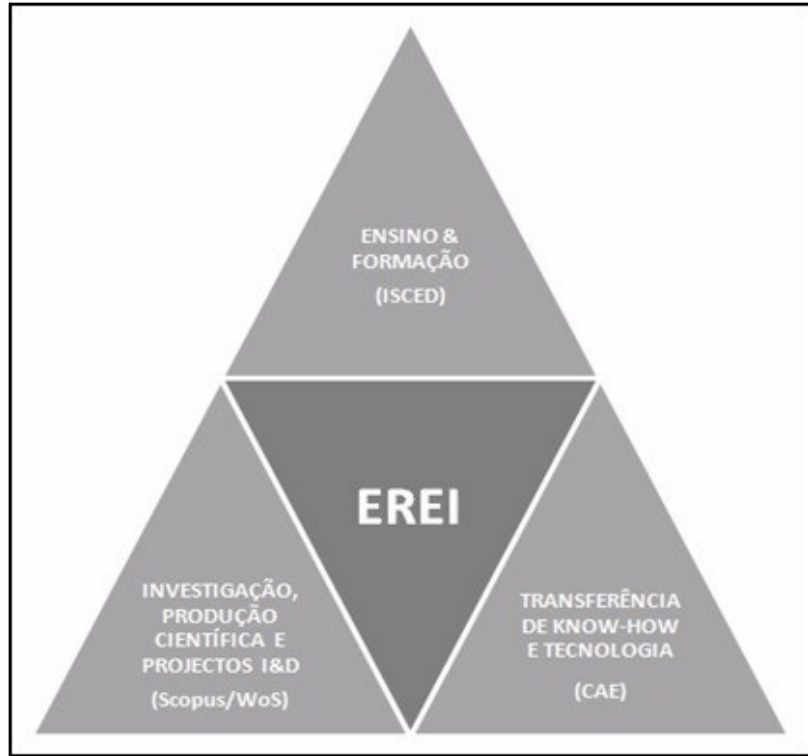

Figura 3 - Principais dimensões analíticas do estudo.

\section{PROPOSTA METODOLÓGICA}

Para cada uma das três dimensões analíticas (ver Figura 3), apresenta-se o tipo de análise a realizar através de tabelas específicas a cada região, exemplificativas do trabalho a desenvolver. Em primeiro lugar, para cada domínio de especialização da EREI (ou RIS3) respetiva, identificam-se as áreas de ensino e formação mais relevantes em cada ISP. Esta distribuição é mutuamente exclusiva; quer dizer, ainda que a mesma área educativa possa ser relevante para mais que um domínio, opta-se por atribuí-la ao domínio mais relevante, de acordo com o racional apresentado para cada EREI. Adota-se, para o efeito, a classificação internacional das áreas educativas do ensino superior consagrada pela UNESCO no International Standard Classification of Education (ISCED, 2013).

O confronto das áreas educativas identificadas com a oferta de cursos em cada ISP, com base

nos dados publicados pela Direção Geral de Estatísticas do Ensino Superior, permite-nos avaliar: (i) as áreas fortes e fracas da oferta educativa do ISP em função da respetiva EREI; (ii) o tipo e o número dos cursos oferecidos que correspondem às prioridades da EREI; (iii) a evolução recente do número de alunos que frequentam esses cursos.

Em segundo lugar, avalia-se a adequação das atividades de investigação e de produção científica dos ISP aos domínios de especialização da EREI. Para isso, recorrendo às bases de dados Scopus e/ou WoS, identificam-se, igualmente de forma mutuamente exclusiva, as áreas de publicação científica relevantes para cada domínio de especialização da EREI. Desta forma, quantificando o número de artigos publicados nos últimos cinco anos e referenciados nas bases Scopus/WoS para cada área de publicação, é possível identificar as atuais áreas dinâmicas do ISP, em termos de produção científica, e compará-las com a respetiva estratégia regional. Considera-se igualmente o envolvimento dos ISP em projetos científicos com financiamento competitivo aos níveis nacional (designadamente os financiados pela FCT e outras instituições de apoio à atividade científica) e internacional (H2020, EEA Grants, ESPON, etc.), verificando-se o seu alinhamento com as prioridades definidas para a estratégia de desenvolvimento da região.

Finalmente, quanto à transferência de know-how e tecnologia pretende-se analisar a relação entre a EREI e a dinâmica do ISP junto às empresas. A partir dos dados a obter junto aos serviços dos ISP, e recorrendo à classificação de atividades económicas (divisões da CAE) será possível determinar o grau de especialização (ou de diversificação) do ISP nas suas relações com o tecido empresarial, nas várias dimensões estratégicas da EREI. Paralelamente, uma análise das tipologias dos projetos apoiados pelo Programa Compete e pelos Programas Operacionais Regionais permitirá identificar o modo como as EREI estão a ser operacionalizadas em cada uma das regiões contribuindo para a validação dos resultados da nossa análise.

Apresentam-se, os instrumentos-tipo de organização da informação nas três dimensões indicadas. No primeiro caso (Ensino e formação) identificam-se as áreas de ensino e formação (ISCED) consideradas relevantes para cada um dos domínios de especialização da respetiva EREI. Para as outras duas dimensões (Investigação e produção científica; Transferência de know-how e tecnologia) apresentam-se apenas as tabelas-base onde se identificam, tal como no primeiro caso, para cada domínio estratégico, nomeadamente: (i) as áreas de publicação científica mais relevantes para as prioridades EREI (a partir das categorias das bases de dados Scopus e/ou WoS); (ii) os projetos de investigação científica em que o ISP esteve ou está envolvido (iii) os projectos apoiados no âmbito do Plano Operacional Regional e as empresas com as quais o ISP contratou prestações de serviços nos últimos 5 anos (a partir das divisões da CAE destas actividades económicas). 
Tabela I - Educação e formação: Análise EREI/ISCED (exemplo região Norte).

\begin{tabular}{|c|c|c|c|c|c|c|}
\hline \multirow{2}{*}{$\begin{array}{l}\text { Domínios de } \\
\text { especialização - } \\
\text { Região NORTE }\end{array}$} & \multirow{2}{*}{$\begin{array}{l}\text { Áreas de Ensino e de Formação (ISCED 2013) relevantes } \\
\text { para as prioridades estratégicas }\end{array}$} & \multirow{2}{*}{$\begin{array}{l}N^{\circ} \text { de Cur- } \\
\text { sos ofereci- } \\
\text { dos entre } \\
2013 \text { e } 2016\end{array}$} & \multirow{2}{*}{$\begin{array}{l}N^{\circ} \text { de Cur- } \\
\text { sos ofereci- } \\
\text { dos em } \\
2015 / 16 \\
\end{array}$} & \multicolumn{3}{|c|}{$\mathrm{N}^{\circ}$ de Alunos por Curso } \\
\hline & & & & $2013 / 14$ & $2014 / 15$ & $2015 / 16$ \\
\hline \multirow{6}{*}{$\begin{array}{l}\text { Recursos do Mar } \\
\text { e Economia }\end{array}$} & 0522 Natural environments and wildlife & & & & & \\
\hline & 0712 Environmental protection technology & & & & & \\
\hline & 0713 Electricity and energy & & & & & \\
\hline & 0724 Mining and extraction & & & & & \\
\hline & 0732 Building and civil engineering & & & & & \\
\hline & 0831 Fisheries & & & & & \\
\hline \multirow{3}{*}{$\begin{array}{l}\text { Capital Humano e } \\
\text { Serviços Especia- } \\
\text { lizados }\end{array}$} & 0612 Database and network design and administration & & & & & \\
\hline & 0613 Software and applications development $\&$ analysis & & & & & \\
\hline & 0619 ICTs not elsewhere classified & & & & & \\
\hline \multirow{7}{*}{$\begin{array}{l}\text { Cultura, Criação e } \\
\text { Moda }\end{array}$} & 0211 Audio-visual techniques and media production & & & & & \\
\hline & 0212 Fashion, interior and industrial design & & & & & \\
\hline & 0213 Fine arts & & & & & \\
\hline & 0214 Handicrafts & & & & & \\
\hline & 0215 Music and performing arts & & & & & \\
\hline & 0723 Textiles (clothes, footwear and leather) & & & & & \\
\hline & 0731 Architecture and town planning & & & & & \\
\hline \multirow{4}{*}{$\begin{array}{l}\text { Indústrias da } \\
\text { Mobilidade e } \\
\text { Ambiente }\end{array}$} & 0714 Electronics and automation & & & & & \\
\hline & 0715 Mechanics and metal trades & & & & & \\
\hline & 0716 Motor vehicles, ships and aircraft & & & & & \\
\hline & 0722 Materials (glass, paper, plastic and wood) & & & & & \\
\hline \multirow{6}{*}{$\begin{array}{l}\text { Sistemas Agro- } \\
\text { ambientais e } \\
\text { Alimentação }\end{array}$} & 0511 Biology & & & & & \\
\hline & 0721 Food processing & & & & & \\
\hline & 0811 Crop and livestock production & & & & & \\
\hline & 0812 Horticulture & & & & & \\
\hline & 0821 Forestry & & & & & \\
\hline & 0841 Veterinary & & & & & \\
\hline \multirow{14}{*}{$\begin{array}{l}\text { Ciências da Vida e } \\
\text { Saúde }\end{array}$} & 0512 Biochemistry & & & & & \\
\hline & 0531 Chemistry & & & & & \\
\hline & 0911 Dental studies & & & & & \\
\hline & 0912 Medicine & & & & & \\
\hline & 0913 Nursing and midwifery & & & & & \\
\hline & 0914 Medical diagnostic and treatment technology & & & & & \\
\hline & 0915 Therapy and rehabilitation & & & & & \\
\hline & 0916 Pharmacy & & & & & \\
\hline & 0917 Traditional \& complementary medicine \& therapy & & & & & \\
\hline & 0921 Care of the elderly and of disabled adults & & & & & \\
\hline & 0922 Child care and youth services & & & & & \\
\hline & 0923 Social work and counseling & & & & & \\
\hline & 0929 Welfare not elsewhere classified & & & & & \\
\hline & 1022 Occupational health and safety & & & & & \\
\hline \multirow{5}{*}{$\begin{array}{l}\text { Capital Simbólico, } \\
\text { Tecnologias e } \\
\text { Serviços do Turis- } \\
\text { mo }\end{array}$} & 0231 Language acquisition & & & & & \\
\hline & 0414 Marketing and advertising & & & & & \\
\hline & 1013 Hotel, restaurants and catering & & & & & \\
\hline & 1014 Sports & & & & & \\
\hline & 1015 Travel, tourism and leisure & & & & & \\
\hline $\begin{array}{l}\text { Sistemas Avança- } \\
\text { dos de Produção }\end{array}$ & $\begin{array}{l}\text { Prioridade transversal a todas as estratégias. } \\
\text { As áreas educativas chave (TIC, Electrónica,Ciências infor- } \\
\text { máticas, Materiais, Metalurgia e Metalomecânica, etc.) } \\
\text { encontram-se contempladas nas outras prioridades estraté- } \\
\text { gicas }\end{array}$ & & & & & \\
\hline \multirow{8}{*}{$\begin{array}{l}\text { Áreas estratégicas } \\
\text { transversais }\end{array}$} & 0311 Economics & & & & & \\
\hline & 0411 Accounting and taxation & & & & & \\
\hline & 0412 Finance, banking and insurance & & & & & \\
\hline & 0413 Management and administration & & & & & \\
\hline & 0415 Secretarial and office work & & & & & \\
\hline & 0416 Wholesale and retail sales & & & & & \\
\hline & 0417 Work skills & & & & & \\
\hline & 0421 Law & & & & & \\
\hline
\end{tabular}


Instituições de Ensino Superior e Especialização Inteligente: o contribu-to dos Institutos Superiores Politécnicos para a Implementação da RIS3 em Portugal

Tabela II. Investigação e produção científica: Análise EREI/WoS/Scopus (exemplo região Norte).

\begin{tabular}{|l|l|l|}
\hline \multicolumn{1}{|c|}{ Domínios de especialização EREI - NORTE } & $\begin{array}{c}\text { Áreas de publicação (Scopus/WoS) } \\
\text { relevantes para as prioridades EREI }\end{array}$ & No de artigos referenciados $^{\circ}$ \\
\hline Recursos do Mar e Economia & & \\
\hline Capital Humano e Serviços Especializados & & \\
\hline Cultura, Criação e Moda & & \\
\hline Indústrias da Mobilidade e Ambiente & & \\
\hline Sistemas Agroambientais e Alimentação & & \\
\hline Ciências da Vida e Saúde & & \\
\hline Capital Simbólico, Tecnologias e Serviços do Turismo & & \\
\hline Sistemas Avançados de Produção & & \\
\hline
\end{tabular}

Tabela III. Investigação e produção científica: Análise EREI/Projetos de investigação científica (exemplo região Norte).

\begin{tabular}{|l|l|l|}
\hline \multicolumn{1}{|c|}{ Domínios de especialização EREI - NORTE } & $\begin{array}{c}\text { Projetos de investigação científica } \\
\text { nacionais (coordenação/ } \\
\text { participação) }\end{array}$ & $\begin{array}{c}\text { Projetos de investigação científica } \\
\text { internacionais (coordenação/ } \\
\text { participação) }\end{array}$ \\
\hline Recursos do Mar e Economia & & \\
\hline Capital Humano e Serviços Especializados & & \\
\hline Cultura, Criação e Moda & & \\
\hline Indústrias da Mobilidade e Ambiente & & \\
\hline Sistemas Agroambientais e Alimentação & & \\
\hline Ciências da Vida e Saúde & & \\
\hline Capital Simbólico, Tecnologias e Serviços do Turismo & & \\
\hline Sistemas Avançados de Produção & & \\
\hline
\end{tabular}

Tabela IV. Transferência de conhecimento e tecnologia: Análise EREI/ PO Compete, POR/CAE.

\begin{tabular}{|l|l|l|}
\hline \multicolumn{1}{|c|}{ Domínios de especialização EREI - NORTE } & $\begin{array}{c}\text { Divisões CAE dos projetos apoiados } \\
\text { no âmbito do Plano Operacional } \\
\text { Regional }\end{array}$ & $\begin{array}{c}\text { Divisões CAE das principais em- } \\
\text { presas com as quais o ISP realizou } \\
\text { contratos de prestação de serviços } \\
\text { nos últimos 5 anos }\end{array}$ \\
\hline Recursos do Mar e Economia & & \\
\hline Capital Humano e Serviços Especializados & & \\
\hline Cultura, Criação e Moda & & \\
\hline Indústrias da Mobilidade e Ambiente & & \\
\hline Sistemas Agroambientais e Alimentação & & \\
\hline Ciências da Vida e Saúde & & \\
\hline Capital Simbólico, Tecnologias e Serviços do Turismo & & \\
\hline Sistemas Avançados de Produção & & \\
\hline
\end{tabular}




\section{CONCLUSÃO E PRÓXIMOS PASSOS}

Esta comunicação apresentou uma proposta metodológica para aferir do contributo e alinhamento das estratégias dos ISP face às EREI dos seus territórios de referencia. Em jeito de conclusão, apresentam-se algumas questões e hipóteses de trabalho, a explorar em momentos subsequentes.

Institutos Superiores Politécnicos: até que ponto regionais? Dado o reforço recente de qualificações dos seus quadros, o aumento da produção científica e a prestação de serviços avançados à empresas, o trabalho responderá sobre até ponto as relações entre os ISP e a base económica é de cariz essencialmente subregional ou se, pelo contrario, se alarga a outras geografias.

- $\quad$ Para além de projetos de I\&D formais: o papel dos ISP no aumento da capacidade de absorção de tecnologia e competitividade das economias regionais. Com base na informação recolhida, a análise procurará responder sobre o tipo de contributos e relações dos ISP com a base económica por via i) da qualificação de pessoas e ii) oferta de serviços complementares que permitam às empresas subir e/ou manter competitividade nas cadeias de valor, aumentando a sua capacidade de participar em projetos de I\&D mais exigentes.

- $\quad$ Face às estruturas económicas regionais, que tipo de transformação estão os ISP a promover por via das suas atividades de I\&D e prestações de serviços? Reforço das especializações existentes, diversificação em sectores conexos, ou emergências de novas atividades?

- $\quad$ Face aos pontos anteriores, será feita uma reflexão sobre o contributo "revelado" dos ISP para as EREI e para a intensificação tecnológica e de conhecimento das suas regiões, nomeadamente em relação ao seu contributo "formal" (i.e. participação institucional na definição de uma estratégia regional).

\section{BIBLIOGRAFIA}

ANTONELLI, C. (1999). The evolution of the industrial organisation of the production of knowledge. Cambridge Journal of Economics, 23, 243-260.

ARNKIL, R., Järvensivu, A., Koski, P., \&Piirainen, T. (2010). Exploring the Quadruple Helix: Report of Quadruple Helix Research for the CLIQ Project. University of Tampere.

BARCA REPORT. (2009). An Agenda for a Reformed Cohesion Policy: A Place-based Approach to Meeting European Union Challenges and Expectations. Brussels.

BENNEWORTH, P. S. and HOSPERS, G. J. (2006), Urban competitiveness in the knowledge economy: universities as new planning animateurs, Cambridge to Consett, Working Paper. Newcastle upon Tyne: CURDS.

BREZNITZ, S., \& FELDMAN, M.P. (2012). The engaged university. J. Technol Transfer, 37, 139-157.

CARAYANNIS, E. G., \&CAMPBEL, D. F. J. (2011). Open innovation diplomacy and a 21st century Fractal Research, Education and Innovation (FREIE) Ecosystem: Building on the quadruple and quintuple helix innovation concepts and the "Mode 3" knowledge production system. Journal of Knowledge Economy, 2, 327-372.

CCDR-Alentejo (2014). Uma Estratégia de Especialização Inteligente para o Alentejo.

CCDR-Centro (2017). RIS3 do Centro 2020: Estratégia de Investigação e Inovação para uma Especialização Inteligente.

CCDR-LVT (2015). Especialização Inteligente de Lisboa 2014-2020.

CCDR-Norte (2014). Norte 2020: Estratégia Regional de Especialização Inteligente.

CHRISTOPHERSON, S., \& CLARK, J. (2010). Limits to the 'learning region': what university-centred economic development can (and cannot) do to create knowledge-based regional economies. Local Economy, 25(5), 120-30.

COOKE, P. (1992). Regional innovation systems: competitive regulation in the new Europe. Geoforum, 23(3), 365-382.

EC (2011). Supporting Growth and Jobs - an agenda for modernisation of Europe's higher education system. Com (2011) (567). CEC, Brussels.

EC (2012). Guide to Research and Innovation Strategies for Smart Specialisation (RIS3). European Commission.

ETZKOWITZ, H., \& LEYDESDORFF, L. (2000). The dynamics of innovation: from National Systems and "Mode 2" to a Triple Helix of university-industry-government relations. Research Policy, 29(2), 109-123.

GODDARD, J., ROBERTSON, D., \& VALLANCE, P. (2012). Universities, technology and innovation centres and regional development: The case of the North-East of England. Cambridge Journal of Economics, 36(3), 609-627.

GODDARD, J., \& VALLANCE, P. (2013). The university and the city. Abingdon: Routledge. 
JAFFE, A. B. (1989). Real effects of academic research. American Economic Review, 79, 957-970.

MARTIN, R. (2010). Roepke Lecture in Economic Geography-Rethinking Regional Path Dependence: Beyond Lock-in to Evolution. Economic Geography, 86(1), 1-27.

OECD (2013). Innovation-driven Growth in Regions: The Role of Smart Specialisation (preliminary version).

OUGHTON, C., LANDABASO, M., \& MORGAN, K. (2002). The regional innovation policy paradox: innovation policy and industrial policy. Journal of Technology Transfer, 27(1), 97-110.

TÖDTLING, F. (1999). Innovation networks, collective learning, and industrial policy in regions of Europe. European Planning Studies, 7(6), 693-697.

UNESCO (2013). ISCED Fields of Education and Training (ISCED-F 2013): Manual to accompany the International Standard Classification of Education 2011. 
Página intencionalmente dejada en blanco 


\title{
Especialização inteligente: as redes de projetos europeus H2020 com ancoragem em Portugal
}

\author{
H. Santos (a), T. Sá Marques (b), P. Ribeiro (c), M. Torres (d) \\ (a) CEGOT/Faculdade de Letras da U.P., hfcs75@hotmail.com \\ (b) CEGOT/Faculdade de Letras da U.P., teresasamarques@gmail.com \\ (c) CEGOT, paularibeiro82@gmail.com \\ (d) FLUP, marcelojbt9@gmail.com
}

Resumo

A especialização inteligente é uma realidade em marcha na Estratégia 2020 da União Europeia (UE). Esta comunicação visa efetuar uma exploração das caraterísticas das regiões portuguesas à saída do anterior Quadro Comunitário de Apoio (QCA), procurando identificar estrangulamentos à aplicação da estratégia de especialização inteligente, e explorar os projetos europeus de I\&D+I Horizonte 2020 (H2020) com ancoragem em Portugal com o objetivo de identificar as mudanças que estão a ocorrer nos ecossistemas de inovação decorrentes dos efeitos da aplicação inicial da estratégia de especialização inteligente nestas regiões. Primeiramente faz-se uma análise da literatura sobre a evolução do conceito de especialização inteligente. De seguida faz-se uma síntese das caraterísticas socioeconómicas das regiões portuguesas. Prossegue-se com uma análise da globalidade da rede de projetos de I\&D+I H2O20 com ancoragem em Portugal, seguindo a lógica de Estratégia Nacional de Investigação e Inovação para uma Especialização Inteligente. (ENEI) e efetua-se uma análise para cada uma das regiões de Portugal, seguindo a lógica das Estratégias Regionais de Investigação e Inovação para uma Especialização Inteligente (RIS3). Identificam-se os atores organizacionais envolvidos nestes projetos e as relações multiescalares que se estabelecem entre eles. Pretende-se contribuir para caraterizar os ecossistemas de inovação (nacional e regionais) que estão a emergir neste período inicial de implementação da Estratégia H2O2O.

Palavras-chave: Especialização Inteligente, Horizonte 2020, Regiões de Portugal, Redes de Inovação, Análise de Redes Sociais.

\section{INTRODUÇÃO}

A especialização inteligente é uma realidade em marcha na Estratégia 2020 da União Europeia. Depois de uma primeira fase de preparação das estratégias à escala europeia (Foray, et al., 2012), à escala nacional (IAPMEI; FCT; ANI; COMPETE, 2014) e à escala regional (CCDRN, 2014; CCDRC, 2014; CCDR Alentejo, 2014; SPI Açores e Governo Regional dos Açores, 2014; CCDRLVT, 2015; CCDR Algarve, 2015; Região Autónoma da Madeira Governo Regional da Madeira, 2015), as estratégias de especialização inteligente estão numa fase de implementação, pelo que faz sentido monitorizar e realizar avaliações preliminares (Capello \& Kroll, 2016).

Nesta comunicação pretende-se explorar as seguintes questões:

- Quais os estrangulamentos à aplicação da estratégia de especialização inteligente que se podem identificar a partir das regiões portuguesas?

- Que ecossistemas regionais de inovação estão a emergir em Portugal a partir do financiamento H2O2O a projetos de investigação e desenvolvimento?

A comunicação começa com uma revisão da literatura, centrando-se na evolução do conceito de especialização inteligente, nomeadamente a transição de uma origem setorial a-espacial para uma aplicação territorial à escala regional, procurando identificar as mudanças e constrangimentos daí resultantes. Prossegue com a apologia de uma abordagem ecossistémica para monitorizar os efeitos das políticas de especialização inteligente à escala regional. Após uma breve apresentação da metodologia, foca-se a análise nas regiões portuguesas, começando por uma síntese das caraterísticas socioeconómicas das regiões funcionais e administrativas de Portugal no final do anterior quadro comunitário, para terminar com uma análise dos ecossistemas que estão a emergir como resultado da aprovação dos projetos de investigação e desenvolvimento.

Por último, apresentam-se algumas conclusões sobre os estrangulamentos da aplicação da especialização 
inteligente às regiões portuguesas e as caraterísticas dos ecossistemas regionais de inovação que estão a emergir em Portugal.

\section{ESPECIALIZAÇÃO INTELIGENTE}

\subsection{Estrangulamentos e desafios que sustentam uma abordagem de base territorial}

O conceito de especialização inteligente "is essentially a way of thinking about local knowledge enhancement and learning-enhancement systems" (McCann \& Ortega-Argilés, Smart Specialization, Regional Growth and Applications to European Union Cohesion Policy, 2015, p. 1295). Incorpora muitas das ideias provenientes da literatura sobre os sistemas de inovação, sobre empreendedorismo e crescimento económico e sobre os vários tipos de custos de transação, mas diferencia-se pela lógica de criar prioridades políticas (McCann \& OrtegaArgilés, Smart Specialization, Regional Growth and Applications to European Union Cohesion Policy, 2015), a partir de processos de descoberta empreendedora (Foray, 2016).

Apesar da sua origem a-espacial e setorial, a lógica da especialização inteligente evoluiu para uma aplicação regional (McCann \& Ortega-Argilés, Smart Specialization, Regional Growth and Applications to European Union Cohesion Policy, 2015; Capello \& Kroll, 2016) no sentido de correlacionar entre si as capacidades de investigação e desenvolvimento, a estrutura industrial e a qualificação do capital humano. Assim, o conceito de especialização inteligente assume que o contexto é importante enquanto ecossistema regional de conhecimento e inovação, o que origina a tendência para a especialização dos países e regiões em torno de determinados setores do conhecimento e capacidades relacionadas, a partir dos quais se devem estabelecer as prioridades (os domínios prioritários) (McCann \& Ortega-Argilés, Smart Specialization, Regional Growth and Applications to European Union Cohesion Policy, 2015).

Segundo Capello \& Kroll (2016) o conceito de especialização inteligente provocou uma mudança estrutural na forma como as políticas de inovação regional são concebidas nos Estados Membros da UE, fazendo-se sentir essas mudanças nos seguintes aspetos:

- Considera uma grande variedade de tipos de inovação;

- Considera que as descobertas empreendedoras não se enraízam apenas nas atividades de alta tecnologia;

- Apela ao desenvolvimento de processos público-privados de aprendizagem e de descoberta empreendedora;

- Assenta em sistemas de governança bottom-up que possibilitem a autodescoberta das capacidades empreendedoras, através da identificação do potencial e das necessidades locais, casando os investimentos em conhecimento e formação de recursos humanos com a matriz industrial e de investigação dos territórios (políticas de base territorial);

- Define prioridades reais e potenciais atendendo ao contexto regional em concreto - as Estratégias Regionais de Inovação para a Especialização Inteligente (RIS3);

- Valoriza os processos participados de escolha e definição dessas prioridades.

No entanto, na UE existe uma grande diversidade de regiões que exibem disparidades complexas entre si (McCann \& Ortega-Argilés, Smart Specialization, Regional Growth and Applications to European Union Cohesion Policy, 2015; Capello \& Kroll, 2016), o que coloca desafios na hora de converter um conceito a-espacial e eminentemente setorial em políticas de base territorial. É sobretudo nas regiões mais periféricas da Europa que o conceito de especialização inteligente encontra mais dificuldades para responder aos desafios estruturais (Boschma, 2016) e de coesão (McCann \& Ortega-Argilés, Smart Specialization, Regional Growth and Applications to European Union Cohesion Policy, 2015; Capello \& Kroll, 2016), que se colocam nessas regiões e entre estas regiões, dado que a diversidade de situações é também muito grande (Naldi, Nilsson, Westlund, \& Wixe, 2015).

São sobretudo as regiões com maior densidade multidimensional e, consequentemente, maior centralidade as que mais beneficiam com a especialização inteligente, mas não estando mesmo estas isentas de riscos (McCann \& Ortega-Argilés, Smart Specialization, Regional Growth and Applications to European Union Cohesion Policy, 2015; Capello \& Kroll, 2016).

Nesta mesma linha de argumentação, Capello \& Kroll (2016) fazem uma análise dos principais riscos de estrangulamento das estratégias de especialização inteligente nomeadamente:

- A falta de vontade política para embarcar em processos participativos do tipo bottom-up;

- A não coincidência entre as regiões funcionais e as regiões administrativas;

- A falta de pré-condições à escala local para a inovação (o que se tem vindo a confirmar nas regiões mais atra- 
sadas) pela falta de massa crítica, conectividade, espírito empreendedor, tamanho, potencial do mercado ou diversidade industrial para qualquer que seja o domínio de especialização, acrescido da falta de massa crítica e de capacidades que possibilitem o desenvolvimento de uma cultura de aprendizagem coletiva na definição da estratégia de especialização inteligente;

- A falta de capacidade para identificar as reais possibilidades de diversificação dos domínios tecnológicos a partir dos padrões de especialização local (reforçando-se o risco de lock-in) e para se envolverem ativamente em processos regionais de descoberta empreendedora;

- A dificuldade em estabelecer prioridades políticas, sobretudo nas regiões menos desenvolvidas, caindo-se na tendência para replicar ao nível local aquelas que são as tendências nacionais e globais, sem que tenham trajetórias prévias, instituições ou outro tipo de massa crítica nessas áreas;

- A dificuldade das regiões periféricas se posicionarem nas cadeias de valor internacionais e, quando posicionadas, a sua dependência das empresas multinacionais que, por um lado, normalmente não se envolvem nestes processos de construção das políticas regionais e, por outro lado, as suas diretrizes obedecem às estratégias corporativas globais, retirando capacidade de controlo às instituições políticas da região;

- Nas regiões onde predominam pequenas e médias empresas com baixa capacidade de absorção de conhecimento, as prioridades acabam por ser definidas pelos atores da ciência local, o que acaba por resultar na definição de estratégias muito pouco orientadas para a aplicação do conhecimento;

- Nas regiões mais centrais de elevada densidade multidimensional, por exibirem uma grande variedade de possibilidades de especialização viáveis, acabam por pretenderem ampliar os domínios de especialização para assegurarem o acesso a financiamentos públicos, podendo originar um processo político pouco direcionado e sem eficácia para equilibrar a variedade presente na região;

\subsection{Uma abordagem ecossistémica territorializada}

Abandonando uma abordagem espacialmente cega e seguindo a via da construção de políticas de base territorial (Boschma, 2014; Boschma, 2016; Camagni \& Capello, 2013; Capello \& Kroll, 2016; McCann \& OrtegaArgilés, Smart Specialization, Regional Growth and Applications to European Union Cohesion Policy, 2015), as políticas devem estar embebidas na realidade local e simultaneamente assegurar o acesso e a incorporação de conhecimento externo à região, através de ligações com o mundo exterior, o que faz dos conceitos de "embededdness", de "conectividade" e de "padrões regionais de inovação" elementos centrais na construção das políticas de inovação inteligentes, capazes de melhorar a especialização regional e de a diversificar para campos tecnológicos relacionados, projetando as trajetórias evolutivas futuras (Camagni \& Capello, 2013). Segundo a visão de Boschma (2016) o conceito de variedade relacionada é também central para identificar as indústrias tecnologicamente relacionadas que existem numa região e as oportunidades de ramificação a partir das existentes e para explorar e recombinar as capacidades e recursos da região para gerarem novas atividades. Além do mais, sublinha também a conectividade dentro e entre as regiões (redes de comércio, cadeias de valor, redes de conhecimento) e o contexto institucional (relações laborais, governança das corporações empresariais, colaborações entre as empresas) para a emergência de processos de variedade relacionada. Esta é mais um contributo que sublinha a diversidade de situações regionais na UE, e que contraria a ideia das políticas do tipo "one-size-fitsall" (Boschma, 2014) e sublinha a constatação de que "one size fits only one in place-based regional policy" (Thissen, van Oor, Diodato, \& Ruijs, 2013).

Pelo exposto, no momento de realizar uma avaliação preliminar aos resultados da estratégia de especialização inteligente, é aconselhável uma abordagem ecossistémica territorializada. Esta abordagem ecossistémica territorializada tem uma quadrupla vantagem:

- Permite contemplar a multiplicidade de esferas institucionais de actores envolvidas em processos de interação dentro e entre regiões, à imagem da hélice trípla (Leydesdorff, 2005; Leydesdorff \& Etzkowitz, 1998; Leydesdorff, 2001) e da subsequente evolução para hélice quadrupla, qíntupla ou n-hélices (Carayannis \& Campbell, 2012; Leydesdorff, 2012) envolvendo as organizações da sociedade civil, a cultura, os estilos de vida, os meios de comunicação social, a criatividade, o multiculturalismo, a dimensão sócio-ecológica e as instituições universitárias de ciências sociais e de artes, para além das de ciências naturais e engenharias, já contempladas na hélice trípla (Carayannis \& Campbell, 2011).

- Considera as ligações que se estabelecem entre as diferentes organizações no âmbito dos processos de produção de conhecimento e inovação, atendendo ao facto de que as redes entre organizações e indivíduos são, 
cada vez mais, a estrutura que suporta os processos de produção de conhecimento e inovação (Amin \& Roberts, 2008) (Bathelt \& Glückler, 2011) (Bathelt \& Turi, 2011) (Liu, Chaminade, \& Asheim, 2013) (Binz, Truffer, \& Coenen, 2014).

- O território não é neutro e a territorialização das redes permite explorar as múltiplas escalas das relações, ligando distintos produtores de conhecimento, pertencentes a diferentes esferas institucionais de ação, localizados em diferentes geografias, possibilitando uma análise da geografia relacional (Massey, 2005) (Amin, 2004) (Amin \& Roberts, 2008) que envolve a articulação entre redes locais/regionais (Moulaert \& Sekia, 2003), nacionais (Lundvall, 2010) e globais de inovação (Coe \& Hess, 2013) (Coe \& Yeung, 2015) suportadas noutras dimensões da proximidade - cognitiva, organizacional, institucional, social (Boschma, 2005) (Knoben \& Oerlemans, 2006) (Amin \& Roberts, 2008) (Boschma \& Frenken, 2010) (Balland, Boschma, \& Koen, Proximity and Innovation: From Statics to Dynamics, 2015) - e por múltiplas estratégias de criação de proximidade geográfica - clusters permanentes e temporários (Bathelt \& Schuldt, 2008) (Torre, 2008) (Bathelt \& Turi, 2011) (Bathelt \& Henn, 2014) e a colocalização virtual (Trippl, Tödtling, \& Lengauer, 2009) (Jones, Spigel, \& Malecki, 2010).

- Permite explorar a coevolução e codesenvolvimento da inovação enquanto processo multilateral (envolvendo diferentes atores), multinodal (interligando diferentes clusters de conhecimento), multimodal (abarcando diferentes modos de produção do conhecimento) e multiescalares (atravessando diferentes escalas geográficas (Carayannis \& Campbell, 2011; Carayannis \& Campbell, 2012; Carayannis, Pirzadeh, \& Popescu, 2012).

Neste sentido, uma análise que considere os stocks de instituições para a inovação de cada região, as esferas institucionais de ação a que pertencem e as redes interorganizacionais multiescalares que se estabelecem, contribui para monitorizar os efeitos das políticas de especialização inteligente.

\section{METODOLOGIA}

A partir da análise de estudos de caraterização da situação das regiões (funcionais e administrativas) portuguesas à saída do anterior quadro comunitário de apoio, elabora-se uma síntese orientada para identificar estrangulamentos da aplicação do conceito de estratégia de especialização inteligente às regiões portuguesas e assim contribuir para o debate em torno das dificuldades resultantes da conversão de um conceito originário das políticas setoriais a-espaciais num instrumento de política de base territorial.

Com o objetivo de avaliar as mudanças em curso resultantes da aprovação dos primeiros projetos $\mathrm{H} 2020$ da Era da especialização inteligente, procedeu-se à recolha dos respetivos projetos de investigação e desenvolvimento aprovados até ao momento, disponíveis na base CORDIS. A partir destes dados, estruturou-se uma base de dados constituída por todos os projetos que envolvem organizações portuguesas, tendo-se georreferenciado as organizações de acordo com a moradas e a região (NUT 2) a que pertencem. Com base na metodologia de análise de redes sociais, procedeu-se à construção das redes interorganizacionais e à análise de comunidades por países e por regiões (NUT 2).

Os resultados destes dois tipos de análise são apresentados nos capítulos que se seguem.

\section{O CENTRO-PERIFERIA NO CONTEXTO DE PORTUGAL}

Retomando o debate sobre as regiões mais centrais (as que mais beneficiam com as políticas de especialização inteligente) e as regiões mais periféricas (as que enfrentam maiores dificuldades em se enquadrarem nestas políticas), e sobre a diversidade de situações que se observam em cada um destes grupos, importa efetuar um breve retrato de Portugal, dado que é sobre este que incide a análise que se segue.

Em Portugal, as regiões funcionais mais centrais são Lisboa e Porto. Concentram um grande volume de emprego (76\% do pessoal ao serviço em Portugal Continental), da capacidade produtiva (81\% do PIB) e das exportações portuguesas (90\%), mas também polarizam o capital social, organizacional e de conhecimento do país, exibindo no entanto diferenças substanciais entre elas. São os principais territórios-âncora dos processos de globalização e de inovação económica em Portugal (Ribeiro \& Ferrão, 2014; Ribeiro, Moura, \& Chorincas, 2015; Marques, Santos, \& Ribeiro, 2016)

No entanto, desde logo não existe uma coincidência entre estas regiões funcionais e as respetivas regiões administrativas em que se inserem. Além do mais, existem sobreposições destas duas regiões funcionais com outras regiões administrativas, como por exemplo a região Centro (Ribeiro, Moura, \& Chorincas, 2016). Por outro 
lado, são regiões com perfis funcionais internamente muito diferenciados (Ribeiro \& Ferrão, 2014; Ribeiro, Moura, \& Chorincas, 2015; Marques, Santos, \& Ribeiro, 2016).

A região funcional de Lisboa estende-se até Évora e Sines. Sinteticamente, segundo (Ribeiro, Moura, \& Chorincas, 2015; Marques, Santos, \& Ribeiro, 2015; Marques, Santos, \& Ribeiro, 2016), no final do período correspondente ao anterior quadro comunitário, esta região funcional exibia as seguintes caraterísticas:

- padrão de localização das atividades económicas concentrado e denso na coroa central e de menor densidade nas áreas periféricas.

- uma base económica polarizada por um centro, qualificado e mais terciarizado;

- uma periferia com menor densidade de atividades, de emprego e de ativos qualificados;

- um perfil claramente terciário (educação, saúde, cultura e comércio), com um forte domínio dos serviços às empresas, da administração pública e do turismo;

- agregadora das empresas dos sectores de infraestruturas

- em termos industriais o tecido é diversificado, com agroindústrias, materiais de construção, automóvel, reparação naval e aeronáutica, petroquímica, papel, a exibirem um perfil exportador e os sectores de construção e obras públicas, engenharia e arquitetura em processo de internacionalização;

- sistema de inovação de alcance multiescalar, com uma boa base de organizações envolvidas em processos de inovação em redes cujas ligações se estendem maioritariamente à escala nacional, mas envolvendo as escalas regional e internacional, ancoradas maioritariamente nas instituições universitárias e de investigação e também nas empresas;

- as áreas tecnológicas dos materiais, TIC, eletrónica e instrumentação, engenharia mecânica e engenharia química são as que se fertilizam um maior número de setores de aplicação (potencial para a fertilização cruzada de conhecimento);

- os setores de aplicação da energia, agricultura, pecuária e silvicultura, serviços e da saúde são os setores de aplicação que se interligam com um maior número de áreas tecnológicas (potencial para a emergência de processos de variedade relacionada).

A região funcional do Porto estende-se de Aveiro a Viana do Castelo, abarcando o Noroeste de Portugal e ultrapassando amplamente as fronteiras da região administrativa no Norte de Portugal. No entanto, insere-se maioritariamente na região administrativa do Norte de Portugal, sendo que o nordeste desta região tem dificuldade em se integrar nesta região funcional, ao apresentar caraterísticas contrastantes, sendo um território dominado por caraterísticas de baixa densidade multidimensional. Por outro lado, o Norte da região funcional do Porto tem relações significativas com Espanha (Galiza) o que a converte num proto-sistema transnacional de inovação (Ribeiro \& Marques, 2016). Isto é, a diversidade de realidades funcionais não coincide com a divisão administrativa da região.

Segundo (Ribeiro \& Ferrão, 2014; Marques, Santos, \& Ribeiro, 2016; Marques \& Santos, Lugares e redes de inovação na área metropolitana do, 2013; Santos \& Marques, Lugares e redes de conhecimento na área metropolitana do Porto, 2013), no final do período correspondente ao anterior quadro comunitário, detinha as seguintes caraterísticas:

- menos densa que a região funcional de Lisboa, mas mais polinucleada e descontínua;

- uma grande heterogeneidade de atividades e níveis de qualificação, mas genericamente empregando ativos menos qualificados;

- perfil industrial acentuado, sobretudo nos sectores ditos tradicionais (têxtil, vestuário, calçado, alimentar, madeira e cortiça, pasta e papel), mas também nos setores tecnologicamente mais exigentes (petrolífera, química, borracha e plásticos, minerais não metálicos, metalúrgicas, máquinas e equipamentos, elétrica e ótica, material de transporte e outras indústrias).

- boa base de serviços às pessoas mas débil nos serviços às empresas;

- expressão exportadora na indústria mecânica e máquinas e nos clusters consolidados do material elétrico, das componentes e da eletrónica para a indústria automóvel, na petroquímica e química industrial, siderurgia, e nos materiais de construção;

- sistema de inovação de alcance multiescalar, com uma boa base de organizações envolvidas em processos de inovação em redes cujas ligações se estendem maioritariamente à escala regional, mas envolvendo as escalas nacional e internacional, ancoradas maioritariamente nas instituições universitárias e de investigação e também nas empresas;

- as áreas tecnológicas das TIC, tecnologias dos materiais, engenharia mecânica, tecnologias agrárias e alimentares, automação e robótica, eletrónica e instrumentação, e engenharia química são as que se fertilizam um maior 
número de setores de aplicação;

- os setores de aplicação da saúde, energia, indústria agroalimentar, construção, fabricação de couro e calçado e outros serviços são os setores de aplicação que se interligam com um maior número de áreas tecnológicas (maior potencial de variedade relacionada).

A região administrativa do Centro surge, à saída do anterior quadro comunitário de apoio, como uma região intermédia no contexto de Portugal, com menos peso que as regiões funcionais de Lisboa e Porto. Segundo (Marques, Santos, \& Ribeiro, 2016; Ribeiro, Moura, \& Chorincas, 2016) dá um contributo significativo, nomeadamente através:

- da oferta de ensino superior na área das ciên-cias exatas e naturais, engenharias e ciências da saúde, contribuindo para a capacitação do capital humano do país e também para a investigação e desenvolvimento com competências significativas em vários domínios científicos (Ciências Básicas, Tecnologias da Informação e Eletrónica TICE e Ciências e Tecnologias dos Materiais em Aveiro e Coimbra; Ciências e Tecnologias da Saúde em Coimbra e na Beira Interior, Engenharia Aeronáutica e Tecnologias Têxteis na Beira Interior, Ciências do Ambiente e do Mar em Aveiro e Ciências Sociais e Humanas em Coimbra;

- de uma rede de centros tecnológicos em vários domínios (biotecnologia, cerâmica e vidro, moldes e ferramentas espe-ciais, têxteis e vestuário, telecomunicações, biomassa para a energia, computação gráfica, entre outras);

- de um sistema urbano policêntrico, com múltiplas geo-metrias de relacionamento territorial, polarizado por um pequeno número de cidades médias que originam sub-regiões funcionais: a sub-região de Coimbra (com maior potencial inovador, sobretudo pela capacidade de investigação e transferência tecnológica das universidades e instituições de investigação localizados na cidade e pela capacidade de amarração de redes multiescalares de conhecimento e inovação), a sub-região de Aveiro (com oferta significativa de serviços na área do conhe-cimento e uma forte vocação industrial, desenvolvendo inten-sas relações com a região funcional do Porto e a sub-região de Coimbra), a sub-região de Leiria (com forte vocação industrial, mantendo relações preferenciais com a região funcional de Lisboa), a sub-região de Viseu (com presença industrial com fortes relacionamentos internacionais), a sub-região Covilhã, Fundão e Castelo Branco (com algumas competências no ensino superior e produção do conhecimento e inovação, na área dos serviços como as telecomunicações e na indústria, por exemplo têxtil, com algumas relações preferenciais com Espanha que origina um proto sistema transfronteiriço de inovação;

- As múltiplas geo-metrias de relacionamentos fazem com que uma parte significativa desta região administrativa se integre nas regiões funcionais de Lisboa (as sub-regiões mais a sul) e do Porto (as sub-regiões mais a norte).

As restantes regiões funcionais do país (caixa de texto) assumem posições de maior periferia, dada a menor espessura multidimensional do território (PNPOT, 2018) (DGT, 2018), (Ribeiro, Moura, \& Chorincas, 2015) e (Marques, Santos, \& Ribeiro, 2015).

A região administrativa do Alentejo é uma região onde predomina nomeadamente o turismo (dada a qualidade ambiental e paisagística) e o setor primário, sobretudo agricultura, pecuária e floresta. Évora destaca-se pela oferta de serviços de ensino superior e capacidade de formação e investigação em algumas áreas, e potencial para localização industrial (ex. o cluster da aeronáutica, dada a proximidade a Lisboa). Sines-Santiago do Cacém-Santo André predominam as atividades relacionadas com o sistema logístico-portuário, (porto de Sines) e indústria petroquímica. As subregiões funcionais de Évora e Sines-Santiago do Cacém-Santo André são atraídas pela região funcional de Lisboa, com quem estabelece relações preferenciais muito intensas.

A região administrativa do Algarve é claramente marcada pelo turismo e respetivos serviços (transportes, alojamento e restauração) e comércio dirigidos a este setor de atividade. Tem uma oferta de formação de nível superior e de investigação e desenvolvimento centrada na Universidade do Algarve com alcance essencialmente regional. Estabelece relações funcionais com Espanha (Andaluzia), pelo que se pode também considerar que existe um proto sistema transfronteiriço de inovação.

As regiões autónomas da Madeira e dos Açores são um caso particular no contexto político de Portugal porque gozam do estatuto de regiões autónomas, as únicas regiões administrativas com autonomia no território Português. Outro elemento distintivo destas duas regiões prende-se com o facto de serem consideradas pela UE como regiões ultraperiféricas:

A Região Autónoma dos Açores é um arquipélago distribuído por 9 ilhas o que por si só representa uma singularidade de fragmentação geográfica, à qual acresce uma grande diversidade de situações demográficas, sociais e económicas dentro e entre as diferentes ilhas. Um dos seus principais ativos reside precisamente na sua posição geográfica singular de extrema importância geoestratégica. Outro dos seus principais ativos reside no capital natural. Cerca de metade do território está afetado à atividade agro-pastoril. Ponta Delgada é a principal cidade. O turismo ainda tem uma expres- 
são reduzida na economia da região, mas está em crescimento, sobretudo no segmento de turismo de natureza. A investigação e a inovação são desenvolvidas fundamentalmente pela Universidade dos Açores, a entidade de maior relevância do Sistema Científico e Tecnológico dos Açores (SCTA), com um alcance essencialmente regional. Merece aqui destaque a localização de uma estação aeroespacial em Santa Maria.

A região Autónoma da Madeira é um arquipélago distribuído por seis ilhas, mas apenas duas estão habitadas. Também neste caso o capital natural é o seu principal ativo. O turismo é a principal atividade económica do arquipélago que envolve uma população flutuante de cerca de 15 mil turistas por dia. As atividades agroflorestais estão muito relacionadas com o setor do turismo e constituem em si mesmo um elemento diferenciador ao originarem uma paisagem singular. Existe uma Agência Regional para o Desenvolvimento da Investigação Tecnologia e Inovação e o principal ator é a Universidade da Madeira, com alcance essencialmente regional. A principal cidade é o Funchal.

A síntese que se acaba de realizar vem comprovar, a partir da situação das regiões portuguesas, alguns dos estrangulamentos identificados por Capello \& Kroll (2016), nomeadamente a não coincidência entre as regiões funcionais e as regiões administrativas, a falta de capacidade para se inserirem nas redes globais e cadeias de valor globais ou a fragilidade e baixa capacidade de absorção do conhecimento por parte do tecido empresarial associado a atores universitários de âmbito regional. Mas esta análise sintética permite identificar mais alguns riscos de estrangulamento, nomeadamente:

- A sobreposição parcial de regiões funcionais, o que aconselharia uma maior articulação inter-regional;

- A existências de possíveis sistemas funcionais transnacionais, o que implicaria uma maior articulação transnacional;

- A contrastante realidade interna de algumas das regiões, o que dificulta a definição de prioridades que respondam a esse mosaico de contrastes.

Após esta exploração das caraterísticas das regiões portuguesas à saída do anterior QCA, com o objetivo de identificar os estrangulamentos à aplicação das estratégia de especialização inteligente, de seguida, exploram-se os primeiros projetos $\mathrm{H} 2020$ aprovados até à data, com o objetivo de efetuar uma análise de alguns dos efeitos da aplicação da estratégia de especialização inteligente nestas regiões.

\section{EXPLORAÇÃO DAS REDES H2020 NA ERA DA ESPECIALIZAÇÃO INTELIGENTE}

A rede $\mathrm{H} 2020$ resulta de 1061 projetos aprovados que envolvem organizações localizadas em Portugal (Quadro 1). Os promotores da grande maioria dos projetos localizam-se fora de Portugal (69,5\%), representando $92,6 \%$ do valor total dos projetos e $91 \%$ do financiamento por fundos comunitários. A grande maioria são projetos desenvolvidos em rede interinstitucional.

Em termos de composição institucional (quadro 2), predominam as organizações do sistema empresarial, com 45,5\% do total de organizações envolvidas nestes projetos, e do sistema científico (ensino superior e secundário + organizações de investigação) com 32,6\% do total de organizações. Este mesmo padrão de distribuição observa-se nas organizações portuguesas envolvidas nestes projetos $(58,6 \%$ de organizações do sistema empresarial e $21 \%$ de organizações do sistema científico) embora se acentue o das empresas. No total, as instituições localizadas em Portugal representam 7,8\% do total de instituições envolvidas nestes projetos de I\&D+l H2020.

Apesar do menor peso quanto à composição institucional, são os projetos liderados pelas organizações do sistema científico que granjeiam a maior fatia do valor total $(66,1 \%)$ e do financiamento total $(70,2 \%)$ destes projetos $\mathrm{H} 2020$ (Quadro 3). Os projetos liderados pelas empresas representam $18,6 \%$ do valor total dos projetos e recebem $18,2 \%$ do financiamento. Este é um indicador que reforça o papel desempenhado pelas organizações universitárias e de investigação na captação de financiamento para o desenvolvimento de $I \& D+\mid$ no âmbito dos projetos H2020. No caso concreto dos projetos liderados por organizações portuguesas, mantém-se esta tendência.

\subsection{Caraterização da rede institucional}

Centrando a análise na rede que resulta destes projetos H2O20 (Figura 1), constata-se que o processo de inovação se estrutura essencialmente a partir de redes interinstitucionais (Quadro 4), dado que apenas 64 organizações desenvolvem estes projetos de I\&D+I H2020 isoladamente. 
Quadro 1 - Projetos H2O20 com amarração em Portugal: total de projetos, valor e financiamento.

\begin{tabular}{|c|c|c|c|c|c|c|c|c|c|}
\hline & $\begin{array}{c}\text { № Total } \\
\text { de } \\
\text { Projetos }\end{array}$ & $\begin{array}{c}\text { Valor Total do } \\
\text { Projeto }\end{array}$ & $\begin{array}{c}\text { Valor de } \\
\text { Financiamento } \\
\text { do Projeto }\end{array}$ & $\begin{array}{c}\text { № Projetos } \\
\text { com } \\
\text { Promotor } \\
\text { em PT }\end{array}$ & $\begin{array}{c}\text { Valor total do } \\
\text { Projeto com } \\
\text { Promotor em } \\
\text { PT }\end{array}$ & \begin{tabular}{|c|} 
Valor de \\
Financiamento \\
Projectos com \\
Promotor em PT
\end{tabular} & $\begin{array}{c}\text { № Total } \\
\text { de } \\
\text { Projetos } \\
\text { Isolados }\end{array}$ & $\begin{array}{c}\text { Valor Total de } \\
\text { Projetos } \\
\text { Isolados }\end{array}$ & $\begin{array}{c}\text { Valor de } \\
\text { Financiamento } \\
\text { de Projetos } \\
\text { Isolado }\end{array}$ \\
\hline Rede H2020 & 1.061 & $6.488 .497 .852 €$ & $4.757 .501 .426 €$ & 313 & $479.188 .692 €$ & $429.879 .831 €$ & 180 & $113.601 .482 €$ & 103.167.789€ \\
\hline Peso dos Projetos com Promotor PT & & & & 29,5 & \begin{tabular}{r|}
7,4 \\
\end{tabular} & 9,0 & & & \\
\hline Peso dos Projetos Isolados & & & & & & & 17,0 & 1,8 & 2,2 \\
\hline
\end{tabular}

Quadro 2 - Projetos H2O20 com amarração em Portugal: distribuição das instituições por esfera de ator.

\begin{tabular}{|c|c|c|c|c|}
\hline Esfera Institucional do Ator & $\begin{array}{l}\mathrm{N} \text { Total de } \\
\text { Instituições }\end{array}$ & \begin{tabular}{|c|}
$\%$ por Esfera de \\
Ator no Total \\
de Instituições
\end{tabular} & $\begin{array}{c}\mathrm{N} \text { de } \\
\text { Instituições } \\
\text { Nacionais } \\
\end{array}$ & \begin{tabular}{l}
\multicolumn{1}{c}{$\mathrm{N}{ }^{\circ}$ de } \\
Instituições \\
Estrangeiras
\end{tabular} \\
\hline Estabelecimentos de Ensino Superior ou Secundário & 910 & 14 & 45 & 865 \\
\hline Organizações de Investigação & 1.162 & 18 & 59 & 1.103 \\
\hline Empresas & 2.895 & 46 & 291 & 2.604 \\
\hline Agências Governamentais & 708 & 11 & 48 & 660 \\
\hline Outros & 682 & 11 & 54 & 628 \\
\hline TOTAL & 6.357 & & 497 & 5.860 \\
\hline
\end{tabular}

Quadro 3 - Projetos H2O20 com amarração em Portugal: distribuição dos promotores por esfera de ator.

\begin{tabular}{|c|c|c|c|c|c|c|}
\hline Tipo de Atividade & $\begin{array}{c}\text { No } \\
\text { Projetos } \\
\text { Liderados } \\
\text { por }\end{array}$ & $\begin{array}{c}\text { Valor total do } \\
\text { Projeto Liderados } \\
\text { por }\end{array}$ & $\begin{array}{c}\text { Valor de } \\
\text { Financiamento do } \\
\text { Projeto Liderados } \\
\text { por }\end{array}$ & \begin{tabular}{|c|} 
No Projetos \\
Liderados \\
por \\
Instituições \\
Nacionais \\
\end{tabular} & \begin{tabular}{|l|} 
Valor total do \\
Projeto \\
Liderados por \\
Instituições \\
Nacionais \\
\end{tabular} & \begin{tabular}{|c|} 
Valor de \\
Financiamento do \\
Projeto Liderados \\
por Instituições \\
Nacionais \\
\end{tabular} \\
\hline Estabelecimentos de Ensino Superior ou Secundário & 333 & $1475732610 €$ & $1354365511 €$ & 71 & $105719269 €$ & $103195814 €$ \\
\hline Organizações de Investigação & 376 & $2814111479 €$ & $1986709032 \varepsilon$ & 122 & $203559457 €$ & $192754417 €$ \\
\hline Outros & 41 & $284861340 €$ & $217914810 €$ & 3 & $5196834 €$ & $5196834 €$ \\
\hline TOTAL & 1061 & $6488497852 €$ & $4757501426 €$ & 313 & $479188692 €$ & $429879831 €$ \\
\hline
\end{tabular}

As 6357 instituições conectadas estabelecem um total 12975 ligações. Esta rede estrutura-se em torno de um componente principal que interliga a esmagadora maioria das organizações envolvidas. Exibe uma estrutura claramente hierárquica, centrada num conjunto de organizações com elevada centralidade global na rede (como se pode comprovar pela diferença entre os valores máximos e mínimos e pela mediana do Betweenness-centrality). Esta centralidade é granjeada pelo desemprenho do papel de proponentes (como se pode comprovar pela grande diferença entre os valores máximo e mínimo e pela mediana do out-degree), e reforçada por aquelas instituições que, frequentemente, desempenham o papel de participantes em múltiplos projetos liderados por diferentes instituições.

As organizações com maior centralidade nesta rede no desempenho do papel de proponentes dos projetos de I\&D+I H2020 são identificadas no anexo 1. De salientar que neste grupo, não se inclui qualquer organização localizada em Portugal. Tal significa que as posições de maior centralidade são ocupadas por organizações de outros estados comunitários como Itália, Suécia, Países Baixos, França, Suíça, Alemanha, Espanha, Áustria, Grécia, Reino Unido, Dinamarca, Noruega ou Finlândia, remetendo as organizações portuguesas para posições mais periféricas neste sistema europeu de projetos de I\&D+I H2O2O.

O desempenho do papel de participante (Anexo 2) já permite um envolvimento de instituições portuguesas no grupo das que obtêm maior centralidade na rede (a FCT, a Universidade do Porto ou a Universidade do Minho, apenas para referir as três instituições portuguesas mais centrais). Ainda assim, esta análise é influenciada pelo critério de seleção dos projetos em análise, nomeadamente a obrigatoriedade de envolverem, pelo menos, uma instituição portuguesa.

Este posicionamento em termos de centralidade adjacente leva a que sejam poucas as instituições portuguesas que assumem uma posição de elevada centralidade no desempenho do papel de intermediação 


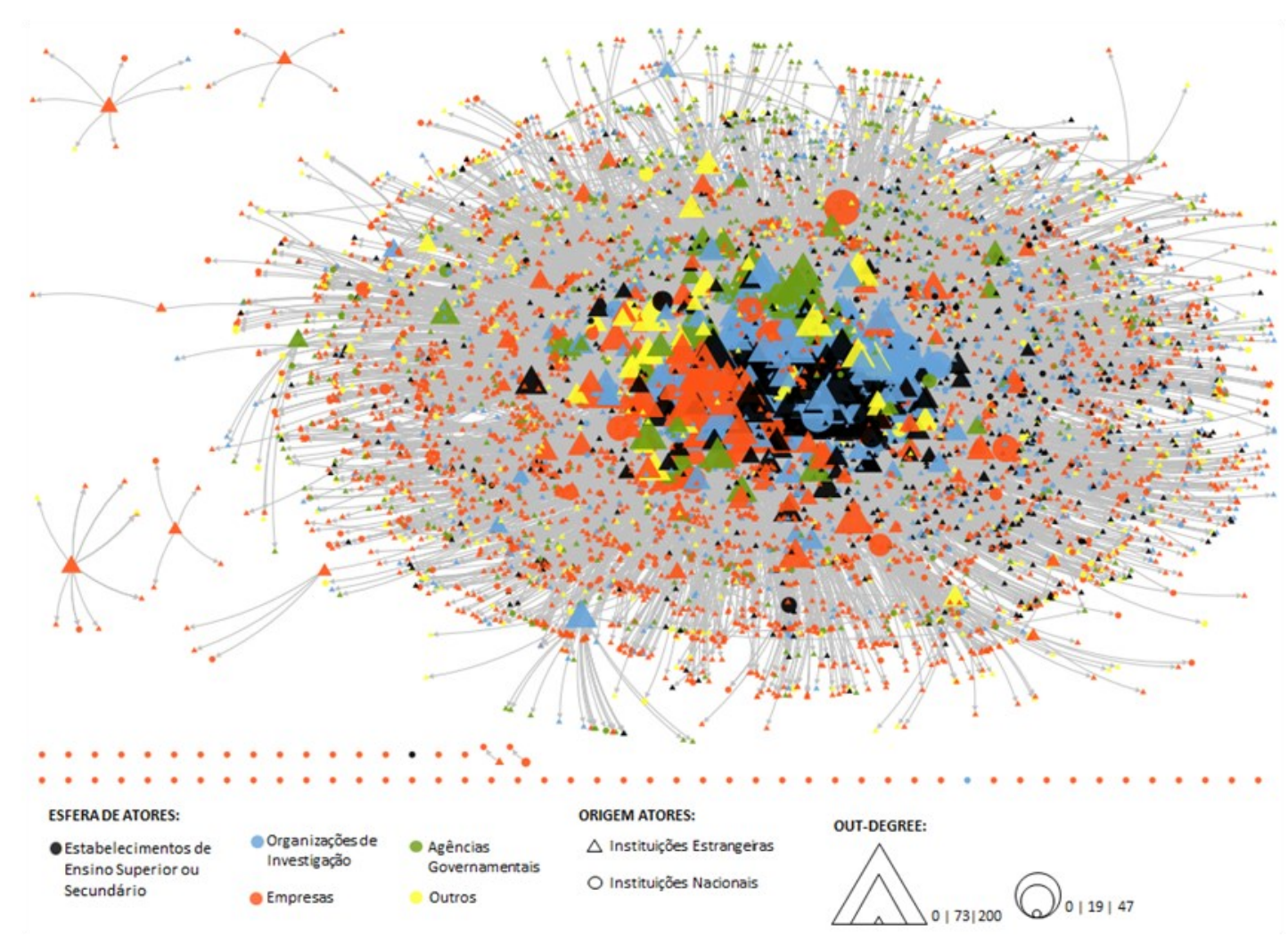

Figura 1-Rede H2O20 com amarração em Portugal: rede institucional

Quadro 4 - Rede H2020 com amarração em Portugal: estatística de caraterização geral da rede.

\begin{tabular}{|l|r|}
\hline Métricas & Valores \\
\hline Vertices & 6357 \\
\hline Ligações únicas & 11769 \\
\hline Ligações duplicadas & 1206 \\
\hline Total de ligações & 12975 \\
\hline Componentes conectados & 7 \\
\hline Vértices isolados & 64 \\
\hline Máximo de vértices num componente conectado & 6260 \\
\hline Máximo de ligações num componente conectado & 12944 \\
\hline In-Degree - mínimo & 0 \\
\hline Maximum In-Degree - máximo & 72 \\
\hline In-Degree - média & 1,9 \\
\hline In-Degree - mediana & 1 \\
\hline Out-Degree - mínimo & 0 \\
\hline Out-Degree - máximo & 200 \\
\hline Out-Degree - média & 1,9 \\
\hline Out-Degree - mediana & 0 \\
\hline Betweenness Centrality - mínimo & 0 \\
\hline Betweenness Centrality - máximo & 19957 \\
\hline Betweenness Centrality - média & 0 \\
\hline Betweenness Centrality - mediana & \\
\hline
\end{tabular}
empresas são aquelas que revelam maior pendor para estabelecerem relações com um alter pertencente à mesma esfera institucional. Do total de relações envolvendo organizações da esfera empresarial, quase metade (48\%) fazem-se entre empresas. Ainda assim, a maioria das relações são exogâmicas, preferencialmente com organizações de investigação e organizações de ensino superior e secundário (38\% das relações envolvendo empresas).

interinstitucional (betweenness-centrality), como se observa no anexo 3. Destacam-se nesta função o INESC TEC, a Universidade do Minho e a Universidade do Porto.

Centrando a análise nas relações, explorou-se a tendência para que as relações interinstitucionais se interlacem, atravessando as esferas institucionais de ação (redes exogâmicas), ou estabelecendo relações preferencialmente entre instituições pertencentes a uma mesma esfera institucional de ação (redes endogâmicas). O resultado desta análise de comunidades é expresso no grafo da figura 2 e no quadro 8.

Apesar da esfera institucional das empresas ser o grupo com maior número de instituições, não é este que estabelece o maior número de ligações (quadro 5). Esse lugar é ocupado pelas instituições de investigação, seguidas de perto pelas instituições de ensino superior e secundário. Isto é, são as instituições da esfera universitária as que revelam maior capacidade relacional interinstitucional, desempenhando um papel importante na translação do conhecimento entre instituições de diferentes esferas de ação.

Em termos de tendência relacional endogâmica, as (n) 


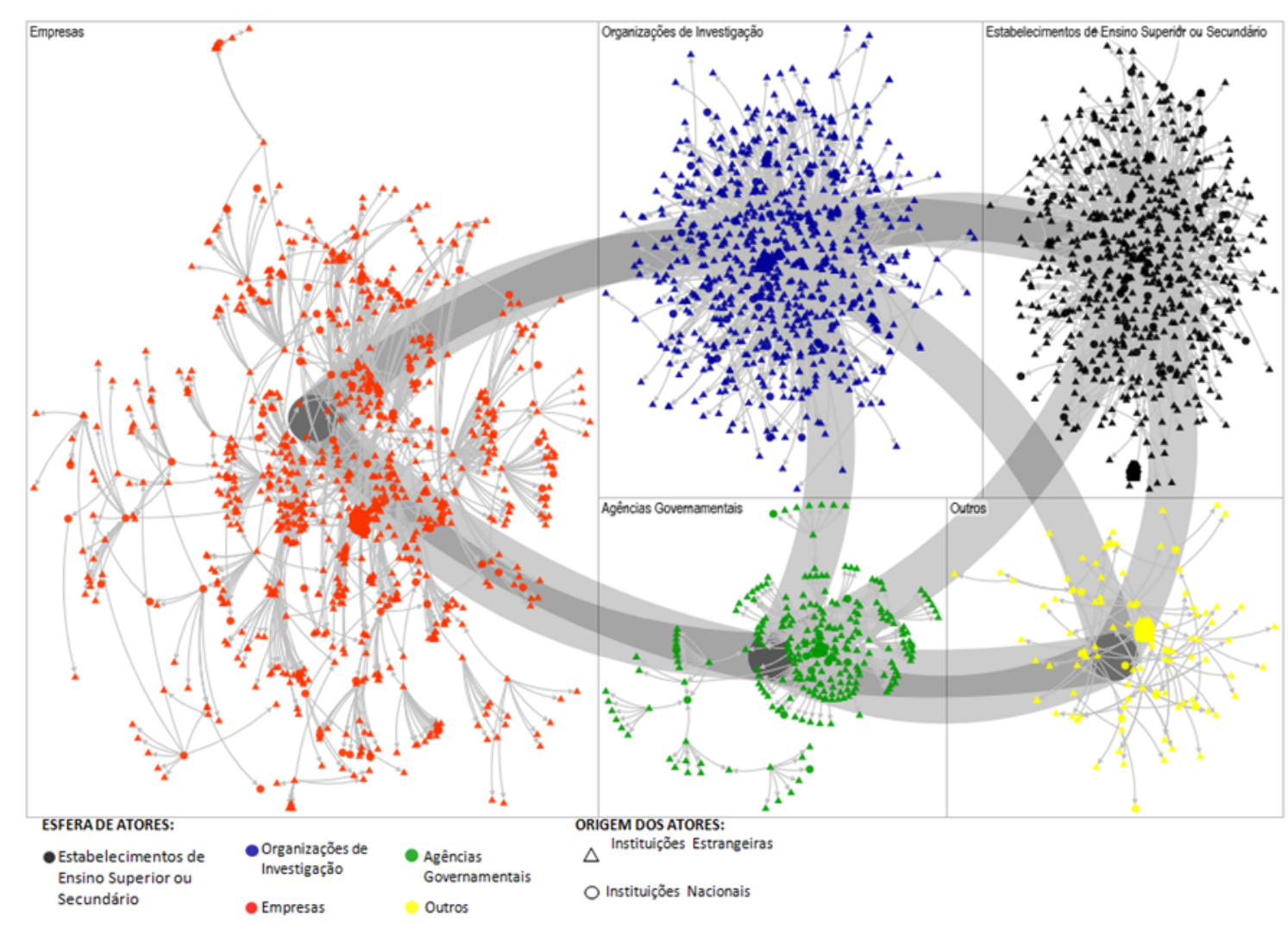

Figura 2 - Rede H2020 com amarração em Portugal: comunidades por esfera de ator.

Quadro 5 - Rede H2020 com amarração em Portugal: estatística geral das relações por esfera institucional de ação

\begin{tabular}{|l|r|r|r|r|}
\hline Esferas institucionais do Ator & Vértices & $\begin{array}{c}\text { Ligaçães } \\
\text { únicas }\end{array}$ & $\begin{array}{c}\text { Ligaçães } \\
\text { duplicadas }\end{array}$ & $\begin{array}{l}\text { Total de } \\
\text { ligações }\end{array}$ \\
\hline Empresas & 2833 & 1078 & 43 & 1121 \\
\hline Organizações de Investigação & 1161 & 1349 & 281 & 1630 \\
\hline Estabelecimentos de Ensino Superior ou Secundário & 909 & 1523 & 101 & 1624 \\
\hline Agências Governamentais & 708 & 383 & 80 & 463 \\
\hline Outros & 682 & 79 & 26 & 105 \\
\hline
\end{tabular}

As instituições de ensino e as agências governamentais são o segundo grupo com maior tendência relacional endogâmica (pouco mais de $40 \%$ das ligações estabelecidas com cada uma destas comunidades institucionais). No entanto acentua-se a tendência para que se estabeleçam relações exogâmicas, envolvendo atores pertencentes a diferentes esferas institucionais de ação. A esfera institucional mais exogâmicas é as das instituições de investigação, onde menos $1 / 3$ das relações se fazem dentro desta esfera institucional. Os restantes $2 / 3$ das relações são exogâmicas, o que converte este grupo institucional naquele que revela melhor perfil para promover a fertilização cruzada de conhecimentos e a sua translação para outras esferas institucionais de ação.

Em síntese, desta análise da rede institucional, pode-se concluir que:

- nestes projetos europeus de I\&D+I H2020 o processo de inovação estrutura-se maioritariamente a partir de redes interinstitucionais;

- Predominam instituições da esfera das universidades/organizações de investigação e da esfera das empresas, sendo estas que granjeiam maior centralidade na rede, seguido pelas agências governamentais (hélice tripla), envolvendo ainda outros perfis institucionais, nomeadamente associações/fundações (hélice quadrupla e nhélices);

- as instituições localizadas em Portugal não são as mais centrais nesta rede europeia de I\&D+I H2020 (esta constatação sai reforçada pelo facto do critério de seleção incluir apenas projetos que envolvam obrigatoriamente pelo menos uma instituição sediada em Portugal); 
Quadro 6 - Rede H2O20 com amarração em Portugal: estatística das relações endogâmicas e exogâmicas.

\begin{tabular}{|c|c|c|}
\hline Esfera institucional do ator & Esfera institucional do ator & Ligações \\
\hline \multirow{5}{*}{ Organizações de Investigação } & Organizações de Investigação & 1630 \\
\hline & Estabelecimentos de Ensino Superior ou Secundário & 1237 \\
\hline & Empresas & 1118 \\
\hline & Agências Governamentais & 593 \\
\hline & Outros & 351 \\
\hline \multirow{5}{*}{ Estabelecimentos de Ensino Superior ou Secundário } & Estabelecimentos de Ensino Superior ou Secundário & 1624 \\
\hline & Empresas & 1026 \\
\hline & Organizações de Investigação & 843 \\
\hline & Outros & 216 \\
\hline & Agências Governamentais & 179 \\
\hline \multirow{5}{*}{ Empresas } & Empresas & 1121 \\
\hline & Organizações de Investigação & 444 \\
\hline & Estabelecimentos de Ensino Superior ou Secundário & 425 \\
\hline & Agências Governamentais & 165 \\
\hline & Outros & 155 \\
\hline \multirow{5}{*}{ Agências Governamentais } & Agências Governamentais & 463 \\
\hline & Organizações de Investigação & 293 \\
\hline & Empresas & 164 \\
\hline & Outros & 127 \\
\hline & Estabelecimentos de Ensino Superior ou Secundário & 89 \\
\hline \multirow{5}{*}{ Outros } & Organizações de Investigação & 180 \\
\hline & Empresas & 162 \\
\hline & Estabelecimentos de Ensino Superior ou Secundário & 144 \\
\hline & Agências Governamentais & 121 \\
\hline & Outros & 105 \\
\hline
\end{tabular}

- As relações interinstitucionais são maioritariamente exogâmicas, o que favorece os processos de fertilização cruzada do conhecimento e a translação do mesmo, ainda que existam esferas institucionais, como a das empresas, que revelam uma tendência relacional endogâmica relevante.

\subsection{Exploração da dimensão geográfica da rede institucional}

A exploração da dimensão geográfica centra-se na análise de comunidades à escala nacional e regional (NUT 2), com um enfoque particular em Portugal.

À escala nacional, as instituições portuguesas estabelecem relações com instituições localizadas em 57 países diferentes, sendo que estabelece relações com todos os Estados Membros da UE. Do total de 2083 relações, a grande maioria (92\%) fazem-se entre instituições localizadas fora de Portugal. Isto é, predominam as relações à escala geográfica internacional, pelo que a maior distância geográfica não é impeditiva da criação de relações no âmbito destes projetos europeus H2020. A maior intensidade relacional faz-se com instituições de Espanha, Reino Unido e Alemanha, havendo um relacionamento claramente preferencial com instituições localizadas nos Estados Membros da UE, o que não impede o estabelecimento de relações com países terceiros, distribuídos pelos cinco continentes (Quadro 7).

Ainda assim, 8\% das relações fazem-se entre instituições localizadas dentro da escala nacional, pelo que esta escala geográfica não é indiferente no que toca às relações interinstitucionais que se estabelecem no âmbito destes projetos. Aliás, invariavelmente, os países com maior presença institucional nestas redes, estabelecem ligações entre instituições colocalizadas dentro das fronteiras do respetivo país. São os casos da Espanha, Alemanha, Itália, Reino Unido ou França, apenas para referir alguns exemplos mais significativos (Figura 3 e Quadro 8).

A escala regional também foi explorada, neste caso, apenas para os países da UE, atendendo à divisão estatística por NUT 2. Nestes projetos em rede estão ligadas 263 regiões pertencentes a 28 Estados Membros da UE.

À esta escala regional, é possível observarem-se relações intrarregionais (Figura 4 e Quadro 9) ainda que a tendência seja para que a maioria das relações se façam entre regiões de países diferentes, isto é, predomina a escala internacional das relações interinstitucionais. No caso de Portugal, essas relações intrarregionais são mais densas na Área Metropolitana de Lisboa e na Região Norte, prevendo-se assim um maior efeito de spillover regional nestes territórios, decorrente da participação nestes projetos europeus. A Região Centro e a Região Autónoma dos Açores exibem redes regionais esparsas, e as regiões do Alentejo, Algarve e Açores não estabelecem qualquer tipo de relações intrarregionais no âmbito destes projetos europeus de I\&D+I H2020. 


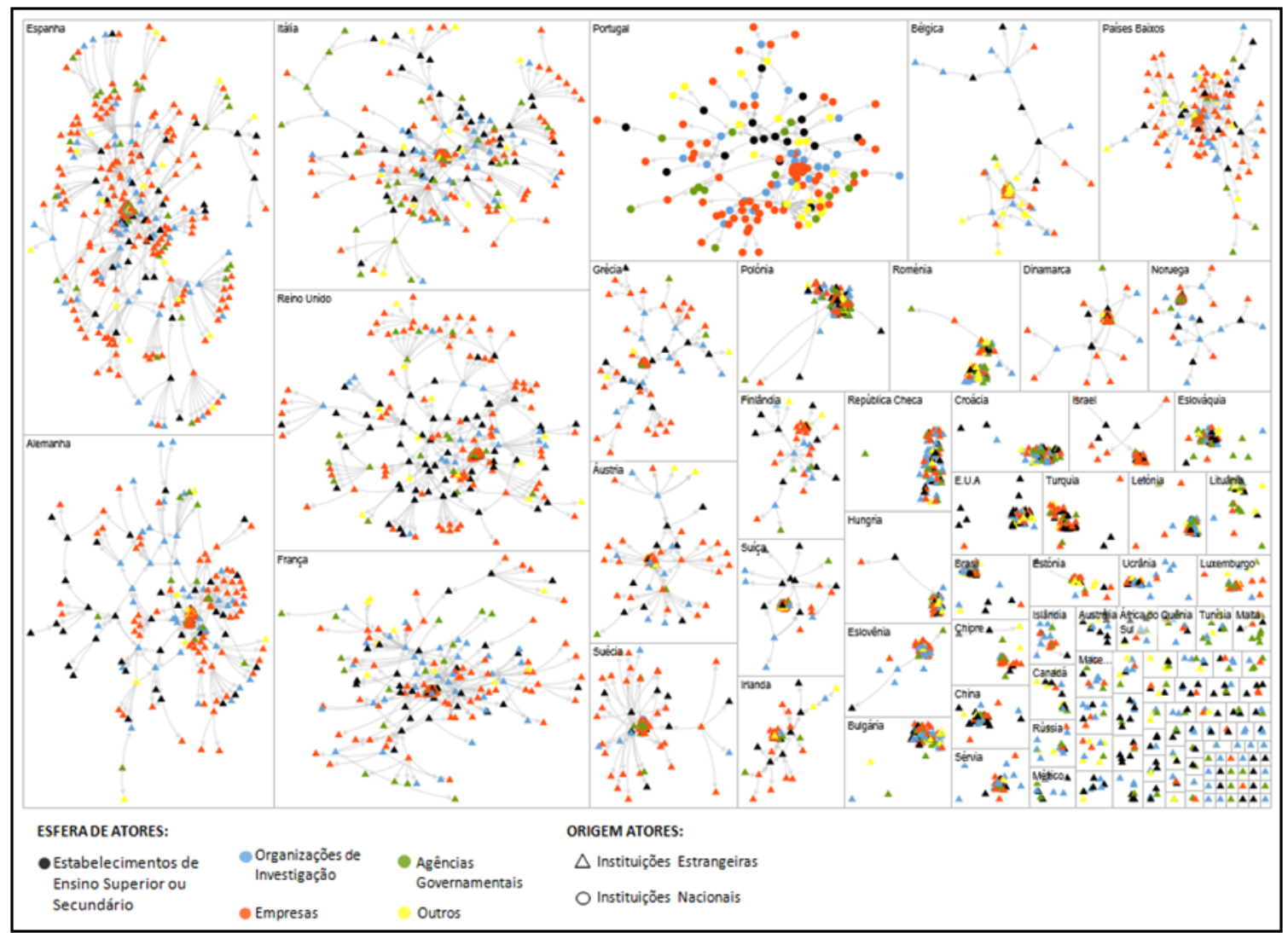

Figura 3 - Rede H2O20 com amarração em Portugal: comunidades por países.

Focando a análise nas regiões portuguesas (quadro 10), estas relacionam-se fundamentalmente com as regiões muito centrais na UE, encabeçadas por grandes cidades (ex. Ille de France, Lazio, Comunidad de Madrid, Région de Bruxelles-Capitale, Oberbayern, Inner London).

Numa análise por regiões, mais uma vez, repete-se o comportamento verificado anteriormente, isto é, são as Regiões da AML, do Norte e do Centro aquelas que exibem maior intensidade de relações e um leque mais amplo de regiões com quem estabelecem maior intensidade relacional. No entanto, estas três regiões exibem ainda a particularidade de, no grupo de maior intensidade relacional se incluírem as relações que ocorrem à escala intrarregional. É um indício de que quando existe espessura institucional interna à região, é possível criação de ligações intrarregionais no âmbito destes projetos europeus de $I \& D+I$, contribuindo para o reforço da translação de conhecimento dentro desta escala geográfica. Outra particularidade é que estas três regiões surgem, no âmbito destes projetos, fortemente conectadas entre si e são pontos de amarração para as restantes regiões mais periféricas portuguesas, contribuindo assim para a estruturação de um sistema relacional inter-regional à escala nacional.

As restantes regiões de Portugal evidenciam intensidades de ligação significativamente mais baixas com um leque muito reduzido de regiões.

Em termos de estratégia nacional de especialização inteligente, importa identificar quais os atores nacionais que, até ao momento, revelaram capacidade para se inserirem nestas redes de projetos europeus de $I \& D+I$ H2020. O mesmo se aplica às diferentes estratégias regionais de especialização inteligente. Assim, com base nos papéis desempenhados e atendendo à sua centralidade na rede, hierarquizaram-se as instituições por regiões (NUT2) para Portugal.

Em Portugal, com capacidade de liderança evidenciada, isto é, que desempenham o papel de proponente, surgem 64 instituições, identificadas, por região, no anexo 4 e hierarquizadas de acordo com a centralidade adjacente granjeada pelo desempenho do papel de proponentes. No entanto, numa análise à escala regional, constata -se que estas se concentram essencialmente nas regiões da AML, Norte e Centro e, dentro destas, localizam-se sobretudo nas principais cidades de cada uma destas regiões, com particular destaque para Lisboa, Porto e Coimbra. Além da maior densidade, é também nestas regiões que se localizam as instituições com maior capacidade 
Quadro 7 - Rede H2020 com amarração em Portugal: ligações das instituições Portuguesas à escala nacional e por países.

\begin{tabular}{|c|c|c|c|c|c|}
\hline & Paises & $\begin{array}{c}\text { No de } \\
\text { Ligaçōes }\end{array}$ & & Paises & $\begin{array}{c}\text { NN2 de } \\
\text { Ligaçöes }\end{array}$ \\
\hline \multirow{30}{*}{ Portugal } & Espanha & 282 & \multirow{29}{*}{ Portugal } & Bulgária & 5 \\
\hline & Reino Unido & 240 & & Turquia & 5 \\
\hline & Alemanha & 223 & & Lituânia & 3 \\
\hline & França & 180 & & Luxemburgo & 3 \\
\hline & Itália & 172 & & Austrália & 3 \\
\hline & Portugal & 169 & & Marroco & 3 \\
\hline & Paises Baixos & 127 & & Argentina & 3 \\
\hline & Grécia & 87 & & Bielorrússia & 3 \\
\hline & Bélgica & 83 & & Chile & 3 \\
\hline & Austria & 58 & & Cabo Verde & 3 \\
\hline & Suécia & so & & Estónia & 3 \\
\hline & Dinamarca & 43 & & Croácia & 2 \\
\hline & Finlândia & 41 & & Letónia & 2 \\
\hline & Irlanda & 41 & & Sérvia & 2 \\
\hline & Noruega & 38 & & I México & 2 \\
\hline & Suiça & 35 & & Quênia & 2 \\
\hline & Polónia & 24 & & Tunisia & 2 \\
\hline & Brasil & 18 & & Vietname & 2 \\
\hline & Chipre & 15 & & Tailândia & 2 \\
\hline & Roménia & 12 & & Rússia & 1 \\
\hline & Eslovênia & 12 & & África do Sul & 1 \\
\hline & E.U.A & 10 & & Coreia do Sul & 1 \\
\hline & Israel & 9 & & Јара̃。 & 1 \\
\hline & Eslováquia & 9 & & Gana & 1 \\
\hline & Ucrânia & 8 & & Malásia & 1 \\
\hline & Hungria & 8 & & Nigéria & 1 \\
\hline & República Checa & 7 & & Peru & 1 \\
\hline & Islândia & 7 & & Azerbaijão & 1 \\
\hline & China & 6 & & Usbequistão & 1 \\
\hline & Malta & 6 & & & \\
\hline
\end{tabular}

Quadro 8 - Rede H2020 com amarração em Portugal: estatística das comunidades por países com relações à escala nacional.

\begin{tabular}{|l|r|r|r|r|r|}
\hline \multicolumn{1}{|c|}{ Paises } & Vértices & $\begin{array}{c}\text { Ligações } \\
\text { únicas }\end{array}$ & $\begin{array}{c}\text { Ligaçōes } \\
\text { duplicadas }\end{array}$ & $\begin{array}{r}\text { Total de } \\
\text { ligaç̄es }\end{array}$ \\
\hline Espanha & 673 & 286 & 4 & 290 \\
\hline Reino Unido & 532 & 192 & 13 & 205 \\
\hline Itália & 552 & 190 & 11 & 201 \\
\hline França & 526 & 169 & 20 & 189 \\
\hline Alemanha & 603 & 166 & 8 & 174 \\
\hline Portugal & 433 & 124 & 45 & 169 \\
\hline Países Baixos & 267 & 96 & 10 & 106 \\
\hline Grécia & 191 & 46 & 10 & 56 \\
\hline Áustria & 174 & 45 & 8 & 53 \\
\hline Suécia & 158 & 38 & 0 & 38 \\
\hline Bélgica & 299 & 31 & 0 & 31 \\
\hline Finlấndia & 102 & 27 & 0 & 27 \\
\hline Irlanda & 91 & 25 & 0 & 25 \\
\hline Noruega & 103 & 17 & 0 & 17 \\
\hline Dinamarca & 108 & 16 & 0 & 16 \\
\hline Suiça & 94 & 13 & 2 & 15 \\
\hline Islầndia & 17 & 5 & 0 & 5 \\
\hline Polónia & 128 & 4 & 0 & 4 \\
\hline Israel & 55 & 4 & 0 & 4 \\
\hline Roménia & 109 & 2 & 0 & 2 \\
\hline Hungria & 78 & 2 & 0 & 2 \\
\hline Eslovênia & 65 & 2 & 0 & 2 \\
\hline Chipre & 33 & 2 & 0 & 2 \\
\hline Estónia & 30 & 1 & 0 & 1 \\
\hline Malta & 11 & 1 & 0 & 1 \\
\hline
\end{tabular}

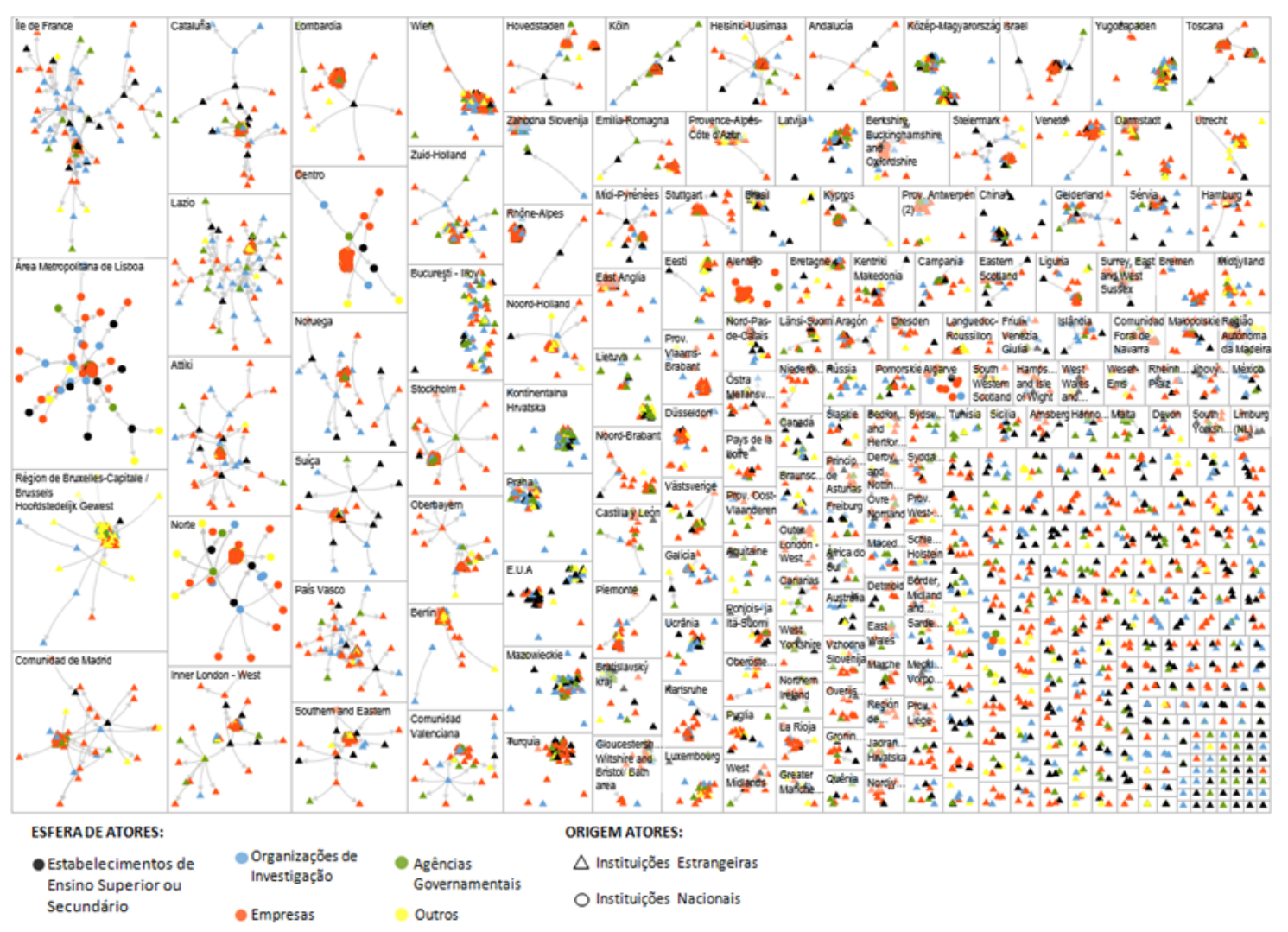

Figura 4 - Rede H2020 com amarração em Portugal: comunidades por regiões (NUT 2). 
Quadro 9 - Rede H2O20 com amarração em Portugal: estatística das comunidades por NUT 2 com maior número de relações à escala intrarregional.

\begin{tabular}{|c|c|c|c|c|}
\hline Regiōes (NUT 2) & Vértices & $\begin{array}{l}\text { Ligações } \\
\text { únicas }\end{array}$ & $\begin{array}{l}\text { Ligações } \\
\text { duplicadas }\end{array}$ & $\begin{array}{l}\text { Total de } \\
\text { ligaçöes }\end{array}$ \\
\hline île de France & 237 & 63 & 13 & 76 \\
\hline Lazio & 129 & 52 & 9 & 61 \\
\hline Área Metropolitana de Lisboa & 196 & 32 & 6 & 38 \\
\hline Attiki & 126 & 25 & 6 & 31 \\
\hline Pais Vasco & 89 & 29 & 0 & 29 \\
\hline Norte & 104 & 13 & 13 & 26 \\
\hline Comunidad de Madrid & 158 & 22 & 2 & 24 \\
\hline Inner London - West & 116 & 19 & 0 & 19 \\
\hline Cataluña & 141 & 17 & 0 & 17 \\
\hline Noruega & 103 & 17 & 0 & 17 \\
\hline Suişa & 94 & 13 & 2 & 15 \\
\hline Southern and Eastern & 81 & 15 & 0 & 15 \\
\hline Oberbayern & 65 & 14 & 0 & 14 \\
\hline Comunidad Valenciana & 62 & 14 & 0 & 14 \\
\hline Steiermark & 39 & 9 & 4 & 13 \\
\hline Région de Bruxelles-Capitale / BrusselsHoofdstedelijk Gewest & 180 & 12 & 0 & 12 \\
\hline Stockholm & 70 & 12 & 0 & 12 \\
\hline Zuid-Holland & 71 & 11 & 0 & 11 \\
\hline Gelderland & 31 & 5 & 6 & 11 \\
\hline Helsinki-Uusimaa & 60 & 10 & 0 & 10 \\
\hline Centro & 83 & 7 & 2 & 9 \\
\hline Lombardia & 109 & 7 & 0 & 7 \\
\hline Hovedstaden & 62 & 7 & 0 & 7 \\
\hline Andalucia & 59 & 7 & 0 & 7 \\
\hline Midi-Pyrénées & 36 & 7 & 0 & 7 \\
\hline Köln & 61 & 4 & 2 & 6 \\
\hline Região Autónoma da Madeira & 14 & 6 & 0 & 6 \\
\hline Canarias & 15 & 6 & 0 & 6 \\
\hline Noord-Holland & 51 & 5 & 0 & 5 \\
\hline Islândia & 17 & 5 & 0 & 5 \\
\hline
\end{tabular}

relacional interinstitucional no âmbito destes projetos e, consequentemente, com maior centralidade na rede. Por outro lado, estas regiões detêm capacidade institucional de liderança distribuída pelas diferentes esferas de ação (sobretudo universidades, organizações de investigação e empresas, mas no caso da AML e Norte surgem ainda agências governamentais e associações/fundações).

$\mathrm{Na}$ região da Madeira apenas duas instituições revelam capacidade de liderança deste tipo de projetos e nas regiões do Alentejo e Algarve apenas uma. No caso dos Açores não existe qualquer instituição proponente destes projetos europeus de $I \& D+I$. Estas são as regiões que revelam menor capacidade institucional instalada para liderar a participação neste tipo de redes internacionais.

Já quanto ao desempenho do papel de participantes, nesta rede existem 425 instituições portuguesas envolvidas. No entanto, mais uma vez, se repete o padrão de distribuição territorial à escala regional observado anteriormente. Isto é, a esmagadora maioria destas instituições localizam-se na AML (193), no Norte (101) e no Centro (82). As restantes regiões continuam a exibir um efetivo reduzido de instituições com capacidade revelada para participarem nestes processos em rede de I\&D+I (Alentejo - 15; Algarve - 14; Madeira - 13; Açores - 7). Ainda assim, o desempenho do papel de participante permite ampliar ligeiramente o número e a diversidade de instituições destas regiões envolvidas nestas redes, o que se pode converter num importante processos de aprendizagem e translação de conhecimento para as regiões em causa.

Através do desempenho do papel de participante nestes projetos, amplia-se a participação institucional de cada região, o que permite estender a amarração destas ligações a um maior número de cidades, inclusivamente de pequenas dimensões (Alijó, Vale de Cambra, Sobral de Monte Agraço, Grândola, apenas para referir alguns exemplos). No entanto, estas assumem um posicionamento muito periférico na rede.

$\mathrm{O}$ anexo 5 identifica as instituições mais centrais, por região, hierarquizadas de acordo com a centralidade adjacente granjeada pelo desempenho do papel de participante. 
Quadro 10 - Rede H2O20 com amarração em Portugal: maior intensidade de ligações entre as regiões portuguesas e outras regiões da UE (NUT 2).

\begin{tabular}{|c|c|c|c|c|c|}
\hline & Regỉies (NUT 2) & $N^{2}$ ligacōes & & Regiöes (NUT 2) & $\mathrm{N}^{9}$ ligaç̄es \\
\hline & Île de France & 62 & & Comunidad de Madrid & 21 \\
\hline & Lazio & 53 & & Norte & 21 \\
\hline & Ärea Metropolitana de Lisboa & 38 & & Área Metropolitana de Lisboa & 20 \\
\hline & Comunidad de Madrid & 37. & & Île de France & 15 \\
\hline & Région de Bruxelles-Capitale / BrusselsHoofdstedelijk Gewest & 29 & & Attiki & 14 \\
\hline & Oberbavern & 28 & & Cataluña & 12 \\
\hline & Norte & 28 & & Lazio & 10 \\
\hline & Inner London - West & 25 & Centro & Centro & 9 \\
\hline & Zuid-Holland & 24 & & Oberbavern & 9 \\
\hline & Pais Vasco & 21 & & Inner London - West & 9 \\
\hline Área & Centro & 20 & & Comunidad Valenciana & 8 \\
\hline Metropolitana de & Cataluña & 19 & & Karlsruhe & 6 \\
\hline Lisboa & Southern and Eastern & 19 & & Pais Vasco & 6 \\
\hline & Hovedstaden & 17 & & Gelderland & 6 \\
\hline & Attiki & 16 & & Région de Bruxelles-Capitale / BrusseisHoofdstedelijk Gewest & 6 \\
\hline & köln & 15 & & Regiã̃o Autónoma da Madeira & 6 \\
\hline & Helsinki-Uusimaa & 14 & & Canarias & 5 \\
\hline & Gelderland & 14 & & Malta & 4 \\
\hline & Utrecht & 13 & & Liguria & 4 \\
\hline & Wien & 13 & Região Autónoma da & Bucuresti - llfov & 3 \\
\hline & East Anglia & 13 & Madeira & Kypros & 3 \\
\hline & Stockholm & 11 & & Toscana & 3 \\
\hline & Karlsruhe & 10 & & Kriti & 2 \\
\hline & Área Metropolitana de Lisboa & 28 & & Southern and Eastern & 2 \\
\hline & Norte & 26 & & Norte & 2 \\
\hline & Centro & 21 & & Île de France & 7 \\
\hline & Comunidad de Madrid & 21 & & Gelderland & 3 \\
\hline & Oberbayern & 21 & & Norte & 3 \\
\hline & Cataluña & 20 & & País Vasco & 3 \\
\hline & Région de Bruxelles-Capitale / BrusselsHoofdstedelijk Gewest & 19 & & Área Metropolitana de Lisboa & 2 \\
\hline & île de france & 19 & Algarve & Berkshire, Buckinghamshire and Oxtordshire & 2 \\
\hline & Inner London - West & 15 & & Comunidad de Madrid & 2 \\
\hline & Pais Vasco & 14 & & Lazio & 2 \\
\hline & Lombardia & 13 & & South Western Scotiand & 2 \\
\hline & Lazio & 11 & & Thessalia & 2 \\
\hline Norte & Attiki & 11 & & Comunidad de Madrid & 7 \\
\hline Norte & Wien & 9 & & Área Metropolitana de Lisboa & 6 \\
\hline & Hovedstaden & 9 & & Île de France & 4 \\
\hline & Zuid-Holland & 8 & Alentejo & Lazio & 5 \\
\hline & Comunidad Valenciana & 7 & & Attiki & 2 \\
\hline & Steiermark & 7 & & Galicia & 2 \\
\hline & Southern and Eastern & 7 & & Helsinki-Uusimas & 2 \\
\hline & Helsinki-Uusimaa & 7 & & Eastern Scotland & 2 \\
\hline & West Midlands & 6 & Região Autónoma & île de france & 2 \\
\hline & Kentriki Makedonia & 6 & dos Açores & Is|ândia & 2 \\
\hline & Noord-Holland & 6 & & Norte & 2 \\
\hline & Stockholm & 6 & & & \\
\hline & Karlsruhe & 6 & & & \\
\hline & Stuttgart & 6 & & & \\
\hline
\end{tabular}

Em síntese, desta análise das comunidades geográficas à escala nacional e regional (NUT 2), pode-se concluir que:

- No ecossistema nacional existe capacidade de liderança e de inserção em redes internacionais de I\&D+I repartido por instituições pertencentes às diferentes esferas institucionais de ação (esfera das universidades/ organizações de investigação, das empresas, das agências governamentais, e das associações/fundações);

- Ainda assim,

- A distribuição pelos ecossistemas regionais destas instituições com capacidade de liderança e participação é desigual, favorável às regiões da AML, Norte e Centro, onde se localizam as maiores cidades portuguesas, revelando a hecticidade institucional das restantes regiões para liderarem e participarem nestes projetos europeus de I\&D+I.

- Ainda assim, o desempenho do papel de participante nestas redes permite estender as ligações a outros territórios menos densos, liderados por pequenas e médias cidades, representando uma oportunidade de aprendizagem e translação de conhecimento através das amarrações a estas redes europeias.

- Em termos de centralidade na rede, o padrão regional repete-se, com as instituições mais centrais a localizarem-se tendencialmente nas regiões da AML, do Norte e do Centro e, dentro destas, nas principais cidades, ainda que, pontualmente, nas regiões do Alentejo, do Algarve e da Madeira, surja uma ou duas instituições com alguma centralidade nesta rede europeia de $I \& D+I$.

- À escala nacional, as regiões da AML, Norte e Centro, isto é, as regiões mais centrais à escala nacional, exibem maior intensidade relacional à escala regional, nacional e internacional, sendo as únicas que exibem um padrão relacional claramente multiescalar no âmbito destes projetos europeus de I\&D+l.

- Em termos de relações internacionais, as regiões portuguesas fazem-no sobretudo com as regiões mais centrais da EU. 


\section{CONSIDERAÇÕES FINAIS}

Inicialmente, propusemo-nos responder a duas questões:

- Quais os estrangulamentos à aplicação da estratégia de especialização inteligente que se podem identificar a partir das regiões portuguesas?

- Que ecossistemas regionais de inovação estão a emergir em Portugal a partir do financiamento H2020 a projetos de investigação e desenvolvimento?

A síntese elaborada sobre a situação das regiões portuguesas à saída do anterior QCA vem comprovar alguns dos estrangulamentos identificados por Capello \& Kroll (2016), nomeadamente a não coincidência entre as regiões funcionais e as regiões administrativas, a falta de capacidade para se inserirem nas redes globais e cadeias de valor globais ou a fragilidade e baixa capacidade de absorção do conhecimento por parte do tecido empresarial associado a atores universitários de âmbito regional. Acrescenta ainda alguns estrangulamentos à lista apresentada por aqueles autores, nomeadamente a sobreposição parcial de regiões funcionais, que deveria conduzir à articulação inter-regional das EREI; a existências de possíveis sistemas funcionais transnacionais que deveria conduzir à articulação transnacional das EREI; e a contrastante realidade interna de algumas das regiões, o que dificulta a definição de prioridades que respondam a esse mosaico de contrastes, que deveriam permitir uma flexibilização intra-regional das EREI atendendo às regiões funcionais e ao mosaico territorial contrastante. Mas a análise aos projetos de I\&D+I H2020, isto é, dos ecossistemas de inovação que estão a emergir da aplicação da estratégia de especialização inteligente, sustenta algumas das constatações anteriores, nomeadamente que as regiões periféricas são as que têm maior dificuldade em se inserirem nestas redes, pelo facto de serem territórios institucionalmente hécticos, cujas instituições aí instaladas assumem um perfil eminentemente local/regional. As regiões mais centrais são as que exibem maior capacidade de ancoragem e amarração a estas redes, com capacidade de estabelecer relações multiescalares, reforçando a sua centralidade.

A partir destes projetos $\mathrm{H} 2020$, pode-se considerar que estes projetos de $\mathrm{I} \& \mathrm{D}+\mathrm{I}$ estão a contribuir para a emergência de três ecossistema regionais de inovação (AML, Norte e Centro), com alguma robustês institucional, incluíndo capacidade de liderança de projetos internacionais, abarcado diferentes esferas institucionais de ação. Estes ecossistemas organizam e inserem-se em redes interorganizacionais multiescalares que potenciam as relações exogâmicas favoráveis à fertilização cruzada do conhecimento e à emergência de processos de variedade relacionada. Estas três regiões são as principais responsáveis pela estruturação do ecossistema nacional e pela inserção deste nas redes internacionais de $I \& D+I$. As restantes regiões portugesas revelam ecossistemas insípidos, com hecticidade institucional e frágil capacidade de liderança, que resulta numa inserção esparsa nestas redes de $I \& D+I$ e num posicionamento periférico.

No entanto, estes são resultados iniciais, tendo ainda como limitação o facto de se centrarem apenas nos projetos europeus de I\&D+I e numa análise essencialmente quantitativa.

\section{BIBLIOGRAFIA}

AMIN, A. (2004). Regions Unbound: Towards a new Politics of Place. Geografiska Annaler: Series B, Human Geography , 86 (1), 33 -44 .

AMIN, A., \& ROBERTS, J. (2008). Knowing in action: Beyond communities of practice. Research Policy, 37, 353-369.

BALLAND, P.-A., BOSCHMA, R., \& KOEN, F. (2015). Proximity and Innovation: From Statics to Dynamics. Regional Studies , 49 (6), 907-920.

BALLAND, P.-A., BOSCHMA, R., CRESPO, J., \& RIGBY, D. L. (2018). Smart specialization policy in the European Union: relatedness, knowledge complexity and regional diversification. Regional Studies .

BARCA, F., MCCANN, P., \& RODRÍGUEZ POSE, A. (2012). The Case for Regional Development Intervention: Place-Based Versus Place-Neutral Approaches. Journal of Regional Science , 52 (1), 134-152.

BATHELT, H., \& GLÜCKLER, J. (2011). The Relational Economy Geographies of Knowing and Learning. Oxford: Oxford University Press.

BATHELT, H., \& HENN, S. (2014). The Geographies of Knowledge Transfers over Distance: Toward a Typology. Environment and Planning A, 46 (6), 1403-1424.

BATHELT, H., \& SCHULDT, N. (2008). Between Luminaires and Meat Grinders: International Trade Fairs as Temporary Clusters. 
Regional Studies , 42 (6), 853-868.

BATHELT, H., \& TURI, P. (2011). Local, global and virtual buzz: The importance of face-to-face contact in economic interaction and possibilities to go beyond. Geoforum , 42, 520-529.

BINZ, C., TRUFFER, B., \& COENEN, L. (2014). Why space matters in technological innovation systems-Mapping global knowledge dynamics of membrane bioreactor technology. Research Policy, 43, 138-155.

BOSCHMA, R. (2014). Constructing Regional Advantage and Smart Specialisation: Comparison of Two European Policy Concepts (Vantaggi regionali e specializzazione intelligente: due concetti di policy europea a confronto). Scienze Regionali , 18, 51-68.

BOSCHMA, R. (2005). Proximity and Innovation: A Critical Assessment. Regional Studies, 39 (1), 61-74.

BOSCHMA, R. (2016). Smart Specialisation and Regional Innovation Policy. Welsh Economic Review , 24, 17.

BOSCHMA, R., \& FRENKEN, K. (2010). The spatial evolution of innovation networks: a proximity perspective. In R. BOSCHMA, \& R. MARTIN, The Handbook of Evolutionary Economic Geography (pp. 120-135). Cheltenham: Edward Elgar Publishing Limited.

CAMAGNI, R., \& CAPELLO, R. (2013). Regional Innovation Patterns and the EU Regional Policy Reform: Toward Smart Innovation Policies. Growth and Change , 44 (2), 355-389.

CAPELLO, R., \& KROLL, H. (2016). From theory to practice in smart specialization strategy: emerging limits and possible future trajectories. European Planning Studies , 24 (8), 1393-1406.

CARAYANNIS, E. G., \& CAMPBELL, D. F. (2012). Mode 3 Knowledge Production in Quadruple Helix Innovation Systems: 21stCentury Democracy, Innovation, and Entrepreneurship for Development. New York: Springer.

CARAYANNIS, E. G., \& CAMPBELL, D. F. (2011). Open Innovation Diplomacy and a 21st Century Fractal Research, Education and Innovation (FREIE) Ecosystem: Building on the Quadruple and Quintuple Helix Innovation Concepts and the "Mode 3" Knowledge Production System. Journal Of The Knowledge Economy , 2 (3), 327-372.

CARAYANNIS, E. G., PIRZADEH, A., \& POPESCU, D. (2012). Institutional Learning and Knowledge Transfer Across Epistemic Communities. New Tools of Global Governance. New York / Dordrecht / Heidelberg / London: Springer.

CCDR Alentejo. (2014). Uma Estratégia de Especialização Inteligente para o Alentejo. Évora: Comissão de Coordenação e Desenvolvimento Regional do Alentejo.

CCDR Algarve. (2015). RIS3 - Agarve 2014-2020 Estratégia Regional de Investigação e Inovação para a Especialização Inteligente. Faro: Comissão de Coordenação e Desenvolvimento do Algarve.

CCDRC. (2014). RIS3 do Centro de Portugal Estratégia de Investigação e Inovação para uma Especialização Inteligente. Coimbra: Comissão de Coordenação e Desenvolvimento Regional do Centro.

CCDRLVT. (2015). Especialização Inteligente de Lisboa 2014-2020. Lisboa: Comissão de Coordenação e Desenvolvimento Regional de Lisboa e Vale do Tejo.

CCDRN. (2014). Norte 2020: Estratégia Regional de Especialização Inteligente. Porto: Comissão de Coordenação e Desenvolvimento Regional do Norte.

COE, N. M., \& HESS, M. (2013). Global production networks, labour and development. Geoforum , 44, 4-9.

COE, N. M., \& YEUNG, H. W.-C. (2015). Global Production Networks 2.0. In N. M. Coe, \& H. W.-C. Yeung, Global Production Networks (pp. 1-31). Oxford: Oxford University Press.

DGT. (2018). PNPOT - Alteração: Diagnóstico (versão para discussão pública). Lisboa: DGT.

European-Commission. (24 de novembro de 2017). SMART SPECIALISATION PLATFORM. Obtido em 2 de maio de 2018, de http://s3platform.jrc.ec.europa.eu/

FORAY, D. (2016). On the policy space of smart specialization strategies. European Planning Studies , 24 (8), 1428-1437.

FORAY, D., GODDARD, J., BELDARRAIN, X. G., LANDABASO, M., MCCANN, P., MORGAN, K., et al. (2012). Guide to Research and Innovation Strategies for Smart Specialisation (RIS 3). Brussels: European Commission.

GULC, A. (2015). Analysis of Methodological Approach to Identify Smart Specialization on the Example of Polish Regions. Procedia - Social and Behavioral Sciences , 213, 817-823.

IAPMEI; FCT; ANI; COMPETE. (2014). Estratégia de linvestigação e Inovação para uma Especialização Inteligente 2014-2020. Lisboa: IAPMEI; FCT; ANI; COMPETE.

JONES, B. W., SPIGEL, B., \& MALECKI, E. J. (2010). Blog links as pipelines to buzz elsewhere: the case of New York theater blogs. Environment and Planning B: Planning and Design , 37, 99-111. 
KEMPTON, L. (2015). Delivering smart specialization in peripheral regions: the role of Universities. Regional Studies, Regional Science, 2 (1), 489-496.

KNOBEN, J., \& OERLEMANS, L. (2006). Proximity and inter-organizational collaboration: A literature review. International Journal of Management Reviews , 8 (2), 71-89.

LEYDESDORFF, L. (2001). Knowledge-Base Innovation Systems and the Model of Triple Helix of University-IndustryGovernment Relations. Paper presented at the 13th Annual Meeting of the Society for the Advancement of Socio-Economics (SASE). Amsterdam (29 June).

LEYDESDORFF, L. (2005). The Triple Helix Model and the Study of Knowledge-based innovation systems. Intenational Journal of Contemporary Sociology , 42 (1), 1-16.

LEYDESDORFF, L. (2012). The Triple Helix, Quadruple Helix, ..., and an N-Tuple of Helices: Explanatory Models for Analyzing the Knowledge-Based Economy? Journal of the Knowledge Economy, 3 (1), 25-35.

LEYDESDORFF, L., \& ETZKOWITZ, H. (1998). The Triple Helix as a Model for Innovation Studies. Science \& Public Policy, 25 (3), 195-203.

LIU, J., CHAMINADE, C., \& ASHEIM, B. (2013). The Geography and Structure of Global Innovation Networks: A Knowledge Base Perspective. European Planing Studies , 21 (9), 1456-1473.

LUNDVALL, B.-A. (2010). User-Producer Relationships, National Systems of Innovation and Internationalisation. In B.-A. Lundvall, National Systems of Innovation Toward a Theory of Innovation and Interactive Learning (pp. 47-70). London: Anthem Press.

MARQUES, T. S., \& QUEIRÓS, J. P. (2017). AMP 2020 Crescimento Inteligente. Casal de Cambra: Caleidoscópio.

MARQUES, T. S., SANTOS, H., \& RIBEIRO, P. (2016). Especialização Inteligente: as complementaridades relacionais da inovação ancorada nas macrorregiões de Lisboa e do Porto. XV Coloquio Ibérico de Geografía.Retos y tendencias de la Geografía Ibérica (pp. 1210-1221). Murcia: Universidad de Murcia-AGE-APG.

MARQUES, T. S., SANTOS, H., \& RIBEIRO, P. (2016). Redes de Inovação Económica Ancoradas na Região Centro (2007-2015). In F. J. Ribeiro, F. Moura, \& J. Chorincas, Portugal no Centro (pp. 464-501). Lisboa: Fundação Calouste Gulbenkian.

MARQUES, T. S., SANTOS, H., \& RIBEIRO, P. (2015). Redes de inovação económica ancoradas no arco metropolitano de Lisboa (2007-2013). In J. M. Ribeiro, F. Moura, \& J. Chorincas, Uma metrópole para o Atlântico (pp. 558-590). Lisboa: Fundação Calouste Gulbenkian.

MARQUES, T., \& SANTOS, H. (2013). Lugares e redes de inovação na área metropolitana do. Geografia: Revista da Faculdade de Letras da Universidade do Porto , 2 (III), 203-225.

MARQUES, T., \& SANTOS, H. (2013). Lugares e redes de inovação na área metropolitana do Porto. Geografia: Revista da Faculdade de Letras da Universidade do Porto , 2 (III), 203-225.

MASSEY, D. (2005). For space. London: Sage.

MAXIMILIAN, B., BIERINGER, L., KNAUPP, M., WITTEMAIER, J., \& WRUCK, A. (2016). Towards a Smart Specialization Strategy for Haifa, Israel. Munich Personal RePEc Archive - Heidelberg University, 1-63.

MCCANN, P., \& ORTEGA-ARGILÉS, R. (2013). Smart Specialization, Regional Growth and Applications to European Union Cohesion Policy. Regional Studies , 49 (8), 1291-1302.

MCCANN, P., \& ORTEGA-ARGILÉS, R. (2015). Smart Specialization, Regional Growth and Applications to European Union Cohesion Policy. Regional Studies , 49 (8), 1291-1302.

MOULAERT, F., \& SEKIA, F. (2003). Territorial Innovation Models: A Critical Survey. Regional Studies, , 37 (3), $289-302$.

NALDI, L., NILSSON, P., WESTLUND, H., \& WIXE, S. (2015). What is smart rural development? Journal of Rural Studies , 40, 90101.

NOVOSÁK, J., HÁJEK, O., ZAHRADNÍK, P., \& NEKOLOVÁ, J. (2013). On Some Aspects of Territorial Competitiveness: Smart Specialization in the Zlín 2020 Strategy. Journal of Competitiveness , 5 (3), 3-13.

REGIÃO AUTÓNOMA DA MADEIRA GOVERNO REGIONAL DA MADEIRA. (2015). Madeira 2020 Estratégia Regional de Especialização Inteligente RIS3. Funchal: Região Autónoma da Madeira Governo Regional da Madeira.

RIBEIRO, J. M., \& FERRÃO, J. (. (2014). Noroeste Global. Lisboa: Fundação Calouste Gulbenkian.

RIBEIRO, J. M., MOURA, F., \& CHORINCAS, J. (. (2016). Portugal no Centro. Lisboa: Fundação Calouste Gulbenkian.

RIBEIRO, J. M., MOURA, F., \& CHORINCAS, J. (2015). Uma Metrópole para o Atlântico. Lisboa: Fundação Calouste Gulbenkian.

RIBEIRO, P., \& MARQUES, T. S. (2016). A Euroregião Galiza-Norte de Portugal: uma plataforma territorial para a inovação. Atas 
do VII Jornadas de Geografía Económica: "Los escenarios económicos en transformación. La realidad territorial tras la crisis económica" (pp. 146-154). Santiago de Compostela: AGE.

SANDU, S. (2012). Smart specialization concept and the status of its implementation in Romania. Procedia Economics and Finance, 3, 236-242.

SANTOS, H., \& MARQUES, T. S. (2013). Lugares e redes de conhecimento na área metropolitana do Porto. Geografia : Revista da Faculdade de Letras da Universidade do Porto , 2, 179-202.

SANTOS, H., \& MARQUES, T. S. (2013). Lugares e redes de conhecimento na área metropolitana do Porto. Geografia: Revista da Faculdade de Letras da Universidade do Porto , 2 (III), 179-202.

SPI Açores e Governo Regional dos Açores. (2014). Estratégia de Investigação e Inovação para a Especialização Inteligente da Região Autónoma dos Açores - RIS3 AÇORES. S. Miguel: SPI Açores e Governo Regional dos Açores.

THISSEN, M., VAN OOR, F., DIODATO, D., \& RUIJS, A. (2013). Regional Competitiveness and Smart Specialization in Europe: Place -based development in International Economic Networks. Cheltenham: Edward Elgar Publishing Limited.

TORRE, A. (2008). On the Role Played by Temporary Geographical Proximity in Knowledge Transmission. Regional Studies , 42 (6), 869-889.

TRIPPL, M., TÖDTLING, F., \& LENGAUER, L. (2009). Knowledge Sourcing Beyond Buzz and Pipelines: Evidence from the Viena Software Sector. Economic Geography, 85 (4), 443-462.

\section{ANEXOS}

Anexo 1 - Rede H2020 com amarração em Portugal: instituições com maior centralidade no desempenho do papel de proponentes.

\begin{tabular}{|c|c|c|c|}
\hline Instituição & Esfera institucional do ator & Pais & Out-Degree \\
\hline Consiglio Nazionale Delle Ricerche & Organizações de Investigação & Itália & 200 \\
\hline Chalmers Tekniska Hoegskola Ab & Estabelecimentos de Ensino Superior ou Secundário & Suécia & 158 \\
\hline Stichting Wageningen Research & Organizações de Investigação & Paises Baixos & 151 \\
\hline Institut National De La Recherche Agronomique_França & Organizações de Investigação & França & 134 \\
\hline Ecole Polytechnique Federale De Lausanne & Estabelecimentos de Ensino Superior ou Secundário & Suiça & 116 \\
\hline Agence Nationale De La Recherche & Agências Governamentais & França & 116 \\
\hline Infineon Technologies Ag & Empresas & Alemanha & 109 \\
\hline Institut National De La Sante Et De La Recherche Medicale & Organizações de Investigação & França & 105 \\
\hline Fraunhofer Gesellschaft Zur Foerderung Der Angewandten Forschung E.V. & Organizações de Investigação & Alemanha & 97 \\
\hline Engineering - Ingegneria Informatica Spa & Empresas & Itália & 96 \\
\hline Fundacion Tecnalia Research \& Innovation & Organizações de Investigação & Espanha & 90 \\
\hline Deutsches Zentrum Fuer Luft - Und Raumfahrt Ev & Organizações de Investigação & Alemanha & 89 \\
\hline Forschungszentrum Julich Gmbh & Organizações de Investigação & Alemanha & 88 \\
\hline Nederlandse Organisatie Voor Toegepast Natuurwetenschappelijk Onderzoek Tno & Organizações de Investigação & Paises Baixos & 88 \\
\hline Wageningen University & Estabelecimentos de Ensino Superior ou Secundário & Paises Baixos & 73 \\
\hline Avl List Gmbh & Empresas & Áustria & 72 \\
\hline Atos Spain Sa & Empresas & Espanha & 71 \\
\hline Institut Francais De Recherche Pour L'exploitation De La Mer & Organizações de Investigação & França & 70 \\
\hline European Organization For Nuclear Research & Organizações de Investigação & Suiça & 70 \\
\hline European Molecular Biology Laboratory & Organizações de Investigação & Alemanha & 69 \\
\hline Ethniko Kai Kapodistriako Panepistimio Athinon & Estabelecimentos de Ensino Superior ou Secundário & Grécia & 68 \\
\hline Helmholtz Zentrum Fur Ozeanforschung Kiel & Organizações de Investigação & Alemanha & 62 \\
\hline Network Rail Infrastructure Limited & Empresas & Reino Unido & 62 \\
\hline Aimplas - Asociacion De Investigacion De Materiales Plasticos Y Conexas & Organizações de Investigação & Espanha & 60 \\
\hline Umweltbundesamt & Organizações de Investigação & Alemanha & 59 \\
\hline Agencia Estatal Consejo Superior Deinvestigaciones Cientificas & Organizações de Investigação & Espanha & 58 \\
\hline Kompetenzzentrum - Das Virtuelle Fahrzeug, Forschungsgesellschaft Mbh & Organizações de Investigação & Áustria & 56 \\
\hline Mercator Ocean & Organizações de Investigação & França & 56 \\
\hline Centre National De La Recherche Scientifique Cnrs & Organizações de Investigação & França & 55 \\
\hline Istituto Nazionale Di Geofisica E Vulcanologia & Organizações de Investigação & Itália & 55 \\
\hline Universita Politecnica Delle Marche & Estabelecimentos de Ensino Superior ou Secundário & Itália & 55 \\
\hline Danmarks Tekniske Universitet & Estabelecimentos de Ensino Superior ou Secundário & Dinamarca & 53 \\
\hline National Technical University Of Athens - Ntua & Estabelecimentos de Ensino Superior ou Secundário & Grécia & 53 \\
\hline Universiteit Utrecht & Estabelecimentos de Ensino Superior ou Secundário & Países Baixos & 53 \\
\hline Stiftelsen Sintef & Organizações de Investigação & Noruega & 53 \\
\hline Agence De L'environnement Et De La Maitrise De L'energie & Agências Governamentais & França & 53 \\
\hline Technische Universiteit Delft & Estabelecimentos de Ensino Superior ou Secundário & Paises Baixos & 52 \\
\hline Teknologian Tutkimuskeskus Vtt Oy & Organizações de Investigação & Finlândia & 51 \\
\hline Coventry University & Estabelecimentos de Ensino Superior ou Secundário & Reino Unido & 51 \\
\hline
\end{tabular}


Anexo 2 - Rede H2O20 com amarração em Portugal: centralidade das instituições no desempenho do papel de participantes.

\begin{tabular}{|c|c|c|c|}
\hline Instituição & Esfera institucional do ator & Pais & In-Degree \\
\hline Fraunhofer Gesellschaft Zur foerderung Der Angewandten Forschung E.V. & Organizações de Investigação & Alemanha & 72 \\
\hline Centre National De La Recherche Scientifique Cnrs & Organizações de Investigação & França & 60 \\
\hline Agencia Estatal Consejo Superior Deinvestigaciones Cientificas & Organizações de Investigação & Espanha & 55 \\
\hline Consiglio Nazionale Delle Ricerche & Organizações de Investigação & Itália & 49 \\
\hline Commissariat A L Energie Atomique Et Aux Energies Alternatives & Organizações de Investigação & França & 40 \\
\hline Fundacao Para A Ciencia E A Tecnologia & Agências Governamentais & Portugal & 37 \\
\hline Danmarks Tekniske Universitet & Estabelecimentos de Ensino Superior ou Secundário & Dinamarca & 36 \\
\hline Deutsches Zentrum Fuer Luft - Und Raumfahrt Ev & Organizações de Investigação & Alemanha & 34 \\
\hline Universidade Do Porto & Estabelecimentos de Ensino Superior ou Secundário & Portugal & 34 \\
\hline University College London & Estabelecimentos de Ensino Superior ou Secundário & Reino Unido & 33 \\
\hline Politecnico Di Milano & Estabelecimentos de Ensino Superior ou Secundário & Itália & 32 \\
\hline Universidade Do Minho & Estabelecimentos de Ensino Superior ou Secundário & Portugal & 32 \\
\hline Teknologian Tutkimuskeskus Vtt Oy & Organizaç̃es de Investigasão & Finlândia & 30 \\
\hline Natural Environment Research Council & Organizações de Investigaç̃̃o & Reino Unido & 29 \\
\hline Alma Mater Studiorum - Universita Di Bologna & Estabelecimentos de Ensino Superior ou Secundário & Itália & 28 \\
\hline Helsing in Yliopisto & Estabelecimentos de Ensino Superior ou Secundário & Finlândia & 28 \\
\hline Inesc Tec - Instituto De Engenharia De Sistemas E Computadores, Tecnologia E Ciencia & Organizações de Investigação & Portugal & 27 \\
\hline Katholieke Universiteit Leuven & Estabelecimentos de Ensino Superior ou Secundário & Bélgica & 27 \\
\hline Instituto Superior Tecnico & Estabelecimentos de Ensino Superior ou Secundário & Portugal & 27 \\
\hline The Chancellor, Masters And Scholars Of The University Of Oxford & Estabelecimentos de Ensino Superior ou Secundário & Reino Unido & 27 \\
\hline Fundacion Tecnalia Research \& Innovation & Organizạ̧ões de Investigação & Espanha & 26 \\
\hline Stichting Wageningen Research & Organizações de Investigaç̃̃o & Paises Baixos & 25 \\
\hline Kobenhavns Universitet & Estabelecimentos de Ensino Superior ou Secundário & Dinamarca & 24 \\
\hline Universidade De Aveiro & Estabelecimentos de Ensino Superior ou Secundário & Portugal & 24 \\
\hline Aarhus Universitet & Estabelecimentos de Ensino Superior ou Secundário & Dinamarca & 23 \\
\hline Ethniko Kentro Erevnas Kai Technologikis Anaptyxis & Organizações de Investigação & Grécia & 23 \\
\hline Universidade Nova De Lisboa & Estabelecimentos de Ensino Superior ou Secundário & Portugal & 23 \\
\hline Turkiye Bilimsel Ve Teknolojik Arastirma Kurumu & Organizações de Investigação & Turquia & 23 \\
\hline Universidad Politecnica De Madrid & Estabelecimentos de Ensino Superior ou Secundário & Espanha & 22 \\
\hline Max-Planck-Gesellschaft Zur Forderung Der Wissenschaften Ev & Organizações de Investigação & Alemanha & 22 \\
\hline Universidade De Coimbra & Estabelecimentos de Ensino Superior ou Secundário & Portugal & 22 \\
\hline Nova Id fct - Associacao Para A Inovacao E Desenvolvimento Da fct & Organizações de Investigação & Portugal & 22 \\
\hline Hellenic Centre For Marine Research & Organizações de Investigação & Grécia & 22 \\
\hline Institut National De La Recherche Agronomique_França & Organizações de Investigação & França & 21 \\
\hline Forschungszentrum Julich Gmbh & Organizạ̧ões de Investigação & Alemanha & 21 \\
\hline Karlsruher Institut Fuer Technologie & Estabelecimentos de Ensino Superior ou Secundário & Alemanha & 21 \\
\hline Norges Forskningsrad & Agências Governamentais & Noruega & 21 \\
\hline Ecole Polytechnique Federale De Lausanne & Estabelecimentos de Ensino Superior ou Secundário & Suiça & 20 \\
\hline Technische Universiteit Delft & Estabelecimentos de Ensino Superior ou Secundário & Paises Baixos & 20 \\
\hline Agenzia Nazionale Per Le Nuove Tecnologie, L'energia E Lo Sviluppo Economico Sostenibile & Organizações de Investigação & Itália & 20 \\
\hline Eidgenoessische Technische Hochschule Zuerich & Estabelecimentos de Ensino Superior ou Secundário & Suiça & 20 \\
\hline Uninova-Instituto De Desenvolvimento De Novas Tecnologias-Associacao & Organizações de Investigação & Portugal & 20 \\
\hline Institut Jozef Stefan & Organizações de Investigação & Eslovênia & 20 \\
\hline
\end{tabular}

Anexo 3- Rede H2020 com amarração em Portugal: centralidade das instituições no desempenho do papel de proponentes.

\begin{tabular}{|c|c|c|c|c|c|}
\hline \multirow{2}{*}{$\begin{array}{l}\text { Instituicōes } \\
\text { Fraunhofer Gesellischaft Zur Foerderung Der Angewandten Forschung E.V. } \\
\text { Consiglio Nazionale Delle Ricerche }\end{array}$} & \multirow{2}{*}{$\begin{array}{l}\text { Estera institucional do ator } \\
\text { Organizaçes de Investigaç̃o }\end{array}$} & \multirow{2}{*}{$\begin{array}{l}\text { Pais } \\
\text { Alemanha }\end{array}$} & \multicolumn{2}{|c|}{ in-degree out-degree } & \multirow{2}{*}{$\begin{array}{l}\text { Betweenness } \\
\text { Centrality } \\
4057880\end{array}$} \\
\hline & & & 72 & 97 & \\
\hline Consiglio Nazionale Delle Ricerche & Organizaçōes de Investigą̧̃o & Itália & 49 & 200 & 3418309 \\
\hline Stichting Wageningen Research & Organizasōes de Investizaş̃o & Paises Baixos & 25 & 151 & 2009838 \\
\hline Chalmers Tekniska Hoegskola Ab & Estabelecimentos de Ensino Superior ou Secundärio & Suécia & 9 & 158 & 1966953 \\
\hline Fundacion Tecnalia Research \& Innovation & Organizaçōes de Investigaş̃o & Espanha & 26 & 90 & 1813810 \\
\hline Institut National De La Recherche Agronomique_franşa & Organizações de Investigạ̧ão & França & 21 & 134 & 1802611 \\
\hline Ecole Polytrechnique Federale De Lausanne & Estabelecimentos de Ensino Superior ou Secundário & Suiça & 20 & 116 & 1614851 \\
\hline Agencia Estatal Consejo Superior Deinvestigaciones Cientificas & Organizą̧̃es de Investigạ̧̃o & Espanha & 55 & 58 & 1397445 \\
\hline Centre National De La Recherche Scientifique Cnrs & Organizaç̃es de Investigą̧̃o & Franşa & 60 & 55 & 1341409 \\
\hline Deutsches Zentrum Fuer Luft - Und Raumfahnt Ev & Organizaş̃es de Investigaş̃o & Alemanha & 34 & 89 & 1212858 \\
\hline Teknologian Tutkimuskeskus Vtt oy & Organizą̧̋es de Investigą̧̃。 & Finländia & 30 & 51 & 1148478 \\
\hline Nederlandse Organisatie Voor Toegepast Natuurwetenschappelijk Onderzoek Tno & Organizaç̄es de Investigąão & Paises Baixos & 17 & 88 & 1094955 \\
\hline Engineering - Ingegneria Informatica Spa & Empresas & Itália & 13 & 96 & 1082299 \\
\hline Infineon Technologies Ag & Empresas & Alemanha & 3 & 109 & 998447 \\
\hline Inesc Tec - Instituto De Engenharia De Sistemas E Computadores, Tecnologia E Ciencia & Organizações de Investigação & Portugal & 27 & 39 & 992786 \\
\hline Institut National De La Sante Et De La Recherche Medicale & Organizaçōes de Investigąão & Franca & 14 & 105 & 987413 \\
\hline Atos Spain Sa & Empresas & Espanha & 13 & 71 & 970582 \\
\hline Danmarks Tekniske Universitet & Estabelecimentos de Ensino Superior ou Secundário & Dinamarca & 36 & 53 & 921093 \\
\hline Wageningen University & Estabelecimentos de Ensino Superior ou Secundärio & Paises Baixos & 16 & 73 & 900453 \\
\hline Politecnico Di Milano & Estabelecimentos de Ensino Superior ou Secundário & Itália & 32 & 38 & 898022 \\
\hline Commissariat A L Energie Atomique Et Aux Energies Alternatives & Organizaçôes de Investigạão & França & 40 & 30 & 873977 \\
\hline Technische Universiteit Delft & Estabelecimentos de Ensino Superior ou Secundário & Paises Baixos & 20 & 52 & 855518 \\
\hline Ethniko Kentro Erevnas Kai Technologikis Anaptyxis & Organiząões de Investigaş̃o & Grécia & 23 & 45 & 834409 \\
\hline Agence Nationale De la Recherche & Agèncias Governamentais & Franşa & 14 & 116 & 804178 \\
\hline Universidad Politecnica De Madrid & Estabelecimentos de Ensino Superior ou Secundário & Espanha & 22 & 42 & 770829 \\
\hline National Technical University of Athens - Ntua & Estabelecimentos de Ensino Superior ou Secundärio & Grécia & 17 & 53 & 748455 \\
\hline Aarhus Universitet & Estabelecimentos de Ensino Superior ou Secundário & Dinamarca & 23 & 45 & 730536 \\
\hline Universidade Do Minho & Estabelecimentos de Ensino Superior ou Secundário & Portugal & 32 & 25 & 725343 \\
\hline Universita Degli Studi Di Roma La Sapienza & Estabelecimentos de Ensino Superior ou Secundário & Itália & 18 & 48 & 702373 \\
\hline Universidade Do Porto & Estabelecimentos de Ensino Superior ou Secundário & Portugal & 34 & 42 & 697140 \\
\hline Forschungszentrum Julich Gmbh & Organizasōes de Investigaş̆o & Alemanha & 21 & 88 & 659327 \\
\hline Avl List Gmbh & Empresas & Áustria & 3 & 72 & 659000 \\
\hline Stiftelsen Sintef & Organizą̧̄es de Investigą̧̃o & Noruega & 11 & 53 & 654855 \\
\hline Katholieke Universiteit Leuven & Estabelecimentos de Ensino Superior ou Secundário & Bélgica & 27 & 31 & 648733 \\
\hline University College Cork - National University of Ireland, Cork & Estabelecimentos de Ensino Superior ou Secundário & Irlanda & 16 & 46 & 631566 \\
\hline Alma Mater Studiorum - Universita Di Bologna & Estabelecimentos de Ensino Superior ou Secundário & Itália & 28 & 18 & 624911 \\
\hline
\end{tabular}


Anexo 4 - Rede H2O2O com amarração em Portugal: centralidade das instituições portuguesas no desempenho do papel de proponentes, por regiões (NUT 2).

\begin{tabular}{|c|c|c|c|c|}
\hline Regiäo (NUT 2) & hastitiviçăo & Estera institucional do atoer & cisade & Out-Degree \\
\hline \multirow{19}{*}{ Norte } & Sociedade Portuguess de inovacao - Consultadocia Empressarial E fomento da inovacao SA. & Empresas & Ponto & \\
\hline & Universidade Do Porto & Estabelecimentos de Ensino Superior ou Secundário & Porto & 42 \\
\hline & Inesc Tec - Instituto De Engenharia De Sistemas E Computadores, Tecnologia E Ciencia & Organizarb̄es de investigą̧ొ॰ & Porto & 39 \\
\hline & Universidade Do Minho & Estabelecimentos de Ensino Superior ou Secundärio & Braga & 25 \\
\hline & Ciimar - Centro Insted disciplinar De Investigaş̆o Marinha E Ambiental & Organizardes de investizoşొ॰ & Porto & 17 \\
\hline & Hos High Performanke Strvecures Gestao E Engenharia, La & Empreses & Ponto & ${ }^{14}$ \\
\hline & Inegi - Instituto De Ciencia E Inovacso Em Ensenharia Mecanica E Engenharia Inoustrial & 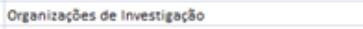 & Ponto & 14 \\
\hline & Iappmei - Agencisa Para A Competitividade E Inovacao ip & Aquências Governamentais & Porto & 11 \\
\hline & Associaccao Universidade Empresa Para Desenvolvimento Tecminho & outros & Guimsraes & 9 \\
\hline & Inova* - Innovation Services, sa & Empresas & Matosinhos & 9 \\
\hline & Laboratorio Iberico Internacional De Nanotechologia & Organizakdes de investigaş̌० & Braga & \\
\hline & Centikx - Centro De Nanorecnolozia E Materiais Tecnices Funciona is E Intelizentes Associacao & Organizacles de investizaş̆० & Vila Nova De Famalicao & 8 \\
\hline & Evoleo Technologies Lda & Empreses & Mais & \\
\hline & Instituto Politecnico Do Porto & Estabelecimentos de Ensino Superior ou Secundário & Ponto & 5 \\
\hline & Ani - Arencia Nacional De Inovacrao, Sa & Outros & Porto & \\
\hline & Fastinor 5a & Empresas & Matosinhos & 4 \\
\hline & Instituto Superior De Engenharia Do Porto & Estrabelecimentos de Ensino Superior ou Secundärio & Porto & \\
\hline & Comissao De Coordenacao E Deservolvimento Rezional Do Norte & Avencias Governamentais & Pono & 3 \\
\hline & ICeta Instituto de Ciencias, Tesnologias E Agroambiente da Universidade Do Porto & Organizasčes de investigosb̆o & Ponto & 2 \\
\hline \multirow{13}{*}{ centro } & Tekever Asds & Empresss & Obidos & 32 \\
\hline & Tekever li Autonomous Systems ldo & Empresas & obidos & 30 \\
\hline & Universidade De Coimbra & Estrabelecimentos de Ensino Superior ou Secundário & Coimbra & 27 \\
\hline & Universidade De Aveiro & Estabelecimentos de Ensino Superior ou Secundário & Aveiro & 21 \\
\hline & Instituto Pedro Nunes Associacao Para A Inovacrao E Desenvolvimento Em Ciencia E Tecnologia & Organizasbes de investizoşొ० & Coimbro & 19 \\
\hline & Centro De Neurociencias E Biologiacelular Associacao & Organizas des de investizasð̋。 & Coimbro & 14 \\
\hline & Universidade Do Beira Interior & Estrabelecimentos de Ensino Superior ou Secundabrio & Covilnz̃ & 9 \\
\hline & Instituto De Telecomunicacoes & Organizasరెes de investigaç̌o & Aveiro & 8 \\
\hline & Centro De Istudos Socisis & 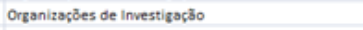 & Coimbra & \\
\hline & Comissao De Coordenacao E Desenvolvimento Regional Do Centro & Aqências Governamentais & Coimbra & 4 \\
\hline & Greensphere Unipessoal Loo & Empresas & Agueda & 3 \\
\hline & Active Spare Technologies, Actividades Aeroespaciais S.A. & Empresas & Coimbro & 2 \\
\hline & Orizonvision Lda & Empreses & Aveito & 1 \\
\hline \multirow{28}{*}{$\begin{array}{l}\text { Área } \\
\text { Metropolitana de } \\
\text { Uisbos }\end{array}$} & Deimos Engenharia SA. A & Empresas & Lisbos & 41 \\
\hline & Instituto De Medicina Molecular & 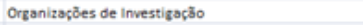 & Lisbos & 35 \\
\hline & Instituto Portugues Do Mar E Da Atmostera Ip & 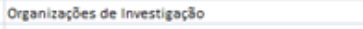 & Lisbos & 34 \\
\hline & Fciencias. Id - Associacao Para A Investizaccao E Desenwolvimento De Ciencias & 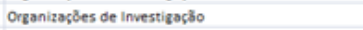 & Lisbor & 26 \\
\hline & Uninova-instituro De Desenvolvimento De Novas Tecnologias-Assciaccao & 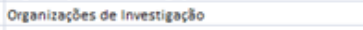 & Almado & 26 \\
\hline & Nova la fet-Associacao Para A inovacao E Desenvolvimento Da fat & Organizasčes de investizaç̋。 & Almado & 23 \\
\hline & Fundactao Para A Ciencis E A Techolosias & Aqências Governamentais & lisbos & 22 \\
\hline & Laboratorio Nacional De Engenharia Civil & Organizaş̄es de investigaç̄o & Lisbos & 21 \\
\hline & Instituto De Soldadura E Qual idade & Organizaç̄es de investigą̧̋” & Oeiras & 17 \\
\hline & Stab Vida Investigacao E Senvicos Em Ciencias Biologicas Lda & Empresas & Almsdo & 16 \\
\hline & Instituto Superior Tecnico & Estrabelecimentos de Ensino Superior ou Secundärio & Lisbor & 15 \\
\hline & Introsss-integration For Robotic Sistems-Integracao De Sistemas Roboricos Sa & Empresas & Moito & 15 \\
\hline & Edp Distribuicao Enertio So & Empresas & Lisbos & 14 \\
\hline & Associaccao Do instituto Superior Tecnico Para A Investigacao E Desenvolvimento & 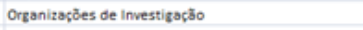 & Lisbos & 11 \\
\hline & Inesc id - Instituto De Engenhariade Sistemas E Computadores, Investigacao E Desenvolvimento Em Lisboa & Organizasర̋̈es de investizaç̄o & Lisbos & 11 \\
\hline & Ispa cri & Estabelecimentos de Ensino Superior ou Secundário & Lisbos & 11 \\
\hline & Levelcardinal Unipessoal Lda & Empresas & Lisbon & 11 \\
\hline & Transportes Aereos Pontugueses Sa"Tap Portugal & Empresas & Lisbor & 11 \\
\hline & Wavec/Ottshore Renewables - Centro De Energis Oftshore Associacso & 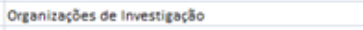 & Lisbos & 11 \\
\hline & Instituto politeenico De Setubal & Estabelecimentos de Ensino Superior ou Secundabrio & Setubal & 9 \\
\hline & Universidade De Lisbos & Estabelecimentos de Ensino Superior ou Secundário & Lisbos & 9 \\
\hline & Inov Inesc Inovacao - Instituto De Novas Tecnologias & 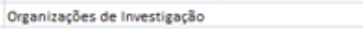 & Lisboos & 6 \\
\hline & Instituto De Biologio Experimental E Tecnologica & 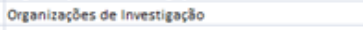 & Deiras & 5 \\
\hline & Thales portugal so & Empresas & Deiras & 5 \\
\hline & Universidade Nove De Lisboos & Estrabelecimentos de Ensino Superior ou Secundabrio & Lisboos & 5 \\
\hline & Ciencia Viva-Agencias Nacional Para A Cultura Cientifica E Tecnologica & Outros & Lisboos & 4 \\
\hline & Instituto Superior De Agronomis & Estabelecimentos de Ensino Superior ou Secundário & Lisbos & 3 \\
\hline & Knowiedgebiz Consulting Sociedade De Consultoria Em Gestao Lda & Empresas & Almada & 3 \\
\hline Alentejo & Universidade De Evora & Estabeleccimentos de Ensino Superior ou Secundário & Evora & 47 \\
\hline Algave & Centro De Clencias Do Mar Do Algane & Organizasdes de investigosho & Faro & 15 \\
\hline \multirow{2}{*}{$\begin{array}{l}\text { Regila Autónomas } \\
\text { da Madeira }\end{array}$} & Horarios do Funchal-Transportes Publicos Sa & Empresas & Funchal & 29 \\
\hline & Miti - Madeira Interactive Technologies institure - Associaccao & Organizaš̆es de Investigaç̃o & Funchal & \\
\hline
\end{tabular}


Anexo 5 - Rede H2O20 com amarração em Portugal: instituições portuguesas por regiões (NUT 2) com maior centralidade no desempenho do papel de proponentes.

\begin{tabular}{|c|c|c|c|c|}
\hline Regiăo (NUT 2) & Instituvisa & Estera institucional do ator & Cidade & Out-Degree \\
\hline \multirow{13}{*}{ Norte } & Universidade Do Porto & Estabelecimentos de Ensino Superior ou Secundärio & Porto & 34 \\
\hline & Universidade Do Minho & Estabelecimentos de Ensino Superior ou Secundärio & Braga & 32 \\
\hline & Inesc Tec - Institurto De Engenharia De Sistemas E Computadores, Tecnologia E Ciencis & Organizaş̄es de investigą̧ొ॰ & Porto & 27 \\
\hline & Laboratorio Nacional De Energia E Geologia I.P. & Organizą̧̃es de investigaรã॰ & Matosinhos & 13 \\
\hline & Sociedade Portuguesa De inovacao - Consultadoria Empresarial E Fomento Da Inovacao S.A. & Empresas & Porto & 12 \\
\hline & Laboratorio Iberico Internacional De Nanotecnologia & Organizaş̌es de investigą̧̃o & Braga & 9 \\
\hline & Inegi - Instituto De Ciencias E Inovacao Em Engenharia Mecanica E Engenharia Industrial & Organizą̧̃es de Investigą̧̆o & Porto & 8 \\
\hline & Instituto Superior De Engenharis Do Porto & Estabelecimentos de Ensino Superior ou Secundärio & Porto & 8 \\
\hline & Globaz, S.A. & Empresas & Oliveiro De Azemeis & 8 \\
\hline & Inova * Innovation Services, Sa & Empresas & Matosinhos & 7 \\
\hline & Climar - Centro Interdisciplinar De Investigą̧̆o Marinha E Ambiental & Organizą̧̋es de investigą̧̆o & Porto & 6 \\
\hline & Iceta Instituto De Clencias, Tecnologias E Agroambiente Da Universidade Do Porto & 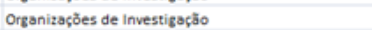 & Porto & 5 \\
\hline & Efacec Energia - Maquinas E Equipamentos Electricos Sa & Empresos & Matosinhos & 5 \\
\hline \multirow{9}{*}{ Centro } & Universidade De Aveiro & Estabelecimentos de Ensino Superior ou Secundário & Aveiro & 24 \\
\hline & Universidade De Coimbra & Estabelecimentos de Ensino Superior ou Secundärio & Coimbra & 22 \\
\hline & Biotrend - Inovacao E Engenharia Em Biotecnologia Sa & Empresos & Cantanhede & 8 \\
\hline & Ubiwhere Ldo & Empresos & Aveiro & 8 \\
\hline & Instituto De Telecomunicacoes & Organizą̧̄es de investigą̧̃o & Aveiro & 7 \\
\hline & Altice Labs So & Empresas & Aveiro & 7 \\
\hline & Laboratorio De Instrumentacao E Fisica Experimental De Particulas & Organizaş̋es de investigaş̃o & Coimbra & 6 \\
\hline & Instituto De Sistemas E Robotica-Associacao & Organizaş̄es de Investigą̧̆̄o & Coimbra & 5 \\
\hline & Instituto Politecnico De Coimbra & Estabelecimentos de Ensino Superior ou Secundário & Coimbra & 5 \\
\hline \multirow{32}{*}{$\begin{array}{c}\text { Área } \\
\text { Metropolitana } \\
\text { de Lisboa }\end{array}$} & Fundacrao Para A Ciencia E A Tecnologia & Agências Governamentais & Uisbor & 37 \\
\hline & Instituto Superior Tecnico & Estabelecimentos de Ensino Superior ou Secundärio & Uisboa & 27 \\
\hline & Universidade Nova De Lisboa & Estabelecimentos de Ensino Superior ou Secundärio & Lisbos & 23 \\
\hline & Nova id fet - Associacao Para A Inovacao E Desenvolvimento Da fet & Organizasర̄es de investigaş̆o & Almada & 22 \\
\hline & Uninova-Instituto De Desenvolvimento De Novas Tecnologias-Associacrao & Orzanizaç̃es de investizaç̃o & Almada & 20 \\
\hline & Associacao Do instituto Superior Tecnico Para A Investigacao E Desenvolvimento & Organizaş̄es de investigaş̃o & Usboa & 13 \\
\hline & Instituto Superior De Astronomia & Estabelecimentos de Ensino Superior ou Secundário & Lisboa & 13 \\
\hline & Laboratorio Nacional De Engenharia Civil & Organizasōes de investigaş̆̄o & Lisbos & 11 \\
\hline & Camara Municipal De Lisbos & Agências Governamentais & Lisbos & 11 \\
\hline & Fundacrao da Faculdade De Ciencias da Universidade De Lisboa $\mathrm{Fp}$ & Organizaş̃es de investigas̃̃o & Lisboa & 11 \\
\hline & Ministério Da Justiça & Agências Governamentais & Lisboa & 11 \\
\hline & Fciencias.ld - Associacao Para A Investigacao E Desenvolvimento De Ciencias & Organizą̧̌es de Investigą̧̋̄o & Lisbos & 10 \\
\hline & Inesc id - Instituto De Engenhariade Sistemas E Computadores, Investigacao E Desenvolvimento Em Lisbor & Organizą̧̃es de investiga̧ã。 & Lisbos & 10 \\
\hline & Instituto De Biologia Experimental E Tecnologica & Organizaş̄es de investizaş̃o & Oeiras & 9 \\
\hline & Instituto De Tecnologia Quimica E Biologica - Universidade Nova De Lisboa & Estabelecimentos de Ensino Superior ou Secundário & Deiras & 9 \\
\hline & Instituto Universitario De Lisboa & Estabeleccimentos de Ensino Superior ou Secundärio & Lisboos & 8 \\
\hline & Universidade Cartlica Portuguesa & Estabelecimentos de Ensino Superior ou Secundabrio & Lisbos & 8 \\
\hline & Edp Distribuicao Energio sa & Empresas & Lisbos & 7 \\
\hline & Ministerio Da Administracao interna & Agências Governamentais & Usboor & 7 \\
\hline & Instituto De Soldadura E Qualidade & Organizą̧̄es de investigą̧̃o & Oeiras & 6 \\
\hline & Inov Inesc Inovacao - Instituto De Novas Tecnologias & Organizą̧̌̃es de investigaç̋。 & Lisbos & \\
\hline & Ciencia Viva-Agencia Nacional Para A Cultura Cientifica E Tecnologica & Outros & Lisbos & 6 \\
\hline & Gmvis skysoft Sa & Empresas & Lisbor & \\
\hline & Tis Pr, consultores Em Transportes, Inovacao E Sistemas, Sa & Empresas & Lisbor & \\
\hline & Instituto Portugues Do Mar E Da Atmostera ID & Organizą̧̄es de investigą̧̃。 & Lisboa & 5 \\
\hline & Adene - Agencia Para A Energio & Outros & Lisbos & 5 \\
\hline & Cnet - Centre For New Energy Technolozies, SA. & Empresas & Loures & \\
\hline & Infraestruturas De Portuzal Sa & Empresas & Usboos & 5 \\
\hline & Instituto De Ciencias Sociais & Estabelecimentos de Ensino Superior ou Secundärio & usboa & 5 \\
\hline & Instituto Nacional De Saude Dr. Ricardo Jorge & Organizaş̋es de Investigą̧̆。 & Lisboa & \\
\hline & Nuclio Nucleo Interactivo De Astronomia Associacao & 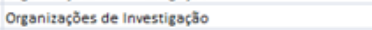 & Cascais & 5 \\
\hline & Spms - Servicos Partilhados Do Ministerio Da Saude Epe & Empresos & Lisbos & 5 \\
\hline \multirow{6}{*}{ Alentejo } & Universidade De Evora & Estabelecimentos de Ensino Superior ou Secundärio & Evora & 14 \\
\hline & Adral - Agencia De Desenvolvimento Regional Do Alentejo Sa & Outros & twora & 3 \\
\hline & Somincor-Sociedade Mineira De Neves-Cono Sa & Empresas & Castro Verde & \\
\hline & Ya Ynvisible So & Empresos & Cartaxo & 3 \\
\hline & Embraer Portugal Sa & Empresas & tvora & 2 \\
\hline & Unbabel, Loa & Empresas & Benavente & 2 \\
\hline \multirow{7}{*}{ Algave } & Unparallel Innovation Lda & Empresas & Portimao & 11 \\
\hline & Centro De Ciencias Do Mar Do Algave & Organizaş̄es de Investigą̧̆o & faro & 10 \\
\hline & Universidade Do Algarve & Estabelecimentos de Ensino Superior ou Secundário & Faro & 5 \\
\hline & Sparos lda & Empresas & Olhao & 4 \\
\hline & Cintal - Centro Investizacao Tecnolog ica Do Algave & Organizą̧̄es de investigą̧̆。 & Faro & \\
\hline & Enercoutim - Associacrao Empresorialde Energia Solar De Alcoutim & Outros & Alcoutim & 2 \\
\hline & Sagremarisco-Viveiros De Marisco Ldo & Empresas & Vila do Bispo & 2 \\
\hline \multirow{3}{*}{$\begin{array}{c}\text { Regiåo } \\
\text { Autónoma da } \\
\text { Madeira }\end{array}$} & Asencia Regional da Energia Eambiente da Regiao Autonoma da Madeira & Organizaş̃es de investizaş̃o & Funchal & \\
\hline & Miti - Madeira Interactive Technolog ies Institute · Associacao & Organizasర̃es de investigaş̃o & Funchal & 2 \\
\hline & Associacra Comercial E Industrial Do Funchal - Camara De Comercio E Industria Da Madeira & Outros & Funchal & 2 \\
\hline \multirow{3}{*}{$\begin{array}{c}\text { Regiß̊o } \\
\text { Autónoma dos } \\
\text { Aşores }\end{array}$} & Imar-Instituto Do Mar & Organizaç̄es de investigą̧̃o & Horts & 6 \\
\hline & Fundo Regional Para A Clencia E Tecnologia & Agências Governamentais & Ponta Delgada & 4 \\
\hline & Fundacao Gaspar Frutuoso & Organizaş̄es de investigasão & Ponta Deligada & \\
\hline
\end{tabular}




\title{
Especialização inteligente e redes de conhecimento. A Universidade de Coimbra num contexto de globalização
}

\author{
R. Gama (a), C. Barros (b), R. David (c), R. Fernandes (d) \\ (a) Universidade de Coimbra/CEGOT, rgama@fl.uc.pt \\ (b) Universidade de Coimbra, cbarros@fl.uc.pt \\ (c) Universidade de Coimbra/Faculdade de Letras (GAPCI), gapci2@fl.uc.pt \\ (d) Universidade de Coimbra/CEGOT, r.fernandes@fl.uc.pt
}

\begin{abstract}
Resumo
A especialização inteligente assume-se como uma abordagem central no âmbito da estratégia europeia 2020, procurando fomentar o desenvolvimento intensivo do conhecimento. Utilizando dados dos projetos de investigação do Horizonte 2020, pretende-se avaliar a configuração das redes estabelecidas, tendo em atenção as instituições/organizações envolvidas e a intensidade e expressão territorial das relações identificadas. Privilegia-se a análise de redes sociais e a leitura dos resultados numa dupla dimensão, topológica e territorial. Em paralelo, e para perceber as lógicas da estratégia de investigação da Universidade de Coimbra caracteriza-se o potencial das unidades de I\&D (recursos humanos, participação em projetos, resultados da investigação). A leitura territorial visa identificar as novas dinâmicas associadas à missão da universidade na qualificação regional no quadro da especialização inteligente e da geografia das redes do conhecimento.
\end{abstract}

Palavras chave: Especialização Inteligente, Redes de Conhecimento, Universidade de Coimbra, Desenvolvimento Regional

\section{INTRODUÇÃO}

A evolução que tem vindo a ser observada nos anos mais recentes, tem conduzido a que as estratégias de desenvolvimento económico e territorial, delineadas às escalas europeia e nacional, consagrem especial importância às atividades de investigação e à ciência, assim como à inovação e ao papel dos territórios inovadores para o desenvolvimento (Patrício, 2010; Heitor \& Horta, 2011; Brandão, 2016).

A realização dos objetivos da Estratégia Europa 2020 de crescimento inteligente, sustentável e inclusivo está dependente da investigação e inovação enquanto motores essenciais de prosperidade social e económica e de sustentabilidade ambiental (CE, 2011). A perspetiva do crescimento inteligente valoriza a educação, a investigação e a inovação como elementos que podem garantir, a prazo, o maior retorno do investimento, em termos de ganhos de produtividade, assegurando, também, a necessária capacidade de adaptação dos recursos humanos aos novos desafios económicos (CE, 2010).

A estratégia de especialização inteligente decorre da natureza sistémica frágil para a difusão de conhecimento e tecnologia ao sistema produtivo na União Europeia. Do pondo de vista teórico procede da economia do conhecimento e da mudança tecnológica e visa construir um quadro lógico que permita definir prioridades em termos de política de desenvolvimento dos territórios. Assenta na trajetória dos territórios, num processo de pesquisa empreendedora, num domínio (espaço tecnológico) com uma dimensão relevante e estabelecendo relações (McCann, 2015). A valorização deste conceito no contexto regional pressupõe que se considere a proximidade tecnológica existente no domínio (espaço tecnológico), o grau de imbricação existente entre as diferentes atividades, competências e instituições e, igualmente, as ligações desenvolvidas e aprofundadas entre os diferentes atores (indivíduos, empresas, instituições e outros) na incorporação de conhecimento de diferentes fontes. Trata-se de identificar e perceber de que forma os diferentes tipos de proximidade (geográfica, institucional, organizacional, cognitiva e cultural), associados ao nível de participação de atores de diferentes esferas e competências e à capacidade resultante dos relacionamentos entre atores se organizam visando a procura de novas soluções que incorporem conhecimento e tecnologia nos territórios.

A produção de conhecimento deve ser analisada considerando as condições do contexto em que é gerado e 
a tradução em inovação (nomeadamente económica), sendo que conhecimento e inovação fazem parte de um todo indissociável. As diferentes abordagens têm vindo a considerar os diferentes tipos e objetivos das atividades de ciência, assim como a forma como o conhecimento é produzido. Desta forma, é necessário centrar a discussão nos processos de produção conhecimento, sendo este o recurso essencial para a inovação (Lundvall \& Johnson, 1994). A complexidade destes processos traduz-se em origens cada vez mais dispersas, numa diversidade de atores envolvidos, ao mesmo tempo que os processos são mais distribuídos quanto ao locus de produção e mais diversificados quanto aos contextos de localização (Marques et al., 2015, 2016). Como consequência tem vindo a ocorrer uma transição acelerada na produção de conhecimento do Modo 1, de tipo disciplinar e assente na investigação universitária de base, para a aplicação de conhecimento e solução de problemas baseada em conhecimento, numa base transdisciplinar (Modo 2) (Gibbons et al., 1994; Nowotny et al., 2001, 2003, 2006). Mais recentemente emergiu a necessidade de existir uma arquitetura de governança que potencie os processos de aprendizagem top-down (envolvendo universidades, indústria e governo) e bottom-up, incorporando as necessidades da sociedade civil (Modo 3 de produção de conhecimento) (Carayannis \& Campbell, 2012). Esta mudança facilita a coevolução dos contextos de produção, aplicação e utilização desse conhecimento e também da inovação (económica).

As parcerias e colaborações entre universidades, instituições públicas e empresas, o designado Triple Helix (Etzkowitz \& Leydesdorff, 1995, 1997, 2000; Etzkowitz, 2008), são cada vez mais valorizadas no processo de produção e valorização do conhecimento. A estes atores pertencentes a diferentes esferas de ação, junta-se a esfera da sociedade civil (quarta hélice), sendo que nos últimos anos tem vindo ser incorporada a dimensão ambiental traduzindo a quinta hélice do modelo de inovação (Carayannis \& Campbell, 2012). Globalmente, e numa visão evolucionista, constituem o ecossistema de inovação (Carayannis \& Campbell 2012). Como consequência, nesta abordagem ecossistémica da inovação (económica) sai reforçado o papel das redes interativas na estruturação dos processos de inovação territorializados. Daí a importância de ser necessário refletir os processos de governança e de participação tendo em vista o reforço das redes de inovação económica (com mais eficiência e eficácia) (Marques et al. 2015, 2016).

As redes de conhecimento científico entre investigadores e instituições são encaradas como a melhor aposta para a produção e difusão do conhecimento, ao criar parcerias entre universidades, institutos de ensino superior, laboratórios, centros de I\&D e empresas (Wagner, 2008). Muitas vezes, estas parcerias são responsáveis pela criação de novas empresas, que acabam por comercializar novos produtos, reconhecendo-se a importância da valorização económica do conhecimento (Etzkowitz, 2000; Goldstein, 2008).

Utilizando dados dos projetos de investigação do Horizonte 2020, pretende-se avaliar a configuração das redes estabelecidas, tendo em atenção as instituições/organizações envolvidas e a intensidade e expressão territorial das relações identificadas. Privilegia-se a análise de redes sociais e a leitura dos resultados numa dupla dimensão, topológica e territorial. Em paralelo, e para perceber as lógicas da estratégia de investigação da Universidade de Coimbra caracteriza-se o potencial das unidades de I\&D (recursos humanos, participação em projetos, resultados da investigação). A leitura territorial visa identificar as novas dinâmicas associadas à missão da universidade na qualificação regional no quadro da especialização inteligente e da geografia das redes do conhecimento.

\section{UNIVERSIDADE DE COIMBRA: INVESTIGAÇÃO E PARTICIPAÇÃO EM REDES DE CONHECIMENTO}

O crescimento económico e futuro da Europa impulsionaram o investimento em investigação e inovação consubstanciado em programas de financiamento competitivo que assentam no estímulo da excelência científica europeia. A implementação de projetos financiados neste âmbito tem vindo a refletir o esforço concertado da ciência e da indústria na busca de soluções para diversos desafios que, ao integrarem a investigação e a inovação, procuram contribuir para a melhoria da vida das pessoas, para a proteção do ambiente, bem como para a sustentabilidade e competitividade da indústria europeia. À semelhança dos programas-quadro anteriores, o Horizonte 2020 afigura-se como uma estratégia da Europa para um crescimento inteligente, sustentável e inclusivo que assenta em três pilares, designadamente: a excelência científica, a liderança industrial e os desafios societais (UE, 2014).

As universidades e instituições de ensino superior assumem-se como fundamentais para a dinamização de cidades e regiões e para a definição de novas estratégias de desenvolvimento, quer considerando as dimensões do ensino e formação de recursos humanos, quer a partir das diferentes unidades de I\&D que constituem os departamentos e institutos (Fernandes 2008). Em Portugal destacam-se três importantes polos universitários (Lisboa, Porto e Coimbra) responsáveis pela maior parte da oferta de ensino superior, bem como pela atividade de 
I\&D e inovação. Dos 322 estabelecimentos de ensino superior identificados pelo Observatório para a Ciência e Ensino Superior, 85 estão localizados em Lisboa, 67 no Porto e 22 em Coimbra. Considerando os estabelecimentos de ensino superior universitário de natureza pública, a oferta integra cerca de 86 estabelecimentos a nível nacional. As Universidades de Lisboa (UL) e Nova de Lisboa (UNL), reúnem um total de 28 estabelecimentos, seguindo-se a Universidade do Porto (UP) com 14 estabelecimentos e a Universidade de Coimbra (UC) com 10 estabelecimentos. Acresce que para a I\&D, inovação e tecnologia devem ser ainda consideradas as diferentes instituições com atividade de I\&D que operam tanto, em contexto das universidades e outros institutos de ensino superior, como noutras organizações governamentais e instituições privadas sem fins lucrativos. Neste contexto foram identificadas 1142 unidades com atividade de I\&D, correspondendo 591 ao setor do ensino superior (51,7\%), 467 ao domínio Estado (40,9\%) e 83 unidades a instituições privadas sem fins lucrativos (7,3\%) (Gama et al., 2017).

Considerando apenas as instituições com atividade de I\&D que integram a esfera do ensino superior (591), 64,6\% (382 unidades) integram o ensino superior público, sendo que as restantes pertencem ao ensino superior privado e politécnico. A localização destas 382 unidades de I\&D reflete o padrão de localização das instituições de I\&D nos concelhos de Lisboa (40,8\%), Porto (12,3\%), Coimbra (11,3\%), Braga-Guimarães (8,4\%) e Aveiro (4,2\%), reforçando a ideia de uma forte polarização das unidades de I\&D ancoradas às principais universidades públicas portuguesas.

A Universidade de Coimbra (UC) tem vindo sucessivamente a reforçar a sua presença no campo da inovação e da transferência de saberes, participando em inúmeras atividades e projetos de I\&D, desenvolvidas por docentes e investigadores (1778) oriundos das suas 8 Faculdades; Centros de Investigação (39 Unidades de I\&D financiadas e avaliadas pela FCT que abrangem as áreas das Ciências e da Tecnologia, das Ciências Sociais e das Humanidades) e Laboratórios Associados. Dados relativos ao ano letivo 2016/2017, indicam que, ao nível da investigação, a UC engloba 40 Unidades de investigação (63\% com avaliação externa excecional, excelente ou muito bom, estando envolvida em diversos projetos de investigação (311) ao longo desse período (http://www.uc.pt/ dados).

\section{REDES DE CONHECIMENTO DA UNIVERSIDADE DE COIMBRA: ATORES, REDES DE COLABORAÇÃO E TERRITÓRIO}

Reconhecendo que os projetos financiados pelo $\mathrm{H} 2020$ fomentam as parcerias entre universidades, associações, centros de investigação, instituições governamentais e empresas nacionais e internacionais, recorreu-se à metodologia de análise de redes sociais baseada na teoria dos grafos. Esta metodologia permite compreender as ligações entre os atores ou grupos intervenientes e as implicações dessas ligações para a estrutura e dinâmica da rede (Barnes, 1972; Barabási, 2002; Butts, 2008; Wal \& Boschma, 2009; Phelps et al., 2012; Scott, 2013).

A aplicação desta metodologia ao presente estudo, permitiu representar e analisar a rede de colaboração científica da Universidade de Coimbra com as outras instituições nos 36 projetos europeus $\mathrm{H} 2020$ identificados no momento do levantamento (março de 2018) (Tabela 1). O total de projetos representou um investimento de 131 milhões de euros. Na qualidade de promotora a UC mobilizou 35 participantes e cerca de 13 milhões de euros. O número médio de participantes por projeto foi de 4 e 13, no caso da UC ser promotora ou participante, respetivamente.

Tabela 1 - Projetos, custos, financiamento e participantes nos projetos H2O2O da Universidade de Coimbra.

\begin{tabular}{|ccccc|}
\hline Papel da UC & $\begin{array}{c}\text { Número de } \\
\text { projetos }\end{array}$ & $\begin{array}{c}\text { Valor total } \\
\text { dos projetos }\end{array}$ & Financiamento & Participantes \\
\hline $\begin{array}{c}\text { Projetos da UC como } \\
\text { promotora }\end{array}$ & 8 & 12944230,0 & 11875096,1 & 35 \\
\hline $\begin{array}{c}\text { Projetos da UC como } \\
\text { participante }\end{array}$ & 28 & 118186789,4 & 112237218,2 & 357 \\
\hline Total & 36 & $\mathbf{1 3 1} \mathbf{1 3 1 0 1 9 , 3}$ & $\mathbf{1 2 4 1 1 2 ~ 3 1 4 , 3}$ & $\mathbf{3 9 2}$ \\
\hline
\end{tabular}


Atendendo à dimensão das equipas envolvidas, mais de $50 \%$ dos projetos analisados apresentam menos de 10 participantes (20 projetos), sendo que 11 projetos (30,6\%) apresentam 15 e mais participantes (Tabela 2). A participação da Universidade de Coimbra faz-se de duas formas, como promotora ou como participante. Nos projetos em que a UC assume a liderança torna-se notório um menor número de organizações participantes. Em geral, dos oito projetos da UC como promotora, seis são constituídos por menos de cinco participantes, o que significa que a instituição tem desenvolvido a sua investigação recorrendo a um menor número de organizações. Acresce que existe um domínio de especialização (saúde) (Figura 1).

A rede de colaboração institucional da Universidade de Coimbra assume uma grande diversidade de atores (englobando cerca de 281 instituições relacionadas), sendo evidente que o grupo mais representativo são as universidades (39,1\%), seguindo-se os centros de investigação (26\%) e as empresas (26\%). Com uma menor representatividade na rede surgem as instituições governamentais $(5,3 \%)$ e as associações/fundações (3,6\%). Nos projetos em que a Universidade de Coimbra se assume como promotora é evidente um grande envolvimento com outras universidades (57,1\%), sublinhando-se a importância da proximidade institucional na justificação das rela-

Tabela 2 - Projetos segundo o número de participantes.

\begin{tabular}{|c|c|c|c|c|c|c|}
\hline \multirow{2}{*}{$\begin{array}{c}\text { Número de } \\
\text { participantes }\end{array}$} & \multicolumn{2}{|c|}{ Projetos } & \multicolumn{2}{|c|}{$\begin{array}{l}\text { Projetos da UC } \\
\text { como promotora }\end{array}$} & \multicolumn{2}{|c|}{$\begin{array}{l}\text { Projetos da UC } \\
\text { como participant }\end{array}$} \\
\hline & $\mathrm{n}^{\circ}$ & $\%$ & $\mathrm{n}^{\circ}$ & $\%$ & $\mathrm{n}^{\circ}$ & $\%$ \\
\hline 1 participante & 3 & 8,3 & 3 & 37,5 & 0 & 0,0 \\
\hline 3-5 participantes & 7 & 19,4 & 3 & 37,5 & 4 & 14,3 \\
\hline 6-10 participantes & 10 & 27,8 & 1 & 12,5 & 9 & 32,1 \\
\hline 11-14 participantes & 5 & 13,9 & 0 & 0,0 & 8 & 28,6 \\
\hline 15-20 participantes & 6 & 16,7 & 1 & 12,5 & 5 & 17,9 \\
\hline Mais de 20 participantes & 5 & 13,9 & 0 & 0,0 & 5 & 17,9 \\
\hline Total & 36 & 100 & 8 & 100 & 28 & 100 \\
\hline
\end{tabular}

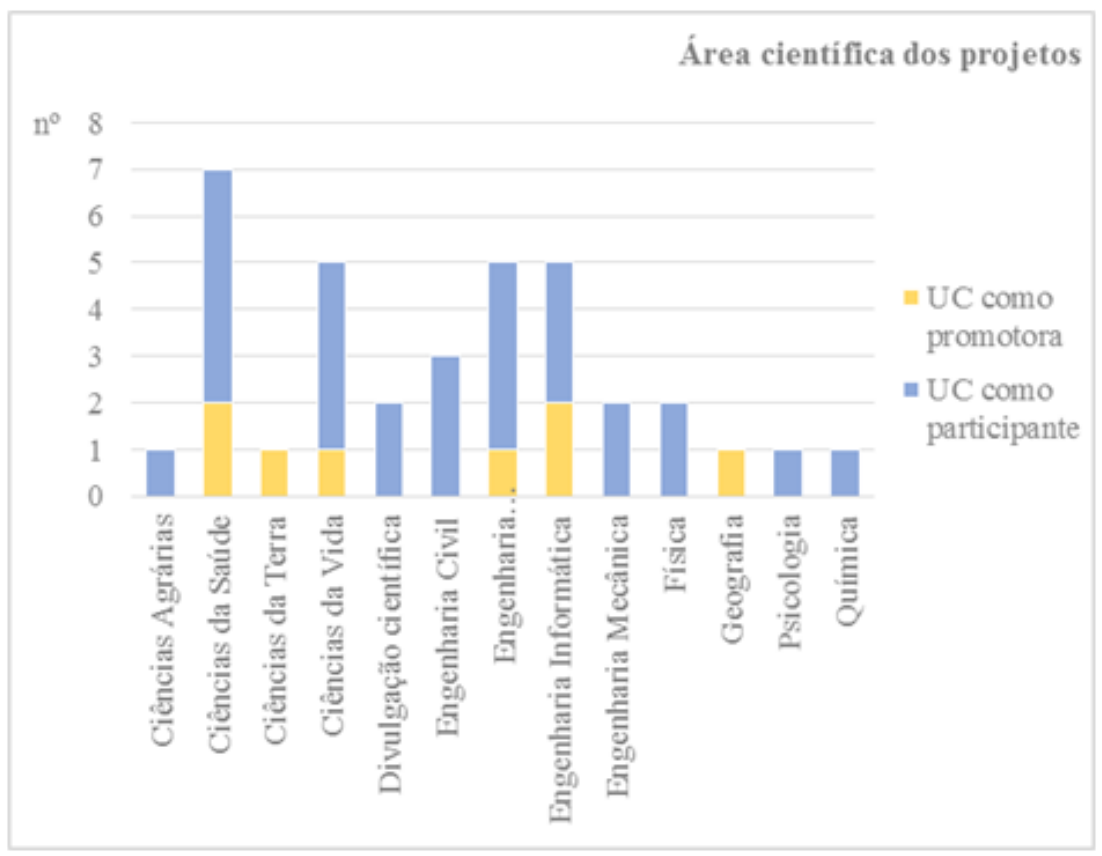

Figura 1 - Domínio científico dos projetos H2O2O com a participação da Universidade de Coimbra. 
ções estabelecidas (Tabela 3). Este aspeto comporta também uma menor diversidade de atores, visível também pelo menor número de organizações envolvidas na rede (28).

Numa leitura à origem dos atores envolvidos nestes projetos de investigação, destacam-se os atores estrangeiros, uma vez que dos 36 projetos, 23 são coordenados por equipas estrangeiras. Refere-se então que dos 281 atores presentes na rede, cerca de $90,7 \%$ são estrangeiros contra 9,3\% de origem portuguesa (Tabela 4). Dos atores estrangeiros, sublinha-se a grande representatividade de empresas (71, correspondendo a 97,3\%) e de universidades (100, correspondendo a 90,9\%).

Tabela 3 - Atores envolvidos no ecossistema de conhecimento da UC.

\begin{tabular}{|c|c|c|c|c|c|c|}
\hline \multirow[t]{2}{*}{ Tipologia } & \multicolumn{2}{|c|}{$\begin{array}{c}\text { Total de } \\
\text { atores }\end{array}$} & \multicolumn{2}{|c|}{$\begin{array}{c}\text { Atores nos } \\
\text { projetos da UC } \\
\text { como promotora }\end{array}$} & \multicolumn{2}{|c|}{$\begin{array}{c}\text { Atores nos } \\
\text { projetos da } \mathrm{UC} \\
\text { como participante }\end{array}$} \\
\hline & $\mathrm{n}^{\circ}$ & $\%$ & $\mathrm{n}^{\circ}$ & $\%$ & $\mathrm{n}^{\circ}$ & $\%$ \\
\hline Associações/Fundações & 10 & 3,6 & 1 & 3,6 & 9 & 3,6 \\
\hline Centros de Investigação & 73 & 26,0 & 3 & 10,7 & 70 & 27,7 \\
\hline Empresas & 73 & 26,0 & 5 & 17,9 & 68 & 26,9 \\
\hline Instituições governamentais & 15 & 5,3 & 3 & 10,7 & 12 & 4,7 \\
\hline Universidades & 110 & 39,1 & 16 & 57,1 & 94 & 37,2 \\
\hline Total & 281 & 100 & 28 & 100 & 253 & 100 \\
\hline
\end{tabular}

Tabela 4 - Atores envolvidos no ecossistema de conhecimento da UC segundo a origem.

\begin{tabular}{|c|c|c|c|c|c|c|}
\hline \multirow[t]{2}{*}{ Tipologia } & \multicolumn{2}{|c|}{$\begin{array}{c}\text { Total de } \\
\text { atores }\end{array}$} & \multicolumn{2}{|c|}{$\begin{array}{c}\text { Atores } \\
\text { estrangeiros }\end{array}$} & \multicolumn{2}{|c|}{$\begin{array}{c}\text { Atores } \\
\text { nacionais }\end{array}$} \\
\hline & $\mathrm{n}^{\circ}$ & $\%$ & $\mathrm{n}^{\circ}$ & $\%$ & $\mathrm{n}^{\mathrm{o}}$ & $\%$ \\
\hline Associações/Fundações & 10 & 3,6 & 9 & 90,0 & 1 & 10,0 \\
\hline Centros de Investigação & 73 & 26,0 & 64 & 87,7 & 9 & 12,3 \\
\hline Empresas & 73 & 26,0 & 71 & 97,3 & 2 & 2,7 \\
\hline Instituições governament ais & 15 & 5,3 & 11 & 73,3 & 4 & 26,7 \\
\hline Universidades & 110 & 39,1 & 100 & 90,9 & 10 & 9,1 \\
\hline Total & 281 & 100 & 255 & 90,7 & 26 & 9,3 \\
\hline
\end{tabular}

Na metodologia de análise de redes sociais são valorizadas as medidas que procuram caraterizar a estrutura da rede e as relações entre os elementos (Tabela 5). De acordo com a classificação de Baur et al (2009), as medidas podem ser agrupadas ao nível da rede, dos elementos e dos grupos.

Tal como vimos a rede total exprime as relações entre os 281 atores, que entre si podem desenvolver cerca de 2600 ligações (Figura 2). Já a rede em que a Universidade de Coimbra assume a liderança, conta com 28 atores que estabelecem entre si 145 relações (Figura 3).

Ao nível da análise da rede são aplicadas medidas para analisar a estrutura global da rede, como sendo a distância geodésica, o número médio de graus de separação e a densidade. A distância geodésica máxima corresponde à distância mais longa de um nó a outro, sendo que a rede total apresenta o valor de 6 e a rede da UC como promotora evidencia uma maior proximidade entre os atores (2). O número médio de graus de separação, ou seja, o número médio de nós que separa cada instituição de uma outra, é de 2,15 e 1,57, respetivamente.

A densidade varia entre 0 e 1 e indica o grau de conexão dos vértices ou nós na rede. Quanto mais nós estiverem conectados de forma direta a outros nós, maior é a densidade. Neste caso, a rede total apresenta o valor de 0,06 como resultado da presença de um elevado número de instituições. 
Tabela 5 - Medidas de análise da rede de colaboração em projetos H2020 com a participação da UC.

\begin{tabular}{|c|c|c|c|}
\hline Medi das & Descrição & Rede Total & $\begin{array}{l}\text { Rede UC como } \\
\text { promotora }\end{array}$ \\
\hline $\mathrm{N}^{\circ}$ de nós & Numero de atores intervenientes na rede. & 281 & 28 \\
\hline $\begin{array}{l}\mathrm{N}^{\circ} \text { de } \\
\text { linhas/relaçốes }\end{array}$ & Número de relações existentes entre os diferentes atores. & 2600 & 145 \\
\hline $\begin{array}{l}\text { Distância geodésica } \\
\text { máxima }\end{array}$ & Distância mais longa de um nó a outro. & 6 & 2 \\
\hline $\begin{array}{l}\text { Número médio de } \\
\text { graus de separação }\end{array}$ & Número médio de nós que separa cada ator/instituição de & 2,15 & 1,57 \\
\hline Densidade & $\begin{array}{l}\text { Expressa a razão entre as relações existentes e as } \\
\text { possiveis. Quantos mais nós estiverem conectados de } \\
\text { forma direta a outros nós, maior é a densidade. Indica o } \\
\text { "grau" de conexão dos vértices na rede. }\end{array}$ & 0,06 & 0,38 \\
\hline Grau médio & $\begin{array}{l}\text { Corresponde ao número médio de intervenientes aos } \\
\text { quais cada nó se encontra ligado. }\end{array}$ & 16,11 & 10,21 \\
\hline Proximidade média & $\begin{array}{l}\text { Mede a proximidade de cada nó a todos os outros nós } \\
\text { com quem estabelece relações (grau de abrangência de } \\
\text { cada ator). Baseia-se na soma das distâncias dos } \\
\text { caminhos mais curtos. }\end{array}$ & 0,002 & 0,02 \\
\hline $\begin{array}{l}\text { Int ermediação } \\
\text { média }\end{array}$ & $\begin{array}{l}\text { Mede o grau de extensão na qual um nó se encontra } \\
\text { situado entre os outros nós da rede. Permite perceber a } \\
\text { centralidade, posição intermediária e prestigio de um } \\
\text { interveniente. }\end{array}$ & 162,06 & 8,43 \\
\hline $\begin{array}{l}\text { Coeficiente médio } \\
\text { de clusterizaçâo }\end{array}$ & $\begin{array}{l}\text { Quantifica quão conectado está um determinado vértice } \\
\text { com os seus "vizinhos". }\end{array}$ & 0,95 & 0,98 \\
\hline
\end{tabular}

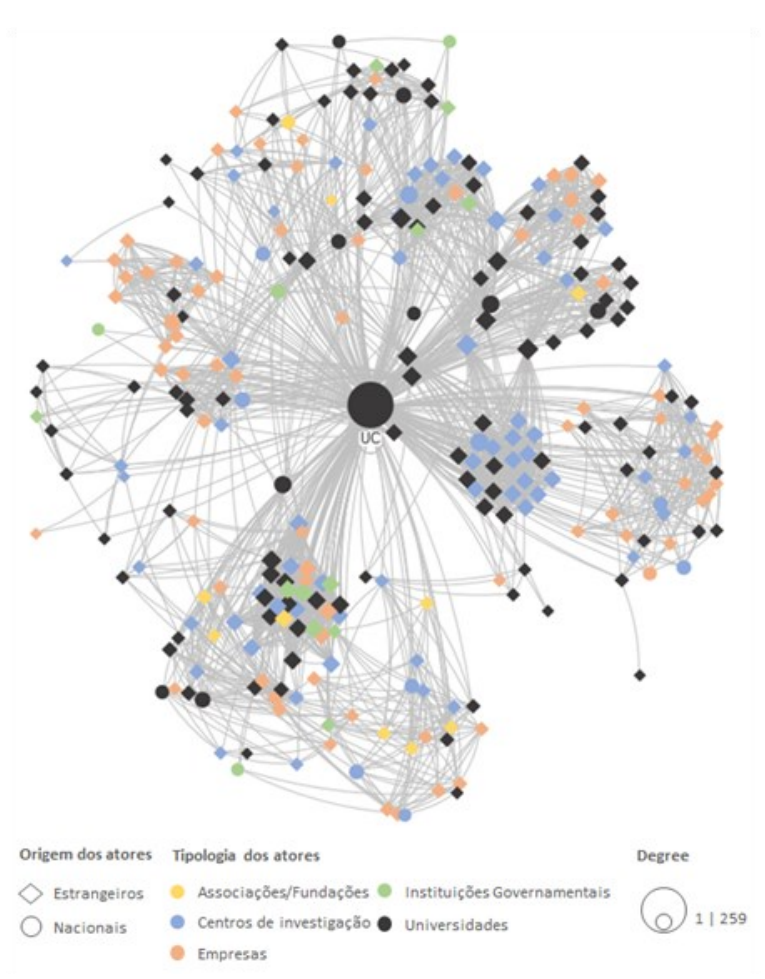

Figura 2 - Rede de colaboração da Universidade de Coimbra em projetos Horizonte 2020.

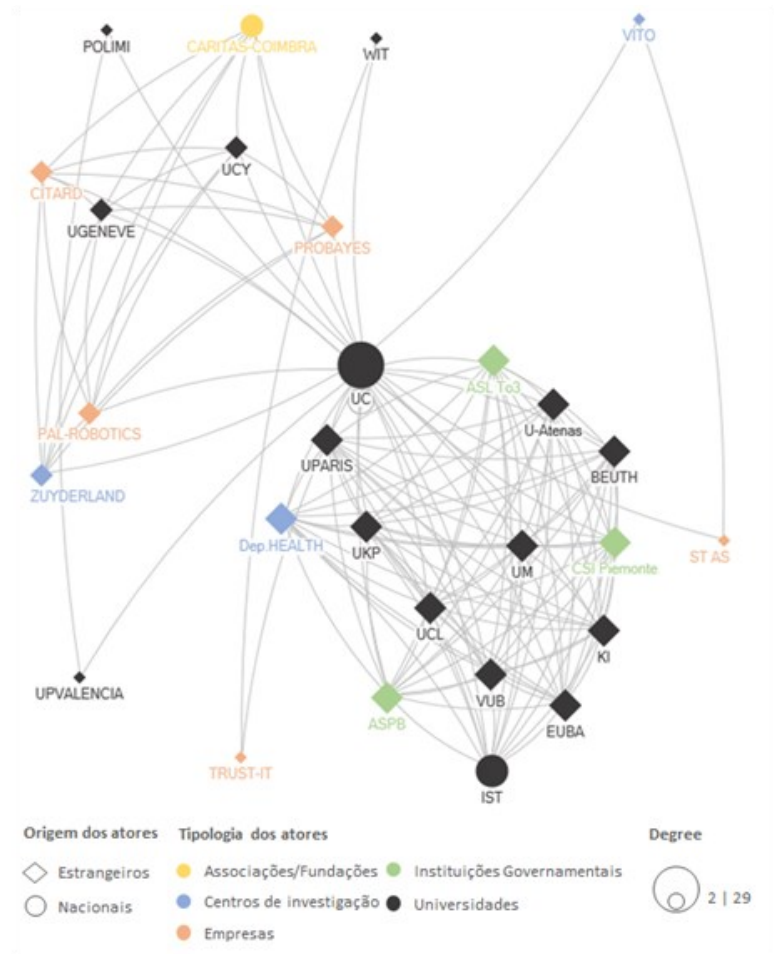

Figura 3 - Rede de colaboração da Universidade de Coimbra como promotora em projetos Horizonte 2020. 
Na análise ao nível dos elementos são valorizadas as medidas de centralidade (Freeman et al, 1979; Gómes et al.,2003), que determinam a importância relativa de um vértice no grafo: centralidade de grau (Degree Centrality), centralidade de proximidade (Closeness Centrality) e centralidade de intermediação (Betweenness Centrality).

O grau médio corresponde ao número médio de nós (organizações) aos quais cada nó da rede se encontra ligado. A rede total apresenta um valor mais elevado $(16,11)$, indicando uma rede alargada com muitas interações entre as instituições, enquanto que a rede da UC como promotora apresenta um valor menor $(10,21)$.

A medida de centralidade de grau, ao medir o número de conexões diretas de cada ator no grafo, dá excelentes indicações sobre a importância das relações de cada uma das instituições com as restantes.

Ao nível da centralidade de grau da rede total, destacam-se algumas organizações com valores muito acima da média, de que é o caso da Universidade de Coimbra, com 259 ligações diretas a outras unidades, uma vez que a recolha dos projetos se fez com base na participação desta instituição. Segue-se o Centre National de la Recherche Scientifique, com 44 ligações, o Stichting VU (42 ligações), a Universidade de Maastricht (38 ligações), a Universidade de Van Amsterdam (38 ligações), o Consiglio Nazionale Delle Ricerche (37 ligações) e a Universidade de Utrecht (36 ligações).

Já no caso da rede em que a Universidade de Coimbra é promotora, para além da UC (29 ligações), sobressaem a Agencia de Salut Publica de Barcelona (14 ligações), o Department of Health (14 ligações), a Universite Paris Ouest Nanterre La Defense (14 ligações), Instituto Superior Técnico (14 ligações) e a Universidade de Maastricht (14 ligações). Estas instituições, por apresentarem uma grande quantidade de contactos diretos, beneficiam de uma maior centralidade, sendo consideradas como as mais populares da rede.

A proximidade é uma medida que assenta na distância geodésica, ou seja, no comprimento do caminho mais curto que liga dois atores (Lemieux et al, 2004). Simboliza a proximidade de cada instituição a todas as outras com as quais estabelece relação. A proximidade média da rede total apresenta um valor muito baixo $(0,002)$, refletindo uma grande proximidade de cada instituição a todas as outras com as quais se encontra ligada.

A intermediação é outra medida de centralidade que permite medir o grau de extensão na qual um nó se encontra situado entre os outros nós da rede, sendo importante para aferir o prestígio das instituições e a sua capacidade para aceder e controlar o fluxo de informação pela posição intermediária que ocupam. Segundo Lemieux et al (2004), quanto mais um ator se encontrar numa posição intermediária, ou seja, quanto mais se encontrar numa situação em que os atores têm de passar por ele para chegar aos outros atores, maior capacidade de controlo terá sobre a circulação da informação entre esses atores. Nesta rede o valor médio é de 162,06, o que revela uma grande importância dos atores intermediários na rede. Já a rede da UC como promotora, em virtude do menor número de atores apresenta o valor de 8,43.

Por fim, ao nível da análise dos grupos, foi destacado o coeficiente de clusterização que quantifica quão conectado está um determinado vértice com os seus vizinhos (Hansen et al, 2011). Os valores calculados para as duas redes são semelhantes, 0,95 e 0,98, respetivamente.

Um último aspeto a valorizar diz respeito à identificação das relações espaciais da Universidade de Coimbra com os restantes territórios, analisada através da representação cartográfica de todas as unidades presentes na rede, bem como as relações potenciais entre a UC e as restantes organizações (Figuras 4 e 5).

No que diz respeito à rede de colaboração nos projetos em que a Universidade de Coimbra é promotora rapidamente se constata que a proximidade geográfica é pouco relevante para o estabelecimento de relações, sendo que a quase totalidade das relações são estabelecidas com organizações estrangeiras.

\section{NOTAS FINAIS}

A leitura das redes de colaboração científica constitui um excelente indicador para o delinear das políticas públicas, no sentido de reconhecer importância às redes existentes e fomentar o aparecimento de novas redes. Estas deverão ser vistas como mais-valias para a produção e difusão do conhecimento científico, capazes de promover processos de inovação determinantes para o desenvolvimento e aumento da capacidade competitiva dos territórios.

A análise sublinha a crescente participação da Universidade de Coimbra em redes de I\&D e inovação, quer como promotora quer como participante. Por outro lado, a análise mostra uma tendência de especialização na área científica das ciências da saúde. Um outro elemento indica a diversidade de atores envolvidos nos projetos de investigação considerando a importância das universidades e centros de investigação, mas também das empresas. As proximidades organizacional e institucional são importantes assim como a proximidade cognitiva, a 


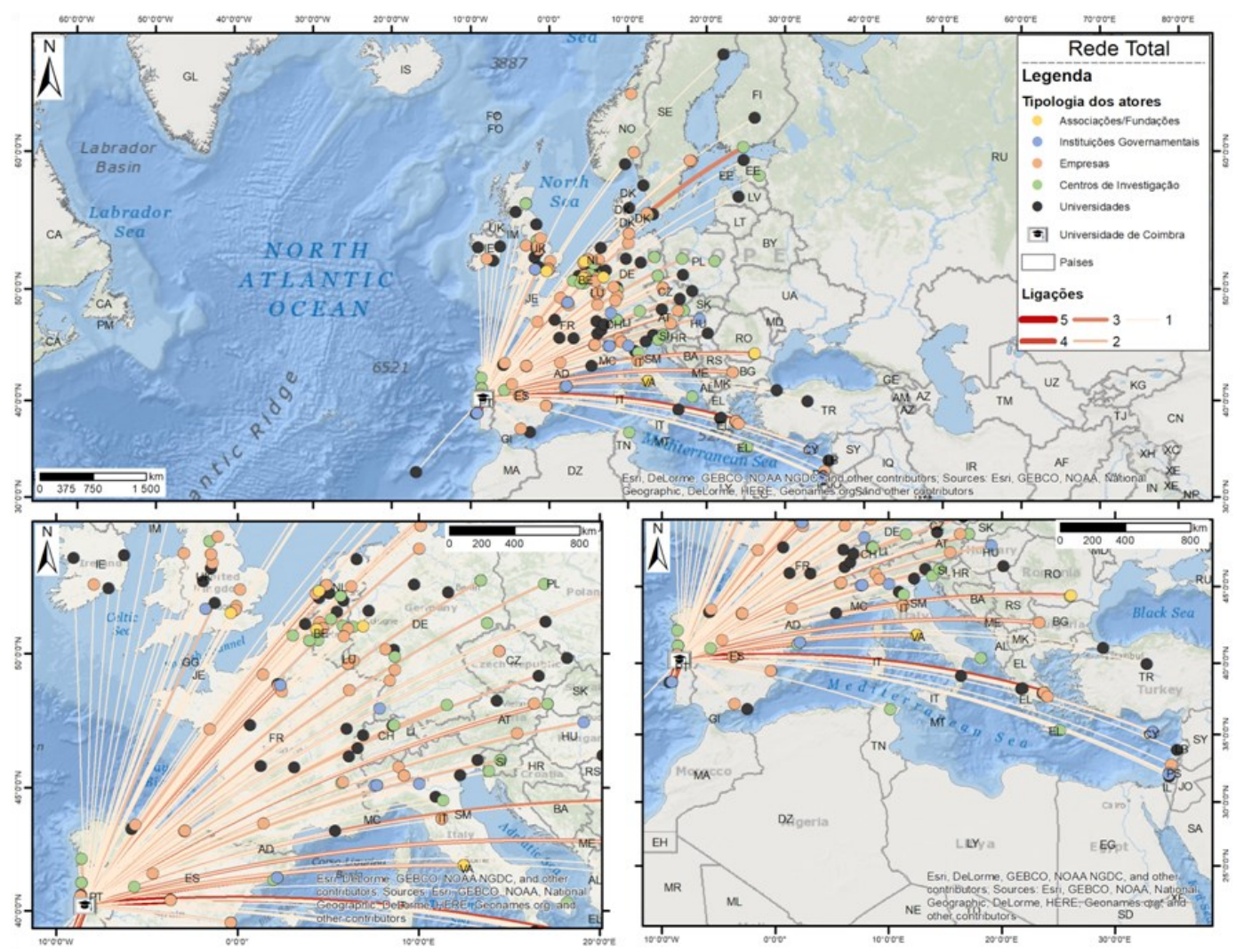

Figura 4 - Rede de colaboração da Universidade de Coimbra em projetos Horizonte 2020 (Rede Total

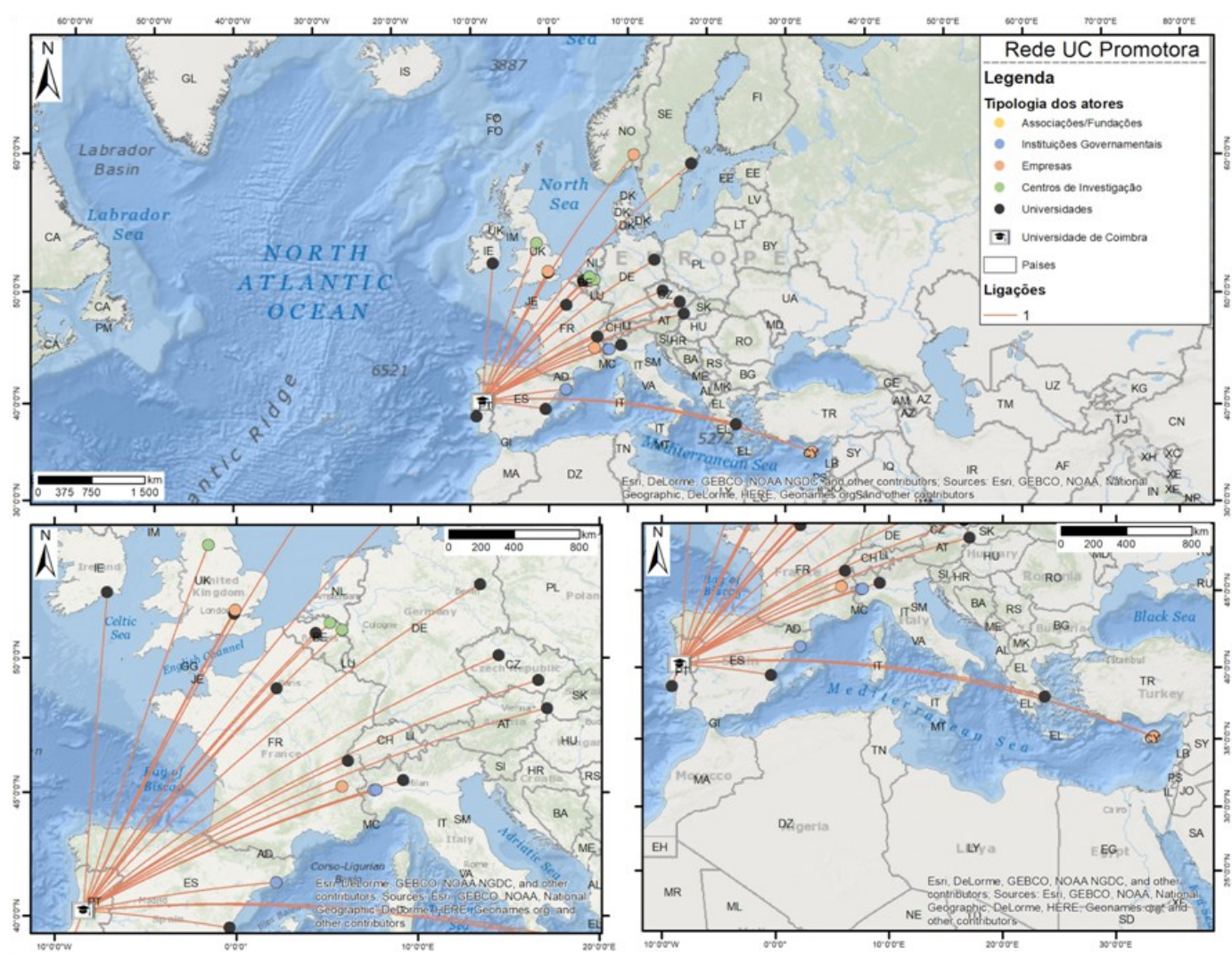

Figura 5 - Redes de colaboração da Universidade de Coimbra em projetos Horizonte 2020 (Rede UC promotora). 
procura de parceiros com as competências necessárias atendendo aos objetivos das colaborações. Neste sentido a proximidade geográfica assume um papel de menor importância no estabelecimento de parcerias.

Importa ainda destacar a crescente importância das parcerias com instituições e unidades de investigação internacionais e, em especial, com empresas estrangeiras.

A leitura da participação da UC em Projetos financiados pelo H2020 deixa antever um fortalecimento nas relações, assente na diversidade de atores (institucional e espacial), internacionalização e crescente participação de empresas que tem contribuído para o alargamento das redes ao longo dos anos.

\section{BIBLIOGRAFIA}

BARABÁSI, A. (2002). Linked-the new science of networks. Cambridge: Perseus Publishing.

BARNES, J. (1972). Social networks. Addison-Wesley Module in Anthropology, 26, 1-29.

BAUR, M., BRANDES, U., LERNER, J., \& WAGNER, D. (2009). Group-level analysis and visualization of social networks (pp. 330 -358). In J. Lerner, D. Wagner \& K. A. Zweig (Eds.), Algorithmics of Large and Complex Networks, Design, Analysis, and Simulation. Heidelberg: Springer

BRANDÃO, T. (2016). Shaping Portuguese science policy for the European horizon: The discourses of technological change. Technological Forecasting \& Social Change, 113, 168-184. doi:10.1016/j.techfore.2015.09.014

BUTTS, C. (2008). Social network analysis: A methodological introduction. Asian Journal of Social Psychology, 11, 13-41. doi:10.1111/j.1467-839X.2007.00241.x

CARAYANNIS, E. G., \& CAMPBELL, D. F. J. (2012). Mode 3 knowledge production in Quadruple Helix Innovation Systems. 21st -century democracy, innovation, and entrepreneurship for development. Springer Briefs in Business. New York: Springer. doi:10.1007/978-1-4614-2062-0

CE (2011). Livro Verde - Dos Desafios às Oportunidades: Para um Quadro Estratégico Comum de Financiamento da Investigação e Inovação da UE. Comissão Europeia. Consultado em http://www.qren.pt/np4/np4/?newsld=1334\&fileName=file879.pdf

ETZKOWITZ, H. (2008). The Triple Helix - University-Industry-Government-Innovation in Action. New York: Routledge. Consultado em https://ssrn.com/abstract=2480085

ETZKOWITZ, H., \& LEYDESDORFF, L. (1995). The Triple Helix University-Industry-Government Relations: A Laboratory for Knowledge-Based Economic Development. EASST Review 14,14-19.

ETZKOWITZ, H., \& LEYDESDORFF, L. (1997). Universities and the Global Knowledge Economy: A Triple Helix of UniversityIndustry-Government Relations. London: Pinter.

EtZkowitz, H., \& LeYdesdorfF, L. (2000). The Dynamics of Innovation: From National Systems and "Mode 2" to a Triple Helix of University-Industry-Government Relations. Research Policy, 29(2), 109-123. doi:10.1016/S0048-7333(99)00055-4

FERNANDES, R. (2008). Cidades e Regiões do Conhecimento: Do digital ao inteligente - Estratégias de desenvolvimento territorial. Coimbra: Universidade de Coimbra. Consultado em http://hdl.handle.net/10316/12399

FREEMAN, L., ROEDER, D., \& MULHOLLAND, R. (1979). Centrality in social networks: ii. experimental results. Social Networks, 2, 119-141. doi:10.1016/0378-8733(79)90002-9

GAMA, R., FERNANDES, R., \& BARROS, C. (2013) Redes de I\&D da Universidade de Coimbra: análise dos projetos de IC\&DT financiados pela Fundação para a Ciência e Tecnologia (FCT). Actas do IX Congresso da Geografia Portuguesa, 241-246.

GOLDSTEIN, H. (2010). The 'entrepreneurial turn' and regional economic development mission of universities. Annals of Regional Science, 44, 83-109. doi:10.1007/s00168-008-0241-z

GÓMES, D. et al. (2003). Centrality and power in social networks: a game theoric approach. Mathematical Social Sciences, 46, 27-54. doi:10.1016/S0165-4896(03)00028-3

HANSEN, D., SHNEIDERMAN, B., \& SMITH, M. (2011). Analyzing Social Media Networks with NodeXL. USA: Elsevier.

HEITOR, M. V., \& HORTE, H. (2011). Science and Technology in Portugal: From Late Awakening to the Challenge of Knowledge Integrate Communities. In G. Neave \& A. Amaral (Eds.), Higher Education in Portugal 1974-2009 A Nation, a Generation (pp. 179-226). Dordrech, Heildelberg, London, New York: Springer.

HENNEMANN, S., \& LIEFNER, I. (2015). Global Science Colaboration. In D. Archibugi \& A. Filippetti (Eds.), The Handbook of Global Science, Technology, and Innovation (pp. 343-36). Chichester: John Wiley \& Sons, Ltd, 3.

LEMIEUX, V., \& OUIMET, M. (2004). Análise Estrutural das Redes Sociais. Epistemologia e Sociedade. Lisboa: Instituto Piaget. doi:10.1080/13662719400000002 
LUNDVALL, B.-Å., \& JOHNSON, B. (1994). The learning economy. Journal of Industry Studies, 1(2), December, $23-42$.

MAISONOBE, M., ECKERT, D., GROSSETTI, M., JÉGOU, L., \& MILARD, B. (2016). The world network of scientific collaborations between cities: domestic or international dynamics? Journal of Informetrics, 10, 1025-1036. doi:10.1016/ j.joi.2016.06.002

MARQUES, T., SANTOS, H., \& RIBEIRO, P. (2015). Redes de inovação económica ancoradas no Arco Metropolitano de Lisboa (2007-2013). In J. M. F. Ribeiro, F. Moura, \& J. Chorincas, Uma Metrópole para o Atlântico (557-590). Lisboa: Fundação Calouste Gulbenkian.

Marques, T., SANTOS, H., \& Ribeiro, P. (2016). Redes de inovação económica ancoradas na Região Centro (2007-2015). In J. M. F. Ribeiro, F. Moura, \& J. Chorincas, Portugal no Centro (464-501). Lisboa: Fundação Calouste Gulbenkian.

NOWOTNY, H., SCOTT, P., \& GIBBONS, M. (2001). Re-thinking science. Knowledge and the public in an age of uncertainty. Cambridge: Polity Press.

NOWOTNY, H., SCOTT, P., \& GIBBONS, M. (2003). Mode 2 Revisited: The New Production of Knowledge. Minerva, 41, 179194. Consultado em http://www.jstor.org/stable/41821245

NOWOTNY, H., SCOTT, P., \& GIBBONS, M. (2006). Re-Thinking Science: Mode 2 in Societal Context. In E. G. Carayannis \& D. F. J. Campbell (Eds.), Knowledge Creation, Diffusion, and Use in Innovation Networks and Knowledge Clusters. A Comparative Systems Approach across the United States, Europe and Asia (pp. 39-51). Westport, Connecticut: Praeger.

PATRÍCIO, M. (2010). Science Policy and the Internationalisation of Research in Portugal. Journal of Studies in International Education, 14(2), 161-182. doi:10.1177/1028315309337932

PHELPS, C., HEIDL, R., \& WADHWA, A. (2012). Knowledge, Networks, and Knowledge Networks. A review and Research Agenda. Journal of Management, 38(4), 1115-1166. doi:10.1177/0149206311432640

SCOTT, J. (2013). Social Network analysis. London: Sage.

WAL, A., \& BOSCHMA, R. (2009). Applying social network analysis in economic geography: framing some key analytic issues. The Annals of Regional Science, 43(3), 739-756. doi:10.1007/s00168-008-0258-3 Wagner, C. (2008). The New Invisible College - Science for Development. Washington: The Brookings Institution Press.

WILSDON, J. et al. (2011). Knowledge, networks and nations: global scientific collaboration in the 21st century. Royal Society Policy document 03/11. London: The Royal Society.

UNIÃO EUROPEIA (2014). Horizon 2020 em breves palavras: o programa quadro de investigação e inovação da UE. Luxemburgo: Serviço das Publicações Oficiais das Comunidades Europeias. doi:10.2777/82557 


\title{
Especialização Inteligente à Escala Urbana: Análise Dirigida ao Diagnóstico do PDM da Cidade do Porto
}

\author{
T. Sá Marques (a), H. Santos (b), D. Ribeiro (c), P. Ribeiro (d) \\ (a) Centro de Estudos de Geografia e Ordenamento do Território (CEGOT). Departamento de Geografia, Faculdade de Letras da Universidade do \\ Porto, teresasamarques@gmail.com \\ (b) Centro de Estudos de Geografia e Ordenamento do Território (CEGOT). Faculdade de Letras da Universidade do Porto, hfcs75@hotmail.com \\ (c) Faculdade de Letras da Universidade do Porto, mrcotgeo@gmail.com \\ (d) Centro de Estudos de Geografia e Ordenamento do Território (CEGOT)/ Faculdade de Letras da Universidade do Porto, \\ paularibeiro82@gmail.com
}

\section{Resumo}

A política de especialização inteligente, tal como foi preconizada pela União Europeia (UE) dirige-se à escala regional. No entanto, à escala local, existem instrumentos de política de desenvolvimento do território que são estruturais para o desenvolvimento e o planeamento e o ordenamento do território. Nomeadamente nos territórios de grande densidade, como é o caso da cidade do Porto, o papel de liderança que desempenham face à região em que se inserem e o peso considerável que têm nas dinâmicas socioeconómicas da região leva-nos a considerar que os instrumentos de política local não devem ser ignorados no processo de construção e aplicação das políticas de especialização inteligente. A presente comunicação apresenta parte da análise desenvolvida para o PDM do concelho do Porto que se centra na exploração de atividades económicas enquadráveis nos domínios de especialização inteligente definidos pela RIS3 Norte e respetiva espacialização intraurbana.

Palavras chave: Estratégia de Especialização Inteligente, escala local, PDM, Porto.

\section{INTRODUÇÃO}

A política de especialização inteligente, tal como foi preconizada pela União Europeia (UE), dirige-se à escala regional. No entanto, à escala local, existem instrumentos de política de desenvolvimento que são estruturais para o desenvolvimento e o planeamento e o ordenamento do território. Nomeadamente nos territórios de grande densidade, como é o caso da cidade do Porto, o papel de liderança que desempenham face à região em que se inserem e o peso considerável que têm nas dinâmicas socioeconómicas da região leva-nos a considerar que os instrumentos de política local não devem ser ignorados no processo de construção e aplicação das políticas de especialização inteligente.

A presente comunicação uma parte do diagnóstico desenvolvido para o PDM do concelho do Porto, nomeadamente no que corresponde à identificação das atividades económicas (estabelecimento) enquadradas nos domínios de especialização inteligente definidos para a RIS3 Norte, o seu peso na economia da cidade (PIB, VAB, exportações e emprego) e a sua distribuição na cidade do Porto.

Começando por apresentar os argumentos teóricos que sustentam esta abordagem à escala local do conceito de especialização inteligente, apresenta-se a metodologia que suporta a subsequente análise da estrutura económica do concelho enquadrável na RIS3 da região Norte e prossegue-se cartografando a sua espacialização na cidade, na procura de tendência para a clusterização. A terminar apresentam-se os contributos para a tomada de decisão em matéria de políticas públicas de ordenamento do território das atividades económicas, que poderão nomeadamente condicionar os usos do solo, nomeadamente no sentido de contribuir para uma implementação mais eficaz da estratégia de especialização inteligente. Apresentam-se ainda algumas limitações relativas à implementação da estratégia de especialização inteligente (RIS3) à escala local.

\section{ESTRATÉGIA DE ESPECIALIZAÇÃO INTELIGENTE: DAS POLÍTICAS REGIONAIS ÀS POLÍTICAS LOCAIS DE DESENVOLVIMENTO ECONÓMICO}

A estratégia de especialização inteligente é atualmente uma realidade no território da União Europeia. 
Concebida originalmente enquanto conceito de política setorial, coloca vários desafios no momento de operacionalização no âmbito das políticas de desenvolvimento territorial e coesão regional (McCann \& Ortega-Argilés, 2013). Dirigida sobretudo à escala regional (McCann \& Ortega-Argilés, 2013; Sandu, 2012; Gulc, 2015; Kempton, 2015; Balland, Boschma, Crespo, \& Rigby, 2018), ainda que enquadrado à escala nacional (IAPMEI; FCT; ANI; COMPETE, 2014), as orientações de política que emanam da União Europeia explicitam a necessidade de uma abordagem bottom-up, que reúna, entre outros atores, as autoridades locais para trabalharem em conjunto no sentido de estabelecerem estratégias de longo prazo na aplicação dos fundos comunitários (EuropeanCommission, 2017). No entanto, estas orientações ignoram o contributo dos instrumentos de política local (planos estratégicos e planos diretores municipais) para a construção e implementação das estratégias de especialização inteligente.

As primeiras avaliações desta fase inicial de implementação da especialização inteligente apontam, entre outros, o estrangulamento provocado pela falta de pré-condições na economia local que possibilitem a sua implementação (Capello \& Kroll, 2016) ou a dificuldade de aplicar este conceito na grande diversidade de regiões rurais (Naldi, Nilsson, Westlund, \& Wixe, 2015). Isto é, nem sempre o conceito de especialização inteligente encaixa nos territórios à escala regional, o que aponta para a necessidade de redirecionar o foco, até agora muito centrado nas indústrias, para estratégias de desenvolvimento de base territorial (Capello \& Kroll, 2016).

Para além da reorientação da estratégia de especialização inteligente na direção das políticas de base territorial (Barca, McCann, \& Rodríguez-Pose, 2012), este apelo ao território pode passar por uma maior atenção à escala local, nomeadamente através do envolvimento dos instrumentos de política elaborados à escala das áreas metropolitanas, das comunidades urbanas ou dos municípios, na construção, articulação e implementação das estratégias de especialização inteligente.

Alguns trabalhos recentes demonstram que o conceito de especialização inteligente pode ser incorporado nos instrumentos de política pública desenvolvidos à escala metropolitana (Marques \& Queirós, AMP 2020 Crescimento Inteligente, 2017) ou à escala urbana (Novosák, Hájek, Zahradník, \& Nekolová, 2013; Maximilian, Bieringer, Knaupp, Wittemaier, \& Wruck, 2016), nomeadamente na formulação de planos estratégicos de desenvolvimento económico.

No caso particular das grandes cidades, estas são os locais onde se colocam os principais desafios e ocorrem os principais processos de desenvolvimento económico e social (ESPON, 15/12/2010). Caracterizadas por uma elevada densidade populacional e um forte fluxo de pessoas (residentes, trabalhadores, visitantes), as cidades são facilitadoras do aumento e da diversificação da procura e possibilitam o acesso a um conjunto de infraestruturas e externalidades fundamentais aos processos de produção de bens e à prestação de serviços, nomeadamente ao capital financeiro, ao capital humano ou ao acesso a fornecedores, entre muitos outros (Boschma, 2010). A cidade é catalisadora de crescimento económico e de desenvolvimento (Marques, 2004; Beaverstock, Faulconbridge, \& Hoyler, 2011; Mendes, 2011), concentrando uma proporção crescente de atividades socioeconómicas, em que a proximidade e a densidade são potenciadoras. A concentração de atividades económicas atrai, por seu turno, novas atividades económicas necessárias para servir a concentração de pessoas e de negócios existentes (CE, março 2014; Nijkamp \& Kourtit, 2013). Em geral, as cidades são motores da economia, espaços de inovação, de competitividade, de cooperação e de concentração de capital humano e social.

No caso concreto do Porto, esta é a cidade com um papel liderante no desenvolvimento económico da Área Metropolitana do Porto (Marques \& Queirós, 2017; Marques \& Santos, 2013; Santos \& Marques, 2013), da região do Noroeste de Portugal (Ribeiro \& Ferrão, Noroeste Global, 2014), e, conjuntamente com Lisboa, é um dos dois motores do desenvolvimento económico de Portugal (Ribeiro, Moura, \& Chorincas, 2015; Marques, Santos, \& Ribeiro, 2016; DGT, 2018). Assim, no momento de, à escala local, selecionar um concelho para explorar a aplicação do conceito de estratégia de especialização inteligente, a cidade do Porto surge como um bom candidato para este ensaio.

Hoje, os PDM são instrumentos de política pública, em primeiro lugar de natureza estratégica e só depois de orientação e regulação dos usos dos solos (Lei n. ${ }^{\circ}$ 31/2014, de 30 de maio). Nesse sentido, é de grande importância elaborar um diagnóstico estratégico que instrua as orientações de política territorial que vão condicionar os usos dos solos. Neste âmbito, o desenvolvimento económico tem de ser uma matéria central neste instrumento de gestão estratégica do território.

A comunicação identifica a estrutura económica enquadrada nos domínios de especialização inteligente definidos para a RIS3-Norte (CCDRN, 2014) e a respetiva distribuição espacial no concelho do Porto. A comunicação estrutura-se da seguinte forma: começa-se por apresentar a metodologia utilizada, seguindo-se uma análise detalhada dos resultados em termos de stocks e distribuição territorial. 


\section{METODOLOGIA}

A estratégia de especialização inteligente para a região Norte (RIS3) identifica oito domínios prioritários de especialização e a respetiva classificação das atividades económicas (CAE) que se enquadram em cada um dos domínios de especialização inteligente. Seguindo esta classificação, identificaram-se as CAE das atividades instaladas no concelho do Porto (quadro 1). De seguida, para cada domínio de especialização inteligente, identifica-se o tecido económico instalado no concelho do Porto, analisa-se a estrutura etária dos estabelecimentos e cartografa-se a respetiva distribuição dos estabelecimentos tendo em vista analisar o padrão da distribuição territorial.

Esta análise suportou-se numa base de dados georreferenciada de estabelecimentos e empresas, localizados no concelho do Porto (à data de 31 de janeiro de 2017), com dados sobre a identificação, localização, atividade e situação económica, referentes ao exercício em 2015/2016. A cartografia temática desenvolvida representa a distribuição espacial das atividades e do emprego, através método de cálculo da densidade Kernel de pontos. Apresentam-se, para cada distribuição, dois modelos, um contendo os valores escalares da distribuição de densidades, e um conceptual, mais simplificado, que demonstra os grandes locais de concentração.

$\mathrm{Na}$ análise dos dados, começa-se por uma visão de conjunto, e prossegue-se com uma análise focalizada em cada domínio de especialização inteligente.

Quadro 1 - Domínios de especialização inteligente da RIS3 Norte

\begin{tabular}{|c|c|c|c|c|}
\hline Domínio & Descrição do Domínio & \multicolumn{2}{|c|}{$\begin{array}{l}\text { CAE (identificados para cada domínio da especialização inteligente } \\
\text { da Região Norte) }\end{array}$} & $\begin{array}{l}\text { Classificação das } \\
\text { Atividades }\end{array}$ \\
\hline $\begin{array}{l}\text { Recursos do } \\
\text { Mar e } \\
\text { Economia }\end{array}$ & $\begin{array}{l}\text { Estabelecimento de relações de articulação } \\
\text { entre engenharias aplicadas (civil, mecânica, } \\
\text { naval, robótica, energia, biociências e tecnolo- } \\
\text { gias de informação, materiais), recursos do } \\
\text { mar (vento, ondas, algas, praias, etc) e ativida- } \\
\text { des económicas que os valorizem (construção } \\
\text { naval, produção de energia em offshore, cons- } \\
\text { trução de plataformas, turismo náutico, bio- } \\
\text { combustiveis, alimentação e aquacultura em } \\
\text { offshore, etc ). }\end{array}$ & $\begin{array}{l}\text { 03111-Pesca marítima } \\
\text { 03112-Apanha de algas outros } \\
\text { produtos do mar } \\
\text { 03121-Pesca águas interiores } \\
\text { 0321-Aquicultura em águas } \\
\text { salgadas e salobras } \\
\text { 0322-Aquicultura águas doces } \\
\text { 10201-Preparação prod. pesca e } \\
\text { aquicultura } \\
\text { 10202-Congelação prod. pesca e } \\
\text { aquicultura } \\
\text { 10203-Cons. prod. pesca e } \\
\text { aquicultura em azeite, e outros } \\
\text { óleos vegetais e outros molhos } \\
\text { 10204-Salga, secagem e outras } \\
\text { act. transf. prod. da pesca e } \\
\text { aquicultura } \\
\text { 2511-Fabr. estruturas constru- } \\
\text { ções metálicas } \\
\text { 2561-Tratamento e revestimen- } \\
\text { to metais } \\
\text { 2711-Fabr. motores, geradores e } \\
\text { transformadores elétricos } \\
\text { 2811-Fabr. motores e turbinas, } \\
\text { exceto motores para aeronaves, } \\
\text { automóveis e motociclos } \\
\text { 30111-Constr. embarcações } \\
\text { metálicas e estruturas flutuantes, } \\
\text { exceto de recreio e desporto }\end{array}$ & 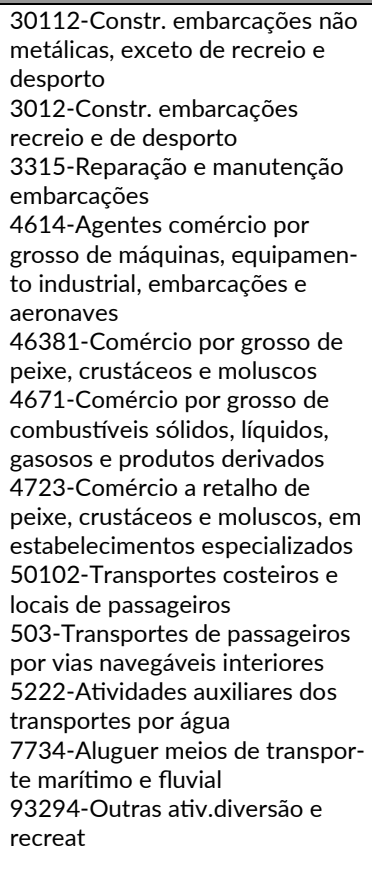 & $\begin{array}{l}\text { Construção Metálica e } \\
\text { Construção Naval } \\
\text { Atividades de Desporto } \\
\text { e Lazer } \\
\text { Transportes e Logística } \\
\text { Agricultura, Agroali- } \\
\text { mentar e Pescas e } \\
\text { Conservas } \\
\text { Comércio por grosso } \\
\text { Comércio a retalho e } \\
\text { Restauração } \\
\text { Máquinas e Equipamen- } \\
\text { tos elétrico } \\
\text { Serviços às Empresas }\end{array}$ \\
\hline $\begin{array}{l}\text { Capital Huma- } \\
\text { no e Serviços } \\
\text { Especializados }\end{array}$ & $\begin{array}{l}\text { Promoção de competências acumuladas na } \\
\text { área das TIC (em particular, no desenv. de } \\
\text { aplicações multimédia e na programação e } \\
\text { eng. de sistemas), para o desenvolvimento de } \\
\text { soluções de e-government, a desmaterializa- } \\
\text { ção de processos e, em associação com a } \\
\text { reconversão de capital humano, o aproveita- } \\
\text { mento das tendências para operações de } \\
\text { Nearshore Outsourcing (centros de engenha- } \\
\text { ria, de serv. partilhados e de contacto). }\end{array}$ & 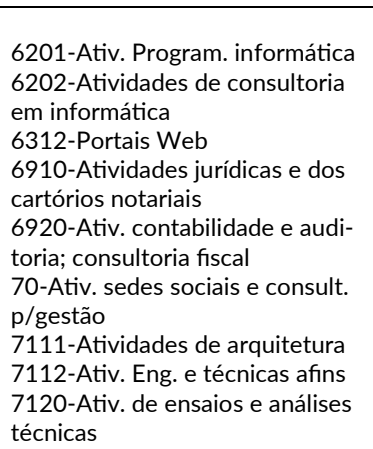 & $\begin{array}{l}\text { 721-I\&D das ciências físicas e } \\
\text { naturais } \\
\text { 722-I\&D das ciências sociais e } \\
\text { humanas } \\
\text { 731-Publicidade } \\
\text { 741-Atividades de design } \\
\text { 743-Atividades de tradução e } \\
\text { interpretação } \\
\text { 749-Outras at. consultoria, cien- } \\
\text { tíficas, técnicas e similares, n.e. } \\
\text { 821-Atividades de serviços } \\
\text { administrativos e de apoio } \\
\text { 822-Atividades dos centros de } \\
\text { chamadas }\end{array}$ & $\begin{array}{l}\text { Serviços às Empresas } \\
\text { Construção e Engenha- } \\
\text { ria } \\
\text { TIC, Indústria e Serviços } \\
\text { Investigação e Desen- } \\
\text { volvimento } \\
\text { Indústrias Criativas }\end{array}$ \\
\hline
\end{tabular}


Quadro 7 - Domínios de especialização inteligente da RIS3 Norte (continuação).

\begin{tabular}{|c|c|c|c|c|}
\hline Domínio & Descrição do Domínio & \multicolumn{2}{|c|}{$\begin{array}{l}\text { CAE (identificados para cada domínio da especialização inteligente } \\
\text { da Região Norte) }\end{array}$} & $\begin{array}{l}\text { Classificação das Ativi- } \\
\text { dades }\end{array}$ \\
\hline $\begin{array}{l}\text { Cultura, Cria- } \\
\text { ção e Moda }\end{array}$ & $\begin{array}{l}\text { Exploração do potencial das indústrias criati- } \\
\text { vas (sobretudo nas áreas de design e arquite- } \\
\text { tura), de novos materiais e de tecnologias de } \\
\text { produção inovadoras, na criação de novas } \\
\text { vantagens competitivas em setores ligados à } \\
\text { produção de bens de consumo com uma forte } \\
\text { componente de design (design based consu- } \\
\text { mer goods), nomeadamente o têxtil e vestuá- } \\
\text { rio, calçado, acessórios, mobiliário, joalharia, } \\
\text { etc. }\end{array}$ & $\begin{array}{l}\text { 1310-Prep. e fiação de fibras } \\
\text { têxteis } \\
1330-\text { Acabamento de têxteis } \\
1392-\text { Fabr. artigos têxteis confe- } \\
\text { cionados, exceto vestuário } \\
1396-\text { Fabr. têxteis para uso } \\
\text { técnico e industrial } \\
1411-\text { Confeção vestuário em } \\
\text { couro } \\
1413-\text { Confeção outro vestuário } \\
\text { exterior } \\
1419-\text { Confeção outros artigos e } \\
\text { acessórios vestuário } \\
1431-\text { Fabr. meias e similares de } \\
\text { malha } \\
1520-\text { Indústria do calçado } \\
1621-\text { Fabr. folheados e painéis à } \\
\text { base de madeira } \\
16293-\text { Ind. preparação da corti- } \\
\text { ça } \\
1811-\text { Impressão de jornais } \\
22191-\text { Fabr. componentes de } \\
\text { borracha para calçado } \\
2341-\text { Fabr. artigos cerâmicos de } \\
\text { uso doméstico e ornamental }\end{array}$ & $\begin{array}{l}\text { 25991-Fabr. louça metálica e } \\
\text { artigos de uso doméstico } \\
\text { 3102-Fabr. mobiliário de cozinha } \\
\text { 3213-Fabr. bijutarias } \\
\text { 5811-Edição de livros } \\
\text { 5814-Edição de revistas e outras } \\
\text { pub. periódicas } \\
\text { 5912-Atividades técnicas de pós } \\
\text {-produção para... } \\
\text { 5914-Projeção de filmes e ví- } \\
\text { deos } \\
\text { 6010-Atividades rádio } \\
\text { 6201-Atividades programação } \\
\text { informática } \\
\text { 6391-Atividades agências de } \\
\text { notícias } \\
\text { 7311-Agências publicidade } \\
\text { 7420-Atividades fotográficas } \\
\text { 9001-Atividades das artes do } \\
\text { espetáculo } \\
\text { 9003-Criação artística e literária } \\
\text { 9523-Rep.o calçado e artigos } \\
\text { couro } \\
\text { 9525-Rep. Relógios,artigos } \\
\text { joalharia }\end{array}$ & $\begin{array}{l}\text { Têxtil, Vestuário e } \\
\text { Calçado } \\
\text { Indústrias Criativas } \\
\text { TIC, Indústria e Serviços } \\
\text { Serviços às empresas } \\
\text { Madeira, Cortiça, Mobi- } \\
\text { liário } \\
\text { Serviços Pessoais } \\
\text { Produtos metálicos e } \\
\text { Mecânica ligeira } \\
\text { Cerâmicas e Outros } \\
\text { materiais de construção } \\
\text { Outros }\end{array}$ \\
\hline $\begin{array}{l}\text { Indústrias da } \\
\text { Mobilidade e } \\
\text { Ambiente }\end{array}$ & $\begin{array}{l}\text { Aproveitamento das competências científicas } \\
\text { nas áreas das tecnologias de produção e dos } \\
\text { materiais, potenciadas pelos contratos de } \\
\text { fornecimento com a Airbus e Embraer, para a } \\
\text { promoção do upgrade das indústrias de com- } \\
\text { ponentes de automóveis e de moldes, tendo } \\
\text { em vista o fornecimento de clientes mais } \\
\text { exigentes nas especificações técnicas, nomea- } \\
\text { damente na área da aeronáutica. }\end{array}$ & $\begin{array}{l}\text { 13962-Fabr. têxteis para uso } \\
\text { técnico e industrial, n.e. } \\
\text { 20592-Fabr. produtos químicos } \\
\text { auxiliares para uso industrial } \\
\text { 2211-Fabr. pneus e câmaras-de- } \\
\text { ar; reconstrução de pneus } \\
\text { 2442-Obtenção e primeira } \\
\text { transformação alumínio } \\
\text { 2511-Fabr. estruturas de cons- } \\
\text { truções metálicas } \\
\text { 2561-Tratam. e revestim. metais } \\
\text { 2562-Atividades de mecânica } \\
\text { geral }\end{array}$ & 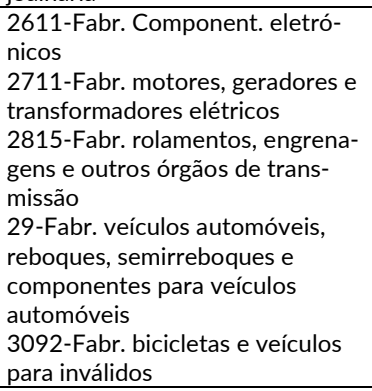 & $\begin{array}{l}\text { Const. Metálica e } \\
\text { Const. Naval } \\
\text { Máq. uso geral e setori- } \\
\text { al } \\
\text { Material de Transporte } \\
\text { - Automóvel e Diverso } \\
\text { Fundição, Siderurgia e } \\
\text { Metalurgia } \\
\text { Química Diversa } \\
\text { Máq. e Equip. elétrico } \\
\text { TIC, Indústria e Serviços } \\
\text { Têxtil, Vestuário e } \\
\text { Calçado }\end{array}$ \\
\hline $\begin{array}{l}\text { Ciências da } \\
\text { Vida e Saúde }\end{array}$ & $\begin{array}{l}\text { Consolidação das dinâmicas de articulação } \\
\text { entre a investigação regional (nomeadamente, } \\
\text { ao nível da eng.de tecidos, do cancro, das } \\
\text { neurociências e do desenv. das técnicas cirúr- } \\
\text { gicas) e as empresas nas indústrias e serv. na } \\
\text { área da saúde em sentido amplo } \\
\text { (farmacêutica, dispositivos médicos, prestação } \\
\text { de serviços saúde, turismo de saúde e bem- } \\
\text { estar e cosmética). }\end{array}$ & $\begin{array}{l}\text { 21-Fabricação de produtos } \\
\text { farmacêuticos de base e de } \\
\text { preparações farmacêuticas } \\
4646 \text {-Comércio por grosso de } \\
\text { produtos farmacêuticos } \\
4773-\text { Comércio a retalho de } \\
\text { produtos farmacêuticos, em } \\
\text { estabelecimentos especializados }\end{array}$ & $\begin{array}{l}\text { 325-Fabricação de instrumentos } \\
\text { e material médico-cirúrgico } \\
4774-\text { Comércio a retalho de } \\
\text { produtos médicos e ortopédicos, } \\
\text { em estabelecimentos especiali- } \\
\text { zados } \\
\text { 86-Atividades de saúde humana }\end{array}$ & $\begin{array}{l}\text { Serviços Coletivos } \\
\text { Comércio a retalho e } \\
\text { Restauração } \\
\text { Comércio por grosso } \\
\text { Indústria Farmacêutica } \\
\text { e Instrumentação Médi- } \\
\text { ca }\end{array}$ \\
\hline
\end{tabular}


Quadro 7 - Domínios de especialização inteligente da RIS3 Norte (continuação).

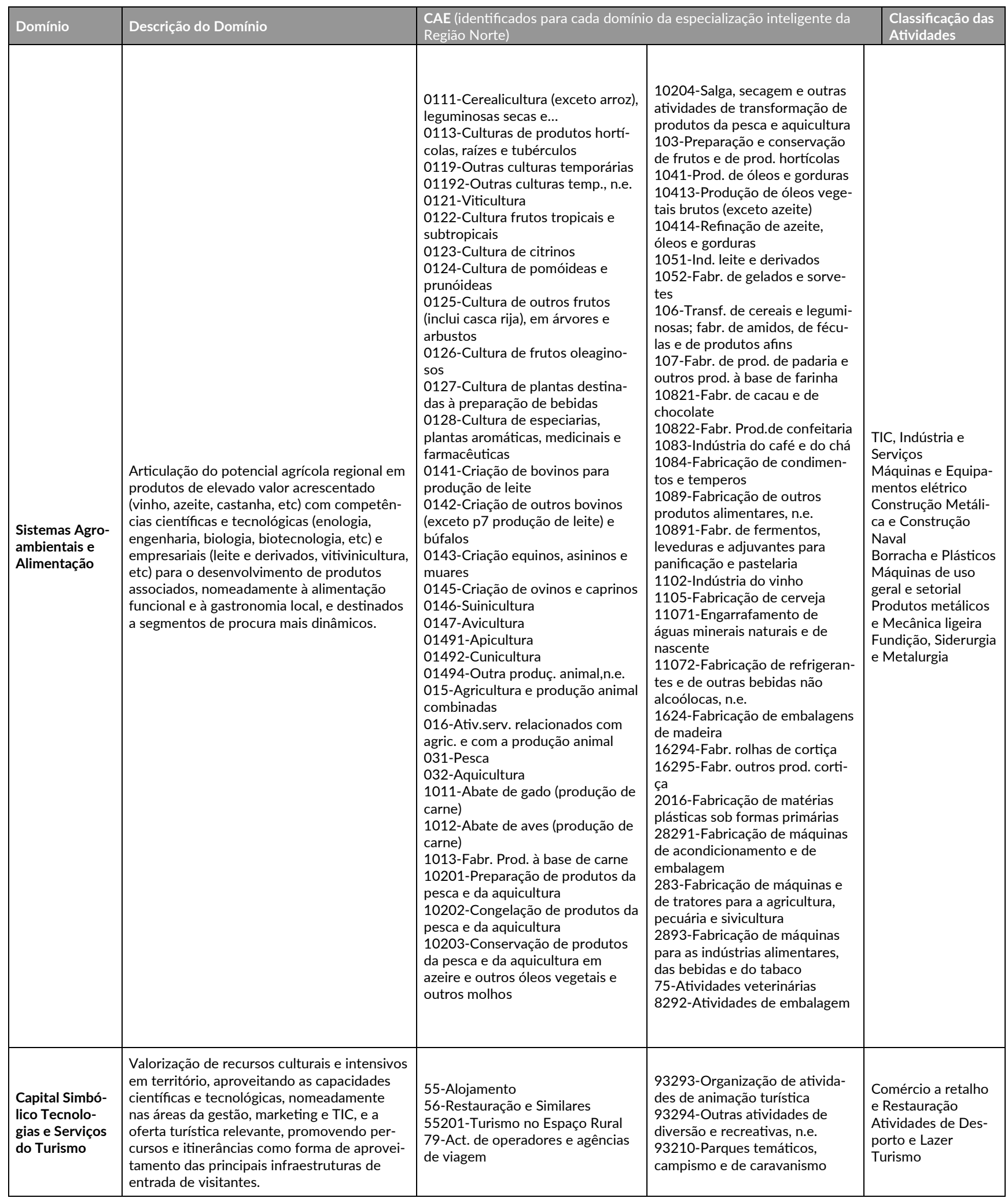


Quadro 7 - Domínios de especialização inteligente da RIS3 Norte (continuação).

\begin{tabular}{|c|c|c|c|c|}
\hline Domínio & Descrição do Domínio & \multicolumn{2}{|c|}{$\begin{array}{l}\text { CAE (identificados para cada domínio da especialização inteligente da } \\
\text { Região Norte) }\end{array}$} & $\begin{array}{l}\text { Classificação das } \\
\text { Atividades }\end{array}$ \\
\hline $\begin{array}{l}\text { Sistemas Avan- } \\
\text { çados de Pro- } \\
\text { dução }\end{array}$ & $\begin{array}{l}\text { Desenvolvimento de fileiras associadas às } \\
\text { Tecnologias de Largo Espectro (Key Enabling } \\
\text { Technologies), nomeadamente os Sistemas } \\
\text { de Produção Avançados (Advanced Manu- } \\
\text { facturing Systems), Nanotecnologias, Materi- } \\
\text { ais e TICE, conjugando a existência de capa- } \\
\text { cidades e infraestruturas cientificas e tecno- } \\
\text { lógicas, e de setores utilizadores relevantes, } \\
\text { através do reforço do tecido empresarial } \\
\text { existente (no caso das tecnologias de produ- } \\
\text { ção e das TICE) ou da criação de novas em- } \\
\text { presas (sobretudo na área da nanotecnologia } \\
\text { e da produção de novos materiais). }\end{array}$ & 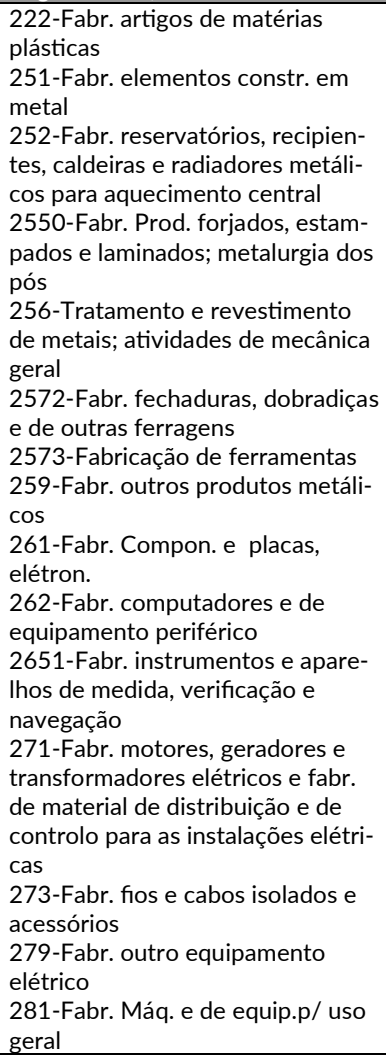 & 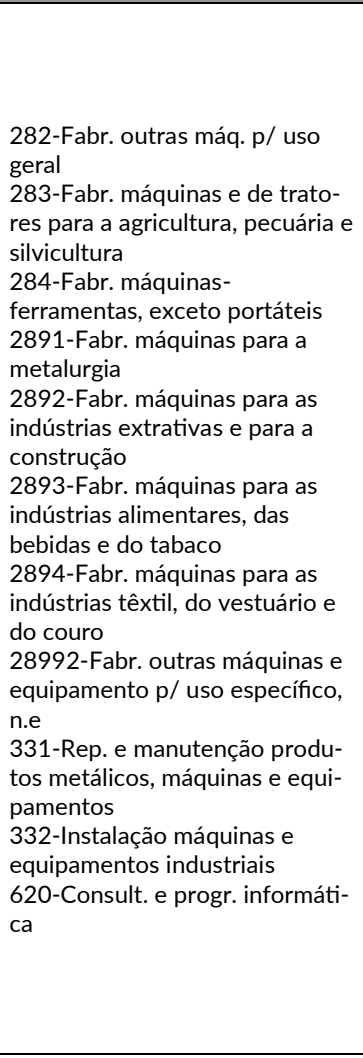 & $\begin{array}{l}\text { TIC, Indústria e } \\
\text { Serviços } \\
\text { Máquinas e Equipa- } \\
\text { mentos elétrico } \\
\text { Construção Metáli- } \\
\text { ca e Construção } \\
\text { Naval } \\
\text { Borracha e Plásticos } \\
\text { Máquinas de uso } \\
\text { geral e setorial } \\
\text { Produtos metálicos } \\
\text { e Mecânica ligeira } \\
\text { Fundição, Siderurgia } \\
\text { e Metalurgia }\end{array}$ \\
\hline
\end{tabular}

Fonte: Elaboração própria a partir do documento RIS3-Região Norte

\section{DOMÍNIOS DE ESPECIALIZAÇÃO INTELIGENTE: ANÁLISE À ESCALA DO CONCELHO DO PORTO}

\subsection{O Porto no contexto regional e nacional}

O concelho do Porto representa a área central de um ecossistema económico existente no Noroeste, uma das duas macrorregiões do país, que se distinguem pela capacidade de criação de valor e riqueza e pela concentração de emprego e atividades económicas.

Este dinamismo empresarial pode ser avaliado a partir do número de sociedades constituídas, que tem vindo a aumentar progressivamente desde 2009 até 2016 (à exceção de 2012) a nível regional e metropolitano (Gráfico 1). Em 2016, o concelho do Porto concentrava $28 \%$ do número de sociedades constituídas ${ }^{1}$ da $A M P$ e era o segundo concelho do país com maior número de constituições (5\% do total), a seguir ao concelho de Lisboa (16\%). Apesar do número de dissoluções ter aumento entre 2009 e 2016 no concelho do Porto, à semelhança da AMP e da Região Norte, os valores registados são inferiores aos nascimentos. O tecido económico do concelho demonstra capacidade de resiliência aos efeitos da crise, patente no progressivo aumento taxa de sobrevivência das empresas (um indicador que mede a proporção de empresas que sobreviviam dois anos após serem criadas). Assim, o Porto passou de uma taxa de sobrevivência de $50 \%$ em 2000 , para $58 \%$ em 2015 , enquanto o país passou de $49 \%$ para $61 \%$.

A evolução do valor acrescentado bruto demonstra os efeitos da crise económica. No período entre 2007 e 2012, o valor do VAB gerado no concelho do Porto registou uma forte quebra (-21\%), acima dos valores nacio-

\footnotetext{
${ }^{1}$ Constituição de Pessoas Coletivas e Entidades Equiparadas por Escritura Pública. Os valores apresentados incluem apenas a indústria, construção e serviços (secções $\mathrm{C}$ a O, exceto administração pública (secção L) da CAE Rev.2 e secções B a S, exceto administração pública (secção O) da CAE Rev.3. O INE disponibiliza os dados do número de nascimentos das empresas (pessoas singulares e coletivas), mas apenas à NUT 3.
} 
nais (-18\%) e regionais (-14\% na Região Norte e $-18 \%$ na AMP). A partir de 2012, a criação de riqueza aumentou e em 2016 o Porto era o concelho com maior capacidade de geração de riqueza na Área Metropolitana do Porto, representando $23 \%$ do valor total do VAB gerado. A nível nacional, o Porto era o terceiro concelho do país com maior riqueza criada, ultrapassado pelo concelho de Lisboa e Oeiras (Gráfico 2).

Entre o ano de 2007 e 2016, o valor das exportações de bens e produtos a nível nacional e regional evoluíram de forma positiva, registando uma quebra em 2009, em consequência dos efeitos de crise económicofinanceira (Gráfico 3). A partir desse ano verificou-se um aumento progressivo das exportações (acima dos 50\%). Apesar de ter registado uma variação positiva das suas exportações entre 2007 e 2016, as exportações do conceIho do Porto apresentam um comportamento diferenciado. Até 2012, as exportações geradas pela base económica do Porto cresceram 123\%, no entanto de 2013 a 2016, as exportações quase estgnaram (cresceram 0,7\%). Em 2016, o Porto só gerou $2 \%$ das exportações nacionais e $9 \%$ da área metropolitana, ficando atrás dos concelhos da Maia (13\%), de Vila Nova de Gaia (13\%) e de Santa Maria da Feira (11\%).

A disponibilidade e a qualificação do capital humano constituem recursos fundamentais para a competitividade dos territórios e para os processos de crescimento económico. Neste sentido, torna-se pertinente avaliar a capacidade de atratividade do concelho do Porto enquanto polo de emprego, de forma a garantir a existência de stocks e a renovação do seu mercado de trabalho.

O concelho do Porto apesar de ter registado uma diminuição do pessoal ao serviço entre 2007 e 2015 ($9 \%$ ), representava, em 2015, 22\% do pessoal ao serviço da AMP e 4\% a nível nacional. A análise das qualificações do capital humano, no concelho do Porto, revela um modelo de emprego cada vez mais qualificado, patente no aumento do pessoal ao serviço com ensino superior (entre 2007 e 2015, o aumento foi de 31\%), seguindo a tendência regional e nacional (sobe 33\% na AMP e 30\% em Portugal). Em 2015, um terço do pessoal ao serviço do Porto tinha ensino superior, o que representa 37\% do total da AMP e 7\% a nível nacional (apenas superado pelo concelho de Lisboa com $24 \%$ do pessoal ao serviço com ensino superior do total do país). O modelo de emprego do concelho carateriza-se por um forte peso do emprego público ( $21 \%$ do total de emprego do concelho, em 2015), concentrando 39\% do emprego público da área metropolitana e $19 \%$ da Região Norte.

Esta evolução da estrutura de emprego é também comprovada pela importância das profissões socialmente mais valorizadas ${ }^{2}$ no conjunto das profissões. Segundo os dados de 2011 do INE, a proporção de profissionais socialmente mais valorizados no concelho do Porto era de $40 \%$ (apenas superado pelo concelho de Lisboa com $42 \%)$, acima da média metropolitana e nacional, com $26 \%$ e $22 \%$, respetivamente.

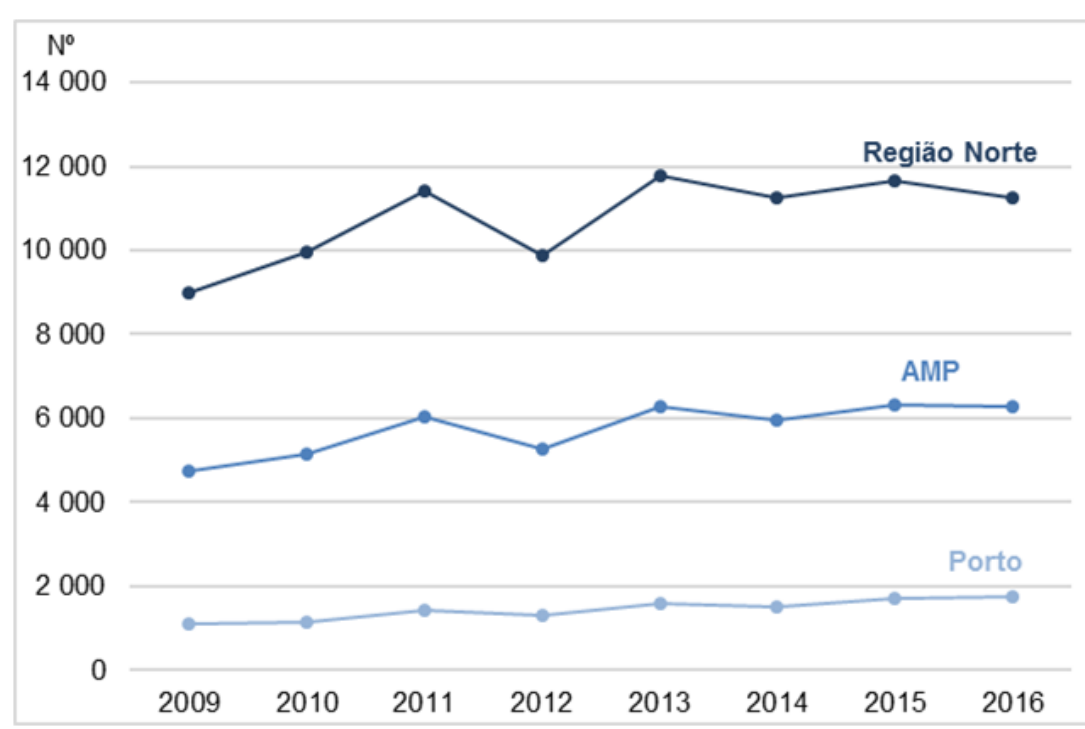

Gráfico 1 - Número de sociedades constituídas (2009-2016). Fonte: Elaboração própria; fonte de dados: PORDATA (2017).

\footnotetext{
${ }^{2}$ Indicador do INE que mede a importância das profissões mais valorizadas no conjunto das profissões (Classificação Nacional das Profissões, CNP). Incluem os representantes do poder legislativo e de órgãos executivos, dirigentes, diretores e gestores executivos (Grupo 1) e os especialistas das atividades intelectuais e científicas (Grupo 2).
} 


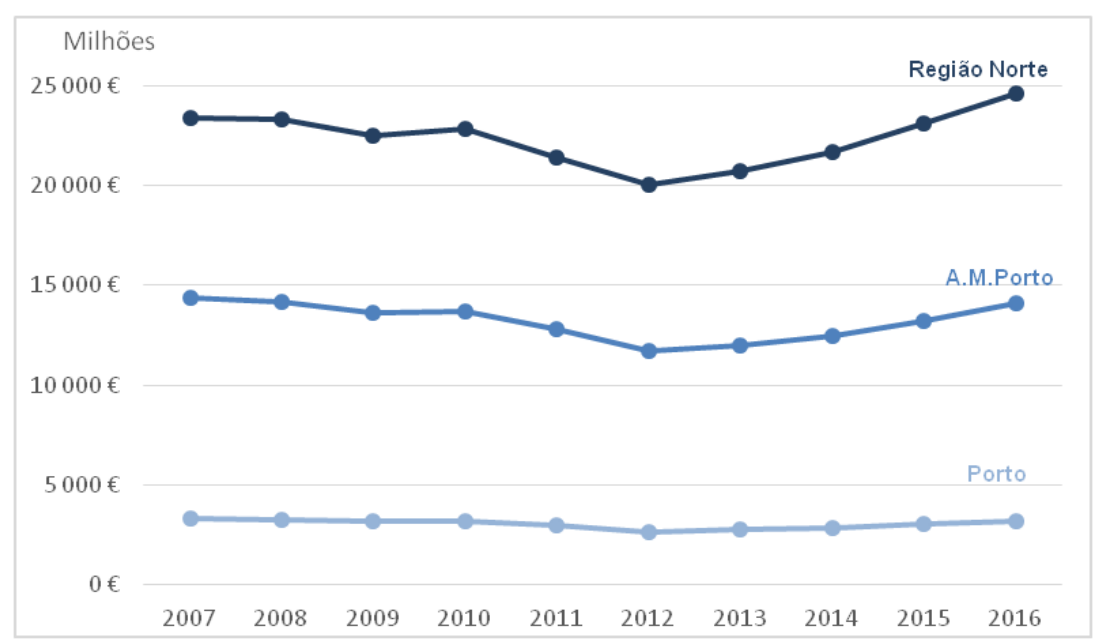

Gráfico 2 - Evolução do VAB (2007-2016). Fonte: Elaboração própria; fonte de dados: INE, Sistema de contas integradas das empresas (2016).

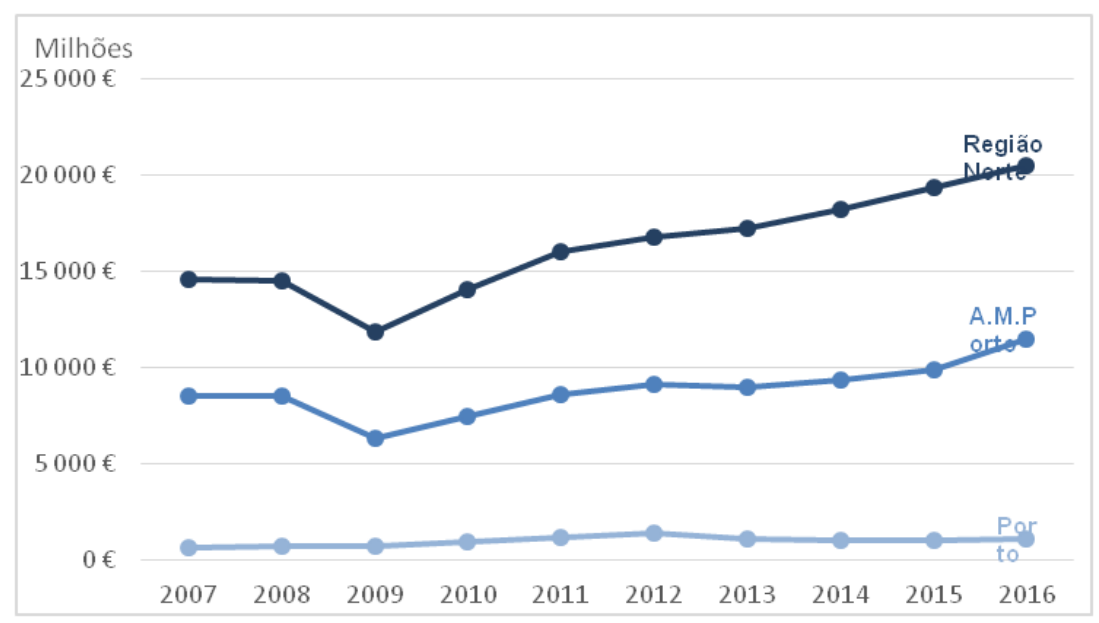

Gráfico 3 - Evolução das exportações de bens e produtos (2007-2015). Fonte: Elaboração própria; fonte de dados: INE, Estatísticas do Comércio Internacional de Bens (2015).

Quadro 2 - Pessoal ao Serviço e Emprego Público em 2015 e Pessoal ao Serviço com ensino superior (2007-2015).

\begin{tabular}{|l|l|l|}
\hline Âmbito Territorial & $\begin{array}{l}\text { Total Pessoal } \\
\text { ao Serviço } \\
2015\end{array}$ & $\begin{array}{l}\text { Total Em- } \\
\text { prego Públi- } \\
\text { co 2015 }\end{array}$ \\
\hline Portugal & 2771272 & 660686 \\
\hline Região Norte & 1002831 & 157770 \\
\hline AMP & 519452 & 80104 \\
\hline Porto & 116390 & 31061 \\
\hline \% Porto em PT & $4,2 \%$ & $4,7 \%$ \\
\hline \% Porto na R. Norte & $11,6 \%$ & $19,7 \%$ \\
\hline \% Porto na AMP & $22,4 \%$ & $38,8 \%$ \\
\hline
\end{tabular}

\begin{tabular}{|l|l|l|}
\hline $\begin{array}{l}\text { Taxa de Pessoal ao } \\
\text { Serviço com Ensino } \\
\text { Superior 2007 }\end{array}$ & $\begin{array}{l}\text { Taxa de Pessoal ao } \\
\text { Serviço com Ensino } \\
\text { Superior 2015 }\end{array}$ & $\begin{array}{l}\text { Variação relativa Pessoal } \\
\text { ao Serviço com Ensino } \\
\text { Superior 2007- } \\
2015\end{array}$ \\
\hline 12,90 & 19,18 & 30,1 \\
\hline 10,52 & 16,02 & 36,0 \\
\hline 13,19 & 19,59 & 33,2 \\
\hline 22,25 & 32,14 & 31,1 \\
\hline
\end{tabular}

Fonte: Elaboração própria; fonte de dados: GEP-MTSSS (2017); DGAEP (2016). 
Mudando de escala, em termos territoriais, verifica-se uma elevada concentração de estabelecimentos nas áreas mais consolidadas da cidade, isto é, na Baixa alargada, bem como na área da Boavista, ao longo de toda a Avenida da Boavista (nomeadamente em torno da Praça de Mouzinho de Albuquerque) (Figura 1). Por freguesias, destaca-se a União de Freguesias de Cedofeita, Santo Ildefonso, Sé, Miragaia, São Nicolau e Vitória, que representa 34\% do total de estabelecimentos da cidade. Seguindo-se Paranhos, Ramalde e a União de Freguesias de Lordelo do Ouro e Massarelos, embora com um peso percentual significativamente inferior (entre 13 a $15 \%$ por freguesia). Na situação mais desfavorável encontra-se a freguesia de Campanhã (6\% do total de estabelecimentos).

A estrutura empresarial do concelho, de acordo com a dimensão das empresas por número de trabalhadores, é dominada pelas empresas com menos de 10 empregados, que representam $68 \%$ do total de empresas com sede no Porto. O peso das pequenas e médias empresas (entre 10 e 250 trabalhadores) no tecido económico é muito inferior, abrangendo apenas $7 \%$ das empresas sediadas no concelho. É ainda de referir que $25 \%$ das empresas não têm ou não declararam empregados.

A concentração de pessoas empregadas acompanha, em termos gerais, a tendência espacial da localização dos estabelecimentos, sendo mais elevada na área central da cidade. Verifica-se pontualmente valores elevados de densidade, nomeadamente em Campanhã onde se localiza a Mota Engil com um número elevado de empregados, em Paranhos com o emprego do Hospital de S. João e do IPO, bem como pelo emprego concentrado em várias empresas na Zona Industrial de Ramalde (Figura 2). Por freguesias, a União de Freguesias de Cedofeita, Santo Ildefonso, Sé, Miragaia, São Nicolau e Vitória representava cerca de 35\% do total de pessoas empregadas no concelho. Seguia-se a freguesia de Paranhos (18\% do total do concelho) e as freguesias de Campanhã, do Bonfim e da União de Freguesias de Aldoar, Foz do Douro e Nevogilde registam o menor peso percentual de empregados (entre 7 a $9 \%$ por freguesia).

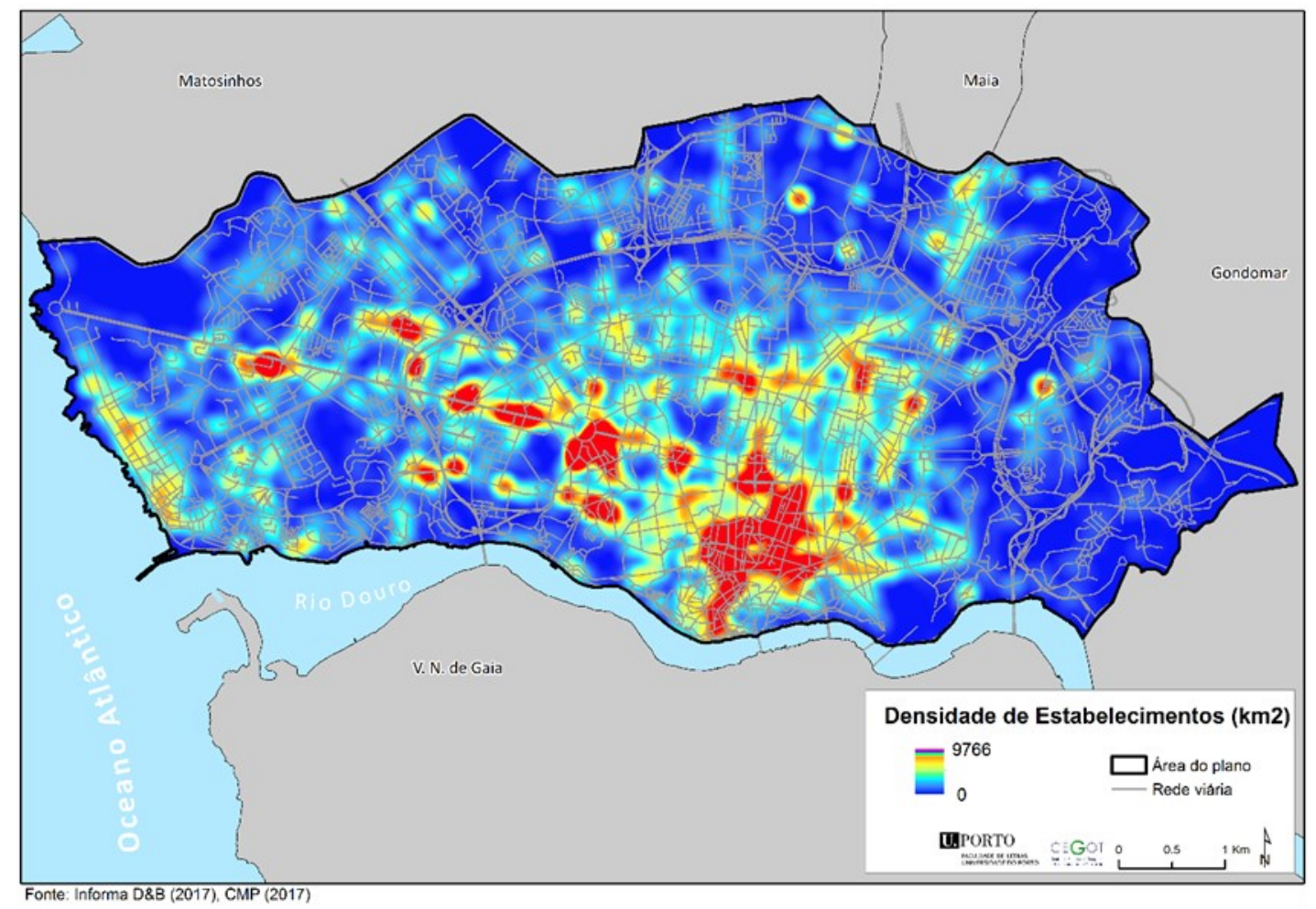

Figura 1 - Densidade de estabelecimentos no concelho do Porto. Fonte: Elaboração própria; fonte de dados: Informa $D \& B(2017)$. 


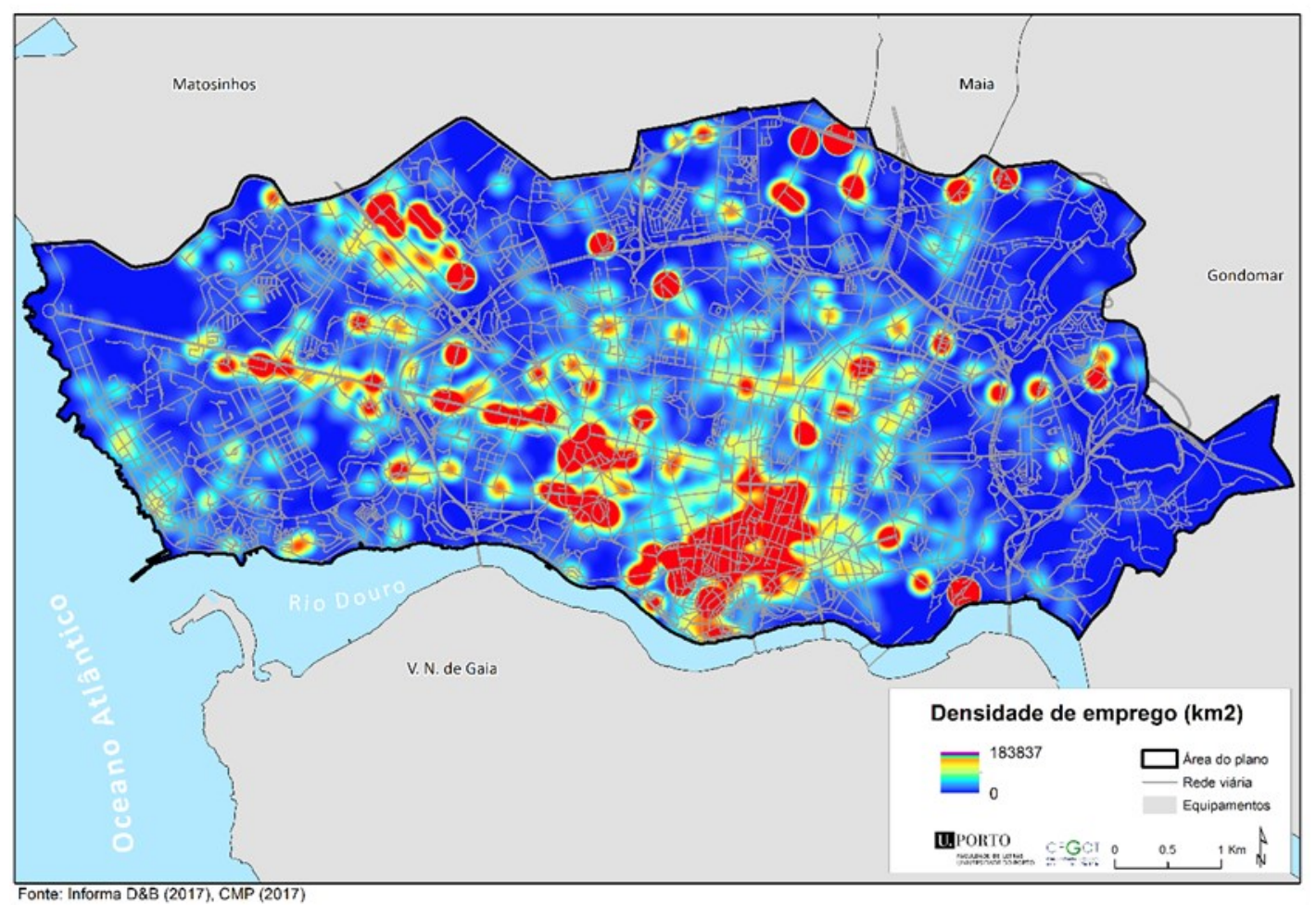

Figura 2 - Densidade de emprego no concelho do Porto. Fonte: Elaboração própria; fonte de dados: Informa D\&B (2017).

\subsection{Os domínios de especialização inteligente: identificação das atividades e distribuição espacial.}

Todos os domínios de especialização inteligente identificados no documento estratégico Norte 2020 (CCDRN, 2014) estão presentes no território da cidade do Porto. Estes correspondem a mais de um terço das empresas sediadas $(37,8 \%)$ e/ou com estabelecimento $(38,7 \%)$ no concelho do Porto. Representam $41,3 \%$ do emprego. O volume de vendas corresponde a 31,7\% do total do concelho. Por si só, os domínios de especialização inteligente são responsáveis por $43,8 \%$ do total das exportações com origem na cidade do Porto e por quase metade da riqueza (VAB) produzida no concelho do Porto $(47,81 \%)$.

Estes indicadores colocam desde já um problema: mais de $60 \%$ das empresas e dos estabelecimentos, mais de $50 \%$ do emprego, mais de $60 \%$ do volume de vendas, mais de $50 \%$ das exportações e da riqueza (VAB) da cidade do Porto não está contemplada nas atividades identificadas como pertencentes aos domínios de especialização inteligente definidos pelo documento Norte 2020 (RIS3). Todas essas atividades económicas, com um peso tão significativo na atividade económica da cidade, ficam excluídas das políticas de aplicação dos fundos comunitários? Será esta uma evidência da dificuldade de encaixar a estratégia de especialização inteligente na realidade que emana do território concreto?

Numa análise mais detalhada, constata-se que nem todos os oito domínios de especialização inteligente definidos pela estratégia Norte 2020 têm importância local. Existem três domínios de especialização inteligente que se constituem como grupo dominante. Esses domínios são:

- O domínio das Ciências da Vida e Saúde, que totaliza 19,4\% das sedes de empresas e 19,1\% dos estabelecimentos integrados na RIS3 e localizados no Porto, gerando uma fatia de 36,3\% do emprego nas atividades RIS3 do concelho e contribuindo com 42,7\% do volume de vendas, 9,7\% do volume de exportações e 40,5\% do VAB produzido pelo total das atividades RIS3 localizadas no Porto.

- O domínio do Capital Simbólico, Tecnologias e Serviços do Turismo, que totaliza 30,3\% das sedes de empresas e $29,2 \%$ dos estabelecimentos integrados na RIS3 e localizados no Porto, gerando uma fatia de $23,5 \%$ do emprego nas atividades RIS3 do concelho e contribuindo com $21 \%$ do volume de vendas, $26,8 \%$ do volume de exportações e 17,6\% do VAB produzido pelo total das atividades RIS3 localizadas no Porto.

- O domínio do Capital Humano e Serviços Especializados, que totaliza 35,6\% das sedes de empresas e $34,7 \%$ dos estabelecimentos enquadrados na RIS3 localizados no Porto, gerando uma fatia de $23,3 \%$ do emprego 
Quadro 3 - Empresas com sede no Porto, Exportações e VAB por domínios de especialização inteligente da RIS3 no concelho do Porto

\begin{tabular}{|c|c|c|c|c|c|c|c|c|c|}
\hline $\begin{array}{l}\text { Domínios da Especialização } \\
\text { Inteligente }\end{array}$ & $\begin{array}{l}N^{\circ} \text { Empre- } \\
\text { sas com } \\
\text { sede no } \\
\text { Porto }\end{array}$ & $\begin{array}{l}\text { \% Empre- } \\
\text { sas Sede } \\
\text { no total } \\
\text { RIS3 }\end{array}$ & $\begin{array}{l}\% \text { Empresas } \\
\text { Sede no } \\
\text { total do } \\
\text { Porto }\end{array}$ & $\begin{array}{l}\text { Total Exporta- } \\
\text { çốes }(€)\end{array}$ & $\begin{array}{l}\text { \% Exporta- } \\
\text { ções no } \\
\text { total RIS3 }\end{array}$ & $\begin{array}{l}\text { \% Exporta- } \\
\text { ções no } \\
\text { total do } \\
\text { Porto }\end{array}$ & Total VAB $(€)$ & $\begin{array}{l}\% \text { VAB } \\
\text { no total } \\
\text { RIS3 }\end{array}$ & $\begin{array}{l}\% \text { VAB } \\
\text { no total } \\
\text { do Porto }\end{array}$ \\
\hline $\begin{array}{l}\text { Capital Humano e Serviços } \\
\text { Especializados }\end{array}$ & 3632 & 35,56 & 13,44 & $147664172 €$ & 24,34 & 10,66 & $301312146 €$ & 23,92 & 11,44 \\
\hline $\begin{array}{l}\text { Capital Simbólico, Tecnologias } \\
\text { e Serviços do Turismo }\end{array}$ & 3099 & 30,34 & 11,47 & $162587869 €$ & 26,80 & 11,73 & $221982380 €$ & 17,63 & 8,43 \\
\hline Ciências da Vida e Saúde & 1983 & 19,41 & 7,34 & $58820933 €$ & 9,70 & 4,24 & $510441095 €$ & 40,53 & 19,38 \\
\hline Cultura, Criação e Moda & 1013 & 9,92 & 3,75 & $68107344 €$ & 11,23 & 4,91 & $116863630 €$ & 9,28 & 4,44 \\
\hline $\begin{array}{l}\text { Sistemas Avançados de Produ- } \\
\text { ção }\end{array}$ & 677 & 6,63 & 2,51 & $104454737 €$ & 17,22 & 7,54 & $139427810 €$ & 11,07 & 5,29 \\
\hline $\begin{array}{l}\text { Sistemas Agroambientais e } \\
\text { Alimentação }\end{array}$ & 458 & 4,48 & 1,69 & $143487973 €$ & 23,65 & 10,35 & $104450207 €$ & 8,29 & 3,97 \\
\hline Recursos do Mar e Economia & 193 & 1,89 & 0,71 & $4413389 €$ & 0,73 & 0,32 & $10365151 €$ & 0,82 & 0,39 \\
\hline $\begin{array}{l}\text { Indústrias da Mobilidade e } \\
\text { Ambiente }\end{array}$ & 62 & 0,61 & 0,23 & $3877032 €$ & 0,64 & 0,28 & $6601867 €$ & 0,52 & 0,25 \\
\hline Total Domínios RIS3 Porto(*) & 10215 & & & $606620936 €$ & & & $\begin{array}{l}1259434089 \\
€\end{array}$ & & \\
\hline Total Concelho Porto & 27023 & & & $\begin{array}{l}1385759900 \\
€\end{array}$ & & & $\begin{array}{l}2634105639 \\
€\end{array}$ & & \\
\hline $\begin{array}{l}\text { Peso dos Domínios da RIS3 no } \\
\text { total do concelho }\end{array}$ & 37,80 & & & 43,78 & & & 47,81 & & \\
\hline
\end{tabular}

$\left({ }^{*}\right)$ - Existem CAE que se repetem nos diferentes domínios da RIS3, pelo que o total não é o somatório dos oito domínios. O Total corresponde à soma das CAE incluídas nas RIS3

Fonte: Elaboração própria; fonte de dados: Informa D\&B (2017).

Quadro 4 - Empregados, Estabelecimentos e Volume de Negócios por domínios de especialização inteligente da RIS3 no concelho do Porto.

\begin{tabular}{|c|c|c|c|c|c|c|c|c|c|}
\hline Tipologia & $\begin{array}{l}\mathrm{N}^{\circ} \\
\text { Empre- } \\
\text { gados }\end{array}$ & $\begin{array}{l}\text { \% Em- } \\
\text { preg. no } \\
\text { total da } \\
\text { RIS3 } \\
\end{array}$ & $\begin{array}{l}\text { \% Empreg. } \\
\text { no total } \\
\text { do Porto }\end{array}$ & $\begin{array}{l}N^{\circ} \text { Esta- } \\
\text { bele- } \\
\text { cimentos }\end{array}$ & $\begin{array}{l}\% \text { Estabe- } \\
\text { lec. no } \\
\text { total da } \\
\text { RIS3 } \\
\end{array}$ & \begin{tabular}{|l|}
$\%$ Estabe- \\
lec. no \\
total do \\
Porto \\
\end{tabular} & $\begin{array}{l}\text { Volume de Ven- } \\
\text { das }(€)\end{array}$ & $\begin{array}{l}\text { \% Volume } \\
\text { de Vendas } \\
\text { no total da } \\
\text { RIS3 } \\
\end{array}$ & $\begin{array}{l}\text { \% Volume } \\
\text { de Vendas } \\
\text { no total do } \\
\text { Porto } \\
\end{array}$ \\
\hline Capital Humano e Serv. Especializados & 13481 & 23,26 & 9,41 & 3811 & 34,70 & 13,43 & $616227833 €$ & 17,31 & 5,53 \\
\hline $\begin{array}{l}\text { Capital Simbólico, Tecnologias e Servi- } \\
\text { ços do Turismo }\end{array}$ & 13632 & 23,52 & 9,51 & 3212 & 29,24 & 11,32 & $749767942 €$ & 21,06 & 6,73 \\
\hline Ciências da Vida e Saúde & 21035 & 36,29 & 14,68 & 2096 & 19,08 & 7,39 & $1519894664 €$ & 42,68 & 13,64 \\
\hline Cultura, Criação e Moda & 7275 & 12,55 & 5,08 & 1506 & 13,71 & 5,31 & $385406626 €$ & 10,82 & 3,46 \\
\hline Sistemas Avançados de Produção & 5517 & 9,52 & 3,85 & 712 & 6,48 & 2,51 & $352062777 €$ & 9,89 & 3,16 \\
\hline $\begin{array}{l}\text { Sistemas Agroambientais e Alimenta- } \\
\text { ção }\end{array}$ & 2285 & 3,94 & 1,59 & 485 & 4,42 & 1,71 & $156132332 €$ & 4,38 & 1,40 \\
\hline Recursos do Mar e Economia & 806 & 1,39 & 0,56 & 205 & 1,87 & 0,72 & $66703732 €$ & 1,87 & 0,60 \\
\hline Indústrias da Mobilidade e Ambiente & 460 & 0,79 & 0,32 & 68 & 0,62 & 0,24 & $35458862 €$ & 1,00 & 0,32 \\
\hline Total Domínios RIS3 Porto (*) & 57958 & & & 10984 & & & $3560836064 €$ & & \\
\hline Total Concelho Porto & 143316 & & & 28380 & & & $11139170702 €$ & & \\
\hline $\begin{array}{l}\text { Peso dos Domínios da RIS3 no total } \\
\text { do concelho }\end{array}$ & 40,44 & & & 38,70 & & & 31,97 & & \\
\hline
\end{tabular}

Fonte: Elaboração própria; fonte de dados: Informa D\&B (2017).

nas atividades RIS3 do concelho e contribuindo com 17,3\% do volume de vendas, $24,3 \%$ do volume de exportações e $23,9 \%$ do VAB produzido pelo total das atividades RIS3 localizadas no Porto.

Segue-se um grupo de mais três domínios, cujo peso na totalidade das atividades enquadradas na RIS3 localizadas no Porto é significativo em alguns dos indicadores analisados:

- O domínio da Cultura, Criação e Moda que totaliza 9,9\% das sedes de empresas e 13,7\% dos estabelecimentos integrados na RIS3 localizados no Porto, gerando uma fatia de $12,5 \%$ do emprego nas atividades RIS3 do concelho e contribuindo com $10,8 \%$ do volume de vendas, $11,3 \%$ do volume de exportações e $9,3 \%$ do VAB produzido pelo total das atividades RIS3 localizadas nesta cidade. 
- O domínio dos Sistemas Avançados de Produção que totaliza 6,6\% das sedes de empresas e 6,5\% dos estabelecimentos integrados na RIS3 localizados no Porto, gerando uma fatia de 9,5\% do emprego nas atividades RIS3 do concelho e contribuindo com 9,9\% do volume de vendas, 17,2\% do volume de exportações e 11,1\% do VAB produzido pelo total das atividades RIS3 localizadas nesta cidade.

- O domínio dos Sistemas Agroambientais e Alimentação, que totaliza 4,5\% das sedes de empresas e 4,4\% dos estabelecimentos integrados na RIS3 localizados no Porto, gerando uma fatia de 3,9\% do emprego nas atividades RIS3 do concelho e contribuindo com $4,4 \%$ do volume de vendas, $23,7 \%$ do volume de exportações e $8,3 \%$ do VAB produzido pelo total das atividades RIS3 localizadas nesta cidade.

Por último, observa-se um grupo composto por dois domínios cujo peso na totalidade das atividades enquadradas na RIS3 localizadas no Porto é muito residual: o domínio dos Recursos do Mar e Economia, que totaliza 1,9\% das sedes de empresas e 1,9\% dos estabelecimentos integrados na RIS3; o domínio das Indústrias da Mobilidade e Ambiente, que totaliza $0,6 \%$ das sedes de empresas e $0,6 \%$ dos estabelecimentos integrados na RIS3.

Em termos territoriais (figura 3), os estabelecimentos dos domínios de especialização inteligente exibem um padrão mais concentrado na Baixa e no Centro Histórico, estendendo-se até à rotunda da Boavista, e prolongando-se até sensivelmente metade da Avenida da Boavista. Paralela à Avenida da Boavista emerge uma concentração linear, estruturada pela Avenida do Bessa. Na Asprela, emergem três polos aglutinados em torno do Hospital de S. João, IPO e UPTEC. Na parte oriental da cidade, correspondente a grande parte da freguesia de Campanhã, observa-se uma redução significativa da densidade de estabelecimentos face ao padrão de distribuição caraterístico da cidade do Porto.

A figura 4 mostra a distribuição territorial dos estabelecimentos por domínio de especialização inteligente, revelando um padrão cuja localização e densidade é variável.

Em síntese, por um lado, os domínios de especialização inteligente representam uma fatia significativa do tecido empresarial localizado na cidade do Porto, assim como do emprego, vendas, exportação e da riqueza aí produzida. Por outro lado, o Porto mostra um perfil que privilegia alguns dos domínios da RIS3.

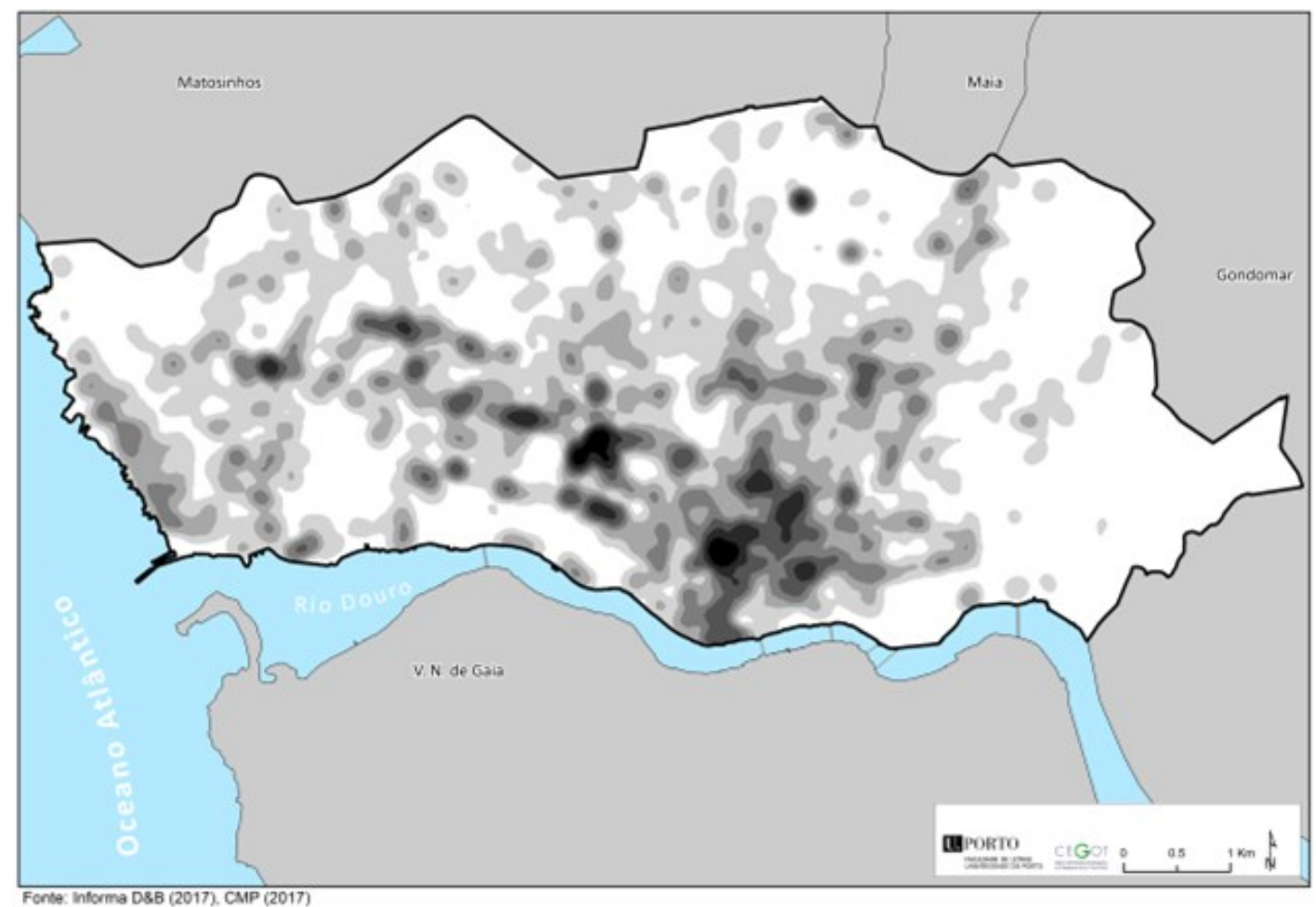

Figura 3 - Densidade e Modelo de distribuição de estabelecimentos do concelho do Porto enquadrados nos domínios da especialização inteligente. Fonte: Elaboração própria; fonte de dados: Informa D\&B (2017). 
Ciências da Vida e Saúde

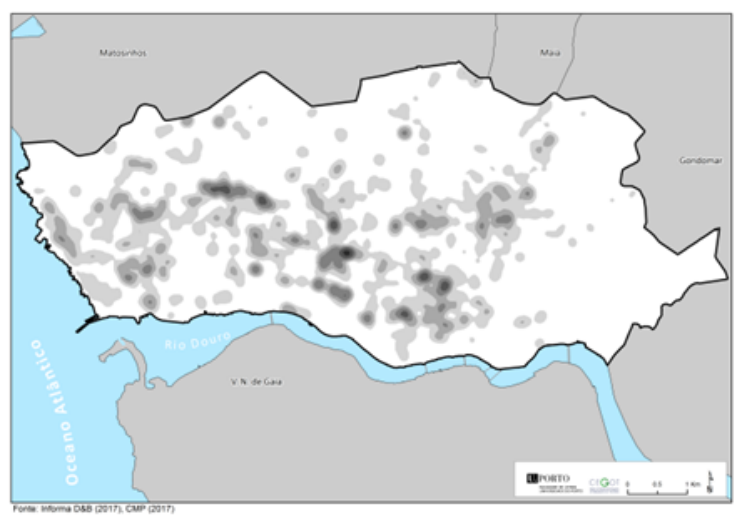

Capital Humano e Serviços Especializado

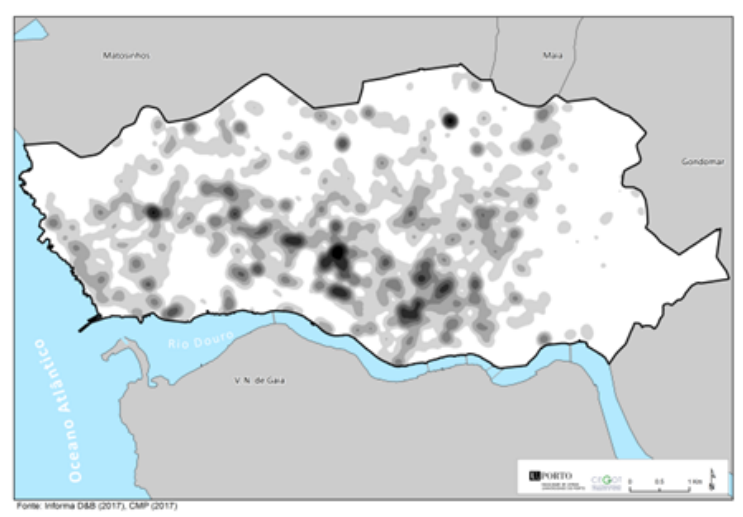

Sistemas Avançados de Produção

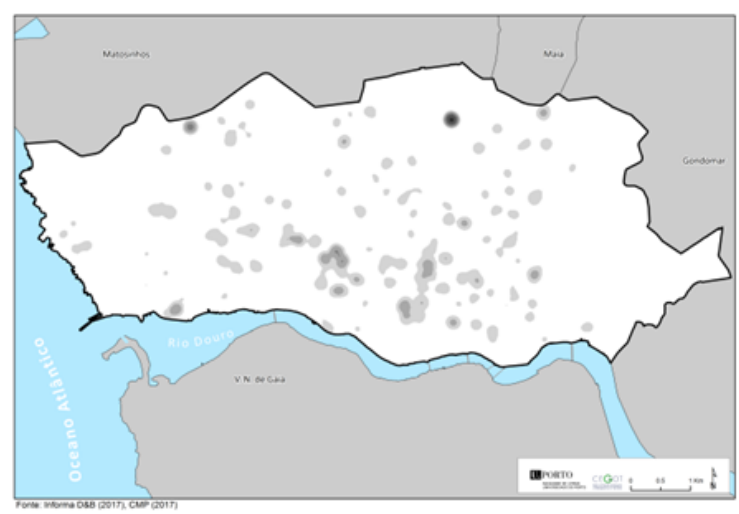

Capital Simbólico, Tecnologias e Serviços do Turismo

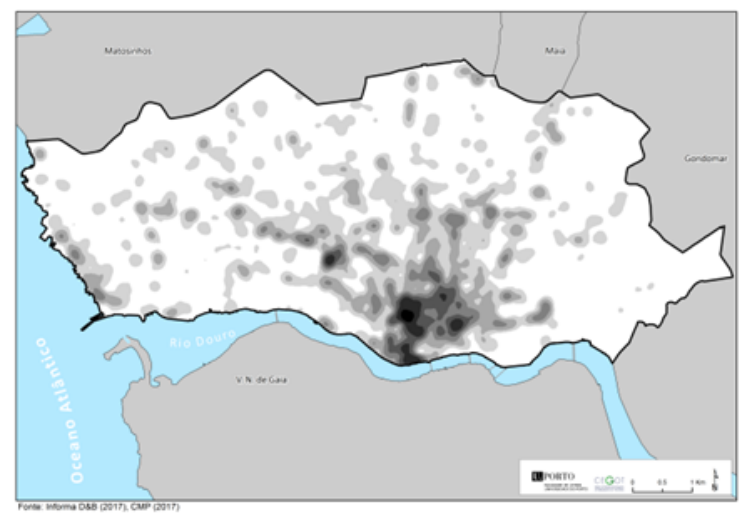

Cultura, Criação e Moda

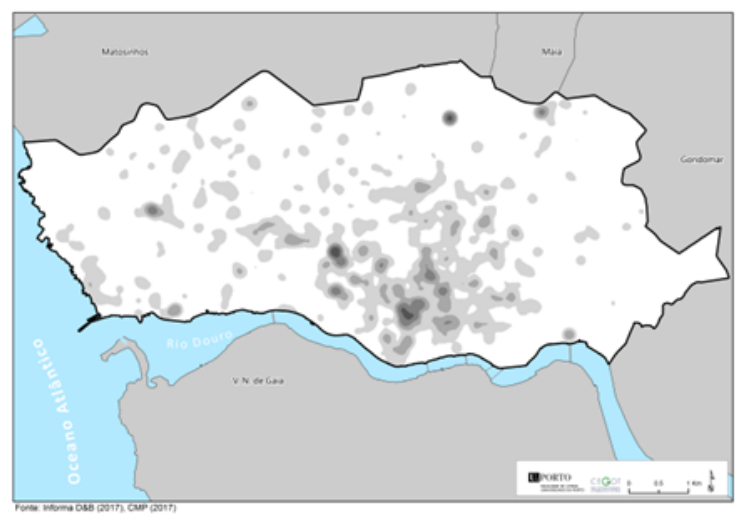

Sistemas Agroambientais e Alimentação

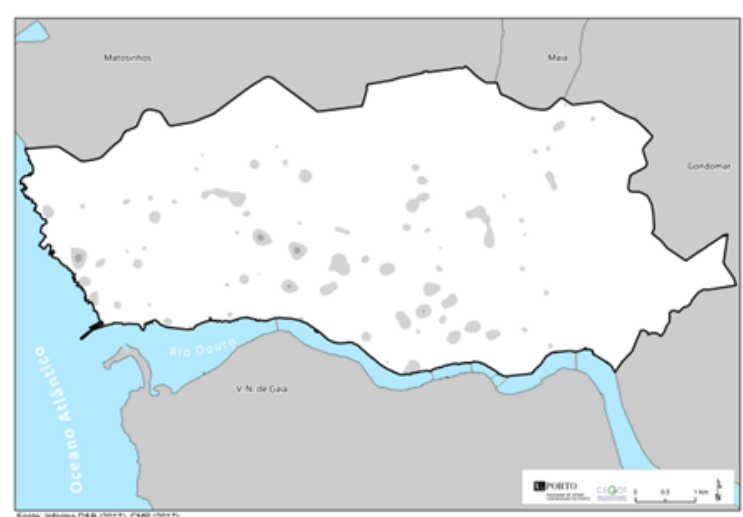

Figura 4 - Densidade e Modelo de distribuição dos estabelecimentos do concelho do Porto enquadrados nos diferentes domínios da especialização inteligente.

\section{CONCLUSÃO}

O diagnóstico elaborado no âmbito do PDM, com base nos domínios de especialização inteligente, permitiu fazer uma reflexão estratégica local, com possíveis implicações em matéria de ordenamento do território:

a) A localização no Porto de um tecido económico direcionado para os domínios de especialização inteligente identificados no documento estratégico Norte 2020, atesta a presença de um amplo leque de competências estratégicas instaladas na cidade. Tal significa que existem recursos que potenciam os processos de fertiliza- 
ção cruzada de conhecimento, com potencial inovador. A criação de ecossistemas favoráveis ao empreendedorismo e inovação que facilitem a polinização cruzada e a troca de conhecimento é uma via para dinamizar a vitalidade económica da cidade. O PDM deve prever a possibilidade de instalação de infraestruturas tecnológicas, de incubação, e de serviços e equipamentos partilhados, e de empresas pertencentes aos domínios de especialização já presentes no concelho. Deve ainda afetar usos de solo dirigidos à instalação de indústrias e serviços, intensivos em conhecimento e fomentar a permanência destas atividades económicas no concelho, ao longo do seu ciclo de vida, criando, para tal, tipologias de uso de solo que possibilitem o crescimento das instalações industriais no concelho.

b) A cidade é ela mesma um ecossistema que pode favorecer a criação de redes locais e a criação de ambiente vibrantes favoráveis à produção económica. A análise dos padrões de distribuição destas atividades económicas revela a tendência para a concentração na Baixa, Rotunda da Boavista e envolvente, Avenida da Boavista e Asprela. A colocalização nestes hot-spots pode favorecer a criação de redes interpessoais e interorganizacionais, incrementando os processos de buzz urbano, a troca de conhecimento e a emergência de processos de inovação e produção económica, pelo que a estratégia de ordenamento do território deve favorecer a instalação de novas atividades ligadas aos diferentes perfis de especialização inteligente.

c) Apesar da abrangência das capacidades e competências económicas instaladas na cidade, a análise efetuada revela que existem três domínios de especialização inteligente mais fortes (Ciências da Vida e Saúde; Capital Simbólico, Tecnologias e Serviços do Turismo; e Capital Humano e Serviços Especializados). Estas são atividades intensivas em conhecimento (analítico, sintético e simbólico), que se sustentam em capital humano com competências altamente especializadas, normalmente bem remuneradas. Estes são trabalhadores do conhecimento e classes criativas com expetativas de qualidade de vida e bem-estar que apontam para padrões médio -altos e altos. As políticas urbanas que favoreçam a atração e fixação (para residir e trabalhar) deste capital na cidade (política de uso do solo, de habitação, de qualificação do espaço público ou as amenidades urbanas e outras externalidades positivas) contribuem para aumentar a dinâmica económica da cidade. Deve ainda apostar em ações de marketing territorial dirigidas à captação de empresas e serviços intensivos em conhecimento e baseados em capital humano qualificado, para reforçar a atratividade nacional e internacional do concelho para os serviços intensivos em conhecimento.

Mas esta experiência também permitiu constatar que uma estratégia de desenvolvimento e ordenamento do território só dirigida às empresas de especialização inteligente iria excluir uma fatia muito significativa das atividades económicas da cidade (mais de $60 \%$ das empresas e estabelecimentos, do emprego, do volume de vendas, das exportações e da riqueza da cidade). Esta observação reforça também a necessidade de se refletir sobre as políticas económicas de base territorial para outros sectores, pois a estratégia de especialização inteligente nem sempre se encaixa na diversidade de atividades económicas existentes, justificando a necessidade de um maior enfoque no território. O risco de exclusão de uma fatia tão significativa de atividades económicas da estratégia de especialização inteligente deve ser acautelado.

\section{BIBLIOGRAFIA}

BALLAND, P.-A., BOSCHMA, R., CRESPO, J., \& RIGBY, D. L. (2018). Smart specialization policy in the European Union: relatedness, knowledge complexity and regional diversification. Regional Studies .

BARCA, F., MCCANN, P., \& RODRÍGUEZ POSE, A. (2012). The Case for Regional Development Intervention: Place-Based Versus Place-Neutral Approaches. Journal of Regional Science, 52 (1), 134-152.

BEAVERSTOCK, J. V.; FAULCONBRIDGE, J. R.; HOYLER, M. (2011). Globalization and the City. In Leyshon, A.; Roger, L.; McDowell, L.; Sunley, P. (Eds.).The SAGE Handbook of Economic Geography. SAGE Publications Ltd., 189-201.

BOSCHMA, R. (2010). The Aims and Scope of Evolutionary Economic Geography. In Boschma, R; Martin, R. (Eds.).The Handbook of Evolutionary Economic Geography. Edward Elgar, 5-39.

CAPELLO, R., \& KROLL, H. (2016). From theory to practice in smart specialization strategy: emerging limits and possible future trajectories. European Planning Studies , 24 (8), 1393-1406.

CE (Março 2014). Política de Coesão 2014-2020: Desenvolvimento Urbano Sustentável Integrado. (978-92-79-37138-7). Disponível em: http://ec.europa.eu/regional_policy/sources/docgener/informat/2014/urban_pt.pdf.

DGT. (2018). PNPOT - Alteração: Diagnóstico (versão para discussão pública). Lisboa: DGT.

ESPON (15/12/2010). FOCI: Future Orientations for Clties. Applied Research 2013/1/1. Final Report | Version 15/ 
December/2010. Disponível em: http://www.espon.eu/export/sites/default/ Documents/Projects/AppliedResearch/ FOCl/FOCI_final_report_20110111.pdf.

EUROPEAN-COMMISSION. (2017, novembro 24). SMART SPECIALISATION PLATFORM. Retrieved maio 2, 2018, from http://s3platform.jrc.ec.europa.eu/

GULC, A. (2015). Analysis of Methodological Approach to Identify Smart Specialization on the Example of Polish Regions. Procedia - Social and Behavioral Sciences , 213, 817-823.

IAPMEI; FCT; ANI; COMPETE. (2014). Estratégia de linvestigação e Inovação para uma Especialização Inteligente 2014-2020. Lisboa: IAPMEI; FCT; ANI; COMPETE.

KEMPTON, L. (2015). Delivering smart specialization in peripheral regions: the role of Universities. Regional Studies, Regional Science , 2 (1), 489-496.

LEI N. ${ }^{\circ}$ 31/2014 , de 30 de maio. Diário da República : N. ${ }^{\circ}$ 104/2014, Série I (2014). Acedido a 02 mai. 2018. Disponível em www.dre.pt.

MARQUES, T. (2004). Portugal na transição do século: retratos e dinâmicas territoriais. Porto: Edições Afrontamento.

MARQUES, T. S., \& QUEIRÓS, J. P. (2017). AMP 2020 Crescimento Inteligente. Casal de Cambra: Caleidoscópio.

MARQUES, T. S., SANTOS, H., \& RIBEIRO, P. (2016). Especialização Inteligente: as complementaridades relacionais da inovação ancorada nas macrorregiões de Lisboa e do Porto. XV Coloquio Ibérico de Geografía.Retos y tendencias de la Geografía Ibérica (pp. 1210-1221). Murcia: Universidad de Murcia-AGE-APG.

MARQUES, T., \& SANTOS, H. (2013). Lugares e redes de inovação na área metropolitana do Porto. Geografia: Revista da Faculdade de Letras da Universidade do Porto , 2 (III), 203-225.

MAXIMILIAN, B., BIERINGER, L., KNAUPP, M., WITTEMAIER, J., \& WRUCK, A. (2016). Towards a Smart Specialization Strategy for Haifa, Israel. Munich Personal RePEc Archive - Heidelberg University , 1-63.

MCCANN, P., \& ORTEGA-ARGILÉS, R. (2013). Smart Specialization, Regional Growth and Applications to European Union Cohesion Policy. Regional Studies , 49 (8), 1291-1302.

MENDES, J. F. G. (2011). O Futuro das Cidades. Coimbra: Edições Minerva.

NALDI, L., NILSSON, P., WESTLUND, H., \& WIXE, S. (2015). What is smart rural development? Journal of Rural Studies , 40, 90 $-101$.

NIJKAMP, P.; KOURTIT, K. (2013). The "New Urban Europe": Global Challenges and Local Responses in the Urban Century. European Planning Studies, 21(3), 291-315. doi:10.1080/09654313.2012.716243.

NOVOSÁK, J., HÁJEK, O., ZAHRADNÍK, P., \& NEKOLOVÁ, J. (2013). On Some Aspects of Territorial Competitiveness: Smart Specialization in the Zlín 2020 Strategy. Journal of Competitiveness , 5 (3), 3-13.

RIBEIRO, J. M., \& FERRÃO, J. (. (2014). Noroeste Global. Lisboa: Fundação Calouste Gulbenkian.

RIBEIRO, J. M., MOURA, F., \& CHORINCAS, J. (2015). Uma Metrópole para o Atlântico. Lisboa: Fundação Calouste Gulbenkian.

SANDU, S. (2012). Smart specialization concept and the status of its implementation in Romania. Procedia Economics and Finance , 3, 236-242.

SANTOS, H., \& MARQUES, T. S. (2013). Lugares e redes de conhecimento na área metropolitana do Porto. Geografia: Revista da Faculdade de Letras da Universidade do Porto , 2 (III), 179-202. 
Página intencionalmente dejada en blanco 


\title{
A especialização inteligente na área central da cidade do Porto: domínios, ação pública e desafios
}

\author{
C. Ferreira (a), T. S. Marques (b), P. Guerra (c) \\ (a) CEGOT/Faculdade de Letras da Universidade do Porto, celiamarisaferreira@gmail.com \\ (b) CEGOT/Faculdade de Letras da Universidade do Porto, teresasamarques@gmail.com \\ (c) CEGOT / Faculdade de Letras da Universidade do Porto; IS -UP / Instituto de Sociologia / Universidade do Porto; Griffith Centre for Cultural \\ Research / Griffith University / Australia, mariadeguerra@gmail.com
}

\begin{abstract}
Resumen
A Comissão Europeia tem vindo a promover as estratégias de especialização inteligente como forma de cada país e, sobretudo, de cada região identificar áreas de investimento prioritárias, potenciando os seus principais ativos e tornando-os em vantagens competitivas face a outros territórios. A geografia da especialização inteligente regional reflete matizes resultantes da sua implementação à escala local. A estratégia de especialização inteligente da Região Norte de Portugal encontra-se patente nas abordagens de política pública do Município do Porto. Tendo como objeto de análise a área central da cidade do Porto, esta comunicação visa identificar e caracterizar os domínios de especialização inteligente mais evidenciados, bem como perceber as dinâmicas recentes e o papel da ação pública. Para o efeito, recorreu-se a uma abordagem predominantemente qualitativa, com recurso à análise de conteúdo de documentos estratégicos e à realização de entrevistas semi-diretivas a agentes locais dos diversos setores culturais, criativos e lúdicos.
\end{abstract}

Palavras chave: Baixa do Porto, Especialização inteligente, Política pública, Dinâmicas económicas.

\section{INTRODUÇÃO}

As estratégias de especialização inteligente foram promovidas pela Comissão Europeia no âmbito do processo de implementação da Estratégia Europa 2020. E, neste contexto, é seu objetivo potenciar as características e os ativos específicos de cada país e região, tornando-os em potencialidades competitivas face a outros territórios. A Estratégia Europa 2020 pressupõe a sua implementação a diferentes escalas, desde a europeia até à escala local, atribuindo particular importância à implementação regional. A necessidade de uma maior eficácia das políticas promotoras da inovação e competitividade e o reconhecimento de que one size does not fit all estão na origem da promoção de estratégias nas quais as regiões são consideradas parte fulcral ao nível da delineação, aplicação e gestão.

A CCDR-Norte foi responsável pela elaboração da estratégia regional de especialização inteligente da Região Norte de Portugal, identificando oito domínios estratégicos prioritários. A área central da cidade do Porto é caracterizada por uma elevada densidade de pessoas e atividades diversas e por uma forte concentração de equipamentos e instituições diversificados. Estes fatores concorrem para a criação de um ambiente propício à criatividade e à inovação, à fertilização cruzada de conhecimentos, ao estabelecimento de redes densas e de configuração variada entre os diversos agentes da área e, por conseguinte, a dinâmicas de competitividade territorial positivas e impulsionadoras de uma economia forte e sustentável. Neste contexto, dada a forte expressão de domínios de especialização inteligente definidos na estratégia regional e dado o facto da estratégia se encontrar patente nos instrumentos de atuação e nas medidas encetadas pelo Município do Porto, nos últimos anos, este trabalho visa identificar e caracterizar os domínios de especialização inteligente mais evidenciados na área central da cidade, bem como perceber as suas dinâmicas recentes e o papel da ação pública local. Para o efeito, recorreu-se a uma abordagem predominantemente qualitativa, com recurso à análise de conteúdo de documentos de estratégia pública local e à realização de oito entrevistas semi-diretivas, realizadas durante o ano de 2017, a agentes da ação pública e dos setores culturais, criativos e lúdicos locais. 


\section{A GÉNESE E AS ESTRATÉGIAS DE IMPLEMENTAÇÃO DA ESPECIALIZAÇÃO INTELIGENTE}

A abordagem da especialização inteligente, também designada por RIS3, teve origem nas estratégias de inovação regional, que tiveram um forte desenvolvimento a partir de 1994. O conceito surgiu no âmbito do desenvolvimento de trabalhos em torno da política de coesão da Comissão Europeia, realizados por Dominic Foray e pelo grupo de peritos Knowledge for Growth. O enfraquecimento dos sistemas nacionais de inovação como unidade de análise para a tomada de decisão e o fortalecimento, por sua vez, dos sistemas regionais e a emergência das redes globais de inovação propiciaram o enfoque nas estratégias de especialização inteligente. Este processo foi reforçado, mais recentemente, pelo reconhecimento por parte de muitos países de que estas estratégias constituem um instrumento mais eficaz para fazer face à crise económico-financeira, por via da liderança regional em matéria do desenvolvimento económico baseado no conhecimento intensivo e na inovação (OECD, 2013).

As estratégias nacionais e regionais de especialização inteligente foram promovidas pela Comissão Europeia no âmbito do processo de implementação da Estratégia Europa 2020. E, neste contexto, visam potenciar as características únicas e os ativos mais relevantes de cada país e região, tornando-os em potencialidades competitivas e em vantagens comparativas face a outros territórios (Ribeiro \& Ferrão, 2014).

A Estratégia Europa 2020 pressupõe a sua implementação a diferentes escalas, desde a europeia até à escala local, atribuindo particular ênfase à implementação regional (CE, 03/03/2010; ESPON, 2013; EU, 2012). A necessidade de uma maior eficácia ao nível da implementação das políticas de suporte à inovação e à competitividade e o reconhecimento de que one size does not fit all estão na origem da promoção, por parte da Comissão Europeia, das estratégias regionais de especialização inteligente nas quais as entidades regionais são parte fulcral na delineação, aplicação e gestão. Considerando-se que as regiões não conseguem ser economicamente muito competitivas em todos os setores, preconiza-se a realização de um exercício de avaliação e identificação das características e dos recursos sobre os quais focar a aplicação dos instrumentos de política pública para que estes tenham impactos significativos em matéria de competitividade, crescimento económico e emprego. A especialização inteligente traduz-se, ainda, na fertilização cruzada de atividades fortes na região, com o intento de gerar mais-valias capazes de atrair pessoas e investimento (CCDR-N, Sem data). No momento atual, pós-crise económico-financeira de 2008, a abordagem da especialização inteligente afigura-se promissora no aumento da eficiência dos investimentos europeus em investigação, inovação e empreendedorismo (Marques, Queiroz, \& Alves, 2014).

O modelo analítico dos sistemas de produção de conhecimento e inovação da hélice quádrupla, apresentado por Carayannis e Campbell em 2011, vai ao encontro das estratégias de RIS3. Este modelo acrescenta às três hélices do modelo inicial de Leydesdorff e Etzkowitz - instituições governativas, academia e setor empresarial a sociedade civil e os cidadãos, considerando que a cultura, os valores, os estilos de vida das sociedades e os meios de comunicação social têm um papel influenciador nada menosprezável (Carayannis \& Campbell, 2011; Ferreira, 2013). Neste modelo, o utilizador final (cidadão, consumidor, utente, empresa, etc.) é envolvido diretamente no processo de inovação (Carvalho, 2013; Winden \& Carvalho, 2015). A implementação de políticas de inovação, enquadradas nas estratégias de especialização inteligente, norteia-se pelo modelo da hélice quádrupla, envolvendo os denominados utilizadores avançados (empresas, instituições de ensino superior e de I\&D, entidades públicas de conceção e gestão de políticas de I\&D, utilizadores de inovação ou entidades representativas da procura e do consumo) num processo integrado e de liderança colaborativa onde cada agente tem um papel pró -ativo (CCDR-N, Sem data). As estratégias de especialização inteligente incentivam os fluxos de conhecimento e as interligações entre os diversos agentes de inovação, a governação multinível e a criação de massa criativa e capital social (Marques \& Santos, 2013; Ribeiro \& Ferrão, 2014).

Os argumentos a favor desta abordagem consistem fundamentalmente: na aplicação mais eficiente dos recursos públicos; na criação de sinergias entre mecanismos de suporte público da I\&D e inovação, promoção industrial e instituições de formação; na identificação dos domínios mais promissores para o empreendedorismo e o crescimento económico através de uma análise cuidada dos objetivos, competências e vantagens competitivas das cidades, regiões ou países; na criação de mecanismos que permitem o desenvolvimento estratégico baseado em interações multifacetadas entre agentes diversificados; no mapeamento de atores chave; e na criação de sistemas de monitorização e avaliação baseados na evidência para selecionar domínios de conhecimento e projetos inovadores (Nijkamp \& Kourtit, 2013). A abordagem à escala urbana encontra-se relacionada com a seleção de prioridades, baseadas nas potencialidades e vantagens comparativas, com o objetivo de canalizar meios e desenvolver estratégias para que a investigação e a inovação vão ao encontro das necessidades de mer- 
cado, alavancando oportunidades emergentes. As cidades detêm importantes concentrações de instituições e atividades de I\&D, o que as torna motores da competitividade às escalas regional e nacional (EU \& UN-Habitat, 2016; Santos \& Marques, 2013).

\section{ESPECIALIZAÇÃO INTELIGENTE NO NORTE DE PORTUGAL E NA ÁREA METROPOLITANA DO PORTO}

A nível da realidade portuguesa, a implementação regional das estratégias de especialização inteligente foi atribuída às Comissões de Coordenação e Desenvolvimento Regional (CCDR). A CCDR da Região Norte (CCDRN) foi responsável pela elaboração da estratégia regional de especialização inteligente da Região Norte de Portugal, na qual se encontram identificados oito domínios estratégicos (Figura 1) para o período de programação 2014 -2020 (CCDR-N, Sem data).

Alinhada com esse documento, bem como com a Estratégia Europa 2020, a estratégia de base territorial para o horizonte 2020 para a Área Metropolitana do Porto (AMP) preconiza o crescimento económico sustentável, através de respostas diferenciadas e adequadas aos desafios específicos da área. Para o efeito, os principais objetivos estabelecidos passam pela integração de instituições e atividades nas redes globais, procurando uma posição de liderança, e pelo apoio e facilitação da inovação. A especialização inteligente é considerada como um modo de atrair e reter talento e de potencializar recursos de produção de conhecimento e inovação (Marques et al., 2014).

\begin{tabular}{|c|c|}
\hline Domínios & Racional de especialização inteligente \\
\hline Ciências da Vida e Saúde & $\begin{array}{l}\text { Consolidação das dinâmicas de articulação entre a investigação regional } \\
\text { e as empresas nas indústrias e serviços na área da saúde. }\end{array}$ \\
\hline Cultura, Criação e Moda & $\begin{array}{l}\text { Exploração do potencial das indústrias criativas (sobretudo nas áreas de } \\
\text { design e arquitetura), de novos materiais e de tecnologias de produção } \\
\text { inovadoras. }\end{array}$ \\
\hline Recursos do Mar e Economia & $\begin{array}{l}\text { Estabelecimento de relações de articulação entre engenharias aplicadas, } \\
\text { recursos do mar e atividades económicas que os valorizem. }\end{array}$ \\
\hline Capital Humano e Serviços Especializados & $\begin{array}{l}\text { Promoção de competências acumuladas na área das Tecnologias de } \\
\text { Informação e Comunicação (TIC) (em particular, no desenvolvimento de } \\
\text { aplicações multimédia e na programação e engenharia de sistemas). }\end{array}$ \\
\hline Indústrias da Mobilidade e Ambiente & $\begin{array}{l}\text { Aproveitamento das competências científicas nas áreas das tecnologias } \\
\text { de produção e dos materiais para promover o upgrade das indústrias de } \\
\text { componentes de automóveis e moldes. }\end{array}$ \\
\hline Sistemas Avançados de Produção & $\begin{array}{l}\text { Desenvolvimento de fileiras associadas às Tecnologias de Largo Espec- } \\
\text { tro, nomeadamente os Sistemas de Produção Avançados, as Nanotecno- } \\
\text { logias Materiais e as Tecnologias de Informação e Comunicação e Eletró- } \\
\text { nica (TICE). }\end{array}$ \\
\hline Sistemas Agroambientais e Alimentação & $\begin{array}{l}\text { Potencialização dos produtos de elevado valor acrescentado e das com- } \\
\text { petências científicas, tecnológicas e empresariais para dar resposta a } \\
\text { segmentos de procura mais dinâmicos. }\end{array}$ \\
\hline Capital Simbólico, Tecnologias e Serviços do Turismo & $\begin{array}{l}\text { Valorização de recursos culturais e intensivos em território, aproveitando } \\
\text { as capacidades científicas e tecnológicas, nomeadamente nas áreas da } \\
\text { gestão, marketing e TIC, e a oferta turística relevante. }\end{array}$ \\
\hline
\end{tabular}

Figura 1 - Domínios de especialização inteligente da Região Norte de Portugal.Fonte: Adaptado de CCDR-N (Sem data), pp. 30 e 31.

\section{E ENTÃO À ESCALA LOCAL? O CASO DA ÁREA CENTRAL DO PORTO.}

A área central da cidade do Porto, como é próprio das áreas centrais, é caracterizada por uma elevada densidade e diversificação de pessoas e atividades e por uma forte concentração de equipamentos e instituições de índole diversa. Estes fatores concorrem para a criação de um ambiente propício à criatividade e à inovação, à fertilização cruzada de conhecimentos, ao estabelecimento de redes densas e de configuração variada entre os diversos agentes da área e, por conseguinte, a dinâmicas de competitividade territorial positivas e impulsionado- 
ras de uma economia forte e sustentável. Neste contexto, e dada a expressão de domínios de especialização inteligente definidos na estratégia regional e dado o facto da estratégia de especialização inteligente definida para a Região Norte de Portugal se encontrar patente nas estratégias e nos instrumentos de atuação do Município do Porto, em anos recentes, este trabalho pretende identificar e caracterizar os domínios de especialização inteligente mais evidenciados na área central da cidade, analisando as suas dinâmicas recentes e o papel da ação pública local na sua potencialização. Para o efeito, recorreu-se a uma abordagem predominantemente qualitativa, recorrendo-se à análise de conteúdo de documentos de estratégia pública local e à realização de oito entrevistas semi-diretivas a decisores públicos e a agentes dos setores culturais, criativos e lúdicos locais. As entrevistas foram realizadas durante o ano de 2017. De referir ainda que a observação direta dos fenómenos mostrou-se essencial para aferir afirmações e confrontar leituras.

\begin{tabular}{|l|l|}
\hline \multicolumn{1}{|c|}{ Domínios } & \multicolumn{1}{c|}{ Descrição } \\
\hline Capital Simbólico, Tecnologias e Serviços de Turismo & $\begin{array}{l}\text { Sobressaem as atividades recreativas e de lazer, que enquadram a valori- } \\
\text { zação dos recursos culturais, patrimoniais e naturais, bem como as ativi- } \\
\text { dades de apoio ao setor do turismo (alojamentos, agências de viagem e } \\
\text { operadores turísticos), o marketing, o comércio a retalho e a restauração. }\end{array}$ \\
\hline Capital Humano e Serviços Especializados & $\begin{array}{l}\text { Estão representados na área central pelos serviços às empresas, pelas } \\
\text { indústrias criativas e pelas atividades de I\&D e atividades relacionadas } \\
\text { com as TIC. }\end{array}$ \\
\hline Cultura, Criação e Moda & $\begin{array}{l}\text { Reflete-se nas indústrias criativas, assim como nas atividades relaciona- } \\
\text { das com o vestuário e o calçado ou nos serviços pessoais e às empresas. }\end{array}$ \\
\hline Recursos do Mar e Economia & $\begin{array}{l}\text { É representado pelas atividades recreativas e de lazer, com particular } \\
\text { destaque para o turismo náutico (na vertente da prática de desporto e na } \\
\text { vertente dos transportes turísticos que operam no Rio Douro), pelos } \\
\text { serviços às empresas e pelo comércio a retalho e restauração. }\end{array}$ \\
\hline
\end{tabular}

Figura 2 - Domínios de especialização inteligente predominantes na área central do Porto. Fonte: Elaboração própria.

\section{DOMÍNIOS DE ESPECIALIZAÇÃO INTELIGENTE, AÇÃO PÚBLICA E PRINCIPAIS DESAFIOS}

Todos os oito domínios prioritários de especialização identificados na estratégia definida para a Região Norte se encontram presentes na cidade do Porto. $\mathrm{Na}$ área central da cidade destacam-se quatro domínios: o Capital Simbólico, Tecnologias e Serviços de Turismo; o Capital Humano e Serviços Especializados; a Cultura, Criação e Moda; e os Recursos do Mar e Economia (Figura 2).

Como podemos verificar pela análise da Figura 2, há diversas atividades que cruzam mais do que um domínio e cujas competências específicas entram na equação da fertilização cruzada de informação, conhecimentos e ideias, gerando mais-valias ao nível da competitividade económica da área e, através dela, da cidade no seu todo.

Desde logo, a elevada oferta de comércio e restauração é, desde longa data, uma característica da área central do Porto. Na atualidade, tradição e modernidade coexistem na mesma rua ou, até, no mesmo estabelecimento ou evento de natureza económica. Os estabelecimentos mais antigos procuram modernizar-se através da meIhoria do serviço prestado, potenciando a sua mais-valia que é, ao fim ao cabo, a venda de produtos que simbolizam as tradições e a identidade local. Os estabelecimentos mais modernos recorrem a estratégias de hibridismo e cosmopolitização, apresentando ambiências apelativas e vendendo, muitas vezes, produtos tradicionais reinventados ou com características globalizadas, atraindo um público mais volátil e muitos turistas (Ferreira, Marques \& Guerra, 2016a).

O turismo assume-se como um dos principais setores económicos da área central do Porto na atualidade. Há uma conjugação de fatores que concorrem para a elevada atratividade da área e para a grande afluência de turistas ao longo de todo o ano. A proliferação do fenómeno low-cost (voos e alojamento), aliada à elevada concentração de estabelecimentos hoteleiros e de operadores de animação turística, à elevada procura do produto city-break a nível nacional e internacional, aos, ainda, relativamente baixos preços da cidade e à segurança (comparativamente com outras cidades europeias) são fatores de atração de pessoas (Ferreira, Marques \& Guerra, 2016b). 


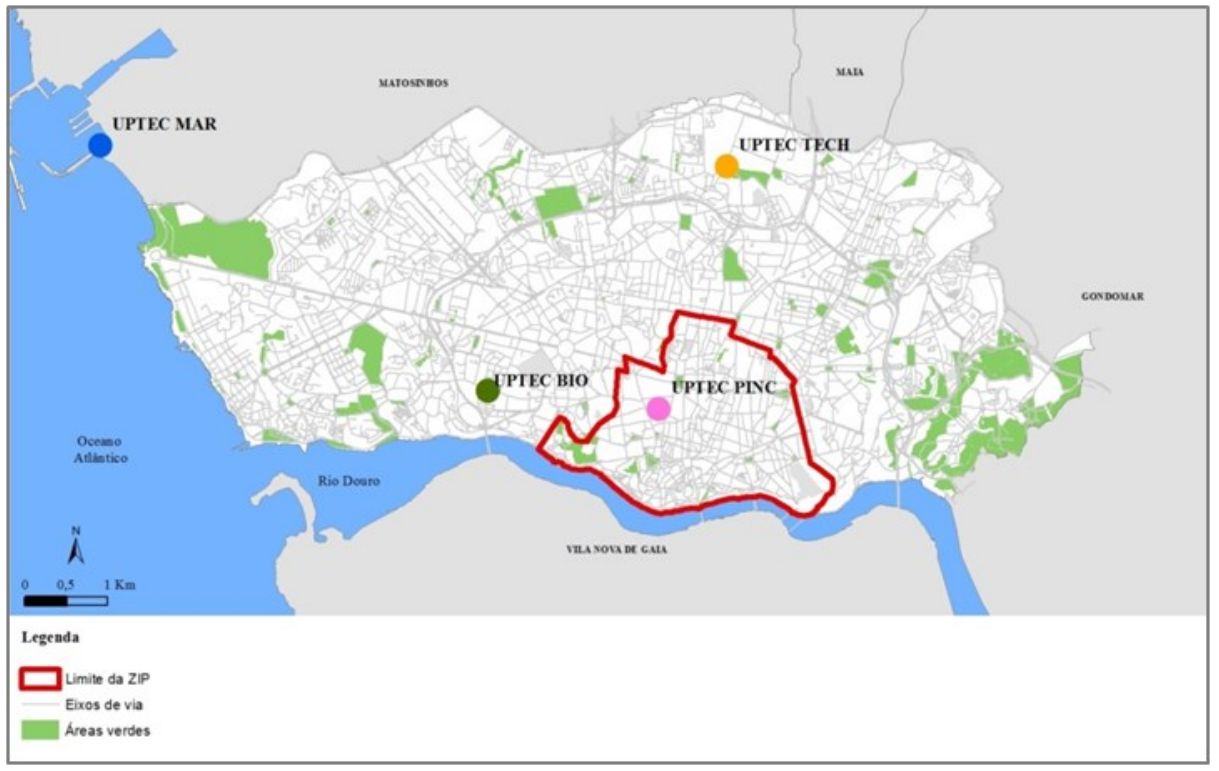

Figura 3 - Localização dos Polos da UPTEC ${ }^{1}$. Fonte: Elaboração própria.

Existem, no momento atual, elementos que concorrem para o reforço do capital sociocultural da área central do Porto. A diversidade de atividades, agentes e eventos que formam a economia cultural e criativa da área concorrem para a ascensão deste setor. Estamos a falar de atividades geridas por entidades de escalas de atuação diferenciadas e onde se encontram diferentes domínios de intervenção. Trata-se de atividades com capacidade para desempenhar um importante papel de adaptação das empresas aos avanços tecnológicos e a tendências de globalização dos mercados. No caso específico das indústrias criativas, de relevar a localização na área (Figura 3) do Polo das Indústrias Criativas do Parque de Ciência e Tecnologia da Universidade do Porto (UPTEC PINC).

O UPTEC PINC encontra-se em funcionamento desde janeiro de 2010 , constituindo um espaço de interação entre pessoas e projetos que procuram desenvolver e explorar a criatividade de forma empreendedora (em áreas como a arquitetura, as artes visuais, as artes performativas, o design, o audiovisual, a publicidade e a comunicação), sempre enquadradas no ambiente de I\&D da Universidade (UPTEC, Sem data). O UPTEC PINC constitui uma das estruturas basilares do Cluster de Indústrias Criativas da Região Norte de Portugal (Ribeiro \& Ferrão, 2014), sendo fortemente orientado para o mercado (Marques et al., 2017). De referir também a presença no local da incubadora Palácio das Artes - Fábrica de Talentos, gerida pela Fundação da Juventude, que existe desde 2009 para apoiar criadores individuais no desenvolvimento e promoção dos seus trabalhos.

A nível da atuação pública municipal, as políticas voltadas para a produção de conhecimento e inovação cimentam-se em redes de atores, formando uma hélice quádrupla que envolve empresas em diversos estados de maturação - desde start-ups a empresas bastante consolidadas no mercado -, instituições de ensino superior e de I\&D ligadas à Universidade do Porto, ao Instituto Politécnico do Porto e demais universidades privadas que se localizam na cidade, entidades públicas e organismos diversos que interagem em projetos diversos, que dinamizam e potenciam recursos humanos e tecnológicos. Pretende-se com esta abordagem a utilização eficiente dos limitados recursos públicos através da sua concentração em setores considerados capazes de alavancar processos de empreendedorismo, de crescimento económico e de reforço da competitividade da cidade no seu todo. Pretende-se captar investimento privado, criar dinâmicas de geração de emprego qualificado e criar condições favoráveis para o empreendedorismo. Nesta matéria, é pertinente referir dois projetos relevantes.

Um deles é o ScaleUp Porto, que tem uma projeção mais ampla, integrando a cidade do Porto no movimento ScaleUp For Europe. Baseia-se nos princípios da confiança, da facilitação de redes e parcerias, na aprendizagem conjunta e na partilha de conhecimento. Resulta de uma iniciativa do Município em parceria com o UPTEC e com

\footnotetext{
${ }^{1}$ ZIP é o acrónimo de Zona de Intervenção Prioritária. Trata-se de uma delimitação apresentada, em 2005, pela Sociedade de Reabilitação Urbana Porto Vivo (Porto Vivo, SRU) no âmbito do seu trabalho de requalificação e revitalização da Baixa portuense. Assume-se, para efeitos deste trabalho, como correspondendo à área central do Porto.
} 
o apoio da Agência Nacional de Inovação (Porto City Hall, 2016). Enquanto o UPTEC e outras incubadoras trabaIham na conceção e implementação de projetos de negócio e na criação de start-ups, o ScaleUp Porto procura trabalhar numa fase subsequente, em que as empresas procuram ganhar dimensão e são já capazes de gerar emprego qualificado. E, neste sentido, visa criar condições para que qualquer scale-up se instale e permaneça na cidade. São tendencialmente as empresas de base tecnológica que conseguem obedecer aos critérios exigidos, mas o projeto está, à partida, aberto a qualquer tipo de atividade. O Município procura através deste projeto reter capital humano, procurando assegurar níveis de qualidade de vida que atraiam e fixem pessoas altamente qualificadas na cidade. O outro projeto relevante é o Porto Innovation Hub. A área central acolheu a edição que decorreu em 2017. O principal objetivo é estabelecer uma ligação próxima entre o Município e o ecossistema de empresas e cidadãos (residentes ou visitantes). Envolve atividades como debates, rastreios de saúde, testes laboratoriais ou mostras de inovação. Pretende dar a conhecer empreendedores e os projetos por si desenvolvidos, projetando assim soluções tecnológicas inovadoras.

Perante o exposto anteriormente, impõe-se agora refletir sobre alguns desafios que se colocam à área central em matéria de domínios de especialização inteligente. Desde logo, coloca-se o desafio aos agentes e às atividades de manter a autenticidade e a identidade locais, ao mesmo tempo que se acompanha as tendências e exigências do mercado, reforçando os processos de competitividade. Um desafio específico se coloca ao setor do turismo: a turistificação excessiva da área (indiciada já pelo surgimento de lojas e produtos estereotipados) pode conduzir à perda de identidade, fator fulcral da elevada atração turística da área central do Porto. Por fim, identifica-se um terceiro desafio, mais voltado para a atuação e interação dos agentes. Desafio para que articulem interesses, estratégias e recursos, potenciando setores cuja capacidade e competências instaladas na área central do Porto os tornam bastante competitivos, inclusive a nível internacional. E desafio para que atuem sobre eventuais problemas e constrangimentos de forma concertada, através de processos de negociação entre todas as partes interessadas.

\section{CONCLUSÕES}

A localização e concentração na área central do Porto de atividades e organizações diversas reflete a presença de um amplo leque de competências instaladas que podem potenciar processos de fertilização cruzada, propiciando a prosperidade do ecossistema de empreendedorismo e inovação da área, com potencial para dar resposta efetiva aos objetivos definidos a nível regional. Enquadrando-se nos domínios de especialização inteligente definidos para a Região Norte, destacam-se na área central do Porto os domínios do Capital Simbólico, das Tecnologias e Serviços de Turismo, do Capital Humano e Serviços Especializados, da Cultura, Criação e Moda e dos Recursos do Mar e Economia. São diversas as atividades económicas presentes na área central do Porto que se enquadram nestes domínios de especialização: os serviços mais especializados, com forte potencial ao nível do capital humano; as atividades da economia cultural e criativa ou o comércio a retalho, restauração e demais atividades que servem o setor do turismo são exemplos de atividades que vão ao encontro da estratégia de RIS3. Estratégia esta também vertida na atuação do Município. Ao nível da estratégia pública, verifica-se a aposta em setores basilares e efervescentes na atualidade, com potencialidades para alavancar processos de empreendedorismo, de crescimento económico e de reforço da competitividade da área em análise, assim como da cidade no seu todo. Os desafios que se colocam prendem-se com a resiliência de atividades e do próprio território e com a capacidade dos diversos agentes atuarem em rede, concertando interesses e dirimindo eventuais pontos de clivagem, em prol do reforço do ecossistema de inovação local.

\section{BIBLIOGRAFIA}

CARAYANNIS, E. G., \& CAMPBELL, D. F. J. (2011). Open Innovation Diplomacy and a 21st Century Fractal Research, Education and Innovation (FREIE) Ecosystem: Building on the Quadruple and Quintuple Helix Innovation Concepts and the "Mode 3" Knowledge Production System. Journal Of The Knowledge Economy, 2(3), 327-372. doi:10.1007/s13132-011-0058-3.

CARVALHO, L. (2013). Knowledge Locations in Cities: Emergence and Development Dynamics (No. EPS-2013-274-S\&E). ERIM Ph.D. Series Research in Management. Erasmus Research Institute of Management. Retrieved from http://hdl.handle.net/1765/38449.

CCDR-N. (Sem data). Norte 2020: Estratégia Regional de Especialização Inteligente. Comissão de Coordenação e Desenvolvimento Regional do Norte Retrieved from https://www.portugal2020.pt/Portal2020/Media/Default/Docs/EstrategiasElnteligente/ EREI\%20Norte.pdf. 
CE. (03/03/2010). EUROPA 2020: Estratégia para um crescimento inteligente, sustentável e inclusivo. Bruxelas: Comissão Europeia Retrieved from http://eur-lex.europa.eu/LexUriServ/LexUriServ.do?uri=COM:2010:2020:FIN:pt:PDF.

ESPON. (2013). ESPON Atlas: Territorial Dimensions of the Europe 2020 Strategy E. Union (Ed.) (pp. 68). Retrieved from http:// www.espon.eu/main/Menu_Publications/Menu_ATLAS2020/.

EU. (2012). Delivering on the Europe 2020 Strategy: Handbook for Local and Regional Authorities. European Union Retrieved from https://portal.cor.europa.eu/europe2020/SiteCollectionDocuments/Europe\%202020\%20Handbook\%20for\%20Local\% 20and\%20Regional\%20Authorities.pdf.

EU, \& UN-Habitat. (2016). The State of European Cities 2016. Retrieved from http://ec.europa.eu/regional_policy/en/policy/ themes/urban-development/cities-report.

FERREIRA, C. (2013). Redes de inovação e políticas públicas: conceitos, modelos analíticos, abordagens empíricas e preocupações das políticas na atualidade. Revista de Geografia e Ordenamento do Território (GOT)(4 (dezembro)), 109-128.

FERREIRA, C. M. F., MARQUES, T. S., \& GUERRA, P. (2016a). Bottom-up Initiatives of Economic and Symbolic Innovation in Oporto City Centre. In T. d. Noronha \& H. Pinto (Eds.), Innovation for Resilience (pp. 149-168): Universidade do Algarve. Retrieved from http://www.cieo.pt/downloads/DIGITAL_Innovation_for_Resilience.pdf.

FERREIRA, C., MARQUES, T., \& GUERRA, P. (2016b). Tourism Dynamics and Architectural, Cultural and Symbolic Heritage: The Case of Oporto City Centre. In C. H. N. Henriques, M. C. Moreira, \& P. A. B. César (Eds.), Tourism and History: World Heritage - Case Studies of Ibero-American Space (Vol. III, pp. 53-72). Braga: CICS.NOVA.UMinho. Retrieved from http:// www.lasics.uminho.pt/ojs/index.php/cics_ebooks/issue/view/212.

MARQUES, T. S., QUEIROZ, J. P., \& ALVES, P. (2014). AMP 2020 Estratégia de Base Territorial. Área Metropolitana do Porto. Retrieved from http://portal.amp.pt/media/documents/2015/06/11/estrategia_amp_2020.pdf.

MARQUES, T. S., SANTOS, H. (2013), Lugares e redes de inovação na área metropolitana do Porto, Geografia: Revista da Faculdade de Letras da Universidade do Porto, Vol. 2, p.203 - 225.

MARQUES, T. S., QUEIRÓS, J. P., MENDONÇA, J. M., SANTOS, H., GUERRA, P., BABO, A. P., MACHADO, R. V., CARVALHO, L. (2017). AMP 2020: Crescimento Inteligente. Porto: Caleidoscópio - Edição e Artes Gráficas, SA, Área Metropolitana do Porto.

NIJKAMP, P., \& KOURTIT, K. (2013). The "New Urban Europe": Global Challenges and Local Responses in the Urban Century. European Planning Studies, 21(3), 291-315. doi:10.1080/09654313.2012.716243.

OECD. (2013). Innovation-driven Growth in Regions: The Role of Smart Specialisation - Preliminary Version. Retrieved from http:// www.oecd.org/sti/inno/smart-specialisation.pdf.

PORTO CITY HALL. (2016). Porto Start \& Scale Guide. 77.

RIBEIRO, J. M. F., \& FERRÃO, J. (2014). Noroeste Global. Lisboa: Fundação Calouste Gulbenkian.

SANTOS, H., MARQUES, T. S. (2013), Lugares e redes de conhecimento na área metropolitana do Porto, Geografia: Revista da Faculdade de Letras da Universidade do Porto, Vol. 2, p.179 - 202.

WINDEN, W. V., \& CARVALHO, L. (2015). Triple Helix (3H): Where are Europe's cities standing? In URBACT (Ed.), New Urban Economies: How can cities foster economic development and develop 'new urban economies' (pp. 10-14). Saint-Denis, France: URBACT. 
Página intencionalmente dejada en blanco 
TICS Y NUEVOS ESPACIOS ECONÓMICOS 
Página intencionalmente dejada en blanco 


\title{
Smart city research meets the geography of innovation The smart city programme of Enel in Rio de Janeiro and Santiago de Chile
}

\author{
L. Carvalho (a) \\ (a) Centro de Estudos em Geografia e Ordenamento do Território (CEGOT), Universidade do Porto, Icarvalho@letras.up.pt
}

\begin{abstract}
Over the last decade, a whole new assemblage of technologies, devices and innovations started to become deployed and experimented in cities under the banner of the "smart city" (e.g. sensors, software, city apps, open data platforms, urban operating systems, etc.). These developments mobilise different types of actors, ranging from global tech companies to local grassroots movements, drawing on multiple geographies, local and global, permanent and temporary. Scholarship in urban studies has developed a vigorous critique on smart city development but has paid less attention to the geographical, economical and (sociotechnical) innovation dimensions associated with it, which may influence how these innovations unfold and become embedded (or not) in society. By combining notions from economic geography and socio-technical studies of innovation, this paper explores how a "mobile" portfolio of smart grid/smart city technologies - developed by a global energy utility corporation - became anchored and recombined in different cities, and what do those processes depended upon.
\end{abstract}

Keywords: Geography of knowledge and innovation; smart city; anchoring; geography of sustainability transitions.

\section{INTRODUCTION}

Over the last decade, a whole new assemblage of technologies, devices and innovations started to become deployed and experimented in cities under the banner of the "smart city" (e.g. sensors, software, smart meters, smart grids, city apps, electric charging stations, etc.). These developments mobilise different types of actors, ranging from global tech companies to local grassroots movements, drawing on multiple geographies, local and global, permanent and temporary (Evans e al., 2016). Scholarship in urban studies has developed a vigorous critique on smart city development (e.g. Kitchin, 2016) but has paid less attention to the geographical, economical and (socio-technical) innovation dimensions associated with it, which may influence how these innovations unfold and become embedded (or not) in society.

By combining notions from economic geography and socio-technical studies of innovation, this paper explores how a "mobile" portfolio of smart grid/smart city technologies - developed by a global energy utility corporation - became anchored and recombined in different cities, and what do those processes depended upon. The research setting is the Global "Smart City Programme" of the Enel Group, the largest Italian electricity company. Since the early 2000 s, in order to cope with changing regulations, tariff prices and to enhance the efficiency in electricity distribution operations in Italy, Enel developed a pioneer investment in smart metering technologies and have been rolling out the technology across Italy; more recently, other technologies associated with smart grids, smart lightning, mobility, etc. were added to this portfolio, seeking to diversify the company's revenues beyond the regulated electricity market. As Enel expanded their operations to Latin America during the last decade (by buying local electricity companies), the group developed a global "Smart City Programme", with the ambition to rollout their Italian-developed technologies in other geographies. To that effect, Enel launched two pioneer smart-city "pilots" in Rio de Janeiro and Santiago de Chile.

The paper explores how the very same portfolio of technologies - championed within the corporate network of Enel - was anchored and recombined in place in rather different ways, ranging from deep modes of reciprocal learning (Rio de Janeiro) to more shallow knowledge contextualization (Santiago). In turn, the paper demonstrates how these different modes of knowledge anchoring - with include the technology, but also narratives and agendas, search heuristics, expectations, theories and values about smart city solutions - were influenced by 
a multi-scalar set of institutional contexts playing out in the two cities, influencing the extent to which knowledge about the smart city technology at stake was transformed and circulated again to new contexts.

The paper is organized as follows. Section 2 frames the conceptual starting points for this research. Section 3 details the research setting. Section 4 present the empirics and Section 5 concludes by highlighting a number of takeaways for research at the interface of smart city and the geography of innovation.

\section{CONCEPTUAL DEBATES}

A number of studies have been recently paying attention to the diffusion of smart city technology in society. One important issue relates to the notion of upscaling, or the extent and the process through which initial immature technologies gain traction and become diffused in places and social contexts different from the ones in which they were originally devised (van Winden and van den Buuse, 2017). Despite the often-positive narratives of policymakers and global technology corporations, these processes are fraught with difficulties. This is largely so because smart city propositions are infused with much more than technology - they involve many social aspects such as networks of actors, business models, expectations about their success, values, agendas, narratives, political and user assumptions, etc. For these reasons, apart from technologies and smart devices, smart city development requires social learning. Hence, a number of scholars started to conceptualize smart city development as a sociotechnical transition, requiring learning (about technology, but also about business models, new applications, perceptions, social and ecological impacts, values, etc.), social network formation (new advocates and wide networks of users and producers) and expectation building about the merits of new technologies and propositions, grounded on concrete initiatives and results (Carvalho et al., 2014; Carvalho, 2015; Sengers and Raven, 2015).

The development and the diffusion of smart meters, smart grids and energy-related innovations have been widely discussed in this literature, namely in a growing research stream focusing on sustainability transitions (Verbong et al., 2013). This research conceptualizes these technologies and innovations as "niches" vis-à-vis contemporary energy regimes, challenging mainstream (centralized, fossil fuel) energy production and distribution regimes. As technologies, markets, regulatory settings, infrastructure and user perceptions are still immature, their gradual diffusion to permeate (or even transform) energy regimes requires experimentation, namely in order to set in motion the aforementioned processes of learning, social network formation and expectation building (Schot and Geels, 2008).

Yet, energy regimes can hardly be challenged by single experiments in particular sites and locales (e.g. Kemp et al., 1998; Smith and Raven, 2012). For this reason, scholars in sustainability transitions speak about a "localglobal" model of diffusion, under which lessons from hands-on experimentation in concrete places - driven local networks of actors with their own interests and agendas - coalesce into a more influent "global niche" level composed by globally shared narratives, problem agendas, expectations, designs, search heuristics, strategies, etc. - that shape the development of the niche further, heightening its capacity to infuse change in dominant sociotechnical regimes (Geels and Deuten, 2006). In other words, knowledge and leanings from experimentation become increasingly "cosmopolitan", non-situated and mobile. As Schot and Geels (2008) put it,

"[niche] developments may start with one or a few projects, carried out by local networks of actors, who are interested in innovations for idiosyncratic or local reasons. The cognitive rules (...) that guide these projects are initially diffuse, broad and unstable. Local projects form test beds for these diffuse ideas (...). If learning processes in local projects are compared and aggregated, the cognitive rules at the more global niche level may gradually become more articulated, specific and stable" (p.543).

This conceptualization provides valuable insights into how the socio-cognitive orientation of the actors involved in socio-technical experimentation are locally formed, re-formed and globally retained, driving (or hampering) experimentation and the diffusion of innovations further. Yet, the local-global niche model has been criticized for saying little about where concretely new socio-cognitive frames become formed, through which channels they travel to become "global", and how they become re-embedded across places (Hansen and Coenen, 2015).

Recent studies have been addressing these geographical shortcomings, namely by highlighting notions of socio-spatial embedding and multi-scalarity (Coenen et al., 2012; Sengers and Raven, 2015). First, notions of sociospatial embedding contribute to understanding why certain experiments, niche activities and ultimately transition processes are more successful in some places than in others. This calls for an understanding of places not simply as 
"sites" where experiments unfold but as distinct assemblages of actors, networks and institutions with cultural, social and political texture, influencing the direction of experimentation and its ability to gain traction. Second, engaging with notions of multi-scalarity can contribute to highlighting the actors, processes and geographical scales through which experiments become intertwined and connect to one another towards the formation of broader alternatives to dominant socio-technical regimes. Overall, by bringing in explicit geographical notions, these studies suggest that sustainability transitions - such as the diffusion of smart city innovation in society evolve and grain traction through intrinsically spatial processes and, therefore, the concrete places where experiments form - and travel to - may largely influence their journeys and upscaling ambitions (positively or negatively).

These geographically informed views suggest that the diffusion and upscaling of smart city innovations involves spatial circuits through which learning, new networks and associated expectations are formed, transformed and (re-) assembled in concrete places before becoming mobile again (Carvalho and Lazzerini, 2008). Such a framework can be grounded on the notions of anchoring and mobility. The notion of anchoring has been used to understand change in territorial production and innovation systems under heightened mobility of production factors, notably knowledge (Crevoisier and Jeannerat, 2009; Vale and Carvalho, 2013). This work posits that under such a circulatory paradigm, the development of localized innovation systems became increasingly reliant on the capacity of a place to engage with resources and knowledge developed elsewhere, being that different localities will mobilise and integrate mobile knowledge in different ways (De Propris and Crevoisier, 2011). According with De Propris and Crevoisier (2011), anchoring is the process through which different places manage to "access, interact and capture knowledge, information, ideas or any form of tangible or intangible asset from other places (...)" (p. 173), relying on the (place-based) capacities of their actors, networks and institutional settings. Anchoring makes sense only in relation to its twin notion of mobility, that is, of movement of tangible and intangible assets across space. Under this perspective, knowledge is still produced and nurtured in concrete sociospatial contexts, and anchoring is the capacity of other places to re-contextualize/assimilate complex knowledge pieces and diffuse it locally, before it eventually becomes mobile again and flow to other contexts.

The concept of anchoring resembles the one of embeddedness. Yet, while embeddedness broadly refers to stable relationships between agents/actions and structures (e.g. social, institutional and cognitive environments) "belonging" to concrete places of origin, "anchoring embodies the idea that there exists an element of mobility between places, namely a tendency to open or a movement towards a new context" (De Propris and Crevoisier, 2011, p. 174), which implies a dynamic and frequent re-contextualization and transformation of knowledge and other mobile resources in the process. Notably, the capacity to re-contextualize mobile resources depend on the actors and relational assets in place, as well as on deliberate actions and policy efforts to strike the necessary alignments between localized assets and mobile resources (e.g. Coenen et. al, 2010; Vale and Carvalho, 2013). These abilities become increasingly pivotal for sustainability transitions and smart city-related experimentation, namely as a growing number of experiments and niche development processes are linked to trans-local and trans -national connections - namely through the deliberate actions of transnational companies to circulate their technologies and associated propositions (e.g. Carvalho, 2015; Hansen and Coenen, 2015, Wieczorek et al., 2015).

The aforementioned, geographically informed notions of anchoring and mobility have been recently applied in studies at the intersection of economic geography and sustainability transitions. For example, Binz et al. (2015) analysed how Beijing became a relevant node in on-site water re-cycling solutions through anchoring of external knowledge, namely by actively creating new local markets, mobilizing investment, fostering local spin-offs and locally legitimizing the solution (e.g. in local hotel segments). Yet, to put those processes in motion and circulate newly created knowledge, the role of foreign international organizations and global companies. In a similar vein, Carvalho et al. (2012) analysed how three cities (Curitiba, Hamburg and Goteborg) developed distinct assets that made them relevant international hubs for the creation, recombination, anchoring and diffusion of knowledge and ideas of sustainable mobility over time. Likewise, the fluid and rich mobility of new concepts and experiments to other places relied on the actions of globally connected yet also locally embedded actors, such as transnational corporations (carmakers and energy utilities) and well-connected mayors. Moreover, in a different vein, the study by Sengers and Raven (2015) showed that a concrete failure to adopt a rapid bus system in Bangkok became a burden to the actors aggregating knowledge on it, hampering the diffusion of the concept in other places.

\section{Summing up}

Smart city-related technologies and innovations are becoming increasingly mobile, namely as they are championed by transnational corporations with a global presence. Yet, the ways these propositions travel in space is far from frictionless. How they engage with particular locales and their socio-institutional configurations 
- or, in other words, how they become anchored - largely influence the ways through which new leanings, social networks, expectations and narratives about it form and transform.

\section{RESEARCH SETTING AND METHODOLOGY}

The remainder of this paper reports how these processes unfolded for the case of the Smart City Programme of Enel - the former, nationally owned Italian Energy Company. Over the last two decades, Enel developed a portfolio of smart, IT-infused energy devices to enhance distribution efficiency (e.g. avoid blackouts, manage energy demand, interact with users, remotely change and monitor energy plans and consumption) such as smart grid and smart metering solutions, as well as to cope with changing energy regimes, including electric charging stations for vehicles, smart lightning solutions, among others. In the early 2010s, Enel started a Smart City Programme in Italy and Spain in order to test the deployment of this portfolio of solutions in specific city districts, in an integrated fashion (e.g. in Genoa, Turin, Malaga and Barcelona). By doing so, the company envisioned to experiment how the assemblage of solutions would work together, involve users and assess their reactions to the new energy solutions, raise interest about their possibilities, develop new commercial opportunities beyond the regulated energy market, and, over time, change regulatory frameworks in favourable directions (e.g. to regulate or support the adoption of related technologies within the energy systems of different countries).

As Enel expanded overseas - namely buying energy production and distribution companies in Latin America - so did the company's smart city programme. In 2013, Enel launched two additional smart city pilots in Rio de Janeiro, Brazil (Municipality of Búzios) and Santiago de Chile, Chile. These pilots were designed in close articulation between the Enel "smart city group" in Rome - responsible for the distribution of smart city solutions worldwide and new Latin American electricity distribution subsidiaries (Distribution System Operators - DSO) in both cities: Ampla (Rio) and Chilectra (Santiago). The Enel smart city group transferred the technology within the corporation's boundary and provided local support to its implementation, while local DSOs would be tasked with the daily implementation of the pilots. To this effect, transnational corporate teams were formed, linking staff in the headquarters and subsidiaries (both through videoconferencing and intense moments of co-presence in Rome, Rio and Santiago), to deal with different sets of technologies and solutions being deployed in the pilots, leading, in general, to very similar organizational models governing the implementation of the pilots in the two cities.

This specific configuration - i.e. the same technologies and organizational models deployed in two subsidiary locations in Latin America - provided for a quasi-experimental research setting, fully controlling for technology, proponents and organization and allowing to observe the impacts of institutional variation in the two cities as explananda for different anchoring modes and processes of localized learning, social network formation and expectation building. In order to deep dive into these processes, and besides the analysis of several documents, reports, websites and other "grey" material, in-depth interviews were conducted in Rome (10), Rio (16) and Santiago (25) during 2013-2014, with global managers of Enel, staff involved in transnational knowledge mobility and several local actors in both cities, namely DSO's staff, experts, researchers, NGOs, local companies, policymakers, etc. Follow-up desk research was conducted during 2017 to assess the current status of the pilots and how knowledge developed in both contexts was transformed and reconfigured, and how it influenced the upscaling of Enel smart city programme.

\section{EMPIRICAL ANALYSES}

\subsection{Experimentation, anchoring and recombination results}

Although the experimentation objectives of Enel for both pilots were posited by their proponents in a very similar way - e.g. involving users, testing their reactions with new technologies, creating new business opportunities, changing regulatory settings - the way both experiments evolved in Rio and Santiago differ markedly, influencing knowledge anchoring and recombination modes and how they coalesced into the formation of delocalized niche learning, assumptions, narratives, search directions.

First, the specific socio-spatial in which both pilots evolved differed markedly, even if Enel Group's criteria was the same for both cases - namely to have local/national visibility; a proper scale to test technologies and monitor results; good energy infrastructure; diversity of users and consumption patterns; and easiness in mobilis- 
ing users to test new solutions. In the case of Rio, the pilot was developed in the Municipality of Búzios, a wellknown tourist city $180 \mathrm{Km}$ away from the city of Rio de Janeiro, catering from seasonal energy consumption, energy peaks, diversity of uses and visibility in a real city context. To this effect, a concrete deal had to be made with the Municipality to support experimentation, and to get local support (namely from municipal departments) for the pilot. In Santiago, the pilot was designed and implemented in a secluded business park (named "Ciudad Empresarial") and adjacent residential area in the periphery of Santiago. According with the pilot proponents, this would make the implementation of solutions more agile and speed up decisions - namely as they would depend essentially on private actors (the local DSO Chilectra and the park's managers) - while still providing for visibility and the experimentation of new technologies and business models with users and companies. The park's managers saw the deployment of these smart-city technologies as a way to enhance the profile of the location as "smart" and "green", and thus keep the park appealing to higher business segments.

The types of networks mobilized for experimentation were also very different across the two cases. In the case of Rio, a wide pallet of stakeholders became involved from the onset; beyond the DSO and the Municipality of Búzios, those included technology companies and manufacturers (e.g. to adapt smart meters to local standards; to develop other redundant wireless IT solutions for connectivity between meters and operative systems; to develop domotics solutions) and knowledge institutes (for the development of new electric vehicles and charging systems - e.g. an electric boat to link different beaches; and also apps and smart displays for remote energy metering linked with locally developed complementary technologies). Moreover, local citizens were involved to the full, namely through i) the widening of former community initiatives of Ampla (called "Consciência Ampla") to local citizens, e.g. training and hands-on mentoring and tips on how to consume energy more rationally; how to change behaviour and reduce consumption; how to balance family budgets; how to deal with smart metering; incentives to replace energy-inefficient home appliances, etc.; and ii) the development of a citizen network and several workshops to discuss energy-related smart city developments (by an independent knowledge institute), with an eye to discuss current developments, issues and "what was in it" for Búzios' citizens. In the case of Santiago, although efforts were made to explain door-to-door the impacts of smart meters on energy savings, the network of advocates was narrower - beyond the DSO and the park's management, it included essentially a number of technology retailers (e.g. sales subsidiaries of global corporations of domestic appliances, CCTV systems and electric buses), involved in showcasing their solutions (developed elsewhere) within the pilot.

These different setting and actor configurations led to different types of learning outcomes. In Rio, the pilot fulfilled its role testing the technologies in a new context, namely by collecting user's data and thinking about the implications of new smart energy solutions for current and prospective business models, as well as the necessary regulatory adjustments. Yet, the scope of experimentation also allowed for the development of new innovations, adaptations, as well as broader reflections about the technology's impacts in society and consumer behaviour (e.g. on the patterns of energy consumption and energy theft in Rio's cities); new modes of social engagement to discuss energy issues with the population; data and privacy agreements (e.g. between DSO and a widening networks of technology providers and knowledge institutes) and associated cooperative issues (and expected tensions) between DSOs and the local administration. In the case of Santiago, the concrete socio-spatial configuration of the pilot facilitated narrower types of learning, essentially focused on whether the technologies were applicable locally, whether users reacted positively, and on new business model development opportunities (e.g. the bundling of Enel's smart city portfolio with other provider's solutions, and the development of turnkey solutions including energy, domotics, water heating, solar panel connections and aftercare services).

In Rio, experimentation and associated social learning led, in general, to the development of favourable expectations about the technologies at stake. Hesitations and suspicions about its true impact and adoption potential remained among citizens, but the pilot managed to open up new horizons and show in practice the potential of the solutions in enhancing citizen's quality of life (e.g. energy savings, less blackouts, better street lightning, etc.) and led to joint discussions about smart city development based on hands-on, concrete experiments. Energy regulation agencies were closely involved and set up discussion groups to fine-tune the regulatory landscape in co-evolution with the piloting process. In Santiago, on the contrary, although regulators also paid attention to the pilot, their design and "habitat" (Ciudad Empresarial) was perceived by some stakeholders as elitist and too focused on local branding, focusing on a limited population cohort.

As a result, the initial Enel solution's portfolio - and their associated knowledge and "rules" (e.g. narratives, expectations, values) - became anchored rather differently in the two locales. In Rio, the mobile portfolio of technology and knowledge(s) was anchored and recombined in place, resulting in reciprocal learning between Italy and Rio before knowledge became mobile again and re-aggregated the "global niche" level. The pilot's design 
led to the "tropicalization" of the initial smart city solutions, with several actors contributing to deepen its fit to other conditions (e.g. new algorithms in the meter's software), but also to add new solutions and technologies to the bundle, developed locally (e.g. linked to water electric mobility, energy storage, new displays, etc.); moreover, new local practices on community engagement ("Consciência Ampla", smart citizen network) became discussed and promoted by Enel in other pilots around the world, notably in Europe. In the case of Santiago, the anchoring mode of the smart city portfolio resembled a pure re-contextualization pattern, in which local social dynamics did assimilate the new solutions in a concrete locale, but did not really transform it, apart from the consideration of new business models that could be tested around the set of pushed technologies, and eventually be tried out in other Latin American contexts. Table 1 synthetizes the analyses.

Table 1 - Experimentation results in Rio de Janeiro and Santiago de Chile. Source: Own elaboration.

\begin{tabular}{|c|c|c|}
\hline & Rio & Santiago \\
\hline $\begin{array}{l}\text { Spatial setting / } \\
\text { "habitat" }\end{array}$ & City-like environment (Búzios) & Business park (Ciudad Empresarial) \\
\hline Social Networks & $\begin{array}{c}\text { Heterogeneous and deep } \\
\text { (DSO, users, communities, manufacturers, SMEs, } \\
\text { R\&D institutes, local government) }\end{array}$ & $\begin{array}{c}\text { Homogeneous and loose } \\
\text { (DSO, tech retailers, users/ consumers); } \\
\text { NGOs, Universities and government at the fringe }\end{array}$ \\
\hline Learning & $\begin{array}{l}\text { Broad } \\
\text { (Tech-data-business models }+ \text { innovation policies, } \\
\text { user behaviour, social engagement, political issues) }\end{array}$ & $\begin{array}{c}\text { Narrow } \\
\text { (Tech-data-business models) }\end{array}$ \\
\hline Expectations & $\begin{array}{l}\text { (Broadly) shared by the actors, based on experi- } \\
\text { mentation, with regulatory feedback }\end{array}$ & Local branding, perceptions of elitism \\
\hline $\begin{array}{l}\text { Anchoring and } \\
\text { recombination }\end{array}$ & $\begin{array}{l}\text { Reciprocal learning (N-S-N) } \\
\text { "Tropicalization": New solutions in the bundle - EV } \\
\text { water mobility, storage, ITs. } \\
\text { New practices to foster community engagement } \\
\text { Positive expectations }\end{array}$ & $\begin{array}{l}\text { Contextualization }(\mathrm{N}-\mathrm{S}) \\
\text { Local tech push } \\
\text { Local business/selling models } \\
\text { Neutral-negative exp. }\end{array}$ \\
\hline
\end{tabular}

\subsection{Local contexts, institutional features and knowledge recombination possibilities}

As it became clear, similar ambitions and narratives around the role of smart city pilots - experiment, involve users, raise interest and change regulations - gave rise to rather different anchoring outcomes in place, thus influencing the ways through which the proposed smart city propositions unfolded, transformed and aggregated lessons as they became mobile again. One explanation for these differences and revealed recombination possibilities lie in the rather different local contexts and institutional features, playing out at different scales.

Experimentation and knowledge anchoring modes in both cities were influenced by higher-order, state-level institutional settings, related with political economy frameworks, regulatory settings and funding contexts. In the case of Rio, both the Federal and State Government had long tradition of deploying active industrial policies since the 1950s, with funding agencies largely supporting technological development and the development of new industries; by the time the Rio pilot was being devised, a new stream of this policy was focusing specifically on smart grids and associated innovations, and could thus shield and promote new technological developments around Enel's portfolio, supporting industrial and university's involvement in the pilot, in close articulation with the Federal electricity regulator (ANNEL). Moreover, DSO's investments in R\&D (e.g. for new appliances, apps, research programmes, etc.) and in community energy programmes (e.g. Consciência Ampla) were institutionally framed and promoted under a national regulation obliging energy companies to reinvest a percentage of their return-on-equity in $R \& D$ and social programmes, which in this case were easily attuned and transposed to feed the smart city pilot in Búzios.

None of these incentives and institutional settings was present in Santiago. On the contrary, the political institutional framing inherited from Pinochet's "Chicago boys" - an ultra-liberal group of economists that reorganized Chiliean's economic institutions in the aftermath of the 1973 cope d'état - limited the ability to nurture any sort of active industrial policy related with smart city and smart energy development. While such a framework largely facilitated the operations of large sales subsidiaries of foreign corporations in the country, it limited the established R\&D potential and advanced manufacturing base as witnessed it the case of Rio. Moreover, such an institutional framework was traditionally adverse to any sort of industrial protection, subsidies or tax 
rebates, which hampered the ability to provide incentives to the adoption of e.g. electric vehicles and other associated technology solutions, directing the experimentation to higher segments willing to pay higher prices for enhanced energy solutions - like the ones present at Ciudad Empresarial.

Moreover, local institutional contexts - such as local practices, social relations and planning routines - also played a significant role too shaping the experimentation directions and the potential for knowledge anchoring and recombination. In the case of Rio, previous social relations existed between Ampla and the Municipality of Búzios; the DSO had had in the past a negative experience with the deployment of another remote metering technology in deprived neighbourhoods (to prevent energy theft in the region), leading to severe societal backlash and political tensions as users felt the burden of paying for energy as formal electric consumption grew massively. Therefore, the development of community initiatives and related energy programmes with citizens became, since them, part of the company's "DNA", leading inclusively to the hiring of sociologists, planners and even local development experts to their staff. This tradition influenced the pilot by bringing citizen engagement programmes to the core of experimentation, namely to avoid similar societal and political backlash as in the past. In Santiago, local planning tradition gave strong leeway to the private initiative and it was thus perceived as normal when Enel's pilot was deployed in a private business condominium, protected from regular planning hurdles and bureaucracies. In this context, the focus on experimentation naturally turned into new business development, the showcasing of technologies and the experimentation of new revenue models associated with energy distribution, hence limiting knowledge recombination in place. Table 2 synthetizes these analyses.

Table 2 - Institutional features in both pilots. Source: Own elaboration.

\begin{tabular}{|c|c|c|}
\hline & Rio & Santiago \\
\hline $\begin{array}{l}\text { Higher order (State } \\
\text { level) institutions: } \\
\text { political economy, } \\
\text { regulatory and fund- } \\
\text { ing frameworks }\end{array}$ & $\begin{array}{l}\text { Active Industrial policy since } 1950 \text { s } \\
\text { ANNEL mandatory regulations for DSOs to invest } \\
\text { R\&D + social programmes } \\
\text { Smart grid industrial/innovation policy }\end{array}$ & $\begin{array}{c}\text { Pinochet's Chicago Boys Liberal Political Economy } \\
\text { Framework } \\
\text { Weak industrial/R\&D base } \\
\text { No room of manoeuvre for "protection", rebates or } \\
\text { subsidies }\end{array}$ \\
\hline $\begin{array}{l}\text { Local contexts: } \\
\text { practices, social } \\
\text { relations, planning } \\
\text { routines }\end{array}$ & $\begin{array}{c}\text { Relations between DSO-Municipality } \\
\text { Bad experience pushing tech; tradition of dealing } \\
\text { with electricity losses in deprived neighbour- } \\
\text { hoods ("Consciência Ampla" as "DNA") } \\
\text { àDSO focus on business + tech development + } \\
\text { engagement modes }\end{array}$ & $\begin{array}{c}\text { Relations between DSO-business park developer(s) } \\
\text { Private dominance/ Inequity tolerance in planning } \\
\text { à DSO focus on new revenue models and business } \\
\text { model innovation }\end{array}$ \\
\hline
\end{tabular}

\section{CONCLUSIONS}

Over the last decade-and-a-half, electric utilities invested in the "smartization" of their operations by developing smart grid-related technology: smart meters, grid automation, lightning systems, renewable-to-grid solutions, fast-chargers for vehicles, etc. By doing so, they envisioned enhancing operational efficiency, diversifying markets, business models and nudge change towards more sustainable modes of energy production and consumption. Moreover, as utilities progressively expand their operations overseas (e.g. through mergers $\&$ acquisitions), one ambition has been to diffuse those smart city technologies towards new geographies.

This paper explored the ways through which a corporate, supposedly "mobile" portfolio of smart-city/smartgrid technology becomes embedded and recombined in different locations, and what does this process depends upon. The research setting was the "Smart City Programme" of the Italian electric utility Enel and its smart-city pilots in South America: Rio de Janeiro and Santiago de Chile. Despite the relatively homogeneous organizational procedures and technologies deployed by Enel in the different locations, the ways the technology and its sustainability propositions became socially embedded and recombined in the two locations differed markedly, varying from rich "reciprocal learning" (Rio) to "allocation/assimilation" (Santiago).

By exploring these nuanced social-spatially dynamics, the paper provided insight into the geographies of smart-sustainability transitions, as well as into the roles (and limits) of transnational corporations nudging processes of global niche formation. As shown, while the pilot in Rio gave rise to new technologies, methods, strategies and expectations related with the upscaling of smart city technology in other parts of the world, the pilot in 
Santiago was essentially focuses on local assimilation of external knowledge, providing neutral to negative feedback to other projects. The analyses revealed many subtle yet very influential differences within "Latin American" institutional features, with impact on learning, the formation of advocacy networks and types of expectations formed in both pilots.

\section{REFERENCES}

BINZ, C., TRUFFER, B., \& COENEN, L. (2015). Path Creation as a Process of Resource Alignment and Anchoring: Industry Formation for On-Site Water Recycling in Beijing. Economic Geography, 1-29.

CARVALHO, L. \& LAZZERINI, I. (2018). Anchoring and mobility of local energy concepts: the case of Community Choice Aggregation, In Turnhein, B., Kivimaa, P. \& Berkhout, F. (Eds), Beyond Experiments: Understanding how climate innovations become embedded, Cambridge: Cambridge University Press.

CARVALHO, L. (2015). Smart cities from scratch? A socio-technical perspective. Cambridge Journal of Regions, Economy and Society, 8(1), 43-60.

CARVALHO, L., SANTOS, I. P., \& VAN WINDEN, W. (2014a). Knowledge spaces and places: from the perspective of a "bornglobal" start-up in the field of urban technology. Expert Systems with Applications, 41(12), 5647-5655.

CARVALHO, L., MINGARDO, G., \& VAN HAAREN, J. (2012). Green urban transport policies and cleantech innovations: evidence from Curitiba, Göteborg and Hamburg. European Planning Studies, 20(3), 375-396.

COENEN, L., BENNEWORTH, P., \& TRUFFER, B. (2012). Toward a spatial perspective on sustainability transitions. Research policy, 41(6), 968-979.

COENEN, L., RAVEN, R., \& VERBONG, G. (2010). Local niche experimentation in energy transitions: a theoretical and empirical exploration of proximity advantages and disadvantages. Technology in Society, 32(4), 295-302.

CREVOISIER, O., \& JEANNERAT, H. (2009). Territorial knowledge dynamics: from the proximity paradigm to multi-location milieus. European Planning Studies, 17(8), 1223-1241.

DE PROPRIS, L., \& CREVOISIER, O. (2011). From regional anchors to anchoring. In Cooke, P., Handbook of regional innovation and growth. Cheltenham: Edward Elgar.

EVANS, J., KARVONEN, A. \& RAVEN, R. (2016). The experimental city: new modes and prospects of urban transformation. London: Routledge.

GEELS, F., \& DEUTEN, J. (2006). Local and global dynamics in technological development: a socio-cognitive perspective on knowledge flows and lessons from reinforced concrete. Science and Public Policy, 33(4), 265-275.

HANSEN, T., \& COENEN, L. (2015). The geography of sustainability transitions: review, synthesis and reflections on an emergent research field. Environmental Innovation and Societal Transitions, 17, 92-109.

KEMP, R., SCHOT, J., \& HOOGMA, R. (1998). Regime shifts to sustainability through processes of niche formation: the approach of strategic niche management. Technology Analysis \& Strategic Management, 10(2), 175-198.

KITCHIN, R. (2016). Reframing, reimagining and remaking smart cities. Programmable City Working Paper 20, Maynooth University, Dublin.

SCHOT, J., \& GEELS, F. W. (2008). Strategic niche management and sustainable innovation journeys: theory, findings, research agenda, and policy. Technology Analysis \& Strategic Management, 20(5), 537-554.

SENGERS, F., \& RAVEN, R. (2015). Toward a spatial perspective on niche development: The case of Bus Rapid Transit. Environmental Innovation and Societal Transitions, 17, 166-182.

SMITH, A., \& RAVEN, R. (2012). What is protective space? Reconsidering niches in transitions to sustainability. Research policy, 41(6), 1025-1036.

VALE, M., \& CARVALHO, L. (2013). Knowledge networks and processes of anchoring in Portuguese biotechnology. Regional Studies, 47(7), 1018-1033.

VAN WINDEN, W., \& VAN DEN BUUSE, D. (2017). Smart city pilot projects: Exploring the dimensions and conditions of scaling up. Journal of Urban Technology, 24(4), 51-72.

VERBONG, G. P., BEEMSTERBOER, S., \& SENGERS, F. (2013). Smart grids or smart users? Involving users in developing a low carbon electricity economy. Energy Policy, 52, 117-125.

WIECZOREK, A. J., RAVEN, R., \& BERKHOUT, F. (2015). Transnational linkages in sustainability experiments: a typology and the case of solar photovoltaic energy in India. Environmental Innovation and Societal Transitions, 17, 149-165. 


\title{
El desarrollo digital de los hogares e individuos. Una tipología de regiones europeas $^{1}$
}

\author{
R. González-Relaño (a), A. L. Lucendo-Monedero (b), F. Ruiz-Rodríguez (c) \\ (a) Universidad de Sevilla. rgrelano@us.es \\ (b) Universidad de Sevilla. angeluis@us.es \\ (c) Universidad de Sevilla. fruiz@us.es
}

\begin{abstract}
Resumen
El objetivo de este trabajo es caracterizar y clasificar las regiones europeas (NUTS2) en función de los niveles de desarrollo digital en los hogares e individuos. El desarrollo digital se mide a partir del acceso y uso que los hogares e individuos hacen de las Tecnologías de la Información y la Comunicación (TICs). La metodología se desarrolla en dos fases: 1) análisis factorial para identificar las variables clave que definen el desarrollo digital de hogares e individuos, a partir de los datos suministrados por Eurostat; y 2) partiendo del resultado anterior, análisis clúster para identificar y definir una tipología de regiones europeas. Se obtienen dos factores: "Disponibilidad de banda ancha y uso diario de comercio, banca y administración electrónica" y "Uso de redes sociales por banda ancha", que permiten definir siete tipos de regiones europeas con diferente grado de desarrollo digital.
\end{abstract}

Palabras claves: Acceso y uso de las TICs; hogares e individuos; regiones europeas; análisis multivariante; banda ancha y uso diario de Internet; redes sociales.

\section{INTRODUCCIÓN}

El crecimiento económico de las regiones y países se ve afectado directamente por el desarrollo, implantación y acceso a las Tecnologías de la Información y Comunicación (TIC). Se entiende por TICs el conjunto de herramientas, habitualmente de naturaleza electrónica, utilizadas para la recogida, almacenamiento, tratamiento, difusión y transmisión de la información. Esto agrupa tanto a los dispositivos físicos (equipos informáticos, redes de telecomunicación, terminales, etc.) como el software o aplicaciones informáticas que funcionan sobre estos equipos (INE, 2017). El proceso de desarrollo y difusión de estas tecnologías mejora la eficiencia y productividad de países y regiones incrementando no sólo las posibilidades de crecimiento económico sino también del bienestar social, ya que pueden mejorar el acceso a los servicios básicos, facilitar la conectividad y crear nuevas oportunidades. En definitiva contribuyen a mejorar la forma en que los individuos se comunican, interactúan y se relacionan entre sí y con sus gobiernos (Baller, S.et al, 2016). Pero a su vez, la dotación de infraestructura y la disponibilidad y uso de las TIC (Barzilai-Nahon, K. 2006; Van Dijk, J.A. 2006, Vu, K.M. 2011) refuerzan las desigualdades existentes (Helsper, E.J. 2012; Witte J.C. y Mannon, S.E. 2010) en la sociedad global de la información. Por ello surge la necesidad de medir y comprender el grado de desarrollo digital que surgen a partir de las diferencias entre tener accesibilidad a la red y usar ordenadores e internet (Yu, L. 2006; Sáinz Peña, R., 2017).

El estudio del desarrollo digital y las diferencias entre los distintos territorios comienza a abordarse por primera vez en la década de 1980, en relación con las carencias de infraestructuras de telecomunicaciones en los países en vías de desarrollo. Es en 1984 cuando se presenta el informe de la Unión Tecnológica Internacional (organismo adscrito a la ONU) que señala el importante desequilibrio tecnológico y de desarrollo digital existente entre los países avanzados y los países en desarrollo (ITU, 2003). Posteriormente, será en la década los noventa del siglo XX cuando los investigadores pretendan explicar la diferencia entre tener o no tener, usar o no usar ordenadores e internet por parte de los ciudadanos (Yu, L. 2006; Contreras-Cabrera, G. 2012). A finales del siglo

\footnotetext{
${ }^{1}$ Este trabajo forma parte de los resultados del Proyecto: "La Brecha Digital en la Unión Europea. Modelos Explicativos, Predictivos y Espaciales" (CSO2015-67662-P), financiado por el Ministerio de Economía y Competitividad (2016-18).
} 
pasado empiezan a desarrollarse investigaciones sobre la dotación de infraestructura, la disponibilidad y la asequibilidad de los ordenadores y el uso de Internet (Barzilai-Nahon, K. 2006; Van Dijk, J. A 2006). Sin embargo, el desarrollo digital se entendía inicialmente de forma binaria (Cruz-Jesus F. et al, 2012) y se limitaba a distinguir entre tener y no tener acceso a las TIC. Esta concepción era útil para describir las desigualdades sociales y tecnológicas, pero era una clasificación binaria muy reductiva, imprecisa e inexacta.

Actualmente, el estudio del desarrollo digital se aborda desde diferentes niveles de análisis: los individuoshogares (individual), las empresas (organizacional) y el estado (global). El nivel individual distingue entre las personas que están dispuestas a integrar las TIC en su vida cotidiana y las que están a la zaga en el acceso y uso de nuevas tecnologías. Por otro lado, el desarrollo digital también se ha abordado desde la perspectiva espacial a diferentes escalas geográficas (Pick J.B. y Nishida, T., 2015): a escala mundial (Yates D.J. et al, 2011; Pick, J.B. y Azari, R. 2011), macrorregional (Kiiski, S. y Pohjola, M. 2002; Lengsfeld, J.H. 2001; Igari, N., 2014), y estatal y/o zonas económicas dentro de las naciones (Vicente, R.M. y López, A.J. 2011; Nishida T. et al, 2014), y en menor medida, estudios a escala regional (NUTS2 ${ }^{2}$ ) para el conjunto de Europa (Vicente, R.M. y Lopez, A.J., 2011).

Por otro lado, el desarrollo digital ha sido estudiado más en términos de acceso (infraestructuras) a las TIC y que en relación al uso (habilidades) de Internet. Sin embargo, la importancia del acceso a internet comenzó a cuestionarse cuando la conectividad a la red mediante banda ancha y los dispositivos digitales se hicieron más frecuentes (Scheerder, A. et al 2017). Esto puso de manifiesto que el desarrollo digital de los hogares e individuos pasó a estar condicionado por el uso de internet que realizan las personas (Brandtzaeg, P.B. et al, 2017, Hargittai, E. 2010) y no por nivel de accesibilidad a internet que es prácticamente generalizado, sobre todo en los países desarrollados (Sáinz Peña, R., 2017). En relación al uso de internet, los estudios generalmente se han centrado en los términos de frecuencia y el tipo de actividades (Scheeder, A. et al, 2017). Estas investigaciones han revelado que, aunque la búsqueda de información general en internet ha sido uno de los usos más comunes (Purcell, K. 2011), el aumento de la popularidad de las redes sociales ha cambiado los tipos de uso hacia aquellos que buscan una mayor interacción social (Van Deursen, A. J. et al, 2015).

En base a estos precedentes y ante la ausencia de estudios geográficos y regionales, este trabajo pretende identificar qué variables de acceso y uso de las TICs definen actualmente el desarrollo digital en hogares e individuos de las regiones europeas para establecer una tipología de las mismas que muestre el grado de desarrollo digital a escala regional.

\section{METODOLOGÍA}

\subsection{Fuentes, variables utilizadas y unidad de análisis}

Los datos que se han empleado en este trabajo proceden de la encuesta "Uso de las TIC en los hogares y por individuos" (isoc_i) de Eurostat para el año 2017. Dicha encuesta proporciona datos sobre el acceso y uso de las tecnologías de la información y la comunicación para dos unidades estadísticas: los hogares (todos los hogares privados con al menos un miembro en el grupo de edad de 16 a 74 años); y los individuos (personas de entre 16 y 74 años). La encuesta proporciona datos de los estados miembros de la UE, países candidatos, e Islandia y Noruega. Además, Eurostat proporciona estadísticas desagregadas por regiones de residencia (NUTS, apartado "isoc_reg"). Las 16 variables utilizadas se detallan en el Cuadro 1 agrupadas por áreas y unidad de medida (porcentajes de hogares y/o de personas).

El área de referencia escogida para el análisis regional del desarrollo digital de Europa en hogares e individuos es el nivel NUTS2 de las regiones de los 28 países del UE más República de Macedonia, Noruega, Islandia, Suiza y Turquía. Sin embargo, las variables de la encuesta "Uso de las TIC en los hogares y por individuos" de Eurostat enumeradas en el Cuadro 1 están desglosadas a nivel de NUTS2 para todos los países indicados anteriormente excepto para Alemania, Grecia, Polonia, Reino Unido y Turquía. Para solventar la falta de datos a escala regional de estos países y, por tanto, evitar realizar un análisis regional incompleto del desarrollo digital en hogares e individuos, se incluye en el estudio las regiones NUTS1 de estos países para los cuales Eurostat sí ofrece datos de las variables seleccionadas en el Cuadro 1. En consecuencia, para llevar a cabo esta investigación se ela-

\footnotetext{
${ }^{2}$ La clasificación NUTS (Nomenclature of territorial units for statistics) es el sistema jerárquico de división de la UE Fuente: Eurostat (2017c) <http://ec.europa.eu/eurostat/documents/345175/7451602/NUTS-map-ES.pdf>.
} 
boró una base de datos con 16 variables de uso de TICs en los hogares e individuos (Cuadro 1) para 242 regiones europeas (190 NUTS2 y 52 NUTS1 ${ }^{3}$ ).

Cuadro 1 - Variables empleadas en el análisis.

\begin{tabular}{|c|c|}
\hline VARIABLE Y UNIDAD DE MEDIDA & ABREVIATURA \\
\hline \% Hogares que tienen conexión a internet & H_ACCESO_Casa \\
\hline \% Hogares que tienen conexión a internet por banda ancha & H_ACCESO_Banda ancha \\
\hline \% Hogares que con acceso a internet & H_ACCESO_Intenet \\
\hline$\%$ Individuos que usan internet diariamente & IND_USO_Diario \\
\hline $\begin{array}{l}\text { \% Individuos que participan en redes sociales (creando perfiles de usurario, } \\
\text { enviando mensajes u otras participaciones en Facebook, Twitter, etc.) }\end{array}$ & IND_USO_Redes sociales \\
\hline \% Individuos que usan internet para banca electrónica & IND_USO_Banco \\
\hline \% Individuos que usan internet para vender bienes o servicios & IND_USO_Vender \\
\hline \% Individuos que usan internet siempre & IND_USO_Siempre \\
\hline \% Individuos que acceden a internet fuera de casa o en el trabajo & IND_ACCESO_Fuera \\
\hline $\begin{array}{l}\text { \% Individuos que interactuaron con las autoridades públicas (en los últimos } \\
\qquad 12 \text { meses) }\end{array}$ & IND_INTER_Autoridades \\
\hline $\begin{array}{l}\text { \% Individuos que interactuaron con las autoridades públicas para enviar } \\
\text { formularios cumplimentados (en los últimos } 12 \text { meses) }\end{array}$ & IND_INTER_Enviar formularios 12 meses \\
\hline $\begin{array}{l}\text { \% Individuos que compraron algún producto o servicio a través de Internet } \\
\text { en los últimos } 3 \text { meses }\end{array}$ & IND_COMPRA_Online_3 meses \\
\hline $\begin{array}{l}\text { \% Individuos que compraron algún producto o servicio a través de Internet } \\
\text { en el último año }\end{array}$ & IND_COMPRA_Online último año \\
\hline $\begin{array}{l}\text { \% Individuos que solicitaron bienes o servicios, a través de Internet, para uso } \\
\text { privado, hace más de un año o nunca }\end{array}$ & IND_COMPRA_Online nunca o hace más de 1 año \\
\hline $\begin{array}{l}\text { \% Individuos que reservaron a través de internet alojamiento de vacaciones } \\
\text { (en los últimos } 12 \text { meses) }\end{array}$ & IND_COMPRA_Viajes \\
\hline \% Individuos que compraron a través de internet a otros países de la EU & IND_COMPRA_A otros paises UE \\
\hline
\end{tabular}

Fuente: Elaboración propia.

\subsection{Análisis factorial}

El estudio conjunto de todos los aspectos que contempla el concepto de desarrollo digital en los hogares e individuos de las regiones europeas demanda el empleo de técnicas estadísticas multivariantes. Este tipo de métodos estadísticos permiten analizar las interdependencias entre el acceso a las TICs, el uso diario de internet en diversos dispositivos en el hogar y fuera de él para el comercio y otras actividades personales. Autores como Cruz -Jesus, F. et al. (2012, 2016) consideran que el análisis factorial (FA) es una técnica estadística especialmente adecuada para el análisis del desarrollo digital, dada la c

omplejidad del estudio de las TIC en la sociedad y la economía.

Para conocer cómo se interrelacionan las variables de uso de las TIC en los hogares y en individuos, se ha llevado a cabo un análisis factorial de tipo exploratorio y por el método de componentes principales mediante el paquete informático estadístico IMB SPSS v23. Mediante el análisis exploratorio se pretende obtener un número óptimo de factores y la estructura factorial que defina el desarrollo digital en hogares e individuos de las regiones europeas. Por su parte, el método de componentes principales es el más adecuado cuando se pretende establecer alguna teoría o modelo de manera inicial ya que busca encontrar el menor número de factores que expliquen la mayor cantidad de varianza o información posible (Frías-Navarro, D. y Pascual Soler, M, 2012). Con este fin se optó por obtener una matriz factorial rotada por el método Varimax.

\subsection{Análisis Clúster}

La identificación de tipologías de regiones europeas implica agruparlas en conjuntos definidos por la homogeneidad de características comunes de acceso y uso cotidiano de las TIC en hogares e individuos. La tipología de las regiones europeas se ha obtenido mediante el análisis clúster a partir de los resultados obtenidos en el AF. EI

\footnotetext{
${ }^{3}$ Por falta de datos se omitieron en el análisis final 7 NUTS2 y 2 NUTS1.
} 
empleo de métodos de análisis multivariantes de conglomerados es de gran utilidad en los casos que se busca resolver problemas de identificación y clasificación en unidades homogéneas a partir de varias variables. Autores como Lebart, L. et al. (1995) y de Pardo, C.E. y Del Campo, P.C. (2007) aconsejan la combinación del AF y del análisis clúster en dos etapas: primero un análisis de conglomerados jerárquicos $\mathrm{y}$, posteriormente, un análisis de $\mathrm{K}$ medias. Este procedimiento soluciona diversos inconvenientes de las técnicas de clustering como pueden ser la clasificación a partir de pocas variables significativas o no correlacionadas (basadas en los factores del AF); o el problema derivado de las diferencias de escala de las variables utilizadas (que se evitaría al utilizar como variables de agrupamiento las puntuaciones $z$ de los factores normalizados).

Mediante el análisis de k-medias se obtuvieron los valores medios de cada grupo (centros de los conglomerados finales) a partir de los cuales se calculan los porcentajes de hogares e individuos que usan TICs en cada región para los dos factores. Cada clúster agrupa regiones que presentan porcentajes similares de desarrollo digital en hogares e individuos en los 2 factores, estableciendo una tipología de desarrollo digital de las regiones europeas. Así, los clústeres que tienen mayor porcentaje de hogares/individuos en los 2 factores tienen un mayor desarrollo digital (y, al contrario).

\section{RESULTADOS}

\subsection{Factores que determinan el desarrollo digital en los hogares y por individuos de las regiones europeas}

El análisis factorial exploratorio se realizó con las 16 variables de uso de las TIC en los hogares y por individuos de las regiones europeas. El AF válido incluye 14 variables y las medidas de adecuación de las variables introducidas (determinante, test de KMO y test de esfericidad de Bartlett, Cuadro 2) muestran que las variables están altamente correlacionadas entre sí y, por tanto, el resultado del AF es correcto. En efecto, el determinante de la matriz de correlaciones es muy bajo (1,89E-012); el test de Bartlett permite contrastar la hipótesis de nulidad de ausencia de correlación entre las variables; y el valor del índice adecuación muestral KMO es igual o superior a 0,80 (en concreto, 0,847) tal y cómo recomienda Kaiser (1970).

La elección del número de factores finales se hizo en función de la Varianza total explicada y el método Kaiser como puede observarse en el Cuadro 3. Se obtuvieron 2 factores porque éstos suman mayor cantidad de información posible (la varianza total explicada acumulada entre los 2 factores es de casi el $80 \%$, cumpliendo el criterio de Pearson) y además son los 2 componentes con un autovalor propio superior a 1 (de acuerdo con el método de Kaiser).

Cuadro 2 - KMO y prueba de Bartlett.

\begin{tabular}{|c|c|c|}
\hline \multicolumn{2}{|c|}{$\begin{array}{c}\text { Medida de adecuación muestral de } \\
\text { Kaiser-Meyer-Olkin. }\end{array}$} & 0,870 \\
\hline & Chi-cuadrado aproximado & 6105,11 \\
\cline { 2 - 3 } $\begin{array}{c}\text { Prueba de esfericidad de } \\
\text { Bartlett }\end{array}$ & gl & 105 \\
\cline { 2 - 3 } & Sig. & 0,000 \\
\hline
\end{tabular}

Determinante de la matriz de correlaciones $=1,89 \mathrm{E}-012$.
Cuadro 3 - Varianza total explicada.

\begin{tabular}{|c|c|c|c|}
\hline \multirow{2}{*}{ Componente } & \multicolumn{3}{|c|}{ Autovalores iniciales } \\
\cline { 2 - 4 } & Total & \% del varianza & $\%$ acumulado \\
\hline 1 & 9,678 & 69,130 & 69,130 \\
\hline 2 & 1,438 & 10,274 & 79,404 \\
\hline 3 & 0,764 & 5,454 & 84,858 \\
\hline 4 & 0,515 & 3,682 & 88,540 \\
\hline 5 & 0,374 & 2,673 & 91,213 \\
\hline 6 & 0,360 & 2,572 & 93,785 \\
\hline 7 & 0,294 & 2,099 & 95,883 \\
\hline 8 & 0,213 & 1,524 & 97,407 \\
\hline 9 & 0,129 & 0,924 & 98,330 \\
\hline 10 & 0,078 & 0,556 & 98,886 \\
\hline 11 & 0,064 & 0,459 & 99,345 \\
\hline 12 & 0,044 & 0,312 & 99,657 \\
\hline 13 & 0,036 & 0,261 & 99,918 \\
\hline 14 & 0,011 & 0,082 & 100,000 \\
\hline
\end{tabular}

Método de extracción: Análisis de componentes principales. 
En el Cuadro 4 muestra la matriz de componentes rotados por el método de Varimax en la que podemos observar las correlaciones entra las variables y los 2 factores obtenidos. La interpretación de los mismos es la siguiente:

El factor 1 aporta el 69,13\% de la varianza. Está formado por 12 variables relacionadas positivamente con:

i) La disponibilidad de Internet y la capacidad de acceso por banda ancha en los hogares (H_ACCESO_Casa y H_ACCESO_Banda ancha).

ii) El uso diario de Internet (IND_USO_Diario y IND_USO_Siempre).

iii) Las actividades realizadas por motivos particulares como: banca electrónica (IND_USO_Banco), venta de bienes o servicios (venta directa, mediante subastas, eBay, etc., IND_USO_Vender); compra a través de Internet en los últimos meses, en concreto algún producto o servicio (IND_COMPRA_Online_3 meses y IND_COMPRA_Online último año), de servicios de alojamiento de vacaciones (hotel, apartamento, etc., IND_COMPRA_Viajes) o a vendedores de otros países del Unión Europea (IND_COMPRA_A otros paises UE); el contacto o interacción con las administraciones o servicios públicos por Internet por motivos particulares (IND_INTER_Autoridades) y/o para enviar formularios cumplimentados (como, p. ej., presentar la declaración del renta u otros impuestos (IND_INTER_Enviar formularios 12 meses), y

iv) Las personas que accedieron a Internet fuera del hogar o del trabajo (IND_ACCESO_Fuera).

Esto indica que, en las regiones europeas, la disponibilidad de acceso a internet por banda ancha en los hogares está asociada al uso diario de internet por motivos particulares de los individuos para el comercio electrónico, banca electrónica y para relacionarse con los entes públicos a través de administración electrónica ya sea en los propios hogares o fuera de éste. Este factor se puede denominar "Disponibilidad de banda ancha y uso diario de comercio, banca y administración electrónica".

El factor 2 representa solo el 10,27\% de la varianza, y establece una relación entre dos variables: utilización de conexión a internet por banda ancha en los hogares (H_ACCESO_Banda ancha) con el uso de redes sociales (IND_USO_Redes sociales). Se denominaría "Uso de redes sociales por banda ancha".

\subsection{Tipología de regiones europeas según desarrollo digital.}

La clasificación de las regiones europeas con el análisis clúster, a partir de los resultados obtenidos en el AF, por el procedimiento del vecino más lejano y el método de Ward con la distancia euclídea al cuadrado permite apreciar a 7 grupos diferenciados de regiones europeas a partir del dendograma obtenido. Por su parte, mediante el análisis de k-medias se obtuvieron los valores medios de cada grupo (centros de los conglomerados finales, Cuadro 5); y se calculó la media del porcentaje de hogares e individuos de los dos factores para el conjunto de regiones europeas de cada clúster, lo que permite determinar el grado de desarrollo digital de las mismas. Como se avanzaba en metodología, cada clúster agrupa regiones que presentan porcentajes similares de desarrollo digital en hogares e individuos en los 2 factores. Si se calcula la media del valor de los porcentajes de hogares/ individuos de los 2 factores para cada grupo (Cuadro 5) se puede establecer una tipología jerarquizada de desarrollo digital de las regiones europeas (Mapa 1). En consecuencia, las regiones europeas (NUTS2) se ordenan de mayor a menor nivel de desarrollo digital de la siguiente manera:

Clúster 1: Regiones con máximo nivel de desarrollo digital. Es el grupo de regiones que presentan mayores 
porcentajes de desarrollo digital de hogares/individuos con una media del 73,7 \%. Lo componen 48 regiones: la mayor parte de las NUTS2 de Noruega, Suecia, Finlandia, Reino Unido, regiones de Alemania occidental, Países Bajos e Islandia. En consecuencia, estas regiones presentan los valores más altos de hogares/individuos tanto en el factor 1 "Disponibilidad de banda ancha y uso diario de comercio, banca y administración electrónica" (63,3 \%); como en el factor 2 "Redes sociales por banda ancha" (84,3\%).

Clúster 2: Regiones con alto nivel de desarrollo digital (70,3\% de media de hogares/individuos). Está formado por 20 regiones: la británica de Northen Ireland, la noruega de Hedmark og Oppland, la sueca de Sydsvrige, la finlandesa Etelä-Suomi, alemana de Hamburg y Berlín, las regiones belgas de Anterwepen, Wlaams-Brabant y Brabant Vallon, la francesa de lle de France y las regiones de Suiza (excepto una), Dinamarca y Estonia. Estas regiones se caracterizan por tener porcentajes más altos de hogares/individuos que usan TICs en los dos factores por detrás de las regiones del Clúster 1: un 61,9\% de hogares/individuos de media para el factor 1 ("Disponibilidad de banda ancha y uso diario de comercio, banca y administración electrónica); y un 78,7\% para el factor 2 "Redes Sociales por banda ancha".

Clúster 3. Regiones con nivel alto-medio de desarrollo digital $(64,6 \%)$ ligeramente por encima de la media europea (62,8\% de media). Es el grupo más numeroso de NUT2s (60) que comprende a las regiones de Irlanda, España (excepto Galicia), Bélgica (excepto las mencionadas en el cluster 2), gran parte de Alemania, sobre todo las regiones orientales, regiones Austriacas, extendiéndose por las regiones del sur de la Republica Checa, Eslovenia, norte de Hungría y Eslovenia, y Letonia. El clúster se sitúa en el tercer nivel de desarrollo digital con casi un 50\% de hogares/ individuos con "Disponibilidad de banda ancha y uso diario de comercio, banca y Administración electrónica"; y porcentajes altos de hogares/individuos que hacen "Uso de redes sociales por banda ancha" (77,9\%).

Clúster 4: Regiones con nivel medio-bajo de desarrollo digital con déficit en el factor 2 ("Uso de redes sociales por banda ancha"). Está compuesto por 21 regiones, todas las francesas menos Isle de France. Estas regiones presentan un nivel en torno a la media europea de desarrollo digital (59,9\% de media de hogares/individuos) que se basa fundamentalmente en un porcentaje alto-medio $(53,6 \%)$ de hogares/individuos en el factor 1 ("Disponibilidad de Acceso a banda a ancha y uso diario de comercio, banca y administración electrónica". Por el contario, los porcentajes de hogares/individuos en el "Uso de redes sociales por banda ancha" (factor 2) se alejan 10 puntos de la media europea (sólo un 66,2\%).

Clúster 5: Regiones con medio-bajo nivel de desarrollo digital con déficit en el factor 1 ("Disponibilidad de banda ancha y uso diario de comercio, banca y administración electrónica"), con valores en ambos factores por debajo de la media europea (un 57,9\% de hogares/individuos). Está formado por 31 regiones: Galicia (España), Región Centro, Algarve e islas de Portugal, regiones del norte y centro de Italia, resto de regiones checas, húngaras y eslovenas no incluidas en el cluster 3, las regiones occidentales rumanas (Nord-Vest, Vest) y la región capital de Bucaresti-fov, la región búlgara de Yugozapaden y las turcas de Ankara y Konya. Estas regiones ocupan la quinta posición en desarrollo digital sustentándose en valores altos del factor 2 ya que el 76,4 \% de los hogares/ individuos usan las redes sociales por banda ancha. Por el contrario, sólo el 39,3\% de ellos en estas regiones tienen "Disponibilidad de banda ancha y uso diario de comercio, banca y administración electrónica" (factor1).

Clúster 6: Regiones con nivel bajo de desarrollo digital (por debajo de la media europea, con el 53,2\% de hogares/individuos) con déficit del factor 2. Este último grupo está formado por 16 regiones de la Europa del Este (la región alemana de Bradenburg, el resto de regiones polacas no incluidas en el grupo 6, Stredné Slovesko en Eslovaquia, Sud-Vest Ottania en Rumanía y las regiones turcas del Noreste, Centro-Este y Sudeste de Anatolia y del Este del Mar Negro). Las regiones de este grupo tienen porcentajes de los hogares/individuos por debajo de la media fundamentalmente en el factor "Uso de redes sociales por banda ancha" (es el grupo de regiones que más se aleja de toda Europa de la media en 7 puntos porcentuales). Igualmente, los porcentajes de hogares/individuos son bajos en el factor 1 "Disponibilidad y acceso a banda ancha para el uso diario de comercio, banca y administración electrónica" (36,9\%).

Clúster 7. Regiones de nivel bajo de desarrollo digital de hogares/individuos con un mayor déficit en el factor 1 ("Disponibilidad de acceso a internet y uso diario de comercio, banca y administración electrónica"). Este conglomerado lo forman 37 regiones: regiones portuguesas e italianas no incluidas en el cluster 4, regiones grie- 
gas, de Macedonía, 3 regiones polacas del sur y este del país (Wschodni y Makroregion Pólnocno-Zachodni), regiones bosnias, búlgaras (excepto Yugozapaden) y las regiones turcas occidentales y centrales (Aegean, Marmara, del Mar Negro, Central Anatolia, etc.). Al igual que las regiones del grupo anterior, tienen valores alejados de la media en los dos factores, pero en este clúster el mayor déficit está en el factor 1 (casi 9 puntos porcentuales por debajo de la media con un 32,9\% de los hogares/individuos); mientras que el factor 2 ("Uso de redes sociales por banda ancha) tiene valores relativamente altos (72,5\% de hogares/individuos).

Cuadro 5 - Tipología de Desarrollo Digital de las Regiones

\begin{tabular}{|c|c|c|c|c|c|c|c|}
\hline Jerarquía & $\begin{array}{l}\text { NIVEL DE DESARROLLO } \\
\text { DIGITAL }\end{array}$ & $\begin{array}{l}\text { Centro de conglo- } \\
\text { merados finales } \\
\text { Factor1 }\end{array}$ & $\begin{array}{l}\text { Centro de conglo- } \\
\text { merados finales } \\
\text { Factor2 }\end{array}$ & $\begin{array}{c}\text { Nivel medio } \\
\text { de desarrollo } \\
\text { digital }\end{array}$ & $\begin{array}{l}\text { Nivel medio } \\
\text { de Factor1 }\end{array}$ & $\begin{array}{l}\text { Nivel medio } \\
\text { de Factor2 }\end{array}$ & $\mathrm{N}^{\circ}$ regiones \\
\hline 1 & MÁXIMO & 1,05 & 0,83 & 73,7 & 63,2 & 84,3 & 48 \\
\hline 2 & ALTO & 1,16 & $-0,19$ & 70,3 & 61,9 & 78,7 & 20 \\
\hline \multirow[t]{2}{*}{3} & ALTO-MEDIO & $-0,06$ & 0,49 & 64,6 & 50,0 & 77,9 & 60 \\
\hline & Media & & & 62,8 & 49,0 & 76,6 & 233 \\
\hline 4 & MEDIO-BAJO F2* & 0,96 & $-2,21$ & 59,9 & 53,6 & 66,2 & 21 \\
\hline 5 & MEDIO-BAJO F1* & $-1,00$ & 0,45 & 57,9 & 39,3 & 76,4 & 31 \\
\hline 6 & BAJO F2* & $-0,61$ & $-1,49$ & 53,2 & 36,9 & 69,6 & 16 \\
\hline \multirow[t]{2}{*}{7} & BAJO F1* & $-1,34$ & $-0,25$ & 52,7 & 32,9 & 72,5 & 37 \\
\hline & & \multicolumn{2}{|c|}{ Puntaciones factoriales } & \multicolumn{3}{|c|}{ \% de hogares e individuos } & \\
\hline
\end{tabular}

Fuente: Elaboración propia.

${ }^{*} \mathrm{~F} 1$ y $\mathrm{F} 2$ : factor 1 y factor 2 , respectivamente.

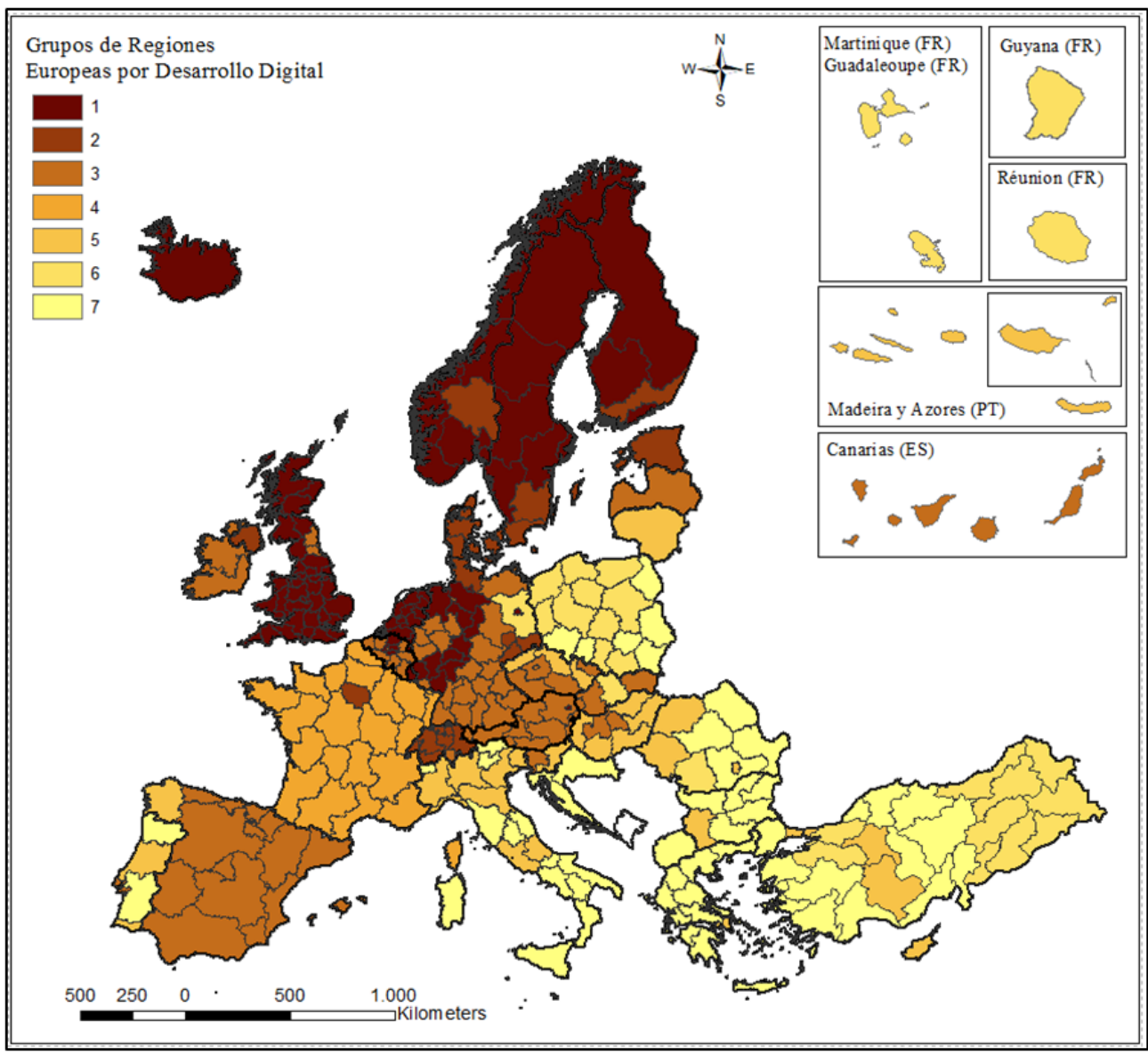

Mapa 1 - Grupos de regiones europeas según el grado de desarrollo digital. Fuente: Elaboración propia. 


\section{CONCLUSIONES}

El uso que los hogares/individuos de las regiones europeas hacen de las TICs viene determinado por la disponibilidad y el acceso a la banda ancha como muestran los resultados del AF. La conexión por banda ancha es el componente más importante y común en el comportamiento respecto al uso de las TICs de los hogares e individuos. Sin embargo, aunque las infraestructuras de banda ancha están extendidas en toda Europa (el $83 \%$ de media de hogares e individuos en las regiones de estudio), las diferencias en los niveles de desarrollo digital entre regiones europeas depende el porcentaje de hogares/individuos que usan a diario las TICs para el comercio, banca y administración electrónica (factor 1); mientras que el uso de internet para participar en las redes sociales (factor 2) al estar más generalizado, no incide en los niveles de desarrollo digital de las regiones europeas.

Igualmente, los resultados de este estudio muestran que más de la mitad de las regiones europeas han alcanzado un nivel medio y alto de desarrollo digital (el 55\% de las mismas). No obstante, en su conjunto, las regiones presentan un comportamiento heterogéneo y jerarquizado en el nivel de desarrollo digital, lo que pone de manifiesto la existencia de desequilibrios espaciales en el nivel de uso y acceso a las TICs en los hogares/ individuos, y, por lo tanto, la existencia de brecha digital entre regiones. Así, por un lado, el mayor acceso y uso de las TICs avanzadas se realiza en las regiones del Norte y Centro de Europa. Mientras las regiones del sur y este de Europa registran menores porcentajes de hogares/individuos que utilizan las TICs respecto a las regiones del norte del continente. Y, por otro, las diferencias en el desarrollo digital en Europa son menores en relación al uso de redes sociales que en el uso diario de comercio, banca y administración electrónica. Desde la perspectiva de la Geografía Económica, las diferencias de desarrollo digital entre regiones europeas que se han identificado en este estudio siguen el comportamiento espacial del modelo de desarrollo centro-periferia (Ruiz-Rodríguez, F. et al, 2018, Billon, M. et al, 2016) imperante en innovación (Jordá-Borrell, R., et al, 2015)

No obstante, esta investigación presenta una serie de limitaciones. En primer lugar, el número de variables incluidas en el análisis (14) es limitado debido a la escasa disponibilidad de datos a escala regional NUTS2 para Europa. Por otra, si bien el uso del análisis clúster permite identificar y comparar a nivel agregado el nivel de desarrollo digital entre los 7 grupos de regiones europeas (clústers), sería conveniente analizar de forma más detallada las diferencias de comportamiento entre las regiones europeas, lo que podría realizarse mediante la elaboración de un indicador complejo que permita medir y comparar el desarrollo digital de las regiones europeas.

Las conclusiones de este trabajo sugieren profundizar en el estudio del desarrollo digital de las regiones europeas a nivel individuos/hogares. Así, sería de interés conocer las causas de las diferencias regionales de desarrollo digital. Ello conllevaría medir la incidencia de diversas variables sobre el desarrollo digital, tanto de tipo socioeconómico como geográficas (estructura empresarial regional, actividades de I+D e innovación, capacidades TICs, sensibilización digital, nivel educativo, renta, políticas digitales y otros aspectos endógenos del territorio, etc.). Ello puede abordarse mediante la aplicación de técnicas de regresión que permite conocer cuáles son los factores que explican las diferencias regionales del uso de las TICs en los hogares/individuos.

\section{BIBLIOGRAFIA}

BALLER, S., DUTTA, S., \& LANVIN, B. (2016). Global Information Technology Report 2016. Ouranos.

BARZILAI-NAHON, K. (2006). Gaps and bits: Conceptualizing measurements for digital divide/s. The information society, 22(5), 269-278.

BILLON, M., LERA-LOPEZ, F., \& MARCO, R. (2016). ICT use by households and firms in the EU: links and determinants from a multivariate perspective .Review of World Economics,152(4), 629-654.

BRANDTZAEG, P. B., HEIM, J., \& KARAHASANOVIĆ, A. (2011). Understanding the new digital divide-A typology of Internet users in Europe. International journal of human-computer studies, 69(3), 123-138.

CONTRERAS-CABRERA, G. (2012). Asociacionismo en red para la integración sociodigital en Andalucía. Revista de Estudios Andaluces, (29), 105-126.

CRUZ-JESUS, F., OLIVEIRA, T., \& BACAO, F. (2012). Digital divide across the European Union. Information \& Management, 49 (6), 278-291.

CRUZ-JESUS, F., VICENTE, M. R., BACAO, F., \& OLIVEIRA, T. (2016). The education-related digital divide: An analysis for the EU-28. Computers in Human Behavior, 56, 72-82.

EUROSTAT (2018): http://ec.europa.eu/eurostat/web/digital-economy-and-society/data/database. Acceso el 10 enero 2018.

FRÍAS-NAVARRO, D., \& PASCUAL SOLER, M. (2012). Prácticas del análisis factorial exploratorio (AFE) en la investigación sobre conducta del consumidor y marketing. Suma Psicológica, 19(1).

HARGITTAI, E. (2010). Digital na ( $t$ ) ives? Variation in internet skills and uses among members of the "net generation". Sociological inquiry, 80(1), 92-113. 
HELSPER, E. J. (2012). A corresponding fields model for the links between social and digital exclusion. Communication theory, 22 (4), 403-426.

IGARI, N. (2014). How to successfully promote TIC usage: A comparative analysis of Denmark and Japan. Telematics and Informatics, 31(1), 115-125.

INE (2017): Encuesta sobre el uso de TIC y comercio electrónico en las empresas Metodología, Spain, Madrid (2017). http:// www.ine.es/daco/daco42/comele/metocor.pdf,Acceso 25 marzo 2018

INTERNATIONAL TELECOMMUNICATION UNION -ITU- (2003): International Telecommunication Union -ITUWorld telecommunication development report 2003: Access indicators for the information society. International Telecommunications Union,Geneva, Switzerland (2003). http://www.itu.int/net/wsis/tunis/newsroom/stats/WorldTelecomDevelopmentReport -2003_E.pdf, Acceso 10 enero 2018.

JORDÁ BORRELL, R., RUIZ RODRÍGUEZ, F., \& GONZÁLEZ RELAÑO, R. (2015). Factors and taxonomy of technology purchase (TP) by internationalized innovative companies in peripheral European regions. Papers in Regional Science, 94(S1).

KIISKI, S., \& POHJOLA, M. (2002). Cross-country diffusion of the Internet. Information Economics and Policy, 14(2), 297-310.

LEBART, L., MORINEAU, A. \& PIRON, M. (1995), Statisitique exploratoire multidimensionnelle, Dunod, Paris.

LENGSFELD, J. H. (2011). An econometric analysis of the sociodemographic topology of the digital divide in Europe. The information society, 27(3), 141-157.

NISHIDA, T., PICK, J. B., \& SARKAR, A. (2014). Japan's prefectural digital divide: A multivariate and spatial analysis. Telecommunications policy, 38(11), 992-1010.

PARDO, C. E., \& DEL CAMPO, P. C. (2007). Combinación de métodos factoriales y de análisis de conglomerados en R: el paquete FactoClass. Revista colombiana de estadística, 30(2).

PICK, J. B., \& AZARI, R. (2011). A global model of technological utilization based on governmental, business-investment, social, and economic factors. Journal of Management Information Systems, 28(1), 49-84.

PICK, J. B., \& NISHIDA, T. (2015). Digital divides in the world and its regions: A spatial and multivariate analysis of technological utilization. Technological Forecasting and Social Change, 91,1-17.)

PURCELL, K. (2011). Search and email still top the list of most popular online activities. Pew Internet \& American Life Project, 9, 1 $-15$.

RUIZ-RODRÍGUEZ, F., LUCENDO-MONEDERO, A. L., \& GONZÁLEZ-RELAÑO, R. (2018). Measurement and characterisation of the Digital Divide of Spanish regions at enterprise level. A comparative analysis with the European context. Telecommunications Policy, Vol. 42, Issue 3, April 2018, Pages 187-211.

SÁINZ PEÑA, R. (2017): Sociedad digital en España, 2017. Fundación Telefónica y Editorial Ariel.

SCHEERDER, A., VAN DEURSEN, A., \& VAN DIJK, J. (2017). Determinants of Internet skills, uses and outcomes. A systematic review of the second-and third-level digital divide. Telematics and informatics.

VAN DEURSEN, A. J., \& HELSPER, E. J. (2015). A nuanced understanding of Internet use and non-use among the elderly. European journal of communication, 30(2), 171-187.

VAN DIJK, J. A. (2006). Digital divide research, achievements and shortcomings. Poetics, 34(4-5), 221-235.

VICENTE, M. R., \& LÓPEZ, A. J. (2011). Assessing the regional digital divide across the European Union-27. Telecommunications Policy, 35(3), 220-237.

VU, K. M. (2011). TIC as a source of economic growth in the information age: Empirical evidence from the 1996-2005 period. Telecommunications Policy, 35(4), 357-372.

WITTE, J. C., \& MANNON, S. E. (2010). The internet and social inequalitites. Routledge.

YATES, D. J., GULATI, G. J., \& WEISS, J. W. (2011, January). Different paths to broadband access: The impact of governance and policy on broadband diffusion in the developed and developing worlds. In System Sciences (HICSS), 2011 44th Hawaii International Conference on (pp. 1-10). IEEE.

YU, L. (2006). Understanding information inequality: Making sense of the literature of the information and digital divides. Journal of Librarianship and Information Science, 38(4), 229-252. 
Página intencionalmente dejada en blanco 


\title{
Factores de mayor incidencia en la adopción de innovaciones tic a escala de pais. Importancia de las relaciones directas e indirectas entre factores ${ }^{1}$
}

\author{
Rosa Maria Jordá-Borrella (a), Javier López-Otero (b), Gustavo Contreras-Cabrera (c) \\ (a) Centro de trabajo, Universidad Sevilla, email borrell@us.es \\ (b) Centro de trabajo, Universidad Isabel I, email javier.lopez.otero@ui1.es \\ (c) Centro de trabajo, Universidad Sevilla, email gcontreras@us.es
}

\begin{abstract}
Resumen
Esta investigación modelizó los factores que influyen en la adopción de innovaciones TIC en las empresas (ICT), determinando su influencia directa e indirecta, y la importancia de cada constructo en el modelo. Se identificaron los factores incidentes en la adopción de ICT mediante el modelo TOE. Las hipótesis se testaron usando una muestra de empresas con información agregada a nivel de país, y se empleó PLS-SEM como método de estimación y comprobación de las hipótesis. Posteriormente, se emplearon los algoritmos Betweenness, y Beta Centrality para determinar el papel de cada factor en la red. El constructo más determinante fue la Globalización de las firmas debido a la influencia indirecta de éste en el modelo. Igualmente, resultó clave el constructo del entorno tecnológico ICT por su gran influencia sobre la adopción de innovaciones, así como por su papel transmisor de los efectos indirectos de los demás constructos.
\end{abstract}

Palabras claves: Adopción Tecnologías TIC, Modelo TOE (Tecnología-Entorno-Empresa), Globalización, PLS-SEM, Análisis de Redes.

\section{INTRODUCTION}

En los últimos años se ha producido un creciente interés por las tecnologías ICT o TIC y su impacto en las empresas debido a los efectos que genera en la productividad (Oliveira et al.,2014; Buyya et al., (2009); Škrinjar et al., 2010), internacionalización (Laursen and Salter, 2006), competitividad, reducción de costes y satisfacción del cliente (Ifinedo, 2011; Capó -Vicedo, 2007).

Durante las últimas décadas, las tecnologías ICT han innovado los procesos productivos a causa de la automatización. Y esa transformación de los procesos productivos ha generado a su vez una mejora en la eficiencia de éstos y un incremento de la internacionalización de la empresa. De forma que la simbiosis de ambos procesos ha dado lugar a la globalización de los procesos de producción (Milberg and Winkler (2013).

Precisamente, el concepto de la globalización de los procesos de producción se apoya en los avances tecnológicos, en la capacidad de los países por atraer inversión directa extranjera, en cómo éstos territorios interrelacionan dichas inversiones con el tejido productivo local y en el surgimiento de la sociedad del conocimiento; constituyendo factores fundamentales para que las naciones (Frenz and Letto-Gillies,2009) desarrollen habilidades para internacionalizarse conectándose a redes globales.

Por otra parte, las tecnologías ICT han posibilitado la comunicación empresarial Business to Business (B2B) al contribuir significativamente a la sincronización productiva con proveedores y otras organizaciones (Armbrust et al., 2010) de distintos países, así como a la sincronización de la actividad global de las multinacionales, reforzando su papel en la globalización (Palafox, 2017). Igualmente, el eCommerce ha favorecido el acceso a clientes remotos reduciendo los costes de la puesta en contacto (Mayer et al., 2013 Hong and Zhu, 2006; Oliveira and Martins, 2010).

Paralelamente a la introducción de estas tecnologías se ha producido una creciente disparidad entre las empresas que las adoptan y las que no (Bach et al, 2013), y un incremento de los flujos de inversión directa extran-

\footnotetext{
${ }^{1}$ Este trabajo forma parte del Proyecto Investigación del Ministerio Economía y Competitividad: La brecha digital en la UE, modelos explicativos,
} predictivos y espaciales (CS2015-67662-P). 
jera desde los países avanzados a determinadas naciones emergentes (Chaminade,2012); generando la interrelación de ambos procesos un aumento de la disparidad digital entre los estados a nivel mundial (Alderete et al.,2014; Addison, and Heshmati, (2003). Ante esta nueva situación, los gobiernos se están preocupado por mitigar las diferencias digitales entre países mediante políticas de fomento y difusión de las tecnologías ICT en la empresa y en la administración (Addison, and Heshmati, (2003).

Sin embargo, el sector no ha parado de crecer y se encuentra en una dinámica en la que están surgiendo nuevas tecnologías que pueden transformar de un modo radical los sistemas de producción actuales (Lin, and Lin, 2008; Tsai et al., 2010). En este sentido, la aparición de nuevas tecnologías ICT (Wang and Wang, 2016) conducirán a cambios profundos en los actuales procesos de producción.

En consecuencia, la literatura científica ha dedicado grandes esfuerzos para analizar los mecanismos que influyen en la adopción de ICT en las firmas. Una parte significativa de los trabajos se han centrado en factores relativos a la organización y la tecnología a adoptar (Oliveira et al.; Alderete et al, 2014), destacando los costes de adopción, la fiabilidad y la seguridad (Gupta et al., 2013), o la falta de destrezas para implementar la tecnología. Sin embargo, son pocos los estudios que hayan realizado un análisis integral, tomando como unidad de análisis el país, que incluya aspectos del entorno científico y económico de las naciones, la influencia que ejerce la globalización en las firmas y en los estados adoptantes de ICT, así como la capacidad de gestión de la innovación en las empresas.

De este modo, en esta investigación se abordan los siguientes objetivos: 1.- modelizar a través de las técnicas PLS ( Partial Least Squares) y SEM (Structural Ecuation Modeling) los factores que influyen en la adopción de las innovaciones ICT, empleando como marco de referencia el modelo TOE (tecnología-entorno-empresa). 2. En dicha modelización se identificarán los efectos directos de los constructos elaborados sobre la adopción ICT, así como los factores que inciden de un modo indirecto sobre la adopción de innovaciones ICT.

\section{MODELO DE INVESTIGACIÓN Y DESARROLLO DE HIPÓTESIS}

La adopción de innovaciones en la empresa es un fenómeno ampliamente estudiado en la literatura científica, sin embargo, existe mucha menos investigación dirigida al análisis de la adopción de innovaciones ICT en los países.

Existen varios modelos que abordan la difusión de las innovaciones ICT, entre ellos están TecnologíaEmpresa-Entorno (TOE) (Tornatzky et al., 1990) y el modelo DOI de Rogers (1995). Si bien, de acuerdo con las características de esta investigación resulta más apropiado utilizar el modelo TOE.

Para ello, se ha considerado al país, como un activo relacional o espacio relacional en construcción permanente en función de la globalización, de la dimensión económica-científica de cada estado, del contexto ICT y de la capacidad de las firmas para adoptar ICT. Después se han adaptado los tres constructos TOE: factor del entorno empresarial, factor tecnológico y factor empresarial del problema estudiado.

El factor entorno se concreta según (Tornatzky et al., 1990) en el entorno de las firmas, las características del sector, el grado de competición de las empresas, acceso a recursos de los proveedores y negociación con las administraciones. En esta investigación el factor se ha subdividido en dos constructos, Grado de Globalización de las empresas de un País (GLOBAL), Entorno Económico y Científico (EEC), debido a que el proceso de difusión/ adopción del conocimiento se ha visto acelerado por la apertura internacional y comercial de los países y, en segundo lugar, porque la globalización y el cambio tecnológico-científico están interrelacionados, reforzándose mutuamente. En este sentido Enkel et al. (2009) afirma al respecto que en el siglo XXI, los procesos de innovación/adopción son cada vez más abiertos y las empresas/países utilizan el conocimiento de fuentes externas de manera mucho más eficiente.

El factor Tecnológico representa a las tecnologías internas y externas relevantes para la firma que se encuentran accesibles, aunque sea en el mercado. En esta investigación a dicho factor se le ha denominado Contexto Tecnológico (TIC). En el factor empresarial se incluyen el tamaño de la empresa y ámbito; grado de centralización, formalización, complejidad de su estructura de gestión, cualificación de los recursos humanos; nivel de disponibilidad de los recursos. En esta investigación se corresponde con el constructo Capacidad de Gestión Empresarial del País para Adoptar ICT (CAGEP)

Y finalmente, se ha considerado como constructo dependiente a Adopción de Innovaciones ICT (ADOPT) en las empresas de cada país, entendiendo que cuantas más adopciones de ICT realice un país mejor situado se 
encuentra éste para acceder y utilizar ICT. Y cuanto mayor es la dimensión de los entornos tecnológico y de carácter empresarial mayor facilidad tiene un país para acceder a las ICT.

\section{MODELO TEÓRICO PROPUESTO}

Los vínculos y el sentido de las direcciones de los factores o constructos representan la relación de causalidad entre ellos. De acuerdo con las características del tema estudiado, las relaciones entre los constructos tendrían que ser bidireccionales pero hasta ahora los modelos SEM-PLS no lo permiten, así que se optó por un modelo unidireccional. Por consiguiente, a partir del análisis bibliográfico realizado se plantean diez hipótesis sobre las que se ha construido el modelo propuesto:

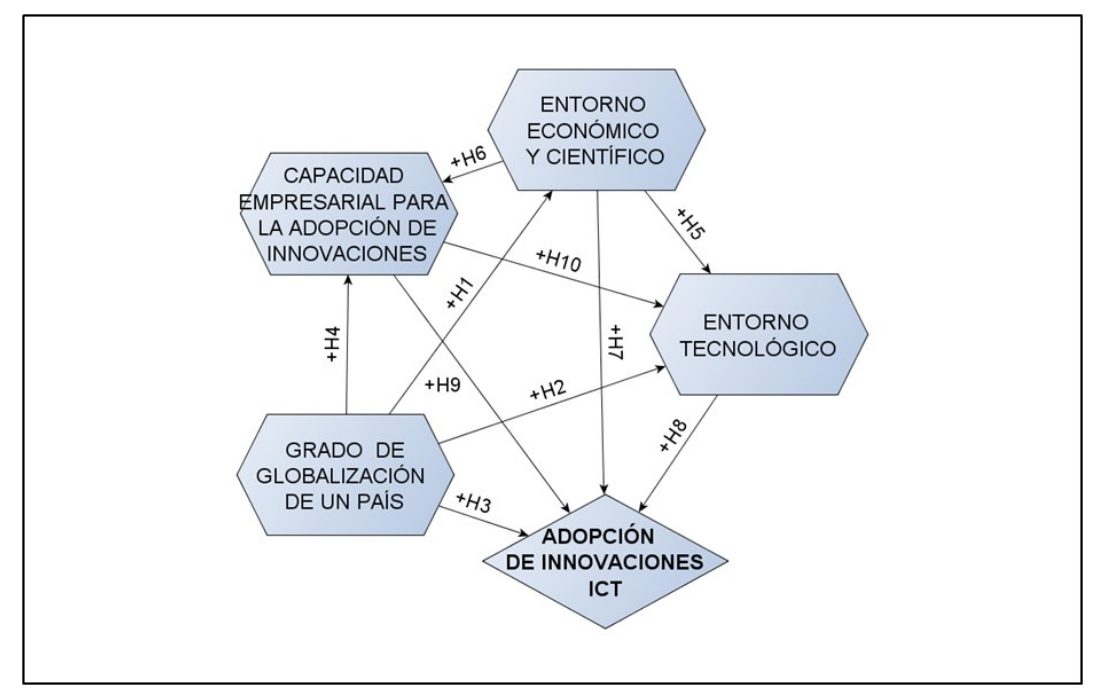

Figura 1 - Modelo de Investigación y desarrollo de hipótesis.

\section{Hipótesis}

Constructo GLOBAL.- El entorno global de cada país evoluciona de acuerdo con el volumen de facturación de las multinacionales fuera de su país de origen, con el valor total de la Inversión Directa Extranjera de las firmas de un país en el extranjero y en función del adquisición de conocimiento tecnológico a través de la Inversión directa Extranjera de tipo tecnológico (Palafox, 2017; Sahoo et al., 2013; Nunnenkamp and Spatz 2004; UNCTAD, 2013).

Pero, para que los países consigan desarrollar y mantener un entorno global significativo, las empresas internacionalizadas deben incrementar su conocimiento, desarrollar y aplicar ICT de forma constante (Gourlay and Pentecost, 2002; Bayo-Moriones and Lera-López, 2007; Wagner et al, 2003), usar intensivamente las redes informáticas y de telecomunicaciones (Vicente and López, 2011; Astrostic and Nguyen 2005), e incrementar la seguridad de los servidores de internet. Por lo tanto el constructo Global puede influir al constructo TIC.

Las multinacionales y las empresas internacionalizadas requieren desarrollar estructuras de organización y coordinación (Dyer y and Singh, 1998) para fidelizar al cliente, crear equipos multidisciplinares de I+D e innovación, generar vínculos duraderos con proveedores, etc para gestionar bien la innovación y la adopción tecnológica; por lo tanto, el constructo Global influye en el de CAGEP.

Así pues, cuanto mayor sea el tamaño de la red empresarial desde la perspectiva de la dimensión sectorial y geográfica mayor conocimiento tendrá la firma de las tecnologías disponibles en el mercado, y se podrá tomar la decisión de adoptar tecnología con mayor prontitud que otras firmas con una red más reducida (Abrahamson and Rosenkopf, 1997; Bayo-Moriones and Lera-López, 2007). Conviene tener en cuenta que la introducción de una firma en una red transnacional implica un reto de coordinación que solamente podrá ser superado mediante el empleo de tecnologías ICT, de ahí que las tecnologías ICT son un gran aliado en la expansión internacional de las empresas (Santangelo, 2001; Akmanligil, and Palvia, 2004).Así pues, el constructo GIOBAL puede influir en TIC. 
Por otra parte, estas empresas internacionalizadas necesitan encontrar en los países donde localizan plantas de producción, comercialización etc un EEC y un TIC bien dimensionados al objeto de que estos entornos favorezcan la adopción de ICT; dado que las infraestructuras digitales son críticas para integrar a los productores locales en las redes B2B y por ende atraer inversión directa extranjera (Addison and Heshmati, 2003).

Así pues, de acuerdo con esta explicación se plantea las siguientes hipótesis

H1.- El Constructo GLOBAL está positivamente relacionado con EEC.

H2.- El Constructo GLOBAL está positivamente relacionado con TIC.

H3.- El Constructo GLOBAL está positivamente relacionado con ADOPT.

H4.- El Constructo GLOBAL está positivamente relacionado con CAGEP.

Constructo EEC. El grado de desarrollo del entorno económico y científico de un país tiene una influencia positiva sobre la buena gestión de las empresas para adoptar innovaciones ICT y sobre el volumen de conocimiento y de infraestructuras ICT de un país. En este sentido, algunos autores (Blien and Maier, 2008; NietoAntolín y González- Álvarez, 2011) consideran que las políticas de los gobiernos para apoyar la disponibilidad de tecnologías ICT y la existencia de leyes y de normativas ajustadas al uso de dichas técnicas resultan fundamentales para las empresas y para la formación de entorno económico. De la misma manera que las adquisiciones gubernamentales de productos de tecnología avanzada impulsan el desarrollo del constructo TIC (Vicente and López, 2011). Todos estos elementos, junto con un índice elevado en la calidad de las escuelas de negocios crean confianza en las empresas y mejoran el rendimiento de las innovaciones ICT adoptadas.

Por lo tanto, en función de estos planteamientos se formula las siguientes hipótesis

H5.- El constructo EEC está positivamente relacionado con TIC

H6.- El constructo EEC está positivamente relacionado con CAGEP

H7.-El constructo EEC está positivamente relacionado con ADOPT

Constructo TIC. La disponibilidad de conocimiento e infraestructuras TIC varía entre países y resulta indispensable en la adopción de un producto o servicio ICT por parte de las empresas. El concepto de disponibilidad de tecnología (Bustamante-Donas, 2004) encierra el grado de difusión de las tecnologías ICT incluidas las infraestructuras, el número de adopciones de patentes ICT, y el grado de seguridad existente en los servidores de internet.

Pero, estas tecnologías para ser adaptadas (Gupta et al., 2013) deben ser fiables al objeto de que no presenten perdida de información, ofrezcan un servicio ininterrumpido y muestren condiciones de seguridad. De ahí que cuanto más importante sea el sector TIC y más seguras las infraestructuras ICT en una nación, más relevante puede ser la acumulación de conocimientos ICT, mayor el mercado de especialistas y la calidad de las infraestructuras ICT y, mayor será también la probabilidad de que las empresas de ese país adopten un producto o servicio ICT. Como consecuencia de ello, la posibilidad de que se produzcan externalidades de conocimiento ICT o spillovers se incrementará.

Así pues, en coherencia con este argumento se formula la siguiente hipótesis:

H8.- El constructo TIC se relaciona positivamente con ADOPT

Constructo CAGEP. El éxito de la buena gestión en la adopción de innovaciones ICT en las empresas obedece a la capacidad de innovación empresarial, al nivel de cualificación de los empleados en ICT (Chun 2003; HoIlenstein, 2004; Alderete, et al, 2014), a la facilidad de obtención de préstamos, a la naturaleza de la ventaja competitiva de las firmas y a la capacidad de organización (Brynjolfsson and Hitt ,2003). Lo que quiere decir que una empresa que cumpla con estas características dispone de recursos intangibles suficientes para gestionar la adopción de innovaciones ICT. Por lo tanto, la capacidad de una empresa para gestionar bien la adopción ICT influye en el nivel de desarrollo de TIC y su madurez, y como consecuencia, en el incremento de la tasa de adopción de ICT.

Pero, a pesar de las ventajas de las tecnologías ICT, el volumen de inversión en éstas, varía sustancialmente entre países, entre sectores y entre empresas. En este sentido, la evidencia sugiere que no todas las empresas de un país se apresuran a adoptar soluciones basadas en las tecnologías ICT (Trigueros- Preciado et al., 2013). Por ejemplo, la cloud computing es una tecnología punta que todavía tiene problemas por resolver (falta de normativa, alto nivel de riesgo, costes altos etc), y, donde su conocimiento por parte de las firmas es reducido (Oliveira et al., 2014).

Así pues, de acuerdo con estos razonamientos se plantean las siguientes hipótesis:

H9.- El constructo CAGEP se relaciona positivamente con ADOP

H10.- El constructo CAGEP se relaciona positivamente con TIC 
El constructo ADOPT representa la adopción de innovaciones ICT. Concretamente se compone de las variables B2B y el grado de presencia de M2M en el mercado. La primera representa la introducción de las ICT en las rutinas empresariales, mientras que la segunda sirve como proxy para valorar la comunicación Machine to Machine.

\section{METODOLOGÍA}

La escasez de fuentes estadísticas ha sido un factor a tener en cuenta en la realización de este trabajo, ya que la mayoría de la información disponible y, que además, fuese comparable internacionalmente se encuentra agregada a nivel de país. Ello obligó a adoptar a éste último como unidad de análisis, y a restringir el número de elementos de la muestra a la información disponible en estas fuentes. Por ello, dicha muestra está constituida por un conjunto de países desarrollados y por diversas economías en vías de desarrollo.

En este contexto, el modelo propuesto fue testado mediante una muestra construida a partir de cuatro fuentes estadísticas: World Competitiveness Report 2016, The Global Information Technology Report 2016, el informe Telecoms, Media and Entertainment Outlook de Ovum 2015 y Estadísticas World Bank 2016. Con la información de estas fuentes se elaboró una base de datos que consta de 18 variables, referidas a la gestión empresarial, entorno económico-científico, globalización empresarial y disponibilidad de tecnologías e infraestructuras TIC en el entorno.

La metodología empleada ${ }^{2}$ para el World Competitiveness Report y The Global Information Technology Report consiste en la realización de 14.000 entrevistas repetidas anualmente y dirigidas a directivos de corporaciones, distribuidas en 138 países. Por su parte World Bank ha realizado entre 1200 y 1800 entrevistas por país, dirigidas principalmente a propietarios y directivos de empresas. Finalmente se construyó una base de datos con 124 casos.

La información obtenida fue analizada mediante PLS-SEM posibilitando relacionar los constructos diseñados de una parte; y por otra, comprobar la validez de las sinergias causales identificadas con cada una de las hipótesis presentadas en el apartado anterior. Esta técnica resulta especialmente apropiada para abordar esta investigación debido al tamaño de la muestra empleada (Reinartz et al., 2009), y porque favorece el análisis simultaneo de los sistemas de variables.

Tras haber validado los constructos y los enlaces, es decir, la significatividad de la relación entre cada par de constructos del modelo se analiza éste último,( excluyendo los enlaces no significativos), como si fuera una red donde los constructos se consideran los vértices y los enlaces. Concretamente se realizan dos análisis. Por una parte, se estudia la influencia de los constructos en la red o modelo, y por otra, la transitividad de los factores dentro de esa red. El primer análisis consiste en la aplicación del algoritmo Beta Centrality, que valora la influencia de cada vértice a partir de la de sus vértices vecinos. El segundo algoritmo consiste en el análisis Betweenness Centrality, que valora la transitividad y por ende la influencia de cada constructo en la red.

\section{RESULTADOS}

Tras haber realizado la estimación del modelo, se han confirmado las hipótesis mediante el análisis de los path que relacionan los constructos (tabla 1). Para ello fue preciso analizar la significación de dichos path utlizando un bootstrap de 5000 muestras (Hair et al.; 2012)

De este modo los constructos CAGEP, TIC, GLOBAL, EEC explican un 85\% del constructo ADOPT, y, las hipótesis vinculadas a este último se han confirmado con una significatividad al $99 \% \mathrm{H} 8(\mathrm{p}<0.01), \mathrm{H} 3(\mathrm{p}<0.0)$, mientras que $\mathrm{H} 7$ ( $p<0.05)$ se confirmó a un $95 \%$ y $\mathrm{H} 9(\mathrm{p}<0.7)$ no resultó significativa.

El constructo CAGEP se explica en un $59 \%$ por los constructos GLOBAL y EEC y las hipótesis que los relacionan $\mathrm{H} 6$ y $\mathrm{H} 4$ respectivamente son significativas al $99 \% \mathrm{H} 6(\mathrm{p}<0.01)$ y $\mathrm{H} 4(\mathrm{p}<0.01)$.

El constructo TIC se explica en un 72\% por los constructos EEC, GLOBAL y CAGEP. Las relaciones con estos constructos han resultado significativas en todos los casos al 99\%, $\mathrm{H} 5(p<0.01), \mathrm{H} 2(p<0.01)$ y $\mathrm{H} 10(\mathrm{p}<0.01)$.

Y por último, el constructo EEC se explica en un 58\% por el constructo GLOBAL y la hipótesis que representa esta relación también ha resultado significativa $\mathrm{H} 1(\mathrm{p}<0.01)$.

\footnotetext{
${ }^{2}$ Del Informe Telecoms, Media and Entertainment Outlook de Ovum de 2015 no se conoce la metodología empleada.
} 
Tabla 1 - Coeficiente y significatividad de cada relación o hipótesis.

\begin{tabular}{|c|c|c|c|}
\hline HIPOTESIS & DEFINICIÓN & $\begin{array}{c}\text { COEFICIENTES } \\
\text { DE LOS ENLACES }\end{array}$ & $\mathrm{t}$-student \\
\hline $\mathrm{H} 9$ & CAGEP $\rightarrow$ ADOPT & 0.05 & 0.74 \\
\hline $\mathrm{H} 8$ & TIC $\rightarrow$ ADOPT & 0.63 & $8.83^{* * *}$ \\
\hline H5 & EEC $\rightarrow$ TIC & 0.32 & $3.29^{* * *}$ \\
\hline H6 & EEC $\rightarrow$ CAGEP & 0.51 & $5.84^{* * *}$ \\
\hline H1 & GLOBAL $\rightarrow$ EEC & 0.73 & $17.44^{* * *}$ \\
\hline H4 & GLOBAL $\rightarrow$ CAGEP & 0.33 & $3,78^{* * *}$ \\
\hline H2 & GLOBAL $\rightarrow$ TIC & 0.24 & $2,42^{* * *}$ \\
\hline H7 & EEC $\rightarrow$ ADOPT & 0.13 & $1.99^{* *}$ \\
\hline H3 & GLOBAL $\rightarrow$ ADOPT & 0.16 & $3.02^{* * *}$ \\
\hline H10 & CAGEP $\rightarrow$ TIC & 0.35 & $4.73^{* * *}$ \\
\hline
\end{tabular}

Los asteriscos, ${ }^{*},{ }^{* *}, \mathrm{y}^{* * *}$ representan la significatividad al $90 \%, 95 \%$, and $99 \%$, respectivamente. Fte: Elaboración propia a partir de las bases de datos

La intensa relación habida entre los constructos que componen el modelo indujo a pensar, de una parte, en la existencia de efectos indirectos en las relaciones de los constructos, y, de otra, que éstos contribuyen a dar explicaciones ulteriores del papel de los constructos en la adopción de innovaciones se muestran en la tabla 2.

En el modelo propuesto se han encontrado hasta 7 posibles efectos indirectos de los constructos GLOBAL, EEC y CAGEP sobre ADOPT (tabla 2). En todos ellos, excepto en uno se han constatado mediaciones parciales, se trata pues de la mediación con origen en CAGEP que es total.

La agregación de los coeficientes de los enlaces indirectos (tabla 2) según origen ha permitido obtener los constructos con mayor influencia en ADOPT. Éstos son: $\operatorname{GLOBAL}(0,4)$, EEC $(0,3)$ y CAGEP $(0,2)$.Por lo tanto, GLOBAL tiene mucha mayor influencia indirecta en el modelo que directa (0,48 indirecto frente a 0,16 directo). Algo similar ocurre con $\operatorname{EEC~}(0,3)$ de efecto indirecto frente a 0,13 directo y especialmente con CAGEP $(0,05)$ efecto directo frente a 0,2 indirecto. De ello se concluye que la influencia indirecta de estos constructos sobre la adopción de innovaciones es mucho mayor que la directa.

Tabla 2 - Análisis de los efectos indirectos de los constructos.

\begin{tabular}{|c|c|c|c|c|c|c|c|c|c|}
\hline \multirow[b]{2}{*}{ ORIGEN } & \multirow{2}{*}{ Mediación } & \multicolumn{3}{|c|}{ Efectos directos } & \multicolumn{3}{|c|}{ Efectos indirectos } & \multirow{2}{*}{ Tipo $^{1}$} & \multirow{2}{*}{ Efectos totales } \\
\hline & & Enlac. & sig. & $+/-$ & Enlac. & sig & $+/-$ & & \\
\hline GLOBAL & $\mathrm{H} 1 \rightarrow \mathrm{H} 7$ & \multirow{4}{*}{0.16} & 99 & + & 0.09 & 90 & + & MP & \multirow{4}{*}{0.64} \\
\hline GLOBAL & $\mathrm{H} 1 \rightarrow \mathrm{H} 5 \rightarrow \mathrm{H} 8$ & & 99 & + & 0,15 & 99 & + & MP & \\
\hline GLOBAL & $\mathrm{H} 2 \rightarrow \mathrm{H} 8$ & & 99 & + & 0.15 & 95 & + & MP & \\
\hline GLOBAL & $\mathrm{H} 1 \rightarrow \mathrm{H} 6 \rightarrow \mathrm{H} 10 \rightarrow \mathrm{H} 8$ & & 99 & + & 0.09 & 99 & + & MP & \\
\hline EEC & $\mathrm{H} 5 \rightarrow \mathrm{H} 8$ & \multirow[t]{2}{*}{0.13} & 95 & + & 0.2 & 99 & + & MP & \multirow{2}{*}{0.43} \\
\hline EEC & $\mathrm{H} 6 \rightarrow \mathrm{H} 10 \rightarrow \mathrm{H} 8$ & & 95 & + & 0.1 & 99 & + & MP & \\
\hline CAGEP & $\mathrm{H} 10 \rightarrow \mathrm{H} 8$ & 0.05 & no & + & 0.2 & 99 & + & MT & 0.25 \\
\hline TIC & $\mathrm{H} 8$ & 0.63 & 99 & + & - & - & - & SM & 0.63 \\
\hline
\end{tabular}

${ }^{1}$ Tipo de mediación: M.P. (Mediación parcial), M.T. (Mediación total), S.M. (Sin mediación).

Fte: Elaboración propia a partir de las bases de datos citadas.

La estimación del algoritmo Beta Centrality (tabla 3) presenta el orden de influencia de los constructos en la red, siendo éste similar a los del análisis anterior. Así pues, el orden de los constructos influyentes en la red es: GLOBAL $(4,30)$, EEC $(2,2)$, TIC $(0,9)$ y CAGEP $(0,8)$; mientras que ADOP no puede tener influencia al ser un mero receptor.

Por último, las estimaciones del algoritmo Betweenness (tabla 3) para cada constructo ha evidenciado al constructo TIC como un transmisor esencial. De todo ello se puede concluir que aunque los constructos más influyentes sobre ADOP son GLOBAL y EEC, su influencia será inexistente si el constructo TIC obtiene un valor de 0 . Para que exista influencia indirecta de los primeros, el constructo TIC debe de tener unos valores mínimos. 
Tabla 3 - Análisis de redes del modelo testado.

\begin{tabular}{|c|c|c|}
\hline & Betweenness & Beta centrality \\
\hline GLOBAL & 0,0 & 4,3 \\
\hline EEC & 0,0 & 2,2 \\
\hline CAGEP & 0,0 & 0,8 \\
\hline TIC & 0,08 & 0,9 \\
\hline ADOPT & 0,0 & 0,0 \\
\hline
\end{tabular}

Fte: Elaboración propia a partir de las bases de datos citadas.

\section{CONCLUSIONES}

La modelización del proceso de innovaciones ICT mediante PLS-SEM, ha constatado:

1.- Que los constructos que más inciden en la adopción de innovaciones ICT fueron GLOBAL debido a la influencia indirecta de éste en el modelo. El constructo del entorno tecnológico ICT (TIC) por su gran influencia sobre la adopción de innovaciones, así como por su papel transmisor de los efectos indirectos de los demás constructos. Y el constructo entorno económico y científico de los países (EEC) por su carácter estratégico dado que es fácilmente manipulable por los estados.

2.- La modelización del proceso de innovaciones ICT ha comprobado la existencia de relaciones de causalidad entre los constructos explicativos, lo que a su vez ha facultado a realizar un análisis de los efectos indirectos de dichos constructos explicativos sobre ADOPT. Tras validar las relaciones entre constructos y comparar la influencia directa e indirecta de éstos sobre ADOPT, se observó que los indirectos son más importantes que los primeros, para la adopción de innovaciones ICT (0,98 en los enlaces directos, frente a 1,021 en los indirectos). Dentro de los efectos directos destaca sobre todos los demás el constructo TIC, mientras que en los indirectos sobresalen GLOBAL y CESE.

En relación a éste último cabe constatar que hasta ahora las investigaciones realizadas a nivel de empresa han prestado poco interés al impacto de las instituciones públicas y privadas sobre la adopción de ICT, a la regulación de éstas últimas y a la influencia de las instituciones que asisten a empresas creando soluciones de ingeniería adaptadas a sus necesidades. Igualmente, la atención de la literatura científica sobre la globalización ha sido más bien escasa, cuestión que llama la atención porque las firmas que se inician en el proceso de globalización y de internacionalización presentan una gran necesidad de adoptar tecnologías ICT que les permita realizar su tarea productiva coordinada en tiempo real; y gestionar, al mismo tiempo, mediante el empleo de TICs un enorme volumen de información. De la misma manera, la existencia de conocimiento ICT accesible en el país a través de rutinas empresariales, equipos TIC integrados en la producción, y la codificación de conocimiento tácito mediante patentes y diseños, es un factor determinante en la canalización de todas las influencias positivas de la globalización y las instituciones en la adopción de tecnologías ICT.

Sin embargo, la influencia de estos dos constructos sobre TIC puede ser unidireccional o recíproca, en este sentido, resulta conveniente mencionar la limitación que ha supuesto la aplicación del modelo PLS-SEM que solo puede establecer relaciones de causalidad unidireccionales. La relación entre el factor TIC y el factor GLOBAL es más bien recíproca, es decir, la existencia de conocimiento ICT posibilita globalizarse, pero a su vez, la globalización de las actividades económicas demanda crecientemente métodos de coordinación de ventas y producción más eficientes. Asimismo, la apertura de una empresa en otros mercados posibilita el conocimiento y adopción de tecnologías ICT no conocidas en el entorno nacional. Igualmente, el factor EEC es reciproco en lo que respecta a las empresas del entorno, especialmente cuando éstas se encuentren en la cadena proveedor cliente de la empresa. Sin embargo, la influencia del entorno institucional es más bien unidireccional, puesto que las instituciones de conocimiento suelen estar enfocadas a auxiliar la actividad productiva y no al revés. Así pues, en futuros trabajos se podría modelizar las relaciones entre los constructos en sentido inverso, a fin de estudiar las relaciones no modelizadas entre los factores explicativos de esta investigación.

Entre las principales implicaciones empresariales e institucionales de este trabajo sobre la adopción de ICT cabe destacar que el fomento de la adopción de innovaciones ICT en empresas debería contemplar la estimula- 
ción de los factores más influyentes en la adopción: la internacionalización de las firmas considerando particularmente la transferencia tecnológica, y el desarrollo del conocimiento tácito y explicito empresarial e institucional en las tecnologías ICT. Éste último es estratégico, por un lado, por ser el más influyente sobre ADOPT; y, por otro, porque es el principal canalizador de los efectos indirectos de los factores estudiados. En este sentido, es preciso tener presente que para que la globalización o las instituciones tengan influencia en el incremento de conocimientos ICT es conveniente que este factor no sea nulo o inexistente. De este modo, si la demanda privada no es capaz de desarrollar competencias ICT en el territorio accesibles a todo el territorio nacional, sería conveniente favorecer desde instancias públicas mediante el esfuerzo de las instituciones que incrementen la producción de conocimiento ICT (patentes, software, etc), el fomento de legislación en materia de ICT y el establecimiento de criterios de contratación pública afines a la innovación y la adopción de ICT.

\section{REFERENCES}

ABRAHAMSON, E. AND ROSENKOPF, L. (1997), "Social network effects on the extent of innovation diffusion: A computer simulation", Organization science, Vol. 8 No. 3, pp. 289-309.

ADDISON, T. AND HESHMATI, A. (2003). The new global determinants of FDI flows to developing countries: The importance of ICT and democratization (No. 2003/45). WIDER Discussion Papers//World Institute for Development Economics (UNUWIDER).

AKMANLIGIL, M. AND PALVIA, P. C. (2004), "Strategies for global information systems development", Information \& Management, Vol. 42 No. 1, pp. 45-59.

ALDERETE, M. V., JONES, C. AND MORERO, H. A. (2014), "Factores explicativos de la adopción de las TIC en las tramas productivas automotriz y siderúrgica de Argentina", Pensamiento \& Gestión, Vol. 37, pp. 1-40.

ARMBRUST, M., FOX, A., GRIFFITH, R., JOSEPH, A. D., KATZ, R., KONWINSKI, A. AND ZAHARIA, M. (2010), "A view of cloud computing", Communications of the ACM, Vol. 53 No. 4, pp. 50-58.

BAYO-MORIONES, A. AND LERA-LÓPEZ, F. (2007), "A firm-level analysis of determinants of ICT adoption in Spain", Technovation, Vol. 27 Issue 6, 352-366.

BACH, M. P., ZOROJA, J., Y VUKŠI, V. B. (2013), "Determinants of firms' digital divide: A review of recent research, Procedia Technology", Vol 9, pp. 120-128.

BLIEN, U. AND MAIER, G. (2008), The Economics of Regional Clusters: Networks, Technology and Policy, Edward Elgar Publisihing, London.

BRYNJOLFSSON, E., AND HITT, L. M. (2000), "Beyond computation: Information technology, organizational transformation, and business performance", Journal of Economic Perspectives, Vol. 14 No. 4, pp. 23-48.

BUSTAMANTE-DONAS, J. (2004), "¿Qué puede esperar la democracia de internet? una reflexión sobre la crítica de Langdon Winner al poder político transformador de la tecnología, Argumentos de Razón Técnica", Revista Española de Ciencia, Tecnología y Sociedad y Filosofía de la Ciencia, No.7, pp. 13-49.

BUYYA, R., YEO, C. S., VENUGOPAL, S., BROBERG, J. AND BRANDIC, I. (2009), "Cloud computing and emerging IT platforms: Vision, hype, and reality for delivering computing as the 5th utility", Future Generation computer systems, vol. 25 No. 6, pp. 599-616.

CAPÓ-VICEDO, J., TOMÁS-MIQUEL, J. AND EXPÓSITO-LANGA, M. (2007), "La gestión del conocimiento en la cadena de suministro. Análisis de la influencia del contexto organizativo", Revista Información Tecnológica, Vol. 18 No. 1, pp. 127-134

CHUN, H. (2003). "Information Technology and the Demand for Educated Workers: Disentangling the Impacts of Adoption versus Use". The Review of Economics and Statistics, Vol. 85 No. 1, pp. 1-8.

DYER, J. AND SINGH, H. (1998), "The Relational View: Cooperative Strategy and Sources of Interorganizational Competitive Advantage", Academy of management, Vol. 23 No. 4, pp. 660-679.

ENKEL, E., GASSMANN, O. AND, H. (2009), "Open R\&D and open innovation: exploring the phenomenon", R\&d Management, Vol. 39 No.4, pp. 311-316.

FRENZ, M. AND LETTO-GILLIES, G. (2009), "The impact on innovation performance of different sources of knowledge: Evidence from the UK Community Innovation Survey". Research Policy, No. 38, pp. 1125-1135

GERTLER, M. S. (2003), "Tacit knowledge and the economic geography of context, or the undefinable tacitness of being (there)", Journal of economic geography, Vol. 3. No. 1, pp. 75-99. 
GUPTA, P., SEETHARAMAN, A. AND RAJ, J. R. (2013), "The usage and adoption of cloud computing by small and medium businesses", International Journal of Information Management, Vol. 33 No. 5, pp. 861-874.

GOURLAY, A., AND PENTECOST, E. (2002), "The determinants of technology diffusion: Evidence from the UK financial sector", The Manchester School, Vol. 70 No. 2, pp.185-203.

HAIR, J. F., SARSTEDT, M., RINGLE, C. M. AND MENA, J. A. (2012), "An assessment of the use of partial least squares structural equation modeling in marketing research". Journal of the academy of marketing science, Vol. 40 No. 3, pp. $414-433$.

HAYES, A. F. AND SCHARKOW, M. (2013), "The relative trustworthiness of inferential tests of the indirect effect in statistical mediation analysis does method really matter?". Psychological science, Vol. 24 No. 10, pp. 1918-1927.

HOLLENSTEIN, H. (2004). "Determinants of the adoption of Information and Communication Technologies (ICT): An empirical analysis based on firm-level data for the Swiss business sector". Structural change and economic dynamics, Vol. 15 No. 3 , pp. 315-342.

HONG, W. AND ZHU, K. (2006), "Migrating to internet-based e-commerce: Factors affecting e-commerce adoption and migration at the firm level". Information \& Management, Vol. 43 No. 2, pp. 204-221.

HOTI, E. (2015), "The technological, organizational and environmental framework of IS innovation adaption in small and medium enterprises. Evidence from research over the last 10 years". International Journal of Business and Management, Vol. 3 No. 4, pp. 1-14.

IFINEDO, P. (2011), "An empirical analysis of factors influencing Internet/e-business technologies adoption by SMEs in Canada", Journal and International Technology and Decision Making, Vol. 10, No. 4, pp. 19-28.

LAURSEN, K. AND SALTER, A. (2006), "Open for innovation: the role of openness in explaining innovation performance among UK manufacturing firms". Strategic Management Journal, Vol. 27 No. 2, pp. 131-150.

LAURSEN, K., REICHSTEIN, T. AND SALTER, A. (2011), "Exploring the effect of geographical proximity and university quality on university-industry collaboration in the United Kingdom", Regional studies, Vol. 45 No. 4, pp. 507-523.

LIN, H. F. AND LIN, S. M. (2008), "Determinants of e-business diffusion: A test of the technology diffusion perspective", Technovation, Vol. 28 No. 3, pp. 135-145.

MAYER-SCHÖNBERGER, V. AND CUKIER, K. (2013), Big data: A revolution that will transform how we live, work, and think, Houghton Mifflin Harcourt, New York.

MILBERG, W. AND WINKLER D. (2013) Outsourcing economics: global value chains in capitalist development. Cambridge university press.

NIETO-ANTOLÍN, M. AND GONZÁLEZ-ÁLVAREZ, N. (2011), "Estructura de la industria, entorno institucional y actividad innovadora en la empresa industrial Española", ICE, No. 860, pp. 57-71.

NUNNENKAMP, P. AND SPATZ, J. (2004), "FDI and Economic Growth in developing Economies: How relevant are host economy and industry characteristics, Transnational Corporations, Vol. 13, No. 3, pp 54-86

OLIVEIRA, T., THOMAS M., AND ESPADAÑAL, M. (2014), "Assessing the determinants of cloud computing adoption: An analysis of the manufacturing and services sectors", Revista Information and Management, Vol. 51, pp. $497-510$.

OLIVEIRA, T. AND MARTIN, M. F. (2010), "Firms patterns of e-business adoption: evidence for the European Union-27". The 
Página intencionalmente dejada en blanco 


\title{
De clústeres a microclústeres: coworkings como nuevos espacios eco- nómicos en el Distrito Textil de Trafalgar en Barcelona
}

\author{
R. Vicente-Salar (a), M. Pallares-Barbera (a)(b), A. Vera-Martin (a)(c) \\ (a) Departament Geografia, Universitat Autònoma de Barcelona, rafael.vicente@uab.cat \\ (b) Montserrat.pallares@uab.cat \\ (c) Ana.vera@uab.cat
}

\begin{abstract}
Resumen
El objetivo de la comunicación es analizar el papel de las economías externas en la evolución productiva del Distrito Textil de Trafalgar (DTT). A lo largo del siglo XX, el DTT albergaba empresas relacionadas con el textil configurándose un clúster. Actualmente, el clúster textil prácticamente ha desaparecido dando lugar a microclústeres creativos y del conocimiento a través de la aparición de los coworkings (CWs). La metodología se enmarca dentro del análisis estadístico espacial y de entrevistas en profundidad. Los resultados muestran que, desde el siglo XX hasta la actualidad, la evolución en la naturaleza de las economías externas que ofrece Barcelona y, particularmente, el DTT está fomentando la evolución productiva del distrito. Consecuentemente, el DTT se considera, actualmente, un espacio económico en transición donde reminiscencias del clúster textil y un número creciente de CWs cohabitan en un mismo espacio urbano.
\end{abstract}

Palabras claves: economías externas, coworkings, microclústeres, estadística espacial, Distrito Textil de Trafalgar, Barcelona.

\section{INTRODUCCIÓN}

En la segunda década del siglo XXI, la crisis financiera ha provocado un cambio profundo en las estructuras económicas de las ciudades reconfigurándose nuevos espacios económicos. El cambio hacia una nueva economía basada en el conocimiento y/o en la creatividad se posiciona para alcanzar un desarrollo económico local capaz de situar a las ciudades en las primeras posiciones en la jerarquía de ciudades globales (Sassen, 2001). Este proceso conlleva una atracción de capital financiero, de pequeñas y medianas empresas (SMEs) y de trabajadores altamente cualificados (creative class) (Florida, 2004). La concentración urbana de este tipo de empresas hace surgir nuevos espacios económicos, en forma de clústeres creativos o del conocimiento (Hutton, 2006; Jayne, 2004). La economía creativa es aquella que enmarca "industrias que tienen su origen en la creatividad, habilidad y el talento individual y que tienen un potencial para la creación de riqueza y trabajo a través de la generación y explotación de la propiedad intelectual" " (DCMS, 2001: 5). Profundizando en las características de la economía creativa, ésta se basa en actividades intensivas en conocimiento, en la mercantilización de la cultura y en recursos humanos altamente cualificados (Méndez et al, 2012). Así, en la configuración de clústeres de base creativa el papel de las economías externas (Marshall, 1890) es importante como fuerzas centrípetas en la atracción y aglomeración de empresas.

Paralelamente, la reconfiguración del mercado de trabajo, el creciente uso de las TICs y el aumento de los flujos económicos globales provoca una fragmentación de la cadena de valor añadido aumentando el número de empresas unipersonales (freelances) basadas en el conocimiento y la creatividad que utilizan espacios "coworking" (CW) (Capdevila, 2013; Gerdenitsch, et al, 2016; Mariotti, et al, 2017; Merkel, 2015; Parrino, 2015). Un CW se define como:

"un espacio compartido por diferentes tipos de profesionales del conocimiento, la mayoría freelances, que trabajan en varios campos dentro del vasto dominio de la industria del conocimiento. Concebido como un espacio donde se alquilan instalaciones como una mesa y una conexión wifi" (Gandini, 2015: 194).

Los CWs funcionan en su estructura interna como microclústeres (Capdevila, 2013) donde la aglomeración y 
las economías de clúster son factores determinantes para su desarrollo. Esta comunicación se centra en el estudio de estos determinantes de localización -la transición productiva de espacios urbanos centrales y la influencia de las economías externas- donde la literatura sobre el tema ha dejado un vacío epistemológico.

El artículo se centra en el Distrito Textil de Trafalgar (DTT) (Barcelona) en el que desde principios del siglo $X X$ se han concentrado las sedes sociales de la manufactura textil, el comercio mayorista y talleres de confección configurándose un clúster textil. Desde mediados del siglo $\mathrm{XX}$, shocks externos a los diversos sectores, como la competencia de países de bajo coste de mano de obra o el cambio de ordenanzas locales sectoriales; e internos, como la desaparición de continuidad empresarial familiar o la inexistencia de una cooperación transversal en el distrito entre las diferentes actividades relacionadas con el textil ha provocado la progresiva disolución del clúster. Este proceso ha creado espacios empresariales vacíos (locales y oficinas) que están siendo ocupados por empresas del conocimiento y la creatividad o transformados en CWs. La pregunta de investigación se fundamenta sobre si las economías externas, que ya fueron importantes como determinantes competitivos del clúster textil tradicional, constituyen factores de la creación de microclústeres; y hasta qué punto la "atmósfera industrial" (Marshall, 1890), como externalidad positiva, ha influenciado el surgimiento de microclústeres con funciones de terciario avanzado.

\section{DE CLÚSTERES A MICOCLÚSTERES URBANOS. LAS ECONOMÍAS EXTERNAS EN LA TRANSFORMA- CIÓN DE ESPACIOS ECONÓMICOS URBANOS}

El factor aglomeración que proporciona la ciudad ha sido el determinante de localización de la actividad económica (Colby, 1933; Porter, 1995). Desde principios del siglo XX, actividades manufactureras se han concentrado en las ciudades beneficiándose de economías externas (Marshall, 1890). Factores tales como un importante mercado de consumo y de trabajo, la concentración de servicios especializados o la existencia de una red de transportes actuaban de fuerza centrípeta en la atracción de empresas industriales. En el siglo XXI, la importancia de las empresas basadas en el conocimiento y en la creatividad conlleva a las ciudades a desarrollar valores y recursos alternativos para atraerlas. Éstos pueden clasificarse entre hard factors y soft factors (Musterd, et al, 2007). Entre los hard factors se encuentran aquellos relacionados con la existencia de servicios públicos de calidad, accesibilidad, redes institucionales de apoyo a la innovación, políticas orientadas a la educación, vivienda y ocio, etc. (Comunian et al, 2010; Gong y Hassink, 2017; Heebels y Van Aalst, 2010). Por otro lado, los soft factors hacen referencia a aquellos elementos más "intangibles" y relacionados con las características culturales, de estilo de vida e, incluso, históricas de las ciudades (Lazzeretti et al, 2012). Así, profesionales altamente cualificados son atraídos hacia ciudades abiertas, cosmopolitas y tolerantes. Este grupo social es lo que se conoce como la creative class (clase creativa) (Florida, 2004).

Las economías externas surgen de la concentración territorial de bienes y servicios urbanos y de la aglomeración de empresas en espacios específicos. Los beneficios relacionados con las economías externas resultan en la reducción de los costes de producción en base a

"la explotación de un capital fijo social, la indivisibilidad en el suministro de bienes o servicios y la creación de efectos de sinergia que se manifiestan en una mejora de la eficiencia conjunta de la producción" (Camagni, 2005:32).

Las economías externas se clasifican en economías de urbanización y de localización. Las primeras están directamente relacionadas con el tamaño de las ciudades y hacen referencia a la utilización indivisible de activos urbanos tales como infraestructuras de transporte y comunicación, mercados heterogéneos de demanda, concentración de mano de obra o la presencia de servicios especializados. Las segundas surgen de la co-localización de empresas del mismo sector o complementarias resultando en una disminución de los costes de información y producción debido a la proximidad entre ellas (Hoover, 1963). La concentración de empresas de un mismo sector en espacios urbanos específicos conlleva la configuración de clústeres urbanos. Un clúster se define como la

"concentración geográfica de empresas interconectadas, proveedores de servicios especializados, empresas relacionadas dentro de una misma industria e instituciones asociadas en un campo particular que compiten y colaboran (...) dentro de una economía nacional, regional o incluso metropolitana" (Porter, 2000: 15)

Las relaciones entre empresas dentro de un clúster estimula la creación de flujos de conocimiento, informa- 
ción y confianza reduciéndose los costes de transacción (Bathelt et al, 2004). La flexibilidad de dichas relaciones ante shocks internos y externos señala la capacidad de respuesta negativa o positiva de los clústeres y, consecuentemente, su evolución económica y espacial (Crespo, 2014). En economías occidentales, la desaparición de clústeres dedicados a actividades en sectores tradicionales (textil, por ejemplo) ha conllevado la aparición de zonas urbanas deprimidas. La entrada de empresas de mayor valor añadido basadas en la creatividad y el conocimiento conlleva la revitalización económica de dichos espacios (Dot, 2015; Hutton, 2006; Pratt, 2009). En este proceso subyace la evolución de las economías externas y la relación entre la competencia por el suelo y la competitividad de las empresas reflejándose en una gentrificación productiva (Dot, 2015).

Tras la crisis financiera del 2008, los espacios económicos creativos y del conocimiento están experimentando una reducción en sus dimensiones físicas. La excesiva flexibilización del mercado de trabajo junto con el creciente uso de las TICs y la intensificación de los flujos económicos globales ha provocado la aparición de los third places y, específicamente, los CWs. Los third places (Brown, 2017) son espacios informales donde se entrelazan actividades de ocio y trabajo -cafeterías, bibliotecas, etc. - siendo ocupados por freelances. Sin embargo, en algunas ocasiones estos espacios informales no ofrecen oportunidades para desarrollar redes económicas y sociales. Para solucionar esta deficiencia, los CWs se presentan como espacios idóneos donde profesionales especializados dentro de la industria del conocimiento y la creatividad comparten un mismo espacio con el fin de interrelacionarse y crear sinergias (Gandini, 2015). Los CWs son considerados como microclústeres (Capdevila, 2013). La concentración de profesionales creativos y del conocimiento en CWs configura flujos de información, conocimiento y confianza a través de la proximidad entre ellos conformando un sentimiento de pertenencia a una "comunidad" (Garrett et al, 2017). Los CWs a través de la concentración de trabajadores enmarcados dentro de la creative class, pueden actuar como actores en la revitalización de espacios urbanos deprimidos donde las rentas del suelo son más bajas. Sin embargo, los CWs también se localizan en zonas urbanas centrales para aprovechar de manera más notoria las economías externas tales como infraestructuras intra-urbanas, servicios de ocio (restauración, comercio minorista y especializado), la proximidad a trabajadores altamente cualificados o a otras empresas de alto valor añadido (Mariotti et al, 2017).

\section{METODOLOGÍA}

\subsection{Datos}

Los datos son cuantitativos y cualitativos. Los datos cuantitativos se han recogido a través de tres fuentes de información. En primer lugar, el trabajo de campo permitió recopilar el número y tipo de empresas localizadas en el DTT. En segundo lugar, el Sistema de Análisis de Balances Ibéricos ${ }^{1}$ (SABI) proporcionó la localización de empresas creativas y del conocimiento. SABI proporciona información precisa aunque su grado de actualización es discutible (Vicente-Salar, et al, 2018). A pesar de ello, SABI proporciona 10681 empresas siendo suficientes para extraer conclusiones. Las actividades creativas y del conocimiento seleccionadas corresponden a la clasificación facilitada por UNCTAD (2008) y Eurostat ${ }^{2}$. Los años escogidos corresponden a la última actualización de empresas en el 2015 y el 2016. En el caso de los CWs, los datos se han extraído de los portales webs coworkingspain.es y comunidadcoworking.es. Se han podido geolocalizar $110 \mathrm{CWs}$ en Barcelona. Las empresas geolocalizadas se han integrado en un grid de una hectárea.

En cuanto a los datos cualitativos, se han realizado entrevistas en profundidad a empresas textiles, asociaciones de vecinos y a dos importantes coworkings en el DTT durante el 2014 y 2018 (Tabla 1).

\subsection{Métodos}

\subsubsection{Métodos cuantitativos}

Para analizar la concentración de CWs en Barcelona y su relación espacial con la actividad creativa y del conocimiento se ha aplicado dos índices estadísticos enmarcados dentro del análisis clúster y, más concretamente, de la autocorrelación espacial. Son el Global Moran's I y el Local Moran's I. El Global Moran's I índica el grado

\footnotetext{
${ }^{1} \mathrm{SABI}$ es una fuente estadística realizada por las empresas Informa D\&B y Bureau Van Dijk.

${ }^{2} \mathrm{http}: / /$ ec.europa.eu/eurostat/statistics-explained/index.php/Glossary:Knowledge-intensive_services_(KIS)
} 
Tabla 1 - Entrevistas realizadas

\begin{tabular}{|c|c|}
\hline Empresa & Actividad económica \\
\hline E1 & Productor y mayorista textil (empresa extinguida) \\
\hline E2 & Mayorista de ropa de hogar y ropa confeccionada \\
\hline E3 & Intermediario de moda \\
\hline E4 & Mayorista de pronto moda y confeccionista \\
\hline E5 & Sastrería \\
\hline E6 & Asociación de vecinos \\
\hline E7 & Coworking 1 \\
\hline E8 & Coworking 2 \\
\hline E9 & Conto moda \\
\hline
\end{tabular}

de concentración espacial de una variable a través de un índice que oscila entre -1 (autocorrelación espacial negativa) y 1 (autocorrelación espacial positiva) siendo el valor nulo una distribución aleatoria de la variable. Por otra parte, el Local Moran's I desagrega el resultado del Global Moran's I a nivel de la unidad de análisis, en este caso celdas de una hectárea. Los índices Global Moran's I (1) y Local Moran's I (2) se definen como, (Anselin, 1995)

$$
\begin{gathered}
I=\left(\frac{n}{S_{0}}\right) \frac{\Sigma_{i} \Sigma_{j} w_{i j} z_{i} z_{j}}{\Sigma_{i} z^{2}} \\
I_{i}=z_{i} \sum_{j} w_{i j} z_{j}
\end{gathered}
$$

Siendo $\mathrm{n}$ el número de observaciones, $\mathrm{S}_{0}$ la suma de todos los pesos espaciales, $\mathrm{w}$ valor del peso ( $1=$ =adyacente; $0=$ no adyacente), $Z_{i}$ valor de la variable de la unidad de análisis y $Z_{j}$ el valor de la media.

Respecto a la representación de los resultados, el scatter plot permite visualizar el resultado del Global Moran's I a través de cuatro cuadrantes. El cuadrante superior derecha (high-high) representa la concentración de valores altos, mientras que el cuadrante inferior izquierda (low-low) los valores bajos. Los cuadrantes superior izquierda (high-low) e inferior derecha (low-high) representan aquellos valores que se alejan de la media, es decir, los outliers. El caso del Local Moran's I, el software GeoDa permite visualizar cartográficamente los resultados obtenidos teniendo en cuenta criterios de contigüidad. El criterio queen tiene en cuenta todas las unidades vecinas alrededor de la unidad de análisis. A través de este criterio se visualiza la concentración de valores altos (highhigh), valores bajos (low-low), outliers (High-Low y Low-High) y valores no significativos. Se ha aplicado un nivel de confianza del 99,9\% (p-valor $=0,01 \%)$.

\subsubsection{Métodos cualitativos}

En cuanto a los métodos cualitativos, la elección de los entrevistados en relación al textil se realizó a través de una búsqueda en internet de la importancia de los mismos en el clúster. En relación a los CWs, los dos escogidos fueron los únicos que aceptaron las entrevistas de todos los que se localizan en el DTT. Las entrevistas en profundidad duraron aproximadamente una hora, fueron grabadas y transcritas.

\section{EL DISTRITO TEXTIL DE TRAFALGAR: DE ECONOMÍA INDUSTRIAL A NUEVA ECONOMÍA}

Desde el siglo XIX, la concentración económica de fábricas y, posteriormente, de despachos y almacenes textiles en el barrio de Sant Pere, en la ciudad amurallada, configuró una "atmósfera industrial". A partir de la segunda mitad del siglo XIX, la falta de espacio urbano y la alta densidad de residentes y empresas en el barrio pro- 
vocaron la aparición de deseconomías de escala. La expansión urbanística de Barcelona fuera de las murallas a través del proyecto urbano del Eixample diseñado por Ildefons Cerdà (1860) estimuló la oportunidad de localizarse en nuevos espacios urbanos. El desplazamiento, en primer lugar, de despachos industriales textiles a zonas adyacentes a Sant Pere fue el inicio de la configuración del DTT (Figura 1). La proximidad a infraestructuras de transporte (puerto y ferrocarril) y al CBD (Colell i Vidal, 1989) conllevó considerar al DTT como un espacio urbano central. A partir de la mitad del siglo XX, juntamente con los despachos se localizaron mayoristas textiles y de ropa confeccionada con el objetivo de beneficiarse de la proximidad a empresas dentro de la cadena de valor. A partir de la década de los setenta, factores tales como la competencia de países de nueva industrialización, la entrada de España en el mercado común y el auge de las multinacionales de moda provocaron la descomposición del clúster textil. A pesar de ello, actualmente, permanecen alrededor de un centenar de mayoristas.

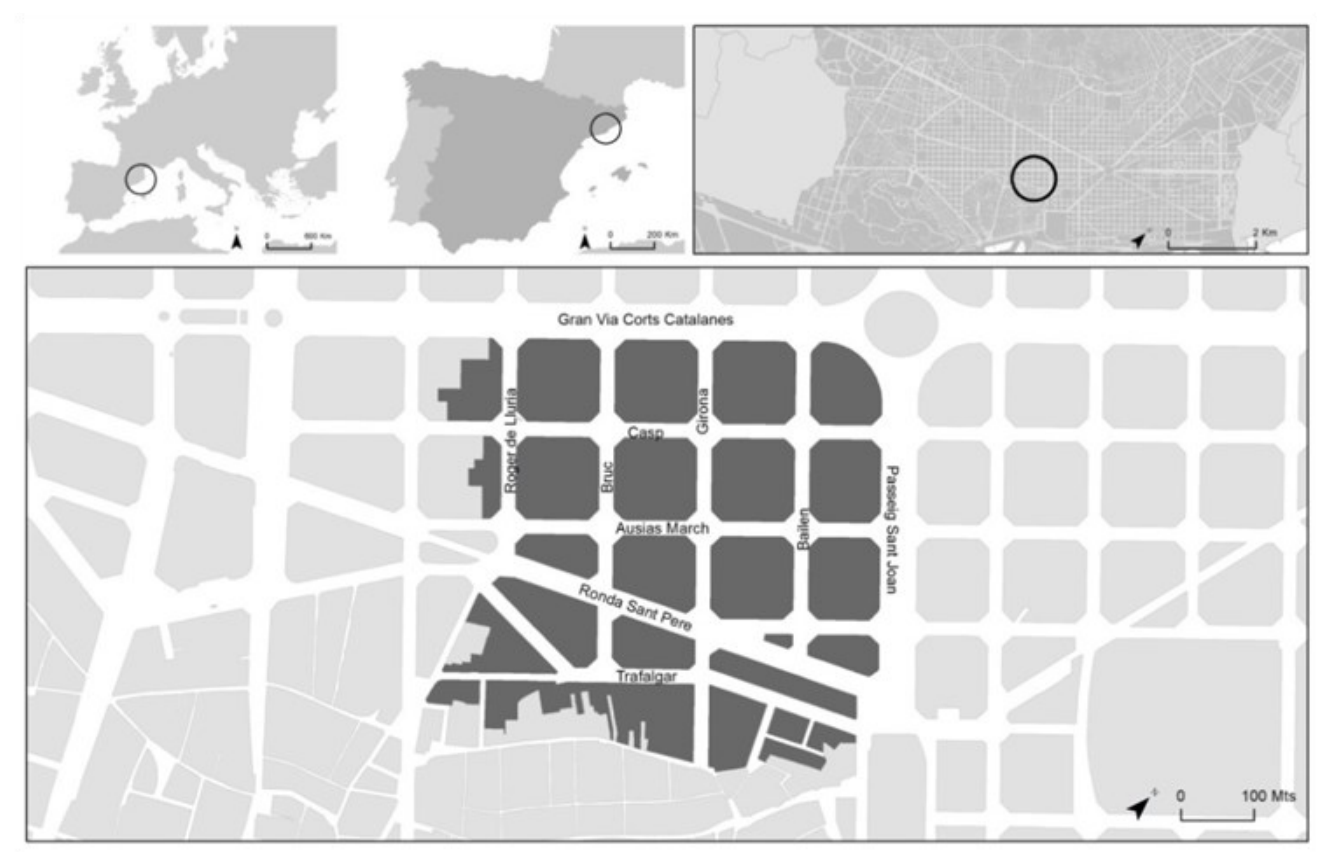

Figura 1 - Localización del Distrito Textil de Trafalgar.

A través de trabajo de campo se ha podido observar que aquellos espacios anteriormente dedicados al comercio mayorista están siendo ocupados por empresas creativas y del conocimiento o de consumo especializado (diseño de interiores, programación audiovisual, galerías de arte, restauración, etc.) Este proceso es un síntoma del cambio económico de Barcelona, a partir del 2000, por convertirse no sólo en una ciudad basada en el conocimiento (Casellas y Pallares-Barbera, 2009) sino también en una ciudad moderna y abierta provocando la atracción de empresas de alto valor añadido.

Durante los años 2015 y 2016 , el DTT ha experimentado un crecimiento de actividades relacionadas con el conocimiento y la creatividad alcanzando el $27,51 \%$ y el $14,13 \%$ del total de empresas, respectivamente (Figura 2). Paralelamente, actividades relacionadas con el turismo (alojamientos) y la restauración comprenden el $24,68 \%$. Sin embargo, el porcentaje de empresas mayoristas de ropa y de confección de prendas de vestir ha disminuido hasta el 7,83\% en el 2016.

\subsubsection{El clúster textil del DTT}

La continua concentración de despachos textiles en el DTT en la primera mitad del siglo XX se beneficiaba de las economías de urbanización a través de la proximidad a infraestructuras de transporte y a servicios especializados. El puerto y el ferrocarril eran indispensables para la importación de algodón, su transporte a las colonias textiles localizadas en las cuencas hidrográficas y la posterior exportación de productos manufacturados: "El tren 


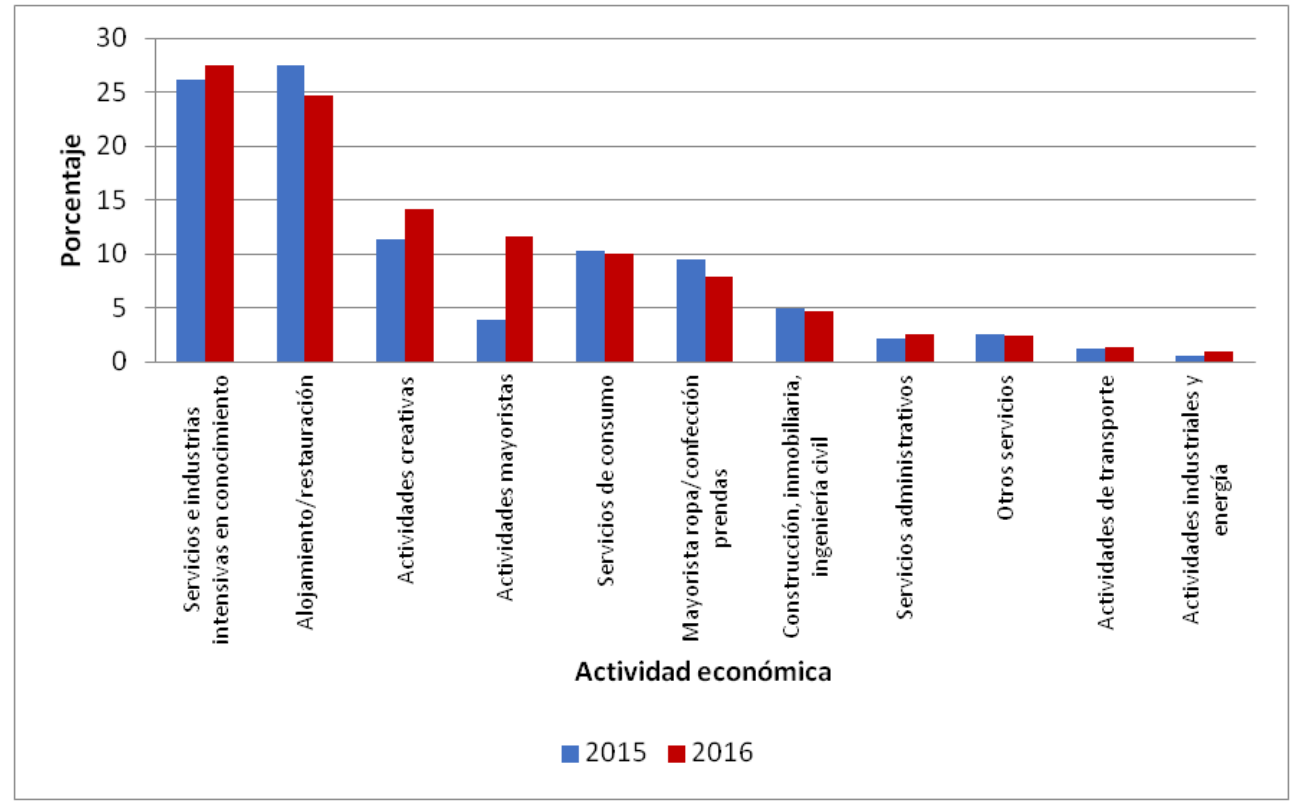

Figura 2 - Porcentaje de empresas por actividad económica en el DTT en el 2015 y 2016 . Fuente: elaboración propia.

bajaba directo de la estación de Granollers. La mercancía venía en sacos grandes, pues te la dejaban en la Estació de França. Allí había una carrera de carros y la distribuían a los almacenes nuestros." (E1). Por otro parte, Colell i Vidal (1989) señala las especializaciones espaciales de Barcelona a finales del siglo XIX destacando el mercado de valores en el distrito de la Lonja (sur del barrio Gótico), abogados y procuradores en el distrito de la Audiencia (norte del barrio Gótico) y comerciantes y transportistas en el distrito del Borne (sur del barrio de Sant Pere). La proximidad a concentraciones de servicios especializados y centros de negocios conllevó que el DTT se considerara un espacio económico de primer orden.

Por otro lado, las empresas se beneficiaban de las economías de localización a través de la proximidad entre ellas configurándose una red económica y social: "Nosotros íbamos cara a cara. Yo salía a buscar género porque en aquella fecha (en la década de los cincuenta) lo que escaseaba era el género. Entonces yo salía a dar una vuelta y venia aquí al lado, iba a Bertrand Serra,..." (E2); "Estos eran 4 pisos grandes [el lugar donde se hizo la entrevista]. Aquí estaban las máquinas, las mujeres cosiendo. Entonces los mayoristas estaban aquí abajo. Si decían que querían unos tejanos o camisetas, aquí lo hacían y en una semana te lo bajaban abajo para vender" (E3). Actualmente, a pesar de la escasa presencia de empresas mayoristas y confeccionistas, su localización en el DTT permite todavía beneficiarse de la presencia de economías externas: "Lo que pasa es que la gente le va cómodo por el tema del metro, están los ferrocarriles, los autobuses, gente que viene en avión viene al centro... esto nos ayuda" (E4); "Los complementos que necesito para la confección de la ropa, los compro en la mercería de aquí al lado, en Castelltort" (E6).

\subsubsection{Evolución de la estructura productiva del DTT. Los CWs como objeto de análisis}

El creciente aumento de CWs en el DTT es consecuencia de varios factores. En primer lugar, el número de locales de grandes dimensiones y diáfanos. La disipación del clúster textil ha provocado que locales dedicados anteriormente a funciones de almacenaje y comercio mayorista sean ocupados actualmente por CWs. Por otra parte, existen también CWs que han aprovechado edificios vacíos antiguamente destinados a juzgados sociales para ocupar plantas enteras como el caso de Aticco o Cloud Coworking.

En segundo lugar, la centralidad urbana permite a los CWs beneficiarse de economías de urbanización específicas del DTT relacionadas con la calidad de vida tales como la disponibilidad de espacio público, movilidad intra -urbana y metropolitana y la proximidad a espacios de consumo, entre otros: "Passeig Sant Joan se ha reurbanizado: carril bus, un carril de coches, carril bici, aceras enormes con un porcentaje de verde muy importante, parques infantiles, etc. (...) el Parque de la Ciutadella está ahí, en un momento, en Gran Vía todos los buses que quieras, el metro tie-

\footnotetext{
${ }^{3}$ http://ajuntament.barcelona.cat/eixample/sites/default/files/documentacio/zona_11.pdf
} 
nes la L3, la L4, la L1, tienes tren y ferrocarriles. Y si quieres pasar una noche tranquila tienes el Born. Y tienes la plaza de la Iglesia [Plaça Santa Maria] que antes no había nada (...) Es una zona brutal para vivir." (E9); "(...) con los coworkers nos vamos de cervezas por la zona o vamos a algún evento... a veces en Arc del Trioumf pasan cosas (...) Yo hago vida aquí. Tengo el tren aquí al lado que te lleva a Molins de Rei y eso me ha facilitado mucho" (E8). En tercer lugar, la creación de proyectos comunitarios evidencia la importancia de las economías de localización del distrito. Es el caso de la iniciativa Zona 11. A pesar de que actualmente no está en funcionamiento, Zona 11 se inició en el 2014 a través de la cooperación entre las empresas localizadas en el DTT y el gobierno local. El objetivo era convertir el DTT y alrededores en "la nueva área creativa del Eixample ${ }^{3}$. Las empresas vinculadas al proyecto eran CWs (MOB), editoriales, escuelas de teatro, de imagen y sonido y de negocios, empresas enmarcadas dentro de la economía social, entre otras.

\section{EL ROL DE LAS ECONOMÍAS EXTERNAS EN LA EVOLUCIÓN PRODUCTIVA DE EL DISTRITO TEXTIL DE TRAFALGAR}

La concentración cada vez más exigua de empresas mayoristas es una reminiscencia del antiguo clúster textil y, consecuentemente, de la importancia de las economías externas industriales que subyacían en el distrito. Por otro lado, el continuo crecimiento del número de CWs en el DTT (actualmente cinco) demuestran un cambio no sólo en las economías externas que el distrito ofrece, sino también en la política económica de Barcelona a través del fomento de mecanismos que apoyan la innovación y la atracción de empresas de servicios avanzados de capital extranjero y nacional.

\subsection{Economías externas industriales}

El clúster textil del DTT se configuró a través de economías externas de naturaleza industrial. La desfragmentación de las empresas textiles conllevó la consideración de varios espacios óptimos para cada función empresarial. En el caso de las funciones productivas, las cuencas hidrográficas ofrecían la proximidad a fuentes de energía. Por otro lado, para las actividades relacionadas con la gestión y logística, el DTT ofrecía unas economías de urbanización enfocadas al transporte de mercancías y a la vertiente financiera industrial. La proximidad a un espacio de transporte intermodal de mercancías compuesto por el puerto y ferrocarril permitía la disminución de los costes de transporte. Además de ello, también articulaba espacialmente la economía de Barcelona atrayendo instituciones económicas como la bolsa de valores y demás actividades relacionadas. La concentración de este tipo de servicios permitía a las empresas textiles reducir sus costes de información. Por otro lado, la conexión ferroviaria entre el DTT y las colonias textiles en la periferia regional permitía extender el poder de influencia del distrito configurándose un sistema centro-periferia (Scott, 1982). De esta manera, el DTT representaba el centro financiero y logístico del textil en Cataluña, siendo la pieza clave dentro de un clúster multi-escalar. La concentración de empresas textiles en el DTT, permitían a las mismas beneficiarse de economías de localización. Las economías de localización se basaban en la proximidad de empresas que ejercían una función específica dentro de la cadena de valor añadido. La especialización textil del DTT permitía disminuir los costes de producción a través de la intensificación de los flujos de información, conocimiento y confianza: "El que tenía que comprar hilados sabía que esto se lo quedaba el vecino de al lado que hacia camisas. Era todo un núcleo hasta Ronda de Sant Pedro, hasta Gran Vía." (E1). La generación de relaciones económicas entre empresas del sector textil no se creó de manera aleatoria sino que fue herencia de una "atmósfera industrial" histórica. La aparición de deseconomías de escala en Sant Pere a lo largo del siglo XIX produjo que se convirtiera en una zona subóptima. La búsqueda por parte de las empresas textiles de nuevos espacios óptimos desplazó la "atmósfera industrial" hacia el DTT quedando fuertemente limitada por Gran Via de les Corts Catalanes y Passeig de Sant Joan actuando como fronteras urbanas.

A finales del siglo XX, el sector con mayor importancia en el DTT era el comercio mayorista. Los despachos de producción textil cerraron por las reestructuraciones industriales o se habían desplazado a la periferia regional. A pesar de la pérdida de elementos del clúster textil, los mayoristas se adaptaron a los cambios expandiendo sus canales de proveedores hacia el extranjero. Consecuentemente, el DTT siguió ejerciendo una fuerza centrípeta como centro textil tan fuerte que el colectivo chino empezó a invertir en el sector y a localizar empresas en el distrito. A pesar de que no existiera relación entre ambos colectivos, las economías de localización permitieron beneficiarse mutuamente a través de la concentración de compradores.

Actualmente, el porcentaje de empresas mayoristas en el DTT está disminuyendo progresivamente debido 
al cierre de las mismas o al desplazamiento hacia otras zonas metropolitanas como Badalona. La cercanía a infraestructuras de transporte -autovías -, el menor precio de suelo y las menores restricciones para la carga y descarga de productos está convirtiendo a Badalona en un espacio óptimo. Uno de los entrevistados señala como causa de la suboptimización del DTT el desinterés del gobierno local por estimular, proteger y dinamizar el distrito como centro textil a través de fuerte restricciones a la hora de obtener permisos de apertura: "te obligan a hacer ignifugaciones, salidas de emergencia,... (...) lo hacen para que te vayas fuera de Barcelona" (E5).

\subsection{Economías externas enfocadas a servicios avanzados}

El crecimiento en el número de CWs en el DTT resulta de varios factores. En primer lugar, la importancia de las economías de localización del distrito con el fin de configurar redes de innovación, conocimiento e información. La relación espacial entre empresas creativas y del conocimiento y los CWs se refleja en los resultados de la autocorrelación espacial bivariable. El índice Global Moran's I señala que la autocorrelación espacial es positiva aunque muy baja $(0,07)$. A nivel de unidad de análisis (grid de una hectárea), el índice Local Moran's I señala, a través de los mapas de clúster LISA, clústeres de valores altos (high-high), principalmente, en tres zonas: el barrio de Gràcia, y en menor grado, el DTT y zonas específicas de Poblenou (Figura 3).
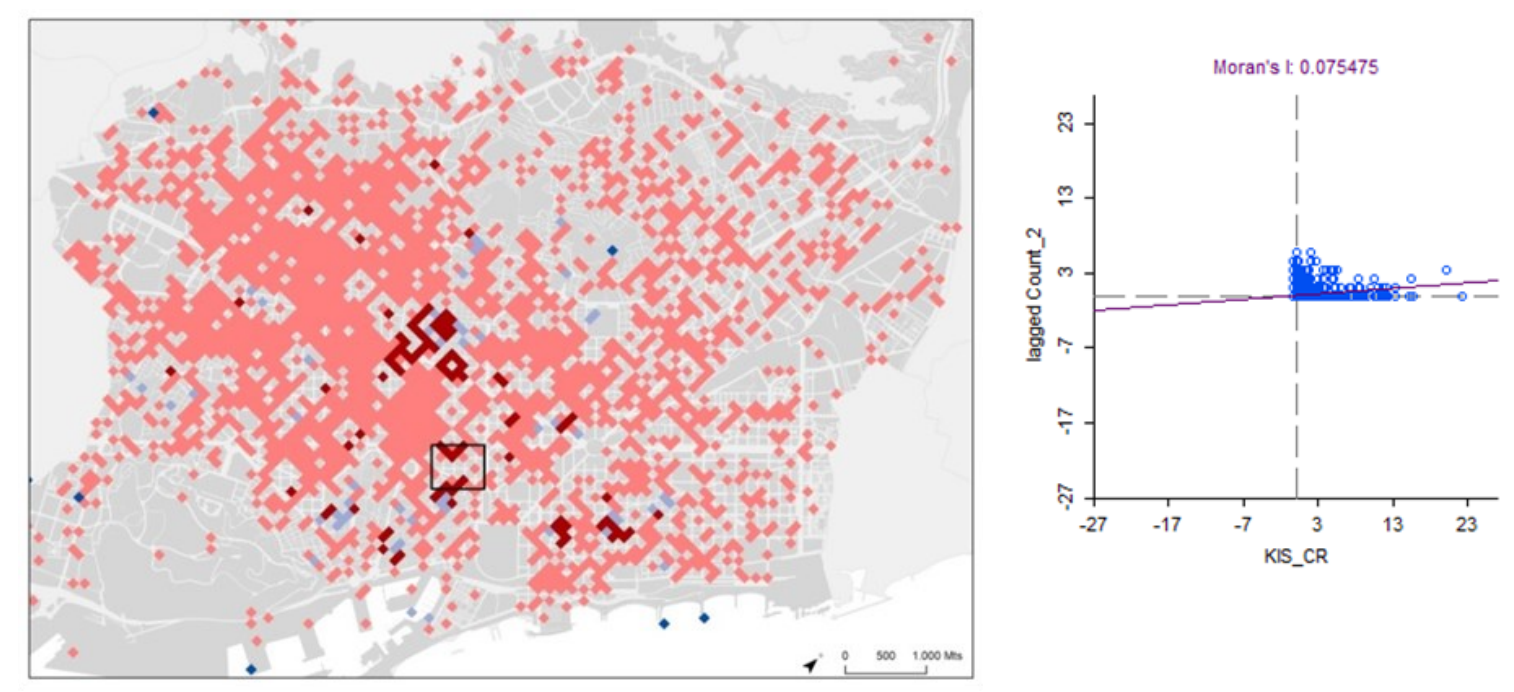

Figura 3 y Gráfico 1 - Izquierda: Mapa cluster del Local Moran's bivariable entre empresas creativas y del conocimiento y CWs; Derecha: Scatterplot del Global Moran's bivariable entre empresas creativas y del conocimiento y CWs.

Dependiendo de cada CWs, éstos pueden actuar como ejes de atracción de trabajadores altamente cualificados a través de los co-workers que forman parte de la comunidad o a través de las diferentes actividades y eventos que organizan para el público:

"Nos contactan emprendedores que tengan algo de fabricación [3D] o del estilo [del coworking] y nosotros les decimos que expongan en la cafetería durante cinco minutos" (CW1).

Así, los CWs son elementos importantes en las economías de localización aprovechados, no solamente por trabajadores locales sino también por trabajadores extranjeros:

"En nuestro caso la proporción de trabajadores extranjeros es cincuenta/cincuenta." (E9);

"El 60\% de la gente que hay aquí dentro debe ser de fuera (...) de toda Europa." (E8).

La alta proporción de trabajadores extranjeros se debe a su dificultad en la configuración de redes económicas y sociales en el desarrollo de sus empresas. Para ello, el personal de los CWs, actúa como gestores en la configuración de redes económicas y personales entre los diferentes co-workers con el fin de afianzar el sentimiento de comunidad pero, especialmente, para asesorar y ayudar en el desarrollo de sus empresas: 
"Los community builder tienen dos funciones. Primero, un catalizador de reacciones (...) Por otro lado, aparte de acelerar, también controlas (...) Oye, me han pedido esto. Sé que no es exactamente lo que tú haces pero creo que lo podrías hacer bien. En dos días esa persona factura cinco mil euros" (E9).

En cuanto a las economías de urbanización, los entrevistados señalan la remodelación del Passeig de Sant Joan como elemento clave en la transformación del distrito:

"Piensa que lo que ha dinamizado terriblemente el barrio es el Passeig de Sant Joan. La riqueza, el cambio, la transformación, la cantidad de gente (...). Incluso en fin de semana ves que la gente... hay multitudes porque es camino para abajo, para Arc del Triomf. Era la idea del corredor verde." (Associació per un Eixample sostenible).

Este proceso simboliza un cambio en las prioridades del gobierno local entorno al eje urbano y, indirectamente, al DTT con el objetivo de cambiar la imagen de un barrio "industrial", logístico y sobre todo, conflictivo (del Arco, 2007).

\section{CONCLUSIONES}

En esta comunicación se ha explicado cómo la evolución de las economías externas ha tenido un rol importante en la transformación económica del DTT. A principios del siglo XX, la proximidad a una red de recursos orientados a la industria (infraestructuras de transporte y servicios especializados) benefició a las empresas textiles del DTT permitiendo la disminución de sus costes de producción y de logística. Por otro lado, la aparición de economías de localización en el distrito se reflejó en la interdependencia de las empresas dentro de la cadena de valor provocando la perdurabilidad de la "atmósfera industrial" heredada del barrio de Sant Pere. Actualmente, el creciente número de CWs refleja un cambio en la naturaleza de las economías externas tanto de Barcelona como del DTT. Desde un punto de vista municipal, la orientación de Barcelona hacia una economía del conocimiento puede considerarse como la base en la que se construye la evolución económica del DTT. La generación de una ciudad innovadora atrae a empresas y trabajadores altamente cualificados. En cuanto al DTT, el distrito ofrece ventajas que estimulan la localización de CWs tales como unos estándares de calidad de vida óptimos (Passeig de Sant Joan). Por otra parte, la localización de empresas de restauración y culturales provoca la consideración del DTT como el nuevo Soho barcelonés (Shank, 2017). En cuanto a las economías de localización, los CWs se benefician de la proximidad de un entorno urbano innovador conformado por empresas creativas y del conocimiento. La consideración de los CWs como motores de atracción de profesionales y, consecuentemente, piezas claves en la generación de economías de localización se debe a dos factores. Por un lado, la atracción de profesionales a través del sentimiento de pertenencia (comunidad) a un entorno específico. Por otro lado, en los servicios que ofrece de apoyo empresarial o de talleres y eventos formativos o sociales.

\section{AGRADECIMIENTOS}

Esta investigación ha sido posible gracias a la financiación recibida a través de una beca pre-doctoral FPI (Ministerio de Industria, Economía y Competitividad ECC/1820/2014) y al proyecto CSO2013-46863-C3-2-R. Finalmente, agradecer a los entrevistados por su confianza y disponibilidad.

\section{BIBLIOGRAFIA}

BROWN, J. (2017). Curating the "Third Place"? Coworking and the mediation of creativity. Geoforum, 82(April), 112-126.

CAMAGNI, R. (2005). Economía Urbana. Barcelona: Antoni Bosch editor.

CAPDEVILA, I. (2013). Knowledge Dynamics in Localized Communities: Coworking Spaces as Microclusters. SSRN Electronic Journal, 1-18.

CASELLAS, A., Y PALLARES-BARBERA, M. (2009). Public-sector Intervention in Embodying the New Economy in Inner Urban Areas: The Barcelona Experience. Urban Studies, 46(5-6), 1137-1155.

COLBY, C. (1933). Centrifugal and centripetal forces in urban geography. Annals of the Association of American Geographers, 23 (1), 1-20. 
COLELL I VIDAL, A. (1989). El centro comercial y de negocios de BCN en el año 1896. En Història urbana del pla de Barcelona. Volum 1 (pp. 441-542).

COMUNIAN, R., CHAPAIN, C., Y CLIFTON, N. (2010). Location, location, location: exploring the complex relationship between creative industries and place. Creative Industries Journal, 3(1), 5-10. https://doi.org/10.1386/cij.3.1.5

CRESPO, J. (2014). Ciclo de vida de los clusters: hacia una conceptualización dinámica de la evolución de los clústers. Economía Industrial, (391), 125-132.

DCMS. (2001). Creating industries mapping documents. Demonstrating the success of our creative industries. Computer. https:// doi.org/10.1080/09548969309364941

DEL ARCO, S. (2007, May 10). Los comerciantes chinos se plantean cerrar hoy por la manifestación en su contra. El País.

DOT, E. (2015). La ciutat emprenedora en un context de crisi urbana: la capacitat d'adaptació del projecte 22@Barcelona (20002013), 273.

FLORIDA, R. (2004). The rise of the creative class: and how it's transformingwork, leisure, community and everyday life. New York: Basic Books.

GANDINI, A. (2015). The rise of coworking spaces: A literature review. Ephemera: Theory and Politics in Organizations, 15(1), 193 -205 .

GARRETT, L. E., SPREITZER, G. M., Y BACEVICE, P. A. (2017). Co-constructing a Sense of Community at Work: The Emergence of Community in Coworking Spaces. Organization Studies, 38(6), 821-842. https://doi.org/10.1177/0170840616685354

GERDENITSCH, C., SCHEEL, T. E., ANDORFER, J., Y KORUNKA, C. (2016). Coworking spaces: A source of social support for independent professionals. Frontiers in Psychology, 7(APR), 1-12.

GONG, H., Y HASSINK, R. (2017). Exploring the clustering of creative industries. European Planning Studies, 25(4), 583-600.

HEEBELS, B., Y VAN AALST, I. (2010). Creative clusters in berlin: Entrepreneurship and the quality of place in prenzlauer berg and kreuzberg. Geografiska Annaler, Series B: Human Geography, 92(4), 347-363. https://doi.org/10.1111/j.14680467.2010.00357.x

HOOVER, E. (1963). The location of economic activity (1948th ed.). New York: McGraw-Hill Book.

HUTTON, T. A. (2006). Spatiality, built form, and creative industry development in the inner city. Environment and Planning A.

JAYNE, M. (2004). City of quarters. Aldershot: Ashgate Publishing Limited.

MARIOTTI, I., PACCHI, C., Y DI VITA, S. (2017). Co-working Spaces in Milan: Location Patterns and Urban Effects. Journal of Urban Technology, 24(3), 47-66.

MARSHALL, A. (1890). Principles of Economics. The Online Library of Liberty, 1-627.

MERKEL, J. (2015). Coworking in the city. Ephemera: Theory and Politics in Organizations, 15(1), 121-139.

MUSTERD, S., BONTJE, M., KOVÁCS, Z., Y MURIE, A. (2007). Accommodating creative knowledge. A literature review from a European perspective. Amsterdam.

PARRINO, L. (2015). Coworking : assessing the role of proximity in knowledge exchange. Knowledge Management Research \& Practice, 13(3), 261-271.

PORTER, M. (1995). The competitive advantage of the inner city. Harvard Business Review, 55-71.

PRATT, A. C. (2009). Urban Regeneration: From the Arts `Feel Good' Factor to the Cultural Economy: A Case Study of Hoxton, London. Urban Studies, 46(5-6), 1041-1061.

SASSEN, S. (2001). The global city: New York, London, Tokyo. Princeton: Princeton University Press.

SCOTT, A. J. (1982). Locational Patterns and Dynamics of Industrial Activity in the Modern Metropolis. Urban Studies, 19(2), 111-141.

SHANK, W. (2017). The new Soho? Metropolitan Barcelona. Be Part of It. Retrieved from http://www.barcelonametropolitan.com/features/the-new-soho/

UNCTAD. (2008). Creative economy outlook and country profiles: Trends in international trade in creative industries. Harvard Business Review (Vol. 8).

VICENTE-SALAR, R., PALLARES-BARBERA, M., Y VERA-MARTIN, A. (2018). Análisis clúster a partir del SABI: Aplicabilidad y viabilidad en la detección de espacios económicos textiles en Barcelona, 2016. En XVIII Congreso Nacional de Tecnologías de la Información Geográfica. Perspectivas multidisciplinares en la sociedad del conocimiento. 


\title{
La aeronáutica como sector estratégico en España. Situación actual y perspectivas en Galicia
}

\author{
Ángel Miramontes Carballada (a) \\ (a) Departamento de Xeografía / Universidade de Santiago de Compostela; angel.miramontes@usc.es
}

\section{Resumen}

\begin{abstract}
La aeronáutica es un sector que, entre otras características, destaca porque reinvierte un porcentaje mayor en I+D+i que otras actividades, provocando un efecto positivo directo en la productividad, competitividad y ocasiona un efecto tractor en otras industrias. Estos son algunos de los hechos que han motivado que la industria aeronáutica lleve unas décadas siendo definida por algunos países, como estratégica para su desarrollo socioeconómico. Entre los que se encuentra España, donde desde el Gobierno español se han redactado y puesto en acción diferentes planes tecnológicos y estratégicos centrados en el desarrollo y apoyo al sector. Aunque con un grado de ejecución y resultados diversos. Además se mostrará la realidad de un territorio concreto como Galicia donde, entre otras actuaciones, se ha creado una red de agentes con el objetivo principal de dinamizar este sector, como el Centro de Innovación Aeroespacial de Galicia, el Consocio Aeronáutico Gallego, la colaboración de la Universidade de Vigo (desde la Escuela de Ingeniería de Telecomunicaciones y la Escuela de Ingeniería Aeronáutica y del Espacio), el Consorcio de la Zona Franca de Vigo o la Xunta de Galicia
\end{abstract}

Palabras claves: Aeronáutica, Sector Estratégico, España, Galicia.

\section{INTRODUCCIÓN}

El presente trabajo sigue una de las líneas clásicas dentro de la Geografía Económica, estudio de la influencia que tiene una determinada actividad económica sobre el territorio. Además de comprobar la evolución y significación de las variables económicas más generales como facturación o empleo, se trata de conocer los procesos de innovación que se generan, si existe una red de agentes o cual es el grado de relación entre los diferentes entes y/o organismos vinculados con esta actividad. Pues con el análisis de estas redes podremos conocer la importancia y futuro próximo que puede llegar a tener, en este caso, el sector aeronáutico en Galicia.

Para alcanzar este objetivo principal, dividimos este trabajo en una introducción centrada en revisar las características generales de los procesos de innovación. Un segundo apartado a modo de "radiografía" del sector aeronáutico en España, para concluir con un estudio de este sector en un espacio concreto como es Galicia. Eso sí, prestándole mayor atención al estudio de la presencia o ausencia de agentes públicos, privados o empresas de este sector y el grado de relación que mantienen entre ellos. Para finalizar con una breve reflexión a modo de conclusión.

Gracias a la amplia relación de trabajos realizados desde el grupo de Geografía Económica de la AGE (Asociación de Geógrafos Españoles), existe un cierto consenso sobre el término de innovación (Méndez, R., 2000, 2006; Méndez, R. y Alonso, J.L. 2000, 2002; Caravaca, I. et al, 2002; Alonso, Mª. P. y Miramontes, Á., 2003; Salom, J. 2003, Alonso, J. L. et al, 2004; Salom, J. y Albertos, J. M. 2009, 2013; Miramontes, Á. y Alonso, M‥ P., 2015). La innovación es un fenómeno social y económico que puede iniciarse desde diferentes ámbitos: por el esfuerzo individual o de un conjunto de actores vinculados con una actividad económica, las características naturales de un espacio, la presencia de un saber hacer fabril o la realización de una estrategia guiada desde la administración pública. Sin embargo, el protagonista y que permite el desarrollo de los procesos de innovación en un territorio son las empresas y, en mayor medida, la capacidad que tengan de conformar una red en la que interactúen los actores públicos, privados, asociaciones, etc. relacionados con esa actividad económica (Aydalot, P., 1986; Camagni, R., 1991, 2003; Maillat, D. 1995; Vázquez, A., 1999; Sforzi, F., 1999).

Por lo que es importante tener claro que la innovación es una actividad colectiva, que proviene de la acción de un conjunto de actores que establecen un sistema de relaciones basadas en la cooperación, pudiendo llegar a configurar una red de innovación. En donde la política de innovación se interpreta de manera genérica como un 
conjunto de acciones cuyo objetivo es incrementar la cantidad y la eficiencia de actividades innovadoras relativas a la creación, adaptación y adopción de nuevos o mejorados productos, procesos o servicios. Ello implica un elevado y heterogéneo número de actores, instrumentos y medidas (Smits et al., 2010; Borrás y Edquist, C., 2013).

Antes de trabajar y conocer las características estadísticas de un sector como es el aeronáutico, es fundamental incidir en que tiene una serie de peculiaridades que se repiten independientemente del territorio en el que se localice y se resumen en tres. En primer lugar se trata de una industria que requiere la existencia de apoyo por parte de las instituciones públicas, entre otros motivos por la necesidad de emplear enormes cantidades de recursos económicos. En segundo lugar, deben existir unas empresas tractoras que centralicen la actividad y, en tercer lugar la industria aeronáutica está sometida a una altísima exigencia de calidad y empleo altamente cualificado. Por estos motivos se incluye a la industria aeroespacial en uno de los pilares de la economía de alto valor añadido a escala mundial.

Según los datos del INE y TEDAE (Asociación Española de Empresas Tecnológicas de Defensa, Aeronáutica y Espacio), la industria aeronáutica española ha triplicado su tamaño en los últimos 15 años. En la actualidad es una actividad con un negocio de cerca de 8.000 millones de euros y más de 100.000 empleos (TEDAE, 2017). Sin embargo, desde el sector español están palpando como en el mercado global cada vez hay más actores y como desde la propia UE, se ha visto a la industria aeronáutica como la clase de industria de alta tecnología y alto valor añadido que no puede ser exportada. A lo que hay que añadir que desde la TEDAE afirman que España es uno de los diez países del mundo capaz de poner en vuelo un avión (TEDAE, 2015).

Todas estas son las motivaciones que justifican la necesidad de comenzar a profundizar en el estudio de este sector en España y, en mayor medida en Galicia que es un territorio localizado en el noroeste de la Península Ibérica y periferia dentro del Sur de Europa, al que se le puede presuponer que no dispone de las características de partida ideales para el desarrollo de una actividad industrial de estas características. De hecho en Galicia, si existe una considerable actividad industrial. Aunque esta industria está focalizada en unas determinadas actividades fabriles tradicionales como la industria textil y moda, la producción y transformación de madera o la pesca. Además estas actividades se caracterizan por concentrar los mayores volúmenes de empleo y facturación en una o dos empresas dentro de cada sector como son los casos de INDITEX, FINSA, S.A. o ENCE. Por lo que aumenta el interés en conocer, cómo se comporta un sector como el aeronáutico y las consecuencias de la red de agentes que existen a día de hoy en torno a su actividad, en un territorio con predominio de actividades industriales tradicionales.

\section{CARACTERÍSTICAS PRINCIPALES DEL SECTOR AERONÁUTICO. EL CASO DE ESPAÑA}

Como ya queda reflejado en el título de este trabajo, tanto de la UE como desde España a la industria aeronáutica se le atribuye un papel estratégico. Sin entrar en más detalle, la Comisión Europea ha integrado la Política Aeroespacial Europea en el núcleo del crecimiento inteligente sostenible e inclusivo al que se refiere la estrategia "Europa 2020".

En el ámbito español, el Plan Integral de Política Industrial 2020 (PIN 2020), elaborado por el Ministerio de Industria, reconoce al sector aeroespacial como uno de los sectores estratégicos futuros para la industria española, habida cuenta de su mayor potencial de crecimiento, su mayor capacidad de arrastre sobre la industria y su orientación a la exportación.

Como adelantamos en la introducción, desde un punto de vista cualitativo este sector presenta una serie de aspectos que le confieren una identidad peculiar y diferenciada del resto de sectores productivos, entre los que se pueden mencionar los siguientes (TEDAE, 2015):

- El mercado aeronáutico tiene un doble componente civil y militar de forma que la demanda en ambos mercados puede oscilar de manera diferente. Además la parte militar tan sólo tiene como clientes a la administración (nacional y/o internacional).

- El sector tiene una estructura empresarial liderada por una serie de grupos industriales, sustentados en una red de grandes, medianas y pequeñas empresas subcontratadas, con una alta dependencia entre ellos.

Por otro lado, su carácter estratégico viene explicado por factores como los siguientes:

- El componente militar de la industria aeronáutica le confiere un carácter clave para la seguridad y defensa nacional. 
- Es un sector generador de riqueza, alto valor añadido e inductor de la cooperación y el comercio internacional.

- Realiza una actividad muy relevante en I+D+i e intensiva en capital, actuando como motor de innovación de la economía, con una gran capacidad de generación de conocimiento y movilización de recursos en el ámbito de la innovación.

- Presenta capacidad de generación de empleo de alta cualificación lo que se refleja en una mayor estabilidad y calidad en el empleo.

En cuanto al número de empresas del sector aeronáutico en España, según la información disponible procedente del Directorio Central de Empresas (DIRCE) del INE (Instituto Nacional de Estadística). El número de empresas que desarrollan la actividad de construcción aeronáutica y su maquinaria (clasificación 30.3 del CNAE 2009) fue de 94 empresas en el ejercicio del 2017. Al retroceder una década y observar su evolución, se comprueba como el sector no ha sido ajeno a la crisis económica vivida en España. De hecho, su comportamiento coincide exactamente con el periodo que se ha estandarizado y generalizado desde diferentes entes públicos y privados que señalan que, la crisis se inició en 2008 y finalizó en 2016 . Pues esta tendencia fue la que mantuvo el número de empresas aeronáuticas en España. Pues su máximo lo tuvo en el 2009 con 101, momento a partir del cual comenzó a perder empresas marcando su mínimo en el 2011 con 75 (ver gráfico 1).

Otra peculiaridad de la industria aeronáutica es el tamaño medio de sus empresas, pues en el 2017 el $63 \%$ de las empresas tenían más de 20 trabajadores y, el intervalo mayor era el de 20 a 49 trabajadores que representaba el $23 \%$ del total. Por lo que agrupando los intervalos de empleados, el mayor lo representan las empresas que tienen de 6 a 49 trabajadores, pero destaca sobre otras actividades industrias que se mantengan en el tiempo un $15 \%$ de media de empresas con una plantilla de 200 a 999 empleados. Sucediendo algo similar con las empresas con más de 1.000 trabajadores que representan entre un 3 y un $5 \%$ del sector a lo largo del tiempo. También se puede deducir que el descenso y posterior aumento del número de empresas que tuvo España en la última década, fue bastante homogéneo con referencia al estrato de empleados.

En cuanto a la distribución territorial a escala de Comunidad Autónoma, según la información del Directorio Central de Empresas del INE, en la década (2008 a 2017), son tres las Comunidades Autónomas que cuentan con

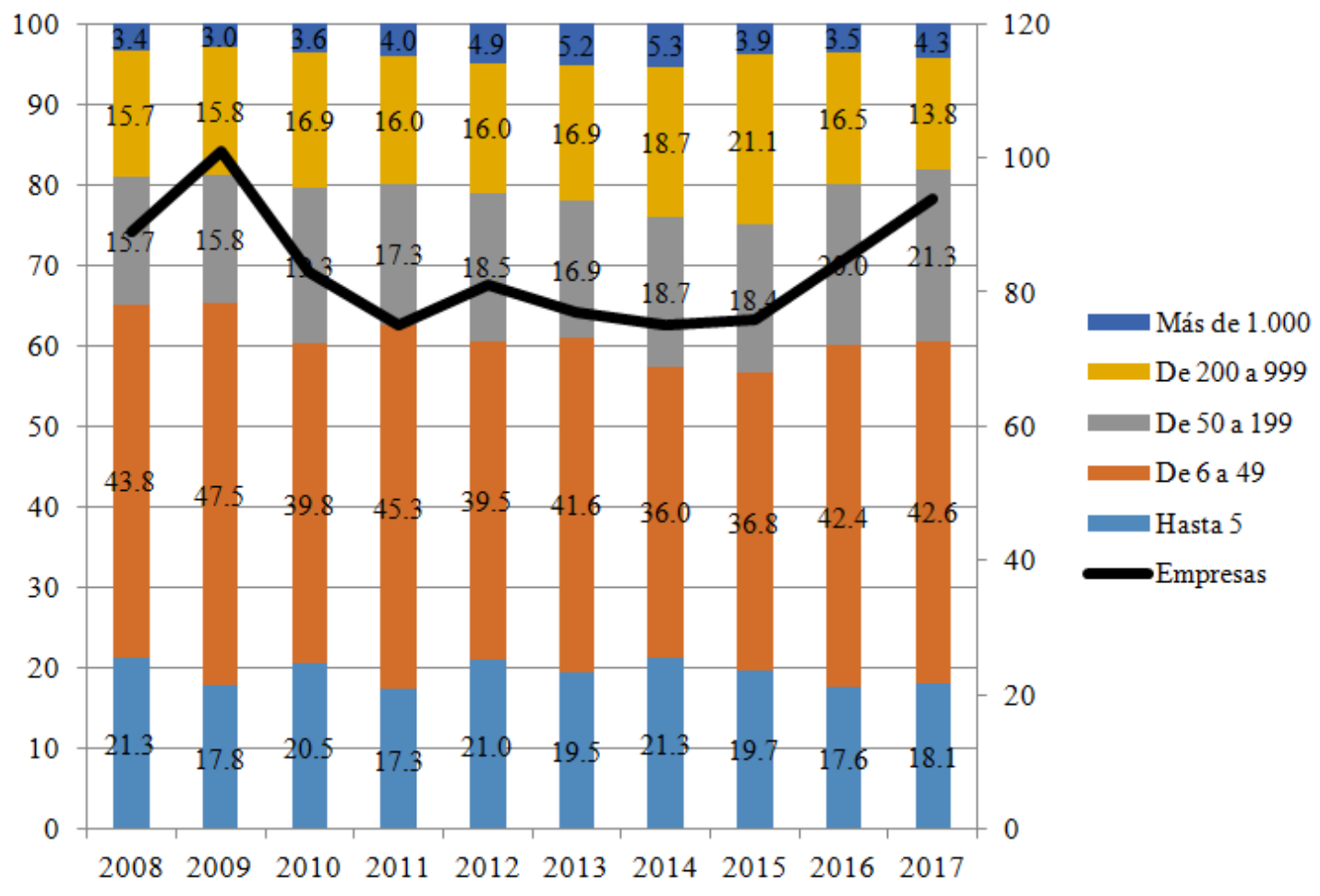

Gráfico 1 - Evolución del número de empresas del sector aeronáutico y porcentaje por estratos de empleo en España. 2008-2017. Fuente: elaboración propia a partir de datos del Instituto Nacional de Estadística, Directorio Central de Empresas, 2018. 
un mayor número de empresas del sector aeronáutico: Andalucía, Madrid y País Vasco. Concretamente en 2017 Andalucía con 25 empresas y, Madrid y el País Vasco con 21 respectivamente.

De hecho este trío autonómico siempre ha superado el $60 \%$ del total de las empresas del sector aeronáutico en España (ver gráfico 2). En el gráfico 2, sólo se representan las Comunidades Autónomas que han tenido alguna empresa en ese periodo de tiempo. Con lo que se desprende otra potencialidad de esta actividad industrial, que es comprobar cómo está presente en prácticamente todo el territorio español. Pues las únicas comunidades autónomas que no han tenido ni tienen empresas aeronáuticas son: Asturias, Cantabria, Navarra y las Islas Baleares. Además de Ceuta y Melilla. Mientras que existe un tercer grupo formado por las Comunidades Autónomas que tuvieron alguna empresa o la tienen en la actualidad, pero a lo largo del periodo 2008 al 2017 han dejado de tener representación como son: Murcia, Extremadura, Comunitat Valenciana y Canarias.

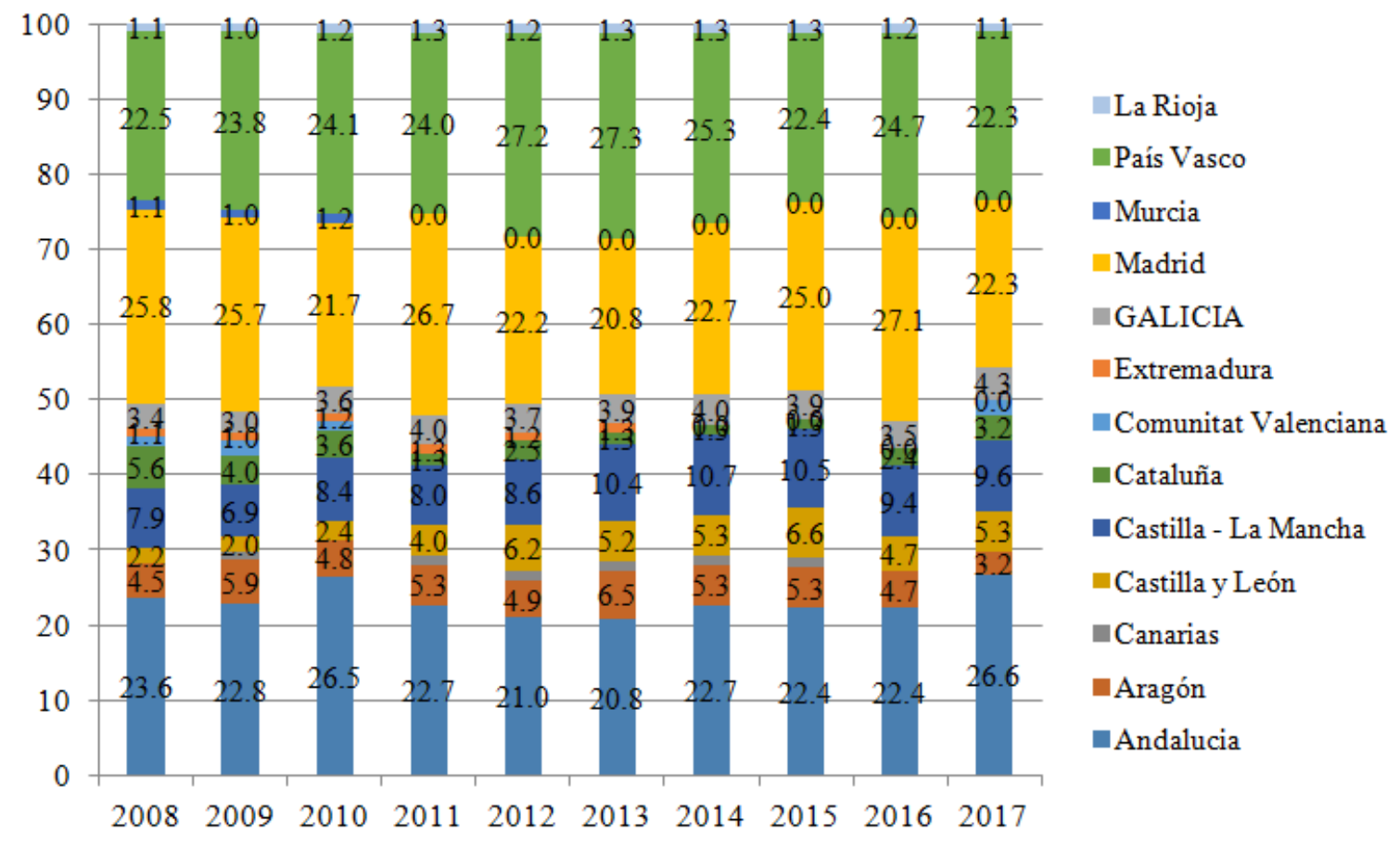

Gráfico 2 - Evolución del número y porcentaje de empresas del sector aeronáutico por Comunidad Autónoma en España. 20082017. Fuente: elaboración propia a partir de datos del Instituto Nacional de Estadística, Directorio Central de Empresas, 2018.

Los motivos de la representatividad del tridente que concentra la actividad aeronáutica española son variados. La importancia del sector aeroespacial en la región madrileña se explica por la existencia de un sistema integrado y diversificado de empresas, con una notable presencia de algunas actividades como estructuras de composites y otros materiales avanzados; comunicaciones, simulación y entrenamiento; sistemas de navegación y aviónica; mantenimiento aeronáutico y de helicópteros o ingeniería de propulsión. Dichas actividades se concentran en tres grandes localizaciones de la industria madrileña: Getafe-Parla-Móstoles, Tres Cantos y el Corredor de Henares.

En Andalucía la presencia del sector es creciente en los últimos años, debido, fundamentalmente, a la existencia de diversos grandes proyectos europeos que se están desarrollando en Andalucía, como son el programa del avión de transporte militar A-400M y la localización de su montaje y pruebas de vuelo en Sevilla. De hecho EADS (European Aeronautic Defence and Space) sólo tiene 3 centros de integración de aviones en Europa, localizados en Hamburgo, Toulouse y Sevilla. Por otro lado, la producción en la región se está diversificando, lo que le permite disminuir riesgos y aumentar las posibilidades de participación en otros programas. Aproximadamente, el 90\% de las actividades del sector se concentran en el eje Sevilla-Cádiz, destacando la presencia de Aerópolis (Parque Tecnológico Aeroespacial de Andalucía) en Sevilla y TecnoBahía en Cádiz.

En el País Vasco el sector aeroespacial está especializado en el diseño, desarrollo y fabricación de motores y componentes, dirigidos tanto a aeronaves como a actividades espaciales. Cuenta además con una infraestructura para realizar sus propios ensayos. El sector surgió a mediados de los años ochenta, fruto de la cooperación entre 
diferentes empresas que iniciaban su actividad en el sector. Entre las empresas se pueden destacar Industria de Turbo Propulsores (ITP), Aernnova o Sener (Ministerio de Energía, Turismo y Agenda Digital, 2011)

Una vez mostradas estas características básicas del sector aeronáutico en España en la última década, según los datos oficiales del INE. Se considera adecuado mostrar algunas de las peculiaridades que hemos conocido del sector después de haber analizado una serie de informes de organismos como TEDAE (Asociación Española de Empresas Tecnológicas de Defensa, Aeronáutica y Espacio). Por lo que primero utilizamos los datos oficiales, pero es información muy general y donde no se recogen todas las actividades incluidas dentro de la industria aeronáutica. Por lo que, como sucede con muchas otras actividades económicas, es necesario recurrir a fuentes de información más especializadas y, que nos permiten profundizar un poco más en la realidad territorial de esta industria.

Desde los informes más actuales realizados por TEDAE, se confirman ciertas magnitudes económicas con unas variables estadísticas que van más allá de las empresas del CNAE con código 30.3. Pues dentro del sector se incluyen otras actividades que son más "difíciles" de encuadrar como las que se dedican a la fabricación de equipos de telecomunicación para satélites, la fabricación de instrumentos de navegación, aparatos utilizados en aeronaves, la fabricación de sistemas de navegación aérea o la fabricación de dispositivos de iluminación para aeronaves.

La actividad del sector incluyendo la aeronáutica civil y militar casi alcanza los 8.000 millones de euros, el volumen de empleo supera los 100.000 empleados (40.000 directo e 60.000 indirecto). En cuanto a la facturación más del $11 \%$ se reinvierte en I+D+i y casi el $85 \%$ proviene de la exportación, dos aspectos muy característicos de la industria aeronáutica española. Al igual que comprobar que es 2,5 veces más productiva que la media española. De hecho, durante la década del 2005 al 2015, uno de los periodos centrales de la crisis socioeconómica vivida en España, la industria aeronáutica pasó de aportar al PIB generado por la industria un 2,2\% en 2005 a un 4,5\% en 2015. Presentando un crecimiento constante y continuo a lo largo de esos años, que se mantiene en la actualidad. Así como ver que por cada 100 euros invertidos por la industria aeronáutica en I+D+i se incrementa el PIB en 700 euros (TEDAE, 2015, 2017).

Otra peculiaridad del sector es que sus productos tienen un ciclo de vida muy largos y con unos costes de producción muy elevados. Con el hándicap añadido que los retornos de beneficios también son a largo plazo, aunque elevados.

Por otro lado nos encontramos con su alta vinculación y en ocasiones dependencia con la Administración, pues está vinculada a departamentos de investigación y educación, transporte, comercio, industria, defensa, seguridad o medio ambiente, que puede llegar a ocasionar graves problemas de coordinación si no son bien planteadas las políticas y convenios entre los gobiernos y la industria aeronáutica.

Por lo que el sector aeronáutico se caracteriza por necesitar empresas tractoras fuertes, personal altamente preparado y enormes recursos económicos. En compensación, los retornos que genera a la sociedad, en términos de reinversión, al Estado vía impuestos, el número de trabajos directos e indirectos, sus valores de comercialización exterior, etc., hacen de este sector uno de los más atractivos como receptor de inversiones de la Administración.

La crisis económica y la situación del mercado global actual, les afecta de forma desigual al subsector civil y al de defensa. La industria mundial de aeronáutica civil está dominada por la empresa norteamericana Boeing y la europea Airbus. Sin embargo, en los próximos años el dominio ejercido por estas dos empresas puede disminuir considerablemente, debido a la transformación de muchas empresas de escala regional de países como China y Rusia que han pasado a construir modelos de segmentos superiores y aptos para todos los mercados.

En España, el primer desarrollo del sector aeronáutico fue a mediados del siglo XX. Gracias a la iniciativa pública a través de la empresa Construcciones Aeronáutica, S.A. (CASA), hoy integrada en el Grupo Airbus. Un segundo periodo de crecimiento fue desde principios de los años noventa y desde el País Vasco, por la iniciativa privada de empresas como Aciturri, Aernnova e ITP, entre otras, ha dado un nuevo impulso al sector civil.

La naturaleza estratégica del sector aeronáutico hace que la participación y la implicación de los estados sea muy relevante, tanto a nivel de cliente, como de regulador, como de proveedor de fondos de I+D+i, (en forma de subvenciones para las actividades o como financiador de los programas de desarrollos más cercanos al mercado), o como accionista en diversos casos. Esto es muy importante e interesante para la geografía económica, pues la búsqueda de la constitución de esas redes entre diferentes agentes y características del territorio es algo que no se les escapa a los responsables de estas empresas. Quizás de la mano de la influencia que siempre han tenido de la Administración pero también ante la necesidad de tener que recurrir a otras empresas para completar un círculo de producción tan complejo como es el de la industria aeronáutica.

Un ejemplo claro y actual es la estrategia de especialización inteligente (RIS3) que significa que las estrategias de innovación nacionales o regionales tienen que definir prioridades para crear ventajas competitivas me- 
diante el desarrollo y la adecuación de los puntos fuertes de la investigación y la innovación a las necesidades empresariales, a fin de abordar las oportunidades emergentes y los avances del mercado de manera coherente y evitar, al mismo tiempo, la duplicación y fragmentación de los esfuerzos.

La Comisión propuso que estas estrategias fueran una condición previa para la financiación del FEDER. En consecuencia, los Estados miembros y regiones de la UE debían establecer las estrategias de RIS3 antes de que se aprobaran los programas operativos que respaldan estas inversiones.

En el caso de España, este trabajo concluyó en 2014, cuando se presentaron las RIS3 de todas las Comunidades Autónomas. Desde el gobierno de Galicia, se reiteró la significación que debe de tener en un futuro próximo la industria aeronáutica dentro de su estructura socioeconómica y las diferentes actuaciones realizadas para llegar a este objetivo.

\section{ANTECEDENTES Y SITUACIÓN ACTUAL DEL SECTOR EN GALICIA}

Dentro de España existen territorios que tienen un volumen de actividad relacionada con la industria aeronáutica mucho mayor que la presente en Galicia, como Madrid, Andalucía o el País Vasco. Sin embargo el caso gallego está adquiriendo cada vez mayor protagonismo debido a la implicación del gobierno autonómico, el crecimiento de las pocas pero grandes empresas localizadas en Galicia y, principalmente por la creación de un entramado, de una red, donde están presentes las empresas, la administración, la universidad y asociaciones que están creando unos cimiento sólidos de innovación y desarrollo sobre la industria aeronáutica.

La industria aeronáutica en Galicia cuenta con más de 40 empresas, ofrece trabajo directo e indirecto a más de 1.500 personas y tiene un volumen creciente de negocio de más de un 7\% en la producción directa (2016). Aunque no son valores muy importantes son varios los motivos que permiten pronosticar que la industria aeronáutica gallega es un sector "que tendrá futuro" en esta Comunidad Autónoma (CINAE, 2018).

Uno de los motivos, como veremos, es la predisposición de la Xunta de Galicia por involucrarse en su desarrollo y haber consolidado la colaboración con otros agentes como la Zona Franca de Vigo o la Universidad de Vigo para la potenciación y desarrollo de esta industria, a través de distintas políticas de apoyo.

Además desde la iniciativa privada, también se han comenzado a realizar actuaciones que tendrán un gran calado en el desarrollo a corto plazo del sector aeronáutico en Galicia. De hecho en el 2016, se realizó una inversión de más de 75 millones de euros en mejoras productivas para proveer (en diferentes niveles de subcontratación) a los cuatro mayores fabricantes de aviones del mundo: Airbus, Embraer, Boeing y Bombardier.

Una de las empresas es COASA, con sede en el Parque Tecnológico de Galicia en San Cibrao das Viñas (Ourense), que inyectó 45 millones de euros en sus instalaciones, para acondicionarlas a nuevos pedidos y llegar a nuevos mercados. Tras unas breves consultas informales, nos confirmaron que poseen convenios con pedidos de un gran país como la India que incrementará de forma importante la actividad de la planta y de sus principales auxiliares gallegas especializadas en mecanizado: Utingal (en Tui, Pontevedra) y Laddes Work, en Ourense. El principal cliente de COASA es Airbus, que al ser una de las empresas del sector más importantes del mundo le permite trabajar con "tranquilidad" e incrementar algunos riesgos. Algunos de sus productos son vendidos al $100 \%$ al mismo cliente.

Otra gran empresa gallega del sector es Delta Vigo, una fábrica de pura ingeniería en pleno proceso de expansión con capital cien por cien gallego. La empresa tiene plantas en Vigo e Illescas (Toledo), y acaba de invertir 30 millones en su tercera factoría en Galicia. La compañía viguesa prevé elevar la facturación desde los 22 millones actuales hasta los 60 , en el horizonte del 2020, con pedidos ya contratados para este periodo.

Otro proceso de expansión se promueve desde UDEGA, la Unión de Empresas Gallegas de Aeronáutica, con una inversión de 4 millones de euros para mejorar las instalaciones y desarrollar nuevas piezas de avión, de la que hablaremos en el próximo apartado.

En los últimos años la parte pública también se ha volcado en impulsar el sector aeronáutico gallego. Una muestra es la apuesta que el Instituto Nacional de Técnica Aeroespacial (INTA), organismo dependiente del Ministerio de Defensa, ha hecho por Galicia al fijar en Lugo la base del Centro de Investigación Aerotransportada de Rozas (CIAR), presupuestado en 10 millones de euros, a los que la Xunta prevé inyectar 45 más hasta el 2020. En la nómina de futuros socios tecnológicos figuran potencias como Airbus, Boeing Indra, Inaer o Thales. Otra actuación significativa fue la creación de la Fundación Centro de Innovación Aeroespacial de Galicia, impulsada por el Consorcio de la Zona Franca de Vigo y la Universidade de Vigo. 
En cuanto a los grandes datos económicos del sector en Galicia, aún no son muy representativos, pero hay que tener en cuenta dos factores: por un lado que es un sector que lleva poco tiempo en funcionamiento y, en segundo lugar que la calidad de la producción es de alto valor añadido pues proviene directamente de diversos procesos de ingeniería. Según los datos del TEDAE, Galicia representa un poco más del $4 \%$ del empleo y número de empresas de la industria aeronáutica de España. Sin embargo, ya existen estimaciones que se mantendrá a lo largo de los próximos años un incremento regional de más del 12\% en el empleo y del 10\% en la facturación.

De todos modos, al aspecto al que desde este trabajo se le quiere dar mayor importancia, es la presencia de una serie de agentes en este territorio del noroeste de la península lbérica que le dan un carácter innovador y una capacidad de crecimiento y expansión esperanzadores. A continuación se presentan brevemente, las características de cada uno de los agentes que forman esta red alrededor de la industria aeronáutica en Galicia (ver figura 1).

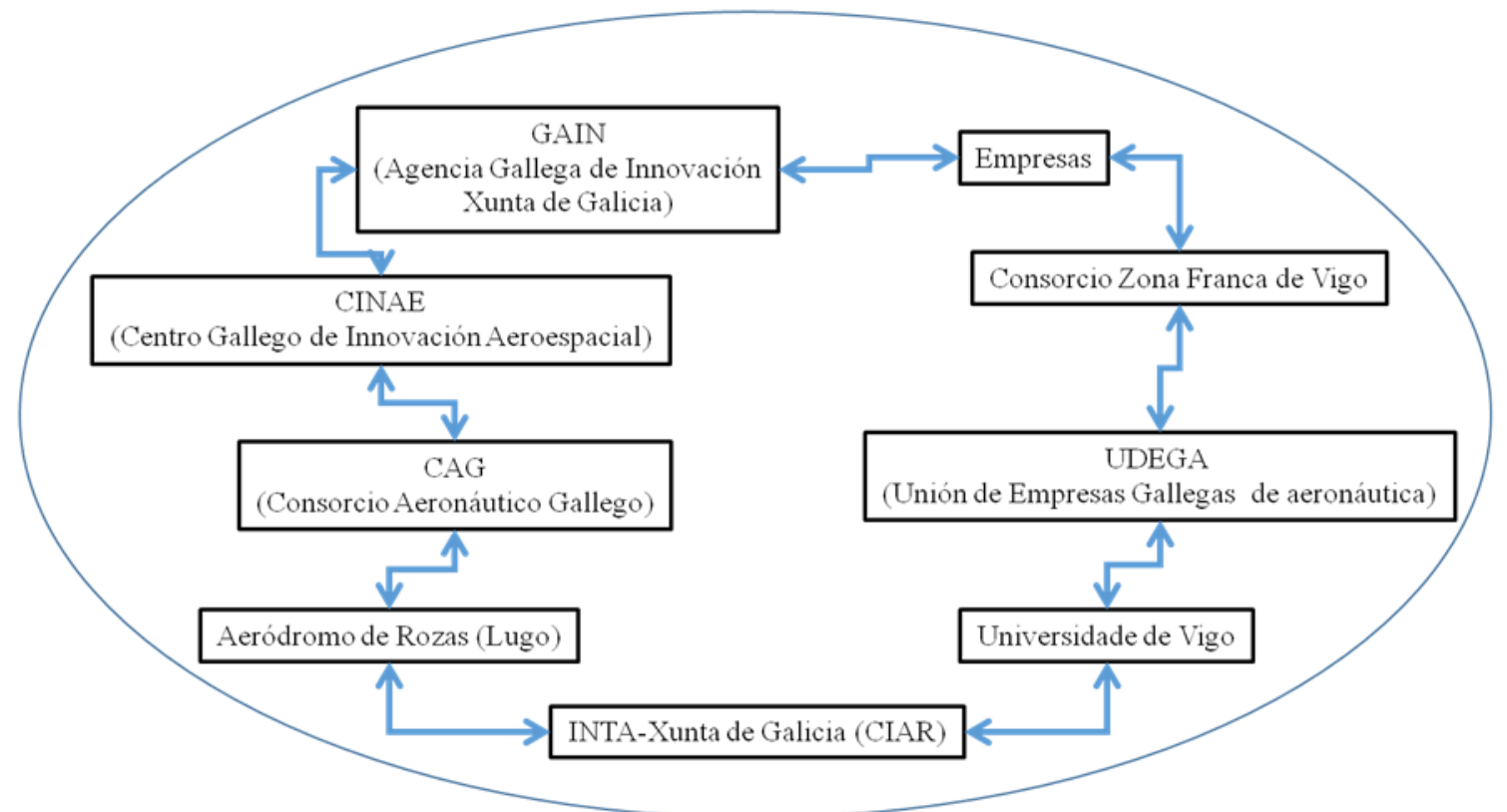

Figura 1 - Relación de agentes públicos, privados y empresariales vinculados con la industria aeronáutica en Galicia. Fuente: elaboración propia.

La Agencia Gallega de Innovación GAIN, es una agencia pública autonómica, adscrita a la Consellería de Economía, Emprego e Industria pero con personalidad jurídica propia, que tiene como finalidad fomentar y vertebrar las políticas de innovación en las administraciones públicas gallegas, y el apoyo e impulso del crecimiento y de la competitividad de las empresas gallegas, a través de la implementación de estrategias y programas de innovación eficientes. Aunque actúa sobre todo el territorio gallego y todas las actividades económicas, una de sus líneas prioritarias es la industria aeronáutica. La sede de la agencia está en la ciudad de Santiago de Compostela (GAIN, 2018).

El Centro gallego de Innovación Aeroespacial (CINAE) es una fundación privada sin ánimo de lucro fundada por la Universidad de Vigo, el Consorcio Zona Franca de Vigo, AIRBUS Defensa y Espacio, UDEGA, Delta Vigo y el Consorcio Aeronáutico Gallego. Sus orígenes se remontan a la actividad tecnológica del Grupo Aeroespacial de la Universidad de Vigo centrado en el desarrollo de pequeños satélites. Como centro se constituyó en el 2007 con el proyecto Xatcobeo y continuó con Humsat y otros proyectos en cooperación con el Instituto Nacional de Técnica Aeroespacial (INTA), la Agencia Espacial Brasileña (AEB), la Agencia Espacial Europea (ESA) y la Oficina de Naciones Unidas para Asuntos del Espacio Exterior (UNOOSA).

En la actualidad el centro se financia el $60 \%$ con fondos privados y un $40 \%$ con fondos públicos. El objetivo principal del CINAE es contribuir al fortalecimiento, potenciación, crecimiento y mejora de la competitividad en la industria de las tecnologías aeroespaciales de Galicia mediante el logro de la excelencia en la investigación y el desarrollo tecnológico. El equipo está compuesto por ingenieros de telecomunicaciones, ingenieros aeronáuticos con especialización en el sector aeroespacial, ingenieros industriales y físicos. La sede del centro está en Parque Empresarial Porto do Molle, en el municipio de Nigrán dentro del área de influencia de Vigo (CINAE, 2018). 
EI CAG (Consorcio Aeronáutico Gallego), también fue creado en el 2007 formado por 53 empresas pertenecientes al sector metalúrgico gallego, con el fin de promover y desarrollar el sector aeronáutico en Galicia y alcanzar un mayor nivel de innovación, investigación y competitividad, en todo el sector. El CAG, entre otras organizaciones en las que participa, es patrono fundador del CINAE y en actividades tan importantes como proyecto UAV'S Initiative de As Rozas (Lugo) o la creación del grado universitario de Ingeniería Aeroespacial de la Universidade de Vigo. EI CAG tiene su domicilio social en la ciudad de Vigo (CAG, 2018).

INTA - CIAR. La Xunta de Galicia está realizando una apuesta decidida por el desarrollo de un centro aeronáutico de referencia europea en Galicia. Alrededor del Parque Tecnológico de Rozas, aprovechando el aeródromo de Rozas (Castro de Rei, Lugo) y la creación del futuro Centro de Investigación INTA-Xunta (CIAR), dependiente del Instituto Nacional de Técnica Aeroespacial del Ministerio de Defensa, en el que se invertirá 55 millones de euros hasta 2020.

En el marco de esta política de promoción del centro tecnológico, el gobierno gallego lanzó la Civil UAVs Initiative para la utilización de sistemas aéreos no tripulados en el ámbito civil y en la mejora de la prestación de servicios públicos (Civil UAVs Initiative, 2018).

Enmarcada en la política de impulso del centro de investigación y tecnología aeronáutica, el gobierno gallego y el instituto Nacional de Técnica Aeroespacial (INTA) ya realizaron una inversión de 10 millones de euros en la adaptación de las infraestructuras del aeródromo de Rozas para acoger al Centro Mixto de Investigación INTAXunta (CIAR). Con el objetivo final de convertirse en el centro de ensayos para el desarrollo de aeronaves y la evaluación de campañas. Posteriormente, la Xunta de Galicia tiene en marcha un procedimiento de compra pública pre-comercial a nivel internacional de hasta 25 millones de euros, para la búsqueda de uno o varios socios tecnológicos industriales, especializados en sistemas aéreos no tripulados, que activen el desarrollo del centro tecnológico.

UDEGA S.L. (Unión de empresas gallegas de aeronáutica), se creó en 2012 de la unión de varias empresas gallegas, con el ánimo de unificar métodos de trabajo y su relación con el contexto externo para optimizar recursos materiales y humanos mediante la cooperación industrial. Capaces de abordar un amplio abanico de proyectos, UDEGA se constituye como un referente a escala española y presencia internacional. El nutrido parque de maquinaria unida a la amplia experiencia acumulada por todas las plantas en diversidad de sectores, como el naval, la automoción o el aeronáutico, hace de UDEGA una gran empresa, capaz de ofrecer a sus clientes variedad de productos y servicios relacionados con la industria aeronáutica (UDEGA, 2018).

El CZFV (Consorcio Zona Franca de Vigo) es una institución pública que gestiona una zona franca de comercio internacional y actúa como agencia de desarrollo económico. Tiene como objetivo principal fomentar el desarrollo económico del área de influencia de Vigo y Galicia en general. Desde el consorcio siempre muestran las ventajas que pueden tener los empresarios y emprendedores para instalar sus centros de negocio en este territorio. De hecho, CZFV posee la capacidad y conocimiento tanto para buscar las mejores opciones para los grandes y pequeños negocios, así como para encontrar el emplazamiento más adecuado para la empresa, dispone de las mejores instalaciones, capital, información, formación y conocimiento.

Al igual que con otras actividades económicas, mantiene una línea de actuación propia y exclusiva con la industria aeronáutica, participando en gran parte de los proyectos vinculados con el sector en Galicia (CZFV, 2018).

A lo largo de este trabajo, también se está comprobando la implicación de la Universidade de Vigo con el desarrollo de la industria aeronáutica en Galicia. Incluso se pude considerar como uno de los agentes que estuvo presente desde los inicios y primeras actuaciones de esta red innovadora, pues participó en la creación del CINAE o el CAG. Así como ser el único centro de Galicia en el que se puede obtener el grado de Ingeniería de Tecnologías de Telecomunicaciones y desde hace un par de años se imparte el grado de Ingeniería Aeroespacial, lo que asegura la creación de un cierto volumen de mano de obra altamente cualificada. La Universidade de Vigo tiene campus en las ciudades de Vigo, Ourense y Pontevedra.

\section{CONCLUSIONES}

Antes de desarrollar una breve reflexión final sobre el sector aeronáutico en Galicia. Consideramos que es muy importante dejar claro que nos encontramos ante un primer trabajo, una primera toma de contacto con un sector económico que en el territorio español y en concreto en Galicia, presenta un bagaje de actividad reciente. Sin embargo pensamos que muy importante y a tener en cuenta a corto y medio plazo. De hecho, se trata de esas 
actividades industriales que se catalogan como estratégicas a escala internacional y que presenta un mercado aun "por ocupar", en el que los territorios más desarrollados desde el punto de vista tecnológico están planteando diferentes estrategias para ocuparlo. De ahí el interés y esfuerzo de conocer este sector y más al ver que Galicia posee una red de innovación vinculada con esta actividad. Por lo que este estudio hay que interpretarlo con cautela, y como una base de análisis que utilizaremos en próximas investigaciones para seguir profundizando en las características de la industria aeronáutica.

De todos modos, una de las conclusiones a las que sí se llega en este trabajo es comprobar cómo en Galicia existe una red de innovación en la que están presentes todo tipo de agentes públicos, privados y un conjunto de empresas que parecen constituir unos cimientos muy adecuados para el desarrollo de este sector y que adquiera mayor protagonismo en la estructura socioeconómica de Galicia. Con lo que un segundo paso a efectuar en próximas investigaciones, será analizar el grado de relación que existe entre cada uno de los agentes.

Otra conclusión que se aprecia en el territorio gallego, es la existencia de una serie de líneas de apoyo promovidas desde la administración pública, muy especializada y dirigida con exclusividad hacia el sector aeronáutico, como son los casos de Civil UAVs Initiative o la dinamización del aeródromo de Rozas, entre otras. Muy superiores en número y dotación a la que encontramos en territorios próximos o con características similares a las que puede tener Galicia.

Esta ventaja se confirma al observar como desde todos los entes relacionados con el sector aeronáutico, se afirma que para su existencia se requiere de un decidido y permanente apoyo de las instituciones públicas. Así como, que el sector aeronáutico español debe aspirar a seguir manteniendo su presencia en los proyectos y productos de vanguardia y de última generación, frente a la competencia de las empresas de los nuevos países que se incorporan al sector.

De todos modos, en España y el caso concreto de Galicia el comportamiento de todas estas asociaciones, la creación de infraestructuras como el aeródromo de Rozas o los centros tecnológicos, nos despiertan dudas y es una incógnita, por lo que tendremos que estar atentos a su evolución y ver cómo se comporta dentro de un sector altamente competitivo y tecnológico.

Por último, señalar que se aprecia una clara especialización y distribución territorial del sector en el sur de Galicia, principalmente en el área de influencia de las ciudades de Vigo y Ourense. No sorprende porque se tratan de territorios donde otros sectores económicos tienen mucha significación a escala internacional como la automoción, textil-moda o agroalimentario. Sin embargo, si es menos normal no encontrar mayor implicación del área de influencia de A Coruña o Santiago de Compostela, más allá de la presencia de alguna empresa o las gestiones realizadas desde la propia sede de la Xunta de Galicia.

\section{BIBLIOGRAFIA}

AGENCIA GALLEGA DE INNOVACIÓN (GAIN) (2018) http://gain.xunta.gal

ALONSO, J. L.; APARICIO, L. J. y SÁNCHEZ, J. L. (2004). Recursos territoriales y geografía de la innovación industrial en España. Ediciones Universidad de Salamanca. Salamanca. Páginas: 352.

ALONSO, Ma . P. y MIRAMONTES, Á. (2003). "La significación de un medio innovador local dentro de la industria de muebles de Galicia: A Estrada (Pontevedra)". Boletín de la Asociación de Geógrafos Españoles. Número 36. Asociación de Geógrafos Españoles. Madrid. Páginas: 93-102.

AYDALOT, P. (1986). Milieux innovateurs en Europe. GREMI. Paris.

BORRÁS, S. Y EDQUIST, C. (2013): "The choice of innovation policy instruments", Technological Forecasting and Social Change, 80, 1513-1522.

CAMAGNI, R (1991). Innovation networks. Spatial perspectives. GREMI-Belhaven Press, Londres.

CAMAGNI, R. (2003). "Incertidumbre, capital social y desarrollo local: enseñanzas para una gobernabilidad sostenible del territorio". Investigaciones Regionales. Asociación española de ciencia regional. Mundi-Prensa. Libros. Número: 2. Madrid. Páginas: 31-58.

CARAVACA BARROSO, I.; GONZÁLEZ, G.; MÉNDEZ, R. y SILVA, R. (2002). Innovación y territorio: análisis comparado de sistemas productivos locales en Andalucía. Junta de Andalucía. Consejería de Economía y Hacienda. Sevilla. Páginas: 392.

CENTRO GALLEGO DE INNOVACIÓN AEROESPACIAL (CINAE) (2018) https://www.cinae.org/

CIVIL UAVS INITIATIVE (2018) http://www.civiluavsinitiative.com/

CONSORCIO AERONÁUTICO GALLEGO (CAG) (2018) http://www.consorcioaeronautico.com/ 
CONSORCIO ZONA FRANCA DE VIGO (CZFV) (2018) https://www.zfv.es/portal/index.html INSTITUTO NACIONAL DE ESTADÍSTICA (INE) (2018) http://www.ine.es/

MAILLAT, D. (1995). "Les milieux innovateurs”, Sciencies Humaines, 8. Páginas: 41-42.

MÉNDEZ GUTIERREZ DEL VALLE, R. (2000). "Procesos de innovación en el territorio: los medios innovadores". Innovación, pequeña empresa y desarrollo local en España. Editorial Civitas. Madrid. Páginas: 23-59.

MÉNDEZ, R. y ALONSO, J. L. (coords.) (2000). Innovación, pequeña empresa y desarrollo local en España. Civitas. Madrid. Páginas: 323.

MÉNDEZ, R. y ALONSO, J. L. (eds.) (2002). Sistemas Locales de Empresas y redes de innovación en Castilla - La Mancha y Castilla y León. Universidad de Salamanca.

MÉNDEZ GUTIERREZ DEL VALLE, R. (2006). "La construcción de redes locales y los procesos de innovación como estrategias de desarrollo rural”. Problemas del Desarrollo. Revista Latinoamericana de Economía, vol. 37, núm. 147. Universidad Nacional Autónoma de México. México. Páginas: 217-240.

MIRAMONTES, A. Y ALONSO, Ma. P. (2015) "Sistemas productivos locales en la industria del mueble en Galicia (España). Su situación ante la crisis". Anales de Geografia de la Universidad Complutense de Madrid, volumen 35. Editorial Servicio de Publicaciones de la Universidad Complutense de Madrid, Madrid (España). Páginas: 22 inicial 63 final 94

MINISTERIO DE ENERGÍA, TURISMO Y AGENDA DIGITAL (2011) El sector aeronáutico y espacial español: Situación actual y perspectivas, MCA-UGT (Metal, Construcción y Afines de la Unión General de Trabajadores, Federación de Industria) Madrid, $122 \mathrm{p}$.

SALOM CARRASCO, J. (2003). "Innovación y actores locales en los nuevos espacios económicos: un estado de la cuestión". Boletín de la Asociación de Geógrafos Españoles. Número: 36. Madrid. Páginas: 7-30.

SALOM, J. y ALBERTOS, J.M. (2009). Redes socioinstitucionales, estrategias de innovación y desarrollo territorial en España. Colección Desarrollo Territorial. Serie Estudios y Documentos, 6. Publicaciones de la Universitat de Valencia. Valencia. Páginas: 202.

SALOM, J. y ALBERTOS, J. M., 2013). "Los efectos de la crisis económica en los distritos industriales valencianos: ¿hacia nuevos desequilibrios territoriales?", En Crisis económica e impactos territoriales. Actas de las V Jornadas de Geografía Económica AGE Universitat de Girona. Páginas 267-284.

SFORZI, F. (1999). "La teoría marshaliana para explicar el desarrollo local", en Rodríguez Gutierrez, F., (coord.), Manual de desarrollo local, Trea ediciones, Gijón. Páginas: 13-22.

SMITS, R, KUHLMANN, S. and SHAPIIRA, PH (2010): The Theory and Practice of Innovation Policy.

An International Research Handbook.Cheltenham, UK, Edward Elgar, $496 \mathrm{pp}$.

TEDAE (2015). Retos del Sector Aeronáutico en España. Guía Estratégica 2015-2025, Madrid, 27 p (https://www.tedae.org/es)

TEDAE (2017). La Aeronáutica española, una apuesta de futuro, Madrid, 2 p. (https://www.tedae.org/es)

UNIÓN DE EMPRESAS GALLEGAS DE AERONÁUTICA (UDEGA) (2018) http://udega.com/es/

VÁZQUEZ BARQUERO, A. (1999). Desarrollo, redes e innovación. Lecciones sobre desarrollo endógeno. Pirámide. Madrid. Páginas: 268. 


\section{INOVACIÓN ECONÓMICA Y SOCIAL}


Página intencionalmente dejada en blanco 


\title{
Redes de inovação no ecossistema da Região Centro de Portugal
}

\author{
T. Sá Marques (a), H. Santos (b), P. Ribeiro (c) \\ (a) Centro de Estudos de Geografia e Ordenamento do Território (CEGOT)/ Faculdade de Letras da Universidade do Porto, \\ teresasamarques@gmail.com \\ (b) Centro de Estudos de Geografia e Ordenamento do Território (CEGOT). Departamento de Geografia, Faculdade de Letras da Universidade do \\ Porto, hfcs75@hotmail.com \\ (c) Centro de Estudos de Geografia e Ordenamento do Território (CEGOT). Faculdade de Letras da Universidade do Porto, \\ paularibeiro82@gmail.com
}

\begin{abstract}
Resumo
Os ecossistemas de inovação sustentam-se em redes de produção de conhecimento e inovação, que envolvem diversos atores e diversas escalas territoriais. Estas redes representam ligações associadas a processos de criação, produção e transferência de conhecimento e inovação, podendo desencadear coespecialização e variedade relacionada entre os diferentes atores localizados na região.

Assim, este trabalho explora o ecossistema regional da Região Centro de Portugal e os subsistemas regionais de inovação , recorrendo à metodologia de análise de redes sociais, com base nos projetos de inovação em parceria dinamizados por organizações localizadas nesta região (entre 2007-2015). Identificam-se as redes organizacionais e territoriais presentes neste ecossistema e as tendências de especialização nos processos de inovação. Reconhece-se o conhecimento base que alavanca esses processos e os setores de aplicação a que se dirigem, de forma a caraterizar as capacidades regionais dirigidas á estratégia regional de especialização inteligente.
\end{abstract}

Palavras chave: Ecossistemas de inovação; redes de inovação; especialização inteligente

\section{INTRODUÇÃO}

A inovação é considerada um processo altamente interativo e sistêmico (Tödtling, F; Trippl,M., 2011), que resulta de diferentes formas de criar, produzir, reconfigurar e transferir o conhecimento. Este processo é organizado e estruturado por redes, compostas por diversificados tipo de atores, que a partir das relações construídas, formam geometrias variáveis a diferentes escalas territoriais. Neste contexto, o conceito de sistemas regionais de inovação incorpora esta interpretação da inovação enquanto processo evolutivo, não linear e dinâmico.

Para aprofundar a territorialidade dos processos de inovação dos ecossistemas sub-regionais localizados na Região Centro de Portugal (ao nível a NUT III) explorou-se e analisou-se, através da metodologia de análise de redes sociais, os projetos de inovação financiados pelo último quadro comunitário com amarração nas subregiões da Região Centro. Para tal, efetuou-se um levantamento dos projetos de inovação em parceria, no período de 2007-2015, que envolveram as organizações localizadas nas seis sub-regiões NUT III da Região Centro. Em termos metodológicos, a base de análise estrutura-se em torno da classificação e localização dos atores da rede e das áreas tecnológicas e setores de aplicação associados a cada projeto. A partir da localização de cada organização e das relações que se estabelecem com as diferentes áreas tecnológicas e com os setores de aplicação, aplicou-se a análise de redes sociais, com recurso ao programa Nodexl. O objetivo é identificar as redes organizacionais, as redes de conhecimento e as redes territoriais. Desta forma, consegue-se analisar a tendência para uma maior ou menor especialização dos territórios nos processos de inovação e identificar as diferentes escalas geográficas de relacionamento.

A análise das métricas das redes permitiu identificar os níveis e os sistemas de polarização intra-regionais (nas sub-regiões de Coimbra, de Aveiro e de Leiria), reconhecer as áreas tecnológicas que lideram a produção de conhecimento (em especial nas TIC e nas tecnologias dos materiais), e a maior ou menor diversidade de sectores de aplicação. Desta forma, identificam-se os processos de cocriação e a variedade relacional e a proximidade geográfica e os relacionamentos de escala regional e sub-regional nos processos inovação. A análise desenvolvida também monstra os fortes relacionamentos com organizações localizadas fora da região (sobretudo com o Noroeste português). 


\section{FUNDAMENTOS TEÓRICOS E METODOLÓGICOS}

A coevolução e codesenvolvimento dos ecossistemas de inovação nas suas múltiplas dimensões - multilaterais (envolvendo diferentes atores), multinodais (interligando múltiplos clusters de conhecimento), multimodais (abarcando diferentes modos de produção do conhecimento) e multiescalares (atravessando diferentes escalas geográficas) -, constituem a base da economia do conhecimento e permite a criação de um sistema multinível de produção de conhecimento e inovação (Carayannis e Campbell, 2011, 2012; Carayannis, Pirzadeh e Popescu, 2012).

A aprendizagem interativa tem um papel central nos processos de inovação económica (Jensen, Johnson, Lorenz e Lundvall, 2007; Caraça, Lundvall e Mendonça, 2009), já que se reconhece que a economia de conhecimento se sustenta na produção e utilização de conhecimento com vista à inovação económica (Lundvall e Johnson, 1994; Lundvall, 2010). Estes processos de aprendizagem são variáveis, abrangendo um amplo leque de atividades económicas que se apoiam em diferentes em formas do conhecimento: analíticas, sintéticas e ainda simbólicas (Asheim e Coenen, 2005). As organizações, nomeadamente as empresariais, enquanto entidades produtoras de conhecimento (Nonaka, 2004), podem direcionar-se para a produção de formas de exploration knowledge $e^{1}$, ou de formas de exploitation knowledge (Nooteboom, 2000), exigindo a incorporação de diferentes taxonomias do conhecimento (know-what; know-why; know-how; know-who) (Jensen et al., 2007). Assim, para a compreensão destes processos de aprendizagem e de produção de conhecimento dirigidos à inovação económica deve-se recorrer a abordagens multidimensionais e dinâmicas, através de redes interativas de geometrias e geografias variadas (Santos, 2013), que possibilitem captar os processos de fertilização cruzada do conhecimento (Gibbons et al., 1994) que se vão gerando ao longo do tempo ${ }^{3}$.

A constatação da natureza indissociável entre o conhecimento e a inovação económica permite reconhecer que os processos de inovação são transversal a todas as atividades económicas, não estando enraizados apenas no conhecimento científico (analítico) e por isso reservado aos setores e às atividades intensivas em I\&D, mas pode abarcar outras formas de conhecimento (sintético e simbólico) (Asheim e Coenen, 2005). Assim, podendo os processos de inovação construir diferentes trajetos (Jensen et al., 2007), é necessário reforçar a adoção de uma visão sistémica constituída por multicanais de aprendizagem interativa (Caraça, Lundvall e Mendonça, 2009). A inovação enquanto processo transversal aos diferentes ramos económicos, associada à admissibilidade da existência de diferentes trajetórias de inovação gera oportunidades para a emergência de processos de variedade relacionada, que podem reforçar a capacidade inovadora das regiões (Boschma e Frenken, 2011). Enquanto processo interativo, a inovação económica estrutura-se em redes relacionais, envolvendo diferentes graus de proximidade cognitiva, organizacional, social e institucional (Boschma, 2005; Balland, Boschma e Koen, 2015), o que favorece a transferência de conhecimento entre organizações e, consequentemente, os processos de variedade relacionada (Boschma e Frenken, 2011). Assim, as redes de inovação assumem um papel estruturador dos processos de inovação económica, exibindo composições variadas (ora mais endogâmicas, ora mais exogâmica ${ }^{4}$ ) e com um número de organizações envolvidas também variável (ora com um perfil relacional essencialmente monogâmico, ora com um perfil relacional poligâmico ${ }^{5}$ ) (Santos, 2013), como demonstram Marques e Santos (2013) para a Área Metropolitana do Porto.

Para a geografia económica relacional, as redes de inovação tendem a exibir um comportamento geográfico que abarcar diferentes escalas relacionais em função das possibilidades de criação de proximidade cognitiva, organizacional, social e/ou institucional. Em termos de políticas de inovação, esta perspetiva defende que se devem considerar as múltiplas escalas através das quais se estabelecem as relações interorganizacionais de inovação, já que a capacidade inovadora das regiões não depende apenas do conhecimento produzido localmente, mas também das estratégias relacionais suprarregionais para a ancoragem do conhecimento produzido interactivamente a maior distância geográfica (Amin, 2004; Massey, 2007). Assim, a geografia das redes de conhecimento e de inova-

\footnotetext{
${ }^{1}$ Aprendizagem e abertura das organizações a novas combinações de formas alternativas do conhecimento (desenvolvimento de novas competências), através da abertura da variedade de contexto a novas redes de relações e, consequentemente, a uma maior variedade do conteúdo do conhecimento (Nooteboom, 2000).

${ }^{2}$ Utilização e refinamento da aplicação do conhecimento já apreendido (aproveitamento das competências existentes), através da redução da variedade do conteúdo do conhecimento, para convergir com o contexto da tecnologia e da organização (Nooteboom, 2000).

${ }^{3}$ Esta abordagem é explorada, por exemplo, por Santos e Marques (2013) para a Área Metropolitana do Porto.

${ }^{4}$ Redes relacionais constituídas por: ligações interorganizacionais homofílicas, isto é, entre atores pertencentes à mesma esfera de ação (endogâmicas); ligações interorganizacionais heterofílicas, isto é, entre atores pertencentes a diferentes esferas de ação (exogâmica) (Santos, 2013).

${ }^{5}$ Relações privilegiadas entre um par de organizações, isto é, ligações díades (monogâmicas); relações entre múltiplas organizações (poligâmicas) (Santos, 2013).
} 
ção apresenta um comportamento multiescalar, capaz de quebrar as fronteiras regionais, de aportar afluxos e fluxos de conhecimento, que contribuem para desenvolver a prestação inovadora das regiões. A estrutura multiescalar das redes de inovação é, a título de exemplo, uma caraterística exibida pelos territórios do Arco Metropolitano de Lisboa (Marques, Santos e Ribeiro, 2015) e da Área Metropolitana do Porto (Marques e Santos, 2013).

A análise que se segue considera precisamente os pressupostos da multidimensionalidade da proximidade, que proporciona uma geografia relacional multiescalar dos processos de produção de conhecimento, aprendizagem e inovação. A análise foca-se na exploração das redes de I\&D+l, a partir de métodos quantitativos (metodologia de análise de redes sociais). Assim, a partir dos projetos listados na Agência Nacional de Inovação, exploram-se as redes que se constituíram em torno dos projetos de apoio à inovação com ancoragem nas seis sub-regiões (NUTs III) da Região (NUT II) Centro de Portugal (Figura 1).

Não se pretende com este exercício explorar a totalidade das redes de inovação da região, mas centrar a análise exclusivamente nas redes de cooperação intensivas em I\&D e nos processos organizacionais de exploration knowledge. Esta reflexão

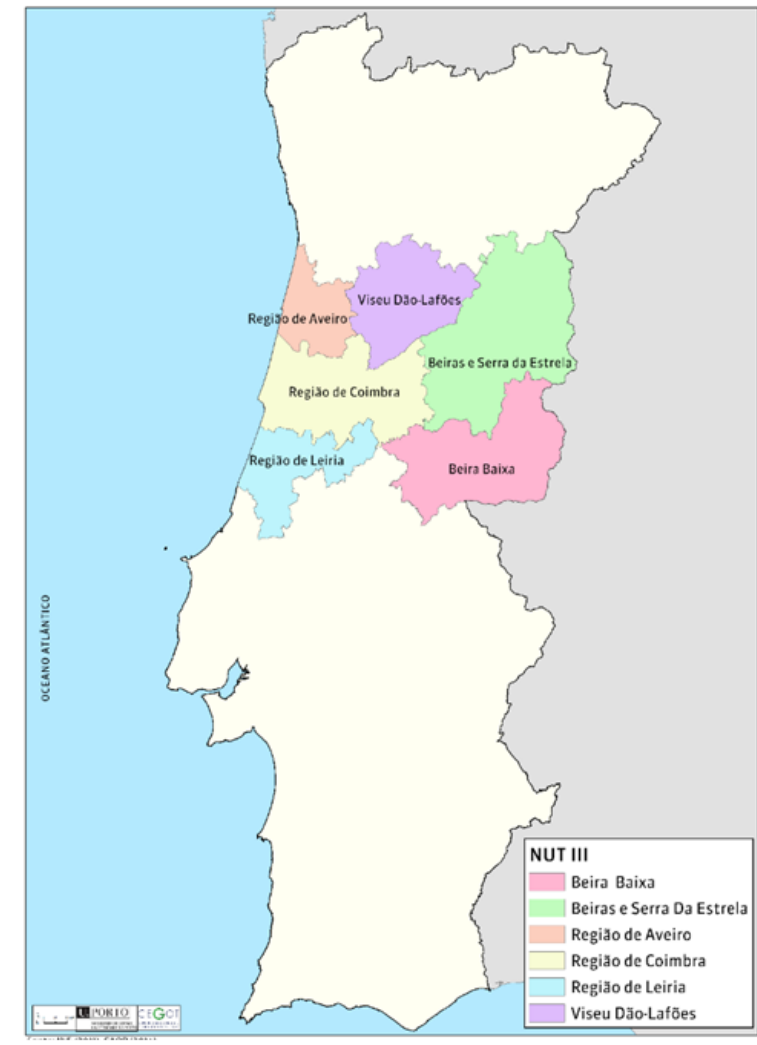

Figura 1 - Área territorial em estudo. Fonte: CAOP (2014). permitiu explorar a densidade relacional entre os diferentes atores e as diferentes escalas geográficas dessas relações. Permitiu ainda identificar e analisar as geometrias de inovação e o grau de especialização territorial, tendo em conta o conhecimento base que suportam os projetos e as atividades económicas a que se dirigem.

\section{ENQUADRAMENTO: EXPLORAÇÃO DA REDE DE INOVAÇÃO DA REGIÃO CENTRO}

A rede dos projetos de I\&D+i (2007-2015) ancorados na Região Centro integra 344 projetos, envolvendo um financiamento total de 199 milhões de euros e a participação de 594 organizações. Neste universo, 265 organizações estão localizadas na Região Centro (44,6\%) e 234 projetos (68\%) são promovidos por organizações localizados nesta Região ${ }^{6}$. Os processos de inovação interativos apresentam uma dimensão relacional limitada, já que se desenvolvem maioritariamente em torno de uma única relação (promotor com copromotor), com as ligações entre 2 organizações a representarem $40 \%$ do total, havendo uma fraca estimulação variadas interações entre atores.

Genericamente conclui-se:

- as empresas surgem como líderes desta rede de I\&D+i e com uma forte capacidade para captar o conhecimento, relacionando-se sobretudo com unidades de investigação e outras empresas, o que revela a importância das ligações homofílicas (entre a mesma esfera de atores, empresas com empresas) e a fraca variedade de ligações heterofílicas (envolvem dominantemente empresas e unidades de investigação).

- as organizações copromotoras inserem-se nestas redes de I\&D.+i, participando na produção e beneficiando do conhecimento produzido por este sistema de incentivos. As universidades/unidades de investigação emergem enquanto principais parceiras, evidenciando o seu papel de produtoras de conhecimento.

- do total de organizações copromotoras, 39,5\% são da Região Centro e 40\% do Noroeste, demonstrando a geografia dominante destas relações. A espacialidade dos projetos de inovação em rede da Região Centro revela a

\footnotetext{
${ }^{6}$ Análise efetuada pelos mesmos autores para o livro "Portugal No Centro" (2016), da Fundação Calouste Gulbenkian.
} 
centralidade das NUT da Região de Coimbra, de Aveiro e de Leiria e a fraca expressão de Viseu Dão-Lafões, das Beiras e Serra da Estrela e da Beira Baixa.

- em termos de conhecimento base, os processos de inovação são alavancados por um leque diversificado de áreas tecnológicas, onde se destacam as TIC, as tecnologias dos materiais, a engenharia mecânica, as tecnologias agrárias e alimentares e da automação. Em termos de setores de aplicação a que se dirigem os projetos, para além das indústrias ditas "tradicionais" como a indústria agroalimentar e a construção, surgem os setores industriais mais intensivos em conhecimento, nomeadamente a saúde, as máquinas industriais e a energia.

Em suma, neste sistema de inovação regional "a proximidade geográfica e os relacionamentos de escala regional são privilegiados nos processos de inovação" ( Marques, Santos e Ribeiro, 2016), mas há um prolongamento do seu espaço relacional para lá das suas fronteiras regionais, sendo estruturado não só por atores da região mas também por outras do sistema nacional de inovação (principalmente do Noroeste). Promove sobretudo o relacionamento entre as organizações empresariais com as universidades/unidades de investigação, melhorando a proximidade relacional entre o sistema empresarial e o sistema científico.

\section{A REDE TERRITORIAL: OS SUBSISTEMAS REGIONAIS DE INOVAÇÃODA REGIÃO CENTRO}

Para aprofundar a análise da territorialidade dos processos de inovação, explorou-se o ecossistema de inovação de cada sub-região individualmente, ou seja, focalizou-se nos projetos que envolvem organizações (promotoras ou copromotoras) localizadas em cada uma das NUT III, que compõem a Região Centro. Assim, importa explorar os processos de inovação de cada um destes ecossistemas sub-regionais, identificando graus de especialização e/ou de variedade territorial tendo por base as áreas tecnológicas que alavancam os projetos e os setores de aplicação a que se dirigem.

\subsection{A rede de inovação das regiões de Coimbra, Aveiro e Leiria}

Os subecossistemas de inovação da Região de Coimbra, da Região de Aveiro e da Região de Leiria sobressaem relativamente aos processos de inovação das restantes NUT III. Neste contexto, em primeiro lugar, destacam-se as redes de I\&D+i da Região de Aveiro e da Região de Coimbra apresentam um denso espaço relacional e organizacional, de grande proximidade territorial, onde sobressaem as ligações dentro da própria NUT, entre estas duas sub-regiões e com a Área Metropolitana do Porto.

Refletindo estes subecossistemas de inovação a partir da base de conhecimento, verifica-se que os processos de inovação são sustentados numa grande diversidade de áreas tecnológicas. A base de conhecimento é muito semelhante, evidenciando-se as mesmas áreas tecnológicas em termos de número de ligações e de financiamentos alocados. Se apenas considerarmos os projetos com promotores localizados nestas duas sub-regiões, destacam-se as TIC nas duas sub-regiões, as Tecnologias dos Materiais na Região de Aveiro (existência na região de empresas e unidades de investigação ligadas aos materiais - plásticos, cerâmicas, entre outros) e as Biotecnologias na Região de Coimbra (forte presença de empresas, unidades de investigação e centros tecnológicos especializadas nesta área em Coimbra e Cantanhede).

Em termos de setores de especialização as duas sub-regiões direcionam os seus esforços tanto para as indústrias ditas "tradicionais", como a Indústria Agroalimentar, a Construção e a Fabricação Couro e Calçado, como para setores industriais mais intensivos em conhecimento como a Saúde, as Máquinas Industriais e a Energia.

Cruzando a base de conhecimento com os setores de aplicação, verifica-se que os dois subecossistemas desenvolvem processos potenciadores de fertilização cruzada, sustentados em relacionamentos entre diferentes áreas tecnológicas e setores de aplicação. Quase todas as áreas tecnológicas dirigem os esforços de inovação para um leque diversificado de setores de aplicação, sendo de destacar as TIC e as Tecnologias dos Materiais. Avaliando os projetos em função dos setores de aplicação, verifica-se que a inovação não segue um perfil concentrado em prole de um reforço da especialização, pois os processos dirigem-se para mais do que uma área tecnológica.

Em segundo lugar, sobressai o ecossistema de inovação da Região de Leiria, que é menos denso (em termos de relações e de organizações), mas apresenta igualmente um importante espaço relacional de vizinhança (na sua NUT) e regional (com a Região de Coimbra e a A.M.Porto). Os projetos são sobretudo dinamizados pelos atores locais, revelando uma capacidade de potenciar a inovação. A rede disciplinar é de menor dimensão e menos diversificada. A Engenharia Mecânica, as Tecnologias dos Materiais e as TIC concentram o maior número de ligações, projetos e financiamento e são as áreas tecnológicas que direcionam os processos de inovação para o maior 
leque de setores de aplicação. A Saúde e as Máquinas Industriais são os setores mais importantes na rede desta sub-região, reunindo o maior número de ligações, projetos e financiamento e são os que alavancam os seus processos de inovação em mais áreas tecnológicas.

\subsection{A rede de inovação das regiões de Viseu Dão Lafões, Beiras e Serra da Estrela e Beira Baixa}
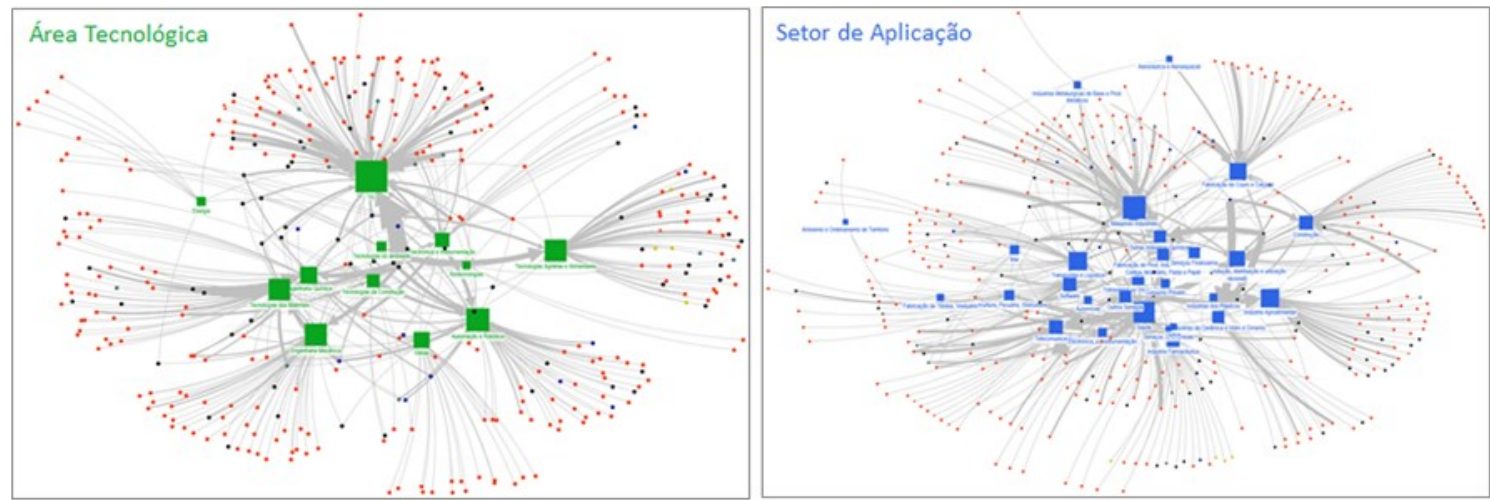

Figura 2 - Rede relacional das organizações com as áreas tecnológicas e com os setores de aplicação - Região de Aveiro.
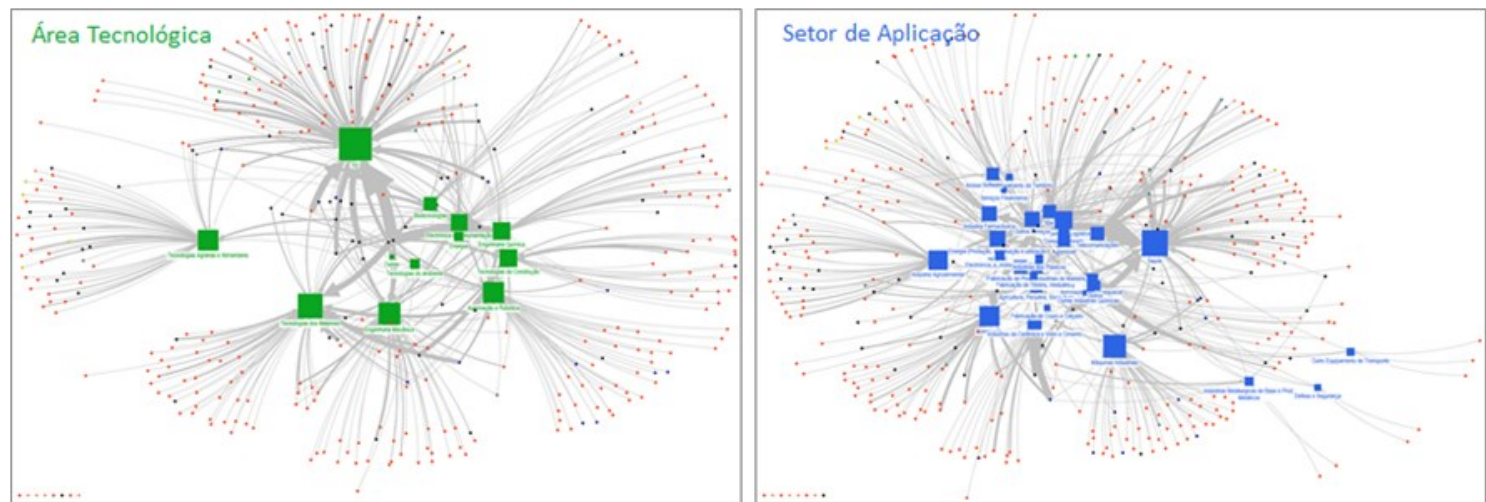

Figura 3 - Rede relacional das organizações com as áreas tecnológicas e com os setores de aplicação - Região de Coimbra.

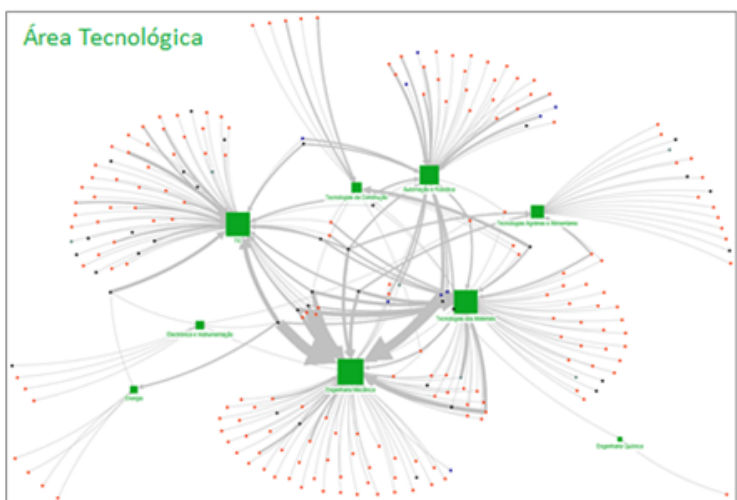

Setor de Aplicação

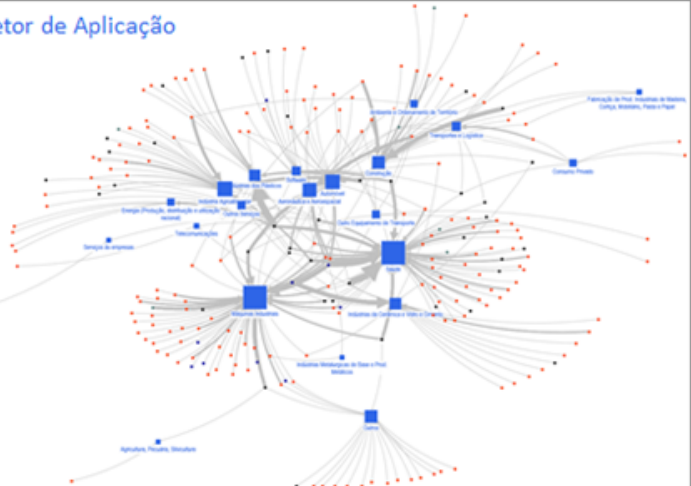

Figura 4 - Rede relacional das organizações com as áreas tecnológicas e com os setores de aplicação - Região de Leiria. 
Tabela 1 - Geografia relacional da Região de Aveiro, da Região de Coimbra e da Região de Leiria

\begin{tabular}{|c|c|c|c|}
\hline & REGIÃO DE AVEIRO & REGIÃO DE COIMBRA & REGIÃO DE LEIRIA \\
\hline $\begin{array}{c}\text { Densidade } \\
\text { Organizacional }\end{array}$ & 359 Organizações & 393 Organizações & 232 Organizações \\
\hline $\begin{array}{l}\text { Projetos de } \\
\text { Inovaçãao }\end{array}$ & $\begin{array}{c}\text { Total: } \\
\begin{array}{l}149 \text { Projetos envolvem um financia- } \\
\text { mento de } 108672251 €\end{array} \\
\text { Projetos com Promotor localizado na } \\
\text { NUT: } \\
\begin{array}{c}48 \% \text { projetos (71 projetos) e } 31 \% \\
\text { financiamento }\end{array}\end{array}$ & $\begin{array}{c}\text { Total: } \\
\begin{array}{c}229 \text { projetos envolvem um financia- } \\
\text { mento de } 122350007 €\end{array} \\
\text { Projetos com Promotor localizado na } \\
\text { NUT: } \\
\begin{array}{c}39 \% \text { projetos ( } 89 \text { projetos) e } 33 \% \\
\text { financiamento }\end{array}\end{array}$ & $\begin{array}{l}\text { Total: } \\
80 \text { projetos envolvem um financia- } \\
\text { mento de } 64567383 € \\
\text { Projetos com Promotor localizado na } \\
\text { NUT: } \\
66 \% \text { projetos (53 projetos) e } 48 \% \\
\text { financiamento }\end{array}$ \\
\hline $\begin{array}{l}\text { Áreas Tecnoló- } \\
\text { gicas (AT) }\end{array}$ & $\begin{array}{c}\text { Rede de inovação estrutura-se em } \\
\text { torno de } 12 \text { áreas tecnológicas: } \\
\qquad N^{\circ} \text { de Ligações: } \\
\text { - TIC (121) } \\
\text { - Automação e Robótica (63) } \\
\text { - Engenharia Mecânica (58) } \\
\text { - Tecn. Agrárias e Alimentares (57) } \\
\text { - Tecnologias dos Materiais (54) } \\
\text { Valor Total de Financiamento: } \\
\text { - TIC (38 712 } 073 € \text { ) } \\
\text { - Automação e Robótica (13 } 087331 \\
\text { - Eng. Mecânica (12 } 587706 € \text { ) } \\
\text { - Tecn. dos Materiais (10 } 673291 € \text { ) } \\
\text { Valor de Financiamento dos projetos } \\
\text { promovidos pela NUT: } \\
\text { - TIC (13 } 139121 € \text { ) } \\
\text { - Tecn. dos Materiais (5 465 } 781 € \text { ) }\end{array}$ & $\begin{array}{l}\text { Rede de inovação estrutura-se em } \\
\text { torno de } 12 \text { áreas tecnológicas: } \\
\text { No de Ligações: } \\
\text { - TIC (134) } \\
\text { - Tecnologias dos Materiais (76) } \\
\text { - Engenharia Mecânica (60) } \\
\text { - Automação e Robótica (55) } \\
\text { - Tecn. Agrárias e Alimentares (53) } \\
\text { Valor Total de Financiamento: } \\
\text { - TIC (46 637 } 183 € \text { ) } \\
\text { - Tecn. dos Materiais (16 085 175 } € \text { ) } \\
\text { - Engenharia Mecânica (10 } 769468 € \text { ) } \\
\text { Valor de Financiamento dos projetos } \\
\text { promovidos pela NUT: } \\
\text { - TIC (22 } 418450 € \text { ) } \\
\text { - Biotecnologias (6 } 486274 € \text { ) }\end{array}$ & $\begin{array}{l}\text { Rede de inovação estrutura-se em } \\
\text { torno de } 9 \text { áreas tecnológicas: } \\
\qquad N^{\circ} \text { de Ligações: } \\
\text { - Engenharia Mecânica (81) } \\
\text { - TIC (69) } \\
\text { - Tecnologias dos Materiais (67) } \\
\text { - Automação e Robótica (44) } \\
\text { Valor Total de Financiamento: } \\
\text { - Engenharia Mecânica (21 } 390652 € \text { ) } \\
\text { - TIC (14 } 307047 € € \text { ) } \\
\text { - Tecn. dos Materiais (13 144 } 042 € \text { ) } \\
\text { Valor de Financiamento dos projetos } \\
\text { promovidos pela NUT: } \\
\text { - Engenharia Mecânica (14 } 782258 € \text { ) } \\
\text { - Tecn. dos Materiais (10 } 334926 € \text { ) }\end{array}$ \\
\hline $\begin{array}{c}\text { Setores de } \\
\text { Aplicação (SA) }\end{array}$ & $\begin{array}{c}\text { Rede de inovação dirige-se para } 29 \\
\text { setores de aplicação: } \\
\text { No de Ligações: } \\
\text { - Máquinas Industriais (65) } \\
\text { - Saúde (56) } \\
\text { - Indústria Agroalimentar (43) } \\
\text { - Transportes e Logística (42) } \\
\text { - Fabricação Couro e Calçado (36) } \\
\text { - Energia (30) } \\
\text { Valor Total de Financiamento: } \\
\text { - Máquinas Industriais (14 } 341490 € \text { ) } \\
\text { - Saúde (13 238 420 €) } \\
\text { - Telecomunicações (10 } 260433 € \text { ) } \\
\text { Valor de Financiamento dos projetos } \\
\text { promovidos pela NUT: } \\
\text { - Telecomunicações (8 } 743354 € \text { ) }\end{array}$ & $\begin{array}{c}\text { Rede de inovação dirige-se para } 29 \\
\text { setores de aplicação: } \\
\text { No de Ligações: } \\
\text { - Saúde (82) } \\
\text { - Máquinas Industriais (63) } \\
\text { - Construção (48) } \\
\text { - Indústria Agroalimentar (45) } \\
\text { - Transportes e Logística (37) } \\
\text { - Energia (30) } \\
\text { Valor Total de Financiamento: } \\
\text { - Saúde (20 733 } 315 € \text { ) } \\
\text { - Máquinas Industriais (10 500 000 €) } \\
\text { - Telecomunicações (10 084 784 €) } \\
\text { Valor de Financiamento dos projetos } \\
\text { promovidos pela NUT: } \\
\text { - Saúde (11 } 850907 € € \text { ) }\end{array}$ & $\begin{array}{c}\text { Rede de inovação dirige-se para } 21 \\
\text { setores de aplicação: } \\
\text { No de Ligações: } \\
\text { - Saúde (68) } \\
\text { - Máquinas Industriais (67) } \\
\text { - Indústria Agroalimentar (27) } \\
\text { - Automóvel (25) } \\
\text { Valor Total de Financiamento: } \\
\text { - Saúde (15 715 946 €) } \\
\text { - Máquinas Industriais (14 638 } 727 € \text { ) } \\
\text { Valor de Financiamento dos projetos } \\
\text { promovidos pela NUT: } \\
\text { - Máquinas Industriais (5 420 642 €) } \\
\text { - Saúde (4 } 651762 € \text { ) }\end{array}$ \\
\hline $\begin{array}{l}\text { Processos } \\
\text { Fertilização } \\
\text { Cruzada }\end{array}$ & $\begin{array}{c}\text { Áreas Tecnológicas: } \\
\text { - TIC ligam-se com } 14 \text { setores de } \\
\text { aplicação } \\
\text { - Tecnologias Materiais: } 12 \text { setores } \\
\text { - Eng. Química: } 11 \text { setores } \\
\text { - Eng. Mecância: } 9 \text { setores } \\
\text { - Automação e Robótica: } 8 \text { setores } \\
\text { - Electrónica e Instrum: } 7 \text { setores } \\
\text { Setores de aplicação: } \\
\text { - Energia liga-se com } 7 \text { áreas tecnoló- } \\
\text { gicas } \\
\text { - Saúde: } 6 \text { áreas tecnológicas } \\
\text { - Agric., Pecuária, Silvic.: } 5 \text { áreas tec- } \\
\text { nológicas } \\
\text { - Ind. Cerâmica,Vidro e Cimento: } 5 \\
\text { áreas }\end{array}$ & $\begin{array}{c}\text { Áreas Tecnológicas: } \\
\text { - TIC ligam-se com } 16 \text { setores de } \\
\text { aplicação } \\
\text { - Tecnologias Materiais: } 16 \text { setores } \\
\text { - Eng. Química: } 15 \text { setores } \\
\text { - Electrónica e Instrum: } 11 \text { setores } \\
\text { - Eng. Mecância: } 11 \text { setores } \\
\text { - Automação e Robótica: } 7 \text { setores } \\
\text { - Tecnologias Construção: } 7 \text { setores } \\
\text { Setores de aplicação: } \\
\text { - Energia liga-se com } 7 \text { áreas tecnoló- } \\
\text { gicas } \\
\text { - Construção: } 6 \text { áreas tecnológicas } \\
\text { - Agric., Pecuária, Silvic.: } 6 \text { áreas tecn. } \\
\text { - Saúde: } 5 \text { áreas tecnológicas } \\
\text { - Ind. Cerâmica, Vidro e Cimento: Ind } \\
\text { Farmacêutica e Mar: } 5 \text { áreas tecn. }\end{array}$ & $\begin{array}{c}\text { Áreas Tecnológicas: } \\
\text { - Tecnologias Materiais ligam-se } 11 \\
\text { setores de aplicação } \\
\text { - Eng. Mecância: } 8 \text { setores } \\
\text { - TIC: } 7 \text { setores de aplicação } \\
\text { Setores de aplicação: } \\
\text { - Não existem setores de aplicação } \\
\text { que alavanquem os seus processos de } \\
\text { inovação em mais de } 5 \text { áreas tecnoló- } \\
\text { gicas. } \\
\text { Saúde; Maq.Industriais; Ind Cerâmica, } \\
\text { Vidro e Cimentos; Ind. Agroalimentar, } e \\
\text { Outros ligam-se com } 3 \text { setores de aplica- } \\
\text { ção }\end{array}$ \\
\hline $\begin{array}{c}\text { Densidade } \\
\text { Relacional e } \\
\text { Proximidade } \\
\text { Territorial }\end{array}$ & $\begin{array}{l}717 \text { Ligações entre organizações e AT } \\
\text { ou SA, das quais: } \\
\text { - 31\% envolve a Região de Aveiro } \\
\text { - } 27 \% \text { envolve a A.M.Porto } \\
\text { - 10\% envolve a Região de Coimbra }\end{array}$ & $\begin{array}{c}841 \text { Ligações entre organizações e AT } \\
\text { ou SA, das quais: } \\
\text { - 33\% envolve a Região de Coimbra } \\
\text { - } 19 \% \text { envolve a A.M.Porto } \\
\text { - 18\% envolve a Região de Aveiro }\end{array}$ & $\begin{array}{c}433 \text { Ligações entre organizações e AT } \\
\text { ou SA, das quais: } \\
\text { - 33\% envolve a Região de Leiria } \\
\text { - } 22 \% \text { envolve a A.M.Porto } \\
\text { - 12\% envolve a Região de Coimbra }\end{array}$ \\
\hline
\end{tabular}


Os subecossistemas das sub-regiões de Viseu Dão Lafões, das Beiras e Serra da Estrela e da Beira Baixa são estruturados por um tecido organizacional pouco denso, desenhando um espaço relacional rarefeito, com pouca capacidade para atrair e dinamizar processos de inovação na Região do Centro. Privilegiam a produção de conhecimento nas TIC e nas Tecnologias Agrárias e Alimentares e tendem a especializarem-se em alguns setores económicos, nomeadamente nas Máquinas Industriais (em Viseu Dão Lafões), na Fabricação de Têxteis e Vestuário e na Saúde (nas duas sub-regiões das Beiras), o que reflete o tecido económico instalado.

Numa análise mais ecossistémica, em que se explora os processos de cocriação que conjugam diferentes áreas de conhecimento, setores de aplicação e indústrias relacionadas, é possível confirmar as dinâmicas econó-

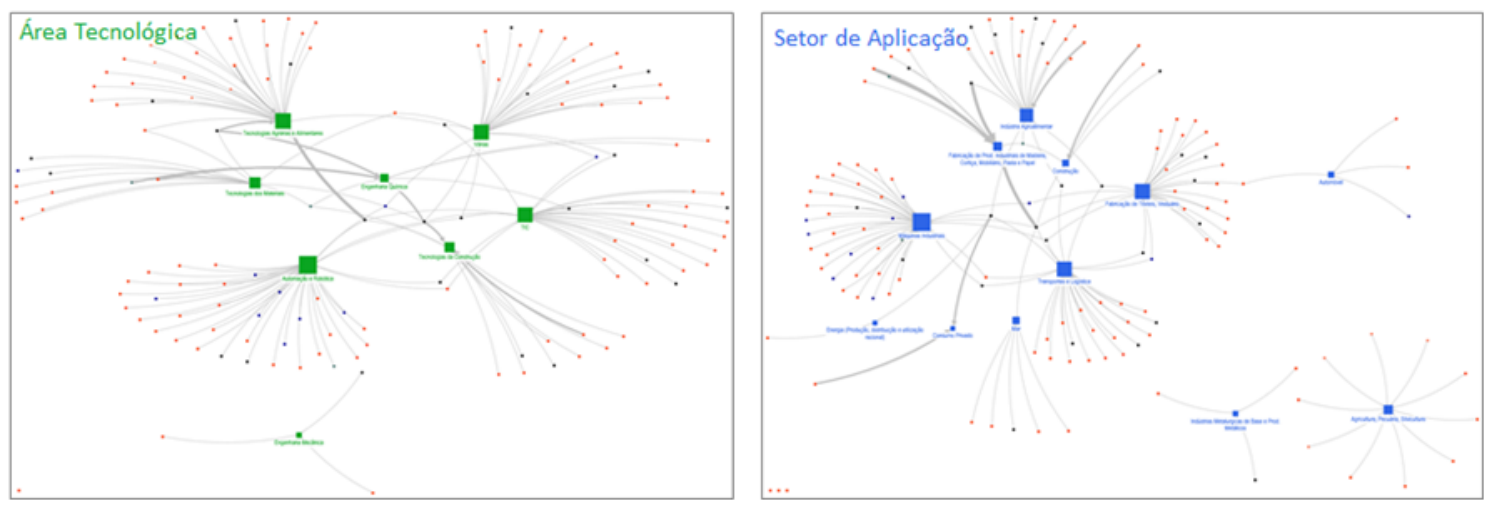

Figura 5 - Rede relacional das organizações com as áreas tecnológicas e com os setores de aplicação - Viseu Dão Lafões.

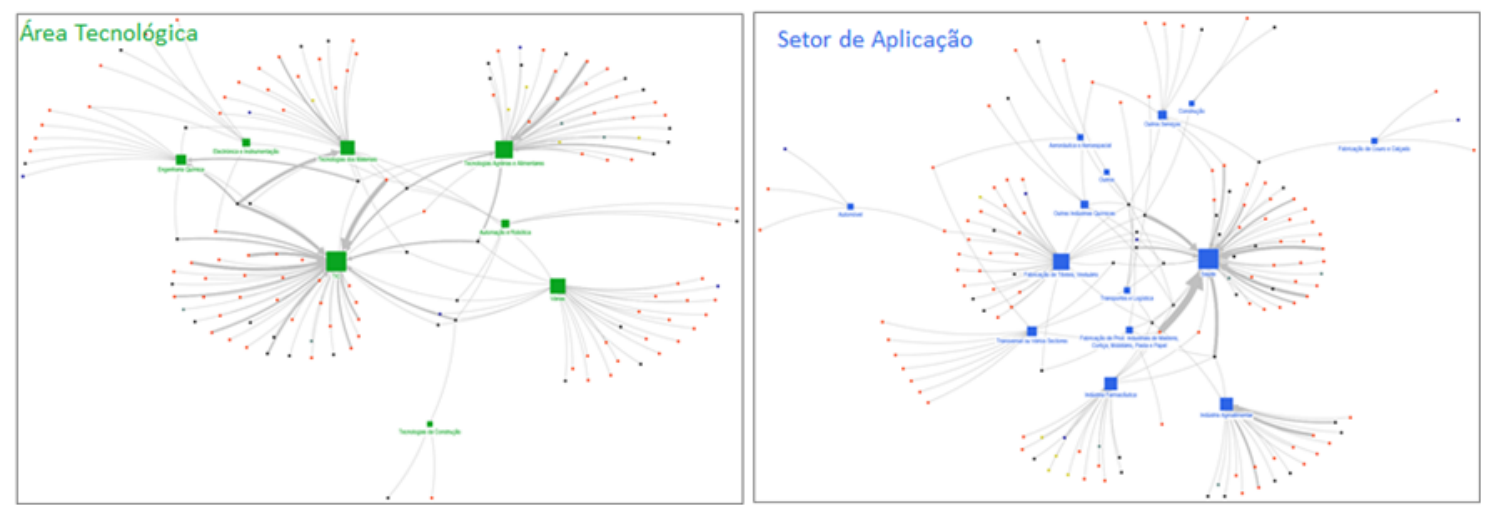

Figura 6 - Rede relacional das organizações com as áreas tecnológicas e com os setores de aplicação - Beiras e Serra da Estrela.
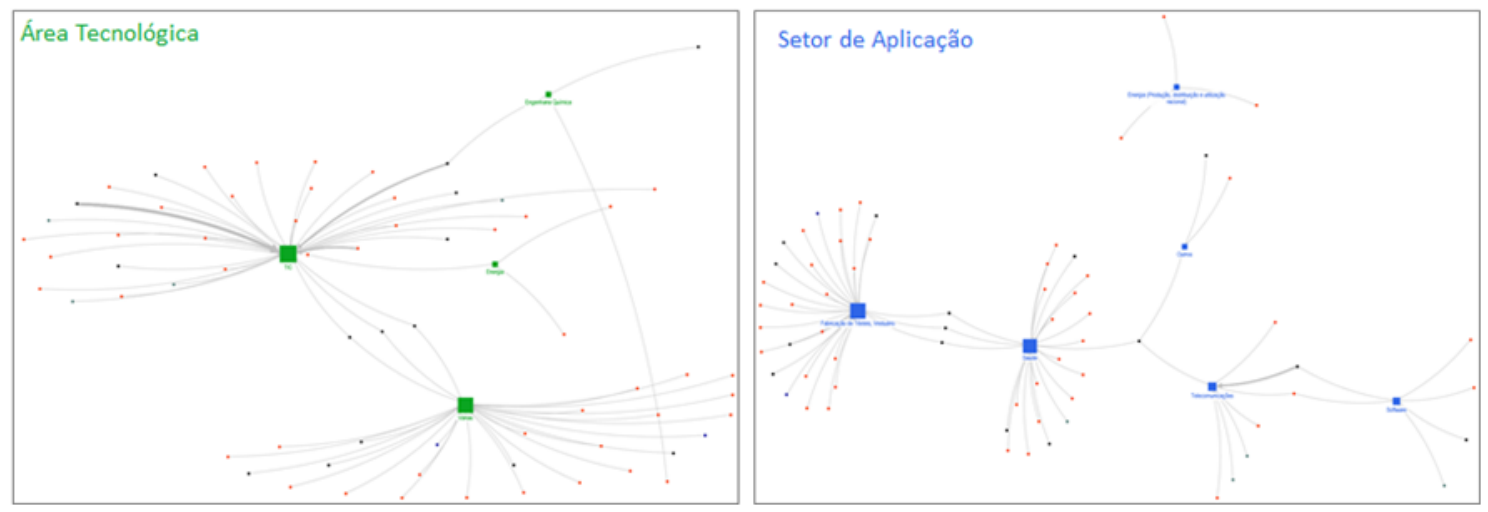

Figura 7 - Rede relacional das organizações com as áreas tecnológicas e com os setores de aplicação - Beira Baixa. 
Tabela 2 - Geografia relacional de Viseu Dão Lafões, Beiras e Serra da Estrela e Beira Baixa.

\begin{tabular}{|c|c|c|c|}
\hline & VISEU DÃO LAFÕES & BEIRAS E SERRA DA ESTRELA & BEIRA BAIXA \\
\hline $\begin{array}{c}\text { Densidade } \\
\text { Organi- } \\
\text { zacional }\end{array}$ & 140 Organizações & 140 Organizações & 66 Organizações \\
\hline $\begin{array}{l}\text { Projetos } \\
\text { de Ino- } \\
\text { vação }\end{array}$ & $\begin{array}{c}\text { Total: } \\
22 \text { Projetos envolvem um financiamento } \\
\text { de } 22573885 € \\
\text { Projetos com Promotor localizado na } \\
\text { NUT: } \\
\begin{array}{c}45 \% \text { projetos ( } 10 \text { projetos) e } 20 \% \text { finan- } \\
\text { ciamento }\end{array}\end{array}$ & $\begin{array}{c}\text { Total: } \\
23 \text { projetos envolvem um financia- } \\
\text { mento de } 33058291 € \\
\text { Projetos com Promotor localizado } \\
\text { na NUT: } \\
22 \% \text { projetos (5 projetos) e } 9 \% \\
\text { financiamento }\end{array}$ & $\begin{array}{c}\text { Total: } \\
8 \text { projetos envolvem um financiamento de } \\
11944402 € \\
\text { Projetos com Promotor localizado na NUT: } \\
50 \% \text { projetos (4 projetos) e } 50 \% \text { financia- } \\
\text { mento }\end{array}$ \\
\hline $\begin{array}{c}\text { Áreas } \\
\text { Tecnológi- } \\
\text { cas (AT) }\end{array}$ & $\begin{array}{c}\text { Rede de inovação estrutura-se em torno } \\
\text { de } 8 \text { áreas tecnológicas: } \\
\text { Nº de Ligações: } \\
\text { - Automação e Robótica (40) } \\
\text { - Tecn. Agrárias e Alimentares (30) } \\
\text { Valor Total de Financiamento: } \\
\text { - Autom. e Robótica (5 } 000000 €)\end{array}$ & $\begin{array}{l}\text { Rede de inovação estrutura-se em } \\
\text { torno de } 8 \text { áreas tecnológicas: } \\
\qquad N^{\circ} \text { de Ligações: } \\
- \text { TIC (50) } \\
\text { - Tecn. Agrárias e Alimentares (38) } \\
\text { Valor Total de Financiamento: } \\
\text { - TIC (11 } 820489 € \text { ) } \\
\text { - Tecn. dos Materiais (7 096 } 796 € \text { ) }\end{array}$ & $\begin{array}{l}\text { Rede de inovação estrutura-se em torno de } \\
4 \text { áreas tecnológicas: } \\
\qquad N^{\circ} \text { de Ligações: } \\
- \text { TIC (35) } \\
\text { Valor Total de Financiamento: } \\
\text { - TIC (6 } 163643 €)\end{array}$ \\
\hline $\begin{array}{l}\text { Setores de } \\
\text { Aplicação } \\
\text { (SA) }\end{array}$ & $\begin{array}{l}\text { Rede de inovação dirige-se para } 12 \\
\text { setores de aplicação: } \\
\text { No de Ligações: } \\
\text { - Máquinas Industriais (40) } \\
\text { Valor Total de Financiamento: } \\
\text { - Máquinas Industriais (5 } 000000 €) \\
\text { - Fabric. Têxteis, Vestuário (5 } 000000 €)\end{array}$ & $\begin{array}{l}\text { Rede de inovação dirige-se para } 14 \\
\text { setores de aplicação: } \\
\text { Nº de Ligações: } \\
\text { - Saúde (51) } \\
\text { - Fabric. Têxteis, Vestuário (33) } \\
\text { Valor Total de Financiamento: } \\
\text { - Saúde (12 } 323848 € \text { ) }\end{array}$ & $\begin{array}{l}\text { Rede de inovação dirige-se para } 6 \text { setores } \\
\text { de aplicação: } \\
\text { No de Ligações: } \\
\text { - Fabric. Têxteis, Vestuário (29) } \\
\text { - Saúde (24) } \\
\text { Valor Total de Financiamento: } \\
\text { - Saúde (5 } 000000 € \text { ) } \\
\text { - Fabric. Têxteis, Vestuário (5 } 000000 € \text { ) }\end{array}$ \\
\hline $\begin{array}{c}\text { Processos } \\
\text { Ferti- } \\
\text { lização } \\
\text { Cruzada }\end{array}$ & $\begin{array}{c}\text { Áreas Tecnológicas: } \\
\text { - Tecnologias Agrárias e Alimentares ligam- } \\
\text { se com } 3 \text { setores de aplicação } \\
\text { - Tecnologias da Construção: } 3 \text { setores } \\
\text { - Tecnologias dos Materiais: } 3 \text { setores } \\
\text { Setores de aplicação: } \\
\text { - Indústria Agroalimentar: } 3 \text { áreas tecn. }\end{array}$ & $\begin{array}{c}\text { Áreas Tecnológicas: } \\
\text { - Tecnologias dos Materiais: } 5 \text { seto- } \\
\text { res } \\
\text { Setores de aplicação: } \\
\text { - Saúde liga-se com } 3 \text { áreas tecnológi- } \\
\text { cas. }\end{array}$ & $\begin{array}{c}\text { Áreas Tecnológicas: } \\
\text { - TIC ligam-se com5 setores de aplicação } \\
\text { Setores de aplicação: } \\
\text { - Não existem setores de aplicação que } \\
\text { alavanquem os seus processos de inovação } \\
\text { em mais de } 3 \text { áreas tecn.. }\end{array}$ \\
\hline $\begin{array}{l}\text { Densidade } \\
\text { Relacional } \\
\text { e Proximi- } \\
\quad \text { dade } \\
\text { Territorial }\end{array}$ & $\begin{array}{c}175 \text { Ligações entre organizações e AT ou } \\
\text { SA, das quais : } \\
-35 \% \text { envolve a A.M.Porto } \\
-12 \% \text { envolve Viseu Dão Lafões } \\
-12 \% \text { envolve o Ave }\end{array}$ & $\begin{array}{l}201 \text { Ligações entre organizações e } \\
\text { AT ou SA, das quais: } \\
\text { - 27\% envolve a A.M.Porto } \\
\text { - 15\% envolve a Região de Coimbra } \\
\text { - 15\% envolve as Beiras e S.Estrela } \\
\text { - } 11 \% \text { envolve a Região de Aveiro }\end{array}$ & $\begin{array}{c}74 \text { Ligações entre organizações e AT ou SA, } \\
\text { das quais: } \\
\text { - 19\% envolve a A.M.Porto } \\
-15 \% \text { envolve o Ave } \\
-15 \% \text { envolve a Região de Coimbra } \\
-14 \% \text { envolve a Beira Baixa } \\
-12 \% \text { envolve a Região de Aveiro }\end{array}$ \\
\hline
\end{tabular}

micas identificadas anteriormente, nomeadamente processos de inovação que:

- aliam as TIC e as Telecomunicações, sustentados nos pólos de conhecimento de Aveiro, Coimbra e Castelo Branco;

- cruzam o setor da Saúde com a área de conhecimento das TIC, impulsionado pela capacidade empresarial instalada na área da farmacêutica, biotecnologia e engenharia biomédica, em particular em Coimbra, Leiria e Covilhã;

- conjugam setores emergentes com indústrias tradicionais, como a Saúde e a Fabricação de Têxteis e Vestuário, particularmente evidente na redes da Beira Baixa e das Beiras e Serra da Estrela, com um conjunto de organizações que potencia a inovação através da variedade relacional entre diferentes setores de aplicação. 


\section{CONCLUSÕES}

Esta reflexão territorial em torno dos sub-ecossistemas de inovação que compõem a Região do Centro, tenta identificar os recursos diferenciadores de cada sub-região, mas simultaneamente complementares e capazes de no contexto regional, potenciar não só a criação de conhecimento como sua transferência para o tecido empresarial e entre sub-regiões, numa lógica de geração de valor acrescentado e de um desenvolvimento integrado e sustentado por via da inovação.

A análise quantitativa e qualitativa das redes de inovação de cada sub-ecossistema da Região Centro permitiu inferir as seguintes conclusões:

- um sistema de inovação regional que mostra claramente as diferenças entre o espaço relacional regional, enfatizando as desigualdades de densidade organizacional;

- um sistema polarizado pelas Regiões de Coimbra, de Aveiro e de Leiria, que dominam os processos de criação e produção de conhecimento, beneficiando dos efeitos da inovação;

- uma tendência para especialização em algumas áreas do conhecimento, em especial nas TIC e nas tecnologias dos materiais, e incorporação de conhecimento em atividades mais intensivas em tecnologia e conhecimento, como a Saúde, bem como em indústrias tradicionais (p.e. fabricação de Têxteis e Vestuário e Máquinas Industriais);

- uma proximidade geográfica nos relacionamentos, onde se privilegia a escala regional nos processos inovação, mas também o alargamento do espaço relacional para o Noroeste português. As relações internacionais são praticamente inexistentes.

Assim, é necessário contrapor as dicotomias territoriais tradicionais e promover e reforçar os domínios mais fortes do conhecimento, que permitem a especialização diferenciadora e complementar que sustenta o desenvolvimento integrado e sustentado.

\section{AGRADECIMENTOS}

Trabalho cofinanciado pelo Fundo Europeu de Desenvolvimento Regional (FEDER) através do COMPETE 2020 - Programa Operacional Competitividade e Internacionalização $(\mathrm{POCl})$ e por fundos nacionais através da $\mathrm{FCT}$, no âmbito do projeto $\mathrm{POCl}$ 01-0145-FEDER-006891 (Ref ${ }^{a}$ FCT: UID/GEO/04084/2013)

\section{BIBLIOGRAFIA}

AMIN, A. (2004). Regions Uunbound: Towards a new politics of place. Geografiska Annaler: Series B, Human Geography, 86 (1), 33-44.

ASHEIM, B.; COENEN, L. (2005). Knowledge bases and regional innovation systems: Comparing nordic clusters. Research Policy, 34, 1173-1190.

BALLAND, P.-A., BOSCHMA, R., \& KOEN, F. (2015). Proximity and innovation: From statics to dynamics. Regional Studies, 49 (6), 907-920.

BATHELT, H., \& GLÜCKLER, J. (2011). The relational economy geographies of knowing and learning. Oxford: Oxford University Press.

BOSCHMA, R. (2005). Proximity and innovation: A critical assessment. regional studies, 39 (1), 61-74.

BOSCHMA, R., \& FRENKEN, K. (2011). Technological relatedness, related variety and economic geography. In P. Cooke, B. Asheim, R. Boschma, R. Martin, D. Schwartz, \& F. Todtling, Handbook of Regional Innovation and Growth (pp. 187-197). Cheltenham: Edward Elgar.

CARAÇA, J., LUNDVALL, B. A., \& MENDONÇA, S. (2009). The changing role of science in the innovation process: From Queen to Cinderella?. Technological Forecasting \& Social Change, 76 (6), 861-867.

CARAYANNIS, E. G., \& CAMPBELL, D. F. (2006). "Mode 3" Meaning and implications from a knowledge systems perspective. In E. G. Carayannis, \& D. F. Campbell, Knowledge Creation, Diffusion, and Use in Innovation Networks and Knowledge Clusters (pp. 1-25). Westport: Praeger.

CARAYANNIS, E. G., \& CAMPBELL, D. F. (2011). Open innovation diplomacy and a 21st century fractal research, education and innovation (FREIE) ecosystem: Building on the quadruple and quintuple helix innovation concepts and the "Mode 3" knowledge production system. Journal Of The Knowledge Economy, 2 (3), 327-372. 
CARAYANNIS, E. G., \& CAMPBELL, D. F. (2012). Mode 3 knowledge production in quadruple helix innovation systems: 21stcentury democracy, innovation, and entrepreneurship for development. New York: Springer.

CARAYANNIS, E. G., BARTH, T. D., \& CAMPBELL, D. F. (2012). The quintuple helix innovation model: Global warming as a challenge and driver for innovation. Journal of Innovation and Entrepreneurship, 1 (2), 1-12.

CARAYANNIS, E. G., PIRZADEH, A., \& POPESCU, D. (2012). Institutional learning and knowledge transfer across epistemic communities. New York: Springer.

ETZKOWITZ, H., \& LEYDESDORFF, L. (2000). The dynamic of innovation: from national systems and "Mode 2" to a Triple Helix of university-industry-govermment relations. Research Policy, 29, 109-123.

GIBBONS, M., LIMOGES, C., NOWOTNY, H., SCHVARTZMAN, S., SCOTT, P., \& TROW, M. (1994). The New production of knowledge: Dynamics of science and research in contemporary societies. London: Sage Publications.

JENSEN, M. B., JOHNSON, B., LORENZ, E., \& LUNDVALL, B.-A. (2007). Forms of knowledge and modes of innovation. Research Policy, 36, 680-693.

LUNDVALL, B.-A. (Ed.). (2010). National System of Innovation: Toward a Theory of Innovation and Interactive Learning. London: Anthem Press.

LUNDVALL, B.-A., \& JOHNSON, B. (1994). The learning economy. Journal of Industry Studies, 1 (2), $23-42$.

MARQUES, T. S., \& SANTOS, H. (2013). Lugares e redes de inovação na área metropolitana do Porto. Geografia: Revista da Faculdade de Letras da Universidade do Porto, 2, 203-225.

MARQUES, T. S., SANTOS, H., \& RIBEIRO, P. (2016). Redes de inovação económica ancoradas na Região Centr (2007-2015). In J. M. Ribeiro, F. Moura, \& J. Chorincas (Ed.), Portugal no Centro (pp. 464-501). Lisboa: Fundação Calouste Gulbenkian.

MARQUES, T. S., SANTOS, H., \& RIBEIRO, P. (2015). Redes de inovação económica ancoradas no arco metropolitano de Lisboa (2007-2013). In J. M. Ribeiro, F. Moura, \& J. Chorincas (Ed.), Uma metrópole para o Atlântico (pp. 558-590). Lisboa: Fundação Calouste Gulbenkian.

MASSEY, D. (2007). World City. Cambridge: Polity Press.

NONAKA, I. (2004). A empresa criadora de conhecimento. In H. TAKEUCHI, \& I. NONAKA, Gestão do conhecimento (A. THORELL, Trad., pp. 39-53). São Paulo: Artmed Editora S.A.

NOOTEBOOM, B. (2000). Learning and innovation in organizations and economies. Oxford: Oxford University Press

SANTOS, H. (2013). Uma visão multidimensional dinâmica da produção do conhecimento dirigido à inovação económica e o espaço dos lugares e dos fluxos das redes. Geografia: Revista da Faculdade de Letras da Universidade do Porto, 2, 145-177.

SANTOS, H., \& MARQUES, T. S. (2013). Lugares e redes de conhecimento na área metropolitana do Porto. Geografia: Revista da Faculdade de Letras da Universidade do Porto, 2, 179-202.

STEINER, M. (2011). Regional knowledge networks. In P. Cooke, B. Asheim, R. Boschma, R. Martin, D. Schwartz, F. Todtling, Handbook of Regional Innovation and Growth. Cheltenham: Edward Elgar, pp. 222-233.

TODTLING, F., \& TRIPPL, M. (2011). Regional innovation systems. In P. Cooke, B. Asheim, R. Boschma, R. Martin, D. Schwartz, \& F. Todtling, Handbook of Regional Innovation and Growth (pp. 455-466). Cheltenham: Edward Elgar 


\title{
Identificando Regiões de Referência na produção de conhecimento: o caso das publicações científicas voltadas para o Ébola
}

\author{
Thiago M. Mendes (a), Teresa Sá Marques (b), Ana Monteiro (b), Luis Carvalho (c) \\ (a) Centro de Estudos de Geografia e Ordenamento do Território (CEGOT) / Fundação para a Ciência e a Tecnologia (FCT) \\ (b) Centro de Estudos de Geografia e Ordenamento do Território (CEGOT) / Faculdade de Letras da Universidade do Porto (FLUP) \\ (c) Centro de Estudos de Geografia e Ordenamento do Território (CEGOT)
}

\begin{abstract}
Resumen
Diferentes abordagens sobre Sistemas Inovação destacam o conhecimento como um subsistema estratégico para a evolução destes processos interativos. É neste sentido que julga-se importante o desenvolvimento de metodologias capazes de identificar a estrutura destas interações. Assim, o presente trabalho busca identificar, através das publicações internacionais relacionadas ao Ébola registradas entre 1995 e 2017 na base Web of Science, as regiões com maior número de conexões em redes dinâmicas segmentadas temporalmente em oito períodos caracterizados pela intensidade dos registros de crises epidemiológicas. Pode-se observar que, ao considerar-se a medida de centralidade betweenness como indicativa de posicionamento referencial de uma região diante das demais, é possível identificar aquelas com maior destaque ao longo do tempo e, ainda, confirmar que regiões centrais de alguns dos países que já passaram por crises epidemiológicas tendem a fazer parte do grupo de regiões de referência para a produção de conhecimento ao longo dos períodos seguintes.
\end{abstract}

Palavras chave: Redes de Conhecimento; Ébola; Inovação Tecnológica

\section{INTRODUÇÃO}

Crises epidemiológicas do Ébola (CID-10 A98) são uma realidade em África ao menos há quarenta anos, quando foi registrada em 1976 no Zaire (atual República Democrática do Congo) e no Sudão (em parte do atual Sudão do Sul). Apesar disso, a última grande crise, ocorrida entre 2014 e 2016, trouxe à tona os impactos sociais, económicos e humanitários provocados pela doença. Especialmente ao atingir regiões de forte mobilidade e grandes centros populacionais, o controle da epidemia torna-se mais difícil, exigindo que diferentes instituições com atuações em diferentes escalas geográficas ariculem-se com o propósito de por fim à disseminação da doença e minimizar os impactos por ela causados.

No caso da crise de 2014, a epidemia teve início na região fronteriça de Guéckédou (Guiné), na África Ocidental, caracterizada pelos intensos fluxos migratórios intrarregionais (Figura 1), e logo chegou aos territórios mais populosos da Guiné, Serra Leoa e Libéria. Além destes países, houve registro de casos em mais três países da região, nos Estados Unidos da América e em três países europeus.

Esta dimensão geográfica da epidemia reflete a dimensão humanitária da mesma, que atingiu diretamente mais de 28600 pessoas, sendo, destas, mais de 11300 casos fatais. A previsão de tal impacto fez a Organização Mundial de Saúde (WHO) anunciar em agosto de 2014 que a epidemia do vírus Ébola na África Ocidental deveria ser encarada como uma "Emergência de Saúde Pública de Interesse Internacional" (Public Health Emergency of International Concern), convocando a comunidade internacional para uma resposta forte e coordenada.

Esta convocação, apesar de tardia sob o ponto de vista de diversas instituições, representou um ponto de virada para os esforços de combate ao vírus (MSF, 2015) uma vez que, mesmo não tendo representado um esperado crescimento do número de profissionais de saúde atuando em campo, significou um considerável aumento do número de equipamentos e infraestruturas, da capacidade de análises laboratoriais, apoio à logística, apoio ao aprimoramento e integração dos sistemas de informações e de comunicação, além da ampliação do apoio financeiro para o combate ao Ébola.

O ano de 2014 foi marcado, ainda, pelo início, no centro dos Médicos Sem Fronteiras em Guéckédou, do primeiro teste de tratamento da droga experimental Favipiravir, desenvolvida pela empresa japonesa Toyama Chemical (Grupo 
Fujifilm) (MSF, 2015). Além desta, outras drogas, em diversas fases do pipeline tecnológico farmacêutico, passaram a ser usadas em pacientes nos países afetados pelo vírus e em experimentos em outros países. Outras características marcantes deste processo foram: a ativação, ainda em Junho de 2014, dos parceiros da rede Global Outbreak Alert and Response Network (GOARN) - organismo técnico da Organização das Nações Unidas para combate a epidemias - foi formalmente alertado sobre o problema, em sua reunião em Genebra; e o aumento exponencial do volume de publicações científicas indexadas à base Web of Science (WOS) (Figura 2).

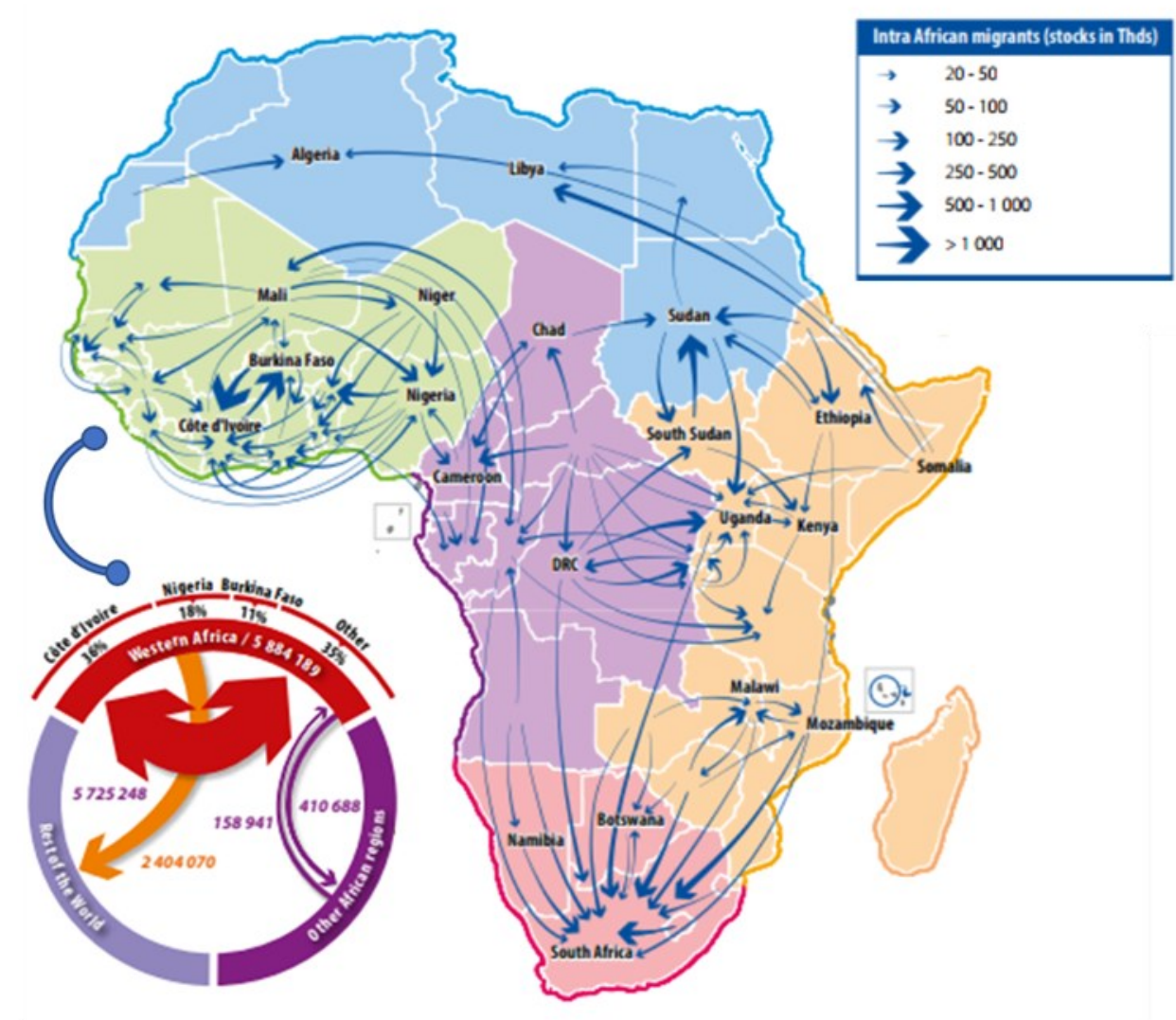

Figura 1 - Intra-Africa and overseas international migration (2015). Fonte: Adaptado de Mercandalli \& Losch (2017).

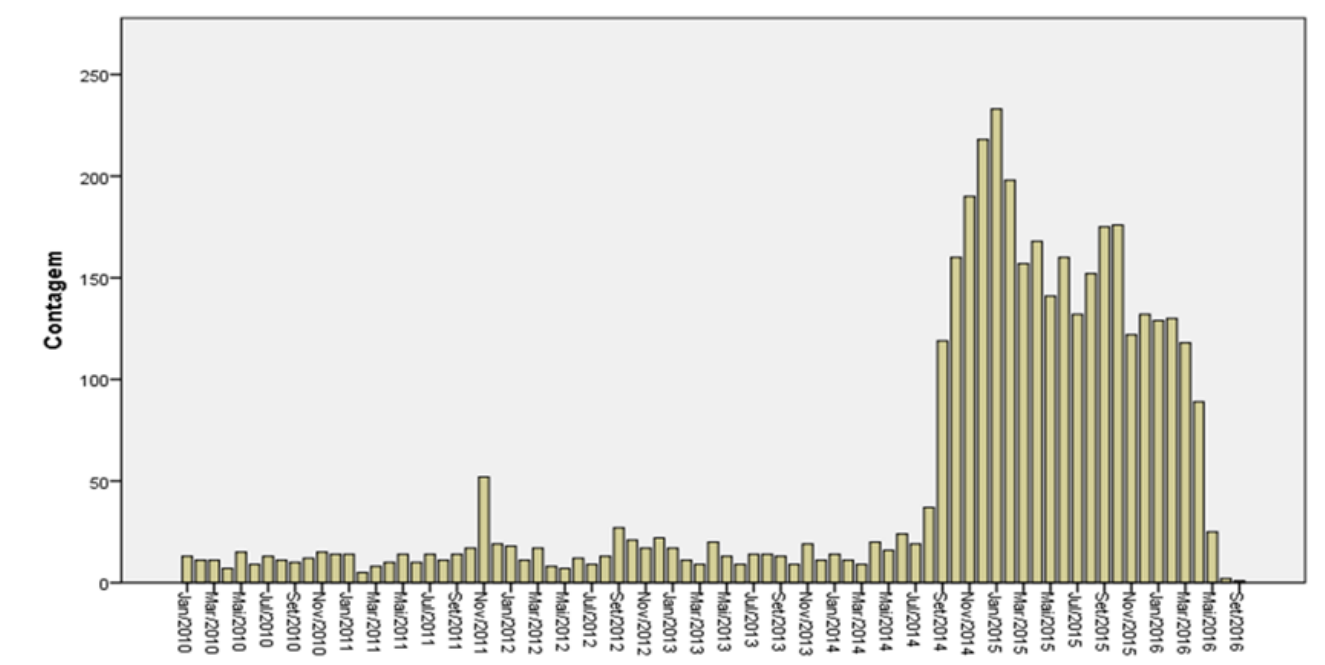

Figura 2. Publicações Totais Registradas na Web of Science (WoS). Fonte: Elaborado pelos autores a partir de levantamento realizado na plataforma WoS em setembro de 2016. 


\section{AS CRISES EPIDEMIOLÓGICAS DO ÉBOLA E OS SISTEMAS DE INOVAÇÃO TECNOLÓGICA}

A contextualização desenvolvida anteriormente ilustra um momento de intensa articulação institucional em diferentes escalas e de diferentes tipos. Esta articulação remete a estruturas descritas por Binz \& Truffer (2017), com base em Lundvall (1992) e Nelson (1993), através das quais os processos de inovação ocorrem. Segundo Lundvall (1992), a inovação emerge a partir de interações complexas entre atores com complementaridades e que operam sob configurações institucionais específicas. Para Nelson (1993), interações entre firmas, universidades, gestores públicos e diversos intermediários criam externalidades positivas que são relevantes no processo de inovação, mas muito difíceis de serem produzidas ou controladas unicamente por qualquer ator.

Já em 1986, Klein \& Rosenberg (1986) criticavam a visão tradicional e linear da inovação difundida após a $2^{a}$ Guerra Mundial, na qual um produz a investigação, investigação leva ao desenvolvimento, desenvolvimento leva à produção e produção ao mercado. Para os autores, este modelo distorcia a realidade da inovação em diferentes formas e, buscando uma melhor conceitualização deste processo, sugerem um modelo apresentado como "The Chain-Linked Model" onde não há apenas um caminho e/ou direção de atividade e articulação. Esta estrutura é retomada pela OECD (1996) para descrever a Economia Baseada no Conhecimento onde firmas buscam por ligações para promover interações de aprendizado e complementaridade. Estas relações ajudam a diluir os custos e os riscos associados à inovação entre um maior número de organizações, a ter acesso a novos resultados de pesquisas, a acessar componentes tecnológicos chave de um novo produto ou processo e compartilhar ativos na produção, comercialização e distribuição. Ainda de acordo com a OECD (1996), enquanto desenvolvem novos produtos e processos, as firmas determinam quais atividades serão levadas em conta individualmente, em colaboração com outras firmas, em colaboração com universidade ou institutos de investigação, e com o apoio do governo.

Estes Sistemas de Inovação são abordados em diferentes escalas, que vão desde a dimensão subnacional mais específica dos distritos industriais, até a dimensão dos Sistemas Globais de Inovação, passando pelos sistemas regionais e pelos sistemas nacionais de inovação (Freeman, 2002). Freeman, ao descrever as grandes mudanças institucionais ocorridas no Reino Unido no século XVIII, nos EUA no séc. XIX e nos países emergentes no séc. XX, destaca a importância dos contextos em diferentes escalas que influenciaram estas mudanças. Binz \& Truffer (2017), porém, reforçam e sistematizam esta estrutura multiescalar, defendendo a existência de subsistemas que variam em escala de acordo com o seu enquadramento tecnológico.

Para os autores:

"De uma forma geral, em uma perspectiva internacionalizada, Sistemas de inovação são constituídos por redes multiescalares de atores e contextos internacionais que de forma cooperativa apoiam (ou entravam) a formação e difusão de uma inovação. Em alguns casos, eles podem ser reduzidos a contextos territoriais específicos. Já em outros, eles dependem das estratégias dos atores, das redes e das dinâmicas institucionais que co-evoluem entre diferentes partes do mundo." (Binz \& Truffer, 2017. p. 1286)

As espacialidades dos Sistemas Tecnológicos de Inovação estarão, assim, configuradas a partir de quatro tipos genéricos de recursos sistêmicos: Conhecimento; Acesso ao Mercado; Investimento Financeiro; e Legitimidade Tecnológica. Estes recursos formam-se em subsistemas através de redes de atores e contextos institucionais, que estão integrados a partir de "Ligações Estruturais".

Estes recursos sistêmicos, compostos por arranjos entre diferentes instituições, podem ser percebidos, ainda, sob a ótica do papel das proximidades em processos de inovação. Segundo Balland, Boschma, and Frenken (2014), existem dinâmicas co evolutivas entre redes de conhecimento e tipos de proximidade, destacando a Proximidade Geográfica (aglomeração), Proximidade Cognitiva (aprendizado), Proximidade Organizacional (integração), Proximidade Institucional (institucionalização) e Proximidade Social (dissociação).

Considerando as diferentes atividades que emergem nos contextos de crises epidemiológicas do Ébola, este trabalho foca-se na produção de conhecimento articulada em uma escala global, buscando identificar as regiões de referência nas redes a ele relacionadas. Acredita-se, aqui, que a identificação destes territórios pode indicar alguns dos elementos que compõem as ligações estruturais entre o subsistema formado pelas redes de conhecimento e os demais subsistemas. 


\section{PROCEDIMENTOS METODOLÓGICOS}

Entre as diferentes abordagens relacionadas ao Ébola, destacam-se aquelas produzidas por Quarcoo et al (2015) e Hagel et al (2017), uma vez que analisam as estruturas das publicações científicas voltadas para esta doença. Enquanto a primeira parte de uma perspectiva cientométrica e analisa a produção dos países, de instituições individuais e das suas redes colaborativas, a segunda parte de uma base bibliométrica para desenvolver análises de redes de coautoria baseadas em metodologias de análise de redes sociais para caracterizar as relações entre países e instituições ao longo dos anos.

Assim como nos trabalhos anteriormente citados, este parte do levantamento de publicações indexadas à base Thomson Reuters Web of Science, coletadas em 24 de outubro de 2016, a partir do termo "Ebola" em procedimento de busca. Vale destacar que outros termos foram utilizados por Hagel et al (2017), como EBV, EBOV or SUDV, mas sem trazerem resultados adicionais.

Por haver um grande número de publicações sem registro de filiação institucional entre 1977 e 1994, as publicações deste período não foram consideradas para a presente análise. Foram, também, descartadas aquelas publicações que não tinham dimensão internacional e desconsideradas aquelas ligações entre instituições de um mesmo território (Self-loops). As instituições relacionadas aos trabalhos produzidos entre 1995 e 2016 foram georreferenciadas através do sistema online Batchgeo (Batchgeo, 2018) e associá-las, em ambiente GIS (Global Information System) à escala das subdivisões de primeiro nível dos países pela base GADM (Database of Global Administrative Areas) (GADM, 2018). A estrutura da base de dados formada a partir destes procedimentos permitu o desenvolvimento de diferentes indicadores de dimensão territorial relacionados a metodologia de análise de redes sociais. Estes indicadores foram calculados através dos softwares NodeXL e UCINET. Entre estes indicadores, dertacar-seá, aqui, o Betweennes.

A escolha pelo Betweennes justifica-se pela própria definição deste indicador. Esta é uma medida de centralidade relacionada à conectividade da rede e que reflete a frequência com que um determinado nó conecta o menor caminho entre todos os outros pares de nós. Considera-se que, quanto maior o Betweennes de um nó, maior a sua capacidade de quebra dos fluxos que circulam pela rede, uma vez que ele conecta maior número de outros nós em seus caminhos mais curtos. (Freeman, 1977)

Sendo uma medida de centralidade que destaca os atores estratégicos em uma rede, a escolha pelo Betweennes é feita no sentido de identificar as regiões que, ao longo do tempo, apresentam centralidade no ecossistema global de produção de conhecimento voltado para o Ébola. Acredita-se, ainda, que algumas destas regiões possam servir como ligações estruturais entre subsistemas em um Sistema Global de Inovação.

As análises realizadas foram, ainda, segmentadas em oito períodos (entre 1995 e 2016) caracterizados pela existência de crises com mais de 100 casos registrados - marcados com $@$ - ou pela ausência de um número superior de casos de acordo com a tabela da Figura 3.

\section{RESULTADOS}

Entre 1995 e 2016, foram efetuadas 9.848 conexões, das quais 2.687 são únicas e 1.744 repetem-se ao menos uma vez em trabalhos diferentes. Tais publicações ligam 414 regiões do mundo em coautorias, somando 1.607 publicações científicas de dimensão internacional. Destas regiões, 239 exerceram algum papel de centralidade e intermediação durante este período (Betweenness). Desconsiderando, porém, o último período (2014-2016) em que o tema ganhou d mensão desproporcional aos demais, observa-se que até então haviam sido realizadas 2.037 conexões territoriais em coautorias, das quais 496 são únicas e 423 repetem-se ao menos uma vez em trabalhos diferentes, ligando apenas 145 regiões. A Figura 4 ilustra como o período de 2014-2016 teve um peso maior que todo o período anterior e, ainda, que 117 das 145 regiões que publicaram entre 1995-2013, publicaram, também, no período 2014-2016.

Entre as regiões que apresentaram algum nível de centralidade ao longo do período de 1995-2016, destacam -se aquelas que figuraram em ao menos quatro dos oito períodos considerados neste estudo: Georgia_United States(8); Hessen_Germany(7); Manitoba_Canada(6); New York_United States(6); Île-de-France_France(6); Tokyo_Japan(6); Wisconsin_United States(6); Maryland_United States(6); Haut-Ogooué_Gabon(6); RhôneAlpes_France(5); Ontario_Canada(5); Pennsylvania_United States(5); Hokkaido_Japan(5); Genève_Switzerland(5); Texas_United States(4); Cataluña_Spain(4); Wakiso_Uganda(4); Kinshasa City_Democratic Republic of the Congo (4); Gauteng_South Africa(4); Bruxelles_Belgium(4). 


\begin{tabular}{|c|c|c|c|c|}
\hline Periods & Year(s) & Country & Ebola subtype & Reported number of human cases \\
\hline $2014 / 2016$ (C) & August-November 2014 & Democratic Republic of the Congo & Ebola virus & 66 \\
\hline $2014 / 2016$ (c) & March 2014-2016 & Multiple countries & Ebola virus & 28.616 \\
\hline $2010 / 2013$ & Novem ber 2012-January 2013 & Uganda & Sudan virus & 6 \\
\hline $2010 / 2013$ & June-November 2012 & Democratic Republic of the Congo & Bundibugyo virus & 36 \\
\hline $2010 / 2013$ & June-October 2012 & Uganda & Sudan virus & 11 \\
\hline $2010 / 2013$ & May 2011 & Uganda & Sudan virus & 1 \\
\hline $2007 / 2009$ (c) & December 2008-February 2009 & Democratic Republic of the Congo & Zaire virus & 32 \\
\hline $2007 / 2009$ (c) & $\begin{array}{r}\text { November 2008 } \\
\end{array}$ & Philippines & Reston virus & 6 (asymptomatic) \\
\hline $2007 / 2009$ (c) & Decem ber 2007-January 2008 & Uganda & Bundibugyo virus & 149 \\
\hline $2007 / 2009$ (c) & 2007 & Democratic Republic of the Congo & Zaire virus & 264 \\
\hline \multicolumn{5}{|l|}{$2005 / 2006$} \\
\hline $2002 / 2004$ (c) & 2004 & Russia & Zaire virus & 1 \\
\hline $2002 / 2004$ (ㄷ) & 2004 & Sudan (South Sudan) & Sudan virus & 17 \\
\hline $2002 / 2004$ (ㄷ) & November-December 2003 & Republic of the Congo & Zaire virus & 35 \\
\hline $2002 / 2004$ (c) & December 2002-April 2003 & Republic of the Congo & Zaire virus & 143 \\
\hline $2000-2002 / 2002-2004$ (c) & October 2001-March 2002 & Republic of the Congo & Zaire virus & 57 \\
\hline $2000-2002 / 2002-2004$ (c) & October 2001-March 2002 & Gabon & Zaire virus & 65 \\
\hline $2000-2002$ (c) & $2000-2001$ & Uganda & Sudan virus & 425 \\
\hline \multicolumn{5}{|l|}{ 1998/1999 } \\
\hline 1995-1997 (C) & 1996 & Russia & Zaire virus & 1 \\
\hline $1995-1997$ (c) & 1996 & Philippines & Reston virus & 0 \\
\hline $1995-1997$ (c) & 1996 & USA & Reston virus & 0 \\
\hline $1995-1997$ (c) & 1996 & South Africa & Zaire virus & 2 \\
\hline 1995-1997 (c) & 1996-1997 (July-January) & Gabon & Zaire virus & 60 \\
\hline 1995-1997 (C) & 1996 (January-April) & \begin{tabular}{|c|} 
Gabon \\
\end{tabular} & Zaire virus & 37 \\
\hline 1995-1997 (c) & 1995 & Democratic Republic of the Congo (formerly Zaire) & Zaire virus & 315 \\
\hline $1980-1994$ & 1994 & Côte d'Ivoire (Ivory Coast) & Taï Forest virus & 1 \\
\hline 1980-1994 & 1994 & Gabon & Zaire virus & 52 \\
\hline $1980-1994$ & 1992 & Italy & Reston virus & 0 \\
\hline 1980-1994 & $1989-1990$ & Philippines & Reston virus & 3 (asymptomatic) \\
\hline $1980-1994$ & 1990 & USA & Reston virus & 4 (asymptomatic) \\
\hline $1980-1994$ & 1989 & USA & Reston virus & 0 \\
\hline $1977-1979 @$ & 1979 & Sudan (South Sudan) & Sudan virus & 34 \\
\hline $1977-1979$ (c) & 1977 & Zaire & Zaire virus & 1 \\
\hline $1977-1979$ (ㄷ) & 1976 & England & Sudan virus & 1 \\
\hline $1977-1979$ (c) & 1976 & Sudan (South Sudan) & Sudan virus & 284 \\
\hline $1977-1979$ (c) & 1976 & Zaire (Democratic Republic of the Congo-DRC) & Zaire virus & 318 \\
\hline
\end{tabular}

Figura 3 - Outbreaks Chronology: Ebola Virus Disease. Fonte: Adaptado de CDC, 2017.

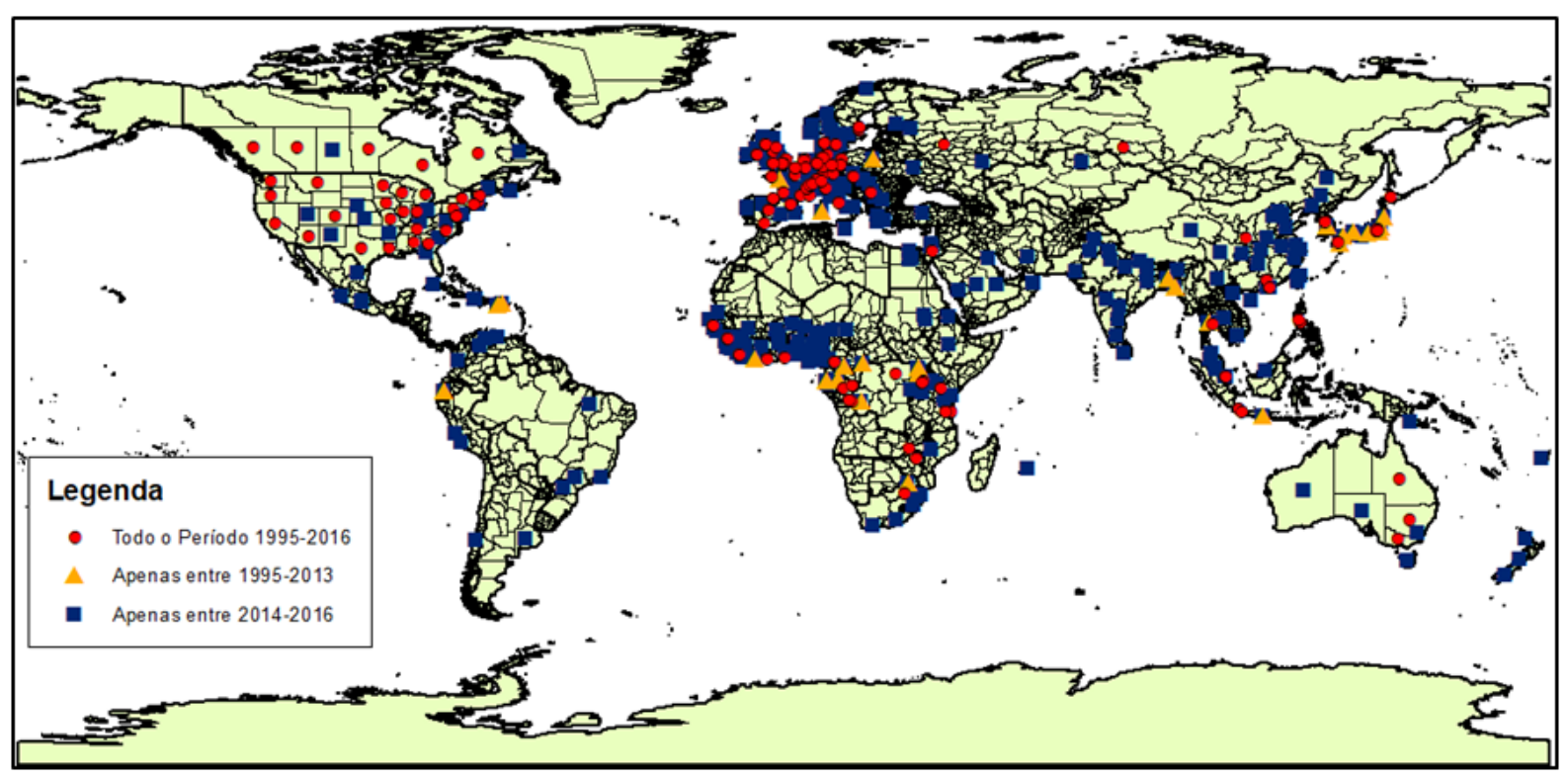

Figura 4 - Regiões conectadas em publicações. Fonte: Elaborado pelos autores. 


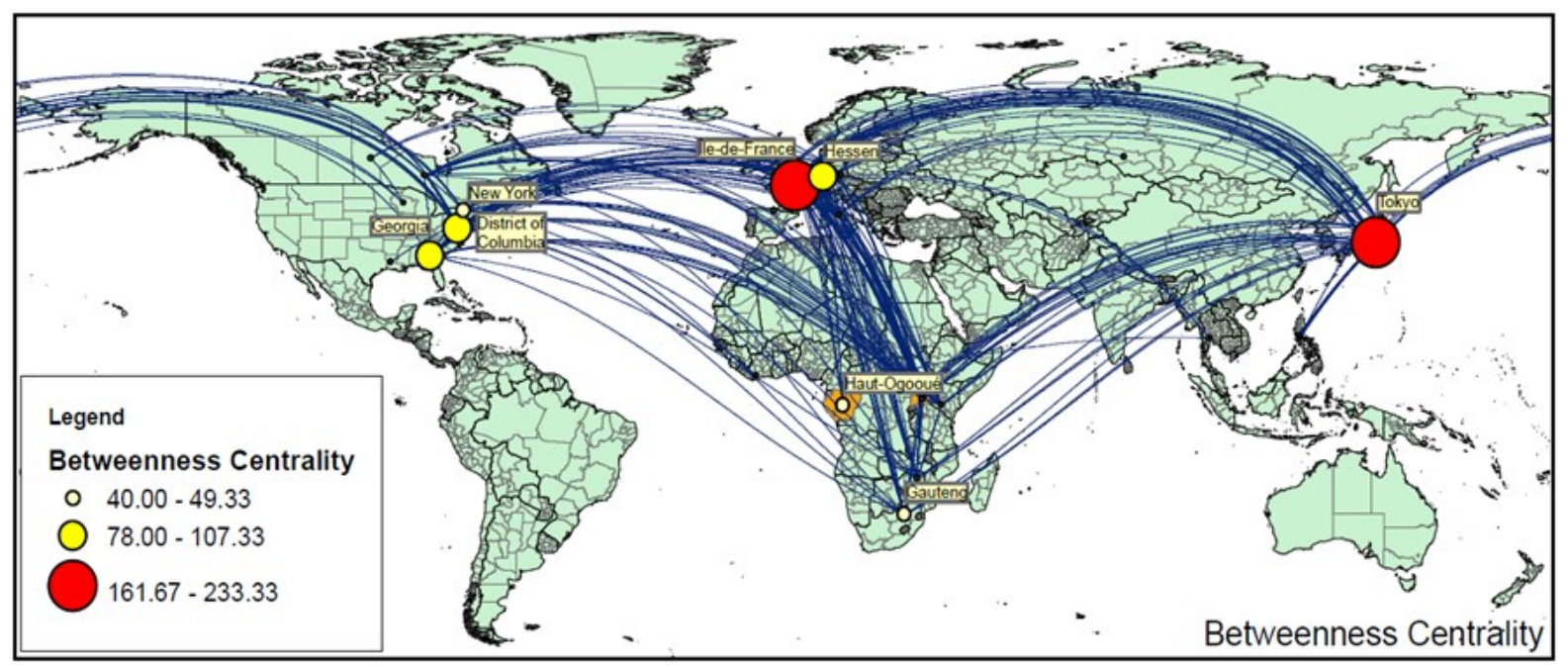

Figura 5 - Betweenness Centrality (2000-2002) Fonte: Elaborado pelos autores.

Vale destacar a importância de regiões de países tradicionais na produção de conhecimento científico, nomeadamente dos EUA, Alemanhã, Canadá, França, Japão, Suíça, Bélgica e Espanha. Ainda que estes países tenham registrado poucos casos em seus territórios, ou nunca tenham registrado casos, algumas das suas regiões estão constantemente entre aquelas que apresentam algum nível de centralidade e que, em geral, tendem a estar entre os maiores em cada período. Como exemplifica o mapa da Figura 5, que representam as redes relativas ao período 2000-2002, destacando as regiões com maior Betweenness Centrality.

Além destas regiões dos países centrais, tendem a ganhar destaque algumas regiões de países que passam ou passaram por crises do Ébola. Abrigando universidades e centros de investigação, estas regiões tendem a ser áreas de destaque económico e/ou populacional no país e atuam como vetores de internacionalização destes territórios. Conectando as demais regiões daqueles países, muitas vezes em crise epidemiológica, com as demais regiões em escala global.

Observa-se, ainda, que algumas destas regiões continuam tendo algum tipo de centralidade mesmo em períodos em que não ocorrem registros de Ébola em seus respectivos países. Outras, porém, apresentam uma centrali-

\begin{tabular}{|c|c|c|c|c|c|c|c|c|c|c|c|}
\hline & $1977-19790$ & $1980-1994$ & $1995-19970$ & $1998-1999$ & $2000-20020$ & $2002-20040$ & $2005-2006$ & $2007-20090$ & $2010-2013$ & $2014-20160$ & \\
\hline $\begin{array}{c}\text { Regiōes } \\
\text { centrais / } \\
\text { Paises com } \\
\text { casos do } \\
\text { Ébola }\end{array}$ & $\begin{array}{c}\text { Sudan; } \\
\text { Democratic } \\
\text { Republic of } \\
\text { the Congo } \\
\text { (formerly } \\
\text { Zaire); } \\
\text { England }\end{array}$ & $\begin{array}{c}\text { Côte } \\
\text { d'Ivoire } \\
\text { (Ivory } \\
\text { Coast); } \\
\text { Gabon; } \\
\text { Italy; } \\
\text { Philippines; } \\
\text { USA }\end{array}$ & \begin{tabular}{|c|} 
Russia; \\
Philippines; \\
USA; South \\
Africa; Gabon; \\
Democratic \\
Republic of the \\
Congo \\
(formerly \\
Zaire) \\
\end{tabular} & & $\begin{array}{c}\text { Republic of } \\
\text { the Congo; } \\
\text { Gabon; } \\
\text { Uganda }\end{array}$ & $\begin{array}{c}\text { Gabon; } \\
\text { Republic of } \\
\text { the Congo; } \\
\text { Russia; } \\
\text { Sudan (South } \\
\text { Sudan) }\end{array}$ & & $\begin{array}{c}\text { Democratic } \\
\text { Republic of } \\
\text { the Congo; } \\
\text { Uganda; } \\
\text { Philippines }\end{array}$ & $\begin{array}{c}\text { Uganda; } \\
\text { Democratic } \\
\text { Republic of } \\
\text { the Congo }\end{array}$ & $\begin{array}{l}\text { Multiple } \\
\text { countries; } \\
\text { Democratic } \\
\text { Republic of } \\
\text { the Congo }\end{array}$ & TOTAL \\
\hline \multicolumn{2}{|c|}{ Haut-Ogooué_Gabon } & & & & & & & & & & 6 \\
\hline \multicolumn{2}{|c|}{ Wakiso_Uganda } & & & & & & & & & & 4 \\
\hline \multicolumn{4}{|c|}{ Kinshasa City_Democratic Republic of the Congo } & & & & & & & & 4 \\
\hline \multicolumn{2}{|c|}{ Gauteng_South Africa } & & & & & & & & & & 4 \\
\hline \multicolumn{3}{|c|}{ Metropolitan Manila_Philippines } & & & & & & & & & 3 \\
\hline \multicolumn{2}{|c|}{ Laguna_Philippines } & & & & & & & & & & 2 \\
\hline \multicolumn{2}{|c|}{ Kampala_Uganda } & & & & & & & & & & 2 \\
\hline \multicolumn{3}{|c|}{ Brazzaville_Republic of Congo } & & & & & & & & & 2 \\
\hline \multicolumn{2}{|c|}{ Abidjan_Côte d'Ivoire } & & & & & & & & & & 2 \\
\hline \multicolumn{2}{|c|}{ Gulu_Uganda } & & & & & & & & & & 1 \\
\hline \multicolumn{3}{|c|}{ Bas-Sassandra_Côte d'Ivoire } & & & & & & & & & 1 \\
\hline \multicolumn{4}{|c|}{ Bandundu_Democratic Republic of the Congo } & & & & & & & & 1 \\
\hline \multicolumn{2}{|c|}{ Estuaire_Gabon } & & & & & & & & & & 1 \\
\hline
\end{tabular}

Figura 6 - Períodos de centralidade para regiões de países impactados pelo Ébola. Fonte: Elaborado pelos autores. 
dade baixa e esporádica, registrada apenas nos períodos de crise epidemiológica registrada em seus países ou naquele período imediatamente posterior. Esta evolução pode ser verificada na tabela da figura 6, onde os períodos marcados são aqueles em que uma determinada região apresentou algum tipo de centralidade. Nesta tabela foram consideradas apenas as regiões dos países impactados pelo Ébola e que fizeram parte das redes de conhecimento antes da crise de 2014-2016. Vale destacar, ainda, que os períodos de 1977-1979 e 1980-1994 não foram contabilizados, aparecendo na tabela apenas para registro dos casos que ocorreram durante os mesmos.

É possível observar que, se por um lado, o número de casos que ocorreram em um determinado país contribui para a participação deste nas redes internacionais com algum grau de centralidade, por outro, geralmente são as regiões com maior centralidade económica e de infraestrutura destes países que mantêm-se como referência para produção e fluxo dos conhecimentos produzidos ao longo dos anos. Este resultado destaca o papel fundamental das universidades, das instituições de Ciência \& Tecnologia e de instituições de apoio social (nomeadamente do terceiro setor) na produção de conhecimento e na interface entre as diversas regiões que compõem este ecossistema, seja nos países tradicionalmente periféricos na produção de conhecimento científico, seja nos países centrais.

\section{CONCLUSÃO}

Com os resultados obtidos é possível destacar que através da medida de centralidade Betweenness, usada tradicionalmente em análises de redes sociais, é possível identificar as regiões de destaque na intermediação dos fluxos de conhecimento e que são ao mesmo tempo sensíveis uma vez que possuem a capacidade de quebrar os caminhos mais curtos destes fluxos entre os atores das redes de conhecimento.

Os resultados reforçam, ainda, o papel de diferentes regiões de alguns dos países tradicionalmente centrais na produção de conhecimento científico. Nomeadamente EUA, Alemanhã, Canadá, França, Japão, Suíça, Bélgica e Espanha. Tais regiões, nestes países, dispõem de instituições de Ciência, Tecnología \& Inovação, Universidades, sedes de instituições do terceiro setor e sedes de organizações supranacionais, com acesso a recursos financeiros, tecnológicos e científicos capazes de dar a elas uma posição de centralidade nas redes internacionais de produção de conhecimento.

Ainda que a maior parte das regiões de maior e mais contínuo Betweenness ao longo dos anos pertença a países tradicionalmente centrais na produção de conhecimento científico e tecnológico, a condição de "lugar" dos episódios epidemiológicos coloca países tradicionalmente periféricos entre aqueles de destaque na produção de conhecimento voltado para o Ébola e de intermediação destes fluxos. Esta posição está ligada não apenas à dimensão do impacto das epidemias sobre os territórios dos seus países, apesar desta ser uma importante variável na definição das centralidades. Deve-se observar, ainda, que a infraestrutura e a presença de recursos científicos, tecnológicos e financeiros é um importante fator de destaque de uma região. Assim, é possível verificar que as maiores regiões destes países são aquelas que exercem o papel de intermediadora do conhecimento entre diversas regiões em escala global, entre as diferentes regiões em escala nacional e, ainda, a intermediação entre as regiões em escala nacional e aquelas em escala global.

Futuros trabalhos podem ser realizados, considerando as publicações de caráter nacional, a fim de verificar se estas regiões centrais nas redes internacionais exercem o mesmo papel nos sistemas nacionais de produção de conhecimento. Sugere-se, ainda, que esta metodologia seja aplicada aos demais subsistemas destacados por Binz \& Truffer (2017), a fim de verificar se as mesmas regiões assumem o papel de centralidade nos mesmos e identificar aquelas figuram como responsáveis pelas ligações estruturais entre tais subsistemas.

\section{BIBLIOGRAFIA}

BATCHGEO (2018) https://pt.batchgeo.com/ . (Acessado em 10 de Maio de 2018)

BALLAND, P.-A; BOSCHMA, R.; FRENKEN, K. (2014) Proximity and Innovation: From Statics to

Dynamics, Regional Studies, 49:6, 907-920.

BINZ, C., \& TRUFFER, B. (2017). Global Innovation Systems-A conceptual framework for innovation dynamics in transnational contexts. Research Policy, 46(7), 1284-1298.

CDC (2017) Outbreaks Chronology: Ebola Virus Disease. - Disponível em: https://www.cdc.gov/vhf/ebola/outbreaks/history/ chronology.html . Acessado em 11/05/2018. 
FREEMAN, C. (2002). Continental, national and sub-national innovation systems-complementarity and economic growth. Research Policy, 31(2), 191-211

FREEMAN, L.C. (1977) A set of measures of centrality based on betweenness. Sociometry 40(1):35-41

GADM (2018) https://gadm.org/data.html (acedido a 09 de Maio de 2018).

HAGEL C, WEIDEMANN F, GAUCH S, EDWARDS S, TINNEMANN P (2017) Analysing published global Ebola Virus Disease research using social network analysis. PLOS Neglected Tropical Diseases 11(10)

KLEIN, S.J. and N. ROSENBERG (1986), "An Overview of Innovation", in R. Landau and N. Rosenberg (eds.), The Positive Sum Strategy: Harnessing Technology for Economic Growth, National Academy Press, Washington, DC.

LUNDVALL, B. (1992). National Systems of Innovation - Toward a Theory of Innovation and Interactive Learning. Pinter, London.

MERCANDALLI, S. \& LOSCH, B., eds. (2017). Rural Africa in motion. Dynamics and drivers of migration South of the Sahara. Rome, FAO and CIRAD. $60 \mathrm{p}$

MSF. (2015). Pushed to the Limit and Beyond. A year into the largest ever Ebola outbreak.: Médicos Sem Fronteira.

NELSON, R. (1993). National Innovation Systems: A Comparative Analysis. Oxford University Press, New York.

OECD. (1996). The Knowledge-Based Economy: OECD.

QUARCOO, D., BRÜGGMANN, D., KLINGELHÖFER, D., \& GRONEBERG, D. A. (2015). Ebola and Its Global Research Architecture-Need for an Improvement. Plos Neglected Tropical Diseases, 9(9) 


\title{
El papel de las redes en la innovación social: la ciudad de Valencia ${ }^{1}$
}

\author{
J. Salom (a), M. Pitarch (b), R. Mesa (c), E.Margaix (d)
}

(a) Instituto Interuniversitario de Desarrollo Local, Universitat de Valencia, Julia.Salom@uv.es (b) Instituto Interuniversitario de Desarrollo Local, Universitat de Valencia, Maria.Pitarch@uv.es (c) Instituto Interuniversitario de Desarrollo Local, Universitat de Valencia, Rafael.Mesa@uv.es

(d) Instituto Interuniversitario de Desarrollo Local, Universitat de Valencia, Elena.Margaix@uv.es

\section{Resumen}

En los últimos años, el uso del concepto de innovación social como estrategia de desarrollo se ha generalizado tanto en el ámbito académico como entre los tomadores de decisiones. La conformación de una red de actores que interactúe y coopere es un factor importante para la creación y difusión de estas innovaciones. Mediante técnicas de análisis cualitativo y de redes sociales, se determina y evalúa la red de actores y la colaboración entre ellos en la ciudad de Valencia (España), con el fin de definir sus aspectos positivos y negativos y elaborar recomendaciones políticas.

Palabras clave: Geografía Económica, Redes, Innovación social, Economía Social, Valencia

\section{INTRODUCCIÓN: REDES E INNOVACIÓN SOCIAL}

En el año 2011, la Unión Europea publicó "Empowering people, driving change: Social innovation in the European Union", un análisis sobre la definición y objetivos de la innovación social desarrollado por el BEPA (Bureau of European Policy Advisers) cuya finalidad era señalar la relevancia de la innovación social en cualquier ámbito de acción pública a nivel europeo. Hasta entonces, la idea de innovación social existía, al menos de manera parcial o fragmentada, en algunos Programas e Iniciativas de la UE. Pero es a partir de este momento cuando pasa a formar claramente parte de los dos documentos principales que marcan la agenda de los siguientes años: la Estrategia 2020 y el Acta del Mercado Único. Además, y de forma más concreta, la Comisión Europea financia un Programa Europeo para el Empleo y la Innovación Social (EaSI), que se define en su página web como un "instrumento financiero a escala de la UE, cuyo objeto es promover un elevado nivel de empleo de calidad y sostenible, que aporte una protección social correcta, combata la exclusión social y la pobreza y mejore las condiciones de trabajo" ${ }^{2}$. Entre sus objetivos finales destacan, entre otros, promover la equidad, combatir las discriminaciones, combatir el desempleo y luchar contra la pobreza y la exclusión. Estos objetivos ya nos dan una idea sobre la definición de un término, innovación social, que se encuentra muy relacionado con nociones como solución y transformación y que se ha generalizado a partir de la crisis económica, financiera e institucional que ha sufrido Europa desde 2008. La innovación social es un concepto complejo por cuanto sus límites son difusos y dependen, en muchas ocasiones, de la concepción política.

De cualquier forma, no es éste el lugar de debatir sobre su definición, por lo que, para concretar seguiremos la tesis fruto de trabajos previos (Salom et al., 2017), en los que proponemos que la innovación social sea entendida como una serie de iniciativas capaces de ir modificando las rígidas estructuras económicas y sociales para conseguir un cambio en las relaciones entre agentes, instituciones y personas.

En este sentido, entendemos innovación social como una idea, o una nueva forma de aplicar una vieja idea, que aparece cuando la sociedad re-examina cómo se pueden hacerse las cosas, es novedosa en el contexto en que se inserta (no es necesario que sea una innovación absoluta), resuelve retos sociales, culturales, económicos

\footnotetext{
${ }^{1}$ Esta comunicación se ha elaborado en el marco del proyecto "Sostenibilidad social, conectividad global y economía creativa como estrategias de desarrollo en el Área metropolitana de Valencia" (CSO2016-74888-C4-1-R), financiado por la Agencia Estatal de Investigación (AEI) y al Fondo Europeo de Desarrollo Regional (FEDER) dentro del Programa Estatal de Investigación, Desarrollo e Innovación Orientada a los Retos de la Sociedad, en el marco del Plan Estatal de Investigación Científica y Técnica y de Innovación 2013-2016, convocatoria de 2016.

${ }^{2}$ http://ec.europa.eu/social/main.jsp?catld=1081\&langld=es
} 
y/o ambientales, puede ser llevada a cabo por el sector público, privado, o tercer sector, puede ser endógena (surgir de las personas que la necesitan) o exógena (de personas que quieren ayudar), se orienta al beneficio común de la población, y se realiza contando con la participación de la comunidad y los beneficiarios, que se transforman en actores de su propio desarrollo. Todo ello fortalece el sentimiento de ciudadanía y es capaz de crear nuevos vínculos de colaboración con fuerte impacto a nivel local (Salom et al., p. 48).

Pero además de tener una definición, es fundamental, como dice Mulgan et al. (2007), conocer por qué es importante, cómo puede acelerarse, qué actores están implicados, qué resistencias existen, y cuáles son las fases de desarrollo de una innovación social, desde su creación hasta su difusión. En este sentido, la literatura económica de los últimos veinte años ha venido subrayando la importancia de las redes de actores en los procesos de innovación y, en particular, en el impacto territorial de estos procesos. Ello se repite en distintos enfoques de análisis que coinciden en la idea de que la existencia de interrelaciones resulta decisiva para la competitividad de los territorios (Camagni, 1991; Cooke y Morgan, 1993; Morgan, 1997; Bathelt et al. 2004, Méndez, 2007, etc.).

El papel de las redes ha sido resaltado en particular por su impacto en los procesos de aprendizaje, a través de los vínculos de cooperación, confianza e interdependencia que favorecen los intercambios de tecnologías, la provisión de servicios especializados, la circulación de flujos de información formal y sobre todo informal, y, en último término, la creación de procesos de aprendizaje colectivo en entornos territoriales innovadores (Maillat, 1996) o regiones inteligentes (Morgan, 1997).

Según Klein et al. (2015, p. 235), lo específico de la innovación social es la creación o adopción de nuevas formas de hacer, nuevas coordinaciones y nuevas regulaciones, tales como la gobernanza distribuida, la coproducción de servicios, o las actividades de co-construcción de políticas públicas, así como el carácter plural de la economía, tanto en cuanto al modo de propiedad como a la capacidad de hibridación de diversos recursos y, por tanto, la pluralidad de actores. Ya que la producción y la asignación de los recursos no está coordinada sólo por mecanismos de mercado, sino también por sistemas de intercambio basados sobre la reciprocidad y la asociación, el entorno institucional democrático es de la mayor importancia a fin de que sirva de catalizador para la cooperación y la interacción de las redes, con actores responsables de la coordinación y de las acciones compartidas entre ellos (Dufays y Huybrechts, 2014, Moulaert y Nussbaumer, 2015, Slimane y Lamine, 2017).

Sistemas de innovación social de éxito, como el de Quebec, muestran algunas peculiaridades en cuanto a las configuraciones institucionales y en las modalidades de coordinación y de gobernanza que es interesante replicar o al menos tener en cuenta. Entre estas peculiaridades destacan la participación de una pluralidad de actores y la hibridación de diversas formas de gobernanza (Klein et al., 2015, p. 193). En este sentido, el denominado "ecosistema de innovación quebequés" (Levesque, 2011) está compuesto por agentes que cumplen de forma interrelacionada cinco funciones principales: financiación, formación, investigación, servicios y gobernanza, con algunas características destacables:

- En relación con la financiación, existen fuentes de financiación suficientes y diversificadas, provenientes tanto de autofinanciación como de los poderes públicos y de fondos específicos

- En cuanto a la formación, existen universidades, fundaciones y/o agrupaciones empresariales que proporcionan una formación profesional transversal a los diversos sectores de actividad económica.

- La investigación es desarrollada por equipos mixtos de universidad y empresas sociales; a partir de fondos regionales y de las propias universidades; y con una metodología de investigación-acción participativa

- Existe una oferta específica de servicios a las empresas y organizaciones sociales, preferentemente a escala local.

- Y, finalmente, se ha articulado una gobernanza partenarial más horizontal que vertical, que ha desarrollado esquemas de co-construcción de políticas en todas las fases, y con una perspectiva transversal a los diversos sectores de actividad

Las redes de actores resultan, pues, básicas para el desarrollo y mantenimiento de iniciativas de innovación social. De hecho, la colaboración, la creación de redes, se encuentra en la base misma de la idiosincrasia de este tipo de innovación, ya que el aislamiento no es deseable ni genera resultados de éxito. Resulta evidente que el grado de desarrollo de las redes sociales es producto del propio desarrollo de la innovación social y su enraizamiento en el territorio. A continuación analizamos el caso de Valencia, en la que desde hace menos de una década se han puesto en marcha interesantes iniciativas de innovación social como respuesta a problemas de diversa índole, sobre todo sociales, y que han generado una serie de redes incipientes de colaboración que hacen prever la consolidación de este fenómeno en la ciudad. 


\section{EL CASO DE LA INNOVACIÓN SOCIAL EN LA CIUDAD DE VALENCIA (ESPAÑA)}

En Valencia, la política desarrollada desde finales de los 90 del siglo pasado, basada en la construcción de edificios singulares y la promoción de grandes eventos, ha generado un espacio urbano fuertemente fragmentado y crecientemente dualizado (Torres y García, 2013). En este contexto, la identificación de las iniciativas de innovación social en esta ciudad resulta de interés para profundizar en las condiciones sociales y territoriales que explican su surgimiento, evolución y desarrollo, con lo que ello supone de cambio y mejora de la calidad de vida en esta ciudad.

La identificación de las iniciativas de innovación social en Valencia se ha realizado a partir del estudio de casos (Salom et al., 2017). Las 79 iniciativas identificadas hasta la fecha se han agrupado en siete categorías ordenadas teniendo en cuenta el objeto de la innovación de cada una de ellas, siendo la categoría "Dinámicas sociales e inclusión" la que agrupa un mayor número, que supone el $24 \%$ del total, seguida de las iniciativas reunidas en la categoría de "Redes de intercambio y economía colaborativa" con un 19\%. Un poco por debajo se encuentra "Ecología urbana y consumo" que supone un 15\%, y "Urbanismo y patrimonio" con un 13\%. Las categorías con un porcentaje menor son las "Estructuras de apoyo al emprendedor" que suponen un 11\% por ciento, "Educación" con un 10\% y "Fomento del empleo y orientación profesional", con un 9\% de las iniciativas identificadas.

Estas iniciativas innovadoras se concentran geográficamente en un número limitado de barrios y distritos de la ciudad, avalando la hipótesis de que su surgimiento está estrechamente relacionado con las condiciones sociodemográficas, económicas y territoriales del entorno en que aparecen. Se trata de procesos sociales complejos en los que intervienen distintas variables, que sólo es posible aprehender mediante un pormenorizado análisis cualitativo, todavía en desarrollo. Con los primeros resultados es posible avanzar algunas hipótesis, como el hecho de que la existencia de iniciativas parece estar relacionada con el nivel de renta de la población, con la vinculación a movimientos ciudadanos y con la tradición asociativa de los barrios.

Sin embargo, el tema que aquí nos ocupa es la creación de redes de colaboración de diverso tipo y entre agentes tanto públicos como privados y del tercer sector. Analizamos, a continuación, los primeros resultados a este respecto.

\subsection{Hipótesis y metodología}

Nuestra hipótesis de trabajo es que la existencia de un sistema regional o local de innovación, articulado por agentes que ejercen distintas funciones, interactúan y cooperan, es un factor importante en el desarrollo de un territorio innovador. Por tanto, hemos intentado verificar si en la ciudad de Valencia se ha desarrollado o se está desarrollando un sistema de este tipo que favorezca y apoye las iniciativas de innovación social.

Para ello, y partiendo de la información recopilada a partir de encuestas a las entidades y empresas que han desarrollado iniciativas de innovación social, hemos aplicado metodologías de análisis de redes sociales ("network analysis") que nos han permitido dibujar la red de actores que participan y colaboran en las iniciativas de innovación social de la ciudad, identificando la existencia de relaciones de colaboración explícitas tanto de las entidades entre sí como con otros agentes económicos, sociales y comunitarios (administraciones, empresas, bancos, asociaciones, etc.). La información de partida es la proporcionada en la red por las entidades que han realizado iniciativas de innovación social, completada posteriormente mediante encuestas telefónicas o personales a los responsables de la iniciativa. Estos han respondido a la pregunta de con qué entidades y organismos habían establecido o establecían frecuentemente relaciones de colaboración (participación conjunta en proyectos, participación en redes más o menos formalizadas, cofinanciación, etc.). A partir de esta información se ha podido representar el sociograma de relaciones de cooperación (figura 1), y medir el papel de intermediación que juegan los distintos agentes. Para la representación gráfica y los cálculos se han utilizado los programas informáticos Gephi y Ucinet.

\subsection{El análisis de redes sociales. Primeros resultados}

El análisis de redes sociales constituye una aproximación teórica que explica los procesos sociales y el comportamiento de los individuos basándose no sólo en sus atributos, sino considerándolos también un resultado de su participación en relaciones sociales estructuradas. Este análisis considera que la estructura de la red de relaciones entre actores, y el posicionamiento del actor en la red son aspectos con importantes consecuencias en el comportamiento, percepción y actitud de las unidades individuales y del conjunto del sistema. Desde esta perspectiva, 


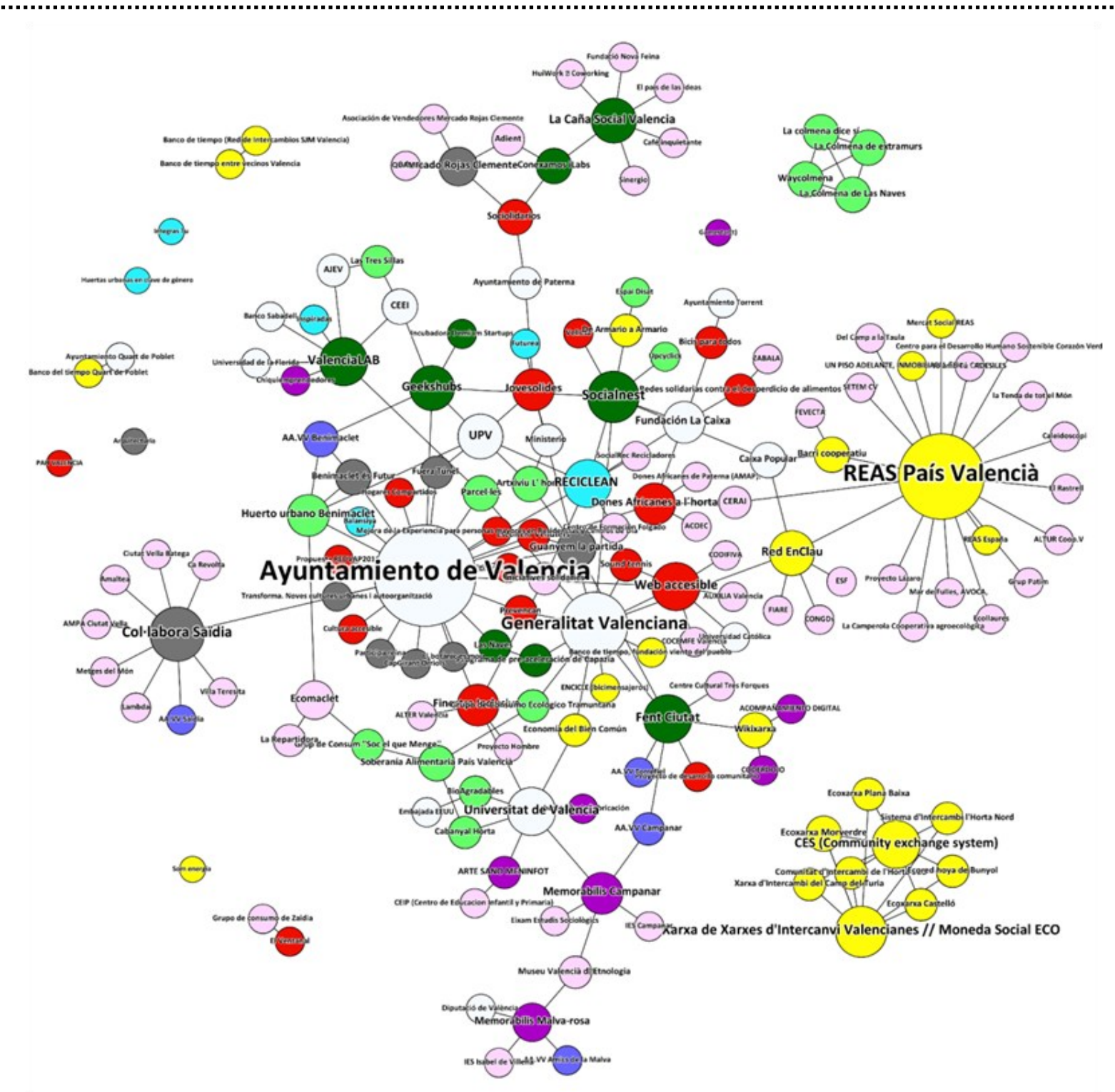

Figura 1 - Red de relaciones de cooperación de las entidades implicadas en la innovación social en la ciudad de Valencia. El tamaño del nodo es proporcional al número de conexiones directas (grado). Fuente: Elaboración propia.

las relaciones entre actores son canales de transferencia y distribución de recursos, materiales o inmateriales; la densidad de los agrupamientos y los tipos de relaciones estructuran el flujo de recursos; y las posiciones estructurales de los agentes, tales como las de gatekeeper (que controla el acceso a la red) o broker (que enlaza dos redes) son características relevantes que permiten obtener poder y mayor acceso a los recursos (Rodríguez, 1995).

Los resultados de nuestro análisis han sido significativos en tres aspectos: la identificación del número y tipo de agentes participantes en la red; la densidad y estructura de la red de relaciones; y la posición de centralidad o marginación de los agentes o tipos de agentes.

Como agentes presentes en el sistema se han considerado no sólo las propias empresas, organismos y entidades que han desarrollado proyectos de innovación, sino también todos los actores, privados, públicos o del tercer sector que mantienen relaciones de colaboración con ellos en el ámbito de la innovación social. Se han diferenciado dos niveles territoriales: el local (área metropolitana) y el supralocal (región, país, otros países). En la red están presentes los siguientes tipos de agentes:

1.- Ámbito local:

1.1. -Empresas y entidades que han desarrollado proyectos de innovación social 
1.2.- Administraciones local y regional

1.3.- Asociaciones y Organizaciones empresariales

1.4.- Universidades y centros de formación

1.5.- Asociaciones sociales y comunitarias

2.- Ámbito supralocal:

2.1.- Administraciones estatales

2.2.- Redes de asociaciones y empresas

2.3.- Entidades financieras

Se han identificado 166 nodos (agentes) con 189 conexiones (relaciones), lo que supone un índice de densidad del 1,4\%, lo que caracteriza la red como muy poco densa, prácticamente incipiente, y todavía con iniciativas desconectadas entre sí, y con el resto de los agentes. El sistema de relaciones se establece preferentemente en el ámbito local, aunque también existen otros agentes, principalmente entidades financieras, asociaciones y organizaciones empresariales, de ámbito regional o estatal.

Para identificar los actores más importantes en la red, se han utilizado dos tipos de índices que tiene en cuenta, respectivamente, la centralidad local (grado o degree) y global (betweenness o posición intermediaria) de los agentes individuales, por un lado, y de los distintos tipos de agentes, por otro (Freeman, 1979). Se supone que a mayor centralidad mayor es la implicación del actor en la red de relaciones, y por tanto más importante su papel.

Un nodo es localmente central si tiene un alto número de conexiones con los nodos de su entorno inmediato; es decir, que un actor es localmente central en términos de conexiones directas con sus vecinos. La figura 2 representa la red de relaciones de colaboración, mostrando los nodos (agentes) en tamaño proporcional al número de conexiones directas o grado. Como puede verse, la mayor centralidad local la ostentan la administración local (Ayuntamiento de Valencia) y, en segundo lugar, estructuras de colaboración de segundo grado como la Red de Economía Alternativa y Solidaria del País Valenciano (que a su vez se incardina en REAS a nivel nacional), y la Xarxa de Xarxes d'Intercamvi Valencianes). A un nivel más modesto, pero también con un importante número de conexiones, se encuentra el Gobierno Regional (Generalitat Valenciana).

El segundo índice calculado mide la centralidad global de los nodos. Un nodo es globalmente central si ocupa una posición estratégicamente significativa en la estructura global de la red. La centralidad global se expresa en términos de distancia entre varios puntos. Betweeness es una medida de centralidad que mide el grado en que un nodo está situado entre los otros nodos de la red. Este índice nos indica en qué medida un actor puede hacer de "broker" (intermediario) o "gatekeeper" (portero), con el consiguiente poder y potencial de control, ya que el actor que está en medio puede controlar interacciones entre otros actores de la red y, por tanto, tiene poder sobre ciertos caminos de interacción.

La tabla 1 y la figura 2 muestran respectivamente los 10 actores mejor posicionados, y la media de este índice para los distintos tipos de actores de la red. Como puede verse (tabla 1), las administraciones local y regional, en particular el Ayuntamiento de Valencia, ocupan un papel central en esta red, seguidos por algunos centros de servicios a las empresas (Fent Ciutat, SocialNest), las universidades, y algunas asociaciones y redes temáticas como REAS País Valenciá, red Enclau, ONGs como Jovesolides, etc. Los agentes externos mejor posicionados son las entidades financieras.

Si entramos en el análisis detallado de las entidades que desarrollan las iniciativas (fig. 2), es posible encontrar diferencias significativas entre las entidades según el tipo de proyectos que han desarrollado. Así, las que han desarrollado proyectos relacionados con las dinámicas sociales y de inclusión, probablemente con una mayor trayectoria de intervención en este ámbito, se encuentran inmersas en una red de relaciones más densa, mientras que las redes de intercambio y economía colaborativa se ubican en el otro extremo, mostrando una dinámica relativamente autónoma.

Si analizamos esta red a la luz de las consideraciones realizadas más arriba, es posible destacar algunos aspectos tanto positivos como negativos. Entre los aspectos positivos cabe señalar la presencia de todos los agentes clave, el papel central de las administraciones públicas y de los centros de servicios a las empresas, y la importante participación de los agentes sociales y comunitarios. Sin embargo, como aspectos negativos hay que señalar la aún escasa densidad de la red y la desigual integración de las iniciativas según su tipo, así como el insuficiente desarrollo de algunas funciones clave como la formación e investigación, y, sobre todo, la ausencia de un sistema de gobernanza transversal y cooperativo que articule el conjunto del sistema. 
Tabla 1 - Actores con mayor centralidad global (índice Beetweenness). Fuente: Elaboración propia.

\begin{tabular}{|c|c|c|c|}
\hline RANGO & NOMBRE & TIPO & BETWEENNESS \\
\hline 1 & Ayuntamiento de Valencia & Institución & 4.030 \\
\hline 2 & Generalitat Valenciana & Redes de Intercambio y economía colaborativa & 3.853 \\
\hline 3 & REAS País Valencià & Dinámicas sociales e inclusión & 2.218 \\
\hline 4 & Jovesolides & Redes de Intercambio y economía colaborativa & 1.916 \\
\hline 5 & Red EnClau & Institución & 1.771 \\
\hline 6 & Ayuntamiento de Paterna & Institución & 1.536 \\
\hline 7 & Universitat de València & Dinámicas sociales e inclusión & 1.493 \\
\hline 8 & Sociolidarios & Fent Ciutat & Estructuras de apoyo al emprendedor social \\
\hline 10 & Socialnest & 1.430 & 1.237 \\
\hline
\end{tabular}

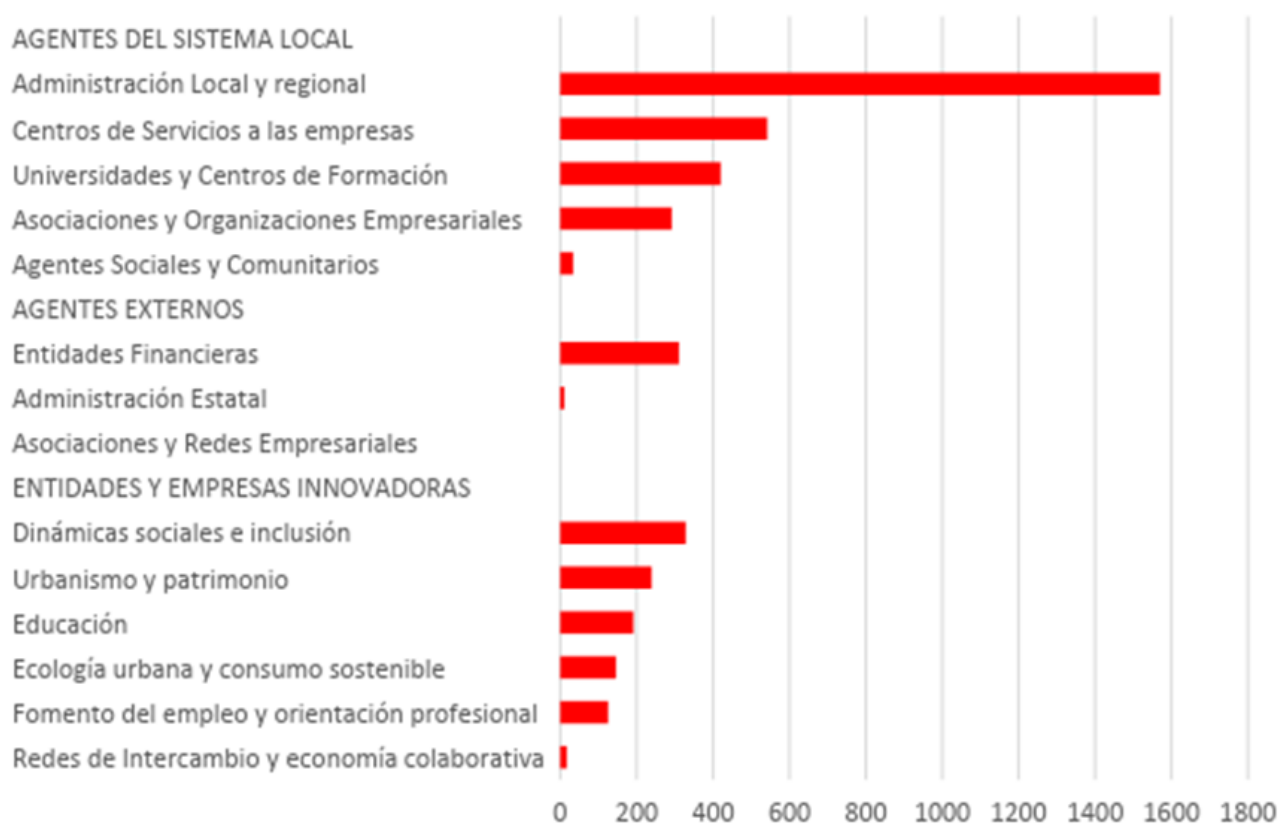

Figura 2. Índice medio de centralidad (Betweenness) de los tipos de actores del sistema local de innovación de la ciudad de Valencia. Fuente: Elaboración propia.

\section{CONCLUSIÓN}

El análisis que hemos realizado nos ha permitido identificar en la ciudad de Valencia el surgimiento reciente de una serie de iniciativas de innovación social en distintos ámbitos temáticos (dinámicas sociales e inclusión, redes de intercambio y economía colaborativa, ecología urbana y consumo, urbanismo y patrimonio, educación, empleo, etc.) cuyo origen está estrechamente relacionado con las condiciones sociodemográficas, económicas y territoriales del entorno en que aparecen, y en particular con el capital social acumulado a lo largo de una trayectoria de movilizaciones sociales y respuestas cooperativas. Los actores que han desarrollado estas iniciativas se relacionan entre sí en un incipiente y aún poco denso sistema de relaciones de colaboración en el que participan también las administraciones local y regional, las universidades y centros de formación, los centros de servicios a las empresas, y algunas entidades financieras, asociaciones y organizaciones empresariales, así como otros agentes sociales y comunitarios tipo asociaciones de vecinos y ONGs. Este sistema muestra un importante déficit en algunas funciones estratégicas, tales como la investigación y la formación, y carece de un marco de gobernanza transversal y participativa, por lo que consideramos que la potenciación de este incipiente ecosistema puede ser una de las políticas locales clave de apoyo a la innovación social. 
El compromiso de la Administración para promover plataformas abiertas hacia la innovación (Laboratorios de Innovación Social) puede satisfacer las necesidades y responsabilidades sociales existentes. El liderazgo público puede mejorar el ecosistema de Innovación Social del territorio, desarrollando mecanismos de financiación de I+D+i social, facilitando la incubación y aceleración de iniciativas, la formación en competencias emprendedoras y haciendo explícitas las demandas de innovación social dentro de la administración. Además, la interacción entre diferentes acciones que surgen a nivel micro genera el ambiente relacional adecuado para crear un sistema reticular articulado entre proyectos o ideas que comparten un objetivo de índole similar. El éxito de estas buenas prácticas reside en su capacidad para hacerlas evidentes y compartirlas en el marco de otras experiencias a diferentes escalas. De este modo, los procesos de Innovación Social en la lógica global de las redes contribuyen a la expansión y a la ampliación de su impacto.

En definitiva, se trata de desarrollar un marco político que conduzca a una transformación socio-cultural que proporcione una mayor resiliencia de los procesos de innovación social, contribuyendo a difundirlos y extenderlos por el territorio.

\section{BIBLIOGRAFÍA}

BATHELT, H., MALMBERG, A. Y MASKELL, P. (2004). Clusters and knowledge: local buzz, global pipelines and the process of knowledge creation, Progress in Human Geography, 28 (1), 31-56.

CAMAGNI, R. (ed.) (1991). Innovation networks. Spatial Perspectives. GREMI, Belhaven Press, Londres

COOKE, PH. Y MORGAN, K. (1993). The network Paradigm. New departures in corporate and regional development. Society and Space, 11, 543-564

DUFAYS, F. Y HUYBRECHTS, B. (2014). Connecting the dots for social value: A review on social networks and social entrepreneurship, Journal of Social Entrepreneurship, 5 (2), 214-237.

FREEMAN, L. (1979): Centrality in Social Networks: I. Conceptual classification, Social Networks, 40, pp. 35-41 1982

KLEIN, J.L.; FONTAN, J.M; HARRISSON, D. Y LÉVESQUE . B. (2015). L'innovation sociale au Québec : un système d'innovation fondé sur la concertation, en Klein. J.-L,; Laville, J.-L, y Moulaert, F. (dirs.) : L'innovation sociale, Érès, Toulouse, 193-218

LÉVESQUE, B. (2011): Innovations sociales et pouvoirs publics: vers un système québécois d'innovtion dédié à l'économie sociale et solidaire. Quelques éléments de problématique, les Cahiers du CRISES, Collection Études Théoriques, ET1106.

MENDEZ, R. (2015): Redes de colaboración y economía alternativa para la resiliencia urbana: una agenda de investigación, Biblio3W. Revista bibliográfica de Geografía y Ciencias Sociales, v XX, 1.139, en red: http://www.ub.edu/geocrit/b3w-1139.pdf

MORGAN, K. (1997). The learning region: institutions, innovation and regional renewal, Regional Studies 31, 491-503

MOULAERT, F. Y NUSSBAUMER, J. (2015). Pour repenser l'innovation: vers un système régional d'innovation sociale, en Klein, J.-L., Laville, J.IL., Moulaert, F. : L'innovation sociale, Eds. Érès, Toulouse. 81-113

MOULAERT, F., MACCALLUM, D., \& HILLIER, J. (2013). Social innovation: intuition, precept, concept. The International Handbook on Social Innovation: collective action, social learning and transdisciplinary research, 13-39.

MOULAERT, F., MARTINELLI, F., GONZÁLEZ, S., Y SWYNGEDOUW, E. (2007). Introduction: Social innovation and governance in European cities urban development between path dependency and radical innovation. European Urban and Regional Studies, 14 (3), 195-209.

MOULAERT, F.; MARTINELLI, F.; SWYNGEDOUW, E. Y GONZÁLEZ, S. (2010): Can Neighbourhoods Save the City? London and New York, Routledge

MULGAN, G., TUCKER, S., ALI, R., Y SANDERS, B. (2007). Social Innovation. What it is, why it matters and how it can be accelerated. Skoll Centre for Social Entrepreneurship. Oxford Said Business School. The Young Foundation.

RODRÍGUEZ, J.A. (1995): Análisis estructural y de redes, Cuadernos Metodológicos, Centros de Investigaciones Sociológicas, Madrid

SALOM J., PITARCH, M.D. Y SALES, A. (2017): "Innovación social: estrategias urbanas en un contexto de cambio. El caso de la ciudad de Valencia", CIRIEC-España, Revista de Economía Pública, Social y Cooperativa, 91, 31-58.

SLIMANE, K.B. Y LAMINE, W. (2017): A transaction-based approach to social innovation, Entrepreneurship and innovation, 18 (4), 231-242.

TORRES, F. Y GARCÍA, P. (2013): La ciudad fragmentada. Análisis comparativo de cuatro barrios emblemáticos, en Cucó i Giner, J. (dir.) (2013): La ciudad pervertida. Una mirada sobre la Valencia global. Anthropos, Barcelona, 191-212 
Página intencionalmente dejada en blanco 


\title{
Resiliencia en ciudades medias españolas: praxis económica y eviden- cias sociales en León y Oviedo ${ }^{1}$
}

\author{
A. López González (a), P. Benito del Pozo (b) \\ (a) Departamento de Geografía y Geología, Universidad de León, alejandro.lopez@unileon.es \\ (b) Departamento de Geografía y Geología, Universidad de León, paz.benito@unileon.es
}

\begin{abstract}
Resumen
Desde la geografía económica y de redes es pertinente el análisis del impacto que la crisis financiera y económica de 2008 ha tenido en las ciudades, al generar vulnerabilidad social y desconfianza en las políticas económicas, lo que a su vez está propiciando acciones/respuestas locales y espontáneas que pueden interpretarse como resiliencia urbana. Esta comunicación tiene como objetico analizar las prácticas económicas que se enmarcan en las coordenadas de la economía social o Tercer Sector, con vínculos también con la denominada economía del bien común, lo que define el marco teórico de discusión, siendo el caso de estudio la comparación entre las ciudades de Oviedo y León, en el norte de España. Se espera identificar pautas de resiliencia comunes, pero también variaciones derivadas de ciertos factores específicos de cada ciudad, pues la resiliencia no es una estrategia uniforme ni de igual intensidad en todos los lugares. Los resultados esperados habrán de servir para orientar la toma de decisiones sobre redes ciudadanas, encauzar las respuestas y fijar el compromiso público en clave de gobernanza urbana.
\end{abstract}

Palabras clave: Geografía Económica, Economía Social, Prácticas Alternativas, Resiliencia Urbana, León y Oviedo

\section{INTRODUCCIÓN}

La sociedad española ha pasado en breve tiempo de un segundo milagro económico, la década que va desde fines de los 1990 a 2008 (Malo de Molina, 2005; Ibáñez y López, 2012) , a una etapa de depresión desde el punto de vista económico y social. Las dificultades propiciadas por el brusco parón del sector más dinámico de la economía (la construcción), la pérdida de valor de los activos inmobiliarios atesorados por las familias, el desempleo rampante, la presencia de una gran cantidad de inmigrantes ahora en buena parte empobrecidos, la aparición de graves problemas sociales que tienen a los desahucios su producto más acabado, etcétera dibujan un panorama sombrío donde el efecto riqueza deja de tener sentido para grandes bolsas de la población, sustituido por un potente efecto pobreza y una lacerante desigualdad debido a que la crisis afectó de manera muy diferente a cada grupo social (Martínez García, 2013).

Las ciudades son la cara más visible de la crisis, siendo en los entornos urbanos donde comienzan a despuntar estrategias desde el activismo social para reforzar la resiliencia de una ciudadanía empobrecida y la falta de perspectivas. Estas estrategias de resistencia ante la adversidad en las ciudades españolas ya han comenzado a ser objeto de estudio desde la Geografía económica (Fernández y Miro, 2016; García García et alii, 2016; Benito del Pozo y López González, 2017; López González y Benito del Pozo, 2017; Méndez Gutiérrez del Valle y Monteserín, 2017; Sánchez Hernández et alii, 2017), y esta comunicación aspira a ser una aportación a esa literatura científica en expansión. En el trabajo tomamos como caso empírico dos ciudades de tamaño medio del norte de España: León (125.317 habitantes en 2017) y Oviedo (220.301 habitantes en ese mismo año). En ambos casos son localidades con un fuerte sesgo hacia la función administrativa y la prestación de servicios, pues la primera es capital de provincia y la segunda de Comunidad Autónoma; otro nexo común es haber experimentado a lo largo de los 1970 y 1980 procesos de desindustrialización, siendo cada vez más dependientes de actividades de servicios y del sector inmobiliario, por lo que han perdido capacidad de arrastre de las respectivas economías provincial y regional. En ambas ciudades las dificultades económicas han tenido un efecto notable: si en enero 2009, en

\footnotetext{
${ }^{1}$ Esta comunicación se encuadra en el proyecto de investigación "Espacios y prácticas económicas alternativas para la construcción de la resiliencia de las ciudades españolas" (2016-2018). Programa Estatal de Investigación, Desarrollo e Innovación Orientada a los Retos de la Sociedad financiado por el Ministerio de Industria y Competitividad y el Fondo de Desarrollo Regional (FEDER), referencia CSO2015-65452-R (MINECOFEDER). Los coautores de esta comunicación pertenecen al grupo de investigación INVESTER de la Universidad de León.
} 
un momento aún incipiente de las turbulencias económicas asociadas a la crisis financiera internacional y que afectó y se complicó en España por la suma de la crisis inmobiliaria, el número de desempleados era de 9.145 en León y de 13.689 en Oviedo; en diciembre de 2017 ha crecido, respectivamente, hasta 9.327 y 15.500 ; cifras que no parecen ser demasiado diferentes a las del año base, aunque en términos relativos el crecimiento del desempleo ha sido sustancialmente mayor dada la caída en población que registraron ambos municipios durante la crisis (en 2009 el porcentaje de paro entre la población de entre 16 y 64 años era del 10,44 \% en León y del 8,78 \% en Oviedo; mientras que en 2017 estas cifras ascendían, respectivamente, al 12,15\% y al 10,76\%).

En ambas ciudades se han identificado casos de prácticas, implícita o explícitamente, dirigidas a reforzar la capacidad resiliente de colectivos sociales concretos. Estas prácticas cubren campos variados, aunque por sí solas no se pueden encuadrar en un modelo alternativo claro, y se caracterizan por las dificultades para constituir un marco solvente de producción e intercambio, tanto por carecer de una masa crítica de participantes como por la precariedad que rodea su funcionamiento. Podríamos pensar en comportamiento sociales alternativos, más que en la expresión de nuevos medios de vida, fruto de las crecientes dificultades derivadas de la menor disponibilidad de excedentes que obligan a una nueva manera de gestionar los recursos disponibles y de afrontar la escasez en general. Dicho con otras palabras, las prácticas sociales que discutiremos en las siguientes páginas no son tanto una respuesta desde la pobreza, como desde ciertos segmentos de la clase media que ven amenazadas sus cotas de bienestar por la reducción de sus rentas (congelación de salarios y/o merma de ingresos no salariales) y menor efecto riqueza (vía devaluación activos, básicamente inmobiliarios).

En el presente trabajo pretendemos elaborar una radiografía de las evidencias de resiliencia social en León y Oviedo. Para ello nos basaremos en las entrevistas realizadas con responsables o portavoces de los colectivos que desarrollan estas prácticas. Para responder a este objetivo organizamos el cuerpo de esta comunicación en cuatro apartados: el primero es una discusión sobre el significado del concepto resiliencia, el segundo describe las tipologías detectadas en este estudio, el tercero se ocupa de las experiencias desarrolladas en Oviedo, el cuarto se refiere a las analizadas en León y, finalmente, el quinto sintetiza los resultados en forma de conclusiones.

\section{EL CONCEPTO DE RESILIENCIA}

El término resiliencia es un concepto de trayectoria dilatada y de aplicación en campos tan diversos como la ingeniería, el estudio del medio ambiente o las ciencias sociales (Cueto et alii, 2017). El término resiliencia comienza a gestarse en las décadas centrales del siglo pasado en el campo de la psicología (Becoña, 2006), desde donde se difundió a otros saberes por la versatilidad de su significado que, en síntesis, hace referencia a la capacidad de resistencia/adaptación de objetos, medios o, incluso, sistemas ante cambios externos. En lo que sigue nos referiremos a autores que proponen definiciones de resiliencia en sus acepciones urbana y social.

Abundan las contribuciones al concepto de resiliencia urbana, por lo general lo circunscriben al campo de las interacciones entre la ciudad y el medio natural en condiciones extraordinarias (catástrofes naturales de distinta naturaleza) o empeoramiento de las de carácter ordinario (caso de cambios significativos y persistentes asociados al cambio climático). Tyler y Moench $(2012,312)$ es una clara manifestación de quienes interpretan la resiliencia desde una perspectiva ambientalista, indicando que la resiliencia se traduce en la capacidad de innovar y aceptar cambios por parte de los individuos para contribuir a la recuperación de la ciudad frente a shocks o tensiones, predecibles o no, en el clima urbano. Leichenko $(2012,164)$ implica un paso más hacia la generalidad del término resiliencia, definiéndola como la capacidad de una ciudad y/o de un sistema urbano para soportar un amplio rango de perturbaciones y presiones; definición que no sólo contempla los riesgos climáticos, sino una gran variedad de circunstancias desfavorables; mientras que Brungmann (2012, 217), manteniendo esta generalidad en la naturaleza de los riesgos, pone el acento en la capacidad de los distintos componentes de la ciudad de seguir proporcionando rentas o beneficios en presencia de diferentes circunstancias y coyunturas. Meerow et alii $(2016,38)$ en una extensa discusión sobre aportaciones a este concepto, señala que resiliencia urbana describe la capacidad de un sistema urbano, tanto si se considera en conjunto como en sus distintos componentes socio-ecológicos y socio-tecnológicos y a lo largo del tiempo y de las diferentes escalas espaciales, de mantener o retomar las funciones deseadas, de adaptarse a los cambios y de transformar aquellos sistemas que limitan en el presente su capacidad de adaptación futura; esta definición es más ambiciosa que las anteriores, pues cubre los mecanismos resistencia-adaptación-cambio-prevención que definen una actitud plenamente resiliente.

Este enfoque ambientalista se mantiene, y enriquece, en la obra de Romero-Pankao et alii (2016), quienes interpretan el concepto resiliencia a la luz de su relación con los conceptos sostenibilidad, vulnerabilidad y capaci- 
dad. Sostenibilidad se refiere a la capacidad de la gente de mantener su base de recursos sociales y naturales, pero también de responder a tensiones y shocks (que en última instancia es lo que es la resiliencia); de hecho, en un trabajo previo señalan que sostenibilidad implica mantener la capacidad del ecosistema natural de un área urbana a las escalas local, regional y global para apoyar las necesidades presentes de la población dentro de sus límites mientras salvaguarda sus recursos para satisfacer las necesidades de futuras generaciones, mientras que resiliencia denota la capacidad de las poblaciones y sistemas urbanos de soportar un amplio rango de riesgos y tensiones (Romero-Pankao and Gnatz, 2013, 358-359).

La resiliencia social cambia de sujeto, no son ya las ciudades las que manifiestan capacidad resiliente, sino los colectivos humanos cohesionados mediante relaciones sociales más o menos estrechas. En palabras de Hall y Lamont $(2013,2)$ "empleamos el término residencia social para referirnos a la capacidad de un grupo de gente unidos en una organización, clase, grupo social, comunidad o nación para sostener y progresar su estado de bienestar frente a los retos que se presentan". Desde otro punto de vista Maguire y Hagan (2007) señalan que "resiliencia social es la capacidad de grupos y comunidades de recuperarse de, o responder positivamente a, crisis". Basten estas dos aportaciones para identificar resiliencia social con la capacidad de Resistencia de colectivos sociales de distinta índole a shocks negativos.

Tal y como se puede apreciar en las definiciones anteriores, la resiliencia es una demostración de capacidad de resistencia frente a una perturbación externa, bien de origen natural (v.g. un terremoto o una inundación) o humano (v.g. un conflicto bélico o una crisis económica); también es la capacidad de adaptación a unas condiciones diferentes a las habituales (v.g. situaciones climáticas crecientemente adversas, recesión económica prolongada en el tiempo), de recuperarse y retomar el estadio precedente o, incluso mejorarlo; e igualmente es la capacidad de eliminar o modificar componentes que debilitan la posibilidad de adaptación a tensiones futuras. Estos rasgos son esencialmente sociales, pues quienes manifiestan la resiliencia son los hacedores de políticas urbanas (los agentes con capacidad de decisión) y los individuos a través de las estrategias y modelos de organización adoptados (ya sea individualmente o de forma colectiva). En esta investigación nos centraremos únicamente en los individuos, en las acciones que plantean para enfrentarse a un medio socioeconómico adverso; estos individuos manifiestan una voluntad resiliente y, por lo general, operan en barrios que han sufrido una prolongada presión asociada al impacto de la crisis desencadenada en 2008.

\section{TIPOS DE PRÁCTICAS RESILIENTES EN LEÓN Y OVIEDO}

La insatisfacción de individuos y colectivos ante las prácticas económicas dominantes en las sociedades occidentales se plasma en iniciativas concretas, generalmente a escala minúscula, de alcance estrictamente local, y de difícil definición por su extrema heterogeneidad (Sánchez Hernández, 2017). Entre dichas prácticas conviven manifestaciones que operan en segmentos del ciclo económico de muy diversa naturaleza (Méndez, 2015) y en las que la alterabilidad frente a las económicas dominantes ofrece muchos matices (Fuller y Jonas, 2003; Jonas, 2010; GibsonGraham, 2010). Siguiendo los criterios establecidos en el proyecto PRESECAL (López y Benito, 2017; Benito y López, 2017), adscribimos estas iniciativas a los siguientes tipos: bancos de tiempo (BT), centros sociales autogestionados (CSA), grupos de consumo (GC), huertos urbanos (HU), mercados de trueque (MT), y moneda social (MS). En esta comunicación tenemos, al menos, un ejemplo de cada uno de estos tipos tal y como muestra la Tabla 1.

La Tabla 1 enumera ejemplos de prácticas identificadas generalmente al margen o en los márgenes de la economía convencional. La información contenida en el cuadro es la siguiente: denominación, localidad en la que opera, tipo a la que responde, momento en la que se crea e implicados, entendiendo como tales los que están vinculados de una manera u otra en su desarrollo. De las variables enumeradas, la mencionada en último lugar es un término ambiguo, primero porque los entrevistados no dan el mismo valor a este concepto (según el caso se denominan socios, asamblearios, vendedores, adjudicatarios... denominaciones variadas porque la naturaleza y/o la filosofía concreta que rige cada una de ella son diferentes); segundo, el número de personas vinculada a estas iniciativa fluctúa bastante a lo largo del tiempo (en ocasiones las respuestas a las preguntas planteadas sobre el particular se ven condicionadas por esta circunstancia, no teniendo claro los informantes cual es el número real de implicados) y, tercero, existe una gran heterogeneidad en el grado de participación real dentro de este colectivo. En conclusión, las cifras que presentamos en esta Tabla sobre el número de implicados son, en todo caso, aproximaciones a una realidad poliédrica.

El número de iniciativas que consideramos son poco más de una decena, repartidas prácticamente a partes iguales entre León y Oviedo. El tipo más frecuente son los grupos de consumo, tres colectivos íntegramente ubica- 
Tabla 1 - Ejemplos de prácticas resilientes en Oviedo y León, 2017. Fuente: Elaboración propia.

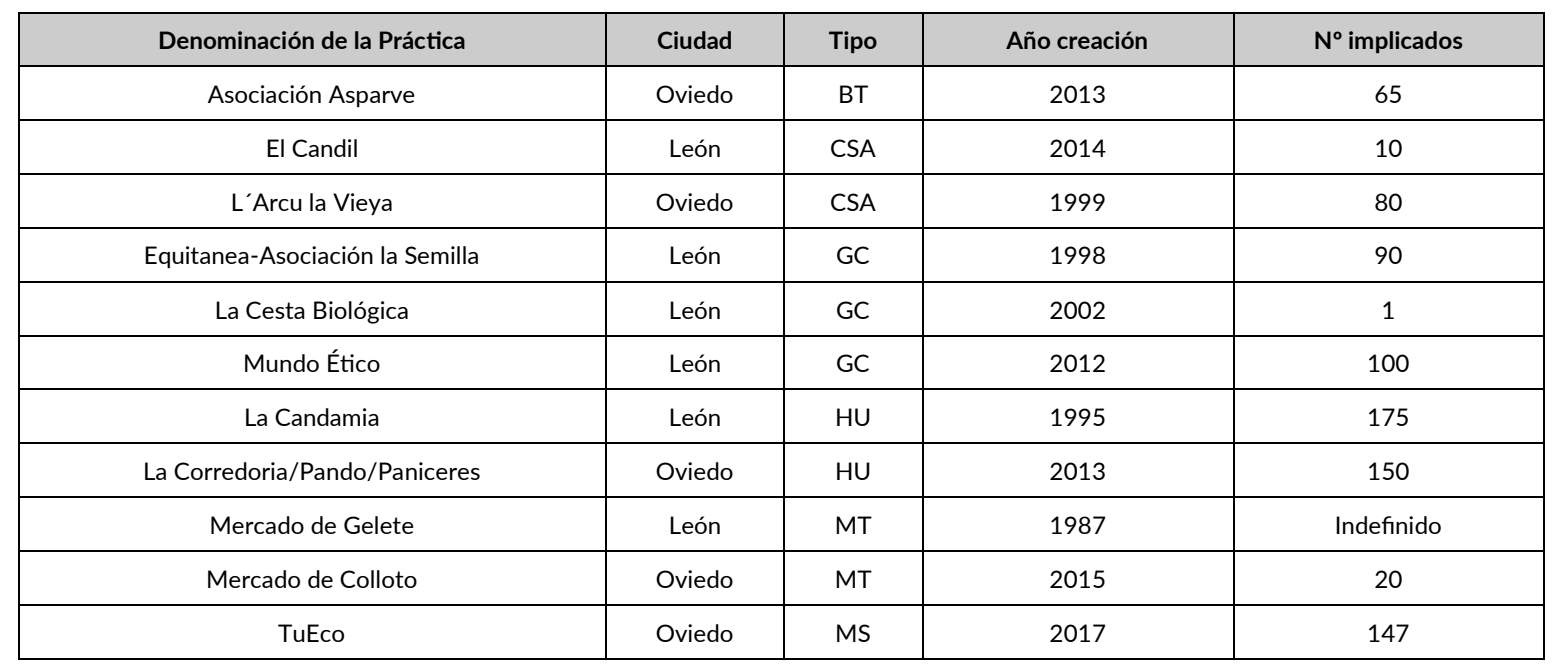

dos en la capital leonesa; en un segundo nivel están los huertos urbanos, centros sociales autogestionados y los mercados de trueque, con un ejemplo en cada ciudad; finalmente, los bancos de tiempo y la moneda social únicamente tienen un representante, en todo caso situados en la localidad asturiana. Esta simple enumeración ya da lugar a un primer elemento diferencial: la diversidad corresponde a Oviedo, la ciudad de mayor tamaño y renta, así como donde las manifestaciones de resiliencia social son más numerosas (aunque León y Oviedo son ciudades con marcado sesgo conservador, la presencia de grupos ideológicamente heterodoxos es más visible en la segunda en forma de un mayor número de locales alternativos e incluso con episodios prolongados de locales "okupados", como fue el caso del centro social autogestionado La Madreña, experiencia que se prolongó entre 2011 y 2014 con la ocupación de las antiguas instalaciones de la antigua sede de la Consejería de Salud del Principado de Asturias).

La antigüedad de estas experiencias es dispar, si bien podemos distinguir entre aquellas que tienen un recorrido previo a la crisis de 2008 , frente a las que nacen durante los años de recesión y estancamiento que se iniciaron en aquella fecha. Las primeras suman un total de cinco, mayoritariamente situadas en León y que operan fundamentalmente en el ámbito de la alimentación saludable y el autoabastecimiento (dos grupos de consumo, un huerto urbano), y en la ayuda a minorar gastos en la educación (el mercado de Gelete, con diferencia el más veterano); en Oviedo de los antiguos solo registramos un CSA, lo que puede resultar paradójico dada la tradición de esta ciudad, volveremos más adelante sobre esta cuestión. En el caso de los que nacen con la crisis el paisaje cambia, mayoritariamente se localizan en Oviedo frente a la escasa actividad registrada en León (dos solamente, concretamente un grupo de consumo y un centro autogestionado); en la capital de Asturias encontramos entre estas nuevas iniciativas a un huerto urbano, un banco de tiempo, un mercado de trueque y una moneda social. Como se puede apreciar existe una clara oposición en cuanto a la naturaleza de las prácticas con una dilatada trayectoria cronológica en relación a las que tienen una vida más corta, la crisis puede ser una explicación, pero también lo es los contextos institucionales en que se mueven unos y otros. Las actividades más veteranas encuentran asidero en las instituciones en las que se apoyan (patrocinios de firmas privadas sostienen el Mercado de Gelete, el ayuntamiento hace lo propio con el huerto urbano de La Candamia) o en la vinculación a un establecimiento comercial, por mucho que esté especializado en el tramo de demanda del comercio justo (es lo que ocurre con los dos GC veteranos, pero también con el CSA radicado en Oviedo). En cambio, para los nacidos con la crisis los argumentos empleados de manera general para las iniciativas de mayor recorrido solo son válidos parcialmente (los HU que se crean muy recientemente en Oviedo y el GC Mundo Ético), mientras el mercado de Colloto, el BT Asparve y TuEco operan desde la base, si bien han recibido apoyos puntuales del consistorio en distintos momentos de su trayectoria.

Un segundo elemento diferencial es el marco institucional actualmente vigente en una y otra ciudad. Tanto León como Oviedo fueron regidas tradicionalmente por el Partido Popular ${ }^{2}$, si bien desde 2015 el gobierno municipal de Oviedo está en manos de una coalición en el que las fuerzas más a la izquierda tienen un peso ostensible

\footnotetext{
${ }^{2}$ En León gobernó el PSOE entre los años 2007-2011, más allá de ese período hay que remontarse a principios de los 1990 para ver un consistorio regido por otro partido que no sea el Partido Popular tanto en esta ciudad como en Oviedo.
} 
(PSOE-Somos Oviedo-IU) mientras que en León sigue en la alcaldía un gobierno del PP. Esta circunstancia implica matices en la actitud institucional y social frente a modelos de comportamiento más o menos marginales en relación con los esquemas convencionales de comportamiento. Las fuentes de información son entrevistas con portavoces, representantes o gestores de los colectivos que organizan o apoyan el funcionamiento de estas iniciativas, si bien en algún caso aislado recurrimos a un representante de la administración local (este es el caso de los huertos urbanos existentes en Oviedo, pequeños lotes de tierra de propiedad municipal y adjudicados temporalmente a particulares para su explotación sin ánimo de lucro). Estas entrevistas se llevaron a cabo a lo largo del verano de 2017, aunque algunas postergaron unos meses. La Tabla 2 muestra los datos básicos de las mencionadas entrevistas.

En la Tabla 2 reseñamos las fechas de realización de la entrevista, el papel dentro de la iniciativa que juega el entrevistado y, a modo de indicadores del contenido, el número de preguntas del cuestionario, el número de las que obtuvieron respuestas y la ratio que representan éstas sobre aquellas. Las entrevistas se realizaron con personas con un papel relevante dentro de la organización, las excepciones son el Rastrueque en que los entrevistados fueron los tres presidentes de las asociaciones vecinales que animan la celebración del mercado, y en el de la moneda social TuEco donde no había una estructura jerarquizada y él interpelado simplemente actuaba como una suerte de portavoz de los demás participantes. La ratio entre las preguntas respondidas y el número de ítems de los cuestionarios es elevada, en cuatro se respondieron a todas las preguntas, mientras que en tan sólo dos ocasiones la tasa de éxito de los cuestionarios estuvo por debajo del $90 \%$ del cuestionario. Los cuestionarios, con las particularidades derivadas de la naturaleza de los tipos analizados, abordan aspectos tales como los datos básicos de la práctica, los principios organizativos, actividades desarrolladas, grado de integración local, objetivos perseguidos y resultados obtenidos, y relaciones con otras prácticas económicas alternativas. En los siguientes apartados se procede a una breve descripción de las iniciativas mencionadas, ordenándose en función del grado de alejamiento a las pautas de la economía de mercado, entendiendo que ninguna de ellas está totalmente al margen de la misma, sino que, por lo general, se limitan a introducir en las relaciones socioeconómicas objetivos y principios de carácter ético y moral.

Tabla 2 - Relación de entrevistas a gestores de entidades alternativas en Oviedo y León. Fuente: Elaboración propia.

\begin{tabular}{|c|c|c|c|}
\hline Práctica & Fecha & Rol del entrevistado & Preguntas/respuestas/ratio \\
\hline Asociación Asparve & $05 / 10 / 2017$ & Gestor & $34 / 34 / 1,0000$ \\
\hline El Candil & $12 / 03 / 2018$ & Responsable & $32 / 30 / 0,9375$ \\
\hline L'Arcu la Vieya & $30 / 08 / 2017$ & Responsable & $32 / 29 / 0,9063$ \\
\hline Equitanea-Asociación la Semilla & $20 / 09 / 2017$ & Responsable & $35 / 35 / 1,0000$ \\
\hline La Cesta Biológica & $06 / 09 / 2017$ & Responsable & $35 / 26 / 0,7429$ \\
\hline Mundo Ético & $23 / 08 / 2017$ & Responsable & $35 / 35 / 1,0000$ \\
\hline La Candamia & $05 / 09 / 2017$ & Responsable & $42 / 41 / 0,9762$ \\
\hline La Corredoria/Pando/Paniceres & $01 / 09 / 2017$ & Responsable & $42 / 31 / 0,7381$ \\
\hline Mercado de Gelete & $12 / 09 / 2017$ & Responsable & $34 / 33 / 0,9706$ \\
\hline Rastrueque & $01 / 07 / 2017$ & Promotores & $34 / 32 / 0,9412$ \\
\hline TuEco & $16 / 03 / 2018$ & Portavoz & $32 / 32 / 1,0000$ \\
\hline
\end{tabular}

\section{PRÁCTICAS EN OVIEDO}

En Oviedo la iniciativa menos alejada de los esquemas socioeconómicos convencionales lo constituyen los HU de La Corredoria. En ellos la administración local está muy presente, pues ella es la propietaria de los terrenos que adjudica por concesión a particulares y asociaciones bajo unas condiciones bastante laxas. Estos terrenos están situados en el borde nororiental de la capital asturiana, en el barrio mencionado y, en menor número, en las laderas del monte Naranco (lugares de Pando y Paniceres). La finalidad de esta iniciativa es eminentemente social, facilitando el desarrollo de la actividad al aire libre y el autoabastecimiento alimentario entre los beneficiarios (la venta de estos productos está vedada) mediante la cesión del terreno, instalaciones para la custodia del utillaje y el suministro de riego. Posiblemente sea esta, entre todas las mencionadas, la que cuenta con un componente menor de alterabilidad debido a la capacidad regulatoria y compulsiva de la administración. 
Un escalón más en la escala economía convencional-propuestas alternativas lo representa el BT promovido por la asociación Asparve desde 2013, circunscrito al barrio de La Corredoria, un extenso sector urbanizado por iniciativa pública a caballo del siglo pasado y el actual. Su crecimiento demográfico ha sido exponencial, convirtiéndose en pocos años en el distrito más populoso de la población asturiana gracias a la llegada de inmigrantes procedentes del resto de la región y de otros países. En este marco sociodemográfico, frágilmente cohesionado y sin tiempo aún para arraigar un sentido de pertenencia e identidad, se ha planteado este BT gracias al impulso de la citada asociación y la ayuda de la Administración local, pues arrancó con la ayuda de fondos públicos vinculados al programa Urban Oviedo-este y opera gracias a la cesión gratuita de un local en el centro sociocultural del barrio. La filosofía subyacente es la de promover la economía colaborativa, actualizando manifestaciones tradicionales de ayuda mutua propia del campo asturiano a las necesidades de la sociedad actual, además de propiciar la socialización e integración de extranjeros en la sociedad local. Los beneficios que propugnan los promotores de la asociación son eminentemente sociales, pues, aunque existen intercambios de tiempo implican servicios de contenido económico (tareas de reparación de electrodomésticos o tareas de asistencia en el campo de la informática), la mayor parte de los servicios mutuos terminan recayendo en acciones para paliar la soledad entre la gente de mayor edad.

El punto medio en la escala que estamos comentando lo constituye el Rastrueque, ejemplo de MT que se celebra mensualmente en Colloto, localidad en la periferia de Oviedo. En este caso la alteralidad de la práctica deviene de la insistencia en su carácter social, prácticamente en los bordes entre un mercado propiamente dicho y una iniciativa de asistencia social. El carácter ambiguo de esta iniciativa se acentúa si se observa la relación con las administraciones públicas: si bien inicialmente la relación entre organizadores-ayuntamiento estaba marcada por la indiferencia, actualmente se detecta una colaboración activa. Los fines de este mercado, además de facilitar un medio de ingresos para personas en riesgo de exclusión (la moneda empleada es el euro, muy esporádicamente se observan trueques), era la de animar la vida social de un vecindario atomizado por procesos de residencialización y la avanzada edad media de la población tradicional de la localidad. En consonancia con los objetivos antes señalados, los promotores explicitan que los beneficios del mercado son sociales (sociabilización del vecindario, promoción del comercio local y mejora en la convivencia vecinal), económicos (propiciar una actividad complementaria a individuos con ingresos ínfimos o nulos) e impulsar determinados valores éticos entre la población en general.

Finalmente, donde si se observa una clara voluntad promover actitudes alejadas lo más posible de los modelos de mercado es en L'Arcu la Vieya y TuEco. Estas dos prácticas, sin estar regidas desde una misma asociación, tienen muchos puntos en común, comenzando por su misma ubicación geográfica: el borde sudoriental del casco histórico de Oviedo, un sector ajeno al proceso de turisitificación de la parte antigua y con evidentes síntomas de degradación social y económica. El primero de los mencionados es un hibrido entre un CSA y un GC, combinando el activismo de las asociaciones autogestionadas con el comercio justo a partir de una tienda abierta al público en la calle Postigo Bajo. L'Arcu la Vieya se rige por el asociacionismo, persiguiendo fines propios de la economía social, el consumo de productos obtenidos por cultivo ecológico y la construcción de redes de apoyo social: promueven actividades sociales de cobro voluntario, ofrecen un lugar para pernoctar a gente de paso por la ciudad y cenadores vegetarianos o veganos. El centro se concibe también como un ente de animación de la vida social del barrio, promueven el voluntariado, el comercio justo, la soberanía alimentaria, la agricultura ecológica y promueven el uso de monedas sociales. Todo ello al margen de las instituciones, pues su relación con el ayuntamiento se limitó a la obtención de la licencia para la tienda de comercio justo.

TuEco es una moneda social, cuya gestión se realiza desde el local de la Asociación Partycipa, radicado en la calle Paraíso y a escasos metros de la sede de L’Arcu La Vieya. Esta moneda es de creación reciente, y es el resultado de la segregación del Nodo Oviedo de la red de intercambios asturiana Rastru lo que, entre otras cosas, significó que abandonasen el Copín, moneda social aún presente en muchos puntos de Asturias, y creasen una propia inicialmente operativa en Oviedo (entre las intenciones de sus usuarios está el extenderla a otros puntos de Asturias). Se configura como una herramienta de trueque indirecto desvinculado de cualquier otra moneda de curso legal, lo que implica la perentoria necesidad de ampliar la base de usuarios para evitar problemas de liquidez y facilitar así cubrir el mayor número de necesidades al margen del euro. Buscan dinamizar la vida del barrio donde se encuentra su sede, empleando los saldos obtenidos de un impuesto sobre las transacciones en TuEcos en actividades en el barrio, pero su objetivo fundamental es la construcción de una red de apoyo social, atendiendo las necesidades sociales de individuos que se ven arrinconados por las crecientes dificultades económicas que están viviendo. 


\section{PRÁCTICAS EN LEÓN}

En el caso de León el ejemplo menos alejado de las pautas dominantes en la sociedad lo constituye el Mercado de Gelete, iniciativa peculiar, que se celebra sólo una vez al año en el Centro Comercial León Plaza, y que implica solo a la comunidad educativa, ya que plantea una red de intercambio de libros de texto en la que, por una parte, alumnos venden libros de texto que no necesitan y, de otra, padres y madres, $u$ otros alumnos, compran esos mismos materiales a precios muy competitivos. El beneficio que mencionan sus organizadores es obvio, reducir gastos a las familias en un momento complicado como es el inicio del curso escolar, al que unen el reciclado de papel.

Los HU de La Candamia es una iniciativa similar a los de La Corredoria, aprovechando parte de las zonas verdes de titularidad municipal en las riberas del río Torío (borde sudoriental de la ciudad). Como en el caso ovetense tienen una función social, e incidentalmente facilitan cierto grado de soberanía alimentaria para los beneficiarios; el sesgo social se acentúa por sólo se pueden adjudicar a jubilados o a otros particulares en situación asimilable. El ayuntamiento de León concibe esta iniciativa con los siguientes objetivos: promover la sociabilidad, la convivencia (fomentando la idea de comunidad), el consumo saludable del tiempo de ocio y mejorando la alimentación propiciando técnicas de cultivo ecológico, el conocimiento de energías limpias y la difusión de prácticas de cultivo ecológico. La gestión de los huertos es responsabilidad de los adjudicatarios, a través de un órgano denominado concejo, y el cuidado de los espacios comunes se lleva a cabo comunalmente mediante una institución tradicional denominada hacendera. Los beneficios propugnados, en buena medida ya enunciados más arriba, son sociales (fomento de la capacidad de autoorganización, la convivencia, integración y relaciones intergeneracionales) y psicológicos (fomento de la ilusión en un colectivo que, por edad, carece de estímulos para mejorar su calidad de vida mediante el esfuerzo físico).

En un nivel intermedio están los GC, que en León aparece representado por Equitanea-Asociación La SemiIla, Mundo Ético y La Cesta Biológica, dando buena cuenta del grado de desarrollo de este segmento en una ciudad de tamaño medio y tendencias en el consumo bastante convencionales. Geográficamente están dispersos por el casco urbano de la ciudad, no existiendo ninguna correlación entre barrios desfavorecidos y su ubicación: Equitánea está en el casco antiguo, en las inmediaciones de la basílica de San Isidoro; Mundo Ético en la Chandría, un barrio acomodado en torno a El Corte Inglés; La Cesta Biológica está el Ensanche capitalino, cerca de donde se concentra el grueso de la actividad comercial especializada de la ciudad. Dadas estas localizaciones no creo que la resiliencia esté tras estas iniciativas, más bien existe un deseo de apoyo y extensión de nuevas formas de concebir el consumo y/o de apoyo al mundo en vías en desarrollo (sin excluir que, en algún caso, se trate únicamente de una estrategia de supervivencia dentro del comercio convencional).

La Cesta Biológica muy discutiblemente se puede calificar como alternativo, todo lo más lo podemos etiquetar como un establecimiento comercial especializado en el segmento de distribución de productos de comercio justo y lo que se viene denominando $\mathrm{km} 0$, o productos ecológicos de temporada. De hecho, en la entrevista no se mencionan beneficios sociales, sino los personales asociados a la satisfacción de poder desarrollar un proyecto de vida. Si contribuye a un patrón de consumo alternativo, es una consecuencia y un resultado incidental.

Mundo Ético no se califica así mismo como GC, aunque tiene rasgos que nos aconsejan a clasificarlo como tal, aunque sea a efectos expositivos: es un hibrido entre una empresa mayorista, especializada en la venta de productos de comercio justo certificados por ellos mismos, y una asociación orientada hacia la sensibilización y promoción de modelos alternativos de consumo. Los beneficios económicos se estiman en la oferta de productos comercializados y de actividades ofrecidas; los beneficios sociales derivan de su actividad didáctica para fomentar el conocimiento de distintos modelos de consumo. En relación con las administraciones públicas se caracterizan por la colaboración con distintos ayuntamientos de la provincia, señalando que buscan cambiar la actitud de las instituciones públicas frente al modelo socioeconómico dominante mediante la persuasión.

Equitanea-Asociación La Semilla tiene rasgos que la singularizan, y la equiparan al modelo hibrido representado por Arcu La Vieya: una institución coral, asamblearia, que posee una tienda para obtener unos ingresos extra para financiar otras funciones; le diferencia que su rango de acciones no es tan amplio como el de un centro social autogestionado, restringiéndolas al mundo del consumo de productos ecológicos y al comercio justo, así como el apoyo a productores locales y la sensibilización de los consumidores para canalizarlos a este mercado. En este sentido, Equitanea emplea la tienda para la venta al detalle de productos de temporada procedentes de agricultores ecológicos del Bierzo y León, así como de productos distribuidos por mayoristas especializados en comercio justo y productos eco. Los beneficios generados por esta asociación son los siguientes: al consumidor le permite obtener precios competitivos para bienes de por si gravosos, para sus asociados sentido de pertenencia a 
un grupo a partir de hábitos saludables y de respeto al medio ambiente, a la comunidad la creación de un entorno de aprendizaje en torno a un consumo responsable, y al productor local ayuda financiera y la participación en los encuentros que ellos promueven.

En León la iniciativa que más se aleja de los estándares convencionales viene de la mano del CSA El Candil, vinculado estrechamente a un partido político (concretamente el PCPE, Partido Comunista de los Pueblos de España), se articula a partir de la asociación juvenil RISCAR, con sede en el barrio de El Ejido, un barrio netamente obrero edificado a lo largo de las primeras décadas de la posguerra. Las actividades que organiza son de carácter cultural, de tiempo libre y de divulgación ideológica; del mismo modo, también emplean sus instalaciones para colaborar con las acciones de otros colectivos con posicionamientos reivindicativos (feminismo, lucha contra los desahucios, defensa intereses de la clase obrera...). Los objetivos de El Candil se dirigen a ofrecer un recinto gratuito para la realización de actividades políticas, culturales y talleres a coste cero; también buscan la concienciación política y la cohesión de la población residente en el barrio, construyendo redes de apoyo social y de lucha frente a las políticas que consideran dañinas como la reforma laboral o los recortes sociales.

\section{CONCLUSIONES}

Se han abordado iniciativas consideradas de forma genérica como "prácticas alternativas" en un contexto de resilicienca urbana en ciudades medias del norte de España, planteadas por colectivos muy concretos, con un alcance limitado y con unas pretensiones, por lo general, modestas. Aunque algunas tienen tras de sí una trayectoria dilatada, pensamos que existe un vínculo razonable entre la persistencia de los sucesivos shock o episodios de crisis socioeconómica experimentados en nuestro país desde 2008 y el funcionamiento de estas prácticas económicas. Los objetivos perseguidos por las iniciativas y entidades analizadas son fundamentalmente sociales, lo que cabe interpretar como síntomas de resiliencia social, y a ello contribuyen la casi totalidad de las mismas, con la excepción de algún ejemplo aislado que no podemos incluir en estas coordenadas (el GC La Cesta Ecológica y, parcialmente, Mundo Ético no entran en estas categorías). Más complicada se presenta la relación entre estas iniciativas y la resiliencia urbana, puesto que la atomización de estas manifestaciones resilientes impide que tengan efectos que alcancen al grueso de la sociedad civil y, por tanto, repercutan en una mayor capacidad de resistencia, no digamos ya de adaptación, de estas ciudades ante las fuertes tensiones socioeconómicas que acompañaron al período de crisis entre 2008 y 2015 como mínimo.

Por otra parte, no sólo existe un componente resiliente en estos ejemplos, también los hay de alternativa a la economía de mercado y al énfasis en el individualismo de la sociedad. En este campo encontramos un gradualismo, aunque no una oposición, desde actuaciones que ofrecen tímidas disonancias (los HU, BT y GC) a otras en que existe mayor ambición y voluntad de generar actitudes y comportamientos al margen de las relaciones socioeconómicas dominantes (CSA y MS, fundamentalmente). Puede afirmarse, en suma, que hay una cierta voluntad de generar actitudes y prácticas ligadas a un capitalismo más humanizado.

\section{BIBLIOGRAFÍA}

ALBERTOS PUEBLA, J. M. Y SÁNCHEZ HERNÁNDEZ, J. L. (Coords.) (2011). Geografía de la crisis económica en España. Universitat de Valencia, Valencia.

BECOÑA, E. (2006). Resiliencia: definición, características y utilidad del concepto. Revista de Psicopatología y Psicología Clínica, $11(3), 125-146$.

BENITO DEL POZO, P. Y LÓPEZ GONZÁLEZ, A. (2017). "Sostenibilidad urbana y economía alternativa en León", XXV Congreso de la AGE "Naturaleza, Territorio y Ciudad en un mundo global". Departamento de Geografía de la Universidad Autónoma de Madrid y AGE. Madrid, DOI 10.15366/ntc.2017, pp. 957-966.

BRUNGMANN, J. (2012). Financing the resilient city. Environment \& Urbanization, 24 (1), 215-232.

CUETO, B.; MAYOR, M. Y SUAREZ, P. (2017). Crisis económica, resiliencia y empleo. Cómo encajan las crisis las regiones españolas. Fundación Persán, Sevilla.

FERNÀNDEZ, A. Y MIRÓ, I. (2016). L’Economia social i solidaria. La Ciutat Invisible-Ajuntament de Barcelona, Barcelona.

FULLER, D. AND JONAS, A. E. G. (2003). Alternative financial spaces. Leyshon, A.; Roger, L. and Williams, C. C. (Eds.), Alternative economic spaces, p. 55-73. Sage, London. 
GARCÍA GARCÍA, A.; FERNÁNDEZ SALINAS, V.; CARAVACA BARROSO, I. Y GONZÁLEZ ROMERO, G. (2016). Actividades creativas, transformaciones urbanas y paisajes emergentes. El caso del casco norte de Sevilla. Documents d'Anàlisi Geogràfica, 62 (1), 27-54.

GIBSON-GRAHAM, J. K. (2010). "Post development for local and regional development". Pike, A.; Rodríguez-Pose, A. and Tomaney, J. (Eds.), Handbook of local and regional development, 226-236. Routledge, London.

JONAS, A. E. G. (2010). Alternative this, alternative that...: Interrogating alterity and diversity. Fuller, D.; Jonas, A. E. G. and Lee, R. (Eds.), Interrogating alterity. Alternative economic and political spaces, p. 3-27. Routledge, London and New York.

HALL, P. Y LAMONT, M. (Eds.) (2013). Social resilience in the neoliberal era. Cambridge University Press, New York.

IBÁÑEZ ROJO, R. Y LÓPEZ CALLE, P.(2012). La ficción del milagro económico español a la luz de la crisis financiera. Cuaderno de Relaciones Laborales, 30 (2), 379-407.

LEICHENKO, R. (2011). Climate change and urban resilience. Current opinion in Environmental Sustainability, 3, 164-168.

LÓPEZ GONZÁLEZ, A. Y BENITO DEL POZO, P. (2017). Prácticas económicas alternativas y resiliencia urbana: los mercados de productores y de trueque en Oviedo. XLIII Reunión de Estudios Regionales, http://old.reunionesdeestudiosregionales.org/ sevilla2017/media/uploads/2017/09/26/alejandro.pdf.

MAGUIRE, B. Y HAGAN, P. (2007), Disasters and communities: understanding social resilience. The Australian Journal of Emergency Management, 22 (2), 16-20.

MALO DE MOLINA, J. L. (2005). Una larga fase de expansión de la economía española. Documentos ocasionales del Banco de España, 0505.

MARTíN ACEÑA, P.; MARTíNEZ RUIZ, E. Y PONS, A. (2013). Las crisis financieras en la España contemporánea, 1850-2012. Crítica, Barcelona.

MARTÍNEZ ESTÉVEZ, A. Y PALLARDÓ LÓPEZ, V. J. (2013), Los siete pecados capitales de la economía española. De la euforia al rescate. Ediciones Nobel, Oviedo.

MARTíNEZ GARCÍA, J. S. (2013). Estructura social y desigualdad en España. Los Libros de la Catarata, Madrid.

MEEROW, S.; NEWELL, J. P. AND STULTS, M. (2016). Defining urban resilience: A review. Landscape and Urban Planning, 147, 38-49.

MÉNDEZ, R. (2015). Redes de colaboración y economía alternativa para la resiliencia urbana: una agenda de investigación. Biblio3W, Revista Bibliográfica de Geografía y Ciencias Sociales, XX (1.139).

MÉNDEZ GUTIÉRREZ DEL VALLE, R. Y MONTESERÍN ABELLA, O. (2017). Redes alimentarias alternativas en grandes ciudades: los mercados de productores agrarios en Madrid. Cuadernos Geográficos de la Universidad de Granada, 56 (1), 193 216.

OLIVER ALONSO, J. (2017). La crisis económica en España. RBA Libros, Barcelona.

ROMERO-LANKAO, P. AND GNATZ, D. M. (2013). Exploring urban transformations in Latin America. Current opinion in Environmental Sustainability, 5, 358-367.

ROMERO-LANKAO, P.; GNATZ, D. M.; WILHELMI, O. AND HAYDEN, M. (2016). Urban sustainability and resilience: from theory to practice. Sustainability, 8, 1224. Doi: 10.3390/su8121224.

SÁNCHEZ HERNÁNDEZ, J. L.; NICOLÁS PENELA, A.; ALONSO SANTOS, J. L. Y MORO GUTIÉRREZ, L. (2017). Regeneración urbana, innovación social y prácticas económicas alternativas en ciudades medias: el ejemplo del barrio del Oeste (Salamanca). Ería (nueva época), 1, 67-82.

SÁNCHEZ HERNÁNDEZ, J. L. (2017), Las prácticas económicas alternativas en perspectiva geográfica. Universidad de Salamanca, Salamanca.

TYLER, S. AND MOENCH, M. (2012). A framework for urban climate resilience. Climate and Development, 4 (4), 311-326. 
Página intencionalmente dejada en blanco 


\title{
Dinámicas espaciales recientes de las redes bancarias de España y Brasil: un estudio de las ciudades de Lleida y Presidente Prudente
}

\author{
Ma Pilar Alonso (a), Juliana Oliveira (b), Fabio Fernández (a) \\ (a) Universitat de Lleida, p.alonso@geosoc.udl.cat, fabiofer3103@gmail.com \\ (b) Instituto de Geociências/Universidade Estadual de Campinas, juliana.oliveira@ige.unicamp.br
}

Resumen

En el sistema financiero mundial se han venido produciendo en las últimas décadas importantes transformaciones que han afectado a la presencia espacial de estas actividades. Entre los elementos que han influido más en estos cambios destacan: la mayor interdependencia entre las entidades bancarias por la conformación de un mercado global de capitales; una mayor concentración económica en el sector con intensos procesos de fusiones y adquisiciones bancarias; o la aceleración de las innovaciones tecnológicas, produciendo un incremento del uso de servicios bancarios vía internet. Todo ello lleva a importantes cambios en las lógicas espaciales de los bancos, que tienden a imprimir mayor selectividad en la distribución de sucursales y oficinas bancarias, generando nuevos patrones espaciales en las ciudades. Este trabajo, se centra en identificar cuáles son los rasgos generales y particulares de estos procesos de reconfiguración de las redes bancarias, considerando los cambios a la escala de los territorios nacionales de Brasil y España en el contexto de distintos procesos de crisis económicas, así como la materialización de estos procesos en dos ciudades medias, Lleida (España) y Presidente Prudente (Brasil) entre los años de 2008 a 2016.

Palabras clave: redes bancarias, lógicas espaciales, Lleida, Presidente Prudente.

\section{LAS REDES FINANCIERAS EN EL CAPITALISMO GLOBAL Y SU MATERIALIZACIÓN ESPACIAL}

La fuerte internacionalización e interdependencia de los mercados financieros se manifiesta en diversas escalas y fenómenos económicos, políticos, sociales y también espaciales. La crisis financiera internacional surgida en el verano de 2007 en Estados Unidos, y que se extendió rápidamente a muchos otros territorios en una cascada de caídas financieras, confirmó que el mercado internacional de capitales es uno de los elementos en los que se apoya el capitalismo global (García, F.,2010; Viera, E., 2014).

Los fundamentos de este capitalismo global financiero, fundado en políticas de desregulación del mercado, están basados en un nuevo paradigma técnico que se desarrolla en función de procesos de innovación que facilitan la conformación de un entramado en red, una variable fundamental de la globalización (Minoi, C.; 2012; Santos, M., 2000 Dias, L.C., 2007). La interconexión de las informaciones fundamenta los procesos financieros y se convierte en un elemento fundamental para su desarrollo. Todo ello va unido a una revolución tecnológica profunda, proporcionada por los avances en el progreso técnico de las telecomunicaciones donde la información es la materia prima principal (Castells, M. 2001; Massanel, A., 2016). De este modo "Podemos entonces hablar de una tecnificación del paisaje (...) La información es el vector fundamental del proceso social y los territorios son, de ese modo, equipados para facilitar su circulación" (Santos, M. 2000, p.160 - traducción de los autores).

La conformación de las redes desarrolla nuevos nexos multiescalares entre los territorios - con infraestructuras materiales (los fijos) e tramos inmateriales (los flujos) - configurando un entramado de relaciones económicas, así como nuevas acciones sobre el territorio, que tienen el poder de conectar, desconectar y reconectar los diferentes lugares a esta red global. Las redes financieras globales, a su vez, mantienen su estructura de funcionamiento fundada tanto en los flujos -sobre todo de informaciones- cuanto en las infraestructuras materiales, o fijos, en territorios concretos (sedes de entidades, oficinas, datacenters, cajeros, etc.) con una plasmación local que refleja diferencias y donde los efectos del funcionamiento en red se vuelven más visibles (Carroué, L., 2015).

La conformación de las redes financieras, fuertemente involucradas en la revolución técnica actual (Dabat, A. y otros, 2015), hace emerger en los momentos de crisis económica importantes procesos de reestructuración. La intensidad y las repercusiones de estos procesos vendrán determinados en cada espacio por las debi- 
lidades en la regulación del capital internacional y la fragilidad de los sistemas financieros locales, donde los elementos territoriales visibles (los fijos/redes de oficinas) que apoyan las redes intangibles se ven afectados en diferentes grados y escalas, según las particularidades internas de cada territorio. Son en estas escalas visibles de las redes financieras donde se dejan apreciar las diferencias que la globalización no ha homogeneizado.

Este trabajo, se centra en construir un análisis comparativo sobre las formas de organización de la banca en Brasil y España -señalando procesos generales y particulares que afectaran el sector- así como los cambios espaciales recientes de las redes bancarias en estos países -considerando las dinámicas económicas propias de los dos territorios nacionales-. El objetivo es buscar el marco de explicación de los procesos de reconfiguración espacial bancaria reciente en la escala de dos ciudades medias de los dos países. Los casos de estudio seleccionados son la ciudad de Lleida (España) y la de Presidente Prudente (Brasil) ${ }^{1}$.

La metodología que se sigue para llevar a cabo el análisis planteado se fundamenta en la recopilación, estudio y representación, en forma de tablas, gráficos y mapas, de una serie de variables significativas para observar los cambios en las reconfiguraciones espaciales de las oficinas de la entidades bancarias (evolución del número de entidades financieras y del número de oficinas bancarias, tasas de bancarización, entre otras variables). Los resultados obtenidos se fundamentan en una amplia revisión bibliográfica, que tiene como objetivo ayudar a comprender las particularidades de las distintas formaciones socio-espaciales en estudio, construyendo análisis comparativos entre ellas.

\section{LAS ORGANIZACIONES BANCARIAS EN BRASIL Y EN ESPAÑA. PROCESOS DE REESTRUCTURACIÓN POST-CRISIS}

La globalización ha puesto en marcha redes financieras a escala global, integrando jerárquicamente los mercados y las economías nacionales, cuyo seguimiento material resulta bastante difícil por la rapidez de integración y de movimientos bancarios apoyados en potentes sistemas de información y conexión (Fernández J.C., 2014). Pero junto con los aparentes rasgos de homogeneización de funcionamiento a estas escalas, también hay que valorar las particularidades de estas actividades en distintos contextos territoriales, tratando de entender las materializaciones de las redes de fijos, o sea, las infraestructuras que apoyan su funcionamiento global.

Para comprobar este aspecto, en este trabajo se presenta una caracterización general de la banca en los dos países de los casos de estudio a comparar, buscando identificar rasgos que indiquen semejanzas y diferencias en la forma de organización de sus sistemas bancarios, considerando que ambos tienen también una articulación dentro del mercado financiero globalizado.

Examinando las formas de organización de los sistemas bancarios de Brasil y de España existen similitudes entre los dos países, con presencia de los bancos privados y cooperativas de crédito como intermediarios financieros (ver tabla 1). Aunque también hay diferencias entre los dos países, especialmente con una importante presencia en Brasil de los bancos públicos (los bancos bajo control público con un importante papel social, atendiendo a demandas que los bancos privados no atienden), que demarca una importante particularidad con respecto a

Tabla 1 - Organización del sistema bancario en Brasil y en España. Principales actores.

\begin{tabular}{|c|c|c|}
\hline \multirow{4}{*}{ País } & Tipo de institución & Establecimientos físicos (fijos) \\
\hline \multirow{3}{*}{ BRASIL } & Bancos múltiplos públicos & $\begin{array}{c}\text { Sucursales, Oficinas, Cajeros automáticos, PAB (Puestos de atención bancária) y } \\
\text { "Correspondentes bancários". }\end{array}$ \\
\cline { 2 - 3 } & Bancos múltiplos privados nacionales & $\begin{array}{c}\text { Sucursales, Oficinas, Cajeros automáticos, PAB (Puestos de atención bancária) y } \\
\text { "Correspondentes bancários". }\end{array}$ \\
\cline { 2 - 3 } & Bancos múltiplos privados internacionales & $\begin{array}{c}\text { Sucursales, Oficinas, Cajeros automáticos, PAB (Puestos de atención bancária) y } \\
\text { "Correspondentes bancários". }\end{array}$ \\
\cline { 2 - 3 } & Cooperativas de crédito & Sucursales y Oficinas \\
\cline { 2 - 3 } ESPAÑ & Banca tradicional & Sedes, oficinas y Cajeros automáticos \\
\cline { 2 - 3 } & Cooperativas de crédito & Sedes, oficinas y Cajeros automáticos \\
\cline { 2 - 3 } & Cajas de ahorro & Sedes, oficinas y Cajeros automáticos \\
\hline
\end{tabular}

Fuente: Elaboración propia, 2018

\footnotetext{
${ }^{1}$ Los resultados presentados en este trabajo son fruto de una cooperación entre la Universitat de Lleida y la Universidade Estadual Paulista, con beca financiada por la Fundação de Amparo à Pesquisa do Estado de São Paulo (Fapesp).
} 
España donde no existe este tipo de instituciones. Por otro lado en España, la presencia de las cajas de ahorro durante mucho tiempo expresaron una particularidad de su sistema bancario. Estas instituciones, a pesar de ser privadas, también tenían un importante papel social y de financiación de familias y pequeñas empresas, componiendo una amplia red de talleres sobre el territorio (Alonso, M.P. y otros, 2014 a).

Además de los aspectos relacionados a los actores que actúan en el sector bancario en los dos países, también identificamos semejanzas y diferencias en los tipos de establecimientos que componen las capacidades instaladas del sector sobre el territorio, que estructuran su red física de gestión e intermediación financiera. En los dos países hay presencia de sucursales/sedes de las instituciones, oficinas bancarias y cajeros automáticos como los fijos fundamentales para el funcionamiento del sistema bancario, y cuyas lógicas de localización son muy similares, pero también hay otras que presentan lógicas espaciales propias que componen la topología del sector en cada país (Contel, F., 2009), como se resume en la tabla 2.

Tabla 2 - Tipos de establecimientos bancarios, funciones y lógicas espaciales.

\begin{tabular}{|c|c|c|}
\hline $\begin{array}{c}\text { Tipo de establecimiento } \\
\text { (Fijo) }\end{array}$ & Funciones & Lógicas espaciales \\
\hline Sucursales/Sedes & $\begin{array}{c}\text { Centraliza la gestión de las actividades administrativas } \\
\text { y financieras de la institución bancaria. }\end{array}$ & $\begin{array}{c}\text { Localización centralizada en ejes especializados, sobre } \\
\text { todo en los centros económicos más importantes del } \\
\text { país. }\end{array}$ \\
\hline Oficinas & $\begin{array}{c}\text { Ofrecen todos los servicios de intermediación finan- } \\
\text { ciera para sus clientes. }\end{array}$ & $\begin{array}{c}\text { Localización más dispersa, pero que privilegia las áreas } \\
\text { centrales con accesibilidad a gran número de perso- } \\
\text { nas. En Brasil, se observa una orientación a la instala- } \\
\text { ción de esos establecimientos en el centro tradicional } \\
\text { y en las áreas de las ciudades donde residen poblacio- } \\
\text { nes de mayor poder adquisitivo. En España también } \\
\text { existe una tendencia a la centralización. }\end{array}$ \\
\hline PAB - Puesto de atención \\
bancária (Brasil) & $\begin{array}{c}\text { Ofrece servicios más específicos y limitados de inter- } \\
\text { mediación financiera para un público específico } \\
\text { (funcionarios, estudiantes, etc.). }\end{array}$ & $\begin{array}{c}\text { Se sitúan lo más cerca posible a los lugares más acce- } \\
\text { sibles a su público: administración, universidades, } \\
\text { centros empresariales, etc. }\end{array}$ \\
\hline "Correspondentes bancá- \\
rios" (Brasil) & $\begin{array}{c}\text { Son establecimientos que actúan ofreciendo algunos } \\
\text { servicios bancarios básicos (jubilaciones, pago de } \\
\text { cuentas, transferencias, etc.). Estos establecimientos } \\
\text { actúan bajo la supervisión de los bancos, sin embargo } \\
\text { de manera externalizada. }\end{array}$ & $\begin{array}{c}\text { Se caracterizan por un mayor acercamiento a los } \\
\text { clientes, aprovechándose de la ubicación central de } \\
\text { establecimientos comerciales de barrios, como merca- } \\
\text { dos, panaderías, farmacias, etc. }\end{array}$ \\
\hline Cajeros Automáticos & $\begin{array}{c}\text { Son equipos electrónicos bancarios, que ofrecen auto- } \\
\text { servicio para realizar algunas transacciones básicas }\end{array}$ & $\begin{array}{c}\text { Ubstratégicos y accesibles a gran número de personas, } \\
\text { como gasolineras, centros comerciales, mercados, etc. }\end{array}$ \\
\hline
\end{tabular}

Fuente: Elaboración propia, 2018.

En el caso de Brasil las dos particularidades más significativas, en relación a los tipos de establecimiento, se refieren la primera a la presencia de los $\mathrm{PAB}$, que son puestos de atención orientados a públicos específicos y ubicados en locales muy accesibles (edificios de administraciones públicas, centros industriales y empresariales, así como en empresas con un gran número de trabajadores), actúan de manera similar a las oficinas, pero ofreciendo servicios más básicos, operaciones más limitadas; el segundo son los "correspondentes bancarios" actúan como intermediarios financieros sobre la supervisión de los bancos tradicionales, ubicados en lugares de paso, cuyas lógicas espaciales están dirigidas a la mayor proximidad a los clientes, sobre todo en áreas no atendidas por establecimientos bancarios como oficinas y cajeros, generando una ampliación de la red de servicios bancarios con una menor inversión del sector, pueden estar instalados en establecimientos como supermercados, oficinas de correos, farmacias, entre otros (Contel, 2011). Tienen una lógica de mayor acercamiento a los clientes.

En el caso español, cabe destacar el papel particular de las cajas de ahorro, que tenían un reparto muy local y próximo a los territorios, con una fuerte dispersión espacial de oficinas por las ciudades y las áreas rurales, por lo tanto, con gran importancia en la composición de las redes bancarias en España. Sin embargo, con el tiempo este tipo de entidades también se fueron involucrando en las inversiones de sus administraciones regionales públicas, y poco a poco cambiando su filosofía hacia la de la banca tradicional y entrando a formar parte de las redes de financiación internacional, lo que llevo con la crisis y los problemas de las inversiones inmobiliarias a su casi desaparición en el contexto post-crisis. El resultado ha sido un refuerzo de la centralización de sedes bancarias (con una ubicación central en todas las escalas) y una menor presencia de oficinas en el territorio tras un fuerte proceso de cierres y una búsqueda también de la centralidad espacial.

Brasil y España parten, por tanto, de algunas diferencias en las tipologías de entidades en su redes bancarias internas aún que sometidas a procesos globales cada vez se asemejan más. Así, hay que indicar que en los últimos 
años, en ambos países, se han vuelto cada vez más importante las funciones de auto-atención al cliente por canales remotos, destacando el uso la banca online, que ha crecido en número de usuarios y en volúmenes de transacciones, afectando los ritmos de expansión de las redes de atención presencial en estos territorios.

Por otra parte, al analizar la trayectoria del número de entidades actuales en los dos países se aprecian procesos parecidos de concentración bancaria en el sector, sobre todo si se consideran los bancos tradicionales en Brasil, y las cajas de ahorro en España. Aunque el estudio de las trayectorias reflejan en ambos un número cada vez más reducido de entidades que lleva a su concentración espacial.

En Brasil, en la década de 1990, actuaban cerca de 240 entidades bancarias (bancos tradicionales), pasando a 157 en el año 2016, tras dos décadas marcadas por importantes procesos de concentración en el sector, sobre todo con la entrada de inversiones internacionales en la economía brasileña a lo largo de los años 90 e inicio de los años 2000 (Días, L., 2009; Contel, F., 2011; Banco Central do Brasil, 2016). En España, en la década de 1990 actuaban 154 entidades bancarias (bancos tradicionales) y 64 cajas de ahorro, ya en el año 2016 se registraron 130 bancos en funcionamiento y solamente 2 cajas de ahorro en funcionamiento (Anuario Banco de España, 2016; Anuario CECA, 2016), fruto de procesos de fusiones y adquisiciones bancarias en función de la reestructuración post-crisis (Ver gráfico 1).

Grafico 1 - Evolución del número de entidades bancarias en Brasil y España, 1990 a 2016.

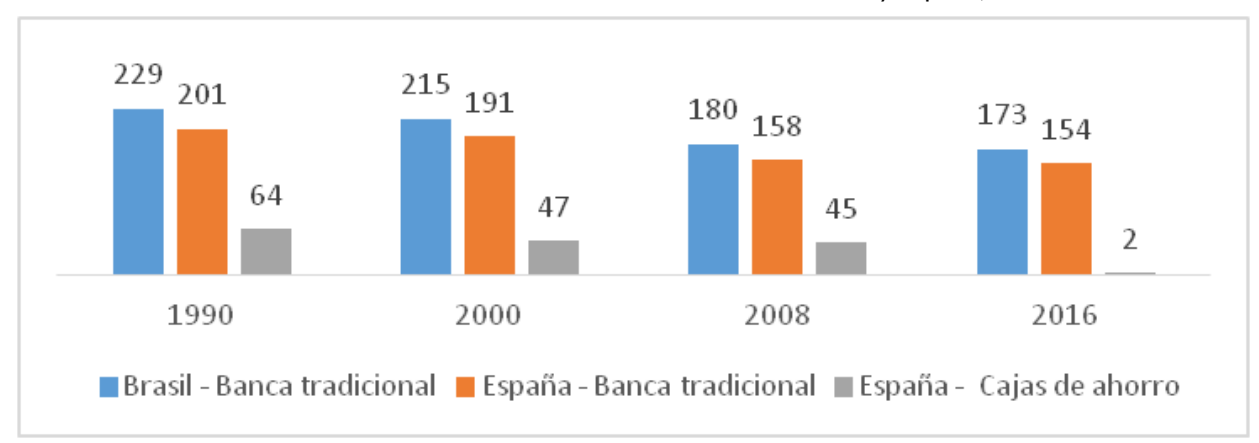

Fuente: elaboración propia a partir de datos del Banco Central do Brasil, 2016, Anuario Banco de España, 2016 y Anuario CECA, 2016

Si se compara la trayectoria de las tasas de bancarización de ambos países se puede observar como, a pesar de los diferentes contextos económicos que registran España y Brasil, ambos países muestran una trayectoria positiva en el número de cuentas bancarias activas en bancos tradicionales ${ }^{2}$, tendencia que se articula a las crecientes capacidades de expansión de las finanzas como variable presente y necesaria en el funcionamiento económico actual y marcada por la hegemonía del mercado globalizado.

En Brasil este crecimiento fue más acelerado en los últimos años, sobre todo a causa de las políticas de inclusión social y el aumento de las tasas de empleo, lo que aumentó el porcentaje de población con acceso a poseer una cuenta bancaria. España, por su parte, también presentó un crecimiento en el número de cuentas bancarias, aunque en menor ritmo que Brasil. A pesar de ello, España presenta mayores tasas de bancarización, es decir, una parte mayor de la población española está incluida en el sistema financiero en comparación con Brasil. En cualquier caso la tendencia de bancarización es creciente en los dos países (Ver gráfico 2).

A pesar de la tendencia de mayor bancarización en cuanto a cuentas abiertas, se puede observar que en los dos países estudiados las redes presenciales de oficinas bancarias ha disminuido su presencia de manera importante - sobre todo en España - fruto del contexto de reestructuración bancaria sufrido, aunque lo han hecho de diferentes maneras y en distintos períodos. Así, en España los cambios económicos generados a raíz de la crisis internacional de 2007 marca el inicio del proceso de reestructuración en su sistema bancario, proceso que dura hasta el presente. Durante los primeros años del S XXI las entidades financieras apostaron por una fuerte concesión de créditos hipotecarios que generó una dinámica insostenible para muchas entidades por su fuerte endeudamiento y que se destapó con la crisis internacional (Alonso, M.P. y otros, 2014 a). Con el estallido de una enorme burbuja inmobiliaria fue necesario un reajuste del modelo financiero que rebota directamente sobre la reestructuración de todo el sistema bancario (Ver gráfico 3), con la reducción de entidades financieras (fusiones, ad-

\footnotetext{
${ }^{2}$ El número de cuentas bancarias se refiere al total de cuentas corrientes y cuentas de ahorro activas en la banca tradicional.
} 
sorciones), de las oficinas de atención al cliente y de los puestos de trabajo del sector (Alonso, M.P. y otros, 2014 a; Mateache, P., 2012).

Gráfico 2 - Número total de cuentas bancarias activas y tasa porcentual de bancarización ${ }^{3}$ en la banca tradicional de Brasil y España, 2008-2016.

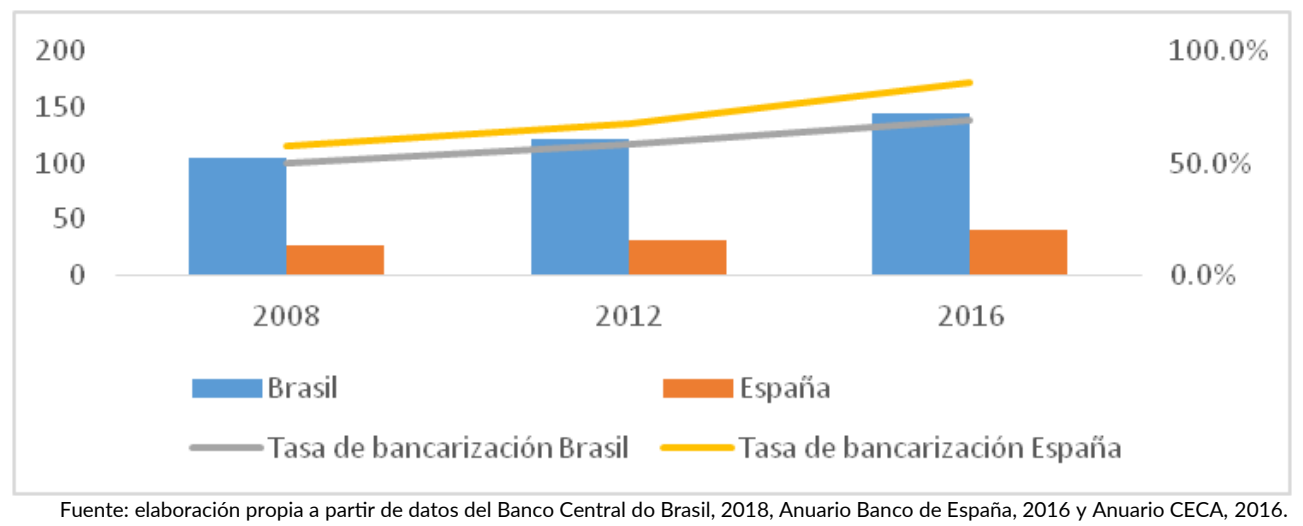

Gráfico 3 - España. Evolución del número de oficinas de bancos tradicionales y cajas de ahorro entre 2000 y 2016.

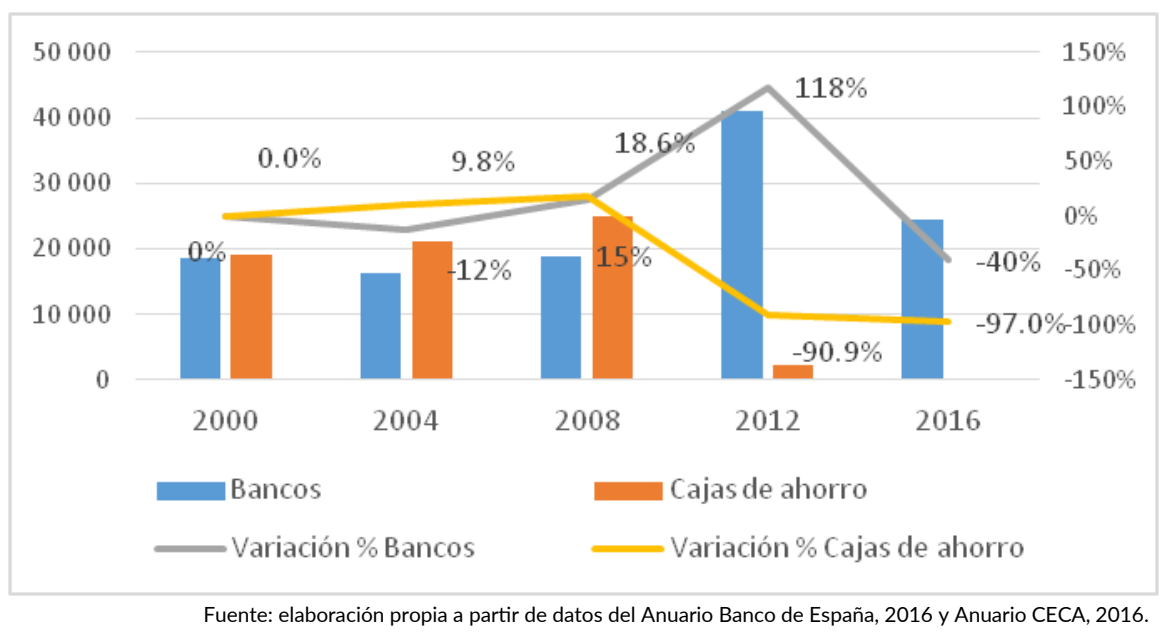

En Brasil los cambios que han afectado a las redes bancarias empezaran más tarde, con la crisis económica y política que estalla en el año 2015 (crisis de precios de las commodities, desaceleración del crecimiento económico, disminución de la recaudación fiscal, implantación de políticas de austeridad fiscal,...), procesos que suponen el inicio de su actual reestructuración bancaria, sobre todo por el intento de reducción de costos operativos del sector y también por el aumento de las inversiones en otros canales de autoservicio vía internet, generando un cambio en la forma de ofrecimiento de servicios bancarios. La consecuencia más visible en el territorio también está siendo la reducción del ritmo de expansión de las entidades y oficinas bancarias (Ver gráfico 4) fundamentada en el discurso de los bancos - sobre todo de los bancos públicos - de reducción de los costos operativos por medio de disminución de las redes de atención presencial, principalmente en las áreas dotadas con mayor número de oficinas, como medio de garantizar liquidez, empezando, así, cambios basados en la disminución de la capacidad instalada (Oliveira, J., 2017).

Por tanto, ambos países, en distintos momentos, sufren una reconfiguración que lleva a esa reducción de entidades y de oficinas, fruto de diferentes procesos de crisis. Estas situaciones han generado efectos particulares sobre las formas de organización de la banca y sobre la distribución y expansión de las redes de atención presencial.

Frente a esto en estos momento ambos países están siendo afectados por las modernizaciones tecnológicas

${ }^{3}$ La tasa de bancarización se calculó con base en la relación porcentual entre el número de cuentas corrientes y cuentas de ahorro y total de población de ambos países. 
Gráfico 4 - Brasil. Evolución del número de oficinas bancarias y variación porcentual entre 1990 y 2016.

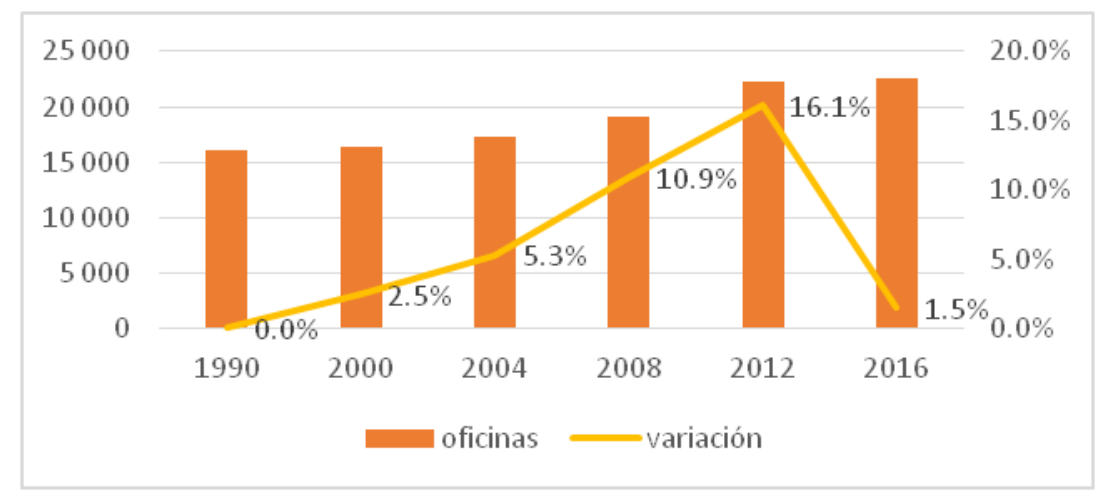

Fuente: elaboración propia a partir de datos del Banco Central do Brasil, 2018.

en el sector bancario de cara al cliente, que repercuten fuertemente en los dos países observados ${ }^{4}$. Los resultados se traducen en la diseminación del uso de servicios digitales, proporcionando un refuerzo de la reducción en el número de oficinas, dada la posibilidad de expansión del autoservicio del cliente, con máxima reducción de los costos por transacción, haciendo reducir la importancia de la atención presencial (Febraban, 2015; Massanell, A., 2016).

En definitiva, la caracterización realizada de la situación de la banca en Brasil y España confirma que sus contextos de configuración de las entidades bancarias han sido distintos y con cronologías de desarrollo diferentes, pero donde parece que para la prestación de servicios on line sí que está generando efectos similares: una importante reducción de las redes de oficinas bancarias en los últimos años, generando una reestructuración espacial, aún en curso, en el sector bancario.

\section{LÓGICAS ESPACIALES DE LA BANCA EN LAS CIUDADES DE PRESIDENTE PRUDENTE Y LLEIDA}

Los procesos particulares de reestructuración de las redes bancarias en Brasil y España -fundados tanto en un contexto de crisis como en una fuerte transformación en el modelo de ofrecimiento de servicios bancarios en razón de las innovaciones en el sector- marcados sobre todo por la disminución de capacidad instalada, repercutirán en nuevas situaciones espaciales de las oficinas en sus ciudades. Se han modificado los modelos de expansión de las redes bancarias así como sus lógicas espaciales y afectando a los hábitos de los clientes. Para una mayor compresión de estos procesos se presenta un acercamiento a lo acaecido sobre dos ciudades medias, una de Brasil -Presidente Prudente- y otra España -Lleida-.

La selección de esta tipología de ciudades medias está relacionada con el importante papel que juegan en intermediación como centros de referencia para un territorio próximo con muy poca presencia de los servicios bancarios, sobre todo en el caso de Brasil, donde la atracción de los servicios bancarios en las ciudades es más importante (Sposito, M.E., 2007:1983; Oliveira, J., 2015; Bellet, C., y otros, 2015). Por este motivo, la selección de las ciudades de Lleida y Presidente Prudente, permiten mostrar los resultados de la reestructuración del sector bancario de una manera más concreta, y donde al igual que otra tipología de ciudades también se ha perdido capacidad de oficinas presenciales (Alonso, M. P. y otros, 2014 b)

Lleida es una capital provincial ubicada en el interior de la comunidad autónoma de Cataluña en el noreste de España. Cuenta con una población de 137.327 habitantes (Idescat, 2017), una superficie de 212,3 Km² y una densidad demográfica de $646,9 \mathrm{hab} / \mathrm{km}^{2}$. En ella, como en otras ciudades de esta categoría, se habían concentrado un número importante de entidades y de oficinas bancarias que acercaban al cliente a estos servicios, desarroIlando un relevante papel de intermediación financiera (Fernández, F., 2014). Proceso similar a muchas otras ciudades españolas, que durante años vieron como la implantación bancaria llegaba a todos los ciudadanos, generando ratios de oficina-cliente muy bajos (Alonso, y otros, 2014, a).

${ }^{4}$ En España según Statista en 2006, el número de usuarios de la banca on line era del 15\%, en 2017 de 46\%, en Brasil, según datos de Febraban (2017), el número de cuentas bancárias con acesso a la banca on line evoluiu de 27 millones, en 2016, a 53 millones en 2016 
La ciudad de Presidente Prudente se ubica en el interior del estado de São Paulo. Su población es de 225.271 habitantes (IBGE, 2017), su superficie de $562,107 \mathrm{~km}^{2}$ y su densidad demográfica de $368,89 \mathrm{hab} / \mathrm{km}^{2}$. Es sede de la mesorregión y microrregión de mismo nombre y también desarrolla importantes funciones de intermediación urbana y financiera (Sposito, M.E., 1983; 2007). Esta ciudad ejemplifica el comportamiento de muchas otras ciudades brasileñas donde no toda la población ha tenido un acceso fácil a disponer de cuentas bancarias y por tanto de necesidades de entidades. Esta situación ha tenido una repercusión espacial, con centralidad hacia la población que tenía capacidad de disponer de cuentas bancarias.

Teniendo en cuenta las características fundamentales de estas ciudades y los contextos económicos y organizativos de las estructuras bancarias de sus países, presentados en lo apartado anterior, el objetivo de este punto es construir un análisis que permita establecer paralelismos entre las lógicas espaciales del sistema bancario en dos ciudades tan distantes y ver si los procesos de globalización financiera en las escalas locales dejan las mismas plasmaciones espaciales en ellas. Para ello se examinan las siguientes variables: trayectorias de evolución del número de oficinas bancarias y lógicas espaciales adoptadas por el sector a partir de las distintas coyunturas de crisis definidas en los dos países a las que pertenecen.

En relación a la trayectoria reciente del número de oficinas bancarias en las dos ciudades, es posible observar que en Lleida (Ver gráfico 5), a partir de 2008, la capacidad instalada ha ido disminuyendo de forma notable, siendo 2012-2013 los años que registraron la mayor caída (-13,7\%). Sin embargo en la post-crisis los cierres han continuado y el balance a finales de 2016 es que de 2008 a 2016 en la ciudad de Lleida han cerrado un total de 97 oficinas es decir casi el $50 \%$ de las que había al inicio de la crisis.

Esta evolución negativa de la trayectoria del número de oficinas bancarias en la ciudad de Lleida se relaciona en su origen, como se ha comentado, con la reestructuración del sector debido a una serie de normativas de la banca española que actuaban en el sentido de un reajuste del modelo financiero y que rebota directamente sobre la reestructuración de todo el sistema bancario español a partir de $2009^{5}$. El resultado fue un endurecimiento de la regulación en el año 2011, generando una aceleración de los cierres y produciendo efectos espaciales en el estudio de caso, Lleida, y en muchas otras ciudades españolas. Se produce una fuerte disminución del número de oficinas y entidades, y como resultado se aprecia como muchos barrios de Lleida se quedan casi sin servicios financieros o como en los espacios centrales también ven reducida la presencia de entidades y oficinas (Fernández, F., 2014).

En los últimos años, Lleida ha seguido perdiendo oficinas, pero en este caso la reestructuración se asocia, como se ha comentado, más a la propia reorganización de las oficinas ante el incremento de la potenciación de la banca on line por parte de las distintas entidades bancarias. En toda la banca española se están reforzando los cierres en razón de la disminución de costos proporcionada por estos nuevos canales de realización de transacciones bancarias fundadas en el autoservicio y en lo digital (Troiano, M., y otros, 2014; Garrido, A., 2017). La consecuencia más visible es el claro recorte de la capacidad instalada, y un descenso el número de empleados que se dedican a la atención presencial al cliente y también en la presencia de la red física de oficinas.

En cuanto a la evolución de las oficinas en la ciudad de Presidente Prudente (Ver gráfico 5), se aprecian importantes diferencias en la cronología con la trayectoria experimentada en Lleida en el periodo examinado. Así entre 2008 y 2011 en Presidente Prudente se registraron pequeños incrementos de oficinas (3\% y $8 \%$ ), eso se debe, como se ha comentado, por el contexto económico de expansión por el cual atravesaba Brasil, conformando condiciones favorables a la expansión de las redes bancarias, aunque en volúmenes por debajo de lo necesario, con un importante proceso de concentración en los lugares centrales. Sin embargo entre los años 2011 y 2013 ocurren pequeñas caídas en los números totales de fijos, respectivamente de $-2 \%$ y $-1 \%$. Esta tendencia se refuerza a partir de 2014, con caídas consecutivas de $-6 \%$ y $-27 \%$ en los años de 2015 y 2016 , fruto de los efectos de la situación de crisis económica desencadenada en Brasil en el año 2015 que, a su vez, reforzó el discurso de necesidad de reducción de la capacidad instalada de los bancos a fin de garantizar la liquidez en esos momentos de crisis. Pero a diferencia de lo ocurrido en las ciudades españolas, donde tras un fuerte ajuste físico del número de entidades y de oficinas, la aceleración en el uso de las TIC fomenta una nueva perdida de la capacidad presencial (Maudos, 2014), en el caso de Brasil se produce todo en paralelo, la reestructuración del sector para adaptarse a la crisis del país y a la vez se está desarrollando con un modelo fundado en la banca digital, sobre todo a partir de 2014, con fuertes inversiones en TIC, de manera que este nuevo modelo repercute también en la disminución del número de oficinas bancarias, privilegiando las plataformas online para ofrecer sus servicios

\footnotetext{
${ }^{8}$ Para Brasil se consideraron las oficinas de bancos tradicionales (oficinas y PAB) y cooperativas de crédito (oficinas); Para Lleida se consideraron las oficinas de bancos tradicionales, cooperativas y cajas de ahorro.

${ }^{5}$ Fondo de Reestructuración Ordenada Bancaria (FROB), establecida en septiembre de 2009.
} 
(Oliveira, J., 2017). Así, la "Federação Brasileira de Bancos" afirma que los puntos más relevantes para entender la diminución de las redes de atención presencial son:

(...) a conjuntura econômica vivida pelo País, que culminou no fechamento de uma série de estabelecimentos; a política de eficiência operacional de alguns bancos, que optaram em realizar uma revisão para solucionar sobreposições de pontos de atendimento existentes; os movimentos de consolidação no mercado por meio de fusões e aquisições; e a própria diversificação dos canais de atendimento (Febraban, 2015, p.27).

Por tanto, es necesario apuntar que las reestructuraciones más recientes sufridas por las entidades financieras en los espacios urbanos están ligadas sobre todo con la renovada ola de innovación en el sector bancario (Cernev, A. et. al., 2009; Oliveira, J., 2017; Carbó, S., 2017), asociada al actual momento de desarrollo técnico a nivel global (Castells, M., 2001; Massanell, A., 2016), y que genera nuevas variables que contribuyen a cambios en el patrón de expansión de los fijos bancarios (red de oficinas) a nivel global, incluso figurando como un rasgo común entre Brasil y España, reflejando un proceso de homogenización técnica propio de la globalización (Santos, M., 2000; Castells, M., 2001; Harvey, D., 1993), aún que repercutiendo de forma particular en los diferentes países. Al creciente uso de los canales digitales contribuyen los nuevos patrones de demanda social, cada vez más implicada en los procesos digitales, así como la presencia de nuevos competidores muy especializados en determinados servicios financieros como las Fintech (empresas apoyadas en nuevas tecnologías para ofrecer servicios financieros), o las firmas de comercio electrónico y telefonía (Amazón, Alibaba, Samsung Pay, Apple Pay, BBV, NFC Movistar, Vodafone, Wallet, etc.) (Rojas, L., 2016), las entidades financieras ven que estas nuevas formas de funcionamiento abaratan costes y por tanto están buscando formas combinadas de funcionamiento.

Gráfico 5 - Evolución del número de oficinas bancarias en Presidente Prudente y Lleida (2008-16).

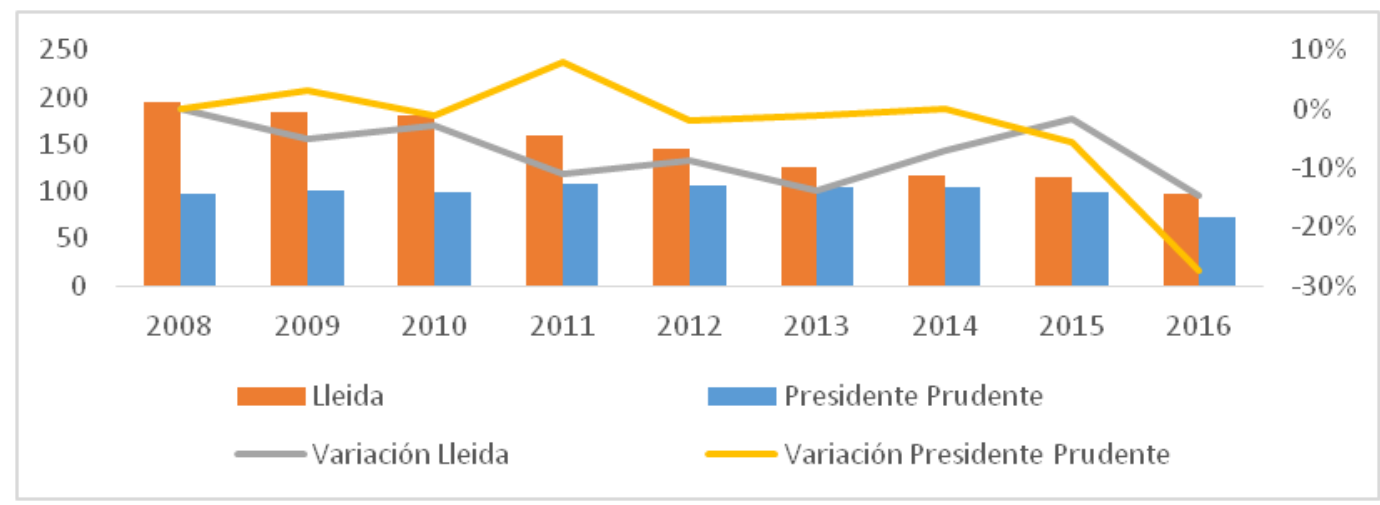

Fuente: Elaboración propia a partir de trabajo de campo y consulta de las webs.

Pero la menor presencia de oficinas de gestión bancaria supone problemas importantes que llevan hacia procesos de exclusión. Hay grupos sociales que todavía dependen mucho de los servicios bancarios presenciales, sobre todo la población de más edad, de menores ingresos y los excluidos digitales, en este sentido, a pesar de la creciente relevancia de los servicios digitales a través de Internet, las redes de atención presenciales siguen siendo parte esencial para la realización de las actividades bancarias cotidianas para una parte muy importante de la población (Garrocho, C.f. y Campos, J., 2010; Oliveira, J., 2017).

En lo que respecta a las lógicas espaciales de este sector en ambas realidades urbanas observadas, se pueden apreciar algunas diferencias originadas por su configuración inicial, pero que con las últimas transformaciones que van sufriendo tienden a asemejarlas. Así, en Presidente Prudente históricamente había una mayor concentración de oficinas en el sector sur de la ciudad, principalmente en el centro tradicional y en algunos otros ejes viarios y comerciales de mayor accesibilidad (Mapa 1) (Oliveira, J., 2015). Con la continua expansión del tejido urbano de la ciudad el sector bancario también llevó a cabo una expansión de las oficinas, aunque se centró en las áreas donde residía la población con mayor poder adquisitivo y no cubriendo a las zonas residenciales con menor poder adquisitivo - sector norte -. Esta situación ha venido reforzando la exclusión financiera en la ciudad, la población que vive más alejada del centro debe realizar mayores desplazamientos para acceder a servicios bancarios (Oliveira, J., 2015), además hay que valorar que se trata de una estructura urbana dispersa en sus bordes que posee baja densidad poblacional, lo que dificulta medios de transporte colectivos. Como se puede observar en la 
cartografía de localización de oficinas (Ver mapa 1), se aprecia la centralidad de oficinas y observando el mapa de cierres, donde los puntos rojos que indican las oficinas cerradas en el período 2010-2015, se detecta que se han perdido oficinas en el área central de la ciudad, pero también se han cerrado establecimientos en barrios ya poco provistos de esos fijos, y donde el problema de exclusión se acentúa más.

En cuanto a la organización del sector bancario en la ciudad de Lleida, se dispone de información de localización para los años de 2010-2015 y de su variación para ver los cambios que se aprecian (Ver mapa 2). Así en 2010 se puede ver una mayor presencia de oficinas por toda la ciudad y, por lo tanto, una oferta más amplia de servicios con presencia de establecimientos en prácticamente todos los barrios y de manera más numerosa en los sectores centrales. Sin embargo, los procesos de cierres de oficinas causados por la reestructuración del sector han hecho disminuir la densidad de la red de oficinas, consolidando una estructura espacial bancaria más central que va dejando sin acceso fácil de estos servicios a las personas que viven en zonas alejadas, comparativamente acercándose a la situación de centralidad de estos servicios que presenta la ciudad de Presidente Prudente (Ver mapas 1 y 2).

Mapa 1 - Distribución de oficinas bancarias e localización de las oficinas cerradas en Presidente Prudente, 2010-2015.
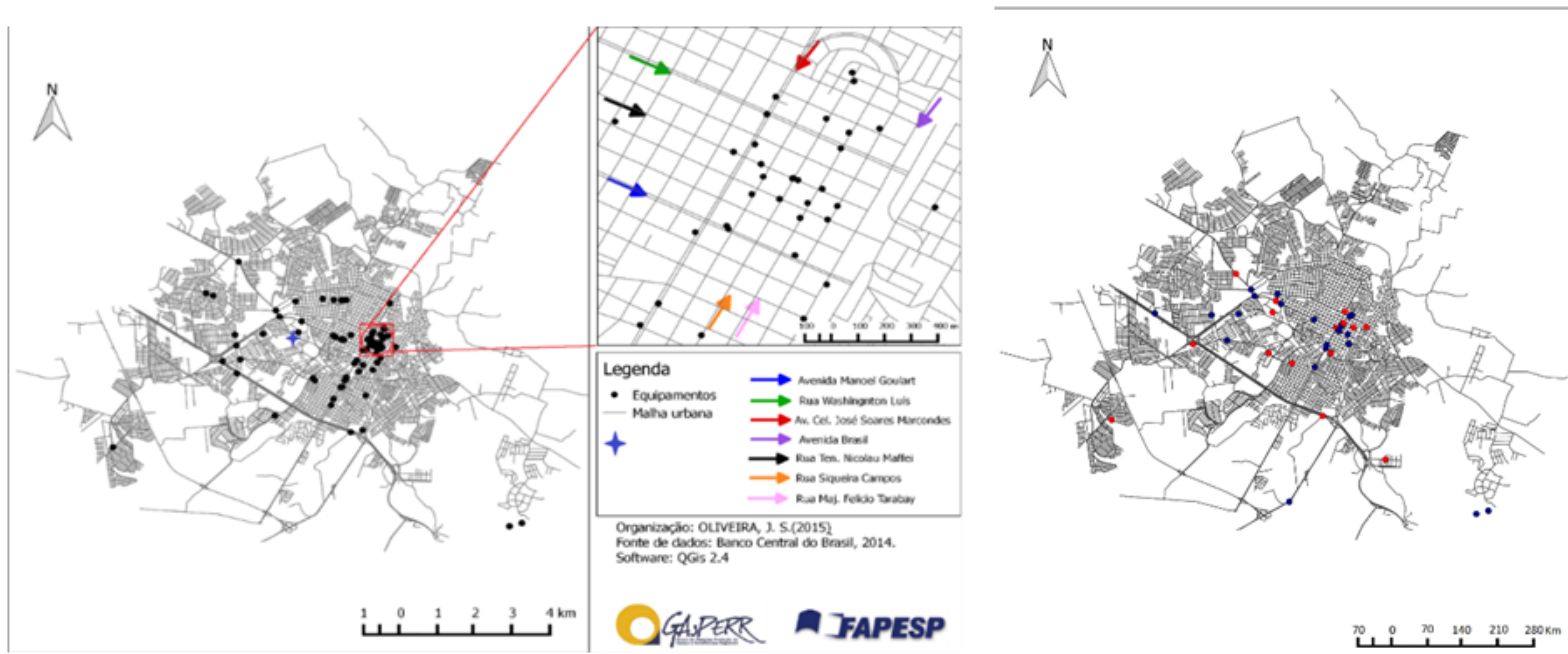

Fuente: Elaboración propia a partir de los datos del Banco Central do Brasil, 2014

Mapa 2 - Distribución de oficinas bancarias en Lleida, 2010-15 y cierres.

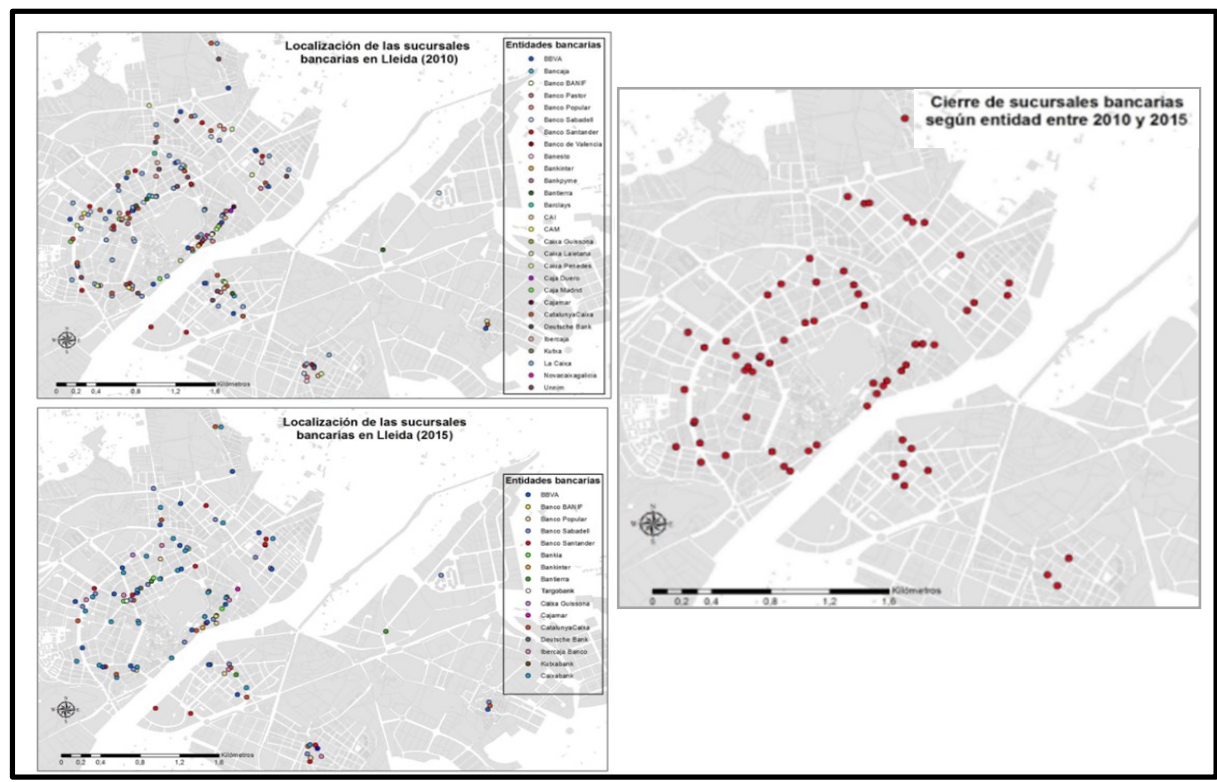

Fuente: Elaboración propia a partir de trabajo de campo y páginas web de sucursales bancarias. 
En resumen, a pesar de que las dos ciudades van a pasar por procesos de reorganización de sus localizaciones de establecimientos bancarios, sus formas de actuar han sido distintas, sobre todo porque partían de tipologías de implantación diferentes. En el caso de Lleida se había tendido hacía un modelo de acercamiento de las oficinas a los clientes, aunque en 2016 la situación era muy distinta, en concreto más de 98 oficinas perdidas, y un refuerzo de la centralidad en las que van quedando. En el caso de Presidente Prudente, ha predominado la centralidad de la función desde el principio, aunque con un período de una relativa difusión selectiva de oficinas que reforzó las desigualdades de acceso a estos servicios, acercándose hacia zonas con clientes potenciales y no hacía las áreas donde residen poblaciones menos favorecidas.

Lo que sí ambas ciudades están llevando más en paralelo es el uso de la banca digital, que también se traduce en cierres de oficinas presenciales, reforzando un modelo concentrado de la banca con presencia física. Estas tendencias de reducción de las capacidades instaladas, imponen un riesgo para el desarrollo pleno de esos territorios, ya que, en un contexto global en que las finanzas son los motores de los territorios es evidente la necesidad de que los lugares sean dotados de oficinas físicas y redes bancarias que propicien capacidades de intermediación financiera (Scherma, R., 2008, Maudos, 2014).

\section{CONCLUSIONES}

Las transformaciones que se desarrollan a nivel global en el funcionamiento del sistema financiero tiene su plasmación en los cambios recientes en la organización de la banca en Brasil y España, pero los procesos de cambios han estado asociados a las particularidades tradicionales de los diferentes territorios. De este modo, los procesos de concentración económica en el sector bancario, así como los recientes cambios tecnológicos incorporados a su estructura de funcionamiento, en ambos países están generando un nuevo modelo de atención bancaria, que repercuten en la reducción de las capacidades instaladas de las redes bancarias en los dos países, acentuándose en los en los últimos años.

Pero en este contexto de cambios hay que valorar que las dinámicas de reestructuración de las redes bancarias en Brasil y en España no se procesaran en el mismo contexto, tanto desde el punto de vista temporal -la reestructuración bancaria en España ocurre en el contexto de la Gran Recesión, mientras que la reestructuración bancaria en Brasil es más reciente, a partir de 2015-, como desde el punto de vista de los diferentes niveles de impacto en las redes de oficinas -siendo en España la reconfiguración de estas redes es bastante más profunda que en Brasil, cuyo proceso ocurre de forma más gradual y concentrada en las áreas con mayores densidades de oficinas -.

Las repercusiones de las reestructuraciones en el sector se materializan de forma más visibles en las escalas locales, así en el análisis realizado sobre las dos ciudades medias, se ha podido observar que se han generado importantes cambios en el número disponible de oficinas bancarias, así como en las lógicas espaciales de estas redes. En Lleida los distintos procesos globales acaecidos ha hecho disminuir el número de oficinas en toda la ciudad, pero sobre todo en los barrios, concentrándose de forma más marcada en el centro tradicional, con menor accesibilidad a las poblaciones más alejadas. En Presidente Prudente los cierres producidos refuerzan una estructura espacial históricamente desigual en la distribución de estos fijos, con fuerte concentración de oficinas en el centro tradicional y en las áreas donde residen las poblaciones de mayores ingresos. Con los cierres recientes de oficinas en las áreas centrales y algunos barrios, y sin perspectivas futuras de expansión de esas redes hasta las áreas donde residen las poblaciones más pobres, la tendencia de exclusión a ciertos servicios bancarios se intensifica en esta ciudad.

Tanto en Lleida como en Presidente Prudente, las nuevas lógicas de localización de las redes de oficinas, con disminución de la presencia en espacios periféricos, están exigiendo mayores desplazamientos para acceder a estos servicios de marera presencial, lo que supone procesos de exclusión hacia ciertos grupos de la población como las personas de más edad, los excluidos digitales e las poblaciones de menores ingresos, grupos sociales que depende mucho más del servicio personal en las oficinas. La ampliación de los canales de atención bancaria por internet, no sirve para toda la población, por tanto las redes de oficinas bancarias siguen siendo fundamentales para el funcionamiento y ofrecimiento de servicios financieros, principalmente los grupos sociales más vulnerables.

Por último, señalar que se aprecia una tendencia clara, tanto en la ciudad de Lleida como en la de Presidente Prudente, siguiendo las lógicas de comportamiento de sus países, de incremento de servicios bancarios por medio redes digitales dirigidos al cliente, lo que refuerza aún más la trayectoria de disminución de las estructuras físicas y presenciales de atención bancaria, tendencia que produce cambios importantes en las prácticas cotidianas de los ciudadanos en el uso del tiempo y el espacio. Es el aprovechamiento de las redes digitales para la reconfiguración de la localización de los servicios financieros. 


\section{BIBLIOGRAFÍA}

ALONSO, M. P.; PUEYO, À.; POSTIGO, R.; LÓPEZ, C.; RUBIO, J. L. (a). La reestuctucturación del sector financiero, en: ALBERTOS, J. M. y SANCHEZ, J. L. (coords). Geografía de la crisis económica en España. Universidad de Valencia: JPM ediciones, 2014. Págs 305-328.

ALONSO, M. P.; PUEYO, À.; POSTIGO, R.; LÓPEZ, C. (b). Los efectos de la crisis financiera en la implantación territorial de los servicios bancarios: el caso de la ciudad de Zaragoza, en: ALBERTOS, J. M. y SANCHEZ, J. L. (coords). Geografía de la crisis económica en España. Universidad de Valencia: JPM ediciones, 2014. Págs 411-433.

BELLET S.,C. (Org.); MELAZZO, E.S. (Org.) ; SPOSITO, M.E.B. (Org.) ; LLOP, Josep M. (Org.) . Urganización, produción y consumo en ciudades medias/intermedias. 1. ed. Lleida: Universidad de Lleida, 2015. v. 1. 515p.

CARBÓ, S.. Mitos y realidades de la digitalización financiera. Los medios de pago como paradigma. Mediterráneo Económico, n²9, 2017, págs. 139-149.

CARROUÉ, L.. La planète financière: capital, pouvoirs, espace et territoires. Collection U, Géographie. Armand Colin. 2015. 250 Págs.

CASTELLS, M. La galáxia Internet - reflexions sobre internet, empresa y sociedad. Madri: Arete, 2001, p. 235 a 274.

CERNEV, A.; DINIZ, E.; JAYO, M.. Emergência da quinta onda de inovação bancária. Americas Conference on Information Systems (AMCIS), 2009

CONTEL, F. B.. Território e finanças. Técnicas, normas e topologias bancárias no Brasil. 1. ed. São Paulo: Annablume, 2011. v. 1. 316p.

DABAT, A.; HERNÁNDEZ, J., VEGA, C.. Capitalismo actual, crisis y cambio global. Economía UNAM, Vol. 12, nº 36., 2015, Pag. 62-89.

DIAS, L. C. Redes de informação, grandes organizações e ritmos de modernização. Etc (UFF), v. n.2, v1, p. 1-4, 2007.

DIAS, L. C.; LENZI, M. H.. Reorganização espacial de redes bancárias no Brasil: processos adaptativos e inovadores. Caderno CRH (UFBA. Impresso), v. 22, p. 97-117, 2009.

FEBRABAN. Pesquisa Febraban de Tecnologia Bancária. 2015. Disponível en: http://www.ciab.org.br/download/researches/ research-2015-en.pdf. Acesso: 02, fev de 2018.

FERNANDEZ, A. F. J.. La repercusión de la crisis en las entidades financieras: el caso de Lleida. Trabajo de fin grado. Departamento de Geografía y Sociología. Universitat de Lleida. 2014.

FERNANDEZ, J.C.. El riedling de la señora watababa. El impacto de la gran depresión en la geografía financiera de la deuda soberanana, en ALBERTOS, J.M. y SANHEZ, J.L. Geografía de la crisis económica en España. Universidad de Valencia, 2015, Págs. 77-99.

GARCÍA, F. J.. Aproximación crítica a la crisis económica mundial: Sistema capitalista, política monetaria y globalización financiera. Pecvnia, Revista de la Facultad de Ciencias Económicas y Empresariales. Universidad de León, nº10, 2010, págs.. 75-94.

GARROCHO, C.F y CAMPOS, J.. Organización espacial del sistema bancario dentro de la ciudad: estrategia territorial, accesibilidad y factores de localización. Economía, sociedad y territorio, n¹0 (33). 2010, págs. 413-453.

GARRIDO, A..Perpectivas del sistema bancario español: ¿evolución o revolución?. Mediterráneo Económico, n²9, 2017 , págs. 49-62.

HARVEY, D.. Condição Pós-Moderna. Uma pesquisa sobre as origens da mudança cultural. São Paulo: Loyola, 1993.

MATEACHE, P.. Las oficinas bancarias y el proceso de reestructuración en marcha. ATKearney, 2012.

MASSANELL, A. La transformación de la banca. Reorientación de los canales y servicios digitales. Papeles de Economía Española. Transformación digital en los medios de pago, $n^{\circ} 149.2016$, págs. 93-99.

MAUDOS, J.. Reestructuración bancaria y accesibilidad financiera. Cuadernos de información económica, enero/febrero, 2014.

MINOI, C., Atrapados en la red. Finanzas y desarrollo. Fondo Monetario Internacional, 49, n³, 2012, págs., 15-17.

OLIVEIRA, J. S.. Processos de inovação bancária recentes: ritmos de expansão e lógicas espaciais seletivas do setor bancário no município de Campinas - SP. In: Congresso Internacional Caleidoscópio da Cidade Contemporânea, 2, Campos dos Goytacazes: Edição Atual, 2017.

OLIVEIRA, J. S.. As lógicas espaciais do setor bancário nas cidades de São José do Rio Preto e Presidente Prudente: da estrutura espacial concentrada à multicentralidade seletiva. 2015.139 f. Monografia (Bacharelado em Geografia) - FCT/UNESP, Presidente Prudente. 2015.

ROJAS, L.. La revolución de las empresas FinTech y el futuro de la Banca. Disrupción tecnológica en el sector financiero. CAF. Banco de Desarrollo de América Latina, 2016, 43 págs. http://scioteca.caf.com/handle/123456789/976.

SANTOS, M.. Por uma outra globalização. Do pensamento único à consciência universal. São Paulo: Record, 2000. 
SCHERMA, R. A.. Topologias Bancárias no Período da Globalização. In: $1^{\circ}$ Simpósio de Pós-Graduação em Geografia do Estado de São Paulo, 2008, Rio Claro. Anais do 1 Simpósio de Pós-Graduação em Geografia do Estado de São Paulo, 2008.

SPOSITO, M. E. B.. Cidades médias: reestruturação das cidades e reestruturação urbana. In: SPOSITO, M. E. B.(Org.); et al. Cidades Médias: espaços em transição. São Paulo: Expressão Popular, 2007.

SPOSITO, M. E.. O chão em Presidente Prudente: a lógica de expansão territorial urbana. 1983. 230f. Dissertação (Mestrado em geografia) - UNESP Rio Claro. Rio Claro.

TROIANO, M.; SONDERGAARD, T.; THEODORE, S.. Multichannel and overcapacity: cost saving opportunity or competitive threat?. Scope Ratings, december, 2014.

VIEIRA, E.. Las crisis financieras de la globalización. Revista Civilizar Ciencias Sociales y Humanas, 14(26), 2014, 115-132. 


\title{
Indagando en Sant Antoni (Barcelona) en torno a la relación de la bicicleta con la gentrificación
}

\author{
À. Cebollada (a), A. Sillero (b), E. Anaya (c) \\ (a) Departamento de Geografía, Universitat Autònoma de Barcelona, angel.cebollada@uab.cat \\ (b) Departamento de Geografía, Universitat Autònoma de Barcelona, azahara.sillero@uab.cat \\ (c) Centre for Environmental Policy, Imperial College London, e.anaya14@imper-ial.ac.uk
}

\begin{abstract}
Resumen
Estamos asistiendo a un profundo proceso de cambio social y económico en las grandes ciudades, o al menos en determinados barrios de las mismas. Las dinámicas de un mercado altamente desregularizado junto con los procesos de globalización llevan a que en determinadas zonas urbanas se den procesos de sustitución de sus residentes por otros de más poder adquisitivo y/o por turistas. En esta comunicación queremos abordar el rol que pueda tener la bicicleta en estos procesos de cambio social y económico asumiendo que los nuevos residentes interpretan la presencia y el uso de este modo de transporte como indicador de mejor calidad urbana. La investigación se ha realizado combinando metodologías cuantitativas y cualitativas.
\end{abstract}

Palabras clave: Bicicleta, gentrificación, Barcelona, cambio social, turismo.

\section{INTRODUCCIÓN. LAS CIUDADES EN LA ECONOMÍA GLOBAL}

En los últimos decenios se han producido importantes cambios económicos y sociales en nuestras ciudades. Estos cambios no se explican solamente por elementos endógenos, sino que se producen principalmente como resultado de un mercado global altamente desregularizado. Capitales internacionales fijan sus objetivos en determinados barrios para clientes internacionales de segmentos de rentas altas. Además, las nuevas tecnologías permiten la aparición de un trabajo en red protagonizado por los denominados nómadas digitales, que deslocalizan absolutamente su lugar de residencia por el de la empresa en la que trabajan. Y todavía, la turificación de las ciudades contribuye a estos cambios. Estos visitantes, generan la demanda de nuevos productos, nuevos comercios, nuevas formas de vida y asimismo introducen nuevos símbolos. Es este capítulo nos planteamos qué rol asume la bicicleta en este proceso de cambio y qué simboliza.

\section{EL ÁREA DE ESTUDIO. SANT ANTONI: UN BARRIO EN TRANSFORMACIÓN}

Sant Antoni es un barrio del Eixample barcelonés, en el sector suroriental. Morfológicamente tiene forma triangular y se encaja entre la Barcelona preindustrial (Ciutat Vella) y el barrio del Poble-sec, en la ladera de la montaña de Montjuïc. Su superficie es de 0,8 km2 y la población de 38.033 habitantes (apenas un 2,4\% de la población del municipio). Se considera uno de los barrios tradicionales de la ciudad, con un sentimiento identitario diferenciado de los adyacentes.

En los últimos años, Sant Antoni está en el foco del debate público debido al proceso de cambio socioeconómico que se está produciendo. La alta proliferación de bares en torno a Carrer Parlament es un ejemplo de ello. A principios de 2017, un artículo en la revista cultural Time Out lo calificaba como "el barrio de moda de Barcelona" por el reciente aumento de "locales nuevos que conviven con los de toda la vida" (Time Out, 2017). Entre los ejemplos de locales a visitar, la revista recomienda varios talleres de motos antiguos hoy restaurados y transformados en bares. Su tradicional mercado dominical de libros ha acentuado el carácter popular y en cierta medida bohemio del barrio. Como la otra cara de la misma moneda, a finales del mismo año, la plataforma ciudadana Fem Sant Antoni sacaba a la luz el Mapa de la Gentrificación, donde señalaba la existencia de 46 bares en sólo 
tres islas de casas que dificultan la capacidad de los vecinos/as de poder hacer vida de barrio (Fem Sant Antoni, 2017).

Pero el proceso de cambio no ha hecho más que empezar. Según los indicios, existen dos actuaciones -ya en marcha- que pueden catapultar al barrio hacia la transformación definitiva. Por un lado, el Mercado de Sant Antoni, fundado en 1882 y centro neurálgico del barrio, ha vivido en obras durante casi diez años, ha vivido abriéndose finalmente al público en mayo de 2018... Teniendo en cuenta las experiencias previas de rehabilitación de mercados en Barcelona, como la rehabilitación del Mercado de Santa Caterina, el miedo a la subida del alquiler en la zona se ha expandido, y en el barrio no hay quien no haya oído la palabra gentrificación. Por otro lado, a principios de 2017 se impulsaba la propuesta de una nueva superilla (supermanzana) en el entorno del citado mercado, que pretende recuperar más de $26.000 \mathrm{~m}^{2}$ para los viandantes (Ajuntament de Barcelona, sin fecha) a través de una operación de pacificación del tránsito. La operación urbanística que se ha iniciado en los entornos del mercado incluye otras manzanas de los alrededores y se prevé que finalice en la primavera de 2019. El proyecto también contempla el incremento del verde urbano.Se intuye que estas operaciones culminarán un cambio sociodemográfico importante ya observable en la zona. Una mezcla de interés por parte de personas de rentas superiores, junto el aumento del turismo (y la consecuente aparición de la ocupación de viviendas para usos estacionales), así como la compra de viviendas como mecanismo de inversión del mercado inmobiliario internacional, han puesto en riesgo la capacidad de los actuales residentes de poder continuar habitando el barrio.
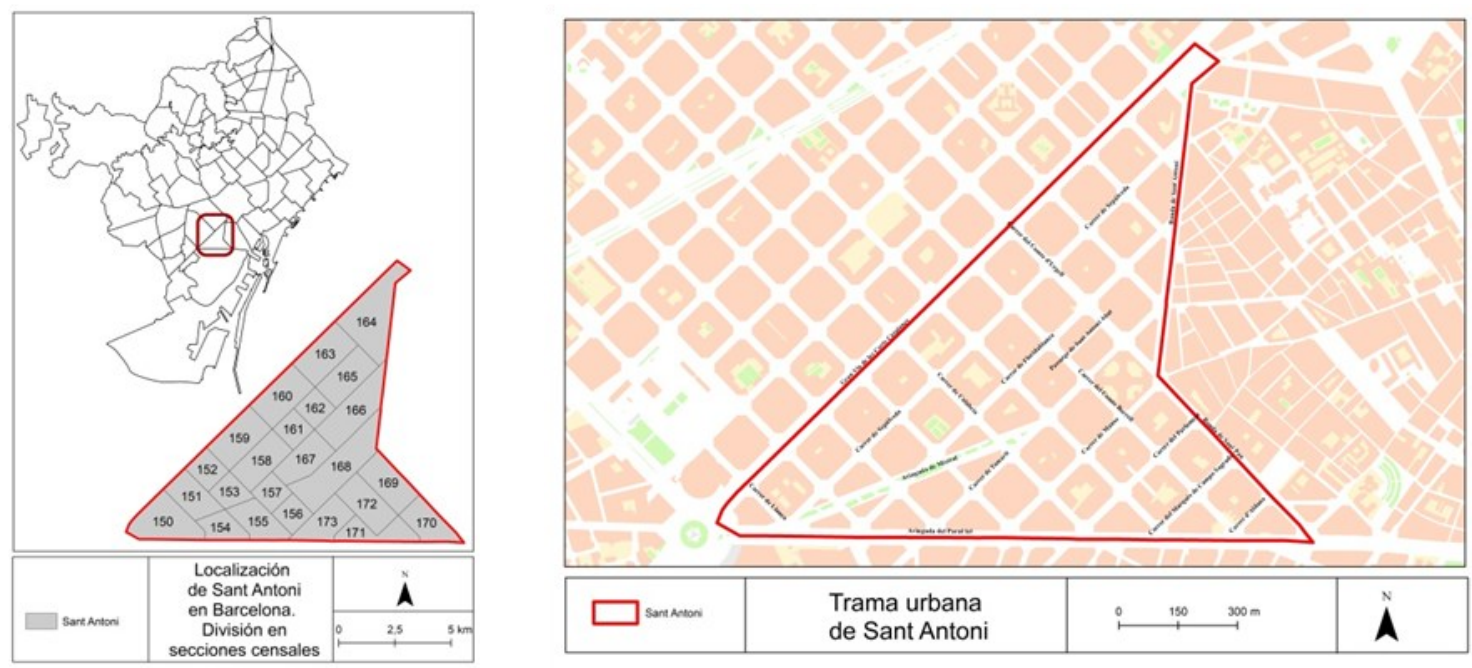

Figura 1.

Fuente: Elaboración propia.

\section{LA RELACIÓN ENTRE LA BICICLETA Y LA GENTRIFICACIÓN}

La elección de Sant Antoni para la realización de este estudio responde a la vinculación del mismo con un proyecto más amplio que se dedica a estudiar el proceso de cambio social, económico y urbano del barrio, así como los efectos de la gentrificación. En lo concreto, el interés de esta comunicación y del estudio que aún está en curso, se centra en el papel que juega la bicicleta en la transformación del barrio.

El concepto de gentrificación fue originalmente acuñado por Ruth Glass en 1964. Desde entonces, este proceso se ha vuelto mucho más complejo, especialmente en su conexión con las nuevas dinámicas de acumulación de capital vinculadas a la globalización. Es, lo que se ha llamado, la tercera ola de la gentrificación (Chan, 2014).

Dentro de las múltiples combinaciones y matices que se presentan, se ha comprobado que gran parte de la producción académica que se encarga de estudiar la relación entre la bicicleta (a nivel general) y la gentrificación, recae sobre estudios de caso en América del Norte: desde el estudio comparativo de Toronto, Montreal y Vancouver (Danyluk y Ley, 2007) pasando por el estudio de diferentes ciudades de los Estados Unidos tales como Nueva York (Stein, 2011), Washington DC (Gibson, 2013), San Francisco (Stehlin, 2014), Portland y Chicago (Flanagan, Lachapelle, y El-geneidy, 2016), Seattle y Los Ángeles (Lugo, 2017) ó Boston (Vith y Mössner, 2017). Es un fenómeno de creciente interés desde principios de la entrada del siglo XXI, vinculado al resurgir de la bici- 
cleta en la ciudad y a la expansión de los procesos de gentrificación que acarrea el urbanismo neoliberal (Smith, 2002).

No es mera coincidencia: el aumento de las investigaciones académicas en esta área geográfica podría explicarse porque según Vith y Mössner (2017) la introducción de infraestructura bici en Estados Unidos se suele dar, de manera frecuente, en barrios o bien que están viviendo un proceso de gentrificación o bien que han sido recientemente gentrificados. Además, la promoción de la bicicleta como forma de transporte, así como la inversión en infraestructura ciclista en la ciudad se ha defendido comúnmente bajo un discurso vinculado al desarrollo económico (Stehlin, 2014; Vith y Mössner, 2017). Es por esto que muchos de los artículos se centran en la correlación entre la inversión en infraestructura ciclista con los fenómenos de gentrificación, o la reproducción de la desigualdad a través de la implantación de la infraestructura en barrios ya acomodados.

Por otro lado, los estudios de gentrificación y movilidad no sólo recaen sobre el impacto de la infraestructura en el propio cambio, sino en los aspectos culturales que llevan consigo los procesos de gentrificación. Es decir, los nuevos habitantes, o las nuevas clases sociales, que -según la teoría- llegan a estos barrios gentrificados, representan y traen consigo un estilo de vida cosmopolita y promovedor de la conciencia medioambiental que, acorde con nuestro estudio, encaja con la bicicleta como símbolo y modo de desplazamiento urbano (Stehlin, en Vith y Mössner, 2017). En nuestro estudio, así como lo hacen Vïth y Mössner (2017), hemos tratado de estudiar la relación de la bicicleta en Sant Antoni con los dos discursos predominantes: por un lado la desigualdad de la infraestructura y por el otro la apropiación de la bicicleta por parte de las clases creativas.

\section{METODOLOGÍA}

Para ello, en primer lugar, se ha realizado un estudio tentativo de las características sociodemográficas de la zona para observar qué datos cuantitativos evidencian la transformación que se está dando en Sant Antoni. También se ha recogido información mediante el trabajo de campo con observaciones (cambios físicos) y entrevistas exploratorias (percepción del cambio). Por último, se han elegido tres plataformas que están vinculadas al cambio cultural en los barrios gentrificados de Barcelona tales como Airbnb, Donkey Republic, así como la iniciativa local The Trend Map.

El análisis sociodemográfico del barrio se ha realizado a partir de los datos existentes de estadísticas oficiales centralizadas por el departamento de estadística de Barcelona que a su vez son de fuentes distintas, según cada variable. La escala territorial trabajada han sido las secciones censales. El barrio de Sant Antoni se divide en 24 secciones censales. En este caso se han utilizado los datos demográficos y espaciales básicos y las variables socioeconómicas que utiliza el mismo ayuntamiento de la ciudad para la realización del indicador indirecto de Renta Familiar Disponible por barrios. En concreto, se han utilizado en esta comunicación: el porcentaje de población con estudios superiores en relación con la población mayor de 25 años, el valor catastral de los locales, el porcentaje de vehículos según población total y el ratio de vehículos de más de $16 \mathrm{CV}$ de potencia fiscal según el número total de vehículos. Además, se han tomado los datos de precios de venta por $\mathrm{m}^{2}$ de la vivienda de segunda mano, en esta ocasión por barrios de la ciudad (73 en total). Los datos sobre la oferta de bicicleta provienen del Open Data del mismo ayuntamiento. Todos estos datos han sido incorporados a un Sistema de Información Geográfico para su análisis espacial y algunas de estas representaciones cartográficas han sido incorporadas a la comunicación.

Con el fin de complementar los datos cuantitativos, se han realizado diferentes salidas y observaciones a lo largo de los meses de febrero, marzo y abril para documentar el papel de la bicicleta en este proceso de cambio.

Se han localizado las tiendas existentes en el barrio vinculadas a la venta o alquiler de bicicletas para poder estudiar el tipo de negocio y sus orígenes. En los locales que ha sido posible, se han realizado entrevistas in situ y exploratorias a los trabajadores o dueños del local.

Por otro lado, para estudiar la vinculación de la bicicleta como reclamo en esta etapa de reurbanización, se ha estudiado:

- La oferta actual de bicicletas de la empresa Donkey Republic en el barrio. Para esto se realizó la descarga de la app de la compañía y se revisó la oferta de aparcamientos durante una semana en tres horas distintas del día.

- $\quad$ Los negocios considerados como trendy (de moda) y su posible vinculación con la bicicleta. Para ello se ha revisado la plataforma The Trend Map, que se dedica a catalogar bares (hace hincapié en que no colabora con cadenas) en distintos barrios según su criterio de lo que es cool. Para ello elaboran ma- 
pas donde muestran, a su criterio, lo mejor de la Barcelona local: "diseñadores, brunch, moda, cultura de vanguardia, bares, slow food, cafés, propuestas eco, coworkings, y todos los lugares cool que no puedes perderte" según se lee en su folleto.

- Qué tipo de reclamo utilizan los apartamentos de Airbnb ofertados en el barrio, revisando aleatoriamente las ofertas disponibles entre junio, julio, agosto y septiembre, en distintos días de la semana, habiendo consultado un total de catorce casos y comprobando si entre los elementos de atracción se incluían la cercanía tiendas de alquiler de bici o la facilidad de ir en bici por la ciudad/barrio.

\section{ALGUNOS DATOS DEL BARRIO}

Según los datos del año 2016, la Renta Familiar Disponible era de 34.127,35 €, ligeramente superior a la media de la ciudad $(32.315,39 €)$. Los otros indicadores sociales asociados a la renta también muestran el carácter medio de Sant Antoni en referencia al conjunto de Barcelona. Si nos fijamos en cuatro indicadores indirectos que nos permiten identificar las características socioeconómicas del barrio podemos observar que:

- $\quad$ Es un barrio densamente poblado, con casi $48.000 \mathrm{hab} / \mathrm{km}^{2}$, el séptimo con una mayor densidad de la ciudad aunque con importantes disparidades internas según secciones censales.

- $\quad$ Presenta una tasa de población con estudios superiores (sobre la población de más de 24 años) ligeramente superior a la media de la ciudad (38,5\% frente a 34,1\%). También, se pueden apreciar las diferencias entre secciones censales dentro del barrio, ya que la población con estudios superiores se concentra a lo largo de la Gran Via y en la Ronda Sant Antoni, mientras que en las secciones más cercanas a Paral·lel y a la zona baja del Raval el porcentaje de población con estudios superiores es menor. La oscilación intrabarrio se sitúa entre $47,8 \%$ y el $30,0 \%$

- $\quad$ El valor catastral de los locales del barrio es $802 € 7 \mathrm{~m}^{2}$, ligeramente superior a la media de la ciudad $\left(795,3 € / \mathrm{m}^{2}\right)$. A pesar de las diferencias internas (entre los 742 y los $906 € / \mathrm{m}^{2}$ ) el barrio constituye unidad más o menos homogénea respecto a los barrios aledaños: mientras en el Raval los valores catastrales son mucho más bajos, en Poble-sec algo más bajos en el Eixample son claramente más altos.

- $\quad$ Si se observan los precios de venta de viviendas de segunda mano, en Sant Antoni el $\mathrm{m}^{2}$ estaba en 2017 a $4591 €$ según datos municipales. Esto sitúa al barrio por encima de la media del conjunto municipal $4284 € / \mathrm{m}^{2}$, pero no entre los más caros (en el ranking se encuentra en la posición 14). La situación cambia si nos fijamos en el incremento porcentual de los precios de venta de la vivienda de segunda mano entre los años 2013 y 2017. Según este indicador, sólo Poble-sec ha tenido un aumento mayor de los precios $(57,6 \%)$ seguido de muy cerca por Sant Antoni $(56,9 \%)$. Y por detrás está el Raval $(54,13)$. Por tanto, el mayor incremento se da en tres barrios contiguos, superior a la media de Barcelona (41,9\%).

En cuanto a los datos sobre movilidad, podemos ver:

- $\quad$ El índice de motorización del barrio es inferior al del conjunto de Barcelona (306,5 vehículos por mil habitantes y 356,6 respectivamente). Fijándonos en el interior del barrio, volvemos a encontrar una mayor tasa de motorización en la zona más próxima a Gran Vía.

- En cuanto a la relación entre los automóviles de mayor potencia (más de 16 caballos fiscales) en relación al total de automóviles, Sant Antoni está en la media municipal $(8,6)$. También en esta ocasión podemos ver desigualdades internas: una vez más, la menor proporción de vehículos más potentes se encuentra en la cercanía de la parte baja del Raval, mientras que en los aledaños a Gran Via la proporción de estos automóviles es más alta. El barrio cuenta con 14 estaciones de bicicleta pública (Bicing). Además de estas, también incluyen parte del barrio otras estaciones fuera de él pero en los límites. En total, el 42,24\% de la superficie del barrio tiene una estación de Bicing a menos de 100 metros y esta cifra alcanza el 74,54\% si la distancia la elevamos hasta los 150 metros (un par de minutos andando). Por lo que respecta a su localización, se pueden distinguir distintas zonas según la intensidad de estaciones. Por un lado, las que se ubican en las avenidas limítrofes del barrio, especialmente en su área central. Por otro lado, la concentración de estaciones en torno al mercado. Una tercera área se localiza en las cercanías de la plaza Universitat, una zona más alejada del corazón del barrio. Finalmente, la zona del barrio centrada en la avenida Mistral es donde menos estaciones hay y la que queda menos servida (es la gran área que está a más de 150 metros de cualquier estación). 


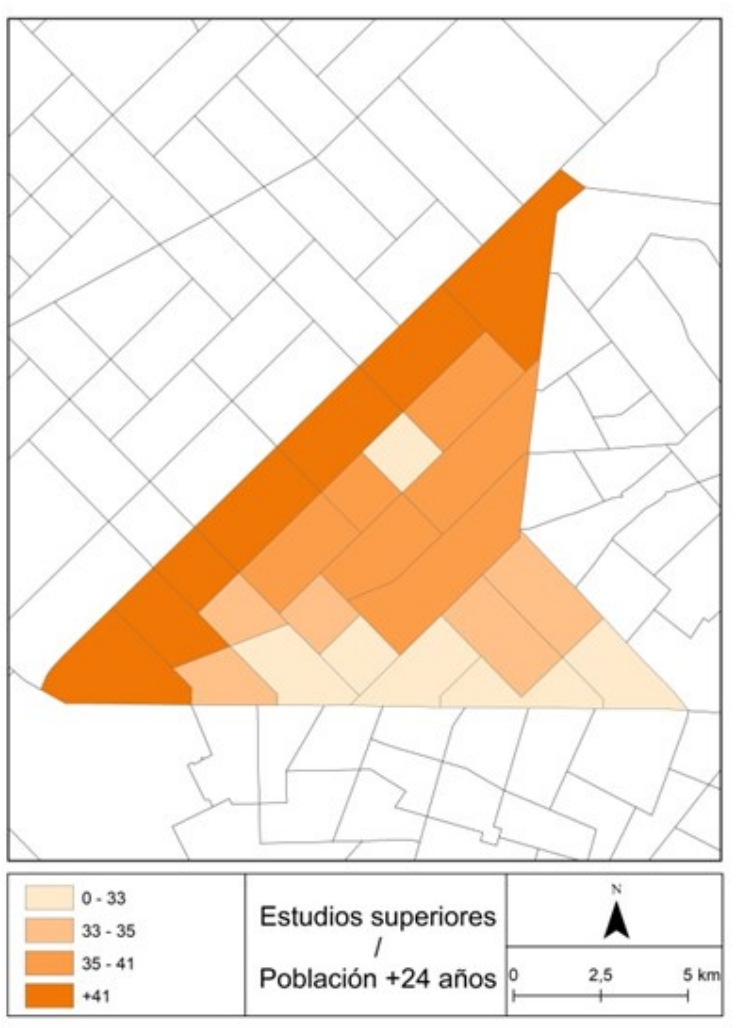

Figura 2.

Fuente: Elaboración propia.

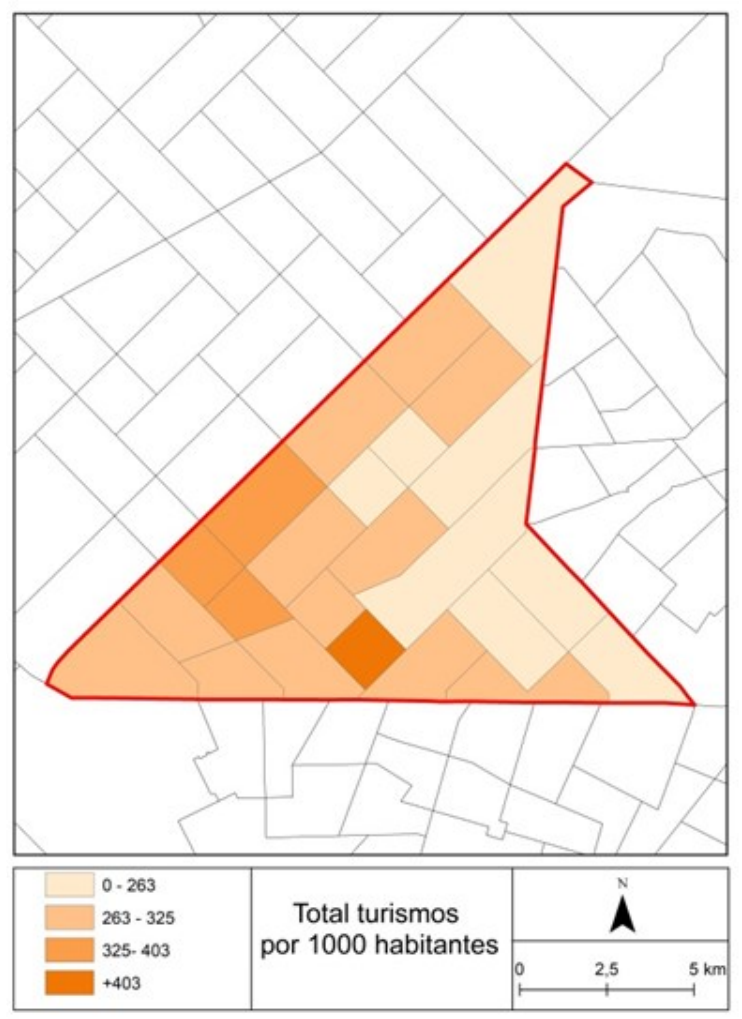

Figura 4.

Fuente: Elaboración propia.

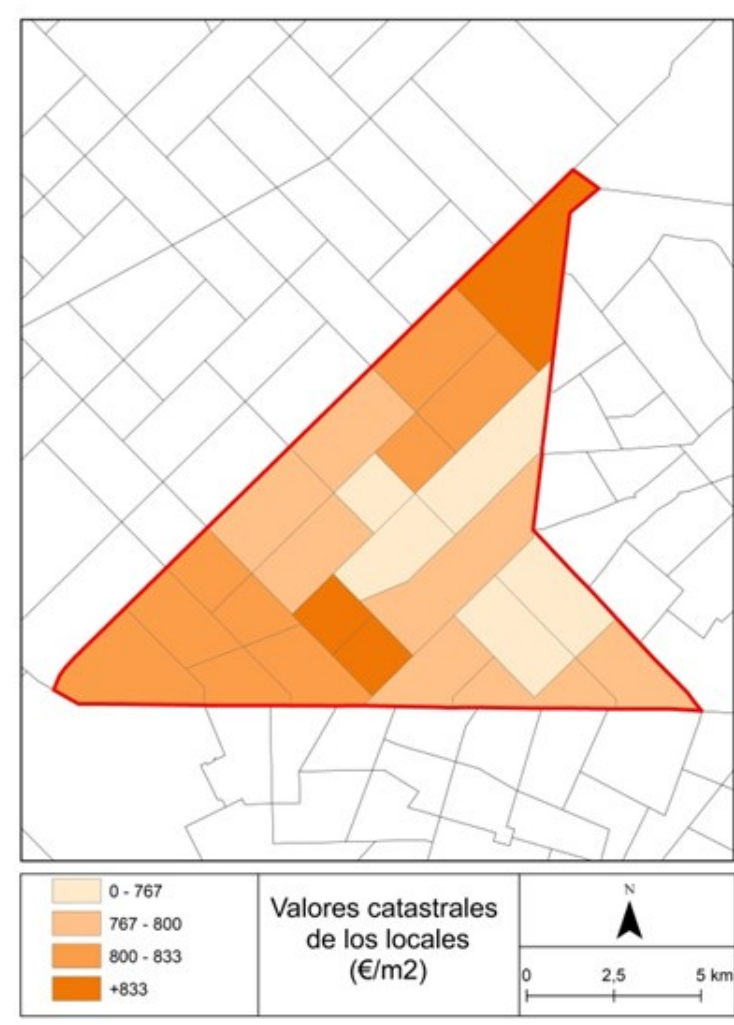

Figura 3.

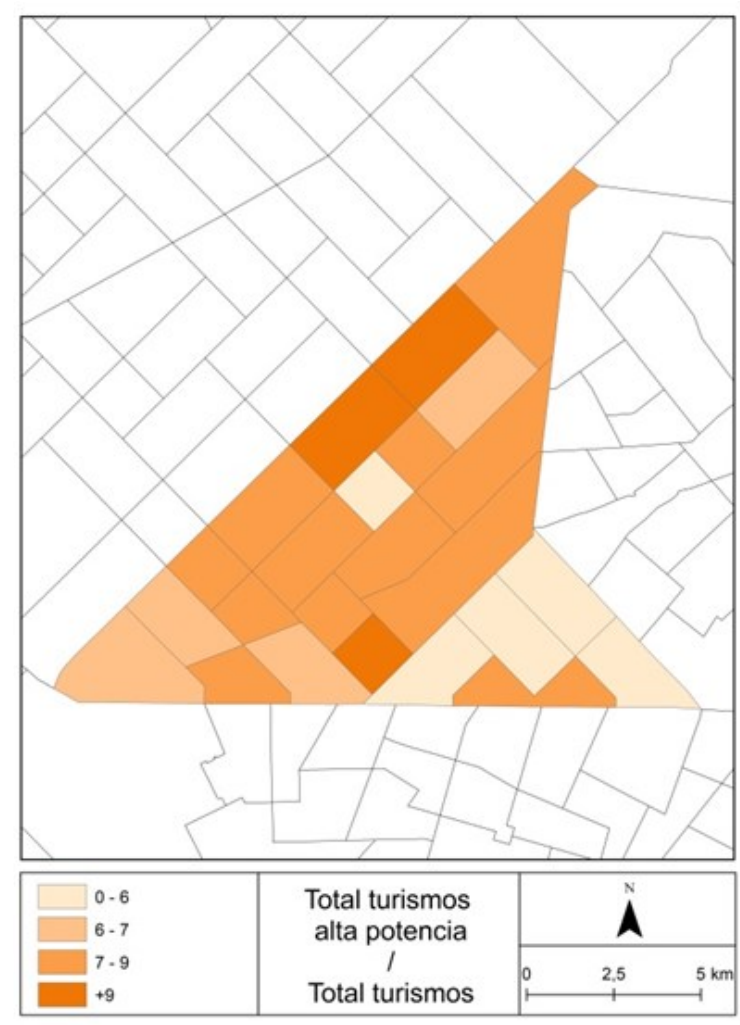

Figura 5. 


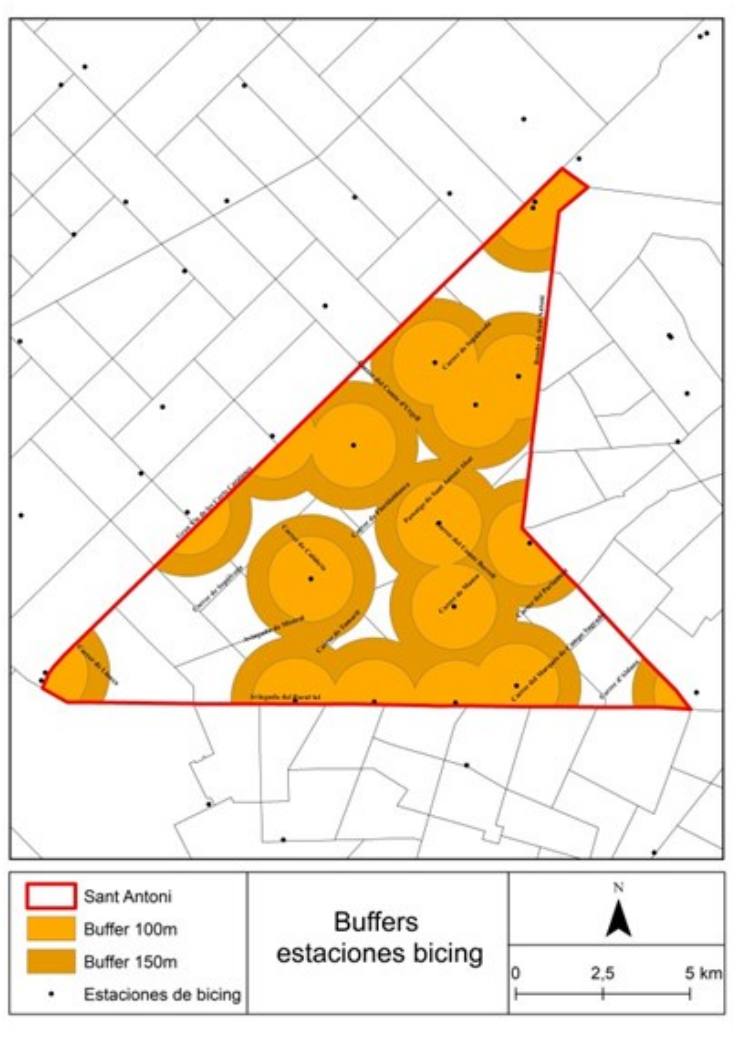

Figura 5.

Fuente: Elaboración propia.

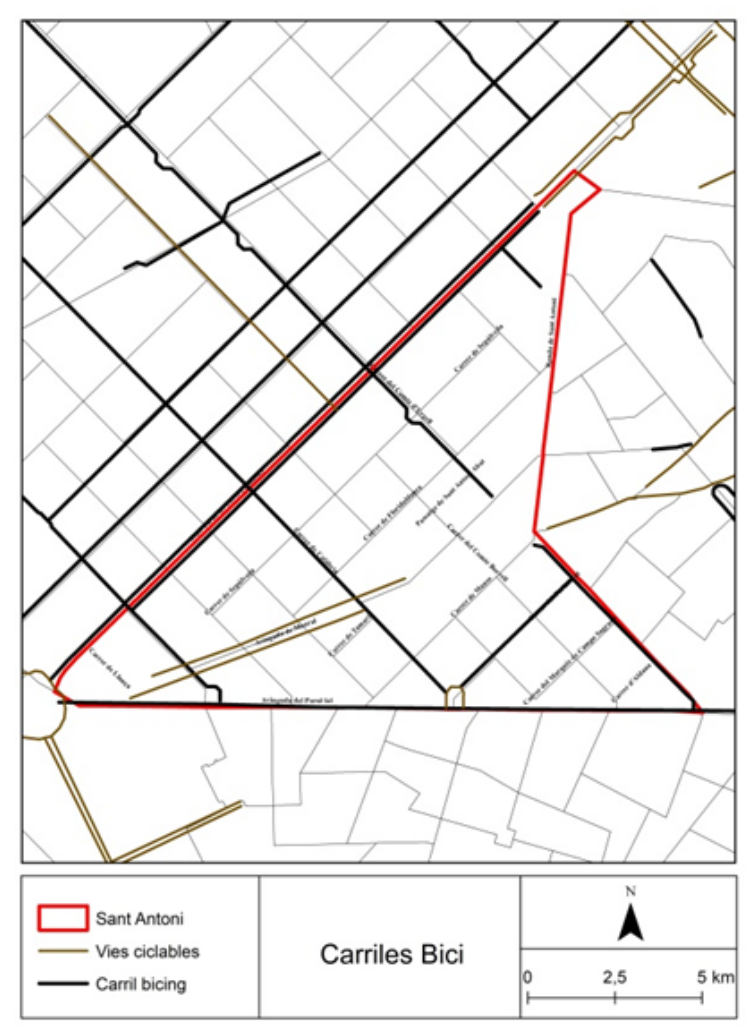

Figura 6

Con respecto a la infraestructura ciclable, el barrio cuenta con distintos carriles bici. Por un lado, encontramos esta infraestructura en las dos grandes avenidas limítrofes (Paral·lel y Gran Via) y además en algunas calles "interiores". En concreto, en NO- SE, encontramos carriles bici cada tres vías. En el sentido transversal, solo existe un carril en la parte baja del barrio. Además de estos carriles, el Ayuntamiento considera como vía ciclable la avenida Mistral. Con la inauguración de la superilla de Sant Antoni, se incrementará el espacio ciclable del barrio.

A pesar de la oferta de infraestructuras para bicicleta en el barrio, se debe tener en cuenta que la apuesta de la ciudad por este modo tiene antecedentes anteriores a lo que se considera el pistoletazo de salida del proceso de gentrificación en Sant Antoni. Aunque la construcción del primer carril bici en la ciudad data de 1990, no es hasta principios del siglo XXI cuando desde el ayuntamiento se impulsa una política de inversión pública en este tipo de infraestructura para el conjunto de la ciudad (o al menos para el conjunto del ensanche). Pero sin duda, el punto de inflexión es la inauguración del sistema de bicicleta pública en 2007. Es en ese momento cuando la bicicleta se incorpora en el imaginario como un elemento más del paisaje urbano. En este sentido, la red de infraestructura bici en la ciudad (sumando carriles y estaciones) rebasa claramente el ámbito del barrio de estudio, que si bien es cierto que cuenta con esta infraestructura, también existe en otros muchos otros barrios de la ciudad. En todo caso, la bicicleta no es un elemento singular de Sant Antoni, aunque también es de Sant Antoni y no deja de ostentar el símbolo cosmopolita, ecológico y cool.

\section{MODERNIZACIÓN Y CAMBIO CULTURAL: LA BICICLETA COMO RECLAMO EN LOS NEGOCIOS DE SANT ANTONI}

En Sant Antoni hay un total de cuatro tiendas de venta de bicicletas, de las cuales se han podido visitar tres. Frente a una que mantiene un carácter deportivo y especializado en ciclismo de montaña, las otras dos presentan un carácter mucho más urbano que se refleja en una estética minimalista y pensada para un barrio de carácter moderno, incluyendo mensajes en inglés destinados a los clientes internacionales. La estética de dichos locales 
encuentra su similitud en un estilo que el periodista Kyle Chayka, de The Guardian, ha bautizado como AirSpace, relacionándolo con los no-lugares de Augé. Según la crítica del periodista, este estilo de decoración de interior basado en el uso mobiliario industrial, maderas claras trabajadas toscamente, bombillas Edison y grandes ventanales destinados a crear interiores más confortables, se extiende globalmente entre los barrios más gentrificados y afecta tanto a bares, restaurantes, oficinas de start-ups, espacios de co-working y a edificios de Airbnb. La manera en la que se globaliza es distinta a las grandes marcas, y no hay una imposición de la cadena para marcar una decoración determinada, sino que es por el uso de las redes sociales por lo que se genera esta homogeneización estética (Chayka, 2016).

Estas dos tiendas de bicicleta de estética -según Chayka- Airspace, son pequeños comercios que aparecieron hace cuatro o cinco años y ambos tienen influencia europea. Corresponden con una época en la que Sant Antoni comenzaba a cambiar el carácter de sus negocios, especialmente por la zona de la calle Parlament, y empezaban a aflorar intentos de remodernizar -quizás con cierto aire posh (pijo, sofisticado)- para darle otro tipo de vida al barrio. Un empuje que venía acompañado por la creación de galerías de arte y preocupación estética de los nuevos locales. Aquel cambio que parecía que seguiría en aumento, ha visto una gran recesión porque a día de hoy los negocios no pueden hacerse cargo de la subida de precio de los alquileres comerciales. La expectación -y la expectativa de muchos propietarios de locales esperando para alquilar- se dirige hacia la apertura del mercado.

El producto a la venta de estos negocios recae mayormente en las bicicletas vintage, llegando incluso a tener técnicos especializados en reparación de las mismas. Estas bicicletas, otrora destinadas a coleccionistas, se han abierto camino entre los ciclistas urbanos que optan por la reutilización de las mismas, en palabras de un vendedor, "por ser consumidores de buen gusto" (entrevista exploratoria, 13/04/2018). Aunque parece que la falta de consolidación del cambio en el perfil de vecino-consumidor ha hecho que disminuya el interés por dichas bicicletas. En su lugar, algunos comercios optan por el alquiler, incluyendo al cliente extranjero con largas estancias. Además de las tiendas visitadas (aunque no todas lo incluyen), hay dos comercios más dedicados exclusivamente al alquiler.

Para profundizar más sobre las posibilidades de alquiler, se han consultado los mapas de disponibilidad de la plataforma Donkey Republic. Donkey Republic es una empresa danesa de alquiler de bicicletas que ofrece la posibilidad de recoger y soltar el vehículo con una mera operación a través de su App, sin preocupación de candados externos o de infraestructura para aparcarlas. No hay horarios ni hay que volver a la tradicional tienda para devolverla. El modus operandis de esta empresa desató las críticas de diferentes sectores, incluidos la Asociación de Bicitours de Barcelona, por utilizar los aparcamientos públicos como almacén de bicicletas (dado que no existe una sede física de almacenamiento y recogida diaria de las mismas) (Franch, 2017). Se ha comprobado que, según lo que afirma la empresa, realizan un control exhaustivo del emplazamiento de sus bicicletas ofertando puntos fijos de recogida/estacionamiento de bicicleta. Mientras que barrios del núcleo central de Barcelona (Raval o Gótico) se mantienen prácticamente libres de estas bicicletas, en Sant Antoni existe una permeabilización entre las calles Manso y Parlament (que tanto por las observaciones de campo como por las entrevistas exploratorias, se muestra como el punto neurálgico del cambio a nivel de comercios en los últimos cinco años). El número de bicicletas disponibles en el barrio oscila entre ocho y trece. En una panorámica más general se observa mucha más concentración de bicicletas en las calles generales que rodean al barrio.

La revisión de la existencia de locales de moda en el barrio vinculados a la bicicleta a través de la plataforma The Trend Map por categorías nos ha permitido observar en qué medida la bicicleta se utiliza como reclamo en este mundo de lo moderno y en qué medida estos bares se encontraban en Sant Antoni. Existen once negocios distribuidos entre el Born, Gòtic y Raval, y uno en Esquerra de l'Eixample, que se proponen como bikefriendly (lugares donde la bicicleta es bien recibida) o vinculados a la bicicleta. En el interior de la trama de Sant Antoni no encontramos ninguno específico de bicicleta, aunque sí que constan diferentes locales calificados como trendy, que van desde gastrobares, como tiendas de ropa o decoración, así como locales de copas. Estos negocios tienen una distribución más concentrada hacia el barrio del Raval, y más concretamente en la calle Parlament.

Por último, atendiendo a la controversia generada por el impacto de la plataforma Airbnb, se ha realizado un rastreo exploratorio en diferentes ofertas de pisos de alquiler comprobando incluyen la bicicleta como un reclamo del propio apartamento o del entorno del barrio. La plataforma Fem Sant Antoni sitúa en 904 las ofertas de alquileres Airbnb en el barrio (además de veintidós agencias inmobiliarias, doce edificios enteros de pisos turísticos, doce hoteles, dieciocho hostales y albergues, y seis edificios completos en venta o ya vendidos como fondos de inversión). A través de la revisión sólo se ha encontrado un caso en el que la bicicleta se utilice como reclamo. 


\section{PRIMERAS CONCLUSIONES PRELIMINARES}

Sant Antoni, a tenor de los datos sociales analizados, es un barrio con características sociales muy próximas a la media de la ciudad. Si nos fijamos a nivel interno, sí que se pueden observar unos indicadores menos favorecidos en la zona del barrio encajada entre el Paral·lel y el Raval, coincidiendo con el espacio en el cual ha saltado la alarma por el proceso de transformación social de los últimos años y cuyo epicentro está en la calle Parlament. Otro indicador de cambio en el barrio lo encontramos en la evolución de precios en el mercado de vivienda de segunda mano puesto que es, junto con el vecino Poble-sec donde más ha aumentado.

El acercamiento a la zona de estudio ha permitido, en primer lugar, establecer que, a diferencia con otros casos observados a nivel internacional -mayormente norteamericano-, la inversión en infraestructura bici no es el motor del proceso de gentrificación que vive el barrio. La transformación -impulsada por la vorágine de un cambio global- que a día de hoy se ve y se ha visto consolidada en diferentes barrios de Barcelona, se maneja en un plano mucho más difuminado que la relación causa-efecto de la construcción de un carril bici. Hablamos de un aumento del turismo en la ciudad hasta niveles antes no alcanzados, de la movilidad y flexibilidad laboral de los nuevos trabajos deslocalizados que permiten trabajar a distancia desde Barcelona o cualquier otra ciudad global, un aumento desmedido del interés del capital internacional por la inversión en la compra de viviendas, y más concretamente del interés por las propiedades verticales, y finalmente, como resultado de estas dinámicas, una crisis de la vivienda cada vez más agudizada.

Sobre esta base, la indagación del papel de la bicicleta en el proceso de cambio social y urbano de Sant Antoni ha girado, por un lado, en un plano más abstracto centrado en el imaginario social y en el papel de la bicicleta como símbolo del cambio, y por otro, en un plano material vinculado a las nuevas tipologías de uso y consumo de la bicicleta que pueden surgir en esta transformación.

La trayectoria observada ya insinúa un cambio en el perfil sociodemográfico de los habitantes del barrio. Este cambio se está observando, paralelamente, en una modificación del carácter de los locales que se evidencia por una estética que tampoco escapa de la globalización. La bicicleta puede convertirse en un símbolo que se inserta en esa revalorización de la estética cosmopolita y preocupada por la sostenibilidad. Esto podría traducirse en una inclinación hacia la posibilidad de los desplazamientos en bicicleta.

El cambio hacia la estética de lo cosmopolita, se ha visto reflejado en un aumento por el interés sobre las bicicletas vintage. La elección de este tipo de bicicletas prioriza lo estético por encima de la funcionalidad. En el caso de Sant Antoni, las tiendas destinadas al ciclismo urbano ofertan este tipo de producto entendiendo que la posibilidad de venta está relacionada con el atractivo de barrio moderno, y por tanto, la aparición de un nuevo perfil de cliente.

Pero no es el único. La llamada de estas tiendas de bicicleta se expande hacia el cliente internacional, que encuentra negocios adaptados al inglés -entre otros idiomas- en los que se ofertan nuevos modelos de intercambio. Es el caso de los residentes de estancias de medio plazo en Barcelona, a los que se le ofrece la posibilidad de comprar la bicicleta y re-venderla en la misma tienda cuando llegue el momento de marchar. A través del boca a boca aparece un nuevo flujo de clientes que se va consolidando.

Por último, se ha observado que tanto la posibilidad del alquiler como de la reparación, abre la relación con los nuevos modelos de negocio de reparto en bicicleta. Los repartidores/as de estos negocios dependen de su propia bicicleta para cumplir con las entregas, y dada la centralidad del barrio encuentran en estas tiendas un punto seguro donde poder dejar la bici en reparación y alquilar otra mientras tanto.

Si bien en la escala de barrio, y según el estudio exploratorio, no se ha percibido una relación directa de la bicicleta con los negocios que se encuentran vinculados a la plataforma The Trend Map, sí que en los barrios circundantes se observa la existencia de la bicicleta, tanto en la decoración como en estrategias de mercado (por ejemplo el concepto bicifriendly) como un reclamo que se vincula a un estilo de vida moderno y saludable.

En cuanto a la relación con el turismo, no se ha observado que en el momento actual Sant Antoni utilice como reclamo la bicicleta o resulte especialmente atractivo para este tipo de uso. Sin embargo, estos resultados son preliminares. Con la apertura del mercado y la superilla se prevé que este proceso se acelere y Sant Antoni, siendo un enclave entre Montjuic y la zona más turística del Gòtic y Born, se convierta en un barrio mucho más atractivo para el uso de la bicicleta -también para los turistas-. Tras la consolidación de las intervenciones urbanísticas que están concluyendo en la actualidad (mayo de 2018), sería oportuno continuar con un análisis más profundo sobre el proceso dialéctico entre los cambios sociodemográficos del barrio y su materialización en las formas de uso y consumo de la bicicleta. 


\section{AGRADECIMIENTOS}

Esta investigación se lleva a cabo con la ayuda financiera de los proyectos 2017FI_B1118 de la Generalitat de Catalunya y CSO2016-74888-C4-2-R del Ministerio de Educación y Ciencia.

\section{BIBLIOGRAFÍA}

AJUNTAMENT DE BARCELONA (sin fecha). El programa Superilles a Sant Antoni, la transformació en marxa. Barcelona, España: Ajuntament de Barcelona. Recuperado de: http://ajuntament.barcelona.cat/superilles/ca/superilla/sant-antoni. [consultado: 16/04/2018]

CHAYKA, K. (2016). Same old, same old. How the hipster aesthetic is taking over the world. The Guardian (7 de agosto de 2016). Recuperado de: https://www.theguardian.com/commentisfree/2016/aug/06/hipster-aesthetic-taking-over-world. [consultado: 24/04/2018]

DANYLUK, M., y LEY, D. (2007). Modalities of the New Middle Class : Ideology and Behaviour in the Journey to Work from Gentrified Neighbourhoods in Canada. Urban Studies, 44(11), 2195-2210.

FEM SANT ANTONI (5 de octubre 2017). El mapa de la gentrificació: carrer Parlament. Barcelona, España: Fem Sant Antoni. Recuperado de: https://femsantantoni.wordpress.com/2017/10/05/el-mapa-de-la-gentrificacio-carrer-parlament/. [consultado: 12/04/2018]

FLANAGAN, E., LACHAPELLE, U., y EL-GENEIDY, A. (2016). Research in Transportation Economics Riding tandem: Does cycling infrastructure investment mirror gentri fi cation and privilege in Portland OR and Chicago , IL? Research in Transportation Economics, 60, 14-24.

FrANCH, S. (2017). El desembarco de las bicis de alquiler 'online' en Barcelona pone en pie de guerra al sector (28 de junio de 2017). Recuperado de: https://www.eldiario.es/catalunya/barcelona/desembarco-alquiler-online-Barcelonaguerra_0_659334609.html. [consultado: 27/04/2018]

GIBSON, T. A. (2015). The rise and fall of Adrian Fenty, Mayor-Triathlete: cycling, gentrification and class politics in Washington DC. Leisure Studies, 34(2), 230-249.

LUGO, A. E. (2012). Can human infrastructure combat green gentrification?: ethnographic research on bicycling in Los Angeles and Seattle. In M. Isenhour, Cindy; McDonogh, Gary; Checker (Ed.), Sustainability in the Global City: Myth and Practice (pp. 306-328). New York: Cambridge University Press

SMITH, N. (2002). New Globalism, New Urbanism : Gentrification as Global Urban Strategy. Antipode, 34(3), 427-450.

STEHLIN, J. (2015). Cycles of investment : bicycle infrastructure, gentrification, and the restructuring of the San Francisco Bay Area. Environment and Planning A, 47, 121-137.

STEIN, B. S. (2011). Bike Lanes and Gentrification: New York City's Shades of Green. Progressive Planning, $188,34-37$.

THE TREND MAP (sin fecha). ¿Qué es trend map?. Barcelona, España: The trend map. Recuperado de: http://trendmap.es/es/ que-es/ [consultado: 04/05/2018]

TIME OUT. (2017). Els millors bars del carrer Parlament. Barcelona, España: Time Out. (27 de febrero 2017)Recuperado de: https://www.timeout.cat/barcelona/ca/bars-pubs/els-millors-bars-del-carrer-parlament. [consultado: 02/05/2018]

VITH, T. A., y MÖSSNER, S. (2017). Contesting sustainable transportation : bicycle mobility in Boston and beyond. Journal of the Geographical Society of Berlin, 148(4), 229-237. 
Página intencionalmente dejada en blanco 
COMERCIO Y SERVICIOS 
Página intencionalmente dejada en blanco 


\title{
Propuesta metodológica para el estudio del uso y dinámicas del espacio público de las áreas comerciales de los centros urbanos
}

\author{
Ana Vera (a), Àngel Cebollada (b), Àngels Pérez (c), Marc Castelló (d) \\ (a) Departamento de Geografía, Universitat Autònoma de Barcelona, ana.vera@uab.cat \\ (b) Departamento de Geografía, Universitat Autònoma de Barcelona, angel.cebollada@uab.cat \\ (c) Departamento de Geografía, Universitat Autònoma de Barcelona, angels.perez@uab.cat \\ (d) Departamento de Geografía, Universitat Autònoma de Barcelona, marc.castello@uab.cat
}

\section{Resumen}

\begin{abstract}
Las áreas comerciales de los centros urbanos son a la vez el pasado y el futuro de la ciudad. Si por un lado suelen presentar espacios económicos con equipamientos comerciales en declive también son esenciales para la transición hacia una ciudad sostenible puesto que aportan un comercio de proximidad, un espacio público concurrido y permiten el fortalecimiento de las relaciones sociales. Esta comunicación tiene por objetivo establecer una metodología para el análisis del uso y las dinámicas del espacio público de los centros urbanos. Esta metodología se realiza combinando metodologías cualitativas y cuantitativas. Para la primera se han realizado entrevistas y observaciones en el espacio público mientras que para el segundo se han georeferenciado y analizado datos de flujos peatonales, características físicas de las calles, del censo de comercios. El caso de estudio comprende los centros urbanos de ocho ciudades medias catalanas.
\end{abstract}

Palabras clave: Áreas comerciales, centros urbanos, flujos peatonales, espacio público

\section{INTRODUCCIÓN}

La actividad comercial está en cambio continuo, como consecuencia de la ley de la oferta y la demanda, y queda directamente relacionada por el espacio donde se desarrolla la actividad. Los procesos de cambio que condicionan a los centros urbanos comerciales son, por un lado, el despoblamiento y la degradación de la edificación pública y privada, así como la deslocalización de equipamientos básicos y la aparición de macro complejos comerciales y de ocio en detrimento del pequeño y diverso comercio tradicional. Y por otro lado los procesos de gentrificación (residencial y empresarial) derivados de las intervenciones de mejora y restauración del patrimonio histórico-cultural y la tematización de las áreas que inciden sustancialmente en el precio y los usos del suelo. Sin embargo, desde el inicio del siglo XXI pues la corriente general aboga por una gestión sostenible de los centros urbanos que tiene en consideración las tres dimensiones: económica, social y ambiental.

El objetivo de esta comunicación establecer una metodología para el análisis del uso y las dinámicas del espacio público de los ocho centros urbanos comerciales.

El marco teórico se apoya por un lado en la actividad económica en los centros urbanos, especialmente la actividad comercial y por otro en la movilidad de la población. La metodología utilizada ha sido cualitativa y cuantitativa.

\section{MARCO TEÓRICO: LA ACTIVIDAD COMERCIAL EN LA CIUDAD}

La actividad comercial ha sido siempre una de las principales actividades económicas que se ha desarrollado en las ciudades. La presencia de comercio en los espacios urbanos (mercados) o en las plantas bajas de los edificios ha caracterizado especialmente a los centros urbanos de las ciudades (Ferrer y Carrera, 1995). La localización de esta actividad se ha ido moviendo a lo largo de los tiempos desde el centro de las zonas urbanas hacia las áreas más suburbanas, según nuevas formas de actuación de la actividad comercial para dar servicio a las necesidades de la población. Los primeros centros comerciales suburbanos surgieron en los años cincuenta del siglo XX, fue en ciudades como Detroit o Baltimore y el acceso se realizaba a través de una vía segregada y en un espacio donde fuera posible aparcar el automóvil. A partir de ese momento empezaron a proliferar centros comerciales en las 
periferias suburbanas que competían con las áreas comerciales de los centros urbanos.

Los centros urbanos tradicionales, se han convertido en áreas de atracción de peatones por la diversidad funcional como es la localización de los equipamientos de alta jerarquía, centros financieros, centros de alto valor histórico y patrimonial, enclaves simbólicos y escaparates de las relaciones de poder entre la sociedad y las élites gobernantes, entre otros. En definitiva, por la heterogeneidad que históricamente las han caracterizadas, tanto en la diversidad de personas como en los diferentes usos del suelo como: el residencial, industrial, residencial, terciario (equipamientos y servicios). A partir del último tercio del siglo $\mathrm{XX}$, coincidiendo con el crecimiento acelerado de las ciudades y los problemas de las áreas suburbanas, se ha perdido la mixtura de usos que caracterizaba el interior de las ciudades y se ha tendido hacia la terciarización en detrimento de la actividad industrial y artesanal. Estos espacios de comercio y consumo actúan como lugares clave para la producción de identidad (Abelson, 1989; Benson, 1986).

\subsection{El Espacio público de los centros urbanos; empezando a recuperar terreno}

La primera aparición del concepto de espacio público fue de Immanuel Kant (1724-1804), que en el siglo XVIII ya defendía la necesidad de un espacio público racional y democrático. A lo largo del siglo XX esta misma idea fue retomada por muchos filósofos y sociólogos (Villafuerte, 2011). Desde la perspectiva urbanística contemporánea, el espacio público es algo tan simple como aquel espacio que no es privado, aunque a menudo las definiciones evidencian el abanico de incongruencias y/o contradicciones que se dan en la realidad. En una primera aproximación queda claro: el espacio público es el área que separa la propiedad pública de la propiedad privada, donde se distingue el dominio y el acceso colectivo al individual y el uso público del uso privado. En las ciudades el espacio público propiedad del Estado es de todos los ciudadanos. Las vías abiertas, las plazas y/o las zonas amplias de cualquier edificio público están consideradas espacio público. La ciudad es el espacio público y el espacio público es la ciudad (Borja, 2010).

No se puede obviar la relación directa entre la explosión automovilística y la pérdida de espacio público en la ciudad. Un artilugio privado que desde principios del siglo XX, con las cadenas de montaje del fordismo y las políticas keynesianas que aumentaron el poder adquisitivo de los obreros, no ha parado de crecer en todo el mundo. Este objeto impulsó de forma exponencial el fenómeno de la urbanización, favoreciendo la extensión territorial de una ciudad de baja densidad, dispersa y con una alta especialización funcional. Se considera que el coche es antidemocrático en tanto que no todo el mundo tiene acceso y porque ha significado la remodelación del espacio en las ciudades para su aprovechamiento casi exclusivo, además de los graves impactos ambientales que conlleva el uso masivo de este medio de transporte en las ciudades.

En las agendas públicas de las administraciones, especialmente las locales, aparece la necesidad de disminuir el uso del vehículo privado y de recuperar el espacio público de calidad, esto es, sin contaminación acústica ni del aire, y que sea accesible y usado por la ciudadanía con independencia de su adscripción social. Si bien la ciudad del siglo XX ha sido planificada en torno el coche, ahora toca desandar el camino realizado. Por lo tanto, el primer paso para la recuperación del espacio público pasa por la diminución del espacio para el coche, la reducción de su velocidad, la pacificación del tráfico, el incremento del espacio para los modos no motorizados (principalmente peatones) así como la dotación de atributos al espacio público que favorezcan las actividades de estar en el mismo.

Este proceso de recuperación del espacio público se ha iniciado en los centros urbanos de las ciudades. Es en estas áreas donde probablemente la vida social de la calle era más activa. Contaba (y cuenta) con elementos tangibles e intangibles de atracción (y que se reseñan en el siguiente apartado), una mezcla de usos que en las otras zonas de la ciudad no se dan, y una alta densidad por el mismo carácter estrecho y multifuncional de las calles (suelen coincidir con los cascos viejos).

\subsection{Tomando el pulso de los centros urbanos: la movilidad a pie y la actividad en la calle}

En estos primeros decenios de siglo XXI, las áreas de los centros urbanos se reivindican como espacios integradores y de calidad de vida a partir de los criterios de sostenibilidad que priorizan los desplazamientos no motorizados y reivindican un espacio público dinámico y diverso. Es en este marco en el que analizamos los flujos de peatones. El contingente de personas que circulan andando por los centros urbanos se debe tanto a motivos ocupacionales como personales. A estos motivos, todavía debe añadirse un motivo de estancia, de disfrute en el espacio público. 
La razón de esta diversidad de motivos de desplazamientos recae en las actividades que albergan estas áreas: residenciales (todo y que cada vez menos), terciarias (principalmente comercio y servicios), equipamientos públicos y elementos del patrimonio cultural entre los principales.

La densidad urbana de estas áreas, un espacio público de más calidad, la existencia de pequeño comercio, el valor simbólico... hace que estos centros urbanos suelan ser las principales (cuando no la únicas) áreas peatonales de las ciudades. En este sentido, de la calidad de estas áreas dependerá en gran parte la capacidad de atracción de personas: como peor sea esta calidad menos flujos y menos motivos de circular por allí. De todas maneras, sí que existen diferencias en estos centros y, comúnmente, estas van ligadas al paso de vehículos autorizados o a las restricciones por franjas horarias del tráfico motorizado.

A una escala mayor, la de la calle, la afluencia de paso y estancia de peatones se relaciona con los elementos de atracción/expulsión de la misma. Podemos distinguir elementos de atracción tangibles (dotación de mobiliario para desarrollar actividades de estar, fisonomía de la calle con esquinas frecuentes, aceras generosas, usos del suelo de las mismas, tipología de la edificación, mezcla de usos, elementos patrimoniales...) y elementos e intangibles (percepción de seguridad, elementos simbólicos....) que favorecen el tránsito de las personas por unos determinadas calles en detrimento de otras.

Los elementos de atracción mantienen una relación dialéctica puesto que una calle animada y viva, es decir frecuentada por diferentes tipos de usuarios, trabajadores, vecinos y visitantes - a diferentes horas del día y en jornadas diferentes retroalimentará el paso de peatones también por la percepción de seguridad que crea. Y para ello, como mayor sea la mezcla de usos y actividades, tanto para las necesidades del vecindario y para los que se desplazan allí a trabajar (que Jacobs, 1961, clasifica

entre usos primarios y usos secundarios) mayor será la capacidad de mantener la atracción de peatones en diferentes horas y días.

\section{3. ÁREA DE ESTUDIO}

El estudio se centra en la dinámica comercial y el flujo de peatones de los centros urbanos de ocho Ciudades Medianas Catalanas. Las ciudades de analizadas son: Figueres, Granollers, Mataró, Olot, Sabadell, Tarragona, Terrassa y Vic (Figura 1a y b). En éstas ciudades se concentra el 11,07\% de la población de Catalunya.

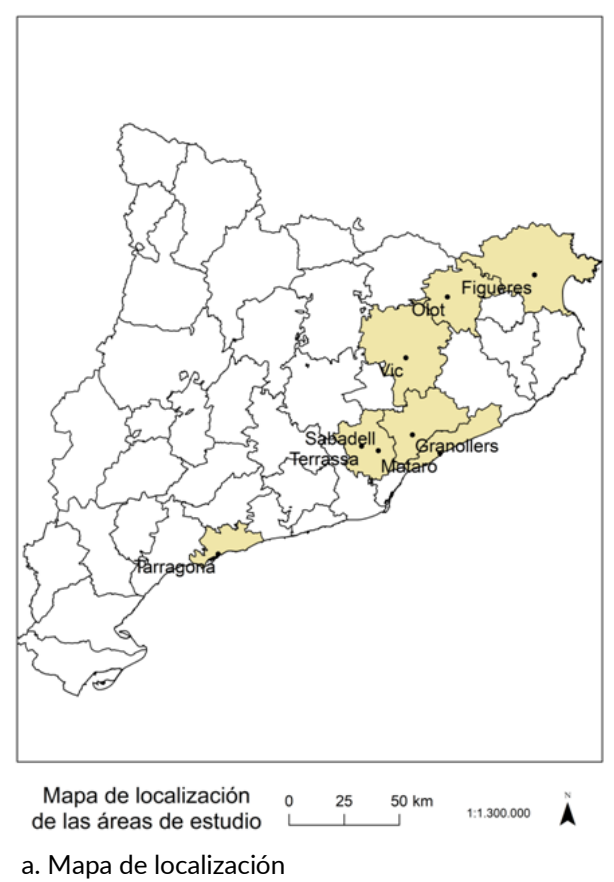

\begin{tabular}{|l|r|}
\hline Ciudad & Población (2017) \\
\hline Figueras & 45.961 \\
\hline Granollers & 60.695 \\
\hline Mataró & 126.127 \\
\hline Olot & 34.194 \\
\hline Sabadell & 209.931 \\
\hline Tarragona & 131.507 \\
\hline Terrassa & 216.428 \\
\hline Vic & 43.964 \\
\hline
\end{tabular}

b. Población de cada ciudad (2017) (hab.).

Figura 1 - Mapa de localización y población (2017) de las ciudades de estudio. Fuente: Elaboración propia. 
Entre las dinámicas comunes cabe destacar dos; la primera es que las ocho ciudades se caracterizan por la centralidad de sus elementos administrativos y culturales. $Y$ la segunda, que al mismo tiempo ejercen de espacios articuladores de un territorio más amplio que el propio núcleo urbana. Las áreas de estudio se corresponden, también, con los centros históricos y primeros ensanches, allí donde se realizaban las primeras actividades comerciales.

\section{METODOLOGÍA: DATOS Y MÉTODOS}

Este proyecto combina técnicas cualitativas y cuantitativas, tanto para la fase de reconocimiento de las áreas de estudio como para la fase de análisis y de interpretación de resultados con dos objetivos:

1- recoger el máximo de información de las funciones y usos del suelo en el espacio público delimitado con el fin de adoptar criterios para la estandarización y homogeneización.

2- analizar los datos de los contadores de personas y relacionarlos con todas las variables implicadas.

El proceso metodológico se divide en tres grandes bloques: en primer lugar, la diagnosis física y documental y la elaboración de una base de datos alfanuméricos y espaciales que permita cartografiar las principales características de cada centro urbano; en segundo lugar, la codificación y elaboración de un censo de actividad comercial; y finalmente, en tercer lugar la recogida y validación de los flujos de peatones.

La metodología cualitativa ha sido la combinación de entrevistas, trabajo de gabinete y trabajo de campo.

1. Entrevistas: con los técnicos de las Asociaciones de Comerciantes de las ocho ciudades, los responsables de la Fundació Comerç Ciutada (FCC), los técnicos de las áreas comerciales o técnicos de movilidad de los ocho ayuntamiento y el técnico de los sensores piroeléctricos. El objetivo de las reuniones con las asociaciones y los técnicos de los ayuntamientos han sido necesaria para delimitar cada una de las áreas de estudio y entender la dinámica interior de cada ciudad, desde los mercados semanales, los horarios comerciales, las ferias especiales o dinámicas específicas de cada ciudad.

2. Trabajo de gabinete: hacer un vaciado de la literatura teórica, informes técnicos, DOGC, prensa para el contexto socioeconómico de cada ciudad. Y una reclasificación de las categorías comerciales.

3. Trabajo de campo: ha sido necesario para hacer observación del espacio público, de la distribución de la actividad comercial y los contracontajes manuales que han servido para calcular el factor corrector.

La metodología cuantitativa ha sido trabajar con bases de datos para cartografiar mediante Sistemas de Información Geográfica los equipamientos públicos y privados, la actividad económica y los elementos de movilidad. Para la elaboración de las bases de datos socioeconómicos para cada ciudad se han consultado: Institut d'Estadística de Catalunya (IDESCAT), Instituto Nacional de Estadística (INE), Servei d'Ocupació de Catalunya (SOC), Xarxa d'Observatoris del Desenvolupament Econòmic Local (XODEL) y Servei Meteorològic de Catalunya (METEOCAT).

Y para la cartografía de cada ciudad se han obtenido las bases del Institut Cartogràfic i Geològic de Catalunya (ICGC) y el open data de las administraciones locales de las ciudades de estudio han permitido cartografiar la siguiente información:

- Servicios de la Movilidad: la oferta de transporte público (localización de paradas de autobús, estaciones de tren y paradas de taxis), la oferta de estacionamiento privado subterráneo (parkings) y superficial (zona azul), las áreas exclusivas para la circulación de peatones.

- Distribución espacial de los equipamientos: la oferta de equipamientos dentro de las áreas de estudio que previamente ha requerido la homogeneización y la clasificación que muestra el siguiente cuadro.

\subsection{Sensores Piroeléctricos, definición del Factor corrector}

Para el recuento de los flujos de población se han utilizado 19 sensores piroeléctricos que contabilizan a las personas por emisión de calor y recogen la dirección de paso (entrada o salida del área de estudio). Los 19 contadores van rotando por las 8 ciudades (un promedio de 14 calles) en dos períodos distintos, con una media anual de 35 días en cada ciudad. La finalidad es contabilizar la realidad de los centros urbanos y se excluyen todos aquellos acontecimientos que alteran la vida diaria de los centros.

Una vez compilada la información es necesario hacer contracontajes manuales para validar la información y calcular el factor corrector. Se han realizado una treintena de muestras de recuentos manuales de 15 minutos realizadas en diferentes ciudades del estudio, en diferentes tipos de calles, tipos de jornadas y en diferentes franjas horarias -horas valle y horas punta. Se irán realizando contracontajes para hacer un seguimiento del factor corrector en distintas rondas. 
Así pues, el principal rasgo que se constata es que en el $100 \%$ de los casos el valor bruto resultante del conteo automático ha sido siempre inferior al resultado de conteo manual, incluso en casos de avería técnica. La principal causa es que el sensor piroeléctrico cuenta por masas de calor que precisan de una distancia mínima para diferenciarlas entre más de una.

Posteriormente se aplican y contrastan dos operaciones para finalmente encontrar la justa proporción a aplicar a los datos en bruto.

Operación factor corrector convencional:

Conteo Pirobox * 100 / Conteo manual - 100 =\% error

Operación factor corrector estimado a partir del estudio de Yang Ozbay \& BART (2011) sobre los patrones de conteo automático de paso de peatones según el formato de llegada y tiempo de conteo manual de 15 ':

- Cálculo aplicado a grupos de paso de 2 personas:

Factor corrector $=(0,106+0,371) *$ núm. conteo automático

- Cálculo aplicado a los grupos de paso de 3 personas:

Factor error $=(-0,187+0,097){ }^{*}$ núm. conteo automático

\subsection{Reclasificación de la actividad comercial}

A partir de los censos semestrales de los locales comerciales suministrados por las asociaciones de comerciantes de las ciudades estudiadas, se ha hecho una estandarización y homogeneización de 224 tipos de establecimientos coincidentes y 147 categorías generales de actividades. Una vez identificadas las coincidencias se ha hecho una reclasificación que ha permitido obtener tres grandes subsectores: comercio, restauración y servicios (Figura 2). Entendiendo que en los comercios es donde hay un intercambio (compra-venta) de productos, la restauración incluye la hostelería y los servicios, donde hay intercambio de servicios.

La nueva clasificación de la actividad comercial ha permitido por un lado cartografiar la distribución comercial por sectores de actividad y, por otro, crear una base de datos con el número de comercios abiertos, cerrados y rotados (aperturas, cierres y/o cambios de actividad) para cada calle dentro de las áreas de estudio delimitadas. La representación gráfica de la actividad comercial ha sido a partir de la construcción de una cuadrícula de $20 * 20$ metros, donde queda representado el sector comercial dominante de la cuadrícula (Figura 3).

\begin{tabular}{|l|l|l|}
\hline COMERCIO & RESTAURACIÓN & SERVICIOS \\
\hline Cotidiano alimentario & Restaurantes, bares, hoteles & Servicios a las personas \\
\hline Cotidiano no alimentario & $\begin{array}{l}\text { Servicio de restauración delibery y take } \\
\text { away }\end{array}$ & Servicios de salud \\
\hline Equipamientos a las personas & & Profesionales colegiados y no colegiados \\
\cline { 1 - 1 } Equipamientos del hogar & & \\
\hline Ocio y tiempo libre & & \\
\hline
\end{tabular}

Figura 2 - Clasificación de los subsectores económicos. Fuente: Elaboración propia.
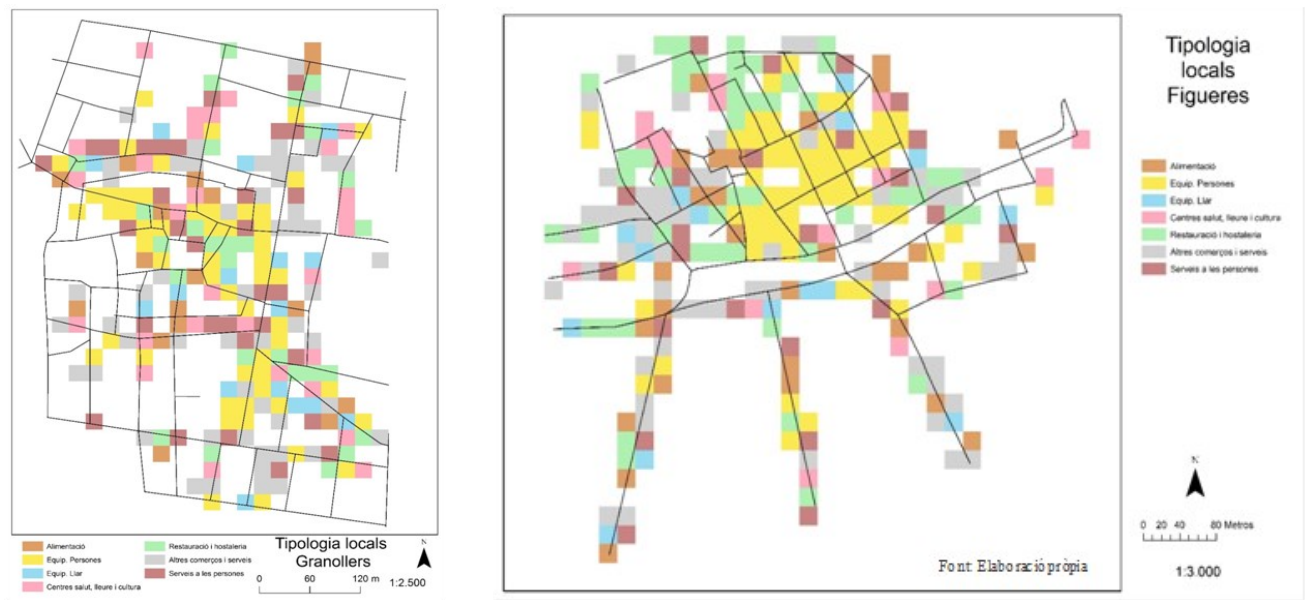

Figura 3 - Tipología de locales de las ciudades de Granollers y Figueras. 


\subsection{Tipología de calles de las áreas de estudio}

El trabajo de campo basado en la observación de las calles de las diferentes áreas de estudio se ha llevado a cabo con el objetivo de establecer criterios para la monitorización (instalación de contadores piroeléctricos peatonal en ambos sentidos de circulación): donde se ponen los contadores y cuántos son necesarios para cubrir el flujo de peatones de una determinada calle. Así, se ha considerado la anchura entre fachadas, el tipo de tráfico (rodado motorizado, peatón, restringido), el tipo de pavimentación (con o sin aceras), el sentido de dirección de los vehículos (única o doble), la anchura de las aceras y la presencia de mobiliario discriminador (monumentos, jardinería ornamental, fuentes, o de otros en medio de las aceras) (Figura 4).

\begin{tabular}{|c|c|}
\hline ID & DESCRIPCIÓN \\
\hline 1 & De peatones de plataforma única (pu) y una amplitud de fachada hasta $4 \mathrm{~m}$ \\
\hline 2 & De peatones de pu y una amplitud de fachada entre $4-8$ \\
\hline 3 & De peatones de pu y una amplitud de fachada entre $4-8 \mathrm{~m}$ con mobiliario urbano \\
\hline 4 & De tránsito rodado y plataforma segregada y ancho entre $4-8 \mathrm{~m}$. \\
\hline 5 & De peatones de pu de doble o triple acera y anchada $>8 \mathrm{~m}$ \\
\hline 6 & De tránsito rodado, de doble y triple vía y plataforma segregada, ancho $>8 \mathrm{~m}$ \\
\hline 7 & De peatones de pu de doble o triple acera y ancho $>8 \mathrm{~m}$ con mobiliario urbano \\
\hline
\end{tabular}

Figura 4 - Clasificación de las calles. Fuente: Elaboración propia.

\section{PRIMEROS RESULTADOS}

En esta primera fase metodológica hay dos grandes resultados obtenidos a partir de las bases de datos, la localización de los 19 contadores de personas piroeléctricos teniendo en cuenta la morfología urbana, los equipamientos y la actividad comercial. Y el segundo gran resultado es la definición de los atributos teóricos de paso y estancia que se han definido para homogeneizar la calidad del espacio público de los diversos centros urbanos a partir de los siguientes criterios, según los teóricos:

- sí circulan o no vehículos motorizados = $1 / 0$

- sí o no, dispone de arbolado o mobiliario y alumbrado = $1 / 0$

- sí o no, dispone de aceras anchas y de calidad = 1/0

El cumplimiento de alguna, varias o todas las restricciones ha permitido clasificar la calidad de las calles en 3 categorías teóricas, tal y como muestra a continuación (Figura 5):

1 Calles con tráfico rodado motorizado, de acera estrecha, sin arbolado ni mobiliario urbano.

2 Calles con tráfico rodado motorizado, acera ancha, con arbolado y mobiliario urbano.

3 Calles peatonales con arbolado y mobiliario urbano.

\section{REFLEXIONES FINALES}

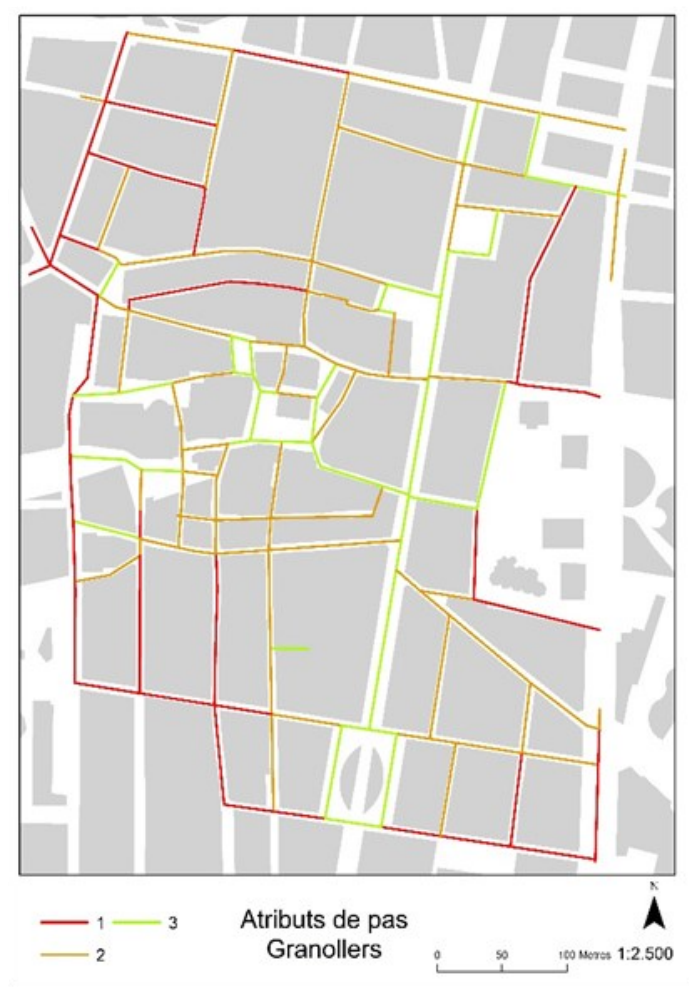

Figura 5 - Adecuación de paso y estancia de la ciudad de Granollers.

Las condiciones del espacio público monitorizado se correlacionan con el paso de peatones y con el sector de actividad.

La estructura comercial de las calles monitorizados, muestra una especialización en la zona centro y una diversificación en los límites de las áreas de estudio.

Se muestran tres dinámicas explicativas del comportamiento de los flujos en las calles monitorizados. Con- 
centran, también, las áreas para peatones, es decir espacios de cohesión social.

En relación a las singularidades de cada una de las capitales de comarca a partir de los flujos y la intensidad de población hay que resaltar la influencia transfronteriza y turística cultural de Figueres, en el norte de Cataluña; la influencia comarcal o el alcance de los equipamientos culturales y científicos y el potencial turístico patrimonial o costero de las capitales metropolitanas -Granollers, Mataró, Sabadell y Terrassa-; los valores naturales, patrimoniales y paisajísticos de atracción turística junto con el carácter articulador de las capitales interiores -Vic y Olot-; y, en el sur de Cataluña, el área de influencia del centro administrativo de la demarcación, la industria, la universidad, el patrimonio histórico y la condición de polo turístico de Tarragona.

\section{AGRADECIMIENTOS}

Esta investigación ha sido realizada con la ayuda de la Fundació Comerç Ciutadà.

\section{BIBLIOGRAFÍA}

ABELSON, E. (1989). When ladies go a thieving: middle class shoplifters in the Victorian department store. Oxford: Oxford University Press.

BENSON, S. (1986). Counter cultures: saleswomen, managers and customers in American department stores. Urbana, IL: University of Illinois Press.

BORJA, J. (2013) “Espacio Público y Ciudadanía” (04/09/2013). Durada 1h 13'40”. Ciclo 4 conferencias on-line organizado por la Federación Iberoamericana de Urbanistas.

BORJA, J. y MUXÍ, Z. (2001). Espai públic: ciutat i ciutadania. Barcelona: Diputació de Barcelona.

BORJA. J. (2010). Luces y sombras del urbanismo en Barcelona. Barcelona: Editorial UOC.

CLARKE, D. (1996). "The limits to retail capital". En Wrigley, N. y Lowe, M., [Eds.] Retailing consumption and capital. Harlow: Longman, 284-300.

CREWE, L. (2000). "Geographies of retailing and consumption" en Progress in Human Geography 24 (2); 275-290.

FERNÁNDEZ DE ROTA, A. (2014). Democratizar el espacio público. Rebelión.

FERRER, A. y CARRERA, J.M. (1995). "L'espai i l'activitat comercial a Barcelona i la seva Área Metropolitana" en Revista Papers de la Regió Metropolitana de Barcelona 22;45-59.

GEHL, J \& SVARRE, B. (2013). "How to Study Public Life". En: Yorokobu (2017). Manual para observar al ser humano en la ciudad. http://www.yorokobu.es/manual-para-observar-el-humano-en-la-ciudad/

HARTWICK, E. (1998). "Geographies of consumption: a commodity chain approach". Environment and Planning D: Society and Space 16, 423-37.

JACOBS, J. (2011). Muerte y vida de las grandes ciudades. (Trad. Abad, A). Madrid: Capitán Swing Libros, S.L. (Original en inglés 1961).

JONES, K. y SIMMONS, J. (1987). Location, Location, Location: Analyzing the Retail Environment. Toronto: Methuen.

KAAN, O et al. (2010). Development of Correction Models for the Accurate Estimation of Pedrestrian Volumes Obtained from Infrared Sensors. Rutgers, The State University of New Jersey.

MOUSSAÏD M., PEROZO N., GARNIER S., HELBING D., THERAULAZ G. (2010). The Walking Behaviour of Pedestrian Socia Groups and Its Impact on Crowd Dynamics. University of Milano-Bicocca. Italy.

OZBAY, YANG y BARTIN (2011). "Enhancing The Data Quality of Infrared-base Automatic Pedestrian Sensors Using a Nonparametric Stadistical Method". Transportation Research Board's 90 Annual Meeting, Washington, D.C., 2011.

TORGIL ABRAHAMSSON. Estimation of Origin-Destination Matrices Using Traffic Counts - A Literatura Survey. International Institute for Applied Systems Analysis. Austria.

VILLAFUERTE, L.F. (2011). Kant y el Espacio Público. UV Universidad Veracruzana. Profesor investigador de la Universidad Autónoma de Tamaulipas. [Consulta 1 de maig de 2017]. 
Página intencionalmente dejada en blanco 


\title{
Multi-diversity clusters of commercial activities in the city of Porto: how neighbourhood concentrations shape the municipal hierarchy
}

\author{
M. Saraiva, T. Sá Marques, D. Ribeiro, P. Ribeiro (a) \\ (a) Faculty of Arts of the University of Porto, CEGOT Research Centre, Via Panorâmica s/n, 4150 - 564 Porto, miguelmsaraiva@gmail.com; tere- \\ sasamarques@gmail.com; mrcotgeo@gmail.com; paularibeiro82@gmail.com
}

Resumen

Today, commerce is regarded as city-shaping activity that has intrinsic connections with the way urban spaces are composed and function, and the choices people make on where to live and how to travel. Hence the literature is concerned about the territorial reflection of commercial hierarchies, particularly as the sector is increasingly changing due to new types of products, stores and purchase and payment options. In this paper we built on previous research associating retail with geo-morphological patterns, by analysing the hierarchies within the city of Porto, in Portugal, and focusing on neighbourhood clusters where all the five categories of retail considered are present (Daily; Occasional; Exceptional (Comparison); Occasional (Comparison); Isolated purchase). By introducing variables related to geographical proximity, morphology (relation to street segments) and the establishments themselves (activity type, opening date) we dig deeper into the organizational aspects of the commercial network, so that in future works causality effects can be understood, leading to a better managment of urban retail in a perspective of cohesion and equitable access.

Keywords: Commerce; neighbourhood scale; economic geography networks; regeneration; urban morphology

\section{INTRODUCTION - THE CHANGING FACET OF COMMERCIAL ACTIVITIES}

The UN's 2030 Agenda for Sustainable Development (UN, 2015) identifies 17 major goals and 169 targets that balance the economic, social and environmental facets of development in order to shift the course of the world towards a more sustainable and resilient path. Although the document has no mention of the word "commerce", only mentions of the word "retail" once, and in Goal 17 the use of the word "trade" relates to world markets and not day-to-day shopping, it is implicit that the equitable and sustainable development of economic activities, of which retail in all its forms is an important part of, is at the core of this policy. Goal 8 relates to the promotion of sustained, inclusive and sustainable economic growth; Goal 11 to making cities inclusive, safer, resilient and sustainable; and Goal 12 to ensuring sustainable consumption and production patterns.

Urban spaces, by the natural agglomeration of people they promote (either residents, workers or visitors), are characterized by large and diversified demand, which is met by a large and diversified offer of functions. The "city" becomes the provider of economic growth and development (Beaverstock, Faulconbridge, \& Hoyler, 2011; Marques, 2004; Mendes, 2011), allowing access to services, infrastructures, human and financial capital, suppliers and other relevant externalities (Boschma, 2010), whilst concentrating an increasing portion of socio-economic activities which gain and strive with density and proximity. These, in turn, attract new economic activities, needed to serve the existing concentrations of people and business (Nijkamp \& Kourtit, 2013).

The city is also more and more an intricate network of lifestyles, ways of life and modes of expression, that range from different forms of sociability, access to culture and leisure, and diversified structures of consumption. In this respect, many economic activities, commerce included, have changed in order to fulfill new societal needs (Reimers \& Clulow, 2004). The consumer has become the consumactor (Cachinho, 2006, 2014) as he no longer shops out of necessity or at the closest store (Rabbanee, Ramaseshan, Wu, \& Vinden, 2012). Shopping is one of the many experiences of the modern glocal metropolis, conditioned by socio-economic and urban changes (P. M. Hart \& Dale, 2014; Vaughan \& Valerie, 2009) and by the specificities of different retail environments (C. Hart, Farrell, Stachow, Reed, \& Cadogan, 2007; Pecoraro \& Uusitalo, 2014; Pine \& Gilmore, 1999).

Indeed, the notion that the distribution of retail was a mere consequence of urbanization and population density has been overcome in the past decades. Commerce can be a city-maker. It can influence market prices of 
surrounding residential areas (Haugen, 2011), and can be a determining factor in the choices of where to live and of how to travel on a daily basis (Christian et al., 2011; Manaugh \& Kreider, 2013; McConville, Rodríguez, Clifton, Cho, \& Fleischhacker, 2011). In the extreme it can drive, and even anticipate, urban development (Beyard, 2009).

Consequently, recent research has strived to understand what Saraiva (2013) termed the "morphological sense of commerce"; i.e. the influence of retail activity in the form and function of urban spaces. Although this is still an emerging field of research (Balsas, 2001; Grant \& Perrott, 2011; Musso, 2011; Saraiva \& Pinho, 2017; Sarma, 2006; Villain, 2011) authors have shown that urban regeneration through retail oriented policies can have a very positive effect in the quality, vitality and resilience of city areas (Barata-Salgueiro \& Erkip, 2014; Brunetta \& Caldarice, 2014; Emery, 2006; Findlay \& Sparks, 2009; Lowe, 2005; Procopiuck \& Djalo, 2008), even outside the city centre (Bolton \& Vaughan, 2014) and even when facing the shock wave of the global economic crisis (Wrigley \& Dolega, 2011).

Consequently, in a post crisis context and when responding to policies for greater equality and cohesion within and between urban spaces, understanding the distribution of economic activities, their relationship with the urban spaces and the processes of attraction/complementarity should constitute main objects of research for decision support. Namely, it is important to measure to what extent the spatiality of commercial spaces at the most basic neighbourhood level and their respective levels of specialization can become an instrument for the holistic requalification of territories. This is the more relevant as the offer of commerce and services is by nature a strong element of urban centrality and vitality, both at metropolitan and regional level. For example, vacant shops have been used a proxy for evaluating the effects of the recession on urban living, wellbeing and the deterioration of the physical environment (Brázio, 2013; Burns \& Willis, 2011; EU, 2016; Katyoka \& Wyatt, 2008; Michou, 2013; Seixas, 2013; Whysall, 2011; Wrigley \& Dolega, 2011).

In this paper, we build on previous research associating retail and retail vitality to geomorphological patterns to uncover hotspots of multi-diversity at neighbourhood scale that are crucial to structure the offer and guarantee a greater access to functions. Using the city of Porto, in Portugal, as a case-study, we first make an overall commercial characterization of the city. Then, we identify clusters at local scale where the five different categories of retail considered are present. Through spatial-statistical analysis we dig deeper into the organizational aspects of the commercial network, so that in future works causality effects can be understood, leading to a better managing of urban retail in a perspective of cohesion and equitable access.

\section{METHODOLOGY}

The database for the commercial structure of the metropolitan area of Porto used in this study derived from a database for all the companies that existed on the $31^{\text {st }}$ of January 2017 , compiled by the company Informa D\&B. This database was compiled from data supplied by the Simplified Company Information (IES); the Bank of Portugal; the General Direction for the Administration and Public Employment; the National Statistics Institute (INE); the Ministry of Justice and the Ministry of Finance. Subsequently, the project team did an extensive and time consuming job of georeferencing, fine-tuning and validating the database. The resulting product is a unique database in Portugal, considered to be very accurate and complete. Social information for the study area in question was obtained through the National Statistics Institute (INE, 2018).

Data compiled refers to the identification of the companies; exact location; the classification of their activity (based on the classification of economic activities - CAE); the date of inception; the economic situation; status of the activity and number of workers. From a total of de 28 thousand establishments, over 10 thousand corresponded to activities related to commerce. This selection was based on the typologies listed on the Portuguese law decree $418 / 2009$ of April the $16^{\text {th }}$, which subdivides commercial activities into eight classes: Food and drinks; Fashion; Home; Home appliances and electronics; Leisure and culture; Hygiene and personal care, Restaurants; and Services and other activities. From the complete database of economic companies in the municipality, the companies that corresponded to each of these eight categories were selected, based on their listed CAE. A total of 163 CAEs were considered, 66 concerning wholesale and the others to traditional forms of retail. A more expedite classification of activities was also devised based on the works of Sarma (2006) and Saraiva (2013; 2017), because commerce is an activity that exists in various levels of proximity and necessity. The categories created were "Daily" (including first necessity retail as coffee shops, bakers, butchers, newsstands); "Occasional" (like bookstores, music shops, toy shops, or specialized restaurants); "Exceptional (Comparison)" (that tend to cluster like shops for home products, appliances or car related); "Occasional (Comparison)" (that combine the previous 
two like fashion shops or travel agencies); "Isolated purchase" (that correspond to very rare purchases in a month like cultural or leisure activities, and that generate their own attraction and hence can be located outside central areas).

The analyses were performed at three different scales: point, street and neighborhood (statistical subsections according to INE). For the cartographic representations of the spatial distribution of activities the Kernel density method using ArcGIS software was applied. Both scalar models with a distribution of densities (with a 10 meter cell size) and more simplified conceptual models to display hotspots (with a 20 meter cell size) were computed. Furthermore, a Multiple Correspondence Analysis (MCA) method was applied to generate spatial summaries of the information and identify homogenous groups.

\section{PRESENTATION OF THE CASE STUDY}

Porto is the second largest city in Portugal. Porto's metropolitan area has about 1,7 million inhabitants (almost $20 \%$ of Portugal's), of which around 240 thousand reside in the city of Porto itself.

Today one of the most popular and successful touristic destinations in Europe, Porto witnessed a very famous recovery process since the 1990s. At that time it was characterized, particularly in the downtown area, by ageing population, a shrinking number of inhabitants, and a considerable slice of derelict buildings. During the crisis years, the municipality also witnessed a large decline in the investment to companies, a relatively small rate of survival of companies, a decline in the number of employees and GVA, and a slight decline in exports from 2013 to 2015 (INE, 2018; PORDATA, 2018).

Although it is still losing population today (other variables are again increasing) the city has been in the past two decades the object of an extensive requalification program of buildings and public spaces, associated to the promotion of cultural activities and endogenous resources. At the same time, Porto developed and cemented its position as the central area of a large economic ecosystem in the Northwest of Portugal. Porto's metropolitan area represented, in 2015, almost $16 \%$ of the national GDP, with Porto itself accounting for $23 \%$ of the gross value added (GVA) and $22 \%$ of employees of the Metropolitan Area (INE, 2018). Today, the municipality of Porto has a powerful attraction as a provider of jobs, retail and services. According to the 2011 Census data (INE, 2018) Porto was only surpassed by Lisbon in the capacity to attract employment. For every 100 residents employed in Porto, there was twice as much employees in the city.

According to the database compiled in this research, there are 10.781 commercial establishments in the municipality, $88 \%$ of which open for business, and which employ a total of 36.967 workers (an average of 3,4 per establishment). Activities are mostly concentrated in two larger poles (Figure 1). The first is in the downtown area, and the second to the northwest, in the areas known as Boavista and Bom Sucesso, generally recognized as the city's second center. These two areas are connected by a series of commercial streets and smaller concentrations, which expand by specific channels particularly towards the North and West of the city.

About $34 \%$ of all street segments (between two intersections) contain at least one commercial establishment, with 15\% containing over 3 establishments (Figure 2). Their distribution is diversified, covering the major points of the city and forming very perceptible axes.

The daily activities are, as was to be expected, the most common, representing one third of all commerce and corresponding to over 12 thousand workers (Table 1). Occasional activities comprise 7\% of the establishments; Exceptional (comparison) 16\%; Occasional (comparison) 11\%; and Isolated purchase 4\%. The percentage of the number of workers in each category is practically the same. It should be noted that these numbers are consistent with those found by Saraiva and Pinho (2017) for four other Portuguese medium-sized cities: Aveiro, Leiria, Vila Real and Évora. This means that these values can represent the natural threshold for commercial activities within a city.

Daily establishments are also dominant in over $40 \%$ of street segments with Exceptional (comparison) dominant in $15 \%$ of segments. The pattern of daily activities follows closely the overall pattern shown in Figure 1 , whilst Exceptional (comparison) also do so but with much less density. Occasional (comparison) and Occasional categories show major poles in the two main areas of the city; the downtown and Boavista, with particular and lower density concentrations in other relevant areas. Isolated activities have only a perceptible density downtown. 


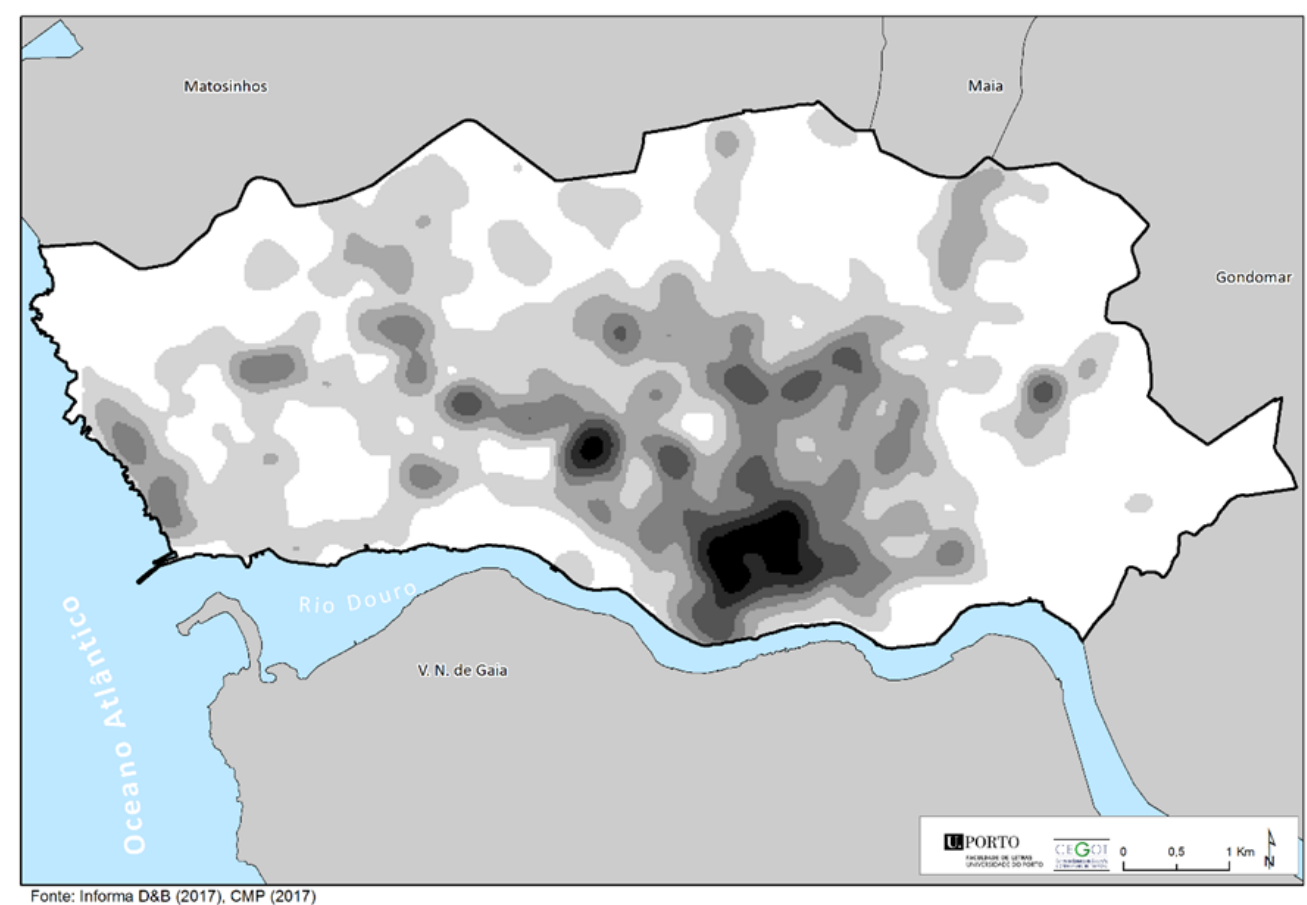

Figure 1 - Distribution model of commercial activities in the city of Porto. Source: Authors based on datasource: Informa D\&B (2017).

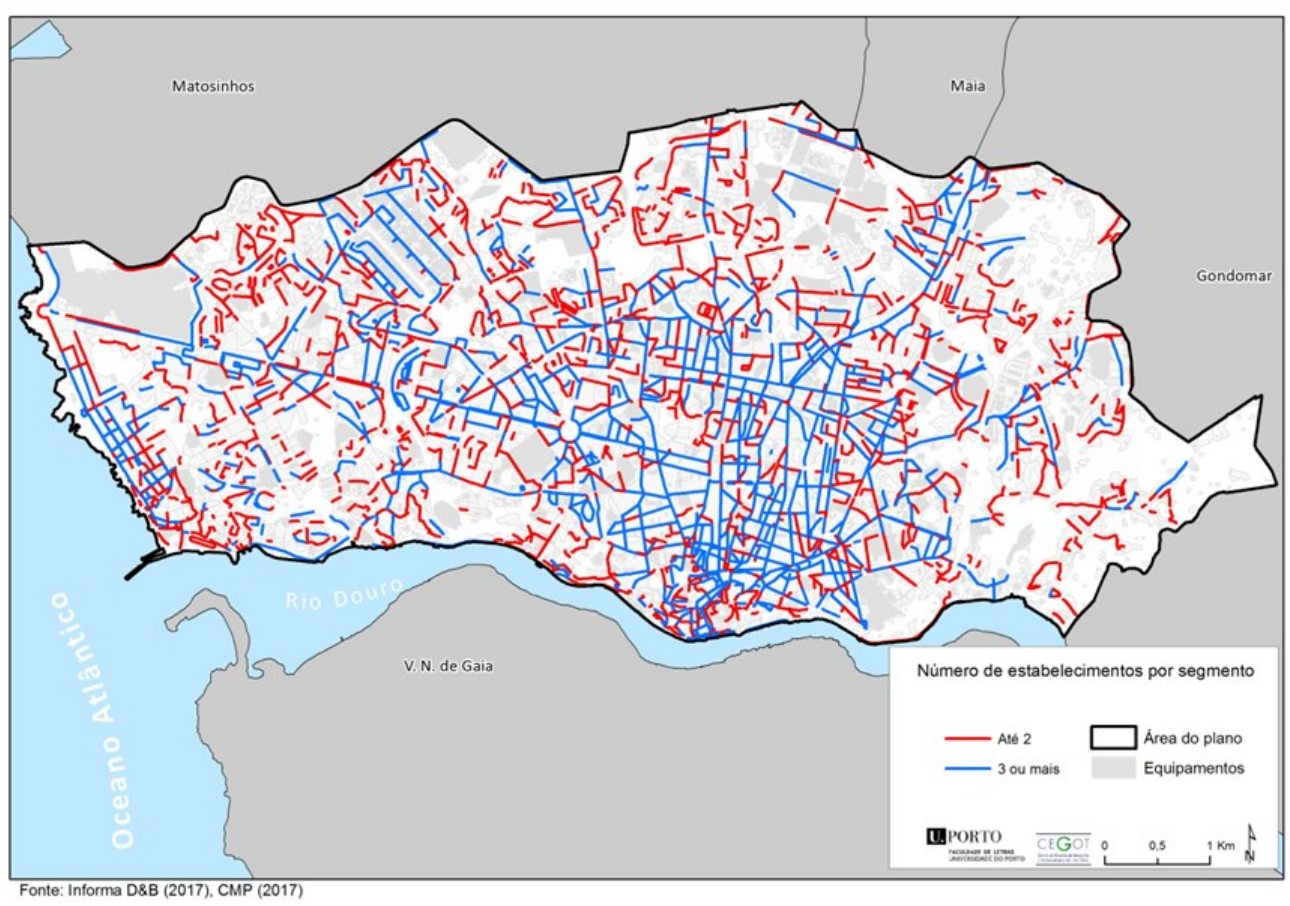

Figure 2 - Distribution of commercial activities by street segments . Source: Authors based on datasource: Informa D\&B (2017). 
Multi-diversity clusters of commercial activities in the city of Porto: how neighbourhood concentrations shape the municipal hierarchy

Table 1 - Frequency of the commercial categories in the municipality of Porto. Source: Authors based on datasource: Informa D\&B (2017).

\begin{tabular}{|c|c|c|c|c|}
\hline \multirow{2}{*}{ Category } & \multicolumn{2}{|c|}{ Establishments } & \multicolumn{2}{c|}{ Jobs } \\
\cline { 2 - 5 } & Frequency & Percentage & Frequency & Percentage \\
\hline Retail & 8265 & 76,7 & 27785 & 75,2 \\
\hline Daily (coffee shops, bakers,...) & 3566 & 33,1 & 12254 & 33,1 \\
\hline Occasional (bookstores, music shops,...) & 719 & 6,7 & 2199 & 5,9 \\
\hline Occasional (Comparison) (fashion, travel agencies,...) & 1164 & 10,8 & 4442 & 12,0 \\
\hline Exceptional (Comparison) (home products, car appliances,...) & 1757 & 16,3 & 6212 & 16,8 \\
\hline Isolated (cinema, rent-a-car,...) & 412 & 3,8 & 1270 & 3,4 \\
\hline Others (not specified) & 647 & 6,0 & 1408 & 3,8 \\
\hline Wholesale & 2516 & 23,3 & 9182 & 24,8 \\
\hline Total & 10781 & 100,0 & 36967 & 100,0 \\
\hline
\end{tabular}

\section{ANALYSIS}

The previous overall geographical analysis reveals the location of the great poles of commerce. Although it is inferred that the greatest concentrations of stores also lead necessarily to diversity in store types, this is not entirely true. Poles of commerce in residential locations, for example, although they present some density, are majorly composed of first necessity (daily) stores, irregularly complemented with Exceptional (comparison) stores like home products or, to a lesser extent, Occasional (comparison) stores like fashion.

Therefore, in this research we tried to find the most diverse locations (poles of commerce) in the city in terms of establishments to see if they coincided, or not, with the overall concentrations at city-scale. For that, an analysis was performed identifying locations at a 50, 100, 150, 200 and 250 meters where all the five categories of stores were present. The distance was measured as a buffer from each store. Stores classified as 'others', as well as wholesale establishments were at this time excluded.

Table 2 shows that at 50 meters, only around 8\% of Daily and Exceptional (comparison) stores are in the vicinity of all other categories which confirms that these are the stores types that most tend to be on their own throughout the city. The other three categories have percentages between 15-20\%. At 100 meters, it is noticeable that half of all the city's Occasional (comparison) and Isolated purchase store categories are in the vicinity of at least one store of all other types. This shows the necessity these stores have to be in denser areas. At 150 meters, the increase is about $20 \%$ in all store categories. Over half of the city's Daily and Exceptional (comparison) stores are around stores of all other types, with the numbers for the other three categories ranging from $60-70 \%$. The values become more even as the distance buffer increases. At 200 meters, between $70-80 \%$ of all store categories are in the vicinity of one another, whereas this percentage increases to between $80-90 \%$ for 250 meters, i.e. around 3 to 5 minutes walking. The remainder $10 \%$ of shops are located in peripheral areas of the city, mostly related to residential quarters, and are majorly of the Daily category (over 50\%) and of the Exceptional (comparative) category (almost 30\%). Around one third of these stores have opened for business after 2010.

Figure 3 shows the locations in the city that have all five store categories within a 50 meter radius. One

Table 2 - Percentage of the overall number of stores, by type, that have at least one store of all the other types at a given distance.

\begin{tabular}{|l|c|c|c|c|c|}
\hline \multicolumn{1}{|c|}{ Category / distance } & $50 \mathrm{~m}$ & $100 \mathrm{~m}$ & $\mathbf{1 5 0} \mathbf{m}$ & $\mathbf{2 0 0} \mathbf{m}$ & $\mathbf{2 5 0} \mathbf{m}$ \\
\hline Daily & $8,2 \%$ & $35,6 \%$ & $57,9 \%$ & $73,1 \%$ \\
\hline Occasional & $14,3 \%$ & $43,3 \%$ & $63,8 \%$ & $78,6 \%$ & $70,4 \%$ \\
\hline Exceptional (Comparison) & $7,4 \%$ & $31,1 \%$ & $54,9 \%$ & $80,3 \%$ \\
\hline Occasional (Comparison) & $16,7 \%$ & $50,2 \%$ & $72,2 \%$ & $83,8 \%$ & $80,3 \%$ \\
\hline Isolated & $19,9 \%$ & $52,0 \%$ & $68,7 \%$ & $81,8 \%$ & $89,1 \%$ \\
\hline
\end{tabular}




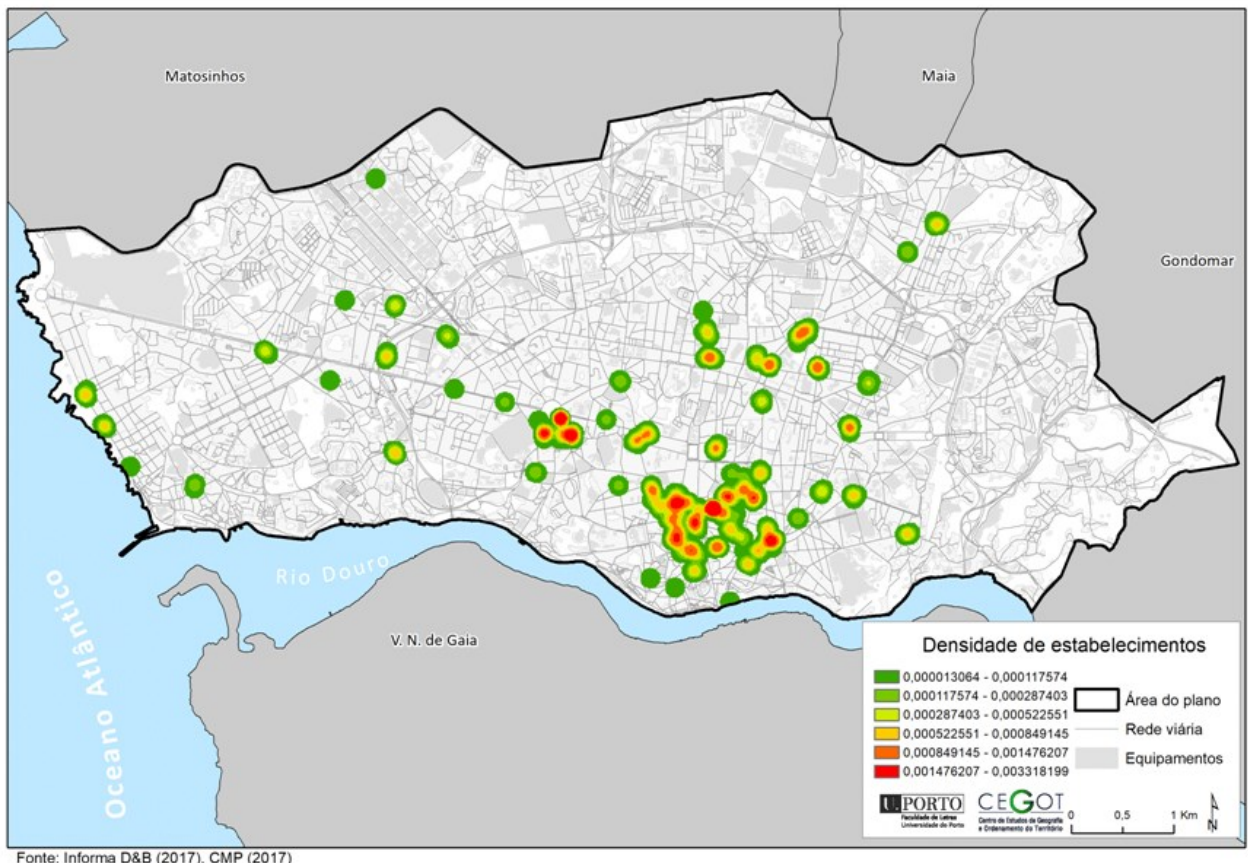

Figure 3 - Density of establishments which, in a 50 meter radius, are close to all the five categories considered. Source: Authors based on datasource: Informa D\&B (2017)

third of these stores opened for business prior to 1990, and another third after 2010. There is a slighter tendency for newer stores in the western side of the city and older stores downtown, but overall both age types co-exist in these locations.

Excluding the downtown and the Boavista concentrations, there are around 35 specific locations around the city where all five types of stores exist within a 50 meter radius. These correspond to major crossings, major residential/service areas with shopping arcades on the ground floors, relevant commercial streets (such as Cedofeita, Constituição, Fernão de Magalhães, or Costa Cabral) and other notable locations such as facing the seaside at Foz (the concentration most to the west). The eastern and northern sides of the city are majorly deprived of these poles.

Through a Multiple Correspondence Analysis (MCA) joining the commercial density by commercial types with the age of the establishments, it is possible to reach an overall classification by subsection (an administrative division more or less corresponding to a city block) (Figure 4). The city is thus divided into five typologies. A first (only $4 \%$ of subsections) represents a high intensity of commercial activity in all categories with both older and newer establishments (average 20 years). The downtown and the Boavista areas belong to this category. A second typology ( $20 \%$ of subsections) has the same variety of establishments and more or less the same average age as the first typology, but the density is clearly lower. The third typology ( $23 \%$ of subsections) has a low density of activities yet an older establishment average age (around 30 years old). The fourth typology (19\% of subsections) has a very low commercial density but a very young establishment average age (10 years, with no activities older than 20 years). These are intrinsically associated to the main and newer residential areas within the city. Finally, the last category (35\% of subsections) represents locations without stores.

But what is interesting is that only half of the stores within the 50 meter clusters are in subsections described in the first typology (intense commercial activity) (see Table 3). This means that the other half are in the other typologies, particularly the second. As the distance increases, multi-diversity clusters containing all five categories are primarily in typology 2 (always around 53\%), whereas the percentage of stores in typology 1 decreases in favor of typology 3. The main commercial areas have so much density that they naturally have a multidiversity of retail categories. But as we move from these areas to lesser dense parts of the city, the importance of such commercial concentrations increases, and as the distance buffer is augmented it is possible to reach a wider variety of stores. To be noted that there is a wider variety of concentrations of the five retail categories within typology 3 (higher store age), than in typology 4 (lower store age). This may attest to the importance of wellestablished commercial concentrations (in roundabouts or older commercial streets) in the structuring of neighborhood retail, particularly outside the downtown and central area. 


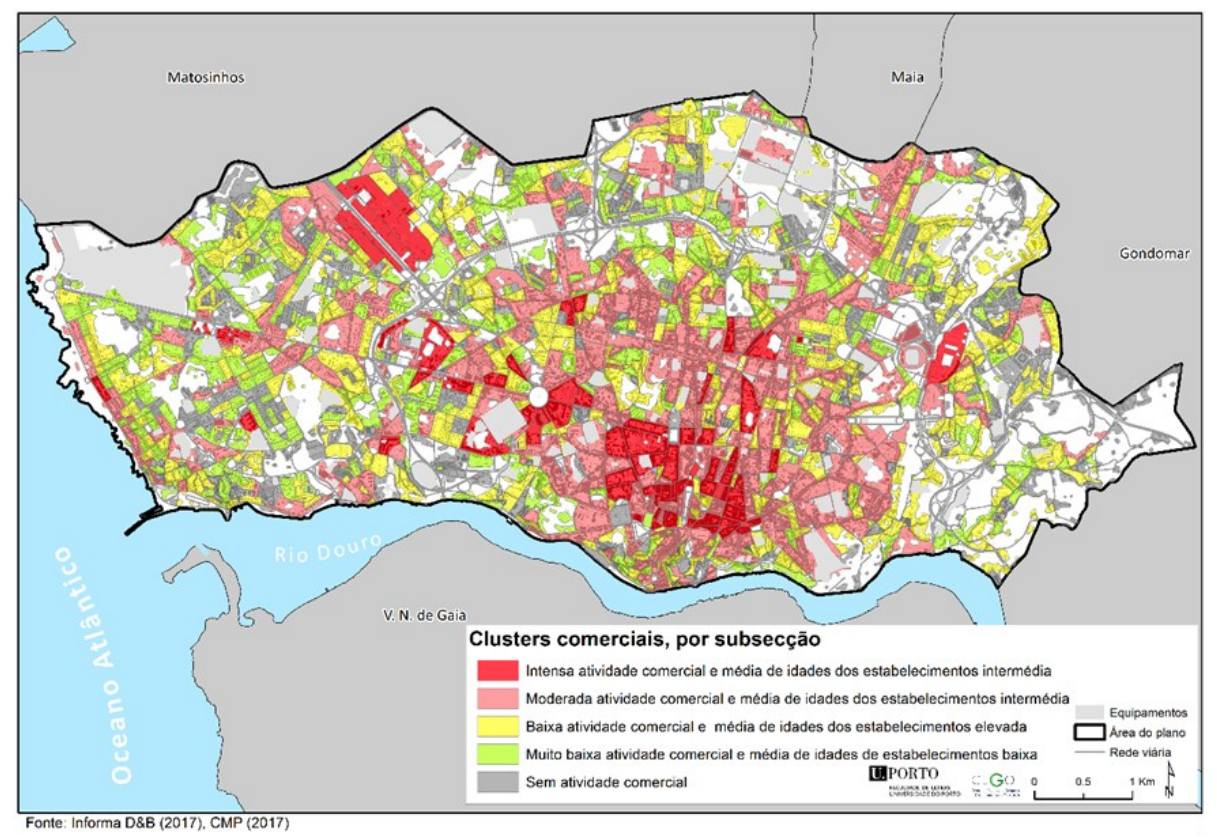

Figure 4 - Commercial clusters by subsection. Source: Authors based on datasource: Informa D\&B (2017).

Table 3 - Percentage of the overall number of stores within the multi-diversity distance clusters, by typology of subsection.

\begin{tabular}{|c|c|c|c|c|c|}
\hline & Typology 1 & Typology 2 & Typology 3 & Typology 4 & Typology 5 \\
\hline 50 meters & $50,9 \%$ & $44,6 \%$ & $3,8 \%$ & $1,8 \%$ & $0,0 \%$ \\
\hline 100 meters & $40,5 \%$ & $51,2 \%$ & $6,5 \%$ & $3,8 \%$ & $0,0 \%$ \\
\hline 150 meters & $35,1 \%$ & $52,5 \%$ & $8,7 \%$ & $4,8 \%$ & $0,0 \%$ \\
\hline 200 meters & $31,7 \%$ & $53,4 \%$ & $10,2 \%$ & $5,8 \%$ & $0,0 \%$ \\
\hline 250 meters & $30,0 \%$ & $52,5 \%$ & $11,7 \%$ & & $0,0 \%$ \\
\hline
\end{tabular}

\section{FINAL REMARKS}

The geography of shops and commercial hierarchies within a city have been extensively debated over almost the last century (see a review in Saraiva \& Pinho, 2017). However, societal, urbanistic and commercial shifts, whether the influence of technology on retail (web-purchases for example), the proliferation of multi-commercial establishments and multinational brands, the rise in tourism and power of purchase and, on the other side of the coin, the economic crisis, have all contributed to challenge these long established hierarchies. Shifts in "street commerce", particularly in city centers have never been as volatile, as the city adapts to post-modern needs and caters to new types of experiences. Yet basic necessities remain the same. Residents still need to buy bread, coffee and newspapers at the corner shop. They value living close to first necessity shops and services. Shops may be attracted to locations with more people, but people are also attracted to locations with more shops.

What this statistical and geographical analysis has shown is that Daily and Exceptional (Comparison) stores are very important to structure neighborhood commercial poles. Cities can only have (and want to have) so much large scale concentrations of commercial establishments, more than often (as in the case of Porto) associated to the downtown or to the major services and employment areas (not counting, of course, shopping malls). But moderate locations of commercial concentration, that make the transition from the central to the residential areas, can and should provide multi-functionalities. These concentrations within 50 meters, appearing in crossroads, structuring streets and near main residential areas, are natural hubs for sociability, but should also be natural hubs to guarantee the access to first necessity functions to the greater number of residents possible. They could also serve as locations for transport stops and so on. 
In this initial analyses we considered clusters containing one shop of each category, regardless of the particular activities within each category. Analyzing more specifically which activities are within these clusters is the next step, uncovering local clusters with a wider range of functions.

\section{REFERENCES}

BALSAS, C. J. L. (2001). Commerce and the European city center: Modernization, regeneration and management. European Planning Studies, 9(5), 677-682. doi:Doi 10.1080/09654310120057377

BARATA-SALGUEIRO, T., \& ERKIP, F. (2014). Retail planning and urban resilience - An introduction to the special issue. Cities, 36(0), 107-111. doi:http://dx.doi.org/10.1016/j.cities.2013.01.007

BEAVERSTOCK, J. V., FAULCONBRIDGE, J. R., \& HOYLER, M. (2011). Globalization and the City. In A. Leyshon, L. Roger, L. McDowell, \& P. Sunley (Eds.), The SAGE Handbook of Economic Geography (pp. 189-201): Sage London.

BEYARD, M. (2009). The retail bubble. Urban Land, 68(1), 30.

BOLTON, T., \& VAUGHAN, L. S. (2014). The Past, Present and Futures of the High Street: report on the Closing Conference of the Adaptable Suburbs project. Retrieved from

BOSCHMA, R. A. (2010). The aims and scope of evolutionary economic geography. In R. A. Boschma \& R. Martin (Eds.), The Handbook of Evolutionary Economic Geography: Edward Elgar, Cheltenham.

BRÁZIO, A. (2013). Vende-se. Lisboa: GHOST Editions

BRUNETTA, G., \& CALDARICE, O. (2014). Self-organisation and retail-led regeneration: A new territorial governance within the Italian context. Local Economy, 29(4-5), 334-344. doi:10.1177/0269094214535555

BURNS, E., \& WILLIS, E. (2011). Empty shops in Australian regional towns as an index of rural wellbeing. Rural Society, 21(1), 2131. doi:10.5172/rsj.2011.21.1.21

CACHINHO, H. (2006). Consumactor: da condição do indivíduo na cidade pós-moderna. Finisterra: Revista portuguesa de geografia, 41(81), 33-56.

CACHINHO, H. (2014). Consumerscapes and the resilience assessment of urban retail systems. Cities, 36(0), 131-144. doi:http://dx.doi.org/10.1016/j.cities.2012.10.005

CHRISTIAN, H., BULL, F., MIDDLETON, N., KNUIMAN, M., DIVITINI, M., HOOPER, P., \& GILES-CORTI, B. (2011). How important is the land use mix measure in understanding walking behaviour? Results from the RESIDE study. International Journal of Behavioral Nutrition and Physical Activity, 8(55). doi:10.1186/1479-5868-8-55

EMERY, J. (2006). Bullring: A case study of retail-led urban renewal and its contribution to city centre regeneration. Journal of Retail and Leisure Property, 5(2), 121-133. doi:10.1057/palgrave.rlp.5100020

EU. (2016). Urban Europe - Statistics on cities, towns and suburbs. Retrieved from Luxemburg. available at: http://ec.europa.eu/ eurostat/documents/3217494/7596823/KS-01-16-691-EN-N.pdf/0abf140c-ccc7-4a7f-b236-682effcde10f:

FINDLAY, A., \& SPARKS, L. (2009). Literature review: policies adopted to support a healthy retail sector and retail led regeneration and the impact of retail on the regeneration of town centres and local high streets. Retrieved from

GRANT, J., \& PERROTT, K. (2011). Where Is the Cafe? The Challenge of Making Retail Uses Viable in Mixed-use Suburban Developments. Urban Studies, 48(1), 177-195. doi:Doi 10.1177/0042098009360232

HART, C., FARRELL, A. M., STACHOW, G., REED, G., \& CADOGAN, J. W. (2007). Enjoyment of the Shopping Experience: Impact on Customers' Repatronage Intentions and Gender Influence. The Service Industries Journal, 27(5), 583-604. doi:10.1080/02642060701411757

HART, P. M., \& DALE, R. (2014). With or without you: The positive and negative influence of retail companions. Journal of Retailing and Consumer Services, 21(5), 780-787. doi:http://dx.doi.org/10.1016/j.jretconser.2014.06.004

HAUGEN, K. (2011). The Advantage of 'Near': Which Accessibilities Matter to Whom? European Journal of Transport and Infrastructure Research, 11(4), 368-388.

INE. (2018). Statistics Portugal. www.ine.pt/.

KATYOKA, M., \& WYATT, P. (2008). An investigation of the nature of vacant commercial and industrial property. Planning, Practice \& Research, 23(1), 125-145.

LOWE, M. (2005). The regional shopping centre in the inner city: A study of retail-led urban regeneration. Urban Studies, 42(3), 449-470. doi:Doi 10.1080/00420980500035139 
Multi-diversity clusters of commercial activities in the city of Porto: how neighbourhood concentrations shape the municipal hierarchy

MANAUGH, K., \& KREIDER, T. (2013). What is mixed use? Presenting an interaction method for measuring land use mix. The Journal of Transport and Land Use, 6(1), 63-72. doi:10.5198/jtlu.v6i1.291

MARQUES, T. (2004). Portugal na Transição do século XX/XXI: Retratos e Dinâmicas Territoriais. Afrontamento: Porto.

MCCONVILLE, M., RODRÍGUEZ, D., CLIFTON, K., CHO, G., \& FLEISCHHACKER, S. (2011). Disaggregate Land Uses and Walking. American Journal of Preventive Medicine, 40(1), 25-32.

MENDES, J. (2011). O Futuro das Cidades Coimbra: Edições Minerva.

MICHOU, M. (2013). Athens streetside arcades: silent gestures of minor occupation. Urbanistica, 1(3), 29-36.

MUSSO, F. (2011). Small Retailing, Town Centres and Inland Territories. An'Extended Town Centre Management'Perspective. Public Administration \& Regional Studies, 3rd Year(2), 6.

NIJKAMP, P., \& KOURTIT, K. (2013). The "New Urban Europe": Global Challenges and Local Responses in the Urban Century. European Planning Studies, 21(3), 291-315. doi:10.1080/09654313.2012.716243

PECORARO, M., \& UUSITALO, O. (2014). Exploring the everyday retail experience: The discourses of style and design. Journal of Consumer Behaviour, 13(6), 429-441. doi:10.1002/cb.1492

PINE, B., \& GILMORE, J. (1999). The Experience Economy: Work is Theatre and Every Business a Stage. Harvard Business School Press, Cambridge, MA.

PORDATA. (2018). Base de dados Portugal Contemporâneo. http://www.pordata.pt.

PROCOPIUCK, M., \& DJALO, A. B. (2008). Comércio como Fator de Coesão dos Centros Urbanos: caso da revitalização comercial do centro de Curitiba. Turismo-Visão e Ação, 10(3), 313-334.

RABBANEE, F. K., RAMASESHAN, B., WU, C., \& VINDEN, A. (2012). Effects of store loyalty on shopping mall loyalty. Journal of Retailing and Consumer Services, 19(3), 271-278. doi:http://dx.doi.org/10.1016/j.jretconser.2012.02.001

REIMERS, V., \& CLULOW, V. (2004). Retail concentration: a comparison of spatial convenience in shopping strips and shopping centres. Journal of Retailing and Consumer Services, 11(4), 207-221. doi:http://dx.doi.org/10.1016/S0969-6989(03)00038-9

SARAIVA, M. (2013). The morphological sense of commerce: Symbioses between commercial activity and the form and structure of Portuguese medium-sized cities. (PhD in Civil Engineering - Planning of Environment and Territory), Faculty of Engineering of the University of Porto, Porto, Portugal.

SARAIVA, M., \& PINHO, P. (2017). Spatial modelling of commercial spaces in medium-sized cities. GeoJournal, 82(3), 433-454. doi:10.1007/s10708-015-9694-7

SARMA, A. (2006). The social logic of shopping - A syntactic approach to the analysis of spatial and positional trends of community centre markets in New Delhi. (MSc Built Environment: Advanced Architectural Studies), University College London, Bartlett School of Graduate Studies.

SEIXAS, J. (2013). A cidade na encruzilhada: repensar a cidade ea sua política: Edições Afrontamento.

UN. (2015). Transforming our world: the 2030 agenda for sustainable development (RES/70/1). Retrieved from Seventieth United Nations General Assembly, New York. available at: http://www.un.org/ga/search/view_doc.asp?symbol=A/ $\mathrm{RES} / 70 / 1 \&$ Lang=E:

VAUGHAN, R., \& VALERIE, C. (2009). Retail centres: it's time to make them convenient. International Journal of Retail \& Distribution Management, 37(7), 541-562. doi:10.1108/09590550910964594

VILLAIN, J. (2011). The impact of urban form on the spatial distribution of commercial activities in Montréal. (M.SC thesis), Concordia University, Canada.

WHYSALL, P. (2011). Managing decline in inner city retail centres: From case study to conceptualization. Local Economy, 26(1), 3-17.

WRIGLEY, N., \& DOLEGA, L. (2011). Resilience, fragility, and adaptation: new evidence on the performance of UK high streets during global economic crisis and its policy implications. Environment and Planning A, 43(10), 2337-2363. 
Página intencionalmente dejada en blanco 


\title{
As feiras de rua em contextos metropolitanos: Porto e Barcelona
}

\author{
Márcio Ferreira (a), Catarina Maia (b), Teresa Sá Marques (c) \\ (a) Faculdade de Letras da Universidade do Porto, marcioferreira16@hotmail.com \\ (b) Centro de Estudos de Geografia e Ordenamento do Território (CEGOT)/Faculdade de Letras da Universidade do Porto (FLUP), \\ catarina.maia2@gmail.com \\ (c) Centro de Estudos de Geografia e Ordenamento do Território (CEGOT)/Faculdade de Letras da Universidade do Porto (FLUP), \\ teresasamarques@gmail.com
}

\begin{abstract}
Resumo
As feiras, enquanto atividade comercial, têm desempenhado um importante papel na dinamização das cidades. Depois de quase terem desaparecido das cidades, nos últimos anos têm reforçado o seu papel na animação urbana e na atração turística. Mas o seu papel, durante a crise e no pós-crise, poderá ter-se alterado.

Esta pesquisa foca-se na cidade do Porto e em Barcelona. Partindo de um levantamento das feiras e das suas principais características sócio-funcionais, desenvolveu-se uma tipologia da oferta e das respetivas procuras para a cidade do Porto, atualmente encontra-se em desenvolvimento na cidade de Barcelona. O principal objetivo é demonstrar a relevância intraurbana destas atividades socioeconómicas na animação dos diferentes sectores destas duas cidades. Neste artigo ir-se-á apresentar os primeiros resultados desta investigação.
\end{abstract}

Palavras chave: Geografia, Feiras, Economia Alternativa, Porto, Barcelona

\section{INTRODUÇÃO}

Ao longo da década passada, grande parte dos países europeus, e nomeadamente Portugal e Espanha, entraram num contexto de crise económica e financeira. Em resposta à crise, os governos implementaram um conjunto de medidas de austeridade que tiveram fortes impactos na vida económica e financeira das sociedades, sobretudo dos grupos sociais mais desfavorecidos e vulneráveis. Simultaneamente, as políticas públicas impulsionaram uma nítida retração dos apoios e da proteção social (Moreira, 2016; Ribeiro, R., Frade, C., Coelho, L., \& Ferreira-Valente, A., 2015).

Face a este contexto, surgiram novas iniciativas económicas, verificou-se um aumento de alternativas para ultrapassar as dificuldades económicas existentes, tendo-se desenvolvido novas atividades ligadas a competências existentes. Surgiram novas formas de pensar, de estar e de agir numa conjuntura de crise, procurando novas soluções e alternativas para combater as necessidades. Desenvolveram-se economias normalmente denominadas alternativas.

As atividades económicas alternativas surgem sobretudo em contextos de crise económica e social, procurando ser uma opção ao atual sistema económico capitalista, pois representam uma tentativa para criar outras opções e soluções, através de planos e estratégias alternativas de desenvolvimento económico, sobretudo a nível comunitário e local.

Algumas das principais atividades que se relacionam com a economia alternativa são: economia de partilha, economia solidária, bancos de tempo, moedas alternativas, hortas comunitárias, mercados de troca, mercados de usados, fleamarkets, espaços de coworking, etc (Botsman \& Rogers, 2009; Schor, 2014; Gibson-Graham, 2006; Hernández, 2017).

Estas atividades são sobretudo suportadas por redes de colaboração entre indivíduos ou organizações, de carácter sobretudo informal, sustentadas na troca de informação e conhecimento, mas também de bens e serviços (Méndez, 2015). Podem ser consideradas como atividades inovadoras, onde há mobilização de diferentes agentes na procura de respostas para problemas concretos. Além de poderem criar inovação económica, criam sobretudo inovação social, na medida em que, com um maior ou menor grau de criatividade, desenvolvem capacidades e competências nos indivíduos ou comunidades (Ferreira, 2017). 
As economias alternativas são consideradas, por alguns autores, como motores essenciais de apoio à resiliência local e urbana. Como refere Thieme (2016) "em questões de resiliência oferecem uma metáfora apropriada para ganhar impulso para futuros econômicos alternativos, baseados em lógicas de solidariedade e reciprocidade" (Thieme, 2016: p.2). Ricardo Méndez refere que "é nas cidades onde as ações de resistência, juntamente com a construção de novas alternativas políticas e económicas, têm uma maior presença e contribuem hoje para delinear novos cenários do futuro que são possíveis pela ação coletiva de uma cidadania progressivamente organizada. É a partir desta dupla perspetiva que o significado dessas redes colaborativas, que propõem uma economia com valores para avançar na recuperação das áreas urbanas após a crise, que pode ser identificado com o conceito de resiliência" (Méndez, 2015: p.15).

Os mercados de troca, fleamarkets, feiras, mercados de levante e os mercados informais são bons exemplos de práticas de economia alternativa. É notório que as feiras, enquanto atividades comerciais que se desenvolveram ao longo dos séculos, têm desempenhado um importante papel na construção e dinamização das cidades.

De acordo com o levantamento efetuado por Ferreira (2017), com a crise de 2008 houve um aumento significativo da criação de novos mercados e feiras na cidade do Porto, que aparecem com novos formatos e conceitos, sobretudo orientados para o artesanato e para a venda de produtos em segunda mão. Atualmente, continuam a estar presentes e perspetiva-se um eventual reforço da sua importância na animação urbana e turística da cidade.

As feiras são espaços económicos alternativos e muitas vezes de animação cultural. São mais que "mercados de trocas", são eventos socioculturais orientados para públicos heterogéneos. Além disso, são espaços que reúnem pessoas, fomentam a sociabilidade urbana e dinamizam os tecidos urbanos envolventes e o comércio local.

\section{ENQUADRAMENTO METODOLÓGICO E OBJETIVOS}

Este artigo é o resultado de um ensaio metodológico que se encontra atualmente em desenvolvimento nas cidades do Porto e Barcelona. O principal objetivo é demonstrar a relevância destas atividades económicas na vida económica e social destas duas cidades, em especial durante a crise e no pós-crise. Apresentar-se-á ao longo do artigo os primeiros resultados obtidos. De referir ainda que se excluiu deste estudo todos os mercados municipais, pois não se enquadram nesta pesquisa ${ }^{1}$. Deste modo, esta investigação tem objetivos:

$\checkmark \quad$ Caraterizar a oferta de feiras e mercados de rua, e de que forma a crise e o pós-crise tiveram impacto nesta oferta;

$\checkmark \quad$ Conhecer as dinâmicas recentes, tanto do lado da oferta e da procura, das feiras nos diferentes sectores da cidade;

$\checkmark \quad$ Demonstrar a relevância destas atividades económicas na vida económica e social destas duas cidades, tanto durante a crise como no pós-crise.

De forma a cumprir estes objetivos adotou-se uma metodologia testada no Porto (Ferreira, 2017). Os dados referentes às feiras da cidade do Porto correspondem a um levantamento efetuando entre 2016 e 2017. Os dados da cidade de Barcelona foram recolhidos em fevereiro de 2018. Em termos metodológicos começou-se por fazer a identificação e inventariação de todas as feiras e mercados de rua existentes, bem como de alguns dados de caraterização geral (por exemplo: periodicidade, horário) com base nas fontes oficiais: Website da Câmara Municipal do Porto, InfoPorto, PortoLazer, Agenda Virtual, mercatsbcn, ajuntament.barcelona e guia.barcelona.cat. De seguida realizou-se a cartografia das feiras, tendo em vista a localização das mesmas, utilizando-se as ferramentas Google Earth e ArcGis.

$\mathrm{Na}$ cidade do Porto já foi realizado todo o levantamento funcional. Na cidade de Barcelona só aplicamos o levantamento a 4 feiras, de forma a testar o método (efetuado presencialmente). Nesse levantamento recolheram -se vários dados para a análise e caraterização das feiras, entre os quais: $n^{\circ}$ de stands/bancas, $n^{\circ}$ de vendedores, $\mathrm{n}^{\circ}$ de clientes, área aproximada da feira em $\mathrm{m}^{2}$, área aproximada das bancas em $\mathrm{m}^{2}$ e tipos de produtos comercializados. Os próximos passos desta investigação passam pela elaboração de um levantamento funcional a todas as

\footnotetext{
1 "A principal razão dessa exclusão passa pelo facto de considerar-se, baseado nesta analise, que os Mercados que são diários, fixos, de venda de produtos de consumo diário e que possuem lojas físicas e fixas, não se enquadram neste tema da Economia Alternativa, pois nesses mercados não existem certas caraterísticas que são necessárias para se considerar como sendo uma economia alternativa. Alguns exemplos: 1) os Mercados Municipais necessitam de ter infraestruturas adequadas ao comércio, entre as quais instalações sanitárias, rede de água pública, rede elétrica, entre outros requisitos que fazem deles atividades de comércio a retalho sedentário; 2) nem sempre, quem comercializa nos mercados municipais, são os próprios produtores, mas sim subcontratados ou apenas comerciantes retalhistas; 3) funcionam praticamente todo o dia, têm um horário mais alargado." (Ferreira, 2017)
} 
feiras da cidade de Barcelona, de modo a ser possível comparar os resultados obtidos com o levantamento realizado às feiras da cidade do Porto.

Em termos metodológicos esta investigação também compreende inquéritos e entrevistas semiestruturadas aos clientes e feirantes das feiras do Porto e de Barcelona, bem como aos seus organizadores, de modo a conhecer e compreender as suas dinâmicas e suas características, antes e no pós-crise. Na cidade do Porto, já foram realizadas um conjunto significativo de inquéritos e entrevistas. Nesta comunicação será apresentada a parte inicial desta investigação, ainda em curso.

\section{AS FEIRAS NAS CIDADES DO PORTO E BARCELONA}

De acordo com o levantamento efetuado na cidade do Porto, existem 34 feiras e mercados de rua, dos quais 28 realizam-se durante o ano inteiro, com diferentes periodicidades, características e localizações. As restantes 6 feiras correspondem às feiras que apesar de terem uma certa regularidade são mais espaçadas no tempo e/ou apresentam uma quebra na sua realização. Essas 6 feiras têm frequências diferentes: 2 delas são anuais e as outras 4 possuem um carácter sazonal, isto é, realizam-se entre março a setembro.

$\mathrm{Na}$ cidade de Barcelona existem atualmente 66 feiras e mercados de rua, das quais 41 realizam-se o ano inteiro $(62,1 \%)$ com diferentes periodicidades, funcionalidades e localizações. As restantes 25 feiras realizam-se também de forma regular, mas têm uma particularidade, encerram em determinados meses, quebrando assim um pouco a sua regularidade. Mais concretamente: 10 feiras encerram durante dois meses (julho e agosto), 8 encerram em agosto e as restantes 7 encerram por mais de 3 meses (sendo consideradas como sazonais, à exceção de uma que é anual).

Na figura 1 pode-se visualizar o mapa da localização das feiras na cidade do Porto, onde se percebe que existe uma grande centralidade na localização das feiras na cidade do Porto. Mais concretamente, 22 das 34 feiras localizam-se no centro histórico e na "Baixa" do Porto e as restantes 12 feiras distribuem-se de forma mais dispersa pelo resto da cidade.

As feiras foram classificadas atendendo a algumas caraterísticas: periodicidade da feira, tipo de localização (fixa, móvel ou ambos), tipo de espaço onde se realizam (ao ar livre, em espaços fechados ou em ambos) e sua nomenclatura (nome atribuído).

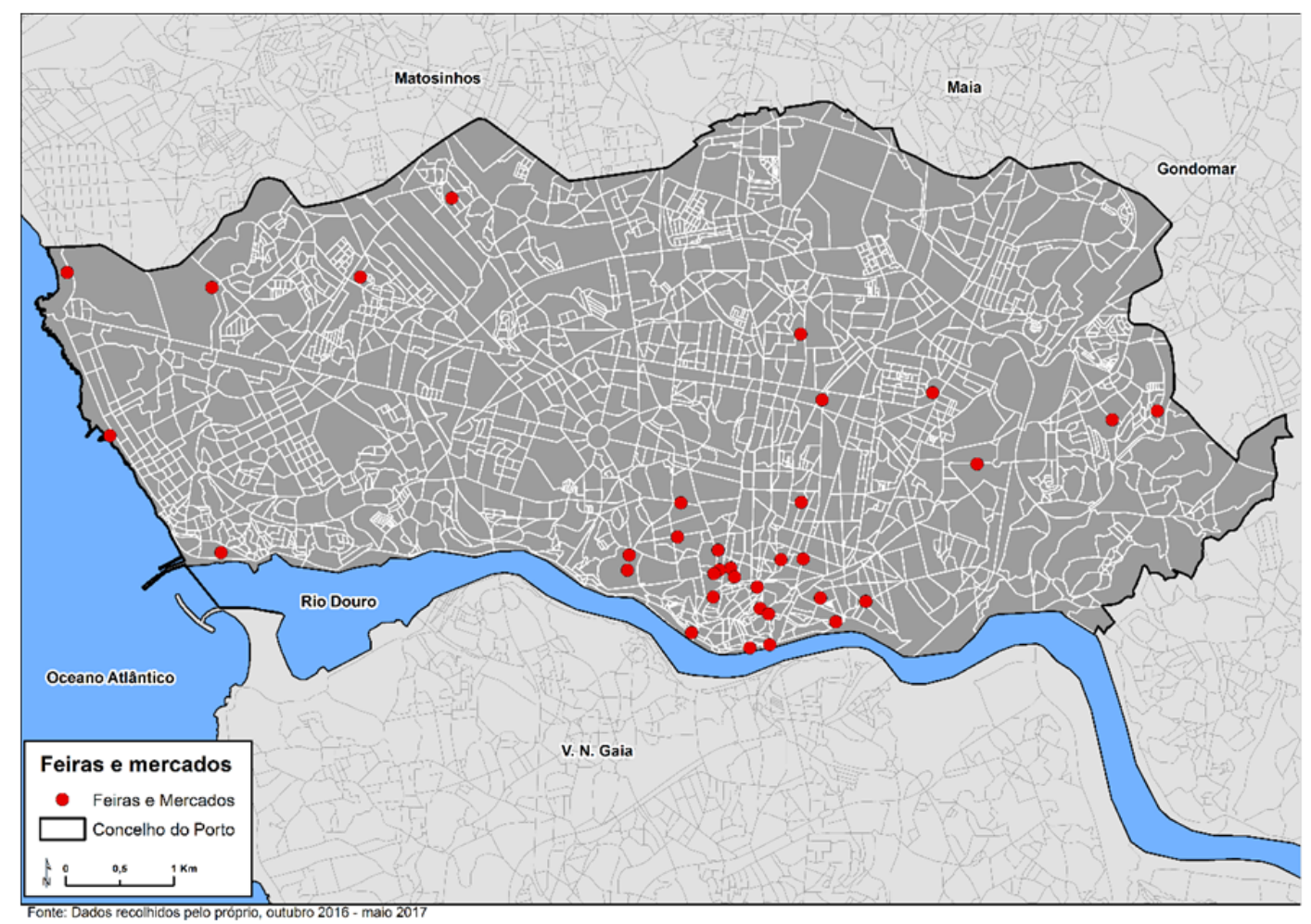

Figura 1 - Localização das feiras na cidade do Porto, 2017. Fonte: Elaboração própria 
Na figura 2 apresenta-se o mapa da localização das feiras na cidade de Barcelona, onde se constata que existe um padrão geográfico menos concentrado, quando comparado com o Porto. As feiras em Barcelona distribuem-se na malha urbana havendo assim um padrão locativo mais ou menos distribuído: 38 das 66 feiras localizam-se sobretudo no sul da cidade (57,6\%); um terço localiza-se junto ao centro histórico de Barcelona e as restantes 44 feiras dispersam-se na cidade. Assim, comparando com o Porto, as feiras da cidade de Barcelona apresentam um carácter mais disperso, com algumas aglomerações. Tal facto poderá relacionar-se com a diferença de tamanhos de ambas as cidades, onde o mais expectável será a existência de uma maior dispersão na cidade com maiores dimensões, como é o caso de Barcelona.

De seguida, efetuou-se uma classificação das feiras, através da informação disponível em alguns sítios: Website da Câmara Municipal do Porto, InfoPorto, PortoLazer, Agenda Virtual, mercatsbcn, ajuntament.barcelona e guia.barcelona.cat.

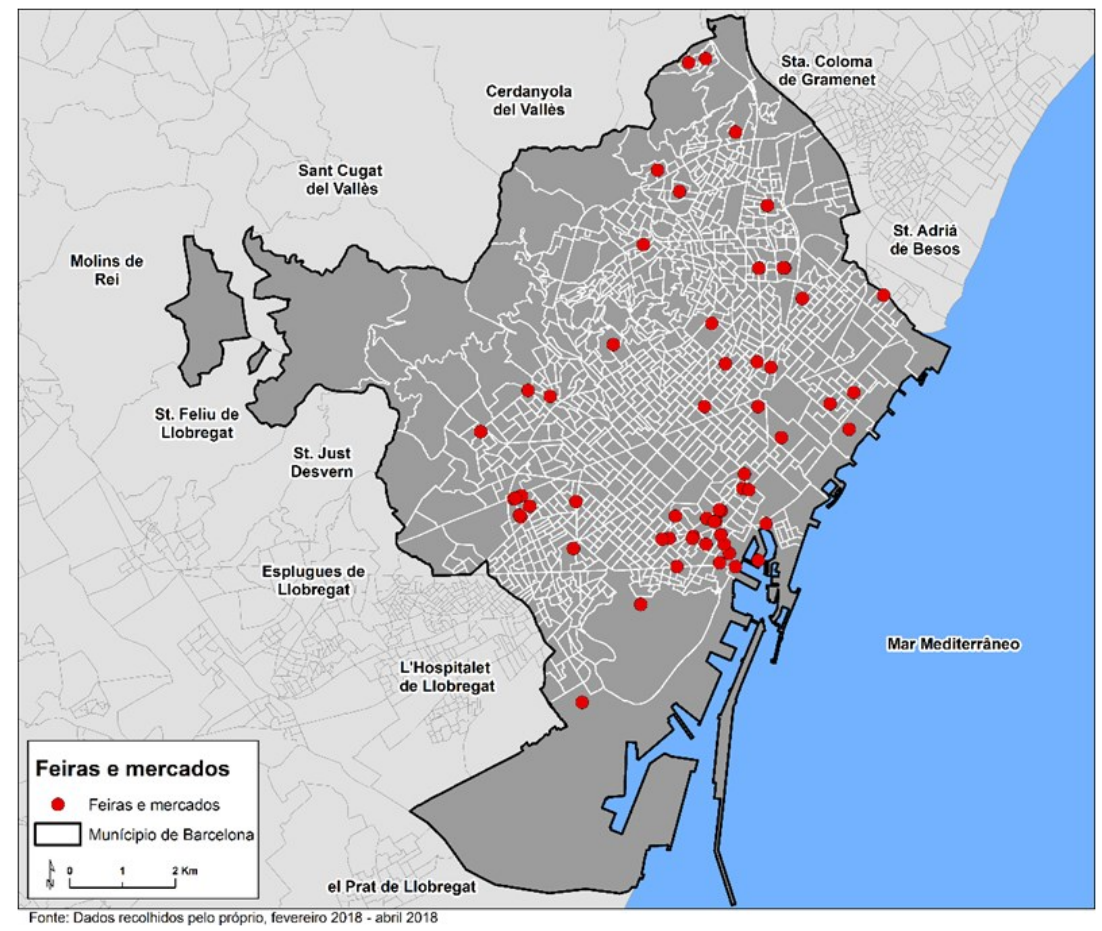

Figura 2 - Localização das feiras da cidade de Barcelona, 2018. Fonte: Elaboração própria

Em relação à periodicidade das feiras na cidade do Porto (figura 3), das 34 feiras existentes, 12 delas têm uma periodicidade semanal, 9 mensal e 8 diária (sobretudo mercados de levante que vendem produtos frescos). Das restantes 5 feiras, 3 apresentam uma periodicidade quinzenal e as outras 2 uma periodicidade anual.

Relativamente à cidade de Barcelona (figura 4), das 66 feiras existentes na cidade de Barcelona, 28 têm uma periodicidade semanal (42,4\%), 28 uma periodicidade mensal (42,4\%) e 6 realizam-se diariamente $(9,1 \%)$. Das restantes 4, 2 têm uma periodicidade quinzenal (3\%), 1 trimensal (1,5\%) e 1 feira realiza-se anualmente (1,5\%). Existe assim uma clara expressão das feiras semanais e mensais na cidade.

Relativamente ao tipo de localização das feiras, na cidade do Porto dominam as feiras que têm uma localização fixa (31 feiras), realizando-se sempre na mesma localização. As restantes 3 feiras têm um carácter móvel, isto é, vão alternando a sua localização geográfica ao longo das suas realizações. As feiras que apresentam essa característica são o Fleamarket, MarketPlace e o Urban Market - Portugal Lovers.

No que diz respeito à cidade de Barcelona, da amostra inventariada de 66 feiras, dominam as feiras que têm uma localização fixa (62 feiras), realizando-se sempre na mesma localização. As restantes 4 feiras têm um carácter móvel (Give me 5 market; Demanoenmano: el mercadillo social; Lost \& Found Market; Fira Tradicional de Productes Naturals de la Plaça Sagrada Família), isto é, vão alternando a sua localização ao longo das suas realizações.

Em relação ao tipo de espaço onde as feiras e mercados se realizam, pode-se identificar 2 tipos: as feiras ao ar livre, em praças, avenidas, jardins, entre outros; ou as feiras que são realizadas em espaços fechados, em pavilhões, 
galerias ou em armazéns. Conclui-se que a maioria das feiras na cidade do Porto se realizam em espaços ao ar livre, mais concretamente 24 feiras (figura 4). As restantes 10 feiras, 6 delas realizam-se em espaços fechados e as outras 4 feiras possuem um duplo carácter, isto é, tanto se realizam ao ar livre como em espaços fechados.

$\mathrm{Na}$ figura 6 observa-se que a esmagadora maioria das feiras na cidade de Barcelona ocorrem também ao ar livre, mais concretamente 56 das 66 feiras (84,8\%). As restantes 10 feiras, 6 apresentam-se de ambas as formas e as outras 4 ocorrem em espaços interiores.

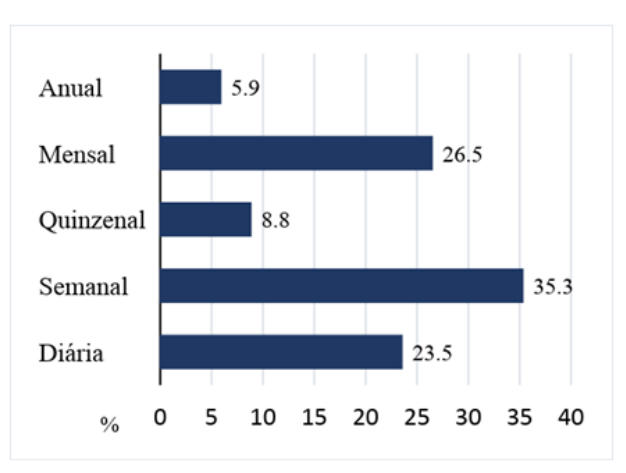

Figura 3 - Periodicidade das feiras no Porto, 2017. Fonte: Elaboração própria

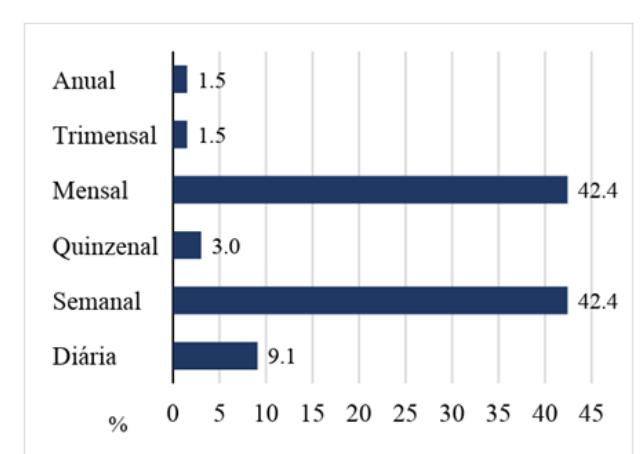

Figura 4 - Periodicidade das feiras em Barcelona, 2018

No que concerne às nomenclaturas atribuídas às feiras na cidade do Porto, como se pode observar na figura 7, no universo das 34 feiras, 14 (41,2\%) são designadas por "Feira", e representam nomenclaturas mais antigas e tradicionais. As restantes dividem-se da seguinte forma: 7 feiras (20,6\%) são designadas "Mercados de Rua", 7 feiras $(20,6 \%)$ "Mercados de Levante" e os outros $6(17,6 \%)$ têm outras designações, nomeadamente estrangeirismos, como é o caso das seguintes feiras: MarketPlace-Casual Style, Urban Market - Portugal Lovers.

Em relação à cidade de Barcelona, como se pode observar na figura 8, as nomenclaturas que mais se destacam são a "Feira" com 25 ocorrências (37,9\%) e o "Mercado" com 23 entradas (34,8\%). As restantes 18 feiras dividem-se da seguinte forma: 13 (19,7\%) são sobretudo estrangeirismos ou outros nomes não habituais, por exemplo: On The Garage, El rastro de la virgen, Give me 5 market, entre outros. As restantes 5 feiras (7,6\%) têm como nomenclatura "Mostra" ou exposição.

Concluindo, com uma breve caracterização inicial conseguiu-se encontrar algumas semelhanças e diferenças: o perfil locativo das feiras da cidade do Porto é mais concentrado do que o perfil de Barcelona, pois esta cidade apresenta uma estrutura de localização mais distribuída com algumas pequenas aglomerações. Nas duas cidades, a maioria das feiras têm uma localização fixa e são normalmente realizadas ao ar livre. Em Barcelona existe uma grande percentagem de feiras que encerram um, dois ou três meses seguidos, algo que no Porto é raro ocorrer. Na periodicidade das feiras, na cidade do Porto predominam sobretudo as feiras semanais enquanto em Barcelona existe um maior equilíbrio (o número de feiras semanais é igual ao número de feiras mensais). Na cidade de Barcelona ocorrem com menor frequência as feiras diárias.

As tabelas 1 e 2 expõem o levantamento parcial efetuado na cidade de Barcelona e o levantamento funcional efetuado na cidade do Porto.

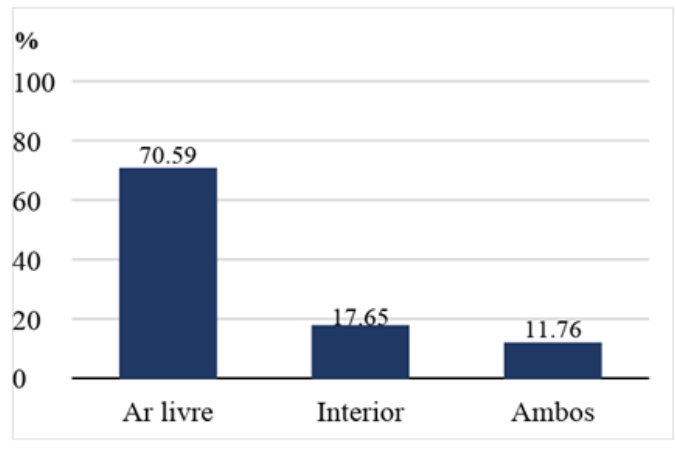

Figura 5 - Tipologia de espaço das feiras, Porto, 2017. Fonte: Elaboração própria.

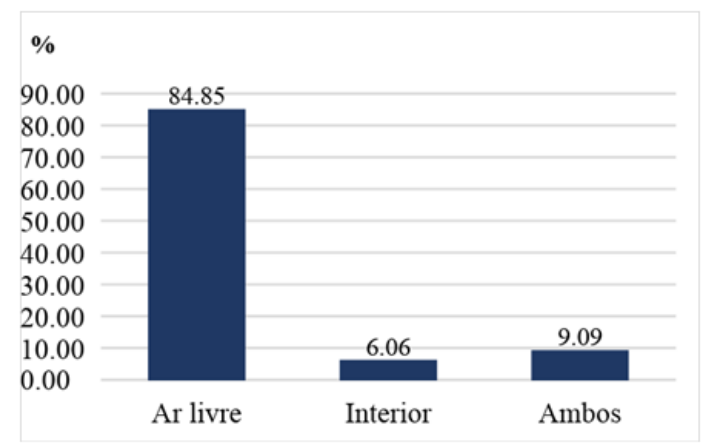

Figura 6 - Tipologia de espaço das feiras, Barcelona, 2018 


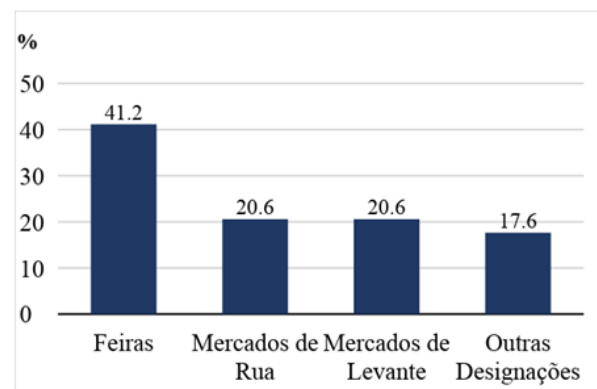

Figura 7 - Nomenclatura das feiras, Porto, 2017. Fonte: Elaboração própria.

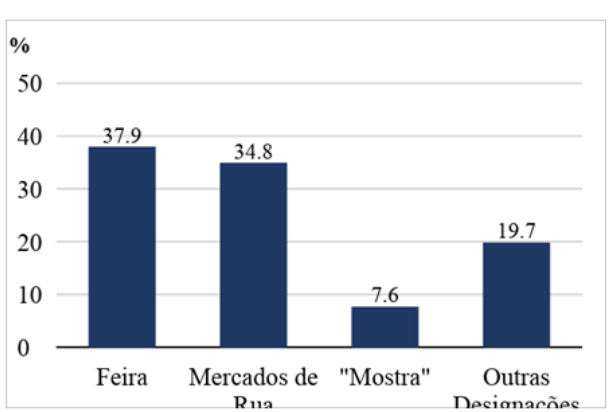

Figura 8 - Nomenclatura das feiras, Barcelona, 2018

Tabela 1 - Levantamento funcional, teste efetuado na cidade de Barcelona. Fonte: Márcio Ferreira (2018).

\begin{tabular}{|l|r|r|r|r|r}
\hline Nome & $\begin{array}{c}\text { No de } \\
\text { Bancas }\end{array}$ & \multicolumn{1}{|c|}{$\begin{array}{c}\text { No de } \\
\text { vendedores }\end{array}$} & $\begin{array}{c}\text { No de } \\
\text { clientes }\end{array}$ & $\begin{array}{c}\text { Área ocupada } \\
\text { aproximada (m2) }\end{array}$ & $\begin{array}{c}\text { Área aproximada } \\
\text { das bancas (m2) }\end{array}$ \\
\hline $\begin{array}{l}\text { Mercat Gòtic Antiguitats } \\
\text { *Plaça Nova }\end{array}$ & 27 & 30 & 120 & 650 & 3 \\
\hline $\begin{array}{l}\text { Fira Nova Artesania } \\
\text { *Rambles }\end{array}$ & 46 & 52 & 150 & 600 & 3 \\
\hline $\begin{array}{l}\text { Fira d'Artesans Moll de } \\
\text { Dipòsit }\end{array}$ & 20 & 22 & 100 & 500 & 3 \\
\hline $\begin{array}{l}\text { Mercat d'Antiguitats Port } \\
\text { Antic }\end{array}$ & 19 & 26 & 50 & 400 & 4
\end{tabular}

Tabela 2 - Levantamento funcional das feiras da cidade do Porto.

Fonte: Márcio Ferreira (2017).

\begin{tabular}{|c|c|c|c|c|c|}
\hline Nome & $\begin{array}{l}\mathrm{N}^{\bullet} \text { de } \\
\text { bancas }\end{array}$ & $\begin{array}{l}\mathrm{N}^{\circ} \mathrm{de} \\
\text { vendedores }\end{array}$ & $\mathbf{N}^{\circ}$ de clientes & $\begin{array}{l}\text { Area ocupada } \\
\text { aproximada }\left(\mathrm{m}^{2}\right)\end{array}$ & $\begin{array}{l}\text { Área } \\
\text { aproximada } \\
\text { das bancas } \\
\left(\mathrm{m}^{2}\right)\end{array}$ \\
\hline Feira da Vandoma & 419 & 635 & $1000+$ & $5440^{*}$ & 6 \\
\hline Fleamarket Porto & 207 & 309 & 500 & 4000 & 5 \\
\hline Feira do Cerco & 174 & 272 & 850 & 9000 & 5 \\
\hline MarketPlace & 87 & 116 & 200 & 3000 & 3 \\
\hline $\begin{array}{l}\text { Feira de Artesanato Urbano } \\
\text { "Familia desce à rua" }\end{array}$ & 81 & 96 & 150 & 800 & 3 \\
\hline $\begin{array}{l}\text { Feira Antiguidades e } \\
\text { Velharias }\end{array}$ & 63 & 82 & 180 & 2500 & 3 \\
\hline Mercado da Alegria & 53 & 66 & 80 & 1600 & 3 \\
\hline Mercadinho dos Clérigos & 44 & 40 & 142 & 350 & 2 \\
\hline $\begin{array}{l}\text { Feira de Numismática, } \\
\text { Filatelia e Coleccionismo }\end{array}$ & 40 & 44 & 55 & 841 & 5 \\
\hline $\begin{array}{l}\text { Mercado de Artesanato do } \\
\text { Porto }\end{array}$ & 37 & 46 & 46 & 600 & 3 \\
\hline Feira dos Passarinhos & 36 & 60 & 250 & 600 & 2 \\
\hline Urban Market & 26 & 32 & 20 & 320 & 3 \\
\hline Mercado Porto Belo & 25 & 29 & 40 & 900 & 3 \\
\hline Pink Market & 22 & 34 & 25 & 140 & 3 \\
\hline Feira de Velharias e Vintage & 21 & 21 & 25 & 2300 & 6 \\
\hline Artesanato de Santa Catarina & 14 & 18 & 100 & 4500 & 3 \\
\hline Mercado Caótico & 14 & 16 & 10 & 150 & 3 \\
\hline $\begin{array}{l}\text { Feira de Produtos de } \\
\text { Agricultura Biológica }\end{array}$ & 10 & 20 & 30 & 300 & 7 \\
\hline O berdinho & 10 & 10 & 15 & 100 & 2 \\
\hline Livros na Reitoria & 10 & 10 & 12 & 200 & 3 \\
\hline Mercado de S. Sebastião & 8 & 10 & 9 & 500 & 4 \\
\hline Feira de artes e culturas & 8 & 10 & 10 & 80 & 2 \\
\hline Mercado das Campinas & 6 & 6 & 5 & 80 & 4 \\
\hline Mercado da Ribeira & 6 & 9 & 5 & 400 & 4 \\
\hline Mercado do Cerco do Porto & 5 & 5 & 4 & 50 & 3 \\
\hline Mercado do Viso & 4 & 4 & 4 & 120 & 3 \\
\hline Mercado do Covelo & 2 & 2 & 2 & 100 & 3 \\
\hline Mercado Praça da Alegria & 2 & 2 & 3 & 80 & 4 \\
\hline
\end{tabular}




\section{DA CRISE AO PÓS-CRISE}

Em termos qualitativos, as entrevistas e os inquéritos estão em curso, tendo avançado sobretudo na cidade do Porto. Em termos sintéticos podem-se desde já referir algumas constatações para a cidade do Porto, que serão posteriormente avaliadas também em Barcelona.

A dinâmica das feiras foi impulsionada pela crise que se instaurou em meados de 2008. As feiras tiveram um papel muito importante na sobrevivência de algumas famílias ao longo da crise, constituindo um rendimento fundamental ou complementar essencial. Com a dinâmica turística da cidade, registada nos últimos anos, algumas feiras registaram um aumentou muito considerável da procura. Atualmente encontram-se numa fase de grande ascensão, havendo cada vez mais e desenvolvendo diferentes conceitos. Portanto, surgiram como resposta à crise, e têm vindo a afirmar-se e a diferenciar-se no período de pós-crise.

$\mathrm{Na}$ cidade do Porto as feiras refletem a segmentação social da cidade, que é visível nas características sociais dos feirantes, mas também nos produtos que são vendidos. A crise e o pós-crise também se manifestam de diferentes formas nos vários sectores da cidade.

No sector oriental da cidade, dominam as feiras mais tradicionais, com produtos convencionais de fraca qualidade e indiferenciados. O perfil de oferta e de procura não variou significativamente na crise e no pós-crise. Uma oferta pouco qualificada e uma procura com fraca capacidade económica e pouco exigente. Em termos comparativos, o sector central e ocidental da cidade, durante a crise, atraiu feiras mais diferenciadoras, com uma oferta mais significativa de produtos criados pelos próprios produtores/vendedores. Aqui a procura evidencia uma maior capacidade económica, com os indivíduos e as famílias a procurem as feiras enquanto espaços de sociabilidade urbana, pretendendo adquirir produtos aparentemente únicos, que incorporam criatividade e conhecimento simbólico. O pós-crise associou-se à atratividade turística da cidade e estas feiras ganharam novos segmentados de procura e ambiências multiculturais.

\section{BIBLIOGRAFIA}

BOTSMAN, R., \& ROGERS, R. (2009). What's Mine Is Yours: Bookman.

FERREIRA, M. (2017). Economia Alternativa: Feiras e AirBnB na cidade do Porto. Dissertação de Mestrado, Faculdade de Letras da Universidade do Porto.

GIBSON-GRAHAM, J. K. (2006). A Postcapitalist Politics: University of Minnesota Press.

HERNÁNDEZ, J. L. S. (2017). Las prácticas económicas alternativas en perspectiva geográfica

MÉNDEZ, R. (2015). Redes de colaboración y economía alternativa para la resiliencia urbana: una agenda de investigación. Biblio3W, XX.

MOREIRA, I. (2016). O impacto da crise económica, financeira e social no acesso aos cuidados de saúde em Portugal. Universidade de Coimbra.

RIBEIRO, R., FRADE, C., COELHO, L., \& FERREIRA-VALENTE, A. (2015). Crise Económica em Portugal: Alterações nas Práticas Quotidianas e nas Relações Familiares. Paper presented at the $1^{\circ}$ Congresso da Associação Internacional das Ciências Sociais e Humanas em Língua Portuguesa Lisboa.

SCHOR, J. (2014). Debating the Sharing Economy. Great Transition Initiative.

THIEME, T. (2016). A Reflection on Resilient Urban Economies. 
Página intencionalmente dejada en blanco 


\title{
El Fondo de Desarrollo de Vuelos de Canarias: incentivos públicos para nuevas rutas aéreas en un destino turístico maduro
}

\author{
David Ramos-Pérez (a) \\ (a) Departamento de Geografía, Universidad de Salamanca, a13004@usal.es
}

\begin{abstract}
Resumen
La generalización de los incentivos públicos para la creación de nuevas conexiones aéreas es una de las consecuencias de la liberalización del mercado comunitario de transporte aéreo. Sin embargo, la literatura académica ha prestado una atención limitada a esta práctica, observándose una escasez de estudios de caso que permitan un conocimiento más detallado de la misma. La comunicación contribuye a solventar esa laguna, presentando los resultados de una investigación sobre el Fondo de Desarrollo de Vuelos vigente desde 2014 en Canarias, un destino turístico maduro que cuenta con una elevada conectividad aérea. A partir del análisis de fuentes documentales y estadísticas se determinan las causas que motivaron la puesta en marcha estos incentivos, la inversión realizada, las características de las rutas apoyadas y su contribución al cumplimiento de los objetivos perseguidos. Aunque el Fondo ha contribuido escasamente a la mejora de la conectividad aérea del archipiélago, puede hablarse de un impacto diferencial en función de la isla considerada.
\end{abstract}

Palabras clave: Transporte aéreo, liberalización, incentivos, rutas aéreas, Canarias.

\section{INTRODUCCIÓN}

Los incentivos económicos de carácter público otorgados a las compañías aéreas para la apertura de nuevas rutas son la consecuencia de dos procesos paralelos que se han desarrollado durante los últimos treinta años: la liberalización del transporte aéreo y la creciente competencia entre territorios que caracteriza la lógica espacial del capitalismo de acumulación flexible. El primero ha restringido notablemente la capacidad de los gobiernos para determinar no solo las conexiones aéreas, sino la capacidad ofrecida y sus tarifas, decisiones ahora en mano de las aerolíneas. Asimismo, al ir acompañada de la progresiva privatización, tanto de las compañías aéreas como de la gestión de los aeropuertos, ha aparecido una intensa competencia entre estos últimos para captar nuevas operaciones que incrementen su tráfico, con el objetivo último de ensanchar los márgenes de beneficio, tal y como exigen sus accionistas de referencia. El segundo, la competencia entre territorios, mantiene una estrecha relación con la creciente financiarización de la economía en el contexto de la globalización y la restructuración económica que ha afectado a un amplio conjunto de ciudades y regiones de los espacios centrales de la economíamundo capitalista, fruto de la intensificación de la división internacional del trabajo y la consiguiente desindustrialización de esos lugares en beneficio de las semi-periferias emergentes.

En ese contexto, las ciudades y regiones han sido impulsadas a competir entre sí a escala mundial con objeto de captar una parte del capital internacional, extremadamente móvil y selectivo, como ha señalado Harvey (1989). De ahí que las administraciones públicas que gestionan ambas escalas utilicen sus competencias para movilizar las ventajas comparativas de sus territorios, fundamentalmente a través de economías de oferta complementarias de las ya practicadas a escala estatal (Jessop, 2008). En estos espacios, las estrategias de desarrollo urbano y regional han seguido dos orientaciones básicas: el fomento de las actividades productivas vinculadas a la economía del conocimiento y creativa y la atracción de consumidores externos, mediante la promoción de los usos turísticos y de una oferta de experiencias (Hall, 2009). En ambos casos, la continua mejora de la conectividad aérea se ha considerado una ventaja comparativa clave a la hora de atraer capitales y turistas. En lo que respecta al turismo, como estos espacios centrales ofrecen productos similares basados en los atractivos de lo que genéricamente podríamos denominar la cultura urbana, su intercambiabilidad como destinos es alta, por lo que las características de la oferta área, como diversidad de rutas y la presencia de compañías que ofrezcan tarifas reduci- 
das, puede ser fundamental a la hora de decantar a los potenciales turistas. De ahí la trascendencia de los incentivos para la apertura de nuevas rutas, pues neutralizan parte del riesgo que para una aerolínea supone es decisión. Si la ruta no se consolida a corto plazo, el operador abandona la explotación del servicio, tras haber minimizado sus costes fijos gracias a esos fondos públicos. Por ello esta práctica, como las restantes que integran el marketing aeroportuario (Halpern y Graham, 2013), constituye un ejemplo meridiano de las economías de oferta a las que alude Jessop, idénticas en su concepción a las transferencias a la administración de ciertos costes en capital fijo que se observan de forma recurrente en todo tipo de inversiones que se materializan en estos espacios centrales del capitalismo.

En el caso de los destinos maduros de sol y playa, la dependencia de la conectividad aérea se remonta, al menos en la cuenca Mediterránea a la década de los años 60 del siglo XX. Asimismo, el producto sol y playa tampoco ha quedado al margen de la intensificación de la división espacial del trabajo, con la creciente concurrencia de nuevos destinos situados en espacios semi-periféricos y periféricos, que toma cuerpo en los años 70 y 80 (Gormsen, 1981) y se acentúa a lo largo del siglo XXI (Navarro Jurado et al., 2015). A ello se le une un cierto cambio en los patrones de consumo de los potenciales turistas, entre los que gana peso el viaje individual frente al tradicional paquete, se observa una mayor demanda de flexibilidad en las fechas de viaje frente a los calendarios fijos de turoperadores y compañías chárter y se constata la tendencia minimizar los costes del viaje aéreo, en consonancia con las pautas derivadas de la difusión de las compañías de bajo coste. En ese sentido, en los destinos emergentes de países menos desarrollados, las compañías aéreas, especialmente de bajo coste, han sido generosamente subsidiadas para asegurar una conectividad mínima que permitiese el arranque de los mismos, como muestran los ejemplos de Marruecos, Egipto, Israel o Tailandia, por citar solo algunos ejemplos de una amplia lista. De ahí que estos destinos hayan terminado diseñando incentivos para intentar asegurar una mayor presencia de operadores de bajo coste y/o una diversificación de los mercados emisores, como se observa en los casos de Malta (Graham y Dennis, 2010) y Faro (Ramos-Pérez e Izquierdo-Misiego, 2015).

La comunicación inserta el análisis del Fondo de Desarrollo de Vuelos vigente en Canarias desde 2014 en ese contexto, presentando a partir de diferentes fuentes documentales sus antecedentes y los factores que justificaron su diseño actual, así como sus principales características. Posteriormente se analizan las 103 convocatorias de rutas abiertas entre julio de 2014 y abril de 2018, para lo que se ha elaborado una base de datos que incorpora la información disponible en la web del Fondo de Desarrollo de Vuelos. Ello permite conocer la distribución de las rutas entre los diferentes aeropuertos de las islas, la situación administrativa de las convocatorias y su contribución a la diversificación de la oferta programada en dichos aeropuertos. También se analiza la inversión realizada y se relaciona con el retorno esperado en función de las llegadas de turistas previstos. Se concluye apuntando la necesidad de comprobar el grado de cumplimento del Fondo de Desarrollo de Rutas una vez termine su vigencia, dada la necesidad de verificar el mantenimiento de las conexiones aérea una vez desaparecidos los incentivos.

\section{ORIGEN DEL FONDO DE DESARROLLO DE VUELOS}

El Fondo de Desarrollo de Vuelos de Canarias es la materialización del Programa de Conectividad Aérea para el archipiélago previsto en el Acuerdo por la Competitividad y la Calidad del Turismo en Canarias 2008-2020, firmado en Fuerteventura en octubre de 2007. En dicho documento, las administraciones públicas canarias y las principales organizaciones empresariales representativas del sector turístico canario acordaron la necesidad de poner en marcha de forma inmediata un conjunto de medidas que permitieran fortalecer las islas como un destino turístico de referencia en los mercados emisores europeos. El contexto de creciente competencia con nuevos destinos especializados en el producto de sol y playa y la amplia difusión de nuevos patrones de consumo entre los potenciales turistas estaba dando lugar a cambios estructurales a los que se quería hacer frente. De ahí que las cuestiones relacionadas con la conectividad aérea fueran consideradas un pilar básico del Plan Estratégico del Destino Canarias, junto con la mejora del conocimiento existente sobre los mercados emisores y la reformulación de la promoción del archipiélago el exterior.

En todo caso, antes de este acuerdo, el Gobierno de Canarias ya había demostrado cierto interés por la conectividad aérea, al poner en marcha a finales de 2006 un Fondo de Desarrollo de Vuelos, dotado de un presupuesto inicial de 1 millón de euros, que estaba previsto incrementar en medio millón cada año. El Fondo se diseñó como un programa de incentivos abierto a cualquier compañía que quisiera incrementar las frecuencias operadas en una ruta existente o poner en marcha una nueva conexión, para lo que se ofrecían 1 y 2 euros respectivamen- 
te por asiento de salida ofrecido. En su corta andadura 7 compañías que respondían a modelos de negocio sumamente diferentes se beneficiaron de estos incentivos. Aunque el Fondo probablemente cumplía con la legislación comunitaria en materia de ayudas de estado en vigor desde 2005, a diferencia de lo que ocurría con las ayudas que otorgaban otros gobiernos locales y regionales del país (Ramos-Pérez, 2016), no era resultado de ningún análisis estratégico previo ni se conocen sus objetivos, más allá de los genéricos de "captar todo tipo de tráfico aéreo" o el "aumento de las conexiones para favorecer un abaratamiento de tarifas" que señalaba el consejero de turismo en su presentación ${ }^{1}$. Todo indica que la acelerada difusión de las compañías de bajo coste en el mercado intracomunitario que se observaba en aquellos años (Dobruszkes, 2006) y la relativa ausencia de las mismas en las rutas que conectaban las islas con sus mercados emisores, llevaron a tomar esa medida en un momento en que eran ampliamente conocidas las exigencias de algunas compañías de bajo coste, especialmente Ryanair, para operar en algunos destinos.

El nuevo Fondo, como hemos anticipado, es el resultado de una profunda reflexión sobre los cambios estructurales que venían afectando al turismo desde hacía al menos una década. De ahí que sólo sea aprobado tras la elaboración de un Plan Estratégico de Conectividad Aérea de las Islas Canarias (PECAIC), (Consejería de Turismo, 2009), que radiografiaba la situación de las conexiones aérea en el archipiélago en aquel momento, analizaba los cambios que se observaban a escala europea en los distintos modelos de negocio de las compañías aérea, señalaba las nuevas demandas de los turistas en cuanto a movilidad aérea e incidía en la debilidad que la excesiva dependencia de los turoperadores suponía para el destino, incluyendo las dificultades de acceso a la compra directa de billetes para ese nuevo perfil de turistas.

En ese contexto de cambios y transformaciones, el Plan apuntaba el desinterés que comenzaban a manifestar los turoperadores por un destino como Canarias, donde los márgenes de beneficio eran claramente inferiores a los que era posible obtener en destinos que ofrecían un producto similar, como Turquía y Egipto (Consejería de Turismo, 2009). De ahí que el riesgo de un creciente desvío de turistas hacia los mismos pudiese reducir la demanda hacia el archipiélago, especialmente durante una etapa en la que la crisis económica y financiera iba a reducir el poder adquisitivo de los potenciales turistas. Si a ello se suma la existencia de incentivos económicos que los destinos turísticos emergentes estaban otorgando a las compañías aéreas y turoperadores para abaratar sus costes operativos, se concluía que Canarias estaba experimentando una pérdida de competitividad que era necesario atenuar. Por ello proponía un conjunto de actuaciones destinadas a desarrollar una verdadera política de conectividad aérea, que permitiese atenuar esa pérdida de competitividad en lo que respecta a las conexiones aéreas. Aunque la propuesta era ambiciosa, incluyendo la creación de un departamento específico sobre conectividad aérea en el seno de la Consejería de Turismo, debido a la notable especialización que requiere la cuestión, únicamente el Fondo de Desarrollo de Vuelos ha terminado adoptándose.

Por tanto, a diferencia de lo que ocurría en otros territorios, en los que los programas de desarrollo de rutas aéreas se han diseñado para abordar los déficits de conectividad aérea detectados, como es el caso del Scottish Route Development Fund (Smyth et al., 2012), en Canarias no existía una situación de reducida conectividad aérea. En ese sentido, el Fondo de Desarrollo de Vuelos es sobre todo un intento de hacer frente a la creciente competencia de destinos turísticos que presentan un menor desarrollo económico y cuentan con una normativa que permite los subsidios directos a las aerolíneas y los turoperadores, lo que incrementa sus márgenes de beneficio. Es decir, el Fondo es una herramienta para paliar las consecuencias de una competencia desigual entre destinos fruto de la globalización del turismo, facilitando los márgenes de beneficio de las aerolíneas y turoperadores interesados en conectar las islas con nuevos mercados emisores.

La cuestión normativa no es un aspecto menor, pues la legislación comunitaria prohíbe las ayudas de estado en sectores liberalizados como el transporte aéreo, aun cuando existen determinadas excepciones al respecto. Las Directrices aprobadas por la Comisión Europea en el año 2005 (DOUE, 2005) venían a clarificar en qué circunstancias eran compatibles con el mercado interior, al objeto de poner fin a los subsidios que mediante diversas fórmulas se otorgaban de forma opaca en múltiples aeropuertos de la Unión Europea. La apertura de varias investigaciones al respecto por parte de la Comisión Europea propició que el Gobierno de Canarias renunciase al antiguo Fondo de Desarrollo de Vuelos y optase por un nuevo planteamiento, que cumpliese con dichas Directrices y tuviese el visto bueno de la Comisión.

\footnotetext{
${ }^{1}$ El Gobierno de Canarias destina un millón de euros a la creación de un Fondo de Desarrollo de Vuelos. Nota de prensa del Gobierno de Canarias (27/09/2006). Disponible en http://www.gobcan.es/noticias/tcd/Turismo/36566/gobierno-canarias-destina-millon-euros-creacion-fondo-desarrollo -vuelos
} 


\section{CARACTERÍSTICAS DEL FONDO DE DESARROLLO DE VUELOS}

En julio de 2013, cuatro años después de elaborado el PECAIC, el Gobierno de Canarias solicita formalmente a la Comisión Europea la autorización para un Programa de desarrollo de vuelos en el territorio de la región ultraperiférica de las Islas Canarias para 2013-2017, dotado con un presupuesto de 10 millones de euros, al objeto de incentivar la puesta en marcha de nuevas rutas aéreas con origen o destino en los aeropuertos del archipiélago (CE, 2014). Estos incentivos se otorgarían mediante convocatorias públicas, tendrían la condición de subvenciones directas a las compañías aéreas con el objeto de financiar hasta el 50\% de los costes asociados al pago de las tasas aeroportuarias y podrían prolongarse durante un periodo máximo de tres años. Al fijar como fecha límite para la apertura de nuevos destinos el 31 de diciembre de 2017, los pagos finalizarían en el año 2020.

Se cumplía así con todos los criterios establecidos en la nueva versión de las Directrices Comunitarias sobre ayudas estatales a aeropuertos y compañías aéreas (DOUE, 2014), cuya aprobación coincidió en el tiempo con la solicitud de autorización del Gobierno de Canarias, pero cuyo contenido era conocido gracias al periodo de consultas abierto por la Comisión antes de su aprobación. Además, el especial tratamiento otorgado en las Directrices a las regiones ultraperiféricas ${ }^{2}$, permitió que todos los aeropuertos del archipiélago pudiesen beneficiarse de estos incentivos, cuando generalmente solo se autorizan para aeropuertos con un tráfico inferior a los tres millones de pasajeros, circunstancia que en Canarias solo cumplirían La Palma, El Hierro y La Gomera.

Al objeto de evitar que estas ayudas pudieran dar lugar a una situación de competencia desleal, los tipos de rutas que podían beneficiarse de las mismas también quedan claramente definidos a través de una serie de criterios acumulativos (CE, 2014, p.6):

- Rutas que no hayan sido operadas por una compañía aérea que ofrezca servicios de transporte de pasajeros de pago en los 12 meses anteriores a la fecha prevista para el inicio de la explotación de los nuevos servicios.

- Rutas en relación con las cuales, con anterioridad a la publicación de la convocatoria de propuestas, no haya habido ningún anuncio por parte de alguna compañía aérea de que se hubiera previsto su explotación durante el período de 12 meses siguiente a la publicación.

- Rutas a destinos que no es probable que den lugar a una transferencia de pasajeros de una ruta existente en otro aeropuerto canario.

- Rutas que conecten exclusivamente otro aeropuerto situado fuera de la región con cualquiera de los aeropuertos canarios.

Asimismo, también se señala que no se otorgarán ayudas cuando se trata de un incremento de frecuencias de una ruta ya explotada, lo que evita también posibles denuncias por competencia desleal en unas conexiones de marcado carácter turístico cuya oferta de vuelos se limita, en la mayoría de las rutas, a una o dos operaciones semanales.

El Programa tenía el objetivo de incentivar un máximo de 50 rutas, cifra que a mediados de 2017 se comprobó que resultaría inalcanzable. Dado que el presupuesto estaba lejos de agotarse, El Gobierno de Canarias solicitó a la Comisión Europea en agosto de 2017 la extensión del programa durante otros cuatro años manteniendo el presupuesto original. De esta manera se podrán conceder incentivos hasta el 31 de diciembre de 2021 y las rutas podrán operar hasta final de 2024 (CE, 2017).

\section{LAS CONVOCATORIAS DE RUTAS DEL FONDO DE DESARROLLO DE VUELOS}

Entre julio de 2014 y abril de 2018, la empresa pública Promotur, responsable del estudio y promoción del archipiélago como destino turístico, ha abierto 103 convocatorias para otorgar incentivos económicos a cargo del Fondo de Desarrollo de Vuelos. Esas 103 convocatorias se corresponden con 81 rutas aéreas, porque en 16 rutas los incentivos se han convocado en dos ocasiones y en otras 3 se ha llegado a las tres convocatorias con la finalidad de que la adjudicación no quedase desierta.

Las convocatorias se han abierto en ocho rondas diferentes que, a partir de 2017, presentan carácter anual.

\footnotetext{
${ }^{2}$ Las Directrices introducen un tratamiento específico en virtud de su enclavamiento para las denominadas regiones remotas, categoría en la que incluyen a las regiones ultraperiféricas, Malta, Chipre, Ceuta, Melilla, islas que forman parte del territorio de un Estado miembro y regiones poco pobladas.
} 
En un primer momento los incentivos se ofrecían para explotar una frecuencia semanal, bien durante la temporada de invierno (21 semanas) bien durante el verano (31 semanas), con una oferta mínima semanal de 180 asientos de llegada durante al menos dos años. Este esquema ha variado ligeramente en las dos últimas rondas de convocatorias, pues ahora no se determina previamente la temporada de operación, aspecto que se deja a criterio de la compañía, existiendo también la posibilidad de proponer una operación permanente durante todo el año.

Hasta el momento, las rutas para las que se convocan incentivos se distribuyen casi exclusivamente entre las islas de Gran Canaria (LPA), Tenerife (TCI), Lanzarote (ACE), La Palma (SPC) y Fuerteventura (FUE), aquellas que cuentan con aeropuertos capaces de recibir reactores de tamaño medio (figura 1). Las dos convocatorias que afectan a la isla de La Gomera (QGZ), que preveían rutas directas con Londres y Frankfurt en pequeños reactores de hasta 100 plazas, constituyen la excepción, y parecen responder más a las presiones políticas del Cabildo de La Gomera para no dejar su aeropuerto al margen del Fondo de Desarrollo de Vuelos que a la posibilidad real de que estos aviones puedan operar en una pista de 1.500 metros de longitud. En caso de El Hierro (VDE), donde la pista aún es de menores dimensiones, no se han propuesto incentivos para ninguna ruta.

De las cinco islas mencionadas, Fuerteventura es la que se ha visto afectada en menor medida por las convocatorias de rutas, mientras Gran Canaria y Tenerife se sitúan en el extremo opuesto, ocupando Lanzarote y La Palma una situación intermedia. La oferta de asientos asociada a las convocatorias de rutas replica esta situación, ya que rige el planteamiento anteriormente esbozado de una oferta mínima semanal de una frecuencia por ruta.

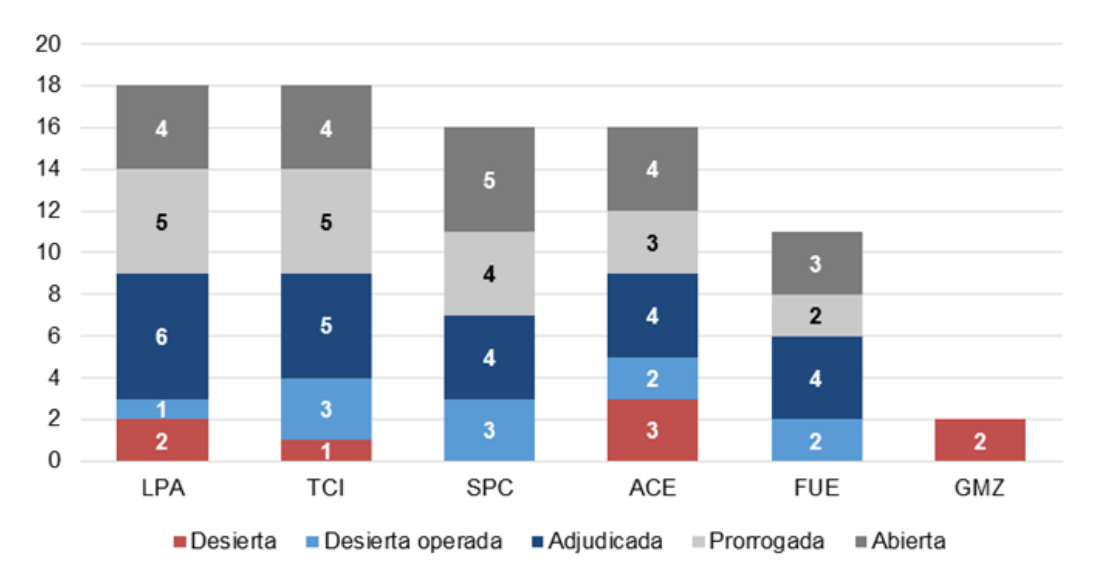

Figura 1 - $\mathrm{N}^{\circ}$ de rutas convocadas por aeropuerto y situación del concurso. Fuente: Elaboración propia a partir de los datos disponibles en http://turismodeislascanarias.com/ es/fondo-de-desarrollo-de-vuelos

Especialmente relevante es el hecho de que únicamente 23 de las convocatorias realizadas hasta el momento han dado lugar a la puesta en marcha de una nueva ruta, lo que supone una efectividad del $28,4 \%$ (figuras 1 y 2). Si no consideramos las últimas 20 convocatorias, que fueron oficialmente presentadas el 20 de abril de 2008 , esa efectividad se eleva al $37,7 \%$. Sumando las 11 convocatorias oficialmente declaradas desiertas pero que durante la temporada de invierno 2017-18 eran operadas por alguna aerolínea, las propuestas exitosas alcanzarían el $56 \%$ de los casos. Es decir, prácticamente la mitad de las nuevas rutas planteadas por Promotur no resultan atractivas para ninguna compañía.

Los datos disponibles también indican que en Fuerteventura y La Palma las posibilidades de que una ruta quede desierta son menores. Además, cuando ello ha ocurrido, al cabo del tiempo una compañía ha terminado ofertando dichas rutas sin recurrir a los incentivos, por lo que el objetivo de establecer esa conexión ha terminado consiguiéndose. Sin embargo, conviene señalar que, a partir de la convocatoria de 2017, Promotur ha decidido no declarar desiertas las adjudicaciones de las rutas, manteniendo una prórroga permanente de las mismas cuando se cumple la fecha límite para presentar solicitudes sin haber recibido propuesta alguna. Ello introduce un sesgo notable a la hora de evaluar los resultados del Fondo de Desarrollo de Vuelos, por lo que solo tras la finalización del mismo en 2021 será posible conocer la totalidad de rutas por las que no se ha interesado ninguna compañía.

Las 81 rutas aéreas incluidas en las convocatorias involucran a 57 aeropuertos situados en 24 países diferentes. Destacan por el número de rutas que concentran Italia (12), Polonia y Francia (9), mercados emisores secundarios para el archipiélago que Promotur trata de consolidar para así reducir la dependencia frente al Reino 


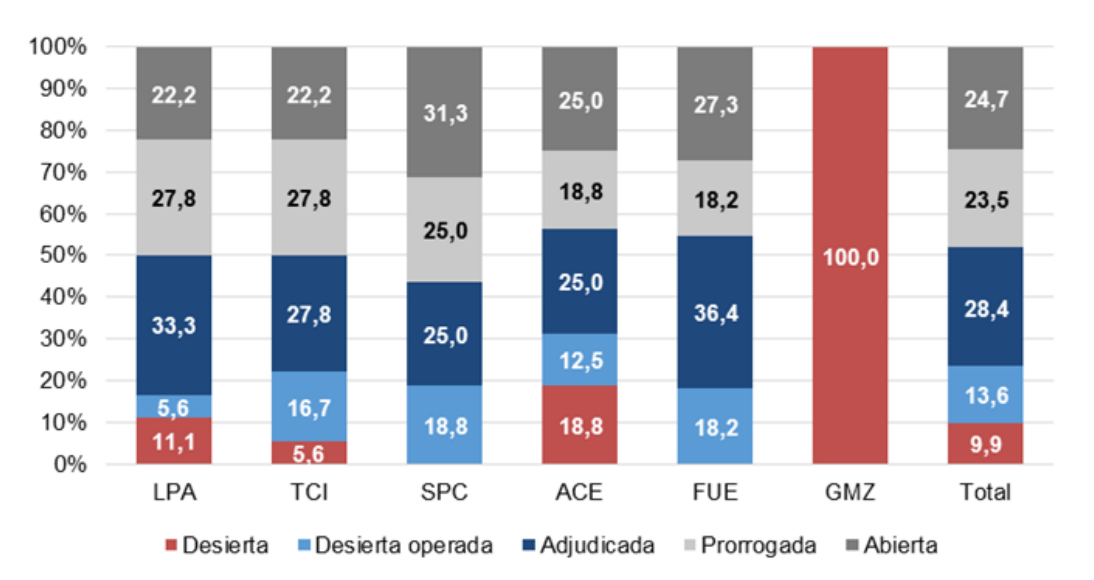

Figura 2 - Porcentaje de rutas convocadas por aeropuerto y situación del concurso. Fuente: Elaboración propia a partir de los datos disponibles en http:// turismodeislascanarias.com/es/fondo-de-desarrollo-de-vuelos

Unido, Alemania y los países escandinavos. A ellos se unen otros mercados emisores emergentes del este de Europa, como Eslovaquia y Hungría, así como otros maduros, caso de Suiza y Austria, en los que había descendido el flujo de turistas emitido hacia el archipiélago. En todo caso, existen situaciones particulares de algunas islas, como La Palma, donde el Reino Unido, Alemania, Dinamarca y Suecia concentran el grueso de las convocatorias de rutas. El menor desarrollo del turismo en la misma y la apuesta por consolidar o incluso abrir esos mercados tradicionales en el resto del archipiélago explican esta especificidad.

Si nos centramos en las 23 rutas operadas gracias a los incentivos, éstas solo involucran a 16 aeropuertos de 10 países, superando en este caso las conexiones con Francia y Hungría a las existentes con Polonia e Italia. Al igual que ocurría con el total de rutas convocadas, los enlaces con esos países son predominantes salvo en el caso de La Palma, donde las rutas con Dinamarca y Suecia son las únicas que por el momento reciben incentivos.

En lo tocante al modelo de negocio de las compañías beneficiadas por los incentivos, las aerolíneas de bajo coste operan 18 de las 23 rutas, destacando la húngara Wizz Air (6 rutas), la española Vueling (5 rutas) o la irlandesa Ryanair (3 rutas). Cabe destacar también la presencia de la antigua compañía chárter escandinava Primera Air, que recibe ayudas por las 4 rutas que conectan La Palma con las principales ciudades suecas y danesas.

Cuadro 1 - Rutas que han recibido incentivos del FDV según el país de origen y el aeropuerto canario de destino. Fuente: Análisis propio a partir de los datos disponibles en http:// turismodeislascanarias.com/es/fondo-de-desarrollo-de-vuelos

\begin{tabular}{|c|c|c|c|c|c|c|}
\hline País & ACE & FUE & LPA & SPC & $\mathrm{TCl}$ & TOTAL \\
\hline Francia & 1 & 2 & 1 & - & 1 & 5 \\
\hline Hungría & 1 & 1 & 1 & - & 1 & 4 \\
\hline Polonia & 1 & - & 1 & - & 1 & 3 \\
\hline Italia & 1 & - & 2 & - & - & 3 \\
\hline Suecia & - & - & - & 2 & - & 2 \\
\hline Dinamarca & - & - & - & 2 & - & 2 \\
\hline Finlandia & - & - & 1 & - & - & 1 \\
\hline Rumanía & - & - & - & - & 1 & 1 \\
\hline República Checa & - & 1 & - & - & - & 1 \\
\hline Portugal & - & - & - & - & 1 & 1 \\
\hline TOTAL & 4 & 4 & 6 & 4 & 5 & 23 \\
\hline
\end{tabular}

\section{EL IMPACTO DEL FONDO DE DESARROLLO DE VUELOS EN LOS AEROPUERTOS CANARIOS}

La oferta anual asociada a las rutas propuestas en las distintas convocatorias se sitúa por debajo de los 700.000 asientos de llegada, lo que, en 2016, último año para el que existen datos oficiales, suponía un 4,3\% de la oferta total de asientos internacionales en los aeropuertos canarios. Salvo en el caso del aeropuerto de La Pal- 
ma, donde el impacto potencial de estas rutas puede ser significativo, ya que la oferta propuesta supone el 55\% de la existente, en los otros aeropuertos los potenciales efectos del Fondo serán mucho más limitados. En todo caso, conviene no minimizar el hecho de que estas rutas pueden estabilizar una conexión con mercados emisores con los que solo existía vinculación a través de operaciones chárter.

En lo que respecta a las rutas puestas en marcha, esa oferta anual se reduce a los 189.000 asientos, apenas un $1,2 \%$ de la oferta total internacional del archipiélago. Al igual que con la oferta convocada, este valor medio encubre la existencia de una notable diferencia entre La Palma y el resto de las islas, siendo el aeropuerto en el que el Fondo de Desarrollo de Vuelos ha tenido una clara repercusión en la evolución reciente de la oferta. Los 15.120 asientos de los vuelos que conectan durante las temporadas de invierno La Palma con Copenhague, Billund, Gotemburgo y Estocolmo supondrían el 7,2\% de la oferta con la que contó la isla en el año 2016. Pero su peso es aún mayor si tenemos en cuenta que se trata de rutas estacionales, por lo que si nos ceñimos a la última te 54 mporada de invierno 2017-18, esas 4 conexiones suponían el 9,1\% de la oferta programada.

Además, al estar asociada la compañía aérea beneficiaria de los incentivos (Primera Air) a uno de los principales turoperadores escandinavos (Primera Travel Group), el resultado ha sido la puesta en marcha también durante la temporada de invierno de una ruta semanal entre La Palma y Oslo, así como de una serie de operaciones con origen en diversos aeropuertos finlandeses, que suman una oferta adicional de 6.897 plazas. Si esas plazas las añadimos a la oferta que recibe incentivos, resulta que el $13,3 \%$ de la oferta de asientos de llegada programada en

Cuadro 2 - Peso de la oferta de asientos de las rutas que reciben incentivos en la programación de la temporada de invierno 2017 18. Fuente: Análisis propio a partir de los datos disponibles en http://turismodeislascanarias.com/es/fondo-de-desarrollo-devuelos y de la oferta de asientos de la temporada de invierno 2017-2018 publicada por AENA en http://www.aena.es/ DescargaNotasPrensa/171031-can-temporada-invierno-20172018.pdf

\begin{tabular}{|c|c|c|c|}
\hline \multirow[b]{2}{*}{ Aeropuerto } & \multicolumn{2}{|c|}{ Oferta de asientos de llegada } & \multirow[b]{2}{*}{$\%$} \\
\hline & $\begin{array}{c}\text { En rutas } \\
\text { internacionales }\end{array}$ & $\begin{array}{l}\text { En rutas con } \\
\text { incentivos }\left({ }^{*}\right)\end{array}$ & \\
\hline LPA & 2.300 .000 & 18.900 & $0,8 \%$ \\
\hline $\mathrm{TCl}$ & 2.563 .500 & 18.900 & $0,7 \%$ \\
\hline ACE & 1.250 .000 & 15.120 & $1,2 \%$ \\
\hline FUE & 1.150 .000 & 15.120 & $1,3 \%$ \\
\hline SPC & 166.000 & 15.120 & $9,1 \%$ \\
\hline TOTAL & 7.429 .500 & 83.160 & $1,1 \%$ \\
\hline
\end{tabular}

NOTA: $\left(^{*}\right)$ Solo se consideran las rutas beneficiadas por los incentivos. La oferta está ajustada al $n^{\circ}$ de semanas (21) de la temporada de invierno. La Palma el pasado invierno puede relacionarse con el Fondo de Desarrollo de Vuelos.

\section{LA RELACIÓN COSTE-BENEFICIO DE LAS RUTAS QUE HAN RECIBIDO INCENTIVOS}

El Plan Estratégico de Conectividad Aérea de las Islas Canarias (Consejería de Turismo, 2009) estimaba el beneficio que cada nueva ruta operada supondría para el archipiélago a partir del gasto medio diario imputable a los nuevos turistas captados por la existencia de estas conexiones. En dicho cálculo no se introducían variables de tipo ambiental, que por ejemplo tuvieran en cuenta la contribución a las emisiones de efecto invernadero de estas nuevas rutas o el incremento de la presión antrópica sobre el medio asociada al aumento de los turistas. $Y$ tampoco sociales, vinculadas por ejemplo con el modelo de relaciones laborales dominante en las compañías seleccionadas.

Si no introducimos dichas variables en el balance, y seguimos el planteamiento del PECAIC, actualizando los valores de la estancia media del turista (9,17 días en 2017$)$ y del gasto medio $(140,18 €)$, considerando una ocupación del $80 \%$ en las rutas y una proporción del tráfico de llegada (inbound) del $95 \%$, se obtiene que las 23 rutas operadas gracias a los incentivos generarían generando anualmente volumen de negocio de 184,6 M€. Dado que el coste anual asociado a los incentivos se sitúa en 1,5 M€, el balance resulta en ese sentido claramente positivo. Es más, si solo tenemos en cuenta el gasto medio diario que los turistas efectúan directamente en Canarias $(39,03 €)$, el volumen de negocio generado por los mismos se situaría en los 51,4 M€, también muy por encima del coste de los incentivos, lo que asegura un elevado retorno de la inversión. 


\section{CONCLUSIONES}

EI PECAIC estableció en 2009 una serie de prioridades respecto a las rutas a las que deberían concederse incentivos, señalando la necesidad de intervención urgente en un conjunto de rutas de los tres principales mercados emisores (Península, Alemania y Reino Unido) en las que se habían detectado grandes caídas de tráfico. Posteriormente recomendaba centrarse en un conjunto de mercados donde se había detectado un mayor potencial de crecimiento, como Francia, Italia, Rusia, Polonia o la República Checa. El cambio en la coyuntura turística explica que los incentivos otorgados hasta el momento se hayan orientado hacia las rutas con los mercados emisores emergentes para el archipiélago, salvo en el caso de La Palma, donde la puesta en marcha de enlaces con los países nórdicos ha sido priorizada.

Sin embargo, el impacto del Fondo en la diversificación de los mercados emisores de turistas hacia el archipiélago resulta marginal, como demuestra el peso de la oferta de asientos asociada a los incentivos sobre la oferta total. Si a ello le unimos que el $46 \%$ de las rutas para las que se ofrecen incentivos no ha recibido propuesta alguna por parte de las aerolíneas, parece existir un cierto desajuste entre una estrategia de captación de rutas ambiciosa y la indiferencia de las compañías aéreas respecto a la mayoría de las mismas, al menos hasta el momento. Es más, el elevado peso que las rutas del Fondo tienen en La Palma refuerza la idea original de la Comisión Europea de que estos mecanismos tienen un mayor impacto en aquellos territorios con una limitada conectividad aérea, siendo mucho más discutible su utilidad cuando se dispone de un amplísimo abanico de conexiones, como ocurre en las restantes islas del archipiélago.

Por otro lado, en Canarias, a diferencia de lo ocurrido en los pequeños aeropuertos regionales del interior peninsular (Ramos-Pérez, 2016), el balance coste-beneficio de los incentivos resulta positivo, puesto que el tráfico que canalizan las rutas a las que se otorgan las ayudas es fundamentalmente de llegada (tráfico inbound). Sin embargo, un análisis detallado de la efectividad del Fondo de Desarrollo de Vuelos sólo será posible a medio plazo, cuando pueda verificarse en qué medida las rutas que se han beneficiado de los incentivos continúan operándose en ausencia de los mismos.

\section{BIBLIOGRAFIA}

CE (Comisión Europea) (2014). Ayudas de puesta en marcha para las compañías aéreas que operan desde las Islas Canarias (SA.37121, 2013/N). Disponible en http://ec.europa.eu/competition/elojade/isef/case_details.cfm? proc_code=3_SA_37121

CE (Comisión Europea) (2017). Ampliación de un régimen de ayudas de puesta en marcha para las compañías aéreas que operan desde las Islas Canarias (SA.48872, 2017/N). Disponible en http://ec.europa.eu/competition/elojade/isef/case_details.cfm? proc_code=3_SA_48872

CONSEJERÍA DE TURISMO (2009). Plan Estratégico de Conectividad Aérea de las Islas Canarias (PECAIC). Gobierno de Canarias y Es klappt Consulting Estratégico \& Calidad. Disponible en http://www.datosdelanzarote.com/itemDetalles.asp? idFamilia=31\&idltem $=4340$

DOBRUSZKES F. (2006), An analysis of European low-cost airlines and their networks, Journal of Transport Geography, 14(4), 249-264.

DOCE (Diario Oficial de las Comunidades Europeas) (2005). Directrices Comunitarias sobre la financiación de aeropuertos y las ayudas estatales de puesta en marcha destinadas a compañías aéreas que operen desde aeropuertos regionales (Diario $\mathrm{n}^{\circ} \mathrm{C} 312$ de 09/12/2005, pp. 1-14). Luxemburgo: Oficina de Publicaciones Oficiales de las Comunidades Europeas.

DOCE (Diario Oficial de las Comunidades Europeas) (2014). Directrices sobre ayudas estatales a aeropuertos y compañías aéreas (Diario n ${ }^{\circ}$ C99 de 04/04/2014). Luxemburgo: Oficina de Publicaciones Oficiales de las Comunidades Europeas.

GORMSEN, E. (1981). The spatio-temporal development of international tourism. Attempt at a centre-periphery model. In Union Geographique Internationale (Ed.), La Consommation d'espace par le tourisme et sa preservation (pp. 150-170). Aix-enProvence: Centre Hautes Etudes Touristiques.

GRAHAM, A. Y DENNIS, N. (2008) The impact of low cost airline operations to Malta. Journal of Air Transport Management, 16 (3), 127-136

HALL, C.-M. (2009). El turismo como ciencia social de la movilidad. Madrid: Síntesis.

HALPERN, N. Y GRAHAM, A. (2013). Airport Marketing. Londres: Routledge.

HARVEY, D. (1989). From Managerialism to Entrepreneurialism: The Transformation in Urban Governance in Late Capitalism. 
Geografiska Annaler Series B, 71(1), 3-17.

JESSOP, R. (2008). El futuro del Estado capitalista. Madrid: Los Libros de la Catarata.

NAVARRO JURADO, E.; THIEL ELLUL, D. Y ROMERO PADILLA, Y. (2015). Periferias del placer: cuando turismo se convierte en desarrollismo inmobiliario-turístico. Boletín de la Asociación de Geógrafos Españoles, n 67, 275-302.

RAMOS-PÉREZ, D. (2016). State aid to airlines in Spain: An assessment of regional and local government support from 1996 to 2014. Transport Policy, 49, 137-147.

RAMOS-PÉREZ, D. E IZQUIERDO-MISIEGO, J.I. (2015). Flying from Europe to the Algarve: The Geographical Impacts of the Growth of Low-Cost Carriers (1996-2013). Journal of Spatial and Organizational Dynamics, 3 (4), 275-295

SMYTH, A., CHRISTODOULOU, G., DENNIS, N., AL-AZZAWI, M. Y CAMPBELL, J. (2012). Is air transport a necessity for social inclusion and economic development? Journal of Air Transport Management, 22, 53-59. 
Página intencionalmente dejada en blanco 


\title{
Relaciones económicas España-México en la era de la globalización. Las exportaciones de España
}

\author{
José Luis Alonso Santos (a), María Teresa Sánchez Salazar (b) \\ (a) Departamento de Geografía , Universidad de Salamanca, jlalonso@usal.es, http://orcid.org/0000-0001-6083-6297 \\ (b) Instituto de Geografía, Universidad nacional Autónoma de México, mtss@igg.unam.mx
}

\begin{abstract}
Resumen
Los intercambios comerciales entre México y España trascienden las relaciones económicas y enraízan con las históricas afinidades de identidad y culturales. La globalización no ha quebrado esa sólida relación. La incorporación de México al Mercado de América del Norte y el Tratado de Libre Comercio UE-México desde 2000, han redefinido el marco regulador de los intercambios. El texto analiza los intercambios en los años 90 y su encaje en el marco regulador del TLC y con la Unión Europea. Sigue el análisis en detalle de las exportaciones españolas a México y concluye con unas observaciones de oportunidad para nuevos segmentos de mercado y constata las debilidades que perviven en el comercio de España hacia México. La metodología seguida tiene como soporte el análisis de la base de datos ESTACOM elaborada por ICEX con desglose de la información por sector y rama de actividad (CNAE-2009), país de destino y por comunidad autónoma de origen. El Banco de México presenta datos de las importaciones y exportaciones con España facilitando el contraste de indicadores.
\end{abstract}

Palabras clave: España-México, comercio internacional, exportaciones, intercambios económicos.

\section{Abstract}

Commercial exchanges between Mexico and Spain transcend economic relations and take root with historical identity and cultural affinities. Globalization has not broken that solid relationship. The incorporation of Mexico to the North American Market and the EU-Mexico Free Trade Agreement since 2000 have redefined the regulatory framework for exchanges. The text analyzes the exchanges in the $90 \mathrm{~s}$ and its fit in the regulatory framework of the FTA and with the European Union. It follows the detailed analysis of Spanish exports to Mexico and concludes with some observations of opportunity for new market segments and confirms the weaknesses that persist in the trade of Spain to Mexico. The methodology followed is based on the analysis of the ESTACOM database prepared by ICEX with breakdown of information by sector and branch of activity (CNAE-2009), country of destination and by autonomous community of origin. The Bank of Mexico presents data on imports and exports with Spain, facilitating the contrast of indicators.

Keywords: Spain-Mexico, international trade, exports, economic exchanges.

\section{ANTECEDENTES Y ESTADO DEL TEMA. OBJETIVOS, FUENTES Y METODOLOGÍA}

Aproximarse a la naturaleza de las relaciones económicas de España con México no puede hacerse al margen de las históricas relaciones culturales y el arraigo de la amistad pues han de interpretarse como vehículos de estímulo del desarrollo de las relaciones económicas entre ambos países. Relaciones que se desarrollan en un contexto histórico del comercio internacional que experimenta una fuerte expansión en la segunda mitad del siglo veinte en los países capitalistas desarrollados o no, al amparo de la reglamentación del GATT (General Agreement on Tariffs and Trade) y sus Rondas, lo que exige la implantación en su política económica de prácticas y procesos de producción que generen ventajas competitivas para sus bienes en los mercados internacionales. En ese contexto de internacionalización de las economías nacionales, países como España y México caminan con rezago en la liberalización de sus mercados hasta mediados de los años 80 en el caso de España (integración al Mercado Común Europeo -enero 1986-) y bien entrados los años 90 (1994) en el caso de México (asociación al Tratado de Libre Comercio de América del Norte -TLC- e incorporación a la OCDE) lo que cuadra bien con la observación del profesor J. Velarde, que citando a The Economist, dice que en los años finales de la anterior centuria en Iberoamérica "muchos gobiernos proclamarán su compromiso con el libre comercio, mientras, de manera discreta, les aprietan las clavijas a las importaciones" (Velarde, 1999:52) debido a que mantienen un desarme arancelario limitado a causa de su arraigado nacionalismo económico. 
Una vez España se incorpora al mercado Común Europeo y posteriormente México lo hace al TLC, la relación económica bilateral se ve incluso potenciada por el sentimiento de que ambos sirven de puente para los mercados de los nuevos socios, si bien sostienen los autores del estudio Las relaciones España-México (Informe ELCANO, 2016: 28) ni España ni México necesitan del otro para acceder al mercado del Norte de América en el caso de España o a los mercados de la Unión Europea por parte de México.

Los intercambios comerciales España/México 2000-2017 presentan frecuentes alternancias superávit/déficit si bien el saldo final es de déficit para España tanto con datos de ICEX como del Banco de México. La posición de México como cliente de las mercancías españolas a escala internacional, en el año 2000 su nivel apenas alcanza el 1,2 por ciento mientras el porcentaje más alto corresponde a 2006 con el 1,8 por ciento y en 2017 es el 1,6 por ciento. Entre los principales clientes de los bienes españoles, en 2016 ocupa el puesto 13 y desciendo al 18 entre los suministradores de bienes (Informe ICEX 2017: 5-6).

Dadas las históricas relaciones comerciales, el desarrollo económico alcanzado por ambos países, la gran apertura comercial existente y la conveniente diversificación geográfica del comercio exterior de México tras cuestionar EE.UU. el TLC, cabe esperar estrategias bilaterales una vez renovado el acuerdo comercial México-UE, orientadas a potenciar los intercambios pues existen oportunidades (sectores/nichos de sector) a implementar en ambas direcciones.

Contextualizado el tema, el texto presenta las relaciones comerciales bilaterales en los años 90 del siglo XX e identifica el marco regulador de las relaciones económicas México-España fraguadas en el contexto bilateral primero y en el marco de los acuerdos multilaterales con el TLC primero y con la U E después. El tercer apartado de 2000 al presente, desglosa la naturaleza e intensidad de las exportaciones españolas a través de la base de datos ESTACOM elaborada por ICEX (Instituto Español de Comercio Exterior) e información de la Secretaria General de Comercio Exterior. Fuente que posibilita el seguimiento desagregado por sector y rama de actividad, por país de destino o comunidad autónoma de origen, tanto en valor como en volumen de las exportaciones e importaciones por años entre España y México. El Banco de México también facilita información desagregada para el análisis de las importaciones y exportaciones con España, lo que estimula contrastar los datos estadísticos. Las conclusiones finales conforman el cuarto apartado del texto.

\section{LOS INTERCAMBIOS COMERCIALES EN LOS AÑOS NOVENTA. LIBERALIZACIÓN Y ESTRATEGIAS DE POTENCIACIÓN DEL COMERCIO. EL ACUERDO COMERCIAL CON LA UE.}

En el cuarto final del siglo XX el comercio bilateral estará marcado por la alternancia de años de déficit y superávit según los ciclos económicos de ambas economías. Antes del ingreso en el mercado común europeo, hacia 1980, las exportaciones de España a México apenas cubren el 41,30 por ciento del valor de unas importaciones de 691,4 millones de dólares, en un contexto en el que América Latina (19 países) representa más del 10 por ciento de las ventas al exterior de España y cobertura del 83,9 por ciento del valor de las compras de España en la región (Instituto de Cooperación Iberoamericana 1981:48).

En los años noventa, de 1993 a 1999, España vende a México por valor de 7.373,6 millones de dólares y México a España por 6.086,6 millones. Montos de intercambios que para la economía de México representan el 0,9 de sus ventas al mundo y el 1,1 de sus compras y que, señala Ceceña, sitúan a España como tercer cliente de México detrás de Estados Unidos y Canadá, a la vez que "México es el tercer importador de productos españoles en Latinoamérica y su octavo socio comercial a nivel mundial" (Ceceña 2000:77). Para la economía española, el comercio con México en 2000 representa el 1,2 por ciento de las ventas al mundo y el 1,0 por ciento de las compras, situando a México como décimo socio comercial más importante en exportaciones y el vigésimo en importaciones.

En los años 90, Argentina aún era el primer socio comercial de España en la región y mercados como Venezuela, Chile o Brasil superan a México, país que tras la crisis económica de diciembre 1994, sufre una grave regresión en 1995 (retroceso del PIB del 5,5\%) si bien el quinquenio siguiente presenta tasa media anual de incremento del PIB del 5,1 por ciento (Informe México 2000:145; Botas 2000:112). La traslación de la depresión económica será automática a las importaciones internacionales (Informe México 2000; Banco de México: 15/02/2018) con regresión del 8,7 por ciento de valor en 1995 respecto de 1994 y con mayor virulencia a las bilaterales con España (pérdida del 48,14\% de valor en1995 sobre el año anterior) que impulsadas en 1993-1994 por el éxito de la línea Rey $^{1}$ experimentan una fuerte desaceleración en 1995-1997 (Ceceña 2000; Moreno y Pérez 2005). No obstante,

\footnotetext{
${ }^{1}$ Línea de crédito a la exportación de bienes de equipo por 1.500 millones de dólares gestionada por el ICO .
} 
la crisis del peso, en absoluto empaña el vigor del comercio exterior de México en los años noventa pues presenta una tasa media anual de crecimiento del 15 por ciento "la tasa más alta registrada en el mundo en los años 90" (Blanco 2000:33) con balance de las exportaciones en 1999 del 262,8 por ciento sobre el valor de 1993 y del 217,2 por ciento las importaciones.

Al filo del cambio de siglo la situación comercial bilateral muestra balances muy superiores a los de fechas precedentes. En 2000 el valor conjunto de las compras y ventas entre ambos países fue superior en el 87 por ciento al de 1980 que ascendía a 1.585 millones de dólares (Romero 2001/2002:73). Por su parte, las exportaciones de España escalan al 361,17 por ciento del valor del deprimido bienio 1995-1996 posicionando al país como el socio comercial más importante en América Latina. En suma, México se abre al presente siglo como primer socio comercial de España en la región (Moreno y Pérez 2005: 227), situación ininterrumpida hasta la actualidad, excepción hecha del año 2013 en que las ventas a Brasil suben al 23,7 por ciento de frente al 21,0 que alcanzan las de México sobre las de América Latina-Caribe.

En esos años noventa, las exportaciones de España a México presentan alto componente en bienes de equipo, semimanufacturas, manufacturas y sector del automóvil, con destacada presencia de bienes como automóviles, material eléctrico, maquinarias-herramientas, libros, productos cerámicos, confección, calzado y vinos (Moreno y Pérez 2005:229; Rodrigo y Arce 1999:128).

El marco de las relaciones económicas España-México en esos años se verá tensionado por el proceso de liberalización de la economía de México en sus relaciones económicas específicas con los países del TLC desde enero de 1994 y, desde julio de 2000, el Acuerdo de Asociación Económica, Concertación Política y Cooperación con la Unión Europea. Acuerdos que dan a México "un acceso libre, con seguridad jurídica y mecanismos eficaces de resolución de conflictos, a sus dos principales socios comerciales, cubriendo entre ambos cerca del 95\% del comercio exterior mexicano" (López 2001/2002:115). Para México los espacios del TLC y la UE son mercados muy desiguales para sus intercambios con tendencia incluso al incremento a partir de 1994 (el TLC acapara el 85\% de sus exportaciones a la vez que la UE pierde peso (Riva de la 2000: 63; Botas 2000:113; Informe México 2000:170) por lo que: "la diversificación del riesgo a plazo es una de las principales motivaciones que llevó al gobierno de México a buscar un acuerdo de Libre Comercio con la UE" (Riva de la 2000:63).

Las relaciones económicas bilaterales serán estimuladas por la firma de distintos acuerdos y el desempeño de instrumentos diversos de promoción, destacando entre ellos los que establecen normas claras y dan seguridad a las empresas o abren líneas de crédito que fomentan las exportaciones e inversiones (Oficina Económica 2004:11/12; Moreno y Pérez 2005:234-235). Son el Tratado General de Cooperación y Amistad que desde 1990 abre una potente línea de crédito en apoyo a las exportaciones de bienes y servicios o inversiones desde España hacia México, así como el acuerdo de Promoción y Protección de Recíproca de Inversiones (APRI) de diciembre de 1996. El Instituto de Crédito Oficial (ICO) y el Instituto Español de Comercio Exterior (ICEX) serán los organismos oficiales encargados de su ejecución y seguimiento.

\section{LAS EXPORTACIONES DE ESPAÑA A MÉXICO EN EL SIGLO XXI}

En los años transcurridos del presente siglo el comercio de España con América Latina-Caribe presenta un bajo perfil ya que apenas representa el 5,6 por ciento de las ventas totales al exterior ${ }^{2}$ de $2000 / 2017$ e incluso sufre deterioro en los bienios $2003 / 2004$ y $2008 / 2009$ con niveles inferiores al cinco por ciento. Pese a ello, hay que señalar que no se observan mayores esfuerzos para incrementar la participación de los países de América Latina en el comercio exterior hasta bien avanzada la crisis económica cuando la débil demanda interna obliga a las empresas a abrir mercados en el exterior de modo que de 2012 a 2015 las exportaciones hacia América Latina se expanden y retornan a niveles superiores al seis por ciento (6,47\% en 2013) de las exportaciones totales como sucedía en 2000 . El mercado de A.Latina-Caribe actual representa más del siete por ciento del PIB mundial, sus clases medias se han incrementado y países como Brasil y México se sitúan entre las 15 mayores economías del mundo en PPA, como destacan los autores del Informe ELCANO (¿Por qué importa América Latina?, 2017: 37). Como hemos documentado (Alonso, 2018: 18) en los peores años del quinquenio inicial del siglo el deterioro de las ventas a México fue menor que el registrado en el conjunto de América Latina-Caribe y sus grandes mercados de Argentina y Brasil. En realidad, los intercambios España/ México se han incrementado en volumen y en porcentaje tanto sobre el comercio regional como sobre el total mundial.

${ }^{2}$ La Ley 14/2013 de apoyo a los emprendedores y la internacionalización dará lugar al primer Plan Estratégico de Internacionalización $2014-2015$ antecedente de La Estrategia de Internacionalización de la Economía Española 2017-2027. 


\subsection{Grado de las exportaciones $2000-2017$ y sus fases}

Las ventas totales de la economía española al exterior de 2000 a 2017 experimentan un crecimiento notable pues más que doblan su valor (223,2\%) al igual que hacia América Latina-Caribe $(207,3 \%)$ si bien las realizadas a México presentan evolución más vigorosa ya que en 2017 suponen el 304,6 por ciento del valor en 2000. La figura 1 muestra las ventas a México respecto a A. Latina-Caribe y al comercio exterior total.

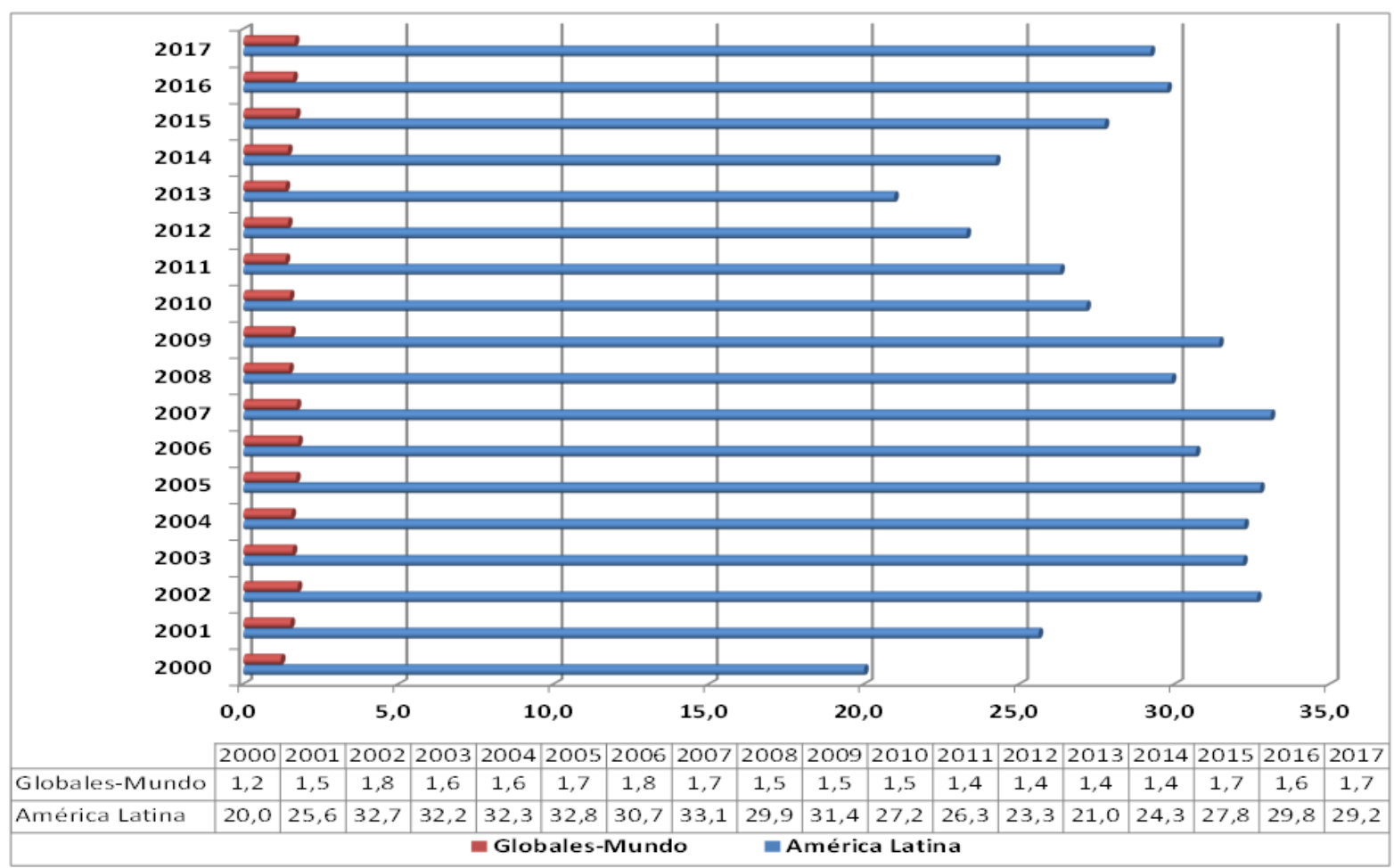

Figura 1 - Exportaciones (\%) de España a México respecto a América Latina y al Mundo 2000-2017. Fte. ICEX. Estacom.

Mientras que en las décadas finales del siglo XX hasta mediados de los años 90, Argentina fuera el mercado principal en el comercio de España con A. Latina, desde los últimos años de la década al presente, México junto a Brasil, engrosan la lista de países de interés estratégico para la economía española pues constituyen dos potentes mercados que sumados superan ampliamente el 50 por ciento de la IED de España en la región (Sánchez, Alonso y Casado, 2017: 12) y apenas les restan unos puntos en el monto de las exportaciones (45,8\% media 2016-2017). Si la IED de España en Brasil supera ampliamente a la recibida por México: 59.327,6 millones de euros por 35.116,8 millones de euros de 1993 a 2015 (Cepal 2000; Alonso, Mendes y Guarnieri, 2017:181) en comercio, excepción hecha de 2013, México supera en mucho a Brasil pues de 2000 a 2017 acapara el 27,6 por ciento de las exportaciones a la región mientras Brasil representa el 17,7 por ciento.

El notable incremento del comercio bilateral arroja saldo global negativo para España pues las ventas de 53.112,6 millones/€ apenas cubren el 95,5 por ciento de las compras por 55.592,3 mills/€. Saldo no exento de años de alternancia déficit/superávit como muestra la figura 2. Hay años como 2000, 2005 y 2008 con saldo negativo para España pero el deterioro grave y prolongado de las ventas españolas define al quinquenio 2010-2014 con muy grave de déficit de cobertura en 2012 (apenas 57,1\%) y 2013 (58,8\%). El periodo más amplio de saldo positivo para las exportaciones de España es el cuatrienio 2001-2004 así como los tres últimos años registran amplios saldos positivos.

Que el déficit comercial caracterice al periodo 2000-2017, no pone en cuestión que en 2007 el valor de las exportaciones respecto a 2000 sea el 210,8 por ciento y en 2017 se haya incrementado al 304,6 por ciento (144,5\% sobre el valor de 2007). Son únicamente cinco los años en los que se registran pérdidas de valor de las exportaciones respecto del precedente $(2003,2008,2009,2013$ y 2016). De ellos, el bienio 2008-2009 presenta tasas interanuales negativas severas $(-11,8 \%$ en 2008 y $-12,0 \%$ en 2009$)$. Es de cierta importancia $(-6,1 \%)$ la 


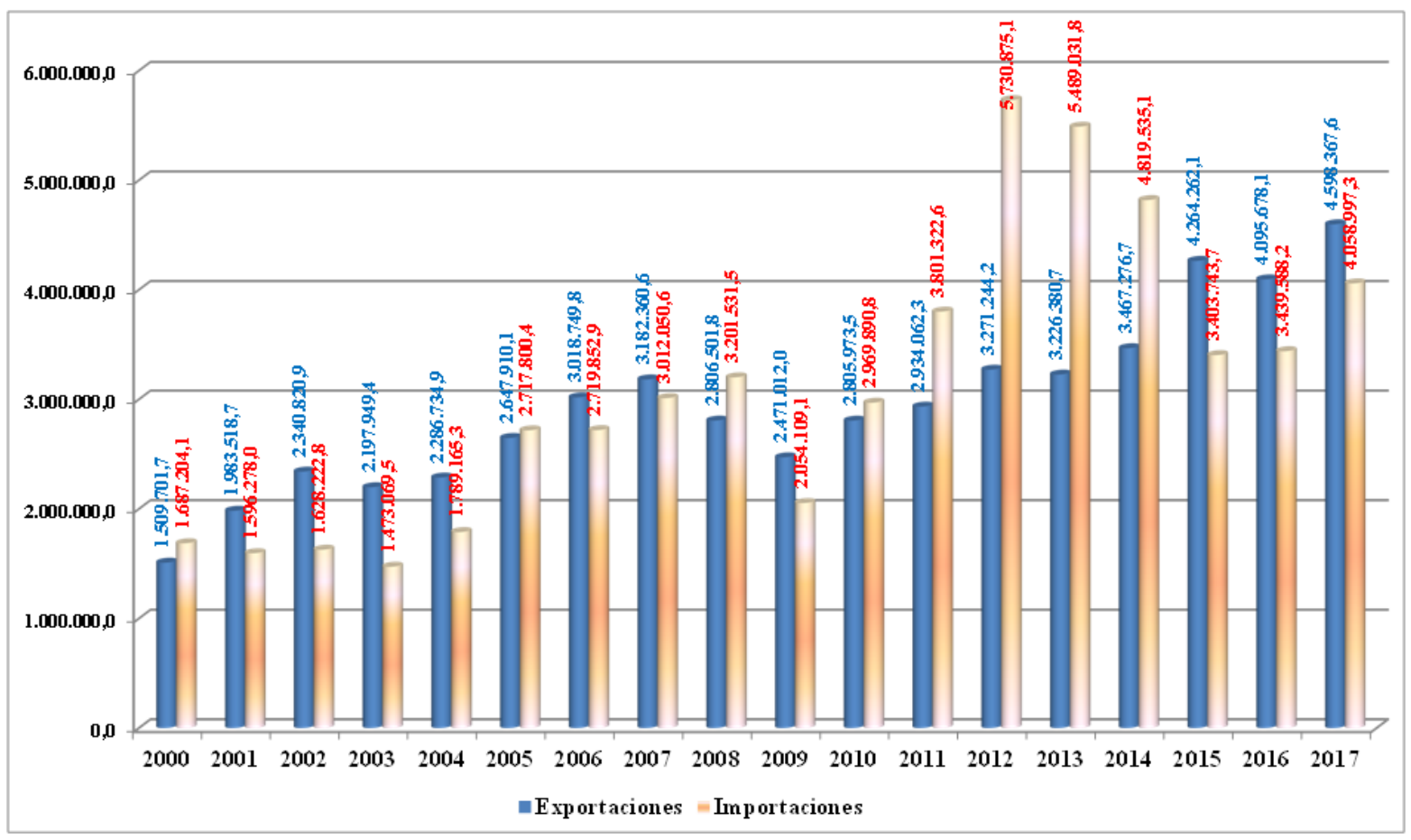

Figura 2 - Comercio entre España y México 2000-2017. Miles de euros. Fte. ICEX. Estacom.

pérdida de valor en 2003, fecha en que registran saldo negativo importante respecto el año anterior capítulos como edición además de actividades manufactureras tan variadas como alimentación, cuero y calzado, química, productos metálicos, fabricación de equipo eléctrico o vehículos de motor. Las exportaciones de 2008-2009 sufren contracción muy marcada y en 2008 su valor se redujo al 89,8 por ciento respecto a 2007 para bajar al 77,6 por ciento en 2009, año en que proliferan ramas de actividad cuyos bienes sufren un descalabro en relación a los niveles de 2007. Registran pérdidas superiores al 50 por ciento las ramas de fabricación de muebles: 35,1\%, así como recogida y tratamiento de residuos sólidos: $46,2 \%$. Nueve ramas presentan valores inferiores a la media (77,6\%) del conjunto (otras industrias manufactureras; edición; vehículos a motor; maquinaria y equipo n.c.o.p.; productos informáticos, electrónicos-ópticos; productos metálicos; otros productos minerales; productos de caucho-plásticos; industria textil). Registran pérdida de valor inferior a la media otras ocho ramas (alimentación, bebidas, confección, cuero y calzado, papel, coquerías y refino de petróleo, química y productos farmacéuticos). En este contexto de regresión comercial, la excepción viene por el incremento de valor de metalúrgia-fab. hierro... $(106,1 \%)$, fabricación de otro material de transporte $(107,9 \%)$ y fabricación de material y equipo eléctrico (123,5\%).

Frente a las coyunturas de regresión de las exportaciones, hasta ocho años presentan sobre el precedente tasas de incremento por encima del 10 por ciento. La grave depresión del bienio 2008-2009 se produce después de una etapa de ocho años de sostenido y sólido ritmo de incremento de las exportaciones excepción hecha de 2003. En esos años la tasa interanual media de incremento del 11,8 por ciento fue más robusta que la del 8,1 por ciento de la etapa que se abre en 2010 hasta 2017, en la que se registra 2013 y 2016 con suaves tasas de regresión $(-1,4$ y $-3,9 \%$ respectivamente).

Las exportaciones a México se presentan muy concentradas en el sector de la industria manufacturera (93,5\%), muy reducida presencia del sector editorial y comunicación $(3,3 \%)$ y el sector tratamiento de aguas y residuos sólidos $(1,6 \%)$ e insignificante presencia de las industrias extractivas $(0,8 \%)$, actividades no clasificadas $(0,6 \%)$ sector primario $(0,2 \%)$, etc.. La situación no siempre fue esta como indican los datos del cuadro-1. En los años anteriores a la crisis económica la polarización en torno a la industria manufacturera no era tan potente como en los años recientes pues su valor del 89,9 por ciento era varios puntos inferior al de los años 2008-2017.

Un análisis más detallado de la información de Estacom en base a la clasificación de actividades de CNAE2009, permite seguir el comportamiento de cada rama de actividad. El cuadro-2 muestra el peso de las 10 ramas de mayor valor aportado de 2000 a 2017 contrastado con los bienios inicial, intermedio y final. El resultado es 
Cuadro 1 - Exportaciones de España a México. Fases en el tiempo. Miles de euros. Fte. ICEX. Estacom.

\begin{tabular}{|c|c|c|c|c|c|c|}
\hline \multirow[b]{2}{*}{ Ram as CNAE-2009 } & \multicolumn{2}{|c|}{$2000-2007$} & \multicolumn{2}{|c|}{ 2008-2017 } & \multicolumn{2}{|c|}{$2000-2017$} \\
\hline & Miles/€ & $\%$ & Miles/€ & $\%$ & Miles/€ & $\%$ \\
\hline Ag ricultura, ganaderia, caza y servicios relacionados con las mismas & $24.052,7$ & 0,1 & $75.610,6$ & 0,2 & $99.663,3$ & 0,2 \\
\hline Silvicultura y explotación forestal & 277,2 & 0,0 & 719,5 & 0,0 & 996,6 & 0,0 \\
\hline Pesca y acuicultura & 133,1 & 0,0 & 776,1 & 0,0 & 909,3 & 0,0 \\
\hline Sector Primario & $24.463,0$ & 0,1 & $77.106,2$ & 0,2 & $101.569,2$ & 0,2 \\
\hline Extracción de antracita, hulla y lig nito & 12,9 & 0,0 & 0,2 & 0,0 & 13,1 & 0,0 \\
\hline Extracción de crudo de petróleo y gas natural & & 0,0 & $155.895,0$ & 0,5 & $155.895,0$ & 0,3 \\
\hline Extracción de minerales metálicos & $5.872,4$ & 0,0 & $74.918,4$ & 0,2 & $80.790,8$ & 0,2 \\
\hline Otras industrias extractivas & $67.727,8$ & 0,4 & $92.417,4$ & 0,3 & $160.145,1$ & 0,3 \\
\hline Indus trias Extractivas & $73.613,0$ & 0,4 & $323.230,8$ & 1,0 & $396.843,8$ & 0,7 \\
\hline Industria de la alimentación & $635.063,0$ & 3,3 & $1.412 .460,8$ & 4,2 & $2.047 .523,8$ & 3,9 \\
\hline Fabricación de bebidas & $475.811,2$ & 2,5 & $981.234,4$ & 2,9 & $1.457 .045,6$ & 2,7 \\
\hline Indus tria del tabaco & $3.219,1$ & 0,0 & $2.088,4$ & 0,0 & $5.307,4$ & 0,0 \\
\hline Industria textil & $567.858,0$ & 3,0 & $550.261,5$ & 1,6 & $1.118 .119,5$ & 2,1 \\
\hline Confección de prendas de vestir & $1.138 .835,9$ & 5,9 & $2.607 .215,6$ & 7,7 & $3.746 .051,6$ & 7,1 \\
\hline Industria del cuero y del calzado & $333.945,9$ & 1,7 & $546.435,7$ & 1,6 & $880.381,6$ & 1,7 \\
\hline Industria de la madera y del corcho, excepto muebles; cesteria y espa & $61.247,4$ & 0,3 & $144.502,1$ & 0,4 & $205.749,4$ & 0,4 \\
\hline Industria del papel & $281.135,7$ & 1,5 & $477.138,7$ & 1,4 & $758.274,3$ & 1,4 \\
\hline Artes gráficas y reproducción de soportes grabados & $1.658,0$ & 0,0 & $1.184,9$ & 0,0 & $2.842,9$ & 0,0 \\
\hline Coquerias y refino de petróleo & $1.291 .889,7$ & 6,7 & $1.464 .440,6$ & 4,3 & $2.756 .330,3$ & 5,2 \\
\hline Industria quimica & $1.351 .902,2$ & 7,1 & $2.780 .942,3$ & 8,2 & $4.132 .844,5$ & 7,8 \\
\hline Fabricación de productos farmacéuticos & $366.523,3$ & 1,9 & $959.022,9$ & 2,8 & $1.325 .546,2$ & 2,5 \\
\hline Fabricación de productos de caucho y plásticos & $430.553,4$ & 2,2 & $804.608,5$ & 2,4 & $1.235 .161,9$ & 2,3 \\
\hline Fabricación de otros productos minerales no metálicos & $632.085,6$ & 3,3 & $771.114,3$ & 2,3 & $1.403 .199,9$ & 2,6 \\
\hline Metalurg ia; fabricación de productos de hierro, acero y ferroaleacion & $526.246,8$ & 2,7 & $1.194 .056,9$ & 3,5 & $1.720 .303,7$ & 3,2 \\
\hline Fabricación de productos metálicos, excepto maquinaria y equipo & $1.009 .071,8$ & 5,3 & $1.742 .129,8$ & 5,1 & $2.751 .201,5$ & 5,2 \\
\hline Fabricación de productos infomáticos, electrónicos y ópticos & $682.052,4$ & 3,6 & $696.722,5$ & 2,1 & $1.378 .774,9$ & 2,6 \\
\hline Fabricación de material y equipo eléctrico & $767.344,4$ & 4,0 & $2.824 .007,5$ & 8,3 & $3.591 .351,9$ & 6,8 \\
\hline Fabricación de maquinaria y equipo n.c.o.p. & $2.663 .840,1$ & 13,9 & $4.254 .608,1$ & 12,5 & $6.918 .448,1$ & 13,0 \\
\hline Fabricacion de vehiculos de motor, remolques y semirremolques & $2.795 .496,8$ & 14,6 & $5.313 .664,7$ & 15,7 & $8.109 .161,6$ & 15,3 \\
\hline Fabricación de otro material de transporte & $615.614,0$ & 3,2 & $2.008 .242,1$ & 5,9 & $2.623 .856,2$ & 4,9 \\
\hline Fabricación de muebles & $222.115,1$ & 1,2 & $327.312,8$ & 1,0 & $549.428,0$ & 1,0 \\
\hline Otras industrias manufactureras & $381.646,0$ & 2,0 & $586.717,9$ & 1,7 & $968.363,9$ & 1,8 \\
\hline Industria Manufacturera & $17.235 .155,7$ & 89,9 & $32.450 .113,0$ & 95,6 & $49.685 .268,8$ & 93,6 \\
\hline Suminis tro de energía eléctrica, gas, vapor y aire acondicionado & 1,0 & 0,0 & & 0,0 & 1,0 & 0,0 \\
\hline Recogida y tratamiento de aguas residuales & & 0,0 & & 0,0 & & 0,0 \\
\hline Recogida, tratamiento y eliminación de residuos; valorización & $665.383,8$ & 3,5 & $163.941,6$ & 0,5 & $829.325,4$ & 1,6 \\
\hline Suminis tro y tratamiento agua, resíduos sólidos y descont. & $665.383,8$ & 3,5 & $163.941,6$ & 0,5 & $829.325,4$ & 1,6 \\
\hline Edición & $1.004 .368,7$ & 5,2 & $697.877,3$ & 2,1 & $1.702 .246,0$ & 3,2 \\
\hline Actividades cinematográficas, de video y de programas de televisión & $23.201,6$ & 0,1 & $5.626,5$ & 0,0 & $28.828,0$ & 0,1 \\
\hline Información, comunic aciones & $1.027 .570,3$ & 5,4 & $703.503,8$ & 2,1 & $1.731 .074,1$ & 3,3 \\
\hline Servicios técnicos de arquitectura e ing enieria; ensayos y analisis téc & 223,7 & 0,0 & 31,7 & 0,0 & 255,4 & 0,0 \\
\hline Otras actividades profesionales, cientificas y técnicas & 340,1 & 0,0 & 31,2 & 0,0 & 371,2 & 0,0 \\
\hline Actividades profes ionales, cientific 0 -técnic as & $\mathbf{5 6 3 , 8}$ & 0,0 & 62,8 & 0,0 & 626,7 & 0,0 \\
\hline Actividades de creación, artisticas y espectáculos & $5.721,2$ & 0,0 & $17.179,8$ & 0,1 & $22.901,1$ & 0,0 \\
\hline Actividades de bibliotecas, archivos, museos y otras actividades cul & 505,0 & 0,0 & $1.899,9$ & 0,0 & $2.404,9$ & 0,0 \\
\hline Actividades artístic as y recreativas & $6.226,3$ & 0,0 & $19.079,7$ & 0,1 & $25.306,0$ & 0,0 \\
\hline Otros servicios personales & & 0,0 & 24,1 & 0,0 & 24,1 & 0,0 \\
\hline Actividades no clasificadas & $134.769,1$ & 0,7 & $203.696,7$ & 0,6 & $338.465,8$ & 0,6 \\
\hline Total Exportaciones & $19.161 .297,6$ & 100,0 & $33.940 .759,0$ & 100,0 & $53.108 .505,0$ & 100,0 \\
\hline
\end{tabular}

que el 72,3 por ciento de lo exportado en el periodo corresponde a las 10 ramas que encabezan el ranking si bien se registran diferencias en el tiempo tanto en porcentaje como en ramas principales. Entre las 10 mayores ramas, seis presentan monto de ventas importante en todo el tiempo, la industria alimentaria está ausente en el bienio inicial; deben su presencia entre las 10 mayores a la envergadura de sus ventas en momentos puntuales coquerías y refino de petróleo en 2007/2008 y en 2016/2017 emergen las ramas de fabricación de otro material de transporte, metalúrgia-fabricación de hierro y fabricación de productos farmacéuticos. En suma, de forma regular unas, más puntualmente otras, son 15 las ramas que aportan más de las 3/4 partes de las exportaciones.

Empresas y territorio son actores imprescindibles del proceso exportador. Respecto a quién exporta, el Informe $^{3}$ facilitado por ICEX sobre las empresas exportadoras a México en 2017 facilita información sobre las em-

${ }^{3}$ Informe solicitado a ICEX el 19/03/2018 y elaborado a partir de los datos suministrados por el Departamento de Aduanas e Impuestos Especiales de la AEAT. 
Cuadro 2 - Valor en \% de las diez ramas mayores sobre las exportaciones totales. Fte. Datos Estacom.

\begin{tabular}{|c|c|c|c|c|}
\hline Ramas de actividad & 2000-2017 & $2000 / 2001$ & $2007-2008$ & 2016-2017 \\
\hline Fabricación de vehiculos de motor, remolques y semirremolques & 15,3 & 14,8 & 13,3 & 16,5 \\
\hline Fabricación de maquinaria y equipo n.c.o.p. & 13,0 & 16,0 & 12,2 & 13,9 \\
\hline Confección de prendas de vestir & 7,1 & 4,8 & 7,0 & 8,4 \\
\hline Fabricación de materialy equipo eléctrico & 6,8 & 4,3 & 5,1 & 8,2 \\
\hline Coquerias y refino de petróleo & 5,2 & & 14,3 & \\
\hline Fabricación de otro materialde transporte & 4,9 & & & 6,4 \\
\hline Industria de la alimentación & 3,9 & & 2,9 & 5,2 \\
\hline Metalurgia; fabricacion de productos de hierro, acero y ferroaleaciones & 3,2 & & & 3,2 \\
\hline Edición & & 8,0 & 3,2 & \\
\hline Recogida, tratamiento y eliminación de residuos; valorización & & 4,3 & 3,2 & \\
\hline Valor de las 10 ramas sobre total & 72,3 & 73,4 & 72,1 & 78,7 \\
\hline
\end{tabular}

presas exportadoras entre 2012 y 2017 y las clasifica por valor de lo exportado desde 2013. Los datos confirman la tendencia general del país en cuento al incremento de exportadores a México en los años recientes habiendo crecido el 23,2 por ciento (de 11.154 en 2012 a 13.739 en 2017) indicador que representa el 8,5 por ciento de los exportadores de España aunque apenas aportan el 1,7 por ciento del valor exportado por el país en 2017.

El Informe revela que buen número de empresas (73,7\% en 2013 y 72,3\% en 2017) incorporadas al mercado de México registran volumen de ventas muy reducido (hasta $50.000 €$ ) aunque en claro incremento (ascenso del 1,1 a $1,5 \%$ del total), mientras las empresas que exportan por encima de cinco millones/€ son muy pocas pero su aportación extraordinaria con tendencia al incremento (50,3\% en 2013 y 56,0\% en 2017). El Informe también muestra la concentración en los niveles inferiores de las ventas de los exportadores irregulares mientras los regulares se concentran en los altos.

\section{2. La naturaleza de los bienes exportados y sus cambios según composición}

El perfil de las exportaciones a México muy concentrado en la industria manufacturera se ha ido reforzando con los años hasta representan el 97,5 por ciento del total en el bienio 2016-2017 frente al 86,4 por ciento en el bienio 2000-2001 o el 92,1 por ciento de 2007-2008. Presentadas por el sector de actividad en el que se encuadran sus productos, las exportaciones a México arrojan los valores que se recogen en el cuadro 3 y la figura 3.

El sector bienes de equipo aunque pierde peso en el total respecto a los años 90 de la centuria anterior (Moreno y Pérez 2005:228) sigue ocupando un lugar destacado con valor superior al 31,3 por ciento de las exportaciones del periodo si bien registra marcados contrastes en el tiempo como indican los datos de 2007-2008. Rasgo a considerar es que su peso en el comercio con México es muy superior al que alcanza sobre las exportaciones totales de España. Las manufacturas de consumo, con el 17,6 por ciento son el segundo sector en importancia si bien registran pérdida notable de valor en los años recientes. A pesar de ello, su presencia en el mercado de México es muy superior a la que tiene en las exportaciones totales. Contraria es la imagen del sector del automóvil, con trayectoria bastante regular y tercero en valor $(14,8 \%)$ aunque con protagonismo varios puntos inferior al que adquiere en las exportaciones totales de España. Productos químicos es el cuarto sector en importancia $(11,6 \%)$ y en el tiempo muestra trayectoria bastante regular así como su peso sigue un patrón muy similar al que ofrece en las exportaciones totales del país.

Con menor valor de sus bienes pero también con sólida y regular presencia están los sectores de alimentos, semimanufacturas sin productos químicos e incluso el débil sector de bienes de consumo duradero. Aleatoria es la trayectoria del sector de productos energéticos ${ }^{4}$ y el de materias primas. Sin relevancia en las exportaciones a México (Cámara Española de Comercio 2017:15) ambos tienen limitada presencia las exportaciones de España.

${ }^{4}$ Concentra el 84,2 por ciento de sus ventas de 2006 a 2010 . 


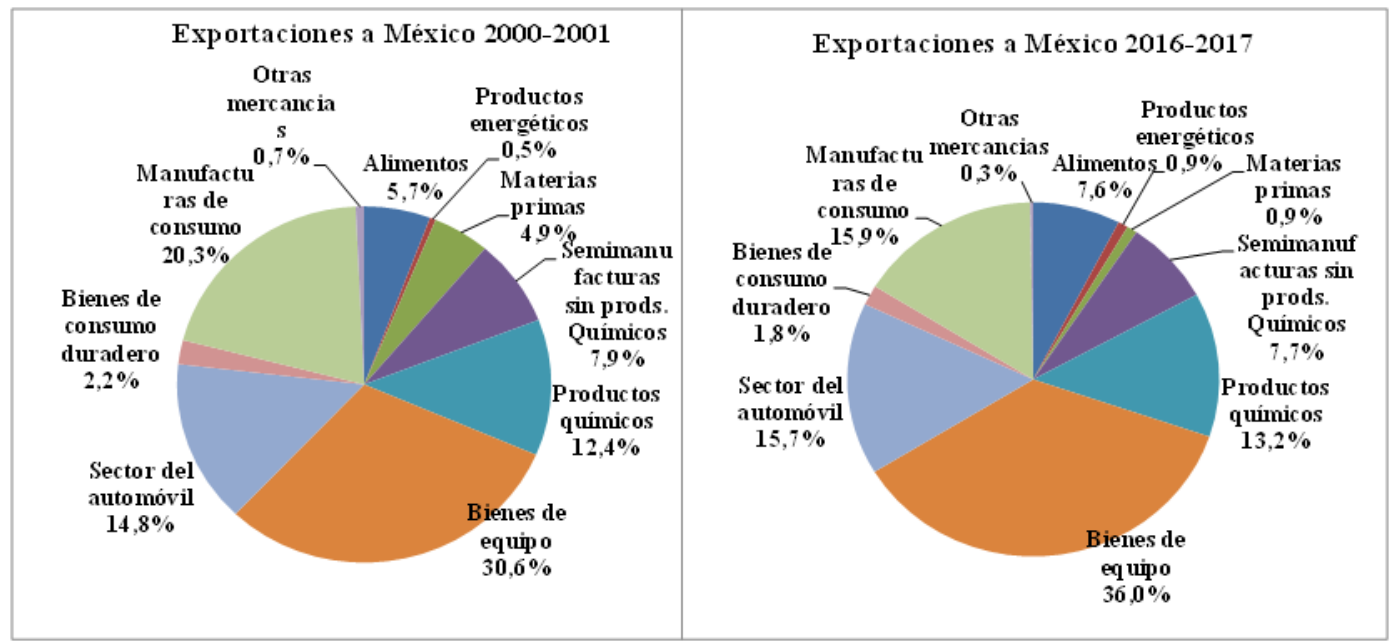

Figura 3 - Exportaciones a México por sectores económicos. Fte. Estacom.

Cuadro 3 - Exportaciones de España a México por sectores económicos. Miles de euros. Fte. Estacom.

\begin{tabular}{|c|c|c|c|c|c|c|c|c|}
\hline Sectores Económicos ICEX & $2000-2001$ & $\% 2000-2001$ & $2007-2008$ & $\%$ 2007-2008 & 2016-2017 & $\%$ 2016-2017 & $2000-2017$ & $\% 2000-2017$ \\
\hline Alimentos & $200.009,8$ & 5,7 & $336.309,4$ & 5,6 & $660.572,9$ & 7,6 & $3.425 .006,8$ & 6,4 \\
\hline Productos energéticos & $18.018,3$ & 0,5 & $864.555,5$ & 14,4 & $75.596,4$ & 0,9 & $2.920 .319,7$ & 5,5 \\
\hline Materias primas & $172.410,9$ & 4,9 & $241.897,6$ & 4,0 & $78.087,8$ & 0,9 & 1.319. 274,5 & 2,5 \\
\hline Semimanufacturas sin prods. Químicos & $276.586,2$ & 7,9 & $416.492,3$ & 7,0 & $669.199,1$ & 7,7 & $4.129 .693,4$ & 7,8 \\
\hline Productos químicos & $432.222,6$ & 12,4 & $561.855,9$ & 9,4 & $1.145 .303,2$ & 13,2 & $6.179 .035,6$ & 11,6 \\
\hline Bienes de equipo & $1.068 .717,1$ & 30,6 & $1.532 .211,5$ & 25,6 & 3.132.210,5 & 36,0 & $16.628 .349,7$ & 31,3 \\
\hline Sector del automóvil & $515.838,7$ & 14,8 & $727.473,3$ & 12,1 & $1.366 .937,5$ & 15,7 & $7.886 .819,3$ & 14,9 \\
\hline Bienes de consumo duradero & $76.249,6$ & 2,2 & $107.621,6$ & 1,8 & $158.699,6$ & 1,8 & $908.574,8$ & 1,7 \\
\hline Manufacturas de consumo & $707.745,6$ & 20,3 & $1.141 .267,0$ & 19,1 & $1.384 .302,8$ & 15,9 & $9.370 .894,5$ & 17,6 \\
\hline Otras mercancias & $25.421,6$ & 0,7 & $59.178,3$ & 1,0 & $23.136,0$ & 0,3 & $340.251,4$ & 0,6 \\
\hline TOTAL & $3.493 .220,4$ & 100,0 & $5.988 .862,4$ & 100,0 & $8.694 .045,7$ & 100,0 & $53.108 .219,7$ & 100,0 \\
\hline
\end{tabular}

Los energéticos en 2016 respecto a 2015, experimentan fuertes contrastes entre sus componentes pues decaen el 56,5 por ciento las ventas de gas natural mientras los derivados del petróleo se incrementan el 14,9 por ciento (ICE 2017: 51).

Dominan las exportaciones automóviles y motos $(61,6 \%)$ junto a componentes, piezas y accesorios $(38,1 \%)$ en el sector del motor; en el área química destacan productos químicos básicos y jabones, detergentes y artículos de limpieza; en bienes de equipo sobresale la maquinaria industrial en general, motores, generadores y transformadores eléctricos. Otros bienes sólidamente implantados son las prendas de vestir, alimentos (aceites y grasas vegetales, frutas y verduras más lácteos, aportan el 52,3\%), los vinos aportan el 46,3 por ciento del valor de todas las bebidas exportadas al país y su cuantía adquiere gran relevancia cuando se mide en el importante mercado de América Latina. Es éste un mercado para los vinos españoles débil aún pero un clara expansión y donde México ostenta posición muy destacada pues aporta el 54,8 por ciento. El Observatorio Español del Mercado del Vino (OEMV) resalta que las exportaciones a México en 2017 crecieron más del seis por ciento de modo que se refuerza su primacía en valor pero también en volumen al desplazar a los vinos chilenos (Memoria 2017: 23 y Boletín 475). En consonancia con la arraigada presencia de las grandes editoriales españolas en México, los libros importados tienen sólida y regular trayectoria si bien desde 2008 decae su intensidad.

Por último, la naturaleza de los bienes vendidos por España a México puede ser considerada en función del grado de intensidad tecnológica que presentan. En este sentido, la base Estacom presenta el balance que recoge el cuadro-4, que también incorpora los índices para las exportaciones totales de España en las mismas fechas lo que facilita la ponderación de las ventas al mundo y a México.

Las exportaciones a México presentan decreciente peso de las más avanzadas a la vez que durante los años de crisis económica se fortalecen notablemente las de intensidad media-alta de modo que el peso conjunto del 51,7 por ciento en 2001 salta al 57,1 en 2017 en detrimento de los bienes de intensidad media y baja. Comportamiento más positivo que el las exportaciones españolas que si en la actualidad tienen un componente de intensidad alta varios puntos superior a las de México en cambio presentan valores en regresión en intensidad media- 
Cuadro 4 - España. Grado de intensidad tecnológica de las exportaciones. Fte. Estacom 19 marzo 2018.

\begin{tabular}{|c|c|c|c|c|c|c|}
\hline \multirow[t]{2}{*}{ Exportaciones de España } & \multicolumn{2}{|c|}{2001} & \multicolumn{2}{|c|}{2008} & \multicolumn{2}{|c|}{2017} \\
\hline & Miles/€ & $\%$ & Miles/€ & $\%$ & Miles/€ & $\%$ \\
\hline Intensidad Alta & $10.979 .197,1$ & 8,8 & $16.569 .016,9$ & 8,8 & $24.866 .168,8$ & 9,0 \\
\hline Intensidad Media-Baja & $23.218 .673,4$ & 18,7 & $42.327 .497,7$ & 22,4 & $52.363 .442,7$ & 18,9 \\
\hline Intensidad Baja & $24.393 .327,6$ & 19,6 & $35.865 .168,3$ & 19,0 & $61.341 .965,4$ & 22,1 \\
\hline \multirow[t]{2}{*}{ Exportaciones a México } & \multicolumn{2}{|l|}{2001} & \multicolumn{2}{|l|}{2008} & \multicolumn{2}{|c|}{2017} \\
\hline & Miles/€ & $\%$ & Miles/€ & $\%$ & Miles/€ & $\%$ \\
\hline Intensidad Alta & $105.635,3$ & 7,0 & $155.043,8$ & 5,5 & $264.429,5$ & 5,8 \\
\hline No clasificable & $183.865,8$ & 12,2 & $197.846,9$ & 7,0 & $110.297,4$ & 2,4 \\
\hline Total & $1.509 .701,7^{\circ}$ & 100,0 & $2.806 .501,8$ & 100,0 & $4.598 .367,6$ & 100,0 \\
\hline
\end{tabular}

alta hasta el punto de que la suma de ambos valores se queda en el 48,2 por ciento mientras en México superan el 57,0 por ciento. Todo indica que la economía de España tiene un problema serio de investigación e innovación técnica que se refleja en el valor añadido de sus exportaciones, circunstancia que implícitamente reconoce el documento "Estrategia de Internacionalización de la Economía Española 2017-2027" cuando sugiere priorizar la producción de bienes de intensidad tecnológica alta ya que "la tasa de exportaciones de alta tecnología está entre las más bajas de la UE" (p. 19).

\section{3. El origen de las exportaciones por CC.AA}

El estudio y conocimiento del origen de los bienes exportados en general o a México en particular, es dimensión relevante del comercio exterior de la economía de España. En especial, desde el inicio de la grave crisis

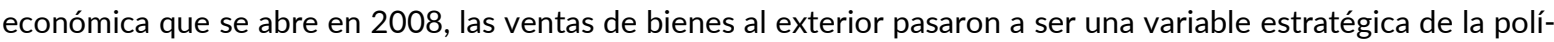
tica económica que ha fraguado notables resultados tanto por su aportación a la actividad económica general en años de muy débil vigor de la demanda interna como porque animó u obligó a dar el salto a la internacionalización de sus mercados a muchas empresas ante la necesidad de sobrevivir.

Un primer hecho contrastado de las exportaciones a México es el valor medio anual de las exportaciones que ha sido desde 2008 el 141,6 por ciento superior al de los años 2000-2007. Únicamente las comunidades de Baleares y Canarias, ambas con reducida exportación, presentan regresión en su exportación anual media (Baleares pierde incluso en valor absoluto). Incrementan su exportación anual media por debajo del total, las comunidades de Andalucía (119,9\%), Cantabria $(128,6)$, Cataluña $(132,4)$, Madrid $(124,6)$ y País Vasco $(125,7)$. Las diez CC.AA. restantes y Ceuta-Melilla, incrementan el valor medio anual por encima de la media total con índices espectaculares en Asturias (355,5\%) y Navarra (410,8\%).

La participación de las CC.AA. en las ventas a México muestra (figura 4) el protagonismo extraordinario de Cataluña a pesar de la regresión en los años de crisis económica. Su aportación es muy superior a su peso real en la economía de España-2016 (19,1\% del PIB) debido a que su industria manufacturera es la mayor de España y está diversificada. Balance similar ofrecen las comunidades de Asturias, C. Valenciana, Galicia, Navarra y País Vasco, todas con mayor índice de exportaciones a México que su PIB nacional. Cantabria y La Rioja registran índice exportador similar a su PIB nacional y las nueve CC.AA. restantes aportan valores siempre inferiores a su PIB nacional. Madrid con PIB rozando el 19 por ciento del nacional apenas aporta el 9,2 de las exportaciones en el periodo así como registra un claro retroceso en los años de crisis. La marcada terciarización de su economía explica su débil capacidad de exportación. En los años de crisis económica respecto a los años previos, pierden porcentaje en las exportaciones además de Baleares y Canarias, las CC.AA. de Andalucía, Cantabria, Cataluña, Madrid y País Vasco. Resulta llamativo que cuatro comunidades (Andalucía, Cataluña, Madrid y País Vasco) que concentran 


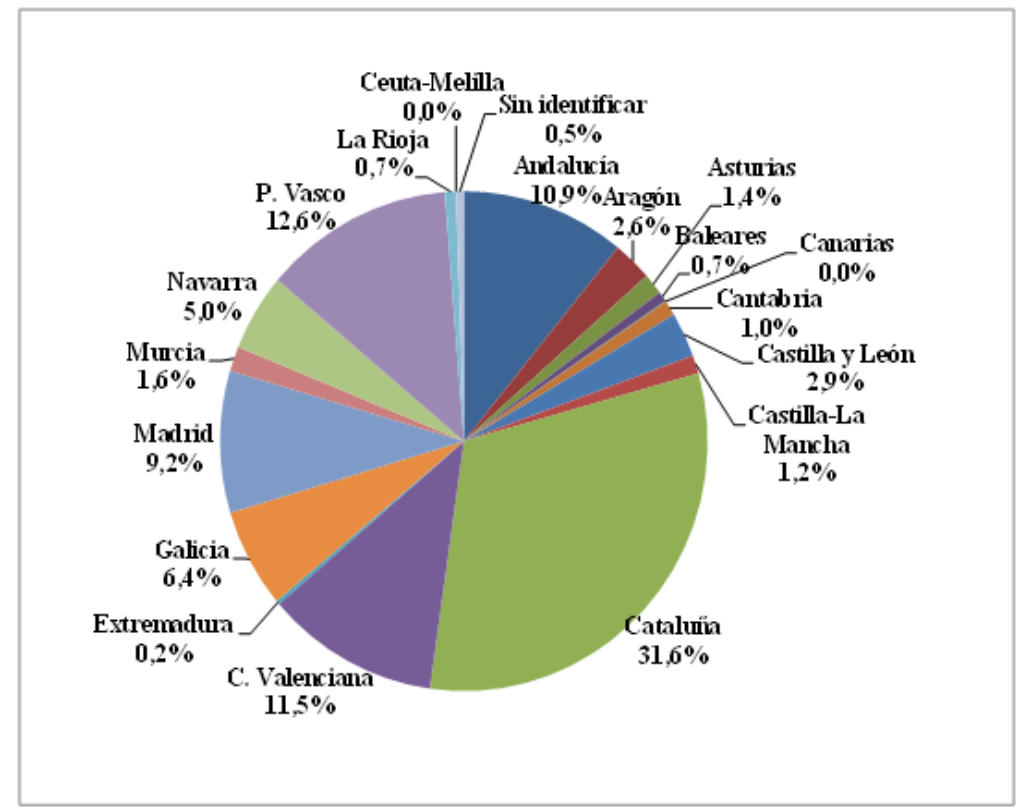

Figura 4 - Exportaciones (\%) de las comunidades autónomas 2000-2017. Fte. Estacom.

más del sesenta y cuatro por ciento de las exportaciones exporten durante la crisis a menor ritmo que el conjunto así como son economías regionales de base económica muy diferente ya que mientras Cataluña y el País vasco son los principales polos industriales del país, Madrid presenta reducida base industrial y Andalucía, aunque ha incrementado su base industrial, sigue muy vinculada al turismo de sol y playa. Con muy dispares grados de mejora en su participación están Aragón, Asturias, Castilla y León, Castilla-La Mancha, C. valenciana, Extremadura, Galicia, Murcia, Navarra y La Rioja.

\section{POTENCIALIDADES ABIERTAS, ESTRATEGIAS A IMPLEMENTAR}

El Plan Integral de Desarrollo de Mercado para el despliegue de estrategias de promoción de las relaciones económicas internacionales como incentivos a pymes, al exportador regular, a sectores como el alimentario, energías renovables, infraestructuras, industria, tics, turismo, culturales (libro), asesoramiento en destino (ICEX. Plan Integral 2015), presenta a México en el grupo de países a los que se presta atención preferente.

La proximidad y afinidad cultural es un vector que debe potenciarse más como vía para que la cultura, el idioma, los intercambios turísticos en ambas direcciones se fortalezcan. Los estudios universitarios y sus intercambios, los programas de intercambio cultural, estimulan las relaciones, el conocimiento de ambas economías y abren vías para que inversiones y comercio se incrementen. España debe potenciar la información y el conocimiento de los productos mexicanos y el acceso a los mismos para compensar el declinante protagonismo de la importación de petróleo.

Desde España, señala el Informe ELCANO 2016, las empresas han de sacar más partido al mercado de México como plataforma de acceso a los mercados de EE.UU. y Canadá. México es además una privilegiada vía de acceso al mercado centroamericano necesitados sus países de mayor cooperación cultural y económica.

\section{FUENTES ESTADÍSTICAS}

ICEX España exportación e Inversión. https://www.icex.es/icex/es. Última visita 23/03/2018

INE: http://www.ine.es/dyngs/INEbase

www.banxico.org.mx/Sielnternet/consultarDirectoriolnternetAction.do?sector=1\&accion=consultarDirectorioCuadros. Última consulta $21 / 03 / 2018$ 


\section{BIBLIOGRAFÍA}

-ALONSO, J.L. (2018): Relaciones económicas entre España y Brasil. Las exportaciones de España a Brasil en el siglo XXI. Rev. de Estudios Brasileños, Vol. 5, nº 9, pp. 11-28, marzo 2018 (DOI: https://doi.org/10.3232)

-ALONSO, J.L.; MENDES, A.A.; GUARNIERI, S.A. (2017): "Inversión exterior directa de España en Brasil 1996-2015", Rev. de Estudios Brasileños, Vol. 4, nº 6, pp. 176-190, abril 2017 (DOI: https://doi.org/10.3232)

BLANCO, H. (2000): "Relaciones hispano-mexicanas, el acuerdo con la UE", Economía Exterior, 12, pp. $33-39$ Botas, R. (2000):«La empresa española tras el acuerdo UE-México», Economía Exterior, 12, Madrid, pp. 112-121

CAMARA ESPAÑOLA DE COMERCIO (2017). MÉXICO-ESPAÑA. Análisis de exportaciones e importaciones, junio 2017, pp. 22. camescom.com.mx

CECEÑA, C. (2000): «Comercio bilateral entre España y México», Economía Exterior, 12, Madrid, pp. 77-87

CEPAL (2000): Ia Inversión Exterior Directa en América latina 1999. Capítulos II y III.

INFORMACIÓN COMERCIAL ESPAÑOLA (ICE): El sector exterior en 2016. Boletín Económico, n $3.088,1$ al 30 de junio de 2017, pp. 292.

ICEX. Informe del perfil de los exportadores a México 2017. Informe solicitado y emitido el 19 de marzo 2018, pp. 11.

ICEX. Plan Integral de Desarrollo de Mercado 2015. Ed. Digital, pp. 30

INFORME MÉXICO (2000). México. Entre dos vertientes económicas, Economía Exterior, 12, pp. 142-174

INSTITUTO DE COOPERACIÓN IBEROAMERICANA (1981): Las relaciones económicas entre España e lberoamérica. I Conferencia Iberoamericana de cooperación económica. Ediciones Cultura Hispánica, Madrid

LÓPEZ, M. (2001): "Relaciones Unión Europea-México", Economía Exterior, 19, pp. 109-116

MINISTERIO DE ECONOMÍA, INDUSTRIA Y COMPETITIVIDAD (2017): Estrategia de Internacionalización de la Economía Española 2017-2027, pp. 125

MORENO, M. Y PÉREZ, A. (2005): «Relaciones económicas y comerciales entre España y México», ICE, 821, pp. 225-237

OBSERVATORIO ESPAÑOL DEL MERCADO DEL VINO (2017): Memoria del mercado exterior del vino 2017 , pp. 62. www.oemv.es

OBSERVATORIO ESPAÑOL DEL MERCADO DEL VINO: Boletín 475 de 15/11/2017, pp.6

OFICINA ECONÓMICA Y COMERCIAL DE ESPAÑA EN MÉXICO (2004): Informe Económico y Comercial México, marzo, p. 27

REAL INSTITUTO ELCANO (2016): Relaciones España-México. Malamud, C. (Coord) Informe 21, pp. 129

REAL INSTITUTO ELCANO (2017):¿Por qué importa A. Latina?. Malamud, C. (Coord) Informe 22, pp. 93

RIVA, A. DE LA (2000): Asociación política y libre comercio", Economía Exterior, 12, pp. 63-67

RODRIGO, F. Y ARCE, L. (1999): México y la Unión Europea después del TLC. Economía Exterior, n 9, 121-128

ROMERO, J.L. (2001): «Relaciones comerciales España-México), Economía Exterior, 19, pp. 69-78

SÁNCHEZ, M. T. Y ALONSO, J.L. CASADO, J. Mª (2017): Inversión extranjera directa de España en México en la era del neoliberalismo económico. Dinámica temporal, estructura sectorial y distribución geográfica. Scripta Nova. Revista Electrónica de Geografía y Ciencias Sociales. Vol. XXI, n 556 , pp. 1-38

VELARDE, J. (1999): "Interrogantes españoles ante el futuro iberoamericano", Economía Exterior, 9, pp. 49-57 
Página intencionalmente dejada en blanco 


\title{
Spices and Medicines Cultivated and Traded in Panama-City
}

\author{
I.M. Madaleno (a) \\ (a) Instituto de Geografia e Ordenamento do Território, Universidade de Lisboa isabel-madaleno@campus.ul.pt
}

\begin{abstract}
Urban agriculture (UA) is frequently perceived as an inadequate activity for a city. According to the United Nations, UA is an industry that produces, processes and markets food and fuel, largely in response to the daily demand of consumers within a city or metropolis, on land dispersed throughout the urban and peri-urban area, applying intensive production methods, using urban wastes and reusing water. This contribution doesn't focus exclusively the cultivation of food, spices and medicinal plant species on the capital city of Panama, but also the trade of American and exotic flora, and their uses. Following a scientific mission to the Central American country, the University of Lisbon conducted a survey to 50 informants, resident in Panama. Results from in-depth interviews gathered a total of 166 plants, corresponding to 171 different species, 96 of which had medicinal or cosmetic applications, 61 were consumed as food and 14 as spices
\end{abstract}

Keywords: Urban Geography, Circular Economy, Panama

\section{Resumo}

Especiarias e Plantas Medicinais Cultivadas e Comercializadas na Cidade do Panamá

A agricultura urbana (AU) é percepcionada como atividade inadequada para as cidades. De acordo com as Nações Unidas a AU é uma atividade destinada a produzir, processar e comercializar produtos alimentares que respondem a uma procura diária dos consumidores das cidades e das áreas metropolitanas, cultivados em parcelas urbanas e periurbanas, usando métodos intensivos, reciclando matéria orgânica proveniente dos lixos e reutilizando as águas residuais. Esta contribuição focará não exclusivamente a agricultura urbana praticada na cidade do Panamá, mas também a venda de especiarias, assim como plantas medicinais consumidas ou aplicadas externamente pelos residentes nesta cidade da América Central. A pesquisa realizada constou de 50 entrevistas, integradas num projecto de investigação científica realizado na América Latina. Os resultados mostram que os cidadãos do Panamá entrevistados utilizam um total de 166 plantas, correspondentes a 171 espécies botânicas diferentes, 96 das quais têm aplicações medicinais ou cosméticas, 61 são consumidas como alimento e 14 como especiarias.

Palavras chave: Geografia Urbana, Economia Circular, Panamá

\section{INTRODUCTION}

During the 1992 Rio Summit a new trend in urban development has been set, the Agenda 21, based on the concept of sustainability established in the 1987 Brundtland report titled "Our Common Future" (Baffour Awuah \& Booth, 2014, Kaklauskas, et al., 2018). The process was continued at the 1996 UN City Summit in Istanbul with the Habitat Agenda (Deelstra, \& Girardet, 2000). Concomitantly the United Nations Development Programme conducted a series of surveys in Latin America, and elsewhere around the world (UNDP, 1996). References to urban farming in Panama City were scarce, but a special report about the existence of various forms of "aquaculture" within a publication series for Habitat II gave grounds to the expectation that in 2017 there should be some urban agriculture (UA) practises inside the urban agglomeration (UNDP, 1996, p. 111, 225). Of course the production of food, spices, medicinal species, as well as fruits is the most common form of gardening in urban areas, and that was exactly what the University of Lisbon survey found in Panama. Urban agriculture can be practised even in tiny front and backyards, in central neighbourhoods, as documented close to the entrance of an apartment block located in the Banking sector of the core capital city of Panama (see Fig. 1). This constitutes a circular economy case-study. 
Urban farming is increasingly considered an ecologically recommended activity, as the carbon footprint is lower when food production is closer to our doorstep (Deelstra, \& Girardet, 2000). But honestly, nobody expects that every single citizen starts growing food in pots on the balcony, begins creating flourishing food gardens on rooftop spaces, or then hang window boxes from high rise buildings; the expectation is that municipalities make idle plots available to urban gardeners, and promote community gardening within city limits (Baffour Awuah \& Booth, 2014, Kita, 2016). As Colin Sage (2012) reminded "reliance upon the market as the sole effective mechanism for the supply and demand of food requires every individual to possess the capacity to buy". In developing countries there is "an estimated one billion people (...) experiencing hunger and malnutrition because of their lack of entitlements through which to express demand for food" (Sage, 2012, p.2-3). Hence, UA can minimise foodinsecurity for vulnerable people (Madaleno, 2017).

The structure of the paper after this introduction is to explain the two-stage methodology, followed by the enumeration of the results, illustrated with tables and photos, and finalised with the concluding remarks. Temporal and spatial comparisons are provided, in order to make both the assessment of the evolution of urban gardening and farming in Panama City, founded in 1519, and to evaluate food, spices and medicinal plants consumed, vis a vis other Latin American (LA) urban agglomerations. This paper will contribute to build a database on the issue of useful flora growth and trade in LA cities.

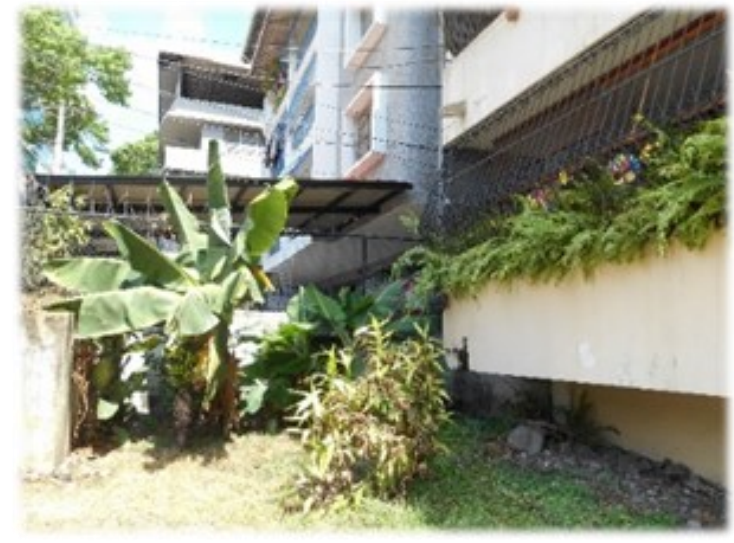

Figure 1 - Banana trees photographedin Panama City.

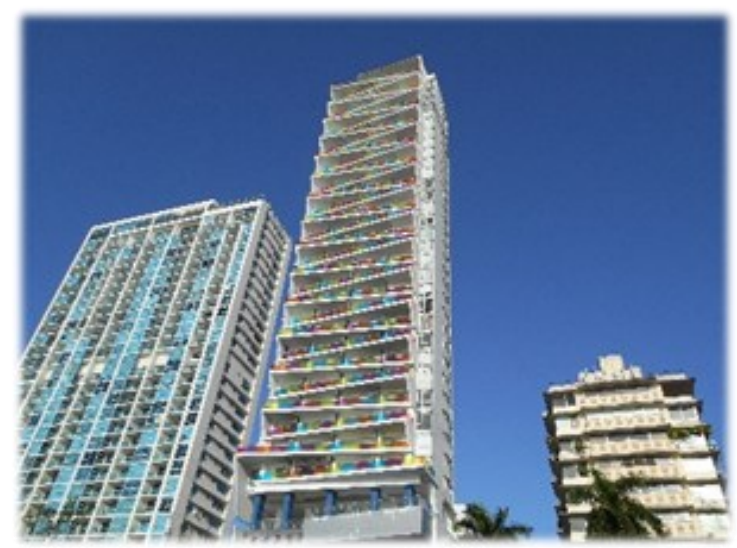

Figure 2 - High-rise buildings from the same capital city.

\section{MATERIALS AND METHODS}

The study followed the procedural sequence listed:

1. Archival examination of manuscripts from the early years of Spanish colonisation;

2. Fieldwork with a ramdom survey to flora consumption and trade conducted in early 2017, in Panama City, under the form of in-depth interviews to two categories of informants: i) urban gardeners, three of them responsible for food, spice and medicinal herbs growth and care; ii) Forty-seven formal and informal traders of fruits, spices, tubers, roots and herbal preparations, pharmacists and medicinal flora traders.

The sample gathered fifty testimonies using an open questionnaire similar to the one used in other Latin American and Asian surveys (Madaleno, 2017). Topics addressed were: the flora grown and traded; their uses; irrigation and fertilisation of the plot or pot planted species; the therapeutic recommendation, in case of medicinals; customers characterisation, in the trading posts; how native vegetables and staples were eaten, cooked or raw. Field observations and meetings with several informants from shopping malls provided clues as to the next locations to select, in a so-called snowball research process. That's the case with San Felipe Neri Market, the Central Market and the municipal plant nursery (Vivero Municipal), detailed in Table 1, which selection was recommended in the first interviews. Participation of respondents was always voluntary and their identity was not recorded.

The archival research was fundamental to make a qualitative evaluation of local flora sustainability, provid- 
ing the possibility to compare plant species mentioned in the 1526 manuscript of Gonzalo Fernández de Oviedo, with the ones consumed in our days (Gaibrois, 2002). Map in Figure 3 shows the location of the informants in a city map. The description of the survey is detailed in Table 1 . Latitude of this capital city is $8^{\circ} 58^{\prime} \mathrm{N}$, longitude is $79^{\circ} 31^{\prime} \mathrm{W}$ and average altitude is 10 metres above sea level. In 2016, the city had 1.544 .185 residents (INE, 2016). Cross-examination of flora consumption in the $16^{\text {th }}$ century and the 2017 survey results will be presented in the next pages.

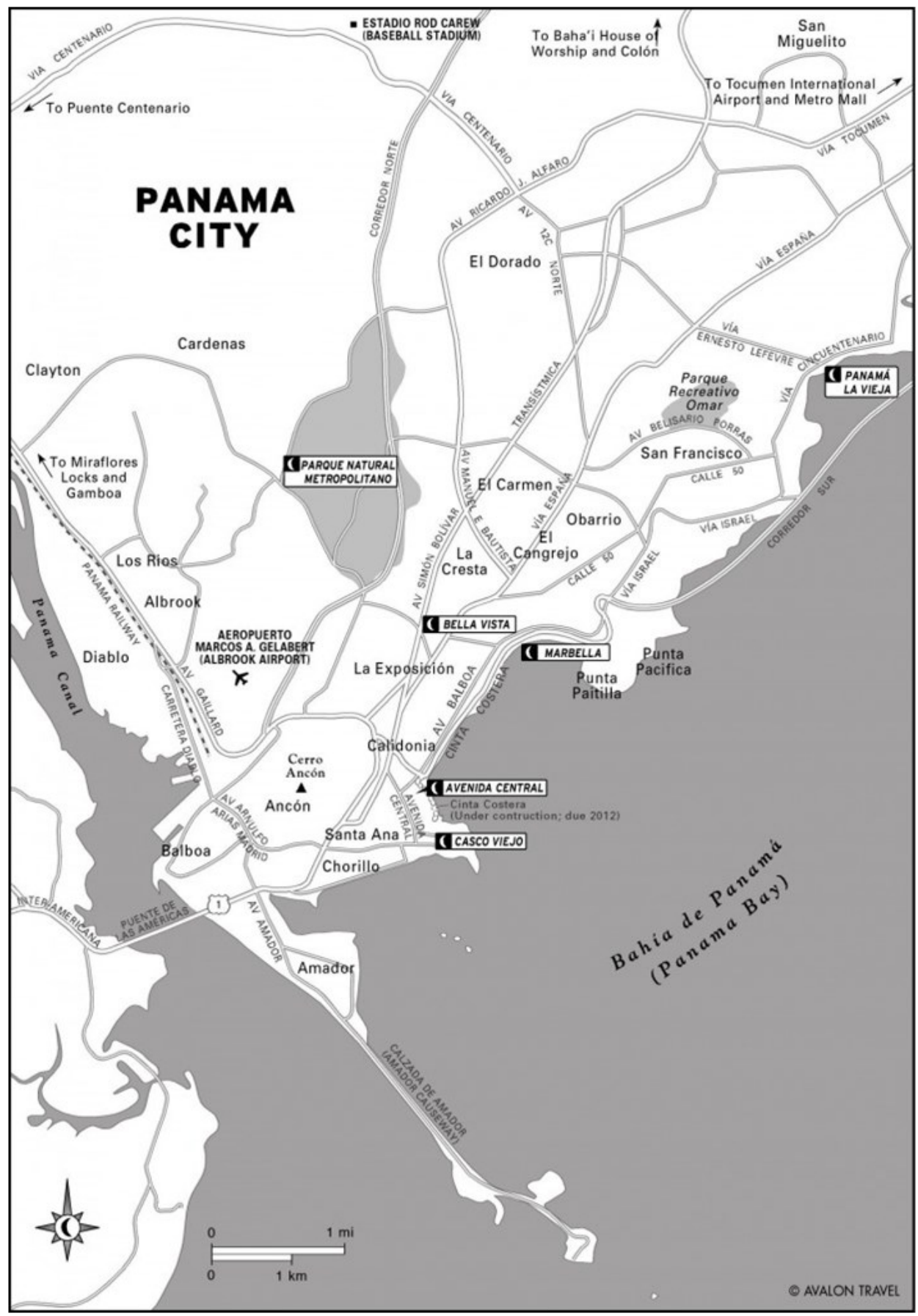

Figure 3 - Map of the city of Panama, with the location of the interview sites. Source: Google Maps. 
Table 1 - Survey Description and Location.

Source: Survey by Madaleno (2017)

\begin{tabular}{|c|c|c|c|c|}
\hline Location of the informants & $\begin{array}{c}\text { Number of } \\
\text { Interviews }\end{array}$ & $\%$ & Males & Females \\
\hline 1.Urban Cultivators (Via Israel) & 3 & 6 & 2 & 1 \\
\hline 2.Trading Posts & 47 & 94 & 19 & 28 \\
\hline $\begin{array}{c}\text { 2.1.San Felipe Neri Market } \\
\text { (Casco Viejo) }\end{array}$ & 3 & 6 & 1 & 2 \\
\hline $\begin{array}{c}\text { 2.2.Central Market } \\
\text { (La Exposición area) }\end{array}$ & 11 & 22 & 9 & - \\
\hline 2.3.Vivero municipal (outside the city map) & 1 & 2 & 1 & 5 \\
\hline 2.4.Multicentro Shopping (Marbella neigh- \\
bourhood)
\end{tabular}

\section{RESULTS AND DISCUSSION}

\subsection{First Result: The Useful Flora Grown During Renaissance in Panama}

The vernacular names of plants mentioned in the $16^{\text {th }}$ century manuscript authored by Oviedo totalled 55 , thirty-five of which (63.6\%) were native American or Asian fruits. Less than a half were consumed as food (40\%), and only four were used as medicine. Previous work cross-examined the top-ranking flora, their therapeutic applications and other uses in the $16^{\text {th }}$ century and in our days (Madaleno, 2017). Preferences for species with dual consumption patterns - such as coconuts (Cocos nucifera) and pineapples (Ananas comosus) - rivalled with the use of ají or Chilli peppers (Capsicum annuum) as spice and also as medicine. Rutaceae fruit trees were probably brought by the Spaniards, namely oranges (sweet and sour), lemons and citrons (Citrus medica). They were planted in their farms and city gardens, including by the Spanish traveller and historian Gonzalo Fernández de Oviedo (Gaibrois, 2002). These species are Eurasian or Asian in origin.

So, as first result the emphasis goes to 30 (54.5\%) vernaculars mentioned in the 1526 manuscript that are still common in modernity. As the French geographer Jean-Bernard Charrier wrote in his 1988 book on the issue of Cities and Countryside (Charrier, 1988), during renaissance numerous European towns mingled urban and rural activities, both animal husbandry and urban gardening, and thus it is not surprising that Latin American colonisers maintained the same habits, abroad. Therefore, the early Panamian cities, the capital of the country included, were green and biodiverse, as total rainfall registered is about 1,750 millimetres annually. Of course verticalisation in construction dominates in contemporaneity, as Figure 2 exemplifies.

\subsection{Second Result: Flora Consumed in Modernity}

The fifty in-depth interviews conducted in Panama City in early 2017 encountered 166 vernaculars corresponding to 171 different species of useful flora. The identification of the fruits, herbs, tubers, and roots gathered, used the Missouri Botanical Garden norm (MBG, 2018), which is available online. Ninety-six species recorded during fieldwork possessed at least one medicinal application (56.5\%); 60 vernaculars, corresponding to 61 species were consumed mainly as food (35.3\%); fourteen plant species were only utilised as spices. Table 2 presents this last category of aromatic flora, together with the number of occurrences, and the origin of the species, 
in order to illustrate the discussion of this second result (Cunha \& Roque, 2015).

Only a couple of aromatic plants were mentioned in the $16^{\text {th }}$ century manuscript by Oviedo (Gaibrois, 2002) and they were not identified as spices. Bay leaves were used in comparisons with newfound species, namely avocado tree leaves; albahaca or basil was used as local food, and it was probably the native Ocimum americanum, Family Lamiaceae, an herb of the same gender but American in origin (MBG, 2018). It is also important to emphasize that two Asian and Eurasian flora specimens, a tiny lemon and the coriander, are tagged as Chinese. That's because the construction of a railway from the Atlantic coast (Colón) to the Pacific (Panama City), in 1848, required about 7,000 immigrant workers from China, India, the Caribbean Islands, as well as Ireland and Spain (Ventocilla \& Dillon, 2010). The international contractors were the North-American Pacific Mail Company, and all these peoples left their imprint in the Central American country under study.

\subsection{Third Result: Staple Food Grown and Traded in 2017}

Food eaten in Panama contains a limited number of plant species, little more than $1 / 3$ of the flora gathered during the survey. Coconuts are the top-ranking fruits consumed, with 11 occurrences (6.4\%), against (3.5\%) for cosmetic and medicinal purposes, corresponding to $9.9 \%$. To this fruit mango follows suit, with 12 records as food (7\%), and two more as medicine, taken in refreshing infusions. Native American pineapple is ex-aequo, registering $7 \%$ of the occurrences, even though it possesses also medicinal properties, a fact already mentioned in Oviedo, in the $16^{\text {th }}$ century (Gaibrois, 2002). The staples range from potatoes (5 records), cassava (2.9\%), ñame ( $2.3 \%$ of the occurrences), corn $(2.3 \%)$, rice (1.8\% of the records), to sweet potatoes (1.8\%). Then come other basic food such as culantro (Eryngium foetidum, with $4.1 \%$ occurrences), peas (3.5\%), pumpkins (5 records or $2.9 \%$ ), green beans (3), lentils (2), and the local otoi (Xanthosoma sagittifolium), with another couple of occurrences (see Fig. 4).

Table 2 - Spices collected in Panama City.

Source: Survey by Madaleno (2017), Gaibrois, 2002.

\begin{tabular}{|c|c|c|c|c|}
\hline $\begin{array}{l}\text { Vernacular } \\
\text { Name } \\
\text { (English) }\end{array}$ & $\begin{array}{l}\text { Scientific } \\
\text { Name }\end{array}$ & Origin & Old uses & $\begin{array}{l}\mathrm{N}^{\circ} \text { in the } \\
\text { survey }\end{array}$ \\
\hline $\begin{array}{l}\text { Limón Mandarino } \\
\text { Chinese Lemon }\end{array}$ & $\begin{array}{c}\text { Citrofortunella microcarpa (Bunge) } \\
\text { Wijnands } \\
\text { RUTACEAE }\end{array}$ & Asian & - & 5 \\
\hline $\begin{array}{l}\text { Perejil } \\
\text { Parsley }\end{array}$ & $\begin{array}{c}\text { Petroselinum crispum (Mill.) Fuss } \\
\text { APIACEAE }\end{array}$ & Eurasian & - & 5 \\
\hline $\begin{array}{l}\text { Cilantro Chino } \\
\text { Coriander }\end{array}$ & $\begin{array}{l}\text { Coriandrum sativum L. } \\
\text { APIACEAE }\end{array}$ & Eurasian & - & 2 \\
\hline $\begin{array}{c}\text { Laurel } \\
\text { Bay Leaves }\end{array}$ & $\begin{array}{l}\text { Laurus nobilis L. } \\
\text { LAURACEAE }\end{array}$ & European & Leaf characterisation & 2 \\
\hline $\begin{array}{c}\text { Albahaca } \\
\text { Basil }\end{array}$ & $\begin{array}{l}\text { Ocimum basilicum L. } \\
\text { LAMIACEAE }\end{array}$ & European & Food & 1 \\
\hline $\begin{array}{l}\text { Estragón } \\
\text { Estragon }\end{array}$ & $\begin{array}{l}\text { Artemisia dracunculus L. } \\
\text { ASTERACEAE }\end{array}$ & Eurasian & - & 1 \\
\hline $\begin{array}{l}\text { Mejorana } \\
\text { Marjoram }\end{array}$ & $\begin{array}{c}\text { Origanum majorana } \mathrm{L} . \\
\text { LAMIACEAE }\end{array}$ & Eurasian & - & 1 \\
\hline $\begin{array}{l}\text { Mostaza } \\
\text { Mustard }\end{array}$ & $\begin{array}{c}\text { Brassica nigra (L.) W.D.J. Koch } \\
\text { BRASSICACEAE }\end{array}$ & Asian & - & 1 \\
\hline $\begin{array}{l}\text { Nuez Moscada } \\
\text { Nutmeg }\end{array}$ & $\begin{array}{c}\text { Myristica fragrans Houtt. } \\
\text { MYRISTICACEAE }\end{array}$ & Asian & - & 1 \\
\hline $\begin{array}{l}\text { Orégano } \\
\text { Oregano }\end{array}$ & $\begin{array}{l}\text { Origanum vulgare L. } \\
\text { LAMIACEAE }\end{array}$ & European & - & 1 \\
\hline
\end{tabular}




\subsection{Fourth Result: Flora no Longer in Use}

Table 3 presents eight "forgotten plants" consumed as food or presenting other uses normal in the beginning of European colonization, but uncommon these days. They range from flora whose shoots serve to make soap, like the plum bush; fruits used as cups, such as the Cucurbitaceae species lagenaria; leaves that covered and insulated roofs, like Caladium striatipes; and rope manufacture, in case of the Agave, both with the species sisalana and fourcroydes. The focus goes to a couple of renown medicines, anticipating the next result, the bark of guayacán tree, exported from Latin America to Europe and Asia, because it was used to cure syphilis; and annatto (Bixa orellana), used to paint the body in Oviedo's time, but still applied and even ingested in concoctions and infusions elsewhere in the America's (Madaleno, 2013). As to food species no longer consumed in Panama, bihaos or wild bananas were replaced by Musa paradisiaca, but genipap fruits are still used to make wine and liquor and the plum bush (Spondias mombim) to make refreshments, in Brazil (Cavalcante, 1991, Gomes, 1972).

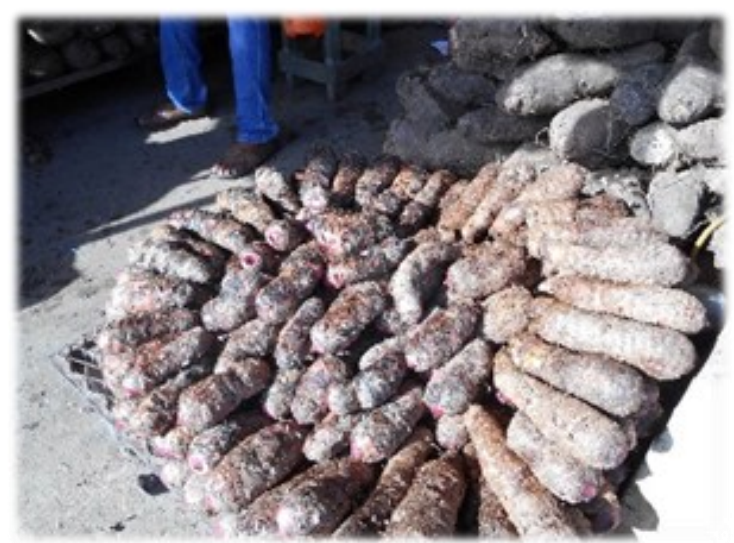

Figure 4 - Otoi or Malanga from a Panamian market.

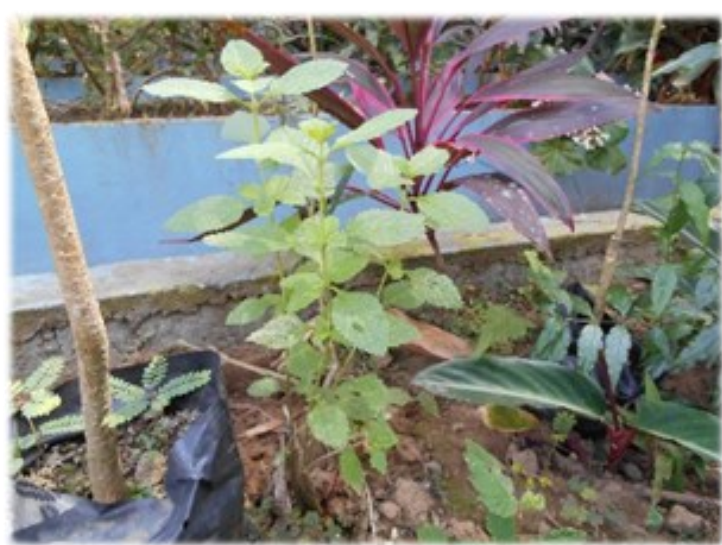

Figure 5 - Mastranto, grown both in pots and urban gardens.

\subsection{Fifth Result: The Growth of Medicines and its Trade in 2017}

More than half the useful flora gathered in the city of Panama had medicinal applications. The top-ranking species solely used for therapeutic purposes encountered during fieldwork was Aloe vera, with 16 records or $9.3 \%$ (Madaleno, 2017). Most of the applications were external, against baldness or to resolve skin problems, which differentiates this case-study from the previous Latin American research (Madaleno, 2012). In fact, in eight other countries (Argentina, Mexico, Costa Rica, Peru, Cuba, Chile, Uruguay and Brazil) Aloe sap was ingested with honey, whiskey, milk or lemon to prevent and even to treat cancer patients. It was consumed to control diabetes, and in Lima (Peru) it was applied to the eyes in case of cataracts (Madaleno, 2012, 2013). The World Health Organization (WHO) has successfully tested the species, recognising its analgesic, anti-fever, hypoglycaemic, anti-tumour and anti-asthmatic properties (WHO, 2009). Pharmacognosy researchers from Portugal also proved the species to have skin healing activities; it was approved in cosmetics as skin softener and considered to have anti-inflammatory properties (Cunha, Silva \& Roque, 2003).

Next comes the native American Chilli pepper (Capsicum annuum), consumed as immune health supplement (8 reports) and as spice (6 occurrences) totalling $8.2 \%$ of the records (Madaleno, 2017). Lemons and citrons (Citrus micrantha and medica), are third (13 occurrences or 7.6\%), applied to the skin for body shaping or as butter creams to the hair. They are consumed as food, either (5.8\% records). Chamomile, with 12 occurrences, goes fourth, and again the cosmetic external usage in hydrating creams is remarkable, but it is recommended for better blood circulation, too. Anti-inflammatory activity was also registered by WHO (WHO, 1999). The plant species is sold fresh in local markets, natural pharmacies, as well as in supermarkets, and under the form of small portions packed for infusion making. This practise was found in other Latin American agglomerations, such as in San José, neighbouring Costa Rica; in Havana, Cuba; in Mexico City, Cuernavaca and Puebla, in Mexico (Cunha, Silva \& Roque, 2003).

Green and black tea (Thea sinensis) are ex-aequo with chamomile, the former being consumed for weightreduction. Figure 5 illustrates Vernonia condensata species, gardened in Panama (2 records, as in Fig. 6), whose 
leaves are consumed in infusions against diarrhoea. Previous fieldwork conducted in St. Louis, Brazil, in 2010, found the species to be planted for another purpose, namely to resolve stomach and hepatic troubles, after excessive drinking (Madaleno, 2011).

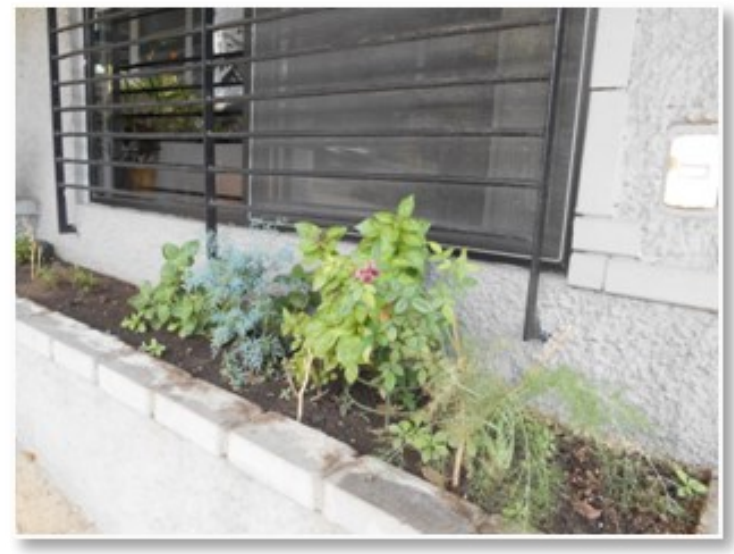

Figure 6 - Window pots in the city of Panama.

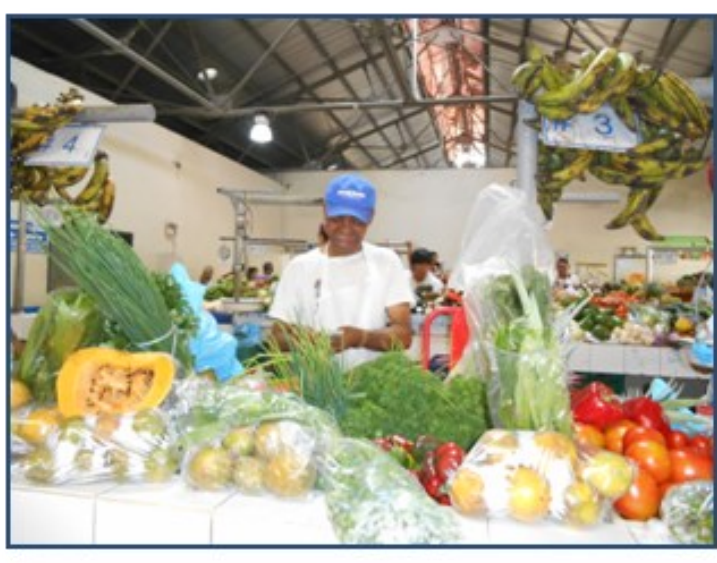

Figure 7 - San Felipe Neri Market fruit and vegetables trader.

Table 3 - Forgotten Flora in Panama.

Sources: Survey by Madaleno (2017); Gaibrois (2002)

\begin{tabular}{|c|c|c|c|}
\hline $\begin{array}{l}\text { Vernacular name } \\
\text { (English) }\end{array}$ & Scientific name & Uses in Oviedo's manuscript & $\begin{array}{c}\text { Contemporary uses in Latin } \\
\text { America }\end{array}$ \\
\hline $\begin{array}{c}\text { 1.Bihaos } \\
\text { Wild Banana }\end{array}$ & $\begin{array}{c}\text { Caladium striatipes (Kunth \& C.D. } \\
\text { Bouché) Schott. } \\
\text { ARACEAE }\end{array}$ & $\begin{array}{c}\text { Fruit and rhizome were food, } \\
\text { while the leaf covered the } \\
\text { shacks. }\end{array}$ & Not recorded \\
\hline $\begin{array}{l}\text { 2. Bija } \\
\text { Annatto }\end{array}$ & $\begin{array}{l}\text { Bixa Orellana L. } \\
\text { BIXACEAE }\end{array}$ & $\begin{array}{l}\text { Used to paint the body } \\
\text { together with genipap. }\end{array}$ & $\begin{array}{l}\text { Leaf and root infusion against } \\
\text { colds, asthma and sore throat } \\
\text { (Peru, Cuba). Seed and leaf } \\
\text { controls diabetes (Peru). Skin } \\
\text { application of the bark against } \\
\text { leprosy (Mexico, Peru), and } \\
\text { insect bites (Brazil, Costa Rica). }\end{array}$ \\
\hline 3.Cabuya & $\begin{array}{c}\text { Agave sisalana Perrine ex Engelm. } \\
\text { ASPARAGACEAE }\end{array}$ & Used to make ropes & Not recorded \\
\hline $\begin{array}{l}\text { 4. Guayacán, Palo Santo } \\
\text { Guaiacum }\end{array}$ & $\begin{array}{l}\text { Guaiacum officinale L. } \\
\text { ZYGOPHYLLACEAE }\end{array}$ & $\begin{array}{l}\text { The bark was used to cure } \\
\text { syphilis }\end{array}$ & Not recorded \\
\hline $\begin{array}{c}\text { 5. Genipapo } \\
\text { Genipap or Marmelade-box }\end{array}$ & $\begin{array}{l}\text { enipa americana } \mathrm{L} . \\
\text { RUBIACEAE }\end{array}$ & $\begin{array}{l}\text { Fruit good to eat. The juice is } \\
\text { used to wash the legs and to } \\
\text { paint the body. }\end{array}$ & Not recorded \\
\hline 6. Henequém & $\begin{array}{l}\text { Agave fourcroydes Lem. } \\
\text { ASPARAGACEAE }\end{array}$ & Used to make ropes. & Not recorded \\
\hline 7. Higuero, guira, guiro & $\begin{array}{l}\text { Cucurbita lagenaria } \mathrm{L} . \\
\text { CUCURBITACEAE }\end{array}$ & $\begin{array}{l}\text { The fruit is good to make } \\
\text { cups. }\end{array}$ & Not recorded \\
\hline $\begin{array}{l}\text { 8. Hobos, jojos } \\
\text { Plum Bush }\end{array}$ & $\begin{array}{l}\text { Spondias mombin } \mathrm{L} \text {. } \\
\text { ANACARDIACEAE }\end{array}$ & $\begin{array}{l}\text { Fruit is food. The shoots are } \\
\text { good to make soap and the } \\
\text { bark improves circulation. }\end{array}$ & Not recorded \\
\hline
\end{tabular}

\subsection{Sixth Result: Flora Consumed in 2017 and in 1526, and the Most Common Uses}

Table 4 cross-examines old and current uses in the city of Panama. Only the vernacular names are listed, referring to the analysis of Gonzalo Fernández de Oviedo's manuscript, but in case of the 2017 survey, the information presents all the plant species gathered during fieldwork. Results show that $40 \%$ of the flora mentioned in the $16^{\text {th }}$ century was referred to food plants or to other uses, which also integrates Eurasian species, introduced in Central America. In modernity, the medicinal applications dominate, with $56.5 \%$ of the records, whereas food plants constitute little more than $1 / 3$ of flora gathered (see fig. 7).

Even though native American flora is so rich, spices were by far imported. The exception goes to Chilli (Capsicum annuum), with 6 records, which presented mixed uses. So, the emphasis should go to the importance of 
plant species introduced during European colonisation or later on, as input of a vague of immigrant workers to Panama. The staple foods, by contrast, included a vast array of native tubers, roots and fruits, widely consumed in the city. Following the trend of previous research missions to Latin America, medicinal flora recorded was quite numerous, standing first in the ranking of preferences. External applications deserve being stressed, as cosmetic uses of flora predominated.

Table 4 - Cross-Examination of Uses, Today and in the Past. Sources: Survey by Madaleno (2017); Gaibrois (2002)

\begin{tabular}{|c|c|c|c|c|}
\hline Uses and Origin & No of Oviedo's Vernaculars & $\%$ & $\begin{array}{c}2017 \text { Survey Plant } \\
\text { Species }\end{array}$ & $\%$ \\
\hline Food & 22 & 40.0 & 61 & 35.7 \\
\hline Medicines & 4 & 7.3 & 96 & 8.2 \\
\hline Spices & 9 & 16.3 & 14 & - \\
\hline Other Uses & 20 & 36.3 & - & 171 \\
\hline Total & 55 & 99.9 & & 100 \\
\hline
\end{tabular}

\section{CONCLUSIONS}

Farming within the urban tissue contributes to diminish the heat island, produces oxygen, and infiltration spaces that minimise flood-risks. In socio-economic terms, it is an opportunity to cope with famine and poverty, providing ways to give the less wealthy households food-security. Urban agriculture is a reconciliatory activity, both with nature and with the city, the so-called urban jungle. It is also a good opportunity to develop the socalled seven Rs, as it provides the opportunity to refuse the idea that a city only produces waste, introducing new concepts as to re-gift or sell used goods, but in case of UA, the proposal is: to reduce the citizens carbon footprint; to reuse waters, as the ones that wash vegetables in the kitchen; to reutilise organic wastes in fertilization; to recycle garbage; to rethink the utilisation of common condominium spaces (as illustrated in Fig. 1); to recuperate window and balcony spaces to grow food, spices and medicinal plants, even ornamental herbs (as shown in Fig. 1 and 6), thus practicing a circular economy.

Research findings reveal that $14.5 \%$ of plants mentioned in Oviedo's "Summary of The Natural History of the Indies" are no longer in use in Panama; yet they do not possess a vulnerable status. In fact, it should be stressed that European colonisation contributed to enrich flora grown and traded in Panama, and so did several vagues of migrants to the capital city and surroundings. Conclusion is that even in capital cities known for their financial status as fiscal paradises, it is possible to observe adhesion to sustainable agriculture and trade practices, which record contributes to give us hope that useful flora will not be depleted in the near future in Panama.

\section{REFERENCES}

BAFFOUR AWUAH, K. G. \& BOOTH, C.A. (2014). Integrated management framework for sustainable cities: insights into multiple concepts and principles. WIT Transactions on Ecology and the Environment, 191, 111-123.

CAVALCANTE, P.B. (1991). Frutas Comestiveis da Amazônia. Belém, Brazil: Museu Paraense Emílio Goeldi/CEJUP.

CHARRIER, J.-B. (1988). Villes et Campagnes. Paris, France: Masson.

CUNHA, A.P.\& ROQUE, O.R. (2015). Especiarias e Plantas Condimentares. Origem, Composição e Utilizações. Lisboa, Portugal: Fundação Calouste Gulbenkian.

CUNHA, A.P., SILVA, A.P. \& ROQUE, O.R. (2003). Plantas e produtos vegetais em fitoterapia. Lisboa, Portugal: Fundação Calouste Gulbenkian.

DEELSTRA, T. \& GIRARDET, H. (2000). Urban agriculture and Sustainable Cities. In. N. Bakker, M. Dubbeling, S. Gundel, U. Sabel-Koschella, H. de Zeeuw (Eds.), Growing Cities, Growing Food (pp. 43-65). Feldafing, Germany: Deutsche Stiftung fur Internationale Entwicklung.

GAIBROIS, M.B. (2002). Sumario de la Natural Historia de las Indias de Gonzalo Fernández de Oviedo. Madrid, Spain: Dastin. 
GOMES, R.P. (1972). Fruticultura Brasileira. S. Paulo, Brazil: Nobel.

INE (2016). Población. Ciudad de Panamá, Panamá: Instituto Nacional de Estadísticas. Retrieved from https:// www.contraloria.gob.pa/inec/archivos/P85512\%20\%20Poblaci\%C3\%B3n\%21.pdf

KAKLAUSKAS, A., ZAVADSKAS, E.K., RADZEVICIENE, A., UBARTE, I., PODVIESKO, A. PODVESKO, V., KUZMINSKE, A., BANAITIS, A., BINKYTE, A., BUCINSKAS, V. (2018). Quality of City Life Multiple Criteria Analysis. Cities, 72, 82-93.

KITA, K. (2016). Multi-stakeholder Policy Influencing and Local Urban Food Initiatives. Urban Agriculture Magazine, 31, $16-17$.

MADALENO, I.M. (2013). Estudo Etnogeográfico de Plantas Medicinais da América Latina. Lisboa: Lisboa, Portugal: Alêtheia Editores.

MADALENO, I. (2017 September). Flora Grown and Traded in Panama City, in the $16^{\text {th }}$ Century and Nowadays. Paper presented at the Deutscher Tropentag Conference. Retrieved from http://www.tropentag.de/2017/abstracts/full/34.pdf.

MADALENO, I.M. (2012). Organic cultivation and use of medicinal plants in Latin America. Pharmacognosy Communications, 2 (4), 34-51.

MADALENO, I.M. (2011). Plantas da Medicina Popular de São Luís, Brasil. Boletim do Museu Paraense Emílio Goeldi. Ciências Humanas, 6 (2), 273-286.

MBG (2018). Missouri Botanical Garden. Retrieved from http://www.tropicos.org.

SAGE, C. (2012). Environment and Food. Abingdon, UK: Routledge.

UNDP (1996). Urban Agriculture. Food, Jobs and Sustainable Cities. New York, USA: United Nations Development Programme.

VENTOCILLA, J. \& DILLON, K. (2010). Gamboa. Una guía para su patrimonio natural y cultural. Panama City, Panama: Instituto Smithsonian de Investigaciones Tropicales.

WHO (2009). Medicinal plants in Papua New Guinea. Manila, The Phillippines: World Health Organization.

WHO (1999). WHO Monographs in Selected Medicinal Plants. Geneva, Switzerland: World Health Organization. 
Página intencionalmente dejada en blanco 
Página intencionalmente dejada en blanco 


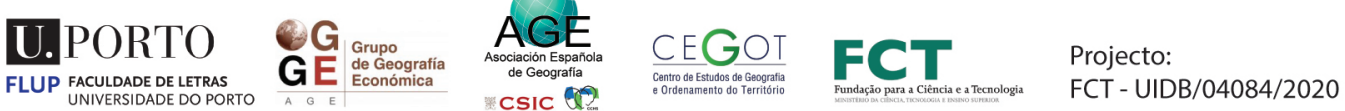

